DOE ID 10732

$61193-$

DOE/ID-99-02

\title{
Federal Geothermal \\ Geoscience Research \\ Fiscal Year 1998
}

Prepared for:

U.S. Department of Energy

Assistant Secretary for Energy Efficiency

and Renewable Energy

Office of Geothermal Technologies

Under Contract AC07,94D13223

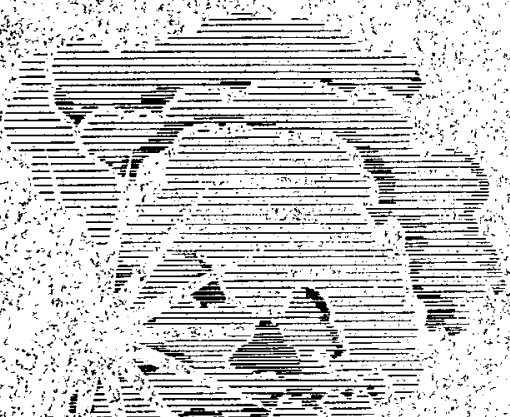

May 1999
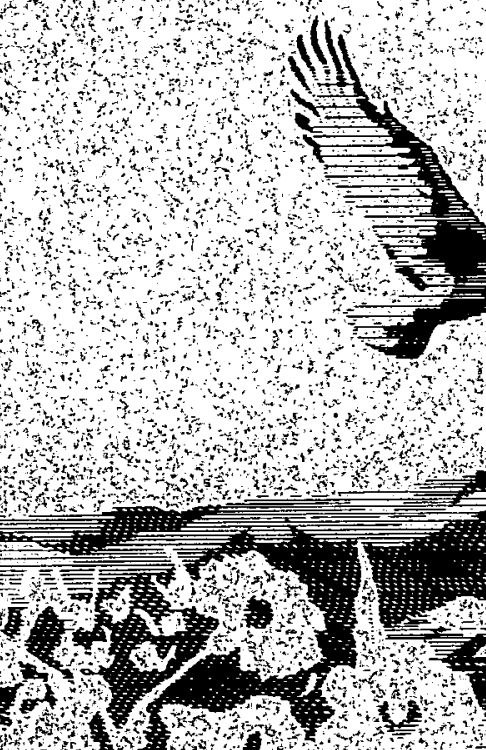

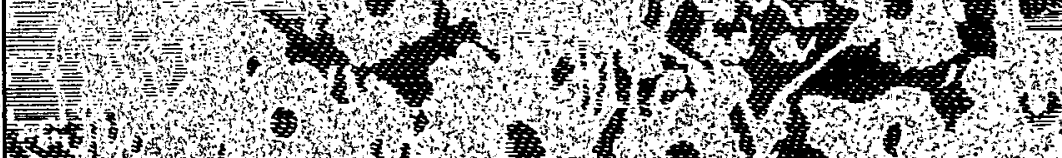

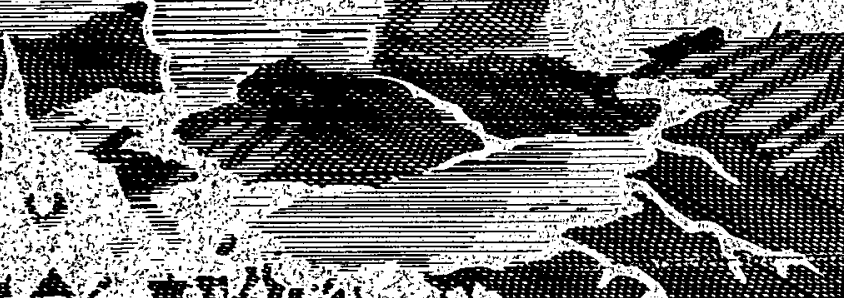




\section{DISCLAIMER}

This report was prepared as an account of work sponsored by an agency of the United States Government. Neither the United States Government nor any agency Thereof, nor any of their employees, makes any warranty, express or implied, or assumes any legal liability or responsibility for the accuracy, completeness, or usefulness of any information, apparatus, product, or process disclosed, or represents that its use would not infringe privately owned rights. Reference herein to any specific commercial product, process, or service by trade name, trademark, manufacturer, or otherwise does not necessarily constitute or imply its endorsement, recommendation, or favoring by the United States Government or any agency thereof. The views and opinions of authors expressed herein do not necessarily state or reflect those of the United States Government or any agency thereof. 


\section{DISCLAIMER}

Portions of this document may be illegible in electronic image products. Images are produced from the best available original document. 


\section{DISCLAIMEA}

This report was prepared as an account of work sponsored by an agency ot the United States Government Neither the United States Govemment nor any agency thereof nor any of their employees makes any warranty express or implied or assumes any logal liability or responsibiliny tor the accuracy completeness of usefulness of any normation apparatus product or process disciosed or represents that its use would nol inthnge privatély owned nghts theferences herein to any specific commercial product process or senvice by trade name trádemank manutacturer or othewise, does not necessanly constitute or imply its endorsement recommendation or tavonng by the United States Government or a ny agency thereot The vews and opinions of authors expressed terein do not necessanily state or refiect those of the United Stales Government or any agency thereot 


\section{CONTENTS}

INTRODUCTION.

$1-1$

\section{EXPLORATION TECHNOLOGY}

\section{GEOPHYSICAL METHODS}

ELECTROMAGNETIC METHODS FOR GEOTHERMAL EXPLORATION

Ki Ha Lee.

GEOPHYSICAL STUDIES OF THE BLUE MOUNTAIN, NEVADA, GEOTHERMAL SYSTEM

Howard P. Ross and David R. Langton

GEOTHERMAL INDUSTRY TEMPERATURE GRADIENT DATA FOR THE GREAT BASIN

Arnold J. Blanton, Penelope C. Sackett, Susan S. Priest, and John H. Sass

GEOTHERMAL RESOURCE/RESERVOIR INVESTIGATIONS BASED ON HEAT

FLOW AND THERMAL GRADIENT DATA FOR THE UNITED STATES

David D. Blackwell, Kenneth W. Wisian, and John L. Steele.

REMOTE SENSING AND GIS: TOOLS FOR GEOTHERMAL EXPLORATION AND FIELD MANAGEMENT

Gregory D. Nash and Michael W. Hernandez

RESULTS OF THE GEOTHERMAL GEOBOTANY HYPERSPECTRAL IMAGING PROGRAM

Brigette A. Martini, S. A. Cocran, D. C. Potts, and E. A. Silver

SP MODELING

Alan C. Tripp and Howard P. Ross.

MICROSEISMICITY SURVEY OF THE EL HOYO-MONTE GALAN GEOTHERMAL REGION IN NICARAGUA

Paul Kasameyer, Albert T. Smith, and Lawrence J. Hutchings.

MT/CSAMT ELECTRICAL METHODS RESEARCH

Philip E. Wannamaker and John A. Stodt.

THREE-DIMENSIONAL SEISMIC IMAGING OF THE RYE PATCH RESERVOIR Mark A. Feighner, Thomas M. Daley, and E. L. Majer.

\section{GEOCHEMICAL METHODS}

ISOTOPE GEOCHEMISTRY IN GEOTHERMAL RESEARCH

B. Mack Kennedy, Donald J. DePaolo, and Alfred H. Truesdell 
THERMODYNAMICS AND PHASE RELATIONS OF SYNTHETIC GRANITE MELTS AND ASSOCIATED AQUEOUS FLUIDS

J. G. Blencoe, L. M. Anovitz, D. R. Cole and J. Horita.

GEOTHERMAL CHEMISTRY, EXPLORATION AND RESERVOIR PROCESSES

Cathy J. Janik and Fraser Goff.

\section{GEOLOGICAL METHODS}

THREE-DIMENSIONAL VISUALIZATION OF THE GEOLOGY, HYDROLOGY AND GEOCHEMISTRY OF THE MEDICINE LAKE HIGHLAND AND SURROUNDING REGION

Jacob B. Lowenstern, and Robert H. Mariner.

STUDY OF THE COSO FORMATION

Diane L. Kamola and J. Douglas Walker

LIST OF CONTACTS FOR EXPLORATION TECHNOLOGY

\section{RESERVOIR TECHNOLOGY}

\section{LABORATORY MEASUREMENTS}

VOLATILITY OF CHLORIDES AND THE THERMODYNAMICS OF BRINES DURING BRINE DRYOUT J. Michael Simonson, Donald A. Palmer, S. L. Marshall, P. C. Ho, and M. S. Gruszkiewicz.

GEOCHEMISTRY OF ALUMINUM IN HIGH TEMPERATURE BRINES

D. A. Palmer, P. Benezeth, D. J. Wesolowski

STABLE ISOTOPE PARTITIONING IN BRINE-GAS-MINERAL SYSTEMS RELEVANT TO GEOTHERMAL RESOURCES

Juske Horita, David R. Cole, and David J. Wesolowski

LABORATORY INVESTIGATION OF FRACTURE CLOSURE UNDER HYDROTHERMAL CONDITIONS

Peter Persoff.

LABORATORY MEASUREMENTS ON CORE SAMPLES FROM THE AWIBENGKOK GEOTHERMAL FIELD, INDONESIA

G. N. Boitnott.

STEAM-WATER RELATIVE PERMEABILITY IN GEOTHERMAL ROCKS

Roland N. Horne

WATER ADSORPTION

Miroslaw S. Gruszkiewicz, Juske Horita, J. Michael Simonson, and Robert E. Mesmer .... 


\section{FIELD INVESTIGATIONS}

THE TWIN FALLS REGIONAL GEOTHERMAL SYSTEM: CHANGES DUE TO OVER UTILIZATION

R. H. Mariner, H. W. Young

COVE FORT RESOURCE EVALUATION

K. K. Bloomfield, M. C. Adams and J. N. Moore

THE SALTON SEA GEOTHERMAL FIELDS

Marcelo J. Lippmann, Alfred H. Truesdell and George A. Frye

GEOLOGIC RESERVOIR CHARACTERIZATION OF THE TELEPHONE FLAT

GEOTHERMAL SYSTEM, MEDICINE LAKE VOLCANO, CALIFORNIA

Jeffrey B. Hulen and Susan J. Lutz.

THE AWIBENGKOK, INDONESIA, GEOTHERMAL RESEARCH PROJECT

Jeffrey B. Hulen.

TRACING FLUID FLOW IN GEOTHERMAL RESERVOIRS

Peter E. Rose

TRACING FLUID SOURCES IN THE COSO GEOTHERMAL SYSTEM USING

FLUID-INCLUSION GAS CHEMISTRY

Susan Juch Lutz, Joseph N. Moore, and Michael C. Adams

A COMPREHENSIVE STUDY OF FRACTURE PATTERNS AND DENSITIES

IN THE GEYSERS GEOTHERMAL RESERVOIR USING MICROEARTHQUAKE

SHEAR-WAVE SPLITTING

Peter E. Malin and Eylon Shalev

\section{INSTRUMENTATION}

INSTRUMENTATION DEVELOPMENT IN SUPPORT OF THE GEOTHERMAL INDUSTRY HIGH-TEMPERATURE ELECTRONICS HARDWARE AND SOFTWARE AND FIBER OPTICS FOR WELLBORE TEMPERATURE

Randy A. Normann and Joseph A. Henfling

\section{DATA BASE DEVELOPMENT}

JAVA ELECTRONIC REPORTING SYSTEM FOR CALIFORNIA GEOTHERMAL DATA Jeff Wagoner, Stephanie Daveler, and Richard Thomas

\section{RESERVOIR SIMULATION}

ADVANCES IN GEOTHERMAL RESERVOIR SIMULATION

Karsten Pruess, Curt Oldenburg, and George Moridis

ADVANCES IN MULTIPHASE INVERSE MODELING

Stefan Finsterle and Karsten Pruess 
CHEMICAL MODELS FOR OPTIMIZING ENERGY PRODUCTION

Nancy Mфller and John H. Weare

INVESTIGATION OF REINJECTION STRATEGIES

Roland N. Horne

OPTIMIZING INJECTION USING TRACERS

G. Michel Shook

PHASE-FRONT PROPAGATION IN GEOTHERMAL SYSTEMS USING

HIGHER-ORDER DIFFERENCING SCHEMES

Curtis M. Oldenburg and Karsten Pruess

TRACER MATCHING AND PRODUCTION/INJECTION STRATEGIES FOR

FAULT DOMINATED GEOTHERMAL RESERVOIRS

Daniel Swenson

LOWER LIMITS OF HYDROTHERMAL CIRCULATION AND CONDUCTIVE HEAT TRANSFER

Dennis L. Nielson and Joseph N. Moore

ON THE EFFECTIVE CONTINUUM METHOD FOR MODELING MULTIPHASE FLOW, MULTICOMPONENT TRANSPORT AND HEAT TRANSFER IN FRACTURED ROCK Yu-Shu Wu

\section{THE GEYSERS FIELD STUDIES}

INVESTIGATION OF INDUCED SEISMICITY AND SURFACE DEFORMATION AT

THE GEYSERS GEOTHERMAL FIELD, N. CALIFORNIA

Paul Segall and Antony Mossop.

ALTERATION/PARAGENETIC STUDIES AND ADULARIA AGE-DATING TO CONSTRAIN THE NATURE AND TIMING OF THE TRANSITION FROM LIQUID-TO VAPOR-DOMINATED CONDTIONS AT THE GEYSERS, CALIFORNIA Jeffrey B. Hulen, Joseph N. Moore and Matthew T. Heizler ....

FIELD STUDIES USING NUMERICAL MODELING

K. K. Bloomfield

GEOLOGIC ANALYSIS AND THERMAL-HISTORY MODELING OF THE GEYSERS HYDROTHERMAL SYSTEM, CALIFORNIA

Denis L. Norton and Jeffrey B. Hulen

MICROSEISMIC MONITORING AT THE GEYSERS

A. Kirkpatrick, E. L. Majer and J. E. Peterson, Jr.

MONITORING $\mathrm{H}_{2} \mathrm{~S}$ AT THE GEYSERS BY CROSS-DISPERSION INFRARED SPECTROMETRY

Charles Stevens, Jim Curry and Carol Bruton 
TRACING THE FLOW OF EFFLUENT INTO THE GEYSERS STEAM FIELD

Michael C. Adams

THE MINERALOGIC AND FLUID-INCLUSION RECORD OF THE TRANSITION

FROM LIQUID- TO VAPOR-DOMINATED CONDITIONS AT THE

GEYSERS CALIFORNIA

J. N. Moore, M. C. Adams and A. J. Anderson

FEDERAL GEOTHERMAL RESEARCH PROGRAM UPDATE FISCAL YEAR 1998 DOWNHOLE MICROSEISMIC MONITORING

James Rutledge and James Albright

DIXIE VALLEY FIELD STUDIES

INDIGENOUS OIL IN THE DIXIE VALLEY GEOTHERMAL SYSTEM, NEVADA, AS A POTENTIAL TRACER OF NATURAL AND PRODUCTION-INDUCED

RESER VOIR PROCESSES

Jeffrey B. Hulen, James W. Collister and Stuart D. Johnson

ALTERATION MINERALOGY AND MAPPING OF OUTCROPS ADJACENT TO THE

DIXIE VALLEY GEOTHERMAL FIELD, NEVADA

Susan Juch Lutz and Joseph N. Moore

SOLUTE ISOTOPIC COMPOSITIONS IN GEOTHERMAL FLUIDS AT THE DIXIE

VALLEY GEOTHERMAL FIELD

Gregory Nimz

APPLICATION OF MICROGRAVIMETRY TO GEOTHERMAL RESERVOIR MANAGEMENT

Rick Allis

LIST OF CONTACTS FOR RESERVOIR TECHNOLOGY

3-209

AUTHOR INDEX

4-1

KEYWORD INDEX 


\section{INTRODUCTION}

The Geothermal Research Program of the Department of Energy (DOE) has as its mission:

To work in partnership with the U.S. industry to establish geothermal energy as a sustainable, environmentally sound, economically competitive contributor to the U.S. and world energy supply.

The Office of Geothermal Technologies in DOE conducts research in Exploration Technology and in Reservoir Technology to provide the tools needed for the discovery and utilization of geothermal resources. These programs focus on the scientific and engineering studies related to the earth sciences, and this compendium of summaries presents a review of progress in the geoscience research projects funded by the DOE Geothermal Research Program.

Exploration Technology and Reservoir Technology research is designed to support the needs of industrial, community, and private utilization of geothermal resources through development and verification of new technologies for exploration, fluid production and injection, and prediction of reservoir lifetime. The approach used to accomplish these objectives is to: (1) conduct DOE-sponsored research to meet the long-term needs of the geothermal industry; and (2) fund cost-shared research with industry in areas of greatest current need. This geothermal research relies on the continuing review and direction of the U.S. geothermal industry.

The multi-disciplinary nature of the problems in exploration technology and reservoir technology leads to a number of interrelated research projects. The organization of this compendium provides groupings of research projects to show this interrelationship. To provide better access to information concerning any single topic or method, the index provides the beginning page number for each summary that deals with the key word listed. The key words indicate several other relationships between the research projects.

These research summaries are intended to clearly present the objectives, technical approach, and project status of each project. Each also contains discussions of the background, research results, and future plans for the project. References are given for recent technical publications related to the projects. Please feel free to contact the investigators if you desire more information or if you have any questions.

\section{Exploration Technology}

This research is conducted to provide the geothermal industry with the theoretical and analytical tools needed to locate and characterize active hydrothermal systems that can provide useful energy. Research projects have advanced the state-of-the-art in geophysical surveys to the point where we are now able to identify fractured rocks which act as fluid flow paths for hydrothermal systems. Efforts are underway to integrate the available tools for geothermal exploration into a relational package with the capabilities of evaluation and decision making for the drilling and characterization of a geothermal prospect. The fundamental testing of an integrated exploration system will rely on several geothermal exploration case histories now being developed in cooperation with the geothermal industry.

\section{Reservoir Technology}

The geothermal Reservoir Technology studies have been able to spur the development of conceptual modeling and computer simulation of geothermal reservoir processes. Research projects at several cooperating institutions have progressed from the reservoir modeling of the petroleum industry into the more complex simulation of fractured, multi-phase, multi-temperature geothermal systems. The development of chemical tracers, which are compatible with the environment and can be detected at 
minute levels, has enabled the geothermal industry to predict the cooling effect of injection, and to distribute injection wells in the most favorable locations to maintain reservoir pressure and flow rate.

Marshall Reed, Program Manager

Office of Geothermal Technologies, EE-12

U.S. Department of Energy

Washington, DC 20585

Telephone: (202) 586-8076

Telefax: (202) 586-8076

E-mail: marshall.reed@ee.doe.gov 


\title{
ELECTROMAGNETIC METHODS FOR GEOTHERMAL EXPLORATION
}

\author{
Ki Ha Lee \\ Lawrence Berkeley National Laboratory
}

\section{KEY WORDS}

MT, CSMT, Source Effects, Single-hole EM, Electrical Conductivity

\section{PROJECT BACKGROUND AND STATUS}

Electromagnetic (EM) methods with applications to geothermal exploration began in 1993, when TransPacific Geothermal Corp. (TGC) consulted with LBNL in evaluating the CSMT data collected near Vale, Oregon; more recently the company has been involved in the exploration of the El Hoyo-Monte Galán field in Nicaragua. Initially LBNL interpreted Controlled Source Magnetotelluric (CSMT) data provided by TGC using available LBNL-two-dimensional MT inversion codes. The MT inversion is based on plane-wave assumption. Data obtained from CSMT surveys are contaminated by source effects, mostly in the form of 'footprints' and multitudes of wavenumber effects. As a result straightforward analysis of CSMT data using MT inversion is sometimes problematic. Therefore, our research has been focused on finding ways to identify source effects and using them to better interpret CSMT data. We plan to continue assisting US geothermal industry's efforts by providing means to correctly interpret data collected from CSMT surveys.

Inductive resistivity logging has long been an important tool because of the sensitivity of electrical resistivity to variations in reservoir properties. Electromagnetic Instruments Inc. (EMI) is engaged in the development of new type of such a tool for geothermal exploration. The new device, termed GEO-BILT (Geothermal Borehole Induction Logging Tool), is based on the US- developed and Japanese-owned prototype MAIL tool. It is anticipated that the new tool will provide EM data suitable for single-hole imaging. The development of imaging methods is an integral part of the overall goal of the borehole EM technology for geothermal applications. Mapping of producing fractures and other high-permeability zones are critically important because they play such an important role in the productivity of geothermal reservoirs. In FY-1988, in support of this critical need, researchers from three National Labs (LLNL, LBNL, and SNL) and the University of Utah started investigating single-hole EM imaging for fracture characterization.

\section{PROJECT OBJECTIVES}

\section{Technical Objectives}

- Advance the utility of the controlled-source magnetotelluric (CSMT) method when used in conjunction with the MT method for

(a) exploration of geothermal fields, and

(b) characterization of reservoirs at a regional scale.

- Develop EM imaging schemes for mapping fractures using single-hole EM data.

\section{Expected Outcomes}

- $\quad$ Provide improved means for interpreting MT and CSMT data. 
- Develop single-hole EM imaging capability for fracture mapping and to improve general reservoir characterization.

\section{APPROACH}

Source effects in CSMT: There is an essential difference between MT and CSMT methods in terms of the nature of the source field. The MT source is natural and the resulting electromagnetic field is a plane wave which reaches the earth surface at angle, but travels vertically once it gets transmitted into the ground. On the other hand, the CSMT source field is man-made and consists of a spectrum of many wavenumbers. The electric-to-magnetic field ratio in regions near the source deviates from plane-wave impedance, thus straightforward application of plane-wave analysis results in erroneous conclusions. Investigation has been focused on the impedance of the CSMT data in the wavenumber domain.

Single-hole EM imaging: The most likely conduit of geothermal fluids is either through fractures or zones of highly permeable porous formations. In order to map and characterize these features we consider two types of inversion/imaging algorithms. The first one will be useful in mapping fractures in an essentially simple formation. A fracture may be described by its location, dipping angle, size, and the electrical property of fluids in it. We have developed the highly efficient forward modeling code HFSHEET for computing EM responses of fractures, and we will use them in the development of an inversion algorithm. The second algorithm consists of an efficient approximate 3-D inversion, specifically designed for analyzing data obtained in single borehole configurations. An integral-equation method formulated in cylindrical coordinates is being considered. In this approach, unlike others such as the finite element method, only the portion of volume in the general vicinity of the borehole needs to be investigated.

\section{RESEARCH RESULTS}

Source effects in CSMT: The finite wavenumber approach leads to an asymptotic expression between the impedance and the various field components. Initial results using a few chosen wavenumbers to approximate fields by finite sources shows limited success. In order to determine the wavenumberdependent source effects, and potential use of wavenumber-domain impedance for estimating MT impedance, we have been investigating harmonic (wavenumber) fields in cylindrical and spherical coordinates. Preliminary results indicate that harmonics in cylindrical coordinates offer better results than those in spherical coordinates (Smith and Lee, 1999). This is because it is more natural to match boundary conditions of the harmonic fields in the cylindrical coordinates.

- Single-hole EM imaging: We began by conducting a numerical feasibility study using computer code HFSHEET developed at LBNL. The code can be used to analyze EM responses of thin conductive or resistive fractures. Preliminary results showed that a fracture can be detected and characterized if a singlehole EM tool is developed with a string of multiple-offset sensor modules, each capable of measuring three components of the magnetic field.

\section{FUTURE PLANS}

Source effects in CSMT: Complete the analysis of source effects and establish methods of interpreting CSMT data with source effects.

Single-hole EM imaging: Analyze existing field data, if any; the results will then be used to update the EMI tool specifications. Complete the formulation of algorithms and the feasibility study for mapping fractures and 3-D approximate inversion. Conduct a feasibility study for fracture mapping using inversion algorithms. Begin development of a 3-D forward modeling method using the integral equation in cylindrical coordinates, which will then be used in the development of the 3-D inversion code. 


\section{INDUSTRY INTEREST AND TECHNOLOGY TRANSFER}

CSMT methods have been widely used in geothermal exploration in hostile environments. This project has been a joint TGC and LBNL effort (other companies might participate in the project the future). TGC will provide field support, CSMT data, and other relevant geophysical and geological information.

EMI is currently developing the single-hole EM system. When completed, the system will be tested in various US geothermal fields (e.g., The Geysers, Dixie Valley) for fracture mapping. Three National Laboratories (LBNL, LLNL, and SNL), the University of Utah, EMI, and US geothermal producers will participate in the imaging system effort in order for the tool to be successfully adapted and deployed in US.

\section{REFERENCES}

Smith T., and Lee, K.H., 1999, Single harmonic approximation of controlled source magnetotellurics, in preparation to submit for publication in Geophysics. 


\title{
GEOPHYSICAL STUDIES OF THE BLUE MOUNTAIN, NEVADA, GEOTHERMAL SYSTEM
}

\author{
Howard P. Ross and David R. Langton \\ Energy \& Geoscience Institute \\ University of Utah
}

\section{KEY WORDS}

Blue Mountain, geophysics, electrical resistivity, self-potential, temperature gradient

\section{PROJECT BACKGROUND AND STATUS}

The Blue Mountain geothermal area is located in Humboldt County, Nevada about $35 \mathrm{~km}$ west of Winnemucca. The geothermal system was discovered during the exploration of a precious metals prospect. Drilling prior to 1997 had focused on the gold mineralization, and the geothermal system was largely unexplored. The geologic setting and exploration results as of 1991 were reported at the Geothermal Resources Council meeting (Parr and Percival, 1991). The Blue Mountain geothermal system is another covered hydrothermal resource, without surface manifestations (hot springs) due to the presentday geothermal system to guide exploration and evaluation. In 1996 Noramex Corporation, the U.S. subsidiary of Blue Mountain Power Company (Brian D. Fairbank, President), was awarded a Cooperative Agreement with the Department of Energy, Office of Geothermal Technology, for cost-shared exploration drilling of the geothermal system. In April 1996 Blue Mountain Power Co. and the Energy \& Geoscience Institute (EGI) completed a Right of Entry Agreement for Technical Data Gathering which provides for cooperative study of the geothermal resource. BMPC has provided access to the property and drill holes, and supporting geologic and geophysical studies, and EGI has completed a number of geophysical surveys and limited geochemical studies.

\section{PROJECT OBJECTIVES}

The objectives of this project are to document the geophysical expression of this geothermal resource area and to interpret and understand the geophysical data sets. This understanding will contribute to a refined model of the geothermal system and may provide guidance for the BMPC drilling of intermediate and/or deep exploration test holes under the BMPC-DOE Cooperative Agreement.

\section{Technical Objectives}

- Complete a detailed self-potential (SP) survey which includes but extends beyond the known thermal occurrence, which will document the SP expression of the known resource and search for additional thermal fluid areas.

- Complete temperature logging of available mineral boreholes and temperature-gradient boreholes to better characterize the thermal potential of the system.

- Work with BMPC geologists to interpret available geological, geochemical and geophysical data to advance the exploration of the system.

- Report the technical data and exploration results to the geothermal community. 


\section{Expected Outcomes}

- The research should contribute to improved siting criteria for the proposed BMPC - DOE cooperative drill holes.

- The research will provide an opportunity to characterize the SP expression of the geothermal resource in a complex area of known artesian thermal fluids and closely related sulfide mineralization.

- An integrated database and exploration strategy will be made available to the geothermal community for this type of geothermal occurrence and geologic setting.

\section{APPROACH}

The objectives will be achieved by completing state-of-the-art geophysical surveys (electrical resistivity, $\mathrm{SP}$, temperature-depth logging) and interpreting the resulting data jointly with BMPC geologists. A careful review of the existing BMPC data package will indicate limitations of the initial database and indicate what new survey work can be completed, at modest cost, to aid in selecting key locations for deeper drill holes. EGI plans to log all new mineral boreholes and temperature gradient holes drilled by BMPC, and to analyze the fluid chemistry of any clean fluid samples obtained from drill holes.

\section{RESEARCH RESULTS}

An SP survey was undertaken in the spring of 1996 and extended in the spring of 1998. The completed survey includes 44.3 line-km (145,480 line-ft) of profiles for an $11 \mathrm{~km}^{2}\left(4 \mathrm{mi}^{2}\right)$ area. Survey results show three major SP minima of $-278,-255$ and $-202 \mathrm{mV}$, and three broad maxima of about 2,30 , and $51 \mathrm{mV}$ which may be (in part) dipolar highs of the minima. The $-278 \mathrm{mV}$ minimum occurs within the known thermal anomaly, including artesian thermal fluids in mineral boreholes, and the main area of known sulfide mineralization. Minima of -255 and $-202 \mathrm{mV}$ occur west of the range front over alluvial cover. BMPC drilled holes BM-88, -90 , and -92 in 1997, partially testing these SP anomalies and substantially enlarging the known area of anomalous subsurface temperatures.

Temperature $\operatorname{logs}$ have been completed for 11 boreholes to date and these data, with additional temperature measurements by BMPC in earlier holes, provide the temperature database for the geothermal area. The highest temperature observed to date is $81.2^{\circ} \mathrm{C}$ at a depth of $108 \mathrm{~m}$ (BM-93). Several holes exhibit bottom-hole temperature gradients greater than $310^{\circ} \mathrm{C} / \mathrm{km}$.

Projected temperatures at depths of $500 \mathrm{~m}$ exceed $200^{\circ} \mathrm{C}$ for nine of the 11 boreholes for which detailed temperature data are available. It is encouraging that no temperature reversals have been noted in the logging to date, although the temperature gradients decrease with depth in several boreholes. Anomalous temperatures have now been recorded along a distance of 11,000 feet $(3.35 \mathrm{~km})$ in a northeasterly direction. Independent information regarding possible reservoir temperatures is available from geothermometry of three fluid samples collected from BM-90 in April 1997 by BMPC geologists. Joseph Moore (EGI) found the samples to be a relatively dilute geothermal water with a salinity slightly more than $3000 \mathrm{ppm}$ TDS and geothermometer temperatures of $103-119^{\circ} \mathrm{C}$. BM-90 is located on the southern limit of the drilled area, about 10,200 feet from drill holes BM-78 through BM-86. BM-90 fluids may represent well-mixed fluids or a secondary reservoir rather than the main higher-temperature reservoir.

BMPC has provided electrical resistivity data obtained as part of a 1988 induced polarization survey which covers much of the thermal area discovered during the mineral exploration program. The five dipole-dipole profiles used electrode separations of $500 \mathrm{feet}$, and probably explored to depths of about 1000 feet. The lowest observed resistivity values associated with the thermal area (in these data) are 10 ohm-m. A preliminary interpretation gives little encouragement for any substantial area of low resistivity 
$(<10 \mathrm{ohm}-\mathrm{m})$ within 1000 feet of the surface. In 1998 EGI and a subcontractor, Consolidated Geophysical Surveys (CGS) completed a second resistivity survey which included four dipole-dipole lines of $500 \mathrm{ft}$ dipoles, and one line of $1000 \mathrm{ft}$ dipoles (to explore to depths of about $2000 \mathrm{ft}$ ).

Numerical modeling of the new profiles reveals several narrow, low-resistivity ( $1-5 \mathrm{ohm}-\mathrm{m})$ bodies associated with the SP anomalies, and at depths of about $1000 \mathrm{ft}$ beneath the thermal and mineralized area. High induced polarization values (Chargeability, $M$ ) associated with most low-resistivity zones suggest sulfide mineralization and alteration may contribute to the low-resistivity bodies. Figure 1 illustrates the numerical model interpretation for resistivity line BM-1, oriented east-northeast across the thermal area, and compares it with SP and temperature data. Note the collocation of low resistivity, high chargeability, and SP minima on this line. The integrated database suggests the low-resistivity bodies may be areas of fluid conduits above a reservoir at depth, and that the fluids follow older mineralized fractures that have been reopened. The new data are encouraging for the presence of a high-temperature reservoir at depth, and offer specific targets for future drilling.

\section{FUTURE PLANS}

Plans for FY-99 include the temperature logging of intermediate-depth gradient holes to be drilled by BMPC, and completion of the integrated geologic and geophysical interpretations. The results will be documented and submitted for presentation at the 1999 Geothermal Resources Council Meeting in Reno.

\section{INDUSTRY INTEREST AND TECHNOLOGY TRANSFER}

\section{Organization}

Blue Mountain Power Company

Newmont Exploration Limited

\section{Type and Extent of Interest}

Resource evaluation and drill target selection Geophysical data regarding mineral potential

\section{REFERENCE}

Parr, A.J., and Percival, T.J., 1991, Epithermal gold mineralization and a geothermal resource at Blue Mountain, Humboldt County, Nevada: Geothermal Resources Council Transactions, v.15, p.35-39. 


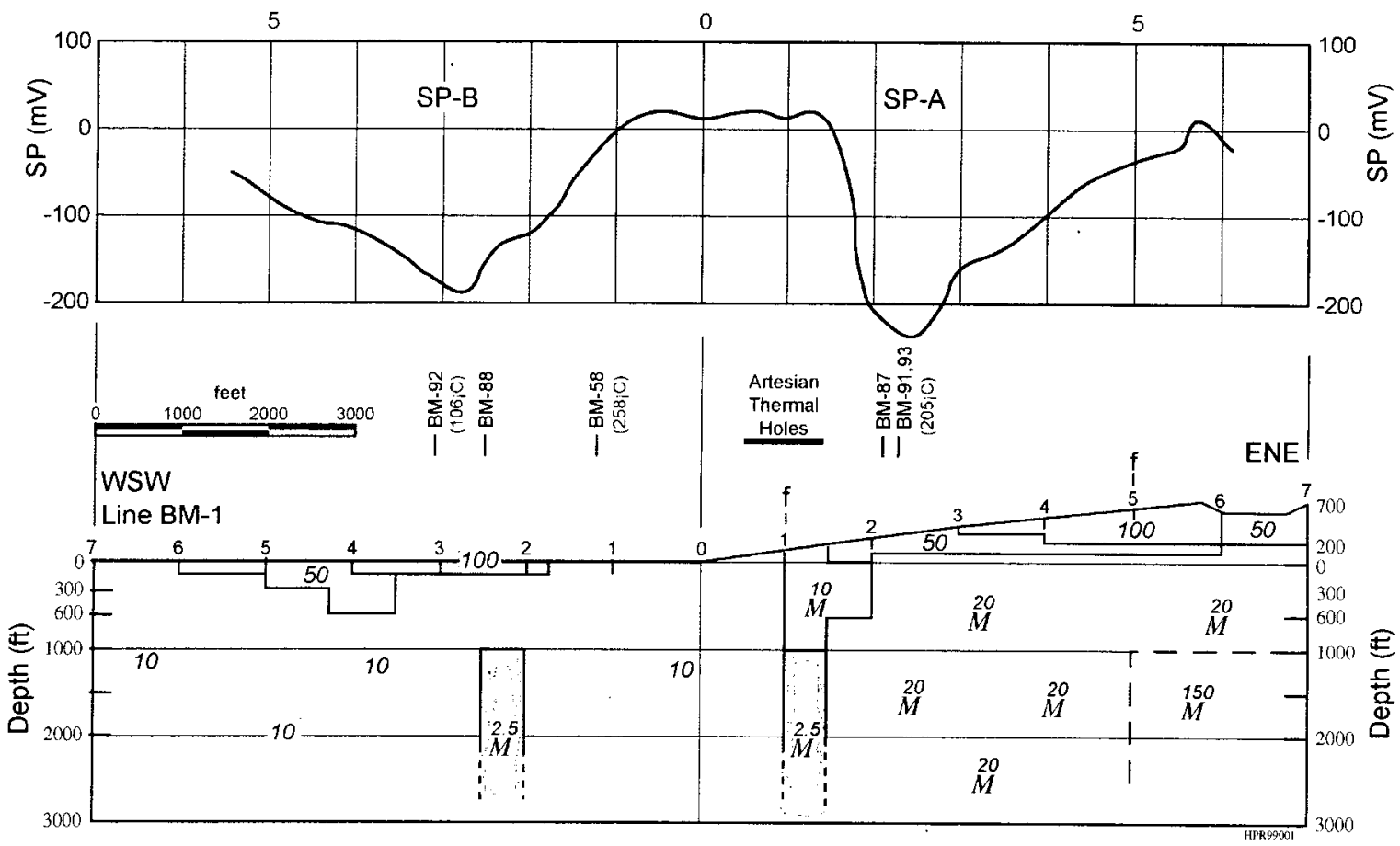

Figure 1. Numerical model for electrical resistivity line BM-1 ( $1000 \mathrm{ft}$ dipoles). Numbers in geometric bodies are intrinsic resistivities (ohm-m). $M$ indicates chargeability greater than 50 milliseconds (ms). Self-potential profile corresponding to the resistivity line is shown above. The locations of nearby drill holes (with projected $\mathrm{T}$ at $500 \mathrm{~m}$ ) and the area of artesian thermal drill holes are also shown. 


\title{
GEOTHERMAL INDUSTRY TEMPERATURE GRADIENT DATA FOR THE GREAT BASIN
}

\author{
Arnold J. Blanton, Penelope C. Sackett, Susan S. Priest, and John H. Sass \\ U. S Geological Survey
}

\section{KEY WORDS}

temperature, geothermal, Great Basin, heat flow

\section{PROJECT BACKGROUND AND STATUS}

The project grew out of an effort by one of us (JHS) to obtain access to industry geothermal gradient data gathered in the 1970s and early 80 s by various geothermal industry groups. The purpose of seeking these data was to provide detailed gradient information to supplement and complement the regional heat-flow data obtained by USGS and other investigators over the past 3 decades. The effort was triggered by a review and update of Great Basin heat-flow data initiated in 1995 with the support of the USGS Volcano Hazards Program (VHP). Initially, data in the public domain held by INEEL was reviewed, copied and processed. Further inquiries revealed that the bulk of the remaining industry data were in the possession of CalEnergy Inc. A joint effort was then established in which USGS personnel visited CalEnergy's offices at Ridgecrest, $\mathrm{CA}$ for an extended period to compile a detailed inventory of the data in the CalEnergy Files. This phase of the study was supported by VHP through its Heat Flow and Heat Mining Project headed by John Sass

\section{PROJECT OBJECTIVES}

The primary objective of the project is to get the heretofore proprietary industry data into the public domain in a format that will provide easy access by all interested parties.

\section{Technical Objectives}

- Digitize location, elevation and temperature data.

- Design a GIS-based display of data locations.

- Establish an Open-File web site to facilitate data retrieval.

\section{Expected Outcomes}

- A web site accessible to any interested industry, government or academic user.

- An updated heat flow map of the Great Basin showing the detailed thermal regimes of selected industry geothermal prospects

\section{APPROACH}

Analog data from CalEnergy Inc.'s files will be digitized as Excel spreadsheets. Locations will be plotted on a page-scale digital map of the Great Basin and subsidiary, more detailed maps will be compiled as required. Each map location will be a "hot button" linking to either a more detailed location or individual temperature profiles. These data will be transformed into "pdf" format and transferred to a USGS OpenFile web site. Lithologic data will be merged with the existing USGS inventory of thermal conductivity 
data to estimate formation thermal conductivities. These, in turn, will be combined with least-squares determinations of temperature gradients to provide estimates of heat flow.

\section{RESEARCH RESULTS}

Inasmuch as the CalEnergy phase of the project was initiated only in the summer of 1998 and the data purchase, consummated late in the year, we have no research results to report at this time.

\section{FUTURE PLANS}

Assembly of the digital data for the web site is proceeding, and we expect to have a draft compilation for review by USGS colleagues and other interested parties by mid-April, 1999. The heat flow paper should be in review on about the same schedule.

\section{INDUSTRY INTEREST AND TECHNOLOGY TRANSFER}

We expect a considerable degree of interest from various geothermal industry sources when the existence of the web site becomes widely known. Also, the heat flow paper should attract considerable attention. In the meantime, details of the thermal regime of various prospects in the Great Basin should be of value in evaluating prospective demonstration sites for Enhanced Geothermal Systems.

\section{Organization}

CalEnergy

PERI

GeothermEx

LANL

\section{Type and Extent of Interest}

Digital presentation, and prospects in regional context

EGS sites

EGS sites

EGS sites

\section{REFERENCES}

Sass, J.H., Lachenbruch, A.H., Munroe, R.J., Greene, G.W., and Moses, T.H., Jr., 1971, Heat flow in the western United States: Jour. Geophys. Research, v. 76, no. 26, p. 6376-6413.

Sass, J.H., Ziagos, J.P., Wollenberg, H.A., Munroe, R.J., di Somma, D.E., and Lachenbruch, A.H., 1977, Application of heat-flow techniques to geothermal exploration, Leach Hot Springs area, Grass Valley, Nevada: U.S. Geol. Survey Open-File Report 77-762.

Example of a thorough heat-flow study of a geothermal energy prospect

Lachenbruch, A.H., and Sass, J.H., 1977, Heat flow in the United States and the thermal regime of the crust, in The Earth's Crust: Am. Geophys. Union Geophys. Mon. 20, Am. Geophys. Union, Washington, D.C., p. 626-675.

\section{Review of regional heat flow with some simple hydrothermal models}

Sass, J.H., Kennelly, J.P., Jr., Wendt, W.E., Moses, T.H., Jr., and Ziagos, J.P., 1981, In-situ determination of heat flow in unconsolidated sediments: Geophysics, v. 46, p. 76-83.

\section{Technique for determination of thermal conductivity in situ}

Duffield, W.A., Sass, J.H., and Sorey, M.L., 1994, Tapping the Earth's Natural Heat: U.S. Geological Survey Circular 1125, $63 \mathrm{p}$. 
Sass, J.H., Lachenbruch, A.H., Galanis, S.P., Jr., Morgan, P., Priest, S.S., Moses, T.H., Jr., and Munroe, R. J., 1994, Thermal regime of the southern Basin and Range Province: 1. Heat flow data from Arizona and the Mojave Desert of California and Nevada: Journal of Geophysical Research, v. 99, p. 22,093-

$22,119$.

Updated study of southern Basin and Range province

Lachenbruch, A.H., Sass, J.H., and Morgan, P., 1994, Thermal regime of the southern Basin and Range Province: 2. Implications of heat flow for regional extension and metamorphic core complexes: Journal of Geophysical Research, v. 99, p. 22,121-22,133.

Compares and contrasts SBR with Great Basin

Sass, J.H., 1995, Mining the Earth's heat in the Basin and Range: Geothermal Resources Council Bulletin, v. 24 , p. $125-129$.

Sass, J.H., 1996, Hot Dry Rock and the U.S. Geological Survey: A question of priorities: Geothermal Resources Council Bulletin, v. 25, no. 8, p. 313-315.

Robertson-Tait, A and Sass, J.H.,1998, Potential sites for "Enhanced Geothermal Systems" in the Western United States: Geothermal Resources Council Bulletin, v27, in press. 


\title{
GEOTHERMAL RESOURCE/RESERVOIR INVESTIGATIONS BASED ON HEAT FLOW AND THERMAL GRADIENT DATA FOR THE UNITED STATES
}

\author{
David D. Blackwell, Kenneth W. Wisian, and John L. Steele \\ Department of Geological Sciences, Southern Methodist University, Dallas, TX 75275-0395
}

\section{KEY WORDS}

Eastern US, Western US, Geothermal Potential, Temperature, Heat Flow, Thermal Conductivity, Geothermal Gradient, Western Geothermal Database, Heat Mining.

\section{PROJECT BACKGROUND AND STATUS}

This project extends the early geothermal resource evaluations of Muffler (1979) and Reed (1985). The detailed geothermal data base developed for the Geological Society of America Decade of North American Geology (DNAG) Geothermal Map of North America (Blackwell and Steele, 1992; Blackwell et al., 1989, 1991) was expanded and updated in a previous project (Blackwell et al., 1996). Publications on the status of the previous project are contained in Blackwell et al. (1992, 1993, 1994, 1995, 1996). This project was initiated in January, 1997 and is focused on specific area heat flow and geothermal data sets in the western United States. The change in focus is due to the different nature of the geothermal resource in the high heat flow areas of the western US.

\section{PROJECT OBJECTIVES}

\section{Technical Objectives}

The generalized technical objectives of this project are to:

- $\quad$ increase the precision and accuracy of geothermal resource estimates and assessments;

- $\quad$ to regionally characterize geothermal resources in the United States.

These objectives will be met by the specific technical objectives:

- develop a data base of, and make available for the process of resource evaluation, site specific heat flow, geothermal gradient, and thermal conductivity information for western United States;

- $\quad$ use results to develop generalized models for the site specific evaluation of resource potential;

- update heat flow, geothermal gradient and ancillary (thermal conductivity, sediment thickness, surface temperature, etc.) data bases and maps for the US as new thermal data are published;

- develop and operate an Internet home page with results of the project available in the form of downloadable data and map summaries of results.

\section{Expected Outcome}

- $\quad$ First, develop the specifications and data for a site specific heat flow and geothermal gradient data base for the western US; 
- $\quad$ Second, new exploration and evaluation models for Basin and Range geothermal systems;

- Third, a digital representation of the heat flow for the western US;

- Fourth, an updated heat flow data base and a series of digital data bases designed to estimate temperature in the depth range 3 to $5 \mathrm{~km}$ at a horizontal resolution of about $5 \mathrm{~km}$ over the US;

- Fifth, an Internet home page: the address is http://www.smu.edu/ geothermal.

The results should increase the accuracy of regional resource estimates by at least $25 \%$ compared to previously available information due to the increased spatial detail and the inclusion of additional geothermal variables.

\section{APPROACH}

This project is in the middle of a multi-year effort to evaluate the geothermal conditions at depths of several $\mathrm{km}$ in the United States. By expanding the focus of the project to the more complex geothermal conditions in the western Cordillera, from the eastern United States focus in the previous study, the information on wells and geothermal conditions is greatly expanded. The data for the resource analysis in the western US are being collected from a variety of published and unpublished sources. A large number of formerly unavailable company temperature gradient and heat flow exploration data are being collected, and are being compiled and synthesized, in addition to the public domain data openly available in papers and open-file reports.

Geothermal resource estimates and assessments by this and other projects are supported by making available for the process the most up to date heat flow, geothermal gradient, and thermal conductivity information in useful digital formats. Distribution of the results in digital form via the World Wide Web on the Internet is part of the project.

\section{RESEARCH RESULTS}

Regional Heat flow and Thermal Properties Data Base. The data base of heat flow measurements in the United States published by Blackwell et al. (1989) and used in the preparation of the (DNAG) 1:5,000,000 Geothermal Map of North America (Blackwell and Steele, 1992, see also Blackwell et al., 1991, 1992) was updated as of September, 1996 with a total of 2191 sites. The entry for each site includes location, thermal gradient, geology, and other pertinent data as described in previous reports. The site information is available for downloading on the Internet home page in spreadsheet form.

Geothermal System Heat flow and Thermal Properties Data Base. One of the main project results is development of the geothermal system specific, thermal well, data base. The ideal set of information for each geothermal gradient/heat flow exploration site includes maximum and bottom hole temperature, depth range(s) of each well, area location (by latitude /longitude and township/range), a thermal gradient(s), heat flow, lithology, and a reference (or references) to any publication of the results as well as the source of the original thermal data. A map is shown (Figure 1) that gives the location of well sites and individual geothermal systems that are available to us at the present time (pluses) and already completed in the western geothermal database. In addition the numerical distribution of the wells is shown in Table 1. The present total is just short of 4,000 wells in 10 western states. 


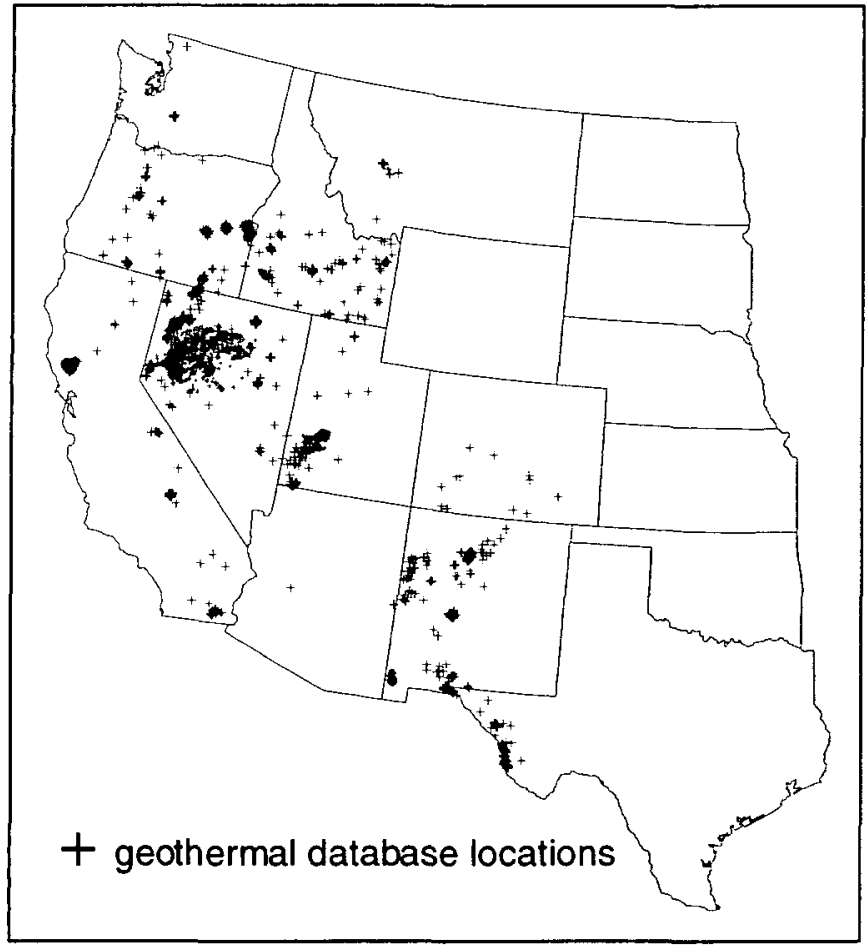

Figure 1. Map of well sites in database.

\begin{tabular}{|lc|}
\hline \multicolumn{1}{|c|}{ STATE } & $\underline{\text { NO. OF }}$ \\
CALIFORNIA & 731 \\
COLORADO & 12 \\
IDAHO & 307 \\
MONTANA & 79 \\
OREGON & 235 \\
NEW MEXICO & 434 \\
NEVADA & 1688 \\
TEXAS & 144 \\
\hline
\end{tabular}

Table 1. Well totals for each state.

Resource Analysis. In addition to compiling the thermal data, a resource analysis is being done. Data sets from individual geothermal areas will be described by maps and other graphical information to allow easier access to the data by interested parties (see the web page discussion below).

Quantitative analyses will also be made. Preliminary results of the analysis of the database were described by Wisian et al. (1999). They found that $95 \%$ of the geothermal systems with temperatures over $150^{\circ} \mathrm{C}$ occur in areas where the regional heat flow is greater than $80 \mathrm{mWm}^{-2}$. This result can be attributed to two factors. Young magma chambers will be found in areas with high regional heat flow as high temperature conditions are required at depth to generate magmas. Secondly, for geothermal systems related to deep circulation of water rather than localized magma systems, there seems to be a "maximum" depth of circulation of about $6 \mathrm{~km}$. Thus the higher the heat flow in an area, the higher will be the temperature experienced by the deeply circulation water.

Web Page Data. A major part of the dissemination of the results is the availability of the data in spread sheet form and downloadable from our home page on the World Wide Web at smu.edu/ geothermal. This site contains the database, reference lists, and US maps of various kinds. The individual geothermal system analysis results will be available on the site as well. Examples of maps of Black Rock Desert, McCoy, Desert Peak, and Grass Valley, Nevada are available and others will be added in the near future.

\section{FUTURE PLANS}

In the future there are plans to add additional data to the regional thermal properties data base and to keep updated results available by operating the home page on the Internet with the up-to-date information available there. The database of exploration heat flow wells in the western US will be developed and expanded. The regional resource evaluation and exploration methodology used in the earlier studies, with 
appropriate modifications, will be applied to the western US. Local evaluation procedures will be developed using the data.

\section{INDUSTRY INTEREST AND TECHNOLOGY TRANSFER}

We have had an increasing number of inquires from World Wide Web contacts and conventional contacts for information on temperatures and geothermal gradients. The data set on the web has been used by at least 8 groups that have sent us specific comments. Some specific interests in the results are:

\section{Organization}

Shell, The Hague

Shell, Houston

Exxon Exploration, Houston

American Electric Power

Geological Survey of Columbia

Geoheat Center

Energy Laboratory, MIT

MultiMax

Numerous Individuals

\section{Type and Extent of Interest}

Dry Hot Rock Resource Potential \& Characteristics

Temperatures at 1, 2, $4 \mathrm{~km}$ Depth, US

Geothermal Map of North America

Ground Temperatures

Thermal Mapping

Geothermal Gradients in US

Temperature for Heat Mining Economic Analysis

Sediment Thickness and Temperature

Various

\section{REFERENCES}

Blackwell, D.D., and J.L. Steele, editors, DNAG geothermal map of North Aimerica, 1:5,000,000, 4 sheets, Geol. Soc. Amer., Boulder, Co., 1992.

Blackwell, D.D., J.L. Steele, and L.S. Carter, Heat flow data base for the United States, in Geophysics of North America CD-ROM, ed. A.M. Hittleman, J.O. Kinsfather, and H. Meyers, NOAA, Natl. Geophys. Data Center, 1989.

Blackwell, D.D., J.L. Steele, and L.S. Carter, Heat flow patterns of the North American Continent; A discussion of the geothermal map of North America, p. 423-437, in Neotectonics of North America, ed. D.B. Slemmons, E.R., Engdahl, M.D. Zoback, and D.D. Blackwell, Geol. Soc. Am. Decade of North Am. Geol., Decade Map V. 1, 498 pp., 1991.

- Blackwell, D.D., J.L. Steele, and L.S. Carter, Heat flow patterns of the United States: a key component of geothermal resource evaluation, Trans. Geothermal Resources Council, 16, 119-124, 1992.

Blackwell, D.D., J.L. Steele, and L.S. Carter, Geothermal resource evaluation for the eastern United States based on heat flow and thermal conductivity distribution, Trans. Geothermal Resources Council, 17, 97-103, 1993.

Blackwell, D.D., J.L. Steele, and K.W. Wisian, Results of geothermal resource evaluation for the eastern United States, Trans. Geothermal Resources Council, 18, 161-164, 1994.

Blackwell, D.D., K.W. Wisian, and J.L. Steele, Geothermal regime in the central and eastern United States east of the Rocky Mountains, pp. 649-653, in Proc. World Geothermal Cong. 1995, ed. E. Barbier, G. Frye, E. Iglesias, and G. Palmason, V. 1, 665 pp., 1995.

Blackwell, D.D., K.W. Wisian, and Maria Richards, Geothermal resources of the United States based on heat flow and gradient information, Final Report DOE contract C91-103450, 75 pp., 1996. 
Muffler, L.J.P., ed, Assessment of Geothermal Resources of the United States--1978, U. S. Geol. Surv. Circ. 790, 163 pp., 1979.

Reed, M.J., ed., Assessment of low-temperature geothermal resources of the United States-1982, U. S. Geol. Surv. Circ. 892, 73 pp, 1983.

Wisian, K. W., D. D. Blackwell, and M. Richards, Heat flow in the western U. S. and extensional geothermal systems, Proceedings, $24^{\text {th }}$ Workshop on Geothermal Reservoir Engineering, Stanford University, Stanford, Ca., January 25-27, 8pp. 1999. 


\title{
REMOTE SENSING AND GIS: TOOLS FOR GEOTHERMAL EXPLORATION AND FIELD MANAGEMENT
}

\author{
Gregory D. Nash and Michael W. Hernandez \\ Energy and Geoscience Institute \\ University of Utah
}

\section{KEY WORDS}

Hyperspectral, Thematic Mapper, AVIRIS, ATLAS, geobotany, thermal, GIS, Dixie Valley, Cove FortSulphurdale, Roosevelt Hot Springs

\section{PROJECT BACKGROUND AND STATUS}

Various remote sensing techniques are being tested for use in geothermal exploration and field management. These include (1) hyperspectral and spectral data analysis to determine geobotanical and soil anomalies associated with hydrothermal convection systems and steam production, (2) testing various types of remotely sensed data for structural mapping, (3) testing airborne thermal data for mapping thermal anomalies and structure, and (4) correlating remotely sensed data with other pertinent data sets using GIS.

Several areas are currently under study including Dixie Valley, Nevada; Cove Fort-Sulphurdale, Utah; and Roosevelt Hot Springs, Utah. It is anticipated that all three areas will remain under study during 1999, although the geobotanical studies are nearing maturity. This report summarizes the research done in these areas in 1998.

\section{PROJECT OBJECTIVES}

The main objective of the above mentioned studies is to test remote sensing and GIS techniques that may be useful in mapping areas that are structurally conducive to hydrothermal fluid flow and potential geothermal power exploitation. An underlying objective is to determine appropriate methodologies that can be applied to data that will soon be produced from satellite based instruments. It has also been discovered that remote sensing can play an important role in monitoring environmental change related to steam production.

\section{Technical Objectives}

- Test current methods for image processing and analysis;

- Determine the best image processing methods for use in exploration and field management;

- Test methods of data integration and analysis in GIS;

- Determine if the techniques will be appropriate for use in future applications.

\section{Expected Outcomes}

These studies have shown that remote sensing and GIS can be useful in many ways for the geothermal industry. Current evidence indicates that these technologies will be useful for:

- Detection of geobotanical anomalies related to hydrothermal convection systems; 
- Detection of soil-geochemical anomalies related to hydrothermal convection systems;

- Characterization of structural fabric, both regionally and locally;

- Early detection of environmental changes related to steam production;

- Monitoring environmental effects related to steam production; and

- $\quad$ Enhanced data integration, correlation, and analysis.

\section{APPROACH}

The approach for these studies has been customized to individual study sites. Flexibility has been emphasized to facilitate the incorporation of new data and processing techniques into the studies as they have and may become available. A number of data types have been acquired for each of the study areas. These include:

- Dixie Valley - AVIRIS airborne hyperspectral and ATLAS airborne thermal data sets;

- Cove Fort - Landsat Thematic Mapper (TM) medium resolution data; and

- $\quad$ Roosevelt Hot Springs - Landsat TM and IRS high resolution panchromatic data.

Research design has been geared toward using these data to address specific problems at each study site. These include:

1. The analysis of the AVIRIS and ATLAS data to monitor environmental change related to production in Dixie Valley;

2. The analysis of TM data, using geobotanical units as constraints, for mapping geobotanical anomalies associated with structural features/hydrothermal convection in the Cove FortSulphurdale area; and

3. The analysis of TM and IRS data in regional and local structural mapping in the Roosevelt Hot Springs area.

All studies include the use of ancillary data, such as field spectrometer data, and field work for verification.

\section{RESEARCH RESULTS}

\section{Dixie Valley}

A geobotanical anomaly began to develop near the production area during 1995. This area was serendipitously flown by NASA Jet Propulsion Laboratory during May, 1995. The first visual manifestation of the anomaly was noticed later during the summer (Johnson, 1996). The first author visited the site during July, 1996 and found obvious signs of stress manifested in Bailey's greasewood (Sarcobatus baileyi), with a number of the shrubs appearing to be dead or dying. Subsequent visits during June, 1997 and 1998 revealed a growing area of dead Bailey's greasewood. The die-off is related to increased activity in the Senator Fumarole and the development of steaming ground. These phenomena appear to be related to reservoir boiling resulting from reduced pressure. 
Initial analysis of the AVIRIS data was finished during 1997. A vegetation index was created to show the relative density of vegetation as a function of chlorophyll. The site which would become the die-off area appeared as a textural anomaly resulting from lower chlorophyll content than surrounding areas. Further analysis using polytopic vector analysis (PVA) clearly defined the anomaly texturally from the lack of a healthy vegetation end-member (Johnson and Nash, 1998).

More recently the AVIRIS data have been reprocessed using a new set of algorithms. The data were preprocessed with ATREM to remove atmospheric effects and convert the data to apparent reflectance (Figure 1) (Gao, B-C et al., 1993). A second application of PVA again produced a healthy vegetation endmember with an improved textural definition of the geobotanical anomaly. Principal components and minimum noise fraction (MNF) were also tested using the ATREM corrected data (Green et al., 1988; Boardman and Kruse, 1994). Both of these techniques also clearly defined the anomalous area (Figures 2 and 3).

The geobotanical anomaly, although of similar albedo to other areas in the images, is easily distinguishable. Other features of similar gray-tone in the images generally consist of outcrops in the Stillwater Range with high carbonate content - probably calcite or travertine - and active channel deposits on the alluvial fans. It is believed that the area of the geobotanical anomaly is defined from the spectral effects of an associated soil anomaly as well as the lack of a healthy vegetation signature. The responsible soil chemistry has not been positively identified, but carbonate absorption is ubiquitous within the defined area.

Field work has shown that this area also contains a thermal anomaly. Therefore, airborne thermal data were acquired during July, 1998 to map thermal anomalies. The processing of these data is being done cooperatively with NASA personnel at Marshall Space Flight Center. The processing and interpretation of this data set is currently underway, but not complete. However, the raw data clearly show a thermal anomaly correlating with the vegetation die-off area (Figure 4).

The ability to map the geobotanical anomaly with hyperspectral data, before it was observed visually, supports the hypothesis that this type of remote sensing can be used to map subtle geobotanical anomalies associated with hydrothermal convection systems in exploration efforts and to monitor field environmental conditions. If vegetation anomalies can be mapped before they become visible to the human eye they can act as early warning systems to geothermal operators of impending problems. Thermal data can enhance and corroborate results.

\section{Roosevelt Hot Springs}

The focus in this area is structural mapping. TM data have been used for many years for lineament mapping as an aid in structural analysis. However, the $28.5 \mathrm{~m}$ spatial resolution of TM data limits its usefulness in the characterization of local structures. Data merging techniques have been developed to improve the spatial resolution of multispectral data, such as TM, by combining it with high spatial resolution panchromatic data. These methods preserve much of the original spectral resolution.

Indian IRS $5 \mathrm{~m}$ spatial resolution panchromatic data recently became available. Upon integration with TM data this results in a 32.5:1 improvement in spatial resolution. The Brovey transform was used to create the merged data set for this study with excellent results. The raw TM data can be seen in Figure 5 and compared to the merged data set in Figure 6. These merged data are currently being used to characterize the structural fabric of the area. It is anticipated that the initial mapping will be completed during winter/spring, 1999. 


\section{Cove Fort-Sulphurdale}

A test to determine if medium resolution multispectral data can be used to establish relationships between geobotanical anomalies and the hydrothermal convection system is the focus for the Cove FortSulphurdale study. It is believed that biogeochemical changes related to structure can occur over these systems. This study integrates processed TM data into a GIS data set consisting of factors comprising geobotanical units. The rational being that anomalies occurring within a given geobotanical unit are likely to be precipitated by an unusual catalyst rather than by normal phenological cycles. The geobotanical units are created within the GIS by integrating soil, climate, geology, topology, and available vegetation data.

Vegetation anomaly mapping is being done using Multitemporal TM data sets to create vegetation change images. The change detection methods have included derivation of percent change using (1) vegetation indices, (2) principal components, and (3) integrated ancillary data. An example can be seen in Figure 7. Final experiments are currently being conducted.

\section{FUTURE PLANS}

Future Plans include: (1) Determination of all spectral factors in the soil anomaly associated with the dieoff area in Dixie Valley; (2) analysis of Dixie Valley thermal data for ground cover/lithologic mapping and derivation of soil temperatures; (3) continuation of structural analysis for Roosevelt Hot Springs, and (4) generation of final geobotanical anomaly maps for Cove Fort-Sulphurdale.

\section{INDUSTRY INTEREST}

Organization

Oxbow Power Services

Utah Municipal Power Agency

\section{Type and Extent of Interest}

Exploration and field management

Exploration

\section{REFERENCES}

Boardman, J. W., and F. A. Kruse, 1994, Automated spectral analysis: a geologic example using AVIRIS data, north Grapevine Mountains, Nevada: Proceedings of the Tenth Thematic Conference on Geologic Remote Sensing, May 9-12, San Antonio, TX., p. I-407 - I-418.

Gao. B-C, K. B. Heidebrecht, and A.F.H. Goetz, 1993, Derivation of scaled surface reflectances from AVIRIS data: Remote Sensing of the Environment, Vo. 44, No. 2, p. 165-178.

Green, A. A., M. Berman, P. Switzer, and M. D. Craig, 1988, A transformation for ordering multispectral data in terms of image quality with implications for noise removal: IEEE Transactions on Geoscience and Remote Sensing, Vol. 26, No. 1, p. 65-74.

Johnson, G. W. and G. D. Nash, 1998, Unmixing of AVIRIS hyperspectral data from Dixie Valley, Nevada: Proceedings: Twenty-Third workshop of Geothermal Reservoir Engineering, Stanford University Stanford, CA, January 26-28, 1998, SGP-TR-158.

Johnson S., 1996, Personal communication. 


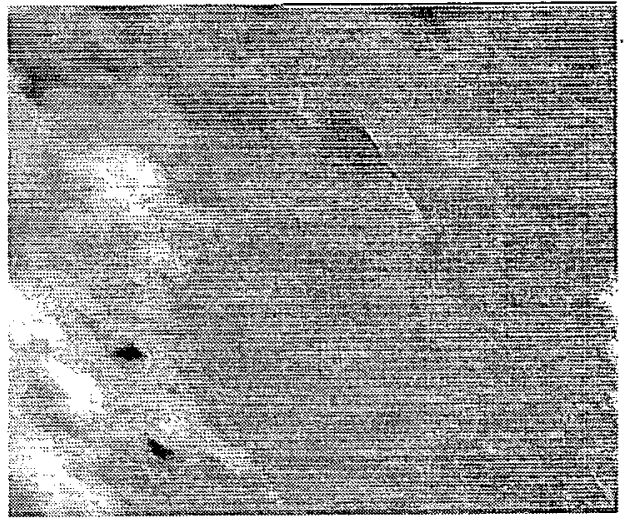

Figure 1. ATREM processed AVIRIS image.

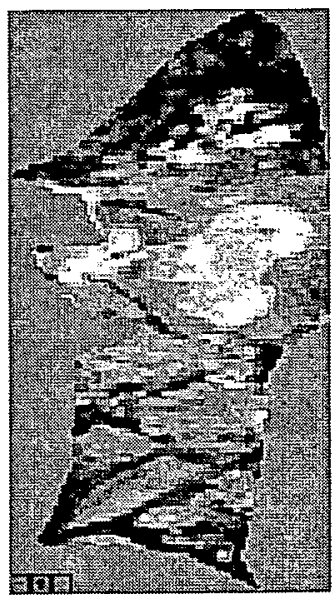

Figure 2. AVIRIS principal components image. The geobotanical anomaly is the light area near the image center.

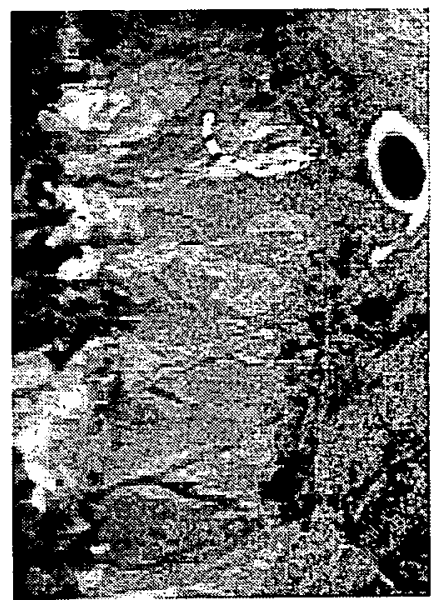

Figure 3. AVIRIS MNF band 8. The geobotanical anomaly is the light area near the image center.

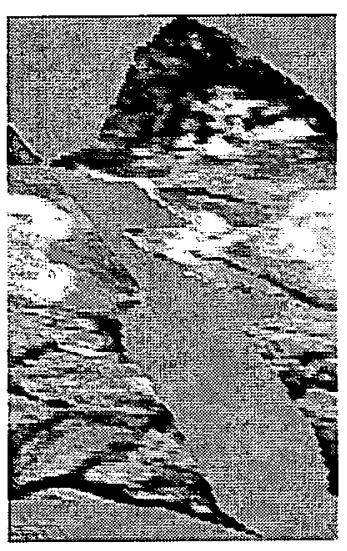

Figure 4. Thermal imagery. Thermal anomalies appear light.

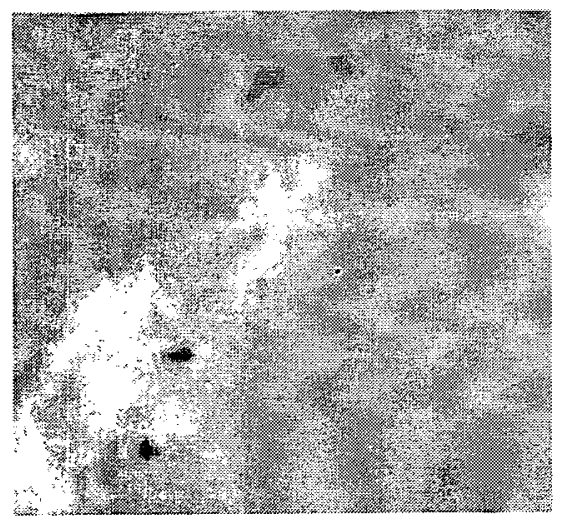

Figure 5. TM image at $28.5 \mathrm{~m}$ spatial resolution.

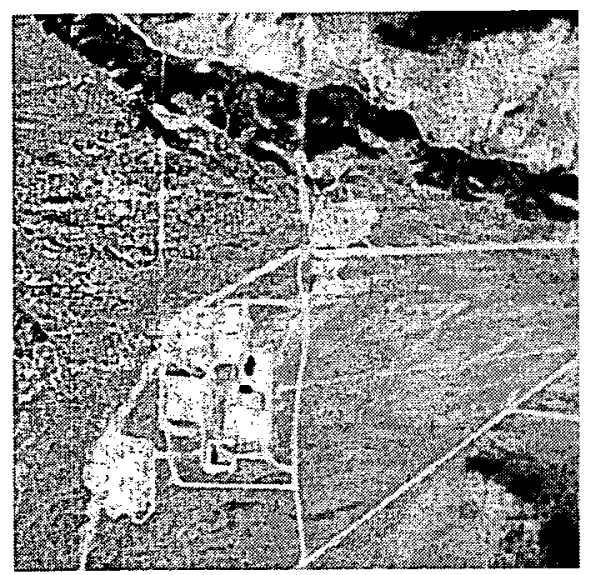

Figure 6. Merged TM/IRS panchromatic data at $5 \mathrm{~m}$ spatial resolution. 


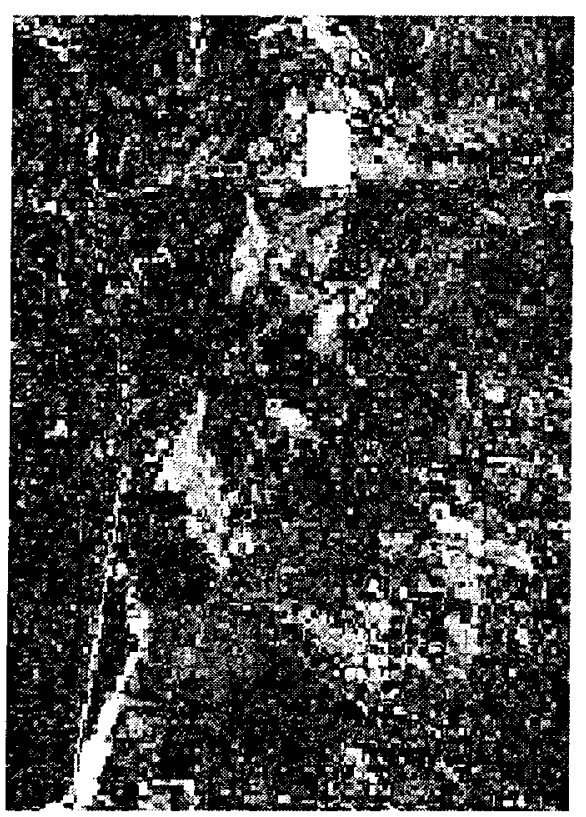

Figure 7. Example of a vegetation change image. Light areas indicate a significant temporal change. 


\title{
Results of the Geothermal Geobotany Hyperspectral Imaging Program
}

\author{
Brigette A. Martini, S. A. Cochran, D. C. Potts, and E. A. Silver \\ University of California at Santa Cruz (UCSC) \\ William L. Pickles \\ Lawrence Livermore National Laboratory (LLNL)
}

\section{KEY WORDS}

geobotany, Long Valley, The Geysers, hyperspectral images, remote sensing

\section{PROJECT BACKGROUND AND STATUS}

The gas and heat emanating from geothermal systems often produce changes in the earth's surface. A team from Lawrence Livermore National Laboratory (LLNL) and the University of California, Santa Cruz (UCSC) are collaborating to develop and validate methods to remotely detect geobotanical signatures of geothermal surface expressions. Toward this goal, we collected a database of "ground-truth" observations at California geothermal fields (1) with known effects (the Long Valley Caldera/Mammoth Mountain region), (2) with possible unknown effects (The Geysers), and (3) at a baseline site (Elkhorn Slough). The geobotanical signatures we discovered were unexpected and were easily detected and mapped across wide regions by airborne hyperspectral imagery when the spatial resolution matched the observed characteristic scale lengths of 1 to $3 \mathrm{~m}$.

In another phase of this project, we analyzed National Aeronautics and Space Administration/Jet Propulsion Laboratory (NASA/JPL) Advanced Visible Infrared Imaging Spectrometer (AVIRIS) hyperspectral images taken previously at all three sites. The analysis of the AVIRIS data shows that in some areas where plant distribution has the same 20- to 30-m spatial resolution as AVIRIS that separation of plant species and mineral types is possible. However, most of the areas we studied have smaller spatial scale lengths for most geobotanical and geological features. We have learned that acquisition of 1- to 3-m spatial-resolution hyperspectral data in the visible and near-infrared bands is required to further develop this suite of techniques. Several companies can provide data on that scale.

Finally, we have an ongoing collaboration with another U.S. Department of Energy (DOE) program at LLNL that developed an advanced hyperspectral airborne imager, called the Hyperspectral Infrared Imaging System (HIRIS). With this system, we acquired hyperspectral thermal infrared imagery from four sites at The Geysers and seven sites in Long Valley and Mammoth. These data have not been analyzed yet.

\section{PROJECT OBJECTIVES}

\section{Technical Objectives}

- Identify the attributes associated with geothermal features in the study areas.

- Collect a database of "ground-truth" observations at geothermal fields with known effects [the Long Valley/Mammoth Mountain (LV-MM) region], with possible unknown effects (The Geysers), and at a baseline site (Elkhorn Slough).

- Develop a catalog of observed plant responses. 
- Interpret aerial and satellite data to determine if geothermally induced plant and mineral variations are detectable and useable.

\section{Expected Outcomes}

- Determine whether this is a low-cost exploration method for characterizing geothermal resources and reservoirs.

\section{APPROACH}

We collected detailed botanical and geological data on the ground at a candidate site to determine the spatial and temporal variations of plant species and health. At the same time, we collected detailed spectrographic data on biota to determine whether variations in plant species or health might be detectable by remote sensing. For example, we observed that the springtime growth of some plants is accelerated over areas of warm ground, and that this growth difference causes significant changes in the reflected spectra of the plants. Once we characterized the spectral signals in an area, we evaluated imagery to determine what signals can be detected and how they might be used.

\section{RESEARCH RESULTS}

Work in Long Valley and adjacent Mammoth Mountain began with a rudimentary analysis of AVIRIS imagery acquired from JPL for these regions. This hyperspectral system produces images from 350 to $2500 \mathrm{~nm}$ with a $10-\mathrm{nm}$ bandwidth. The 224 band images have a swath length of approximately $11 \mathrm{~km}$ with a spatial resolution of $20 \mathrm{~m}$. Datasets used include a set of 1992 images covering part of the central and eastern regions of the caldera and a 1996 dataset encompassing the Mammoth Mountain region. Imagery was initially processed with ERMapper software.

Our goal at the beginning of the image analysis was to survey the study region for 'plant stress' as a function of geothermal activity using previously derived vegetation indices (Carter, 1993; Carter and Miller, 1994). Features, such as hot springs and fumaroles, can induce plant stress in the context of a hydrothermal system in a volcanic region. Elevated ground temperatures, degassing of high quantities of noxious gasses, increased acidity or alkalinity, and increased temperature of surface and groundwater can all lead to plant stress. Consequences of hydrothermal activity can include acceleration of life cycles, preferential growth of certain species as a function of type and degree of stressor, and death. Various indices sensitive to the region of plant spectral signature known as the red edge $(680-760 \mathrm{~nm})$ were performed on the images. Such indices have been used successfully in previous imaging spectroscopy studies.

High-resolution data acquired with handheld sensors have small pixels that are populated by a single species, and allow highly accurate image analysis. Airborne imagery, which has lower spatial resolution, requires advanced examination. The larger pixels of datasets, such as AVIRIS imagery, result in a high percentage of mixed pixels that cannot be interpreted unambiguously. Additionally, changes in the red edge geometry may also be due to processes outside of the hydrothermal system such as drought or anthropogenic activity. Plant stress as a function of red edge geometry is therefore more difficult to study with AVIRIS imagery. We plan to evaluate processing techniques to deal with this problem.

Initial image analysis was followed by the inception of monthly field excursions to the study areas. Fieldwork in Long Valley Caldera commenced in September 1997 and continues. Our inaugural field observations focused on major expressions of geothermal activity. We have studied and continue to monitor tree kills at both Mammoth Mountain and near Casa Diablo Hot Springs, as well as the general 
hydrothermal character of Hot Creek and Little Hot Creek, Whitmore Hot Tubs, and the Alkali Flats region.

\section{Mammoth Mountain}

Located at the far southwestern rim of the caldera, Mammoth Mountain has one of the largest expressions of geothermal activity in the region. Tree kills totaling 100 acres or more on the flanks of Mammoth Mountain are quite visible in the imagery. These kills are thought to be the result of elevated $\mathrm{CO}^{2}$ levels from degassing of magma beneath the volcano (Farrar et al., 1995). Dominant tree species in the large kill zones include Lodgepole Pine, Red Fir, and Jeffrey Pine. There is typically a zone within these kills devoid of life, which grades into dead trees with or without bark, which then grades into very unhealthy 'stressed' trees and other stressed vegetation. Stress usually takes the form of chlorosis and/or loss of needles as well as increased sap production coalescing under and over the bark. Eventually, healthy. trees and vegetation are observed in the outer limits of this gradation. This pattern is one that is echoed throughout the caldera in relation not only to elevated $\mathrm{CO}^{2}$, but also to hot spring waters and elevated soil temperatures.

Hyperspectral AVIRIS data allow identification of earth materials, whereas multispectral data, such as Landsat, are only capable of discrimination. To classify images, a set of known material spectra are needed. Extensive handheld spectra have been obtained in the Mammoth Mountain region. This collection of plant and mineral spectra is part of a growing Long Valley spectral library, which includes a myriad of earth materials from the study region. Extensive mineral libraries are available from the U.S. Geological Survey and JPL. However, vegetation libraries must necessarily be site and time specific. Biological entities are more susceptible to changing environmental conditions than are minerals. Our Long Valley library is specific to the latitude and mean elevation of the region. It also encompasses seasonal variation as well as stressed and healthy specimens.

\section{Casa Diablo}

Tree kills are also observed on the Caldera floor. Northwest of the Casa Diablo Hot Springs there is a moderately sized tree kill of exclusively Ponderosa/Jeffrey pines. Ground temperatures in this area can be as much as $72^{\circ} \mathrm{C}$ at only a depth of 6 inches and as much as $94^{\circ} \mathrm{C}$ in the soil immediately adjacent to fumaroles. However, these temperature regimes seem to be dynamic in nature. Visits throughout the year indicate that temperatures for this area certainly change seasonally, if not monthly to weekly. Two roughly north-south striking normal faults bound this kill area with the concentration of fumarolic activity coinciding with fault location. Trees on or within approximately $8 \mathrm{~m}$ of these faults are dead or dying. In fact, the fumarolic gasses are using the tree roots as flow pathways just as they commonly utilize faults and fractures. Most fumaroles therefore are found at the base of or within tree stumps. Sulfur deposition occurs very near to the fumaroles. The life cycle of grasses near the fumaroles is accelerated. Away from the fumarole, grasses then transition into several species of sagebrush and other low-growing shrubs. Only mosses local to the fumaroles themselves seem to thrive in the steamy organic rich environment created by these geothermal features. The pattern described above is best seen in mid-to-late spring when grasses that should be just blooming are in fact entering the late stages of maturation and germination. This is the best time to use the vegetation to map spatial variation in temperature regimes. We will monitor this area monthly to assess the variation of these characteristics.

\section{Caldera Hot Springs}

To the east of Casa Diablo, the caldera flattens out with only solitary volcanic flows to mar the surface. Geothermal expression in the caldera east of Casa Diablo Hot Springs manifests itself mainly as hot springs and pools. The largest of these features is the north-flowing Hot Creek, which is approximately 8 
$\mathrm{m}$ wide. Hot Creek has the highest discharge of hot waters in the caldera. Upwelling of hot water is facilitated by faults acting as flow conduits. The banks of the creek nearest to these centers of upwelling are either lush with vegetation or home to extensive hot pools hosting vivid orange microbial mats and dark green alga populations, providing possible exploration targets.

To date at Hot Creek, we have collected spectroscopy on the bacteria and algae of the hot pools, but not on nonvascular vegetation or bacteria. However, studies of these thermophiles are quite valuable with respect to characterizing geothermal regions. Narrow high-temperature thresholds for specific species allow for the temperature characterization of specific pools and creeks. Location of these signatures in imagery indicates areas of hydrothermal activity. Currently, we have two separate datasets covering the Hot Creek region; the 1992 AVIRIS dataset and the 1998 HIRIS dataset. The short-wave infrared from AVIRIS has large, mixed pixels, and we are working on spectral unmixing software to interpret it to the extent possible. The recently acquired HIRIS provides hyperspectral data well into the thermal at higher resolution, and will be studied in the future.

Little Hot Creek is home to several hot pools containing microbial mats and algae populations. Its headwaters are characterized by a geobotanical pattern seen throughout the caldera in the vicinity of hot springs. Closest to the hot-water source are lush marsh grasses, which are dark green in color and up to $30-50 \mathrm{~cm}$ in height. Different, less healthy grasses characterize the next zone. These grass-covered areas are ringed by an abrupt inception of rabbitbrush. Rabbitbrush is a stress-tolerant species capable of withstanding drought and high alkalinity better than other large vascular plants common to the caldera. A ring of rabbitbrush (3-4-m wide) surrounds hot spring localities, which is in turn surrounded by the ubiquitous sagebrush population. Spectral signatures of these four populations appear to be different enough from one another to allow vegetal classifications to occur. Because green plants all have a similar chemistry, they can be difficult to spectrally differentiate. However, preliminary analysis of handheld spectroscopy suggests species around Long Valley hot springs can be differentiated.

Similar patterns are seen at other springs in the Long Valley Caldera. These vegetation patterns and spectra can be combined with mineral spectra known to occur in hydrothermal environments resulting in geobotanical classifications of hot spring regions. The geology cannot be divorced from the vegetation and vice versa. Spectral knowledge and spatial distribution is required of both to gain a synoptic view of these environments.

\section{The Geysers/Clear Lake Area}

We made preliminary observations at a level that is considered to be reconnaissance in The Geysers/Clear Lake region of central California. We collected spectra from various common plant species in the region and inspected the area of the Sulfur Creek mine, now a superfund site. We have obtained several hyperspectral thermal datasets from The Geysers, and we also have a 1997 AVIRIS image of the Sulfur Bank mine.

\section{FUTURE PLANS}

Further analysis of the AVIRIS images will be completed with an eye to improving initial classification efforts on the basis of both the mineralization and the vegetation. Solving the problem of the small size and spatial extent of vegetation indicative of hydrothermal activity will be attempted through partial unmixing of pixels as outlined in Kruse et al., (1993). The quality of the classified image produced is limited by the greater age of this dataset. More recent AVIRIS imagery of this region would be ideal. Of course another solution to the problem of small features is to increase the resolution of the imagery. Ideally, higher resolution imagery in the range of $1-5 \mathrm{~m}$ would allow classifications with a lower amount of pixel unmixing required. Obtaining such a dataset of the caldera is of primary concern for future 
studies. Final classified images, post-rectification, will be groundtruthed for the accuracy of the mineral and plant species identification.

Future work will also include analysis of imagery acquired from a thermal hyperspectral imager operated by LLNL. This is a 792-band instrument, which images from $750-1250 \mathrm{~cm}^{-1}$. Images of Long Valley were acquired by this instrument in July 1998. Issues addressed in the analysis of the imagery will include surface temperature extraction, mineral identification, and whether acquisition of hyperspectral thermal data is a valuable addition to lower wavelength hyperspectral acquisitions such as AVIRIS.

Ultimately, we plan to develop and evaluate an improved exploration technique using remote sensing to define spatial and temporal variation in plant characteristics.

\section{INDUSTRY INTEREST AND TECHNOLOGY TRANSFER}

\section{Organization}

Unocal Geothermal

Pacific Gas and Electric Company

\section{Type and Extent of Interest}

Technical guidance and access to areas and data.

Technical interchange of information.

\section{REFERENCES}

Kruse, F.A., A.B. Lefkoff, J.W. Boardman, K.B. Heidebrecht, A.T. Sharpiro, P.J. Barloon, and A.F.H. Goetz (1993), "The spectral image-processing system (SIPS)-Interactive visualization and analysis of imaging spectrometer data," Remote Sensing of Environment 44(2-3), 145-163.

Carter, G.A. (1993), "Responses of leaf spectral reflectance to plant stress," Am. J. Botany 80(3), 239234.

Carter, G.A., and R.L. Miller (1994), "Early detection of plant stress by digital imaging within narrow stress-sensitive wavebands," Remote Sensing of Environment 50(3), 295-302.

Farrar, C.D., M.L. Sorey, W.C. Evans, J.F. Howle, B.D. Kerr, B.M. Kennedy, C.Y. King, and J.R. Southon (1995), "Forest-killing diffuse $\mathrm{CO}^{2}$ emission at Mammoth Mountain as a sign of magmatic unrest," Nature 376(6542), 675-678. 


\title{
SP MODELING
}

\author{
Alan C. Tripp and Howard P. Ross \\ Energy \& Geoscience Institute \\ University of Utah
}

\section{KEY WORDS}

self-potential, geophysics, numerical modeling

\section{PROJECT BACKGROUND AND STATUS}

The spontaneous potential (SP) method measures the electrical manifestation of primary flows, such as heat flow or fluid flow. As such, it has been often mentioned as a method of detecting or monitoring geothermal systems. One problem with such applications is that interpreting SP data has always been daunting due to the number of degrees of freedom in the SP interpretation problem and to the scarcity of versatile numerical interpretation algorithms. One school of SP interpretation avoids these problems by interpreting surface SP data solely in terms of source lateral position. Although this approach is valid for reconnaissance surveying, it does not fully address or utilize the information content of SP data. Our goal has been to develop means of quantifying reservoir information in SP data.

Investigation of three-dimensional modeling of SP data was initiated at EGI in the Spring of 1996. An initial effort concentrated on using the approach of Sill $(1982,1983)$ with a fully three-dimensional electrical modeling code. The objectives of this phase were to test our understanding of the Sill approach to SP modeling and to modify a suitable 3D electrical code to accept equivalent sources at depth. The code used was an integral equations algorithm, originally described by Hohmann (1975). The research effort mainly involved reviewing Sill's approach, placing the equivalent electrical sources at depth, and developing appropriate presentations for the subsequent potentials. This phase resulted in the successful generation of SP responses to 3D flows, such as those examined by Sill (1982). This approach facilitates the generation of SP responses to quite general models using versatile flow algorithms, such as those discussed by López and Smith (1995a,b,c) and Pruess (1991). A discussion of this 3D forward modeling is contained in Tripp et al. (1998).

The ability to generate the SP response of an arbitrary flow model, while important, is subsidiary to the task of interpreting SP data in terms of source location, source character, and flow parameters. This inverse problem, unlike the forward solution, is ill-conditioned and ill-posed. Characterization of this inverse problem was given in Tripp et al. (1998). This paper also presented an analysis of the SP anomaly at Newcastle, including flow parameter non-uniqueness for a simple point source.

The inverse problem has been specialized to the case of forced convection along a fault in the work of Tripp et al. (1999). With such a flow geometry specification, a rigorous definition of the non-uniqueness of the problem is again possible.

Since any approach to SP modeling depends on a realistic estimation of the cross-coupling coefficients, an initial effort in FY 97 was a review of the cross-coupling literature and a compilation of existing pertinent data. Both review and data compilation have been summarized in a draft document (Tripp and Ross, 1999), which has been submitted to the journal Geophysical Prospecting. 


\section{PROJECT OBJECTIVES}

\section{Technical Objectives}

At the beginning of the SP project, our technical objectives were to:

- Demonstrate the applicability of the Sill approach to SP modeling for 3D geothermal flows.

- Perform a critical review of the cross-coupling literature, emphasizing functional relationships between the coefficients and reservoir properties.

- Assemble a collection of 3D flow-modeling algorithms for generating equivalent electrical sources for substitution into the $3 \mathrm{D}$ electrical algorithm. Place these algorithms on a PC platform.

- $\quad$ Model SP data over geothermal reservoirs using 3D algorithms.

- Investigate theoretically and numerically the use of SP for reservoir description.

\section{Expected Outcomes}

- Technical outcomes should be equivalent to technical objectives.

- The practical outcome of this research should be an increased level of appraisal and use of SP by industry for reservoir detection, delineation, and description.

\section{APPROACH}

The technical approach is to combine theoretical and numerical analysis for SP modeling with a critical review of the technical literature. Analysis of field data is used to guide the research.

\section{RESEARCH RESULTS}

- A compilation of cross-coupling coefficients has been completed and submitted to Geophysical Prospecting.

- A theoretical analysis of the SP response of a forced convection system has been completed and presented at the Stanford Geothermal Reservoir Engineering Workshop.

- A catalog of theoretical SP responses for forced convection systems has begun and will form the basis of a short paper.

- Various suites of field data have been examined and are in the process of being interpreted. These interpretations will be reported in a short paper.

\section{FUTURE PLANS}

- The electrical response of migrating steam can be significant. We plan to model the electrical manifestation of vapor dominated systems, both as a means of monitoring boiling and as a physicochemical phenomena. 
- Source location using SP has been practiced extensively. We plan a critical analysis of the literature on this topic, coupled with a mathematical analysis of the problem. Some simplified existing techniques may be preferred alternatives for source depth and location determination when cross-coupling coefficients and other physico-chemical data are lacking.

- Analysis of SP logs in geothermal wells may provide a means of determining fracture characteristics. We plan to examine this topic, in conjunction with analysis of other logs of interest in geothermal resource development.

- $\quad$ All Fortran software used in the project will be placed on a Pentium II platform under a Windows NT operating system, and hence will be readily usable by industry.

- All research is to be discussed in relevant industry and technical journals.

- Active involvement of industry in identifying applications of SP in reservoir description and delineation is sought.

\section{INDUSTRY INTEREST AND TECHNOLOGY TRANSFER}

\section{ORGANIZATION}

- Trans-Pacific Corp.

- $\quad$ New Mexico State University (Jim Witcher)

- Utah Geological Society (Robert Blackett)

\section{EXTENT OF INTEREST}

Modeling El Hoyo - Monte Galan, Nicaragua, SP Data

Source Location and Depth

Source Location and Depth

\section{REFERENCES}

López, D.L. and L. Smith, 1995a, Fluid flow in fault zones: Analysis of the interplay of convective circulation and topographically driven groundwater flow: Water Resources Research, 31, 1489 - 1503.

López, D.L. and L. Smith, 1995b, Fluid flow in fault zones: Influence of hydraulic anisotropy and heterogeneity on the fluid flow and heat transfer regime: Preprint.

López, D.L. and L. Smith, 1995c, Fluid flow and heat transfer within connected, range-bounding faults: A possible example at Leach Hot Springs, Nevada: Preprint.

Hohmann, G.W., 1975, Three-dimensional induced polarization and electromagnetic modeling: Geophysics, 40, 309 - 324.

Pruess, K., 1991, TOUGH2 - A general purpose numerical simulator for multiphase fluid and heat flow: Lawrence Berkeley Laboratory Report, LBL-29400, Berkeley, California.

Sill, W.R., 1982, Self-potential effects due to hydrothermal convection-velocity cross-coupling: DOE/DGE Report, Contract DE-AC07-80ID12079, Univ. of Utah, Depart. of Geology and Geophysics, $15 \mathrm{p}$.

Sill, W.R., 1983, Self-potential modeling from primary flows: Geophysics, 48, 76-86. 
TOUGH '95 WORKSHOP : Proceedings, Lawrence Berkeley Laboratory, March 20-22, 1995.

Tripp, A.C., Ross, H.P., and Cherkaeva, E., 1998, Three - dimensional modeling of SP data: Proceedings of The Stanford Workshop on Geothermal Reservoir Engineering, p. 2-69-2-71.

Tripp, A.C. and Ross, H.P., 1999, Spontaneous potential heat and fluid flow cross-coupling coefficientsA literature review: submitted to Geophysical Prospecting.

Tripp, A.C., Ross, H.P., Moore, J., and Cherkaeva, E., 1999, SP interpretation for forced convection along a vertical fracture zone: presented at the Twenty-fourth Stanford Workshop on Geothermal Reservoir Engineering.

Tripp, A.C., 1998, The promise of electrical geophysics in developing geothermal resources: Invited talk, DOE Geothermal Program Review XVI. 


\title{
Microseismicity Survey of the EI Hoyo-Monte Galan Geothermal Region in NICARAGUA
}

\author{
Paul Kasameyer, Albert T. Smith, and Lawrence J. Hutchings \\ Lawrence Livermore National Laboratory (LLNL)
}

\section{KEY WORDS}

microseismicity, geothermal conduits, velocity structure, modeling, El Hoyo-Monte Galan geothermal region, Marabios Range, volcano, Nicaragua

\section{PROJECT BACKGROUND AND STATUS}

At LLNL, we are collaborating with seismologists from the Trans-Pacific Geothermal Company, the Nicaraguan geological agency INETER, and the Swiss group ETH-Z to study the geothermal potential of the Nicaragua's El Hoyo-Monte Galan geothermal region in the Marabios Range volcanoes (Figure 1). INETER and ETH-Z operate a seismic network to monitor seismicity and geologic hazards in the Marabios. A planned series of seismic experiments (recording micro-earthquakes, explosions, and airgun blasts) and possible exploratory drilling in the El Hoyo-Monte Galan region gave researchers an opportunity to test various geophysical methods for locating geothermal conduits. One of these methods, microseismicity, may help discern the locations of active faults, and the characteristics of seismic propagation may point toward regions of high crack density and fluid content. Combining these potential diagnostics with electromagnetic gravity methods, near-surface temperatures, and the locations of hot springs may reveal conduits for near-surface geothermal activity. LLNL's contribution to this effort was to deploy an array of 12 seismometers in the El Hoya-Monte Galan area, and then to record and analyze microseismic data for seismic signatures of geothermal conduits. Defining possible fracture zones requires microseismicity observations to magnitude 1.5 or less. We recorded data for 20 days in March and April 1996. Additional data were collected with a similar network for three months in 1998 (W. Honjas, personal communication). From the 1996 dataset, we detected a vertically elongated cluster of episodic microseismicity 3 to $6 \mathrm{~km}$ deep to the northwest of El Hoyo. This seismicity consisted of small clusters of events, the structure of which could not be resolved. Our composite focal mechanism model indicates nearly horizontal $\mathrm{N} 30^{\circ} \mathrm{W}$ compression or nearly horizontal $\mathrm{N} 60^{\circ} \mathrm{E}$ tension.

\section{PROJECT OBJECTIVES}

Our ultimate objective is to use conceptual and mathematical models of geothermal fields as a basis for interpreting multiple datasets of geophysical data and for improving geothermal exploration techniques. The objective of this effort is to collect and interpret microseismicity data.

\section{Technical Objectives}

- Plan and carry out a joint seismic deployment in Nicaragua, recording microseismicity activity at magnitude 1.5 or less.

- Analyze microseismicity data to define possible fracture zones/geothermal conduits.

- Determine the velocity and possibly the attenuation structure in the El Hoyo-Monte Galan area.

- Work with the staff of the Trans-Pacific Geothermal Company to evaluate existing geological and geophysical data. 


\section{Expected Outcomes}

- Identify a localized swarms of microseismicity that are potential geothermal drilling targets.

- To the extent the data allow, identify zones of unusually high or low attenuation that might indicate partially saturated zones or steam zones.

- Complete initial analyses of explosions and airgun recordings, and discuss results with the TransPacific Geothermal Company.

\section{APPROACH}

We installed 12 three-component REFTEK seismic-recording systems with Sprengnether S-6000 seismometers. We recorded natural and man-made seismic signals continuously from March 20 to April 9, 1996, at frequencies up to $50 \mathrm{~Hz}$. On behalf of INETER, we recorded a number of oceanic airgun shots, and two moderately sized explosions that took place in Lake Managua. In addition, we recorded several thousand seismic events at distances ranging from $100 \mathrm{~km}$ to less than $2 \mathrm{~km}$ from the center of the network.

The existing INETER/ETH-Z network did not have many stations in the El Hoyo area. Thus, only events larger than a 2.5 magnitude could be located in the area of interest. We designed the 1996 seismic experiment to accurately locate microseismicity and profile the velocity structure using explosions in the adjacent lake and airgun blasts in the Pacific Ocean. During the short 1996 deployment, difficult physical access restricted instrument locations to areas accessible by road and made deploying stations in mountainous areas, such as El Hoyo, impractical. The 1998 survey provided better coverage high on El Hoyo.

\section{RESEARCH RESULTS}

To date, we have completed the analysis of the microseismicity data collected in 1996 (Smith and Kasameyer, 1997), and we have cataloged the data collected in 1998. During the 1996 deployment, the seismicity was primarily clustered in a $4-\mathrm{km}^{3}$ volume just northeast of El Hoyo. Examination of longerterm seismicity data from the Nicaraguan seismic network suggests that this cluster has persisted for decades (W. Teplow, personal communication). It is tempting to conclude that this area is related to either volcanic activity (as is the large cluster under Momotombo) or to intense hydrothermal flow. The overall pattern of seismicity suggests a northwest-southeast trend extending from El Hoyo to Momotombo, with a strike that is distinctly more northerly than that of the volcanic trend. However, the limited spatial extent of our network and the fact that we only recorded data for 20 days must be considered when drawing conclusions from these data sets.

The velocity structure calculated from our data (Figure 2) is consistent with Elming and Rasmussen's (1997) descriptions of geophysical interpretations in the Nicaraguan graben. They inverted magnetotelluric and gravity data in the Nicaraguan graben about $40 \mathrm{~km}$ southwest of our site, and found that the conductive, low-density alluvial and volcanic rocks filling the graben are up to $2 \mathrm{~km}$ thick, consistent with our thick, near-surface zone. This zone is underlain by a resistive $(1000 \mathrm{ohm}-\mathrm{m})$ layer that corresponds in depth to our rapidly increasing velocities to above $6 \mathrm{~km} / \mathrm{s}$. They also see a lower crustal conductor (deeper than $13 \mathrm{~km}$ ) that they attribute to partial melt. If this feature corresponds to the lower velocities we see at depth, it must be considerably shallower. 
Approximately 100 local events were recorded during the 20-day 1996 deployment. The 1996 and 1998 station locations are shown in Figure 3(a). Seismicity rates continued to be high during the 1998 deployment, which recorded 3-5 local events per day.

\section{Location Analysis}

Earthquake location accuracy depends on the number, distribution, and quality of observations, and on the appropriateness of the seismic velocity model determined during the location process. Our initial model and hypocentral locations use the output from HYPO71, a standard location code that uses a fixed velocity model with station-specific corrections. We start with the velocity model normally used by the Nicaraguan network. To prevent the near-surface velocity structure under each station from dominating the velocity iterations during solutions using VELEST, we damped the changes to the P- and S-wave velocity models more strongly than the station corrections. This allows the "best" solution to start from an initial set of station corrections, which should accommodate the near-surface heterogeneity. Figure 3(b) plots the locations to obtain the best solution for events over the whole region. Shallow events are plotted with larger symbols. The plot suggests a northwest-southeast trend of microseismicity from the northwest side of El Hoyo to the southwest of Momotombo. Locations of the events to the southwest, near Momotombo, are outside the network. In those situations, events have a large uncertainty, especially in depth, and are probably placed too deep. Within this general trend of seismicity, there is a shallow cluster northwest of the peak of El Hoyo. Experimentation with a variety of velocity models did not significantly change the location of this cluster.

The 1998 survey had better coverage to the southwest of the cluster described above. Figure 3(c) shows the results of a preliminary joint location determination for a subset of the 1996 data, and the data from the first 5 days of the 1998 deployment. The new data show that the cluster discussed above was still active, and suggest that additional events exist to the southeast.

\section{Focal Mechanism}

The stress field associated with the shallow cluster of events located northwest of El Hoyo can be derived from a compilation of the first motions observed at the seismic stations. The solutions are influenced by the velocity model and location of the events; however, this group of events is sufficiently well controlled to yield good estimates of the stress field. Figure 3(d) plots lower-hemisphere projections of the focal mechanisms for each event within the cluster. The filled quadrants represent compressional first motion; the open quadrants denote dilational first motion. As a result, the compressional $P$ axis of stress for the solution is centered within the open quadrant, while the tensional $\mathrm{T}$ axis falls within the filled quadrants. Within this group of events, the most consistent stress axis appears to be the $\mathrm{P}$ compressional axis along a northwest-southeast trend.

\section{Other Structural Constraints}

The 1996 seismic deployment has provided strong evidence for an earthquake cluster that is associated with localized extension within an active extensional area. Because of the limited spatial extent of seismic sources and receivers, we cannot determine whether other features in the data are caused by structural variations or by attenuation variations. Under certain assumptions that have not been fully evaluated, we see some evidence for constraints on the depth of volcanic and alluvial fill, and for very high crustal velocities at depths shallower than $5 \mathrm{~km}$. Finally, this study has provided tantalizing suggestions that there is a velocity inversion in the upper crust and that zones of high attenuation are associated with some volcanoes. These observations will contribute, along with other geophysical, geological and geochemical observations, to the development of conceptual model for the El Hoyo-Monte Galan area. 


\section{FUTURE PLANS}

We need to complete the analysis of the 1998 microseismic data and to evaluate it in conjunction with resistivity, self-potential, thermal, and geochemical data collected by others. During part of the 1998 deployment, INETER/ETH-Z set up an additional array on an intermediate scale between our detailed survey and the Nicaraguan National network. We intend to combine the data from these three deployments.

\section{INDUSTRY INTEREST AND TECHNOLOGY TRANSFER}

Interest in this research is potentially very high.

Organization

Trans-Pacific Geothermal

\section{Type and Extent of Interest}

Supported costs of the 1998 deployment and is providing other geophysical data.

\section{REFERENCES}

Elming, S- $\AA$, and T. Rasmussen (1997), "Results of magnetotelluric and gravimetric measurements in western Nicaragua, Central America," Geophys. J. Int. 128, 647-658.

Smith, A.T., and P. Kasameyer (1997), Microseismicity Study of the El Hoyo-Monte Galan Geothermal Prospect, Nicaragua, Lawrence Livermore National Laboratory, Livermore, CA, UCRL-ID-127876.

Weinberg, R.F. (1992), "Neotectonic Development of Western Nicaragua," Tectonics 11, 1010-1017. 


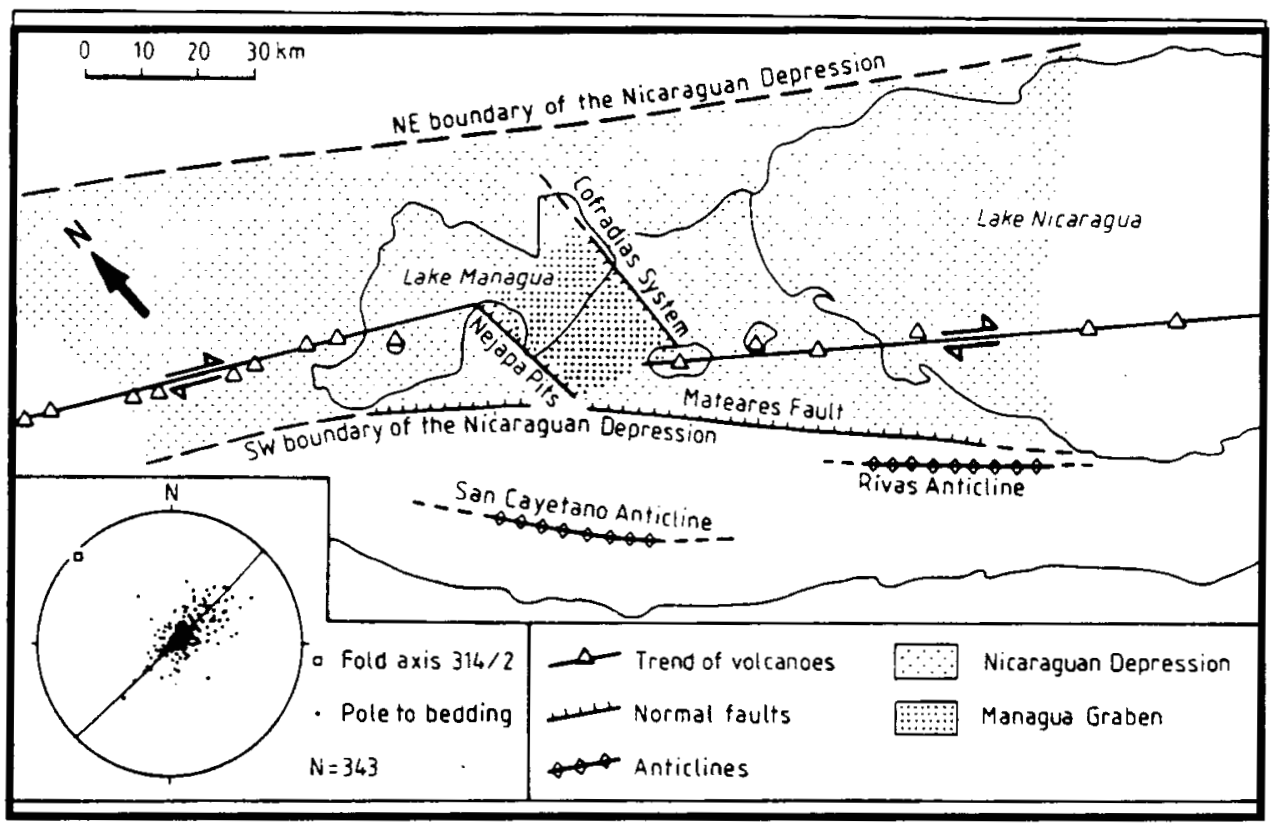

Figure 1. Map of western Nicaragua, showing major structural features (from Weinberg, 1992). The current deformation occurs as right-lateral slip along the NW-SE line of volcanoes, and in pull-apart basins caused by leftward offsets of those features. The western tip of Lake Managua is visible in subsequent figures; the first two triangles northwest of the lake are Momotombo and El Hoyo volcanoes.

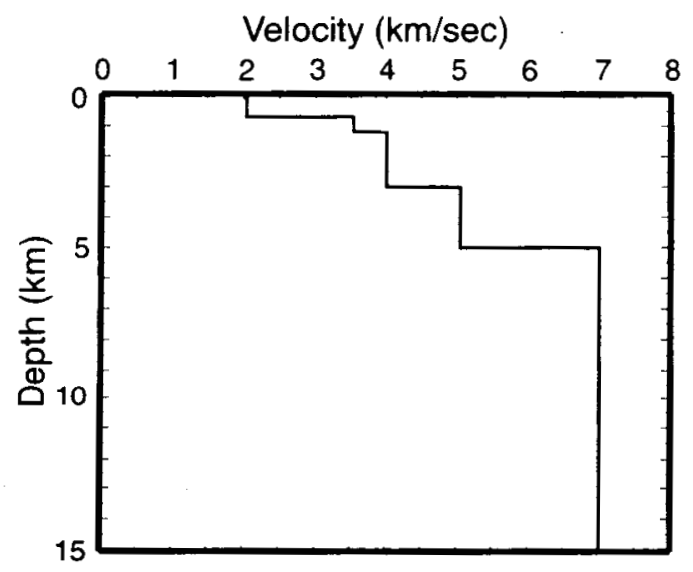

Figure 2. Candidate velocity-depth model for the El Hoyo-Monte Galan area. 


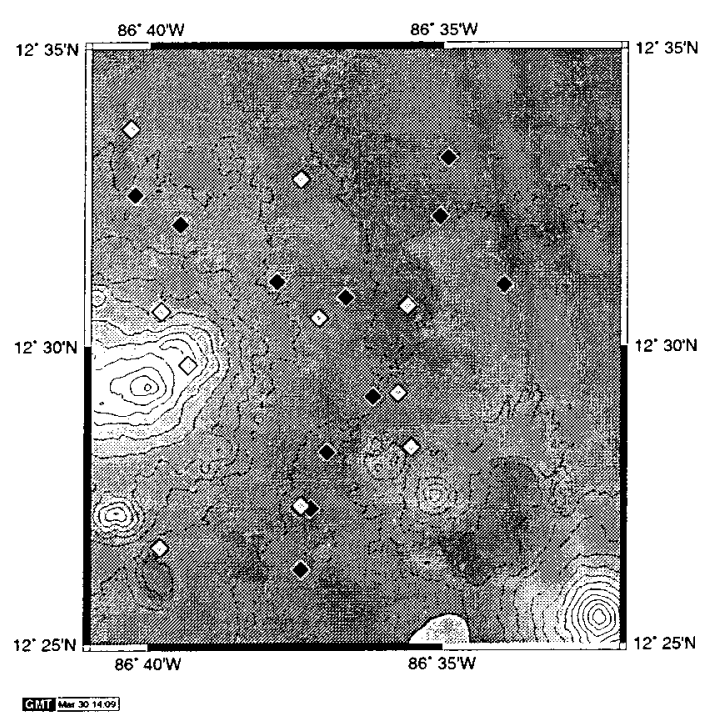

(atari

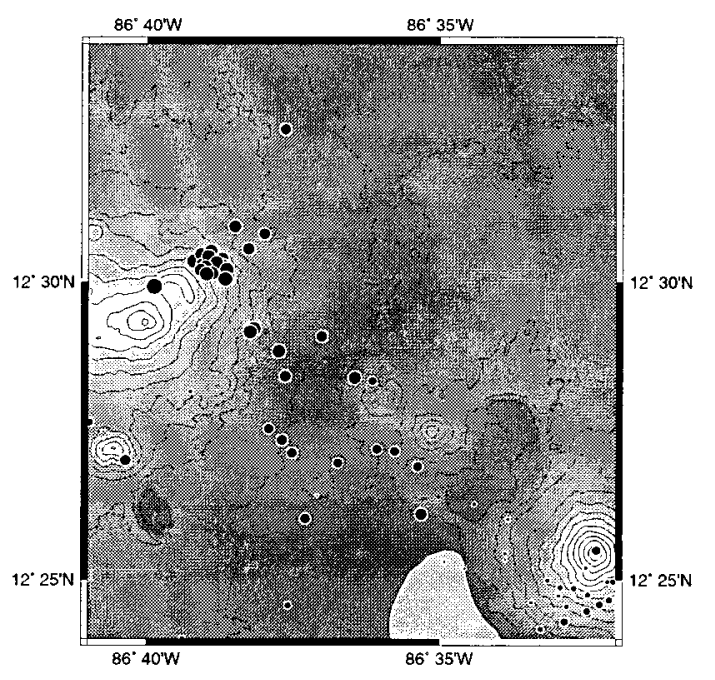

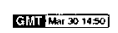

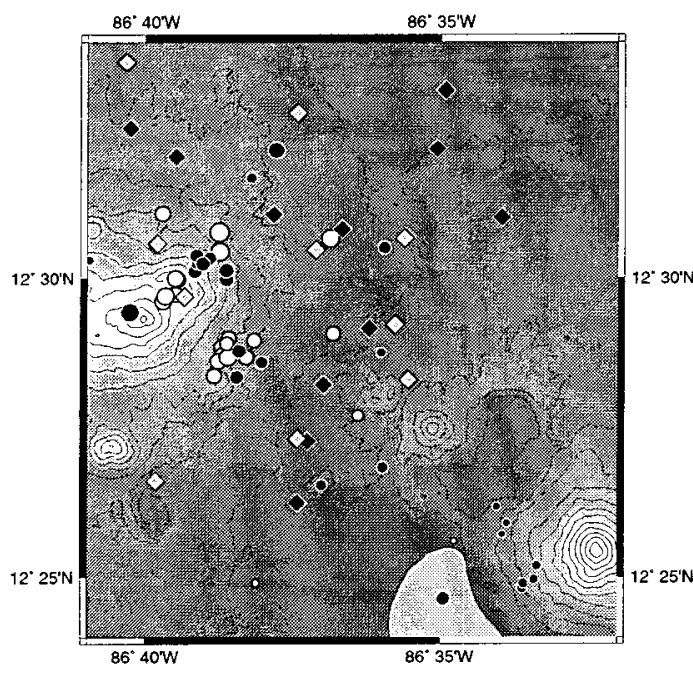

GMTI (b)

(c)

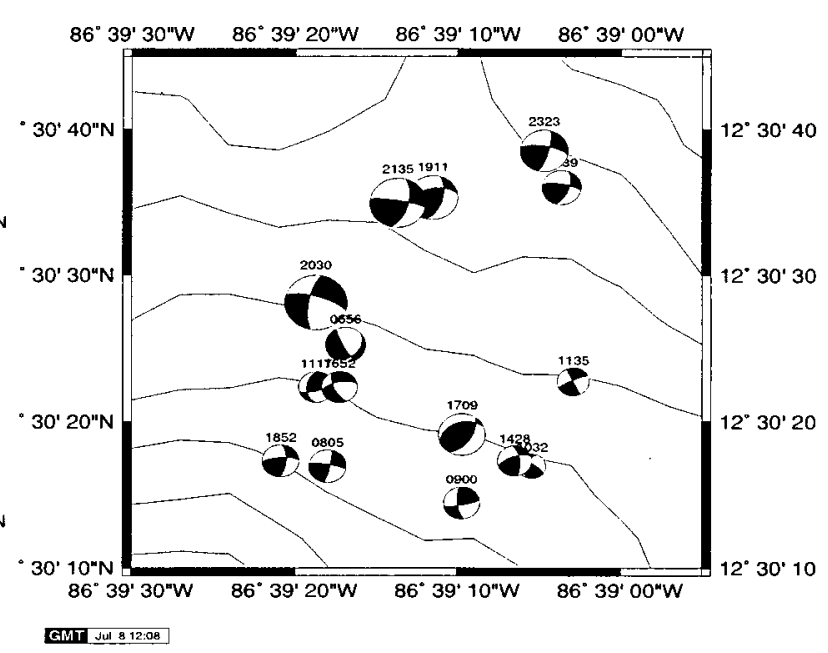

(d)

Figure 3. (a) Locations of El Hoyo-Monte Galan seismic stations from 1996 (black diamonds) and 1998 (white diamonds). Higher elevations have lighter shading. The topographic contour interval is 50 . The two largest peaks are Momotombo (southeast) and El Hoyo (west). (b) Global location results for the 1996 seismic deployment. The black circles are locations for small $M=<3.0$ events, and the shallow events are indicated by larger circles. The deepening of events to the southeast near Momotombo is probably an artifact of trying to determine locations outside the seismic network. (c) Comparison of the location of events detected in 1996 and 1998. The black circles are 1996 events recorded with stations at the black diamonds. The white circles are locations of the first 5 days of seismicity recorded in 1998 on the stations located at the white diamonds. (d) Focal mechanism solutions for the cluster detected in 1996. 


\title{
MT/CSAMT ELECTRICAL METHODS RESEARCH
}

\author{
Philip E. Wannamaker and John A. Stodt \\ Energy \& Geoscience Institute \\ University of Utah
}

\section{KEY WORDS}

Electromagnetics, magnetotellurics, CSAMT, instrumentation, algorithms

\section{PROJECT BACKGROUND AND STATUS}

EGI (formerly UURI) has maintained a long-term (over 15 years) effort devoted to upgrading MT. data acquisition and interpretation, and has received support from the Department of Energy (DOE) and the National Science Foundation (NSF) for this effort. EGI has developed and field-tested a wideband MT system which includes simultaneous, dual-site measurement utilizing digital FM telemetry and coherencebased data quality sorting in real time. In addition to defining a platform for instrumentation research, our MT system has been intended as insurance against the often fragile stability of MT contractors in the unsteady petroleum and geothermal exploration markets. The anticipated benefits of this research are reduced drilling costs (through increased drilling success) and better evaluation of reservoir potential which reduces front end costs and facilitates better plant design. Our research group also has taken a lead role in the development of more efficient and accurate algorithms for interpreting electrical and electromagnetic (including MT/CSAMT) data for the geothermal, petroleum and mining industries. Finally, EGI has provided new understanding of the relationship of resistivity models to structure and physico-chemical state in the Earth as a result of the large, field-based component of our research. New advances in data acquisition efficiency and field noise reduction are coupled to field data acquisition supported by other funding sources because this has been very instructive as to interpretation needs.

\section{PROJECT OBJECTIVES}

The general objectives of this project are to improve the methodology and interpretation of electrical geophysical techniques by making them more accurate, more efficient, and easier to implement so that they will be available for increased use by the geothermal industry and researchers. EGI has chosen to address the magnetotelluric (MT) method and its controlled source analog CSAMT, in particular, because of their importance in geothermal exploration.

\section{Technical Objectives}

- Improve interpretation of MT/CSAMT data through new algorithm development and response characterization.

- Improve the quality of MT field data through improved instrumentation and field techniques.

- Demonstrate improved capabilities of MT and CSAMT through carefully selected field studies.

\section{Expected Outcomes}

- Demonstrate improved data quality and structural resolution.

- Increase use of MT/CSAMT by industry, enabling large savings in exploration and drilling costs. 


\section{APPROACH}

EGI concentrates on developing electrical geophysical techniques since they have broad applicability to mapping geothermal resources on both regional and detailed scales. EGI continues to test existing methods, to improve techniques and equipment for gathering field data, and to improve interpretation algorithms. DOE research support for instrumentation and algorithm development has been complemented strongly by DOE and NSF support for MT field programs which test the method.

\section{RESEARCH RESULTS}

Significant progress has been made in the areas of MT field instrumentation, numerical analysis methods, and in interpretation methodology for the CSAMT technique. These will be detailed below in turn.

\section{Magnetotelluric Instrumentation}

We are in the process of redesigning and rebuilding our MT system. DOE funding is being used in addition to support from NSF and the University of Utah to develop a pool of instrumentation to be made available for DOE-and NSF-funded academic research. Figure 1 is a block diagram which reflects our current goals for redesign of our MT instrumentation. It shows the major subsystems and components which comprise the equipment normally deployed at one measurement site. Our goal is to build and maintain equipment sufficient to instrument four measurement sites. A minimum of two sites, recording data synchronously, is required to implement remote reference processing, which is standard procedure. Additional hardware will provide additional recording capability and a pool of spares in case of equipment breakdown.

An algorithm, which utilizes the IPPS timing pulse from the GPS receivers we have acquired for this project, was designed to discipline a precision oscillator which in turn provides the clock signals for time-critical instrument operations. This provides a locally-generated, absolute time reference for synchronization of data collection between multiple instruments at different locations. The algorithm is implemented as firmware in a Field Programmable Gate Array (FPGA). A prototype device was build and tested which provides timing accuracy to $\sim 50 \mathrm{nS}$ while 1PPS timing pulses are being received. Prototype designs for analog signal paths for low-, mid-, and high-band data acquisition have been developed, as have power distribution, interconnect, and packaging schemes. Component engineering and parts acquisition is ongoing.

\section{Magnetotelluric Surveying and Interpretation}

Phil Wannamaker and John Stodt obtained 24 MT tensor sites using the University of Utah MT system across the Dixie Valley geothermal area. The total survey spanned Dixie Valley, the Stillwater Range, and western Buena Vista Valley to the northwest of the producing system. Purposes of the survey were to test for the existence of a deep heat source for the system, of possible fluid and alteration pathways in the immediate vicinity of production, and to compare the thermal regime below the southeastern Stillwater Range with other domains of varying thermal activity in the Great Basin. The MT transect is coincident with the high-resolution seismic reflection survey described by Okaya and Thompson (1985, Tectonics), which currently is being reprocessed by J. Louie and students at University of Nevada/Reno. Initial inspection of the results indicates a highly conductive, enhanced thermal state to the deep crust of the area. This is similar to our previous studies of active western Utah, but unlike the relatively subdued Great Basin interior of northeastern Nevada (Wannamaker, 1998a; Wannamaker et al., 1997a,b).

Our capabilities in MT instrumentation and survey execution were exemplified further by two highly successful deployments supported by the NSF. The first was acquisition of a $54 \mathrm{~km}$ long profile of sites 
across South Pole station, East Antarctica, over the regional polar ice sheet $3 \mathrm{~km}$ in thickness (Wannamaker et al., 1998). Second, Wannamaker and Stodt together with G. Jiracek of San Diego State University and G. Caldwell of the New Zealand IGNS completed their MT transect of the New Zealand South Island (Davey et al., 1998; Stern et al., 1997). This last phase was almost entirely by helicopter support through the rugged Southern Alps with the MT system running on batteries throughout. These are examples where our leveraging DOE-supported instrumentation research with non-DOE funding for field programs has been an effective means of proving system performance.

\section{Algorithm Development}

Wannamaker has constructed a prototype, regularized inversion program for 2-D MT/CSAMT data. It is programmed within the framework of finite element program PW2D, hundreds of copies of which have been distributed. The approach damps model structure against an apriori constraint, and any combination of TE, TM or vertical H-field functions can be inverted depending upon one's assessment of possible 3-D effects (de Lugao and Wannamaker, 1996; Wannamaker, 1998b). The code has undergone top-down, structured programming, with accuracy verified for both first and second-order auxiliary field derivatives, and for topography and bathymetry. PW2D also is the computational engine for the widely-used, Occam2 minimum structure inversion code. Occam-2, however, utilizes the older perturbation method of derivatives and is very slow.

\section{FUTURE PLANS}

Funding from NSF/EAR/IF has been received to establish the University of Utah/EGI as a national instrument facility for MT, in cooperation with the University of Washington and the University of California at Riverside. Wannamaker is Scientist-in-Charge of the facility. This award will substantially complement DOE/GT support for instrumentation at EGI by providing multiple site modules and incorporating our high-impedance electrometer design into a modernized overall platform. Joining the facility, to be maintained and operated by EGI under NSF support, will be three, five-channel MT-24 units made by EMI, Inc., and twenty long-period MT recorders for deep crust and upper mantle surveying made by Phoenix Geophysics. We will continue to maintain older hardware to address upcoming projects in the interim until new hardware can be brought online.

In 2-D inversion, we prefer regularization with apriori models because it allows ready incorporation of constraints. Our present algorithm needs more testing for arbitrary structures including topography and bathymetry. Flexibility will be implemented to damp model variations in a more arbitrary manner versus position in the model. Storage and run time will be improved by solving the parameter step estimate using a symmetric L-U solver and packed storage. Routines are to be written to generate the regularization mesh more automatically and with the option of having the pixels growth in both width and height versus depth, to preserve pixel influence on the response at the surface. Finally, the algorithm will be applied to our new data set from the Dixie Valley thermal area and to other existing data sets.

\section{INDUSTRY INTEREST AND TECHNOLOGY TRANSFER}

\section{Organization(s)}

National Science Foundation

Unocal - Geothermal Division, Trans-Pacific Geothermal

Mining, Petroleum and Geothermal Research Consortium, U. of Utah

\section{Type and Extent of Interest}

Crustal-scale MT surveys; MT equipment upgrades

MT/CSAMT interpretation and equipment

MT/CSAMT and finite-source

$M$ interpretation 


\section{REFERENCES}

Davey, F. J., Henyey, T., Holbrook, W. S., Okaya, D., Stern, T. A., Eberhart-Phillips, D., McEvilly, T., Urhammer, R., Anderson, H., Jiracek, G. R., Wannamaker, P. E., Caldwell, G., and Christiansen, N., 1998, Preliminary results from a geophysical study across a modern, continent-continent collisional plate boundary - the Southern Alps, New Zealand: Tectonophysics, Special Issue on VIIth Int. Symp. Deep seismic profiling of the continents, 288, 221-235.

de Lugao, P. P., and Wannamaker, P. E., 1996, Calculating the two-dimensional magnetotelluric Jacobian in finite elements using reciprocity: Geophys. J. Int., 127, 806-810.

Stern, T. A., Wannamaker, P. E., Eberhart-Phillips, D., Okaya, D., Davey, F. J., and the South Island working group, 1997, Crustal Structure experiments across the Southern Alps of New Zealand: EOS Article, Trans. AGU, 78, 329, 335-336.

Wannamaker, P. E., 1998a, Comment on "The petrologic case for a dry lower crust", by Yardley, B. W. D., and Valley, J. W., J. Geophys. Res:, 102, 12,173-12,185, 1997, in press.

Wannamaker, P. E., 1998b, Magnetotelluric surveying one can afford: interpretation of MT sounding profiles from natural environments, in Three-dimensional electromagnetics, ed. by M. Oristaglio and B. Spies, Soc. Explor. Geophys., Invest. Geophys., Tulsa, in press.

Wannamaker, P. E., Johnston, J. M., Stodt, J. A., and Booker, J. R., 1997a, Anatomy of the southern Cordilleran hingeline, Utah and Nevada: implications from deep electrical resistivity profiling: Geophysics, 62, 1069-1086.

Wannamaker, P. E., W. M. Doerner, J. A. Stodt, and J. M. Johnston, 1997b, Subdued state of tectonism of the Great Basin interior relative to its eastern margin based on deep resistivity structure: Earth Planet. Sci. Lett., 150, 41-53.

Wannamaker, P. E., J. A. Stodt, and L. Pellerin, 1998, Magnetotelluric (MT) soundings across South Pole region, East Antarctica: Antarctic J. of the U. S., National Science Foundation, Washington, 32, in press. 

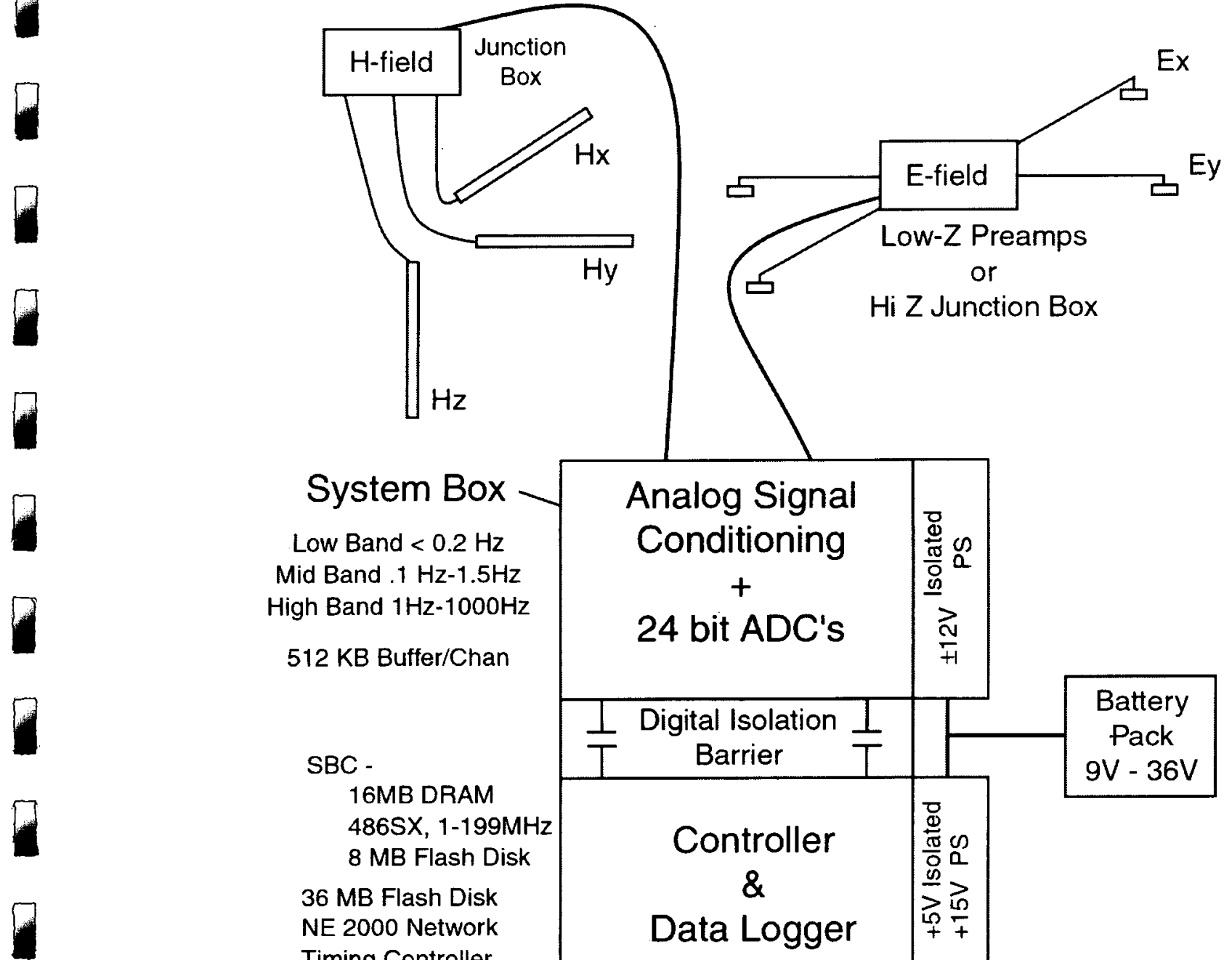

SBC -

16MB DRAM 486SX, 1-199MHz

$8 \mathrm{MB}$ Flash Disk

36 MB Flash Disk NE 2000 Network

Timing Controller
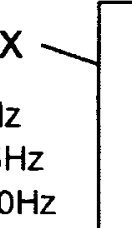

High Band $1 \mathrm{~Hz}-1000 \mathrm{~Hz}$

512 KB Buffer/Chan

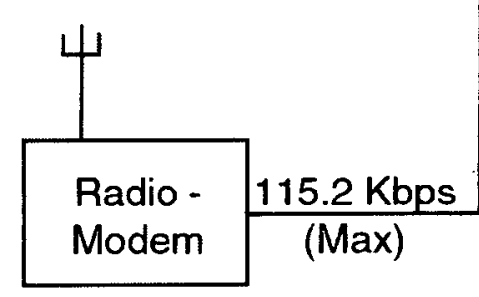

Analog Signal Conditioning $+$

Hi Z Junction Box
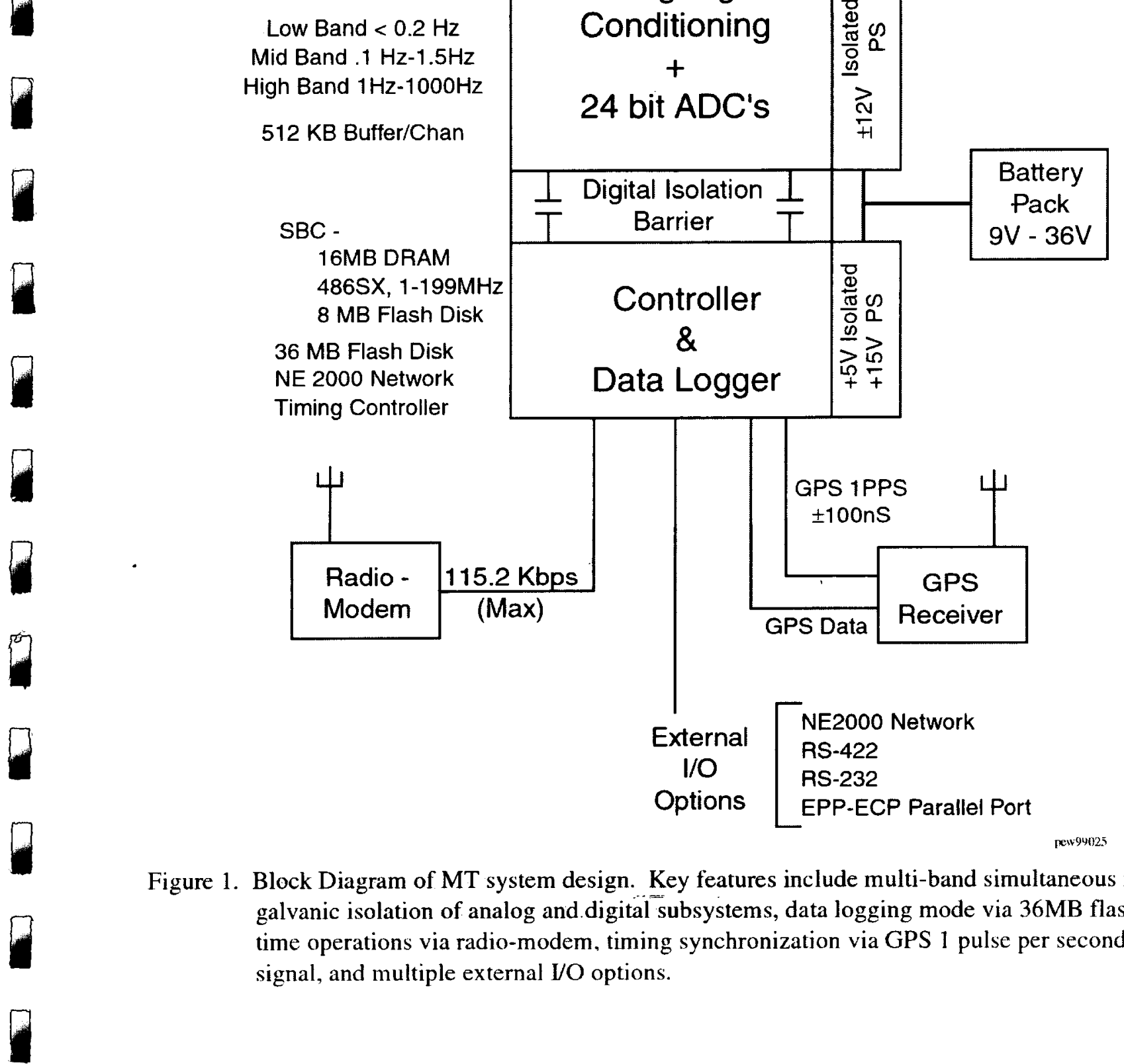


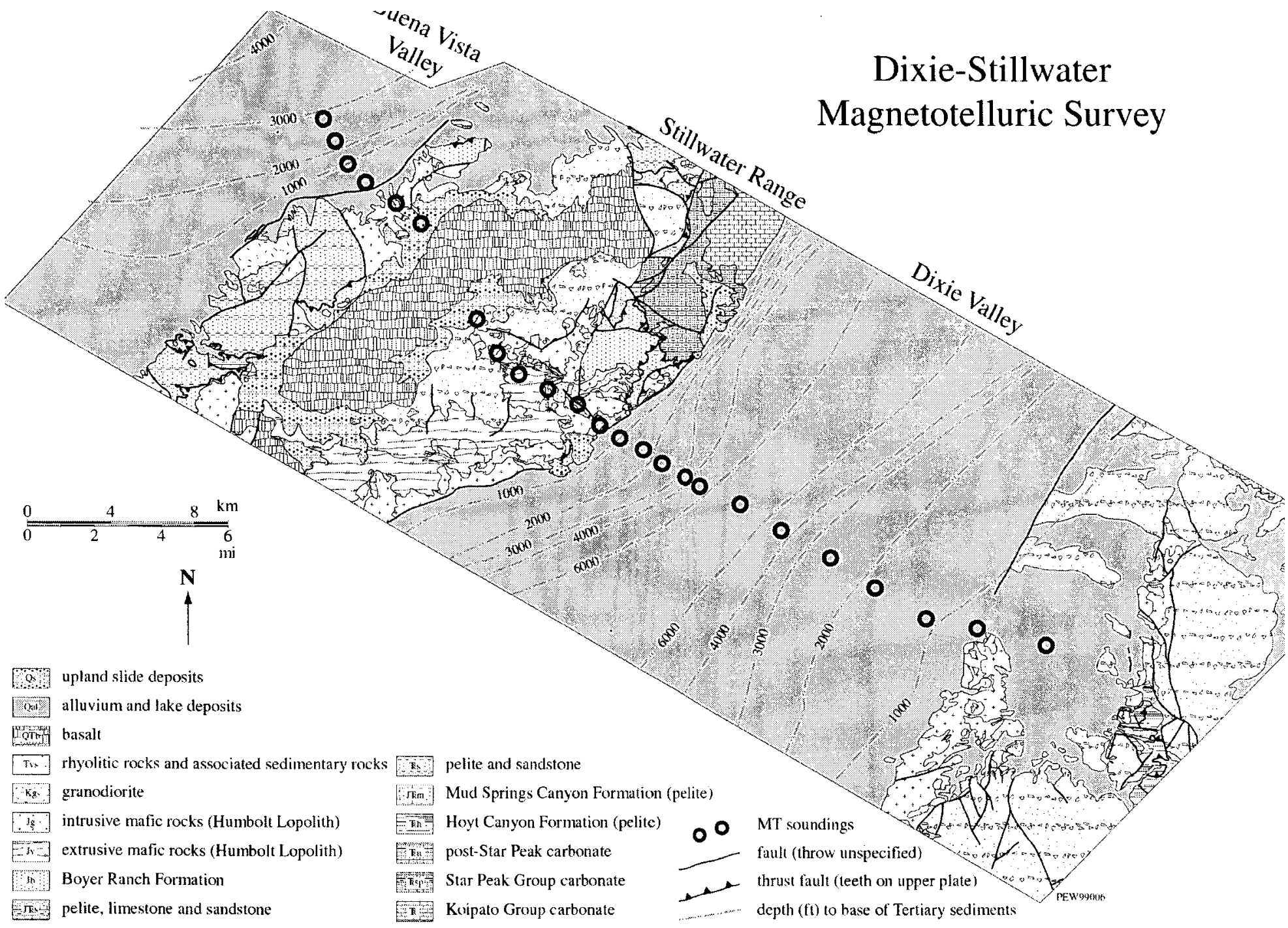

Figure 2. Site location and geological map for recently completed MT transect of the Dixie Valley thermal area using the University of Utah/EGI instrumentation. 


\title{
THREE-DIMENSIONAL SEISMIC IMAGING OF THE RYE PATCH RESERVOIR
}

\author{
Mark A. Feighner, Thomas M. Daley, and E.L. Majer \\ E.O. Lawrence Berkeley National Laboratory
}

\section{KEY WORDS}

3-D seismic, VSP, imaging, seismology

\section{PROJECT BACKGROUND AND STATUS}

Initial exploration efforts at the Rye Patch, Nevada reservoir in the late 1980s and early 1990s resulted with one successful well (\#44-28). Other wells were either too cold or had no flow. In 1997 TransPacific Geothermal Inc. (TGI) proposed a 3-D seismic survey to determine the geologic structure on the (hypothesized) fault-controlled reservoir. This would be possibly the first application of the 3-D seismic method to a geothermal field and therefore of interest to the entire geothermal community. The 3-D seismic method has proven an integral part of modern oil and gas exploration efforts, however the heterogeneous and hydrothermally altered nature of geothermal reservoirs makes all seismic imaging more difficult. It was not known if the methods used in the petroleum industry could be directly transferred to the geothermal industry.

Before conducting a full-scale 3-D survey, DOE contracted LBNL to investigate the viability of seismic imaging in the Rye Patch area. LBNL obtained a Vertical Seismic Profile (VSP) in well 46-28 to test the seismic reflectivity in the area and to obtain velocity information for designing and potential processing of the proposed 3-D seismic survey. The results of the VSP were positive and TGI proceeded with the collection of 3.0 square miles of 3-D surface seismic data over the Rye Patch reservoir. The data acquisition (including the unique use of LBNL's three-component borehole geophone in well 44-28) was accomplished in August 1998. Initial processed results provided by the subcontractor Subsurface Exploration Co. (SECO) was delivered to TGI in December 1998.

After the initial analysis of SECO's results, it was decided that the processing was insufficient for correct analysis. LBNL will be funded by DOE to reprocess the field data and asses the interpretability of the entire 3-D data set. This effort will be carried out during FY1999; it is expected to be completed by October 1999.

\section{PROJECT OBJECTIVES}

The Rye Patch 3-D seismic project is intended to assess the applicability of 3-D seismic exploration techniques to geothermal reservoirs. The initial stage used a Vertical Seismic Profile to establish the seismic reflectivity of the Rye Patch area. The acquisition of the 3-D seismic data set is also intended to map the structural features which may control geothermal production in the Rye Patch reservoir.

\section{Technical Objectives}

1. Acquire a VSP in the Rye Patch area to asses seismic reflectivity and obtain seismic velocity information.

2. Use the VSP results to decide on the feasibility of 3-D seismic at Rye Patch.

3. Acquire a 3-D seismic data set appropriate to the Rye Patch reservoir. 
4. Process and analyze the 3-D seismic data for structural information.

5. Develop and apply innovative processing for 3-D seismic data in geothermal regions.

\section{Expected Outcomes}

1. A successful 3-D seismic survey can guide an exploration effort and reduce overall costs by increasing the success rate of well drilling.

2. An assessment and guide to the applicability and use of 3-D seismic imaging at other geothermal fields, potentially reducing exploration and exploitation costs.

\section{APPROACH}

Our initial efforts in the viability assessment for 3-D seismic at Rye Patch focused on acquisition, processing and analysis of a VSP to determine if there was sufficient reflectivity at the hypothesized reservoir horizon in order to justify a full 3-D seismic survey. The VSP results were positive, providing a go ahead for the survey. Initial analysis of the 3-D survey led to significant questions about the processing used and the interpretability of the results provided by the sub-contractor. We believed that reprocessing was necessary to provide a high-quality result. In particular, more effort needed to be applied to static corrections for lateral heterogeneity in near-surface velocity and to 3-D velocity analysis throughout the data volume. The final analysis of the results will follow the completion of reprocessing effort.

\section{RESEARCH RESULTS}

\section{Vertical Seismic Profile (VSP) Results}

A VSP was recorded by LBNL in December 1997. Figure 1 shows the location of the Rye Patch geothermal field with Well 46-28 located within the marked Rye Patch Anomaly (this is Figure 1.2 from the GeothermEx [1997] report). The VSP in Well 46-28 used a vibroseis source and a single-level, high temperature, hydraulic wall-locking, three-component seismometer. Data was acquired from 400 to 4200 $\mathrm{ft}$ depth using two-source offsets. The first break arrival times gives a direct measure of the P-wave velocity with depth. The far-offset dataset was processed to image any reflections in the data. Details are given in Feighner et al. (1998). Two prominent, coherent reflectors can be seen. Using the measured seismic velocities, the VSP reflectors are mapped to depth using the Common Depth Point (CDP) transform module.

To interpret the VSP data the VSP data (at the correct scale) were superimposed onto a geologic cross section in order to compare the reflections with mapped geologic units. Figure 2 (from the GeothermEx [1997] Figure 4.13) is a north-south cross section that intersects Well 46-28. The upper reflector correlates with the sandstone/siltstone (upper member) of the Natchez Pass Formation. This is the main permeable clastic unit which supplies the thermal fluids to the Rye Patch wells.

The deeper reflector appears within the lower member of the Natchez Pass Formation, and may occur at a limestone/siltstone interface. The VSP data collected at Well 46-28 did produce a coherent reflection from the permeable clastic unit which is the main production unit in this geothermal field at a depth of about 3000 feet. The reflection was continuous for about 180 feet northwest of the well. A second, deeper reflector was seen at about $4800 \mathrm{ft}$ depth, probably within the lower member of the Natchez Pass Formation, and was coherent over 285 feet northwest of the wells. The deeper reflector appears within the lower member of the Natchez Pass Formation, and may occur at a limestone/siltstone interface. Also 
obtained in this study was a velocity versus depth function to a depth of 4200 feet, which was very useful in designing the 3-D seismic survey.

\section{3-D Seismic Acquisition}

The 3-D seismic survey was performed in June-July 1998 and covered about 2.5 square miles of the Rye Patch reservoir area at a 50-by-50 foot common mid point (CMP) grid size. LBNL aided in the design and oversight of the 3-D data acquisition. The field data and processing results from Subsurface Exploration Company (SECO) will become available to us during FY-1999.

The velocity analysis performed by SECO appears to have been insufficient for the scale of heterogeneity in the Rye Patch field. Also, more innovative approaches are needed than "conventional" processing of 3$\mathrm{D}$ data in geothermal regions where there is often several surface static problems and layer lateral heterogeneity in the subsurface.

\section{FUTURE PLANS}

We intend to complete the reprocessing of the 3-D seismic data set, providing a 3-D data volume which can be interpreted for structural control of the Rye Patch reservoir.

We will carry out a more detailed velocity analysis in order to get better information on reflecting horizons by getting better definition of bedding offsets. The development of a 3-D velocity model to use for CMP imaging, tomographic imaging and migration (pre- or post-stack) is a crucial step for the development of a final 3-D image. Our current work is looking at various 2-D velocity analysis to determine the scale of variation which must be used in the final 3-D velocity model. An example of the imaging improvement which is possible (as compared to the SECO processed result) is shown in Figure 3.

We will also investigate the unique borehole geophone data which recorded good quality arrivals from the grid of surface sources. These data should provide both velocity control and potentially improved tomographic imaging of subsurface heterogeneity.

We also plan to use the data provided by the borehole geophone and far offset sources to investigate the applicability of large scale tomography as an independent imaging technique and as velocity control for the 3-D surface seismic imaging.

\section{INDUSTRY INTEREST AND TECHNOLOGY TRANSFER}

Three-dimensional seismic imaging techniques have applicability to geothermal exploration and exploitation throughout the industry. The technology is highly developed in the oil and gas industry. If this project can address the problem of generally poor seismic reflection data acquired in geothermal fields because of subsurface heterogeneity and hydrothermal alterations, then the technology is readily available to the industry.

\section{REFERENCES}

GeothermEx (1997), Geology of the Rye Patch Geothermal Field, Pershing County, Nevada, Internal Report, GeothermEx, Inc., Richmond, California, December, 1997. 
Feighner, M., Daley, T.M., Majer, E.L., Results of Vertical Seismic Profiling at Well 46-28, Rye Patch Geothermal Field, Pershing County, Nevada, Lawrence Berkeley National Laboratory report LBNL41800, February 25, 1998. 

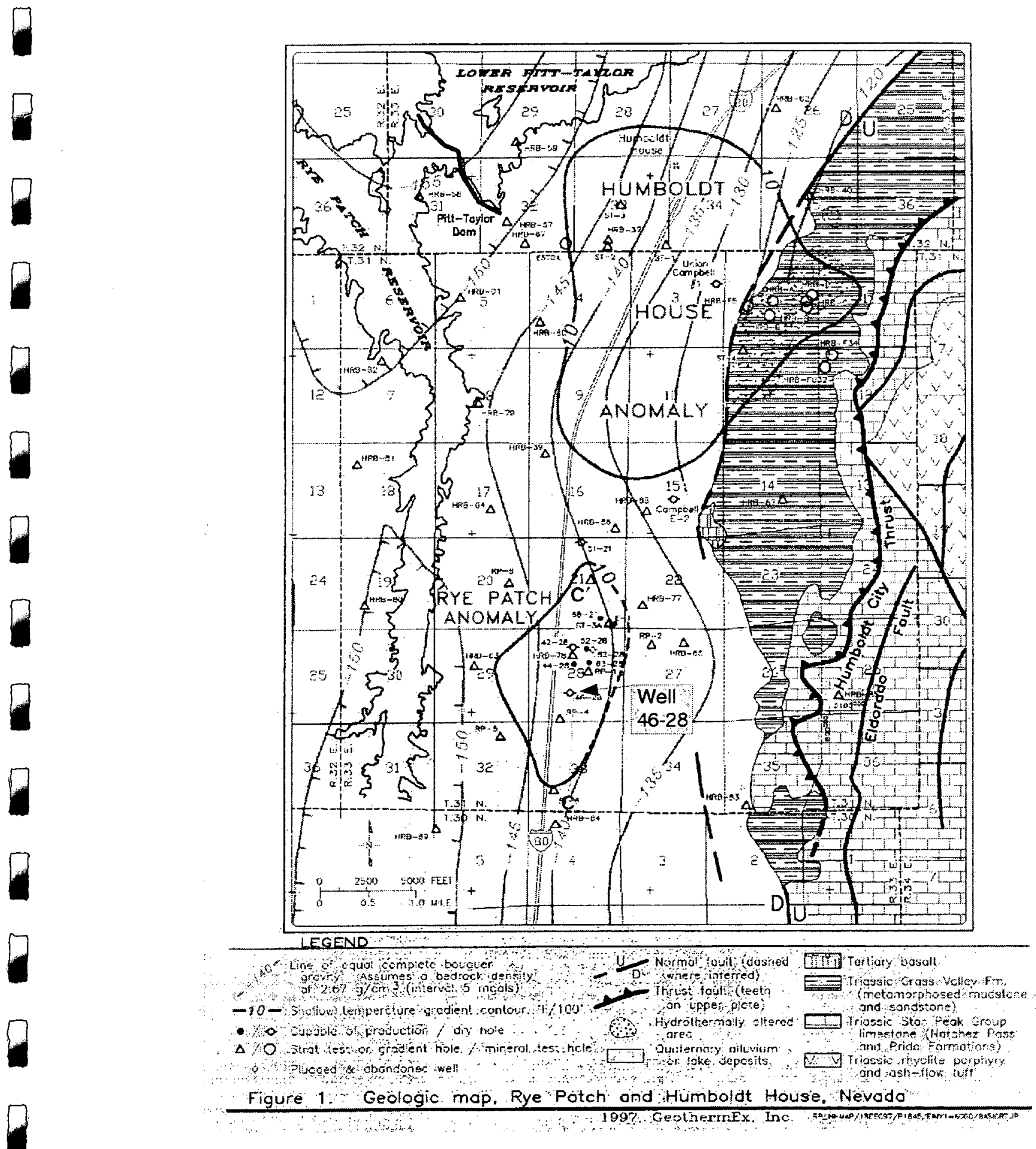

Figure 1. Geologic map, Rye Patch and Humboldt House, Nevada (from GeothermEx, 1997). 


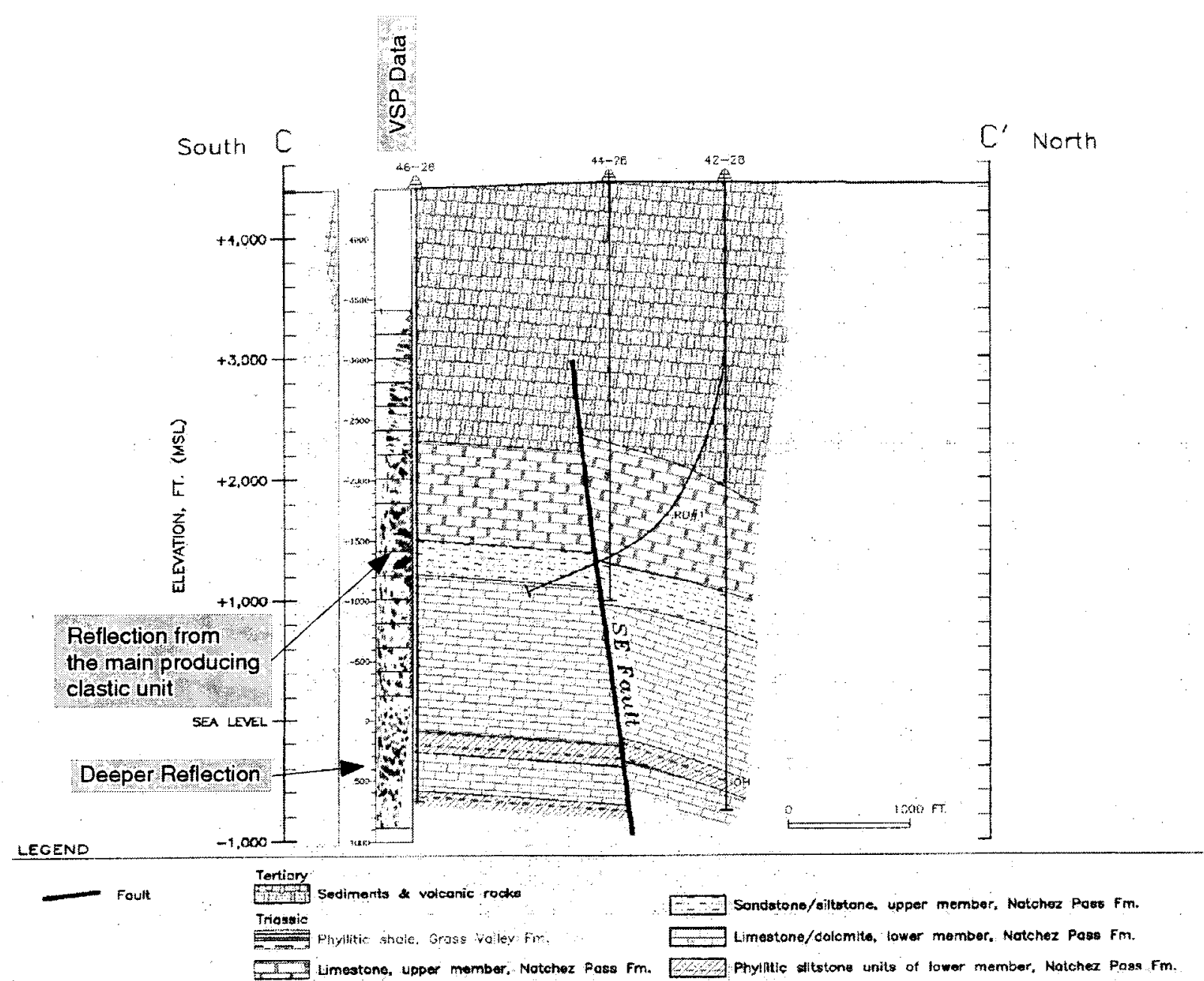

Figure 2. Vertical geologic section, C-C', Rye Patch, Nevado

Figure 2. Vertical geologic section C-C', Rye Patch, Nevada (from GeothermEx, 1997). 
Comparison of Previous 3-D Seismic Processing and Preliminary LBNL Processing

Along an W-E Line Passing Near the VSP Well 46-28
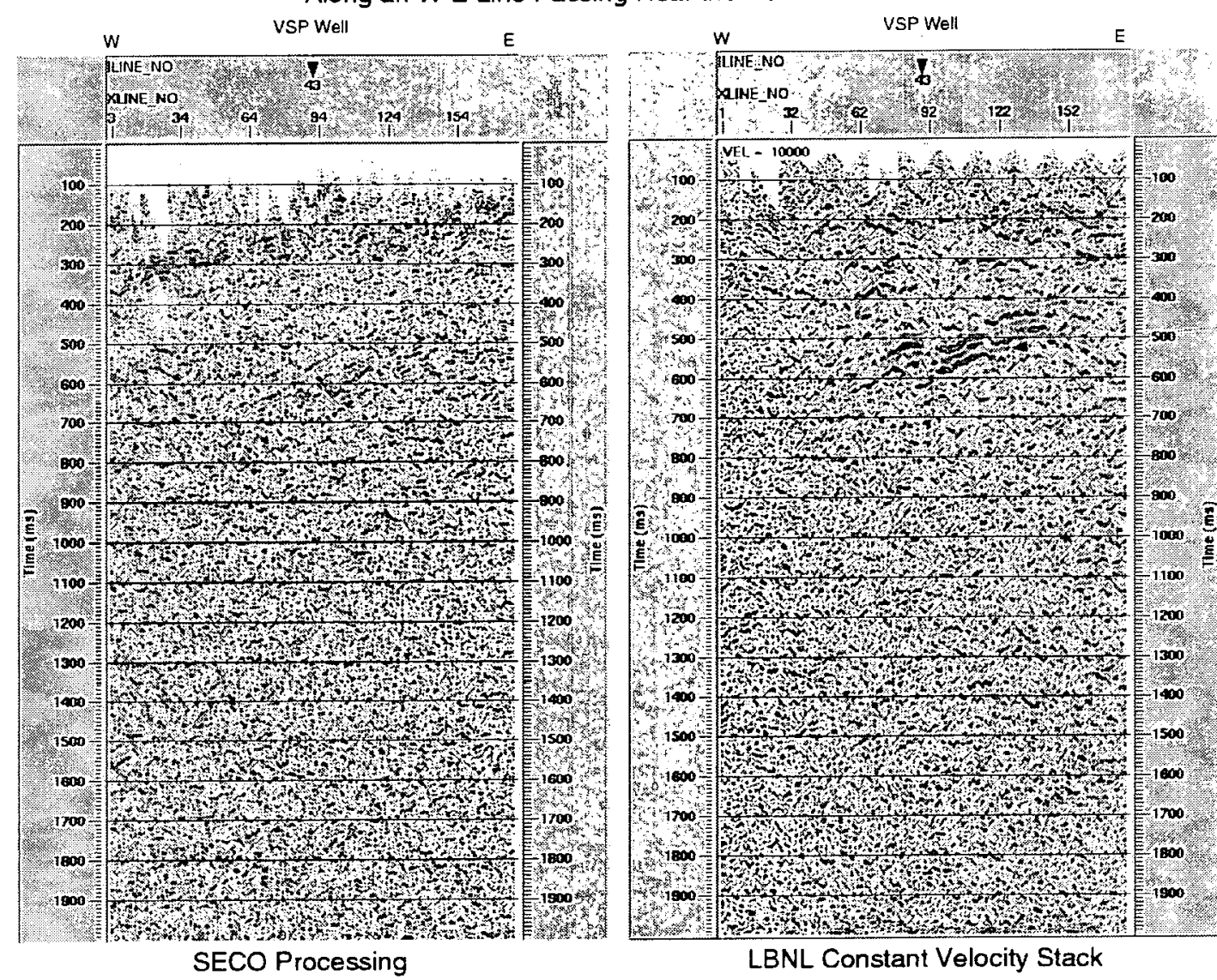

pieflection from

the main producing

clastic unit :

Figure 3. Comparison of previous 3-D seismic processing and preliminary LBNL processing along a WE line passing near the VSP well 46-28. 


\title{
ISOTOPE GEOCHEMISTRY IN GEOTHERMAL RESEARCH
}

\author{
B. Mack Kennedy \\ Lawrence Berkeley National Laboratory \\ Donald J. DePaolo \\ Department of Geology and Geophysics \\ University of California, Berkeley \\ Alfred $\mathrm{H}$. Truesdell \\ Consultant to LBNL and GTO
}

\section{KEY WORDS}

Magmatic gas, acid fluids, fluid inclusions, noble gases, isotopes, heat content, magma chamber evolution, Dixie Valley, Coso, Mahanadong and Mt. Apo, Tibet, The Geysers, Tiwi, Awibenkok.

\section{PROJECT BACKGROUND AND STATUS}

Dixie Valley: Injection of spent production fluids back into the geothermal reservoirs from which they are produced is now widely recognized within the geothermal industry as the single most important factor in conserving reservoir pressure and extending the productive lives of geothermal systems. Continued improvements in environmental awareness throughout the world also generally require that spent geothermal fluids be returned to the reservoir to protect surface and subsurface waters. Injectate is always colder than reservoir temperatures so eventually returning injectate will cool individual production wells and entire reservoirs. The timing of the onset of cooling has ranged from weeks or months in a worst case to decades or perhaps longer in rare instances. To predict the likelihood or onset of cooling resulting from injectate returns it is necessary to develop reliable quantitative techniques to determine the volume of injectate co-produced with the indigenous reservoir fluid and the rate at which the injectate volume increases. To this end, it is necessary to evaluate the reliability of using natural chemical tracers for injectate, such as chloride, non-condensable gases, and water isotopes.

The Dixie Valley geothermal field has been in operation for $101 / 2$ years and during this time an aggressive injection policy has been in effect (e.g. Benoit, 1992). The production and injectate fluids have been thoroughly documented with quarterly brine analyses, annual non-condensable gas samples, and intermittent stable isotope analyses. In the past two years analyses of noble gases and their isotopes have been obtained to give a complete evaluation of the available natural chemical tracers for injectate fluids in a well documented geothermal field. These data allow: (1) an evaluation of the reliability and limitations of the various natural chemical tracers, (2) a quantitative assessment of the volume of injectate coproduced with indigenous reservoir fluid, (3). the rate at which injected fluids are replacing indigenous reservoir fluids, (4) an estimate of the reservoir volume, and (5) an estimate of the relative fluxes of indigenous fluid into the reservoir.

The Coso Geothermal System: It is known that production fluids from the Coso Geothermal Field have an elevated helium- 3 isotopic composition indicative of magma degassing and magma influence. However, there have only been a few measurements and a more extensive study of isotope systematics in the Coso reservoir will provide a better understanding of the distribution and influence of the magmatic source(s). Specific topics to be addressed include: (1) the identification of heat and fluid source(s), particularly the fluids feeding the deep high temperature Coso reservoirs and (2) a determination of the spatial distribution of fluid types, their potential migration paths, and the connectivity within the geothermal reservoir. Samples of production fluid have been collected from 10-15 selected wells along with 1 sample 
of injectate fluid and analyzed for noble gas and $\mathrm{Sr}$ isotopic compositions. The project is conducted in collaboration with Mike Adams, EGI, University of Utah.

Philippine Geothermal Systems: This is a joint LBNL-PNOC research project to characterize deep geothermal fluids using isotope and geochemical techniques. Fluids encountered in several Philippine geothermal fields have a wide range of chemical compositions, some if which are highly acid. Understanding the origin, occurrence, and evolution of these diverse fluid types may allow the detection and avoidance of acid fluids and more confident reservoir management. For the initial survey of Philippine geothermal systems, two fields were selected for study: Mahanadong, Leyte and Mt. Apo, Mindanao. Because these fields are jointly developed by the Philippine National Oil Company (in charge of the steam fields) and, in part by U.S. companies (CalEnergy Co. Inc. and Ormat Int'l. Inc., operating power plants under BOT contracts), the origin and location of acid reservoir fluids is of international economic interest. The problem of potentially acid reservoir fluids is common to most geothermal fields associated with recent andesitic volcanoes and it is greatly in the interests of the world geothermal community as well as the Philippine and U.S. governments to understand and anticipate the occurrence of these fluids. This joint research project and continuing cooperation by the research team will contribute to these objectives.

Yangbajing Field, Tibet: The Yangbajing geothermal field, located in a NE-SW trending basin $\sim 94 \mathrm{~km}$ northwest of Lhasa, the capital of Tibet's Autonomous Region, has an installed capacity of $\sim 26 \mathrm{MWe}$. Production is from liquid dominated shallow moderate temperature $\left(150-165^{\circ} \mathrm{C}\right)$ reservoirs in Quaternary alluvium and altered granite and is fault controlled. $\mathrm{Na} / \mathrm{K}$ ratios of the shallow geothermal fluids imply the possible influence of higher temperature $\left(\sim 300{ }^{\circ} \mathrm{C}\right)$ deep reservoirs. Recent drilling in the northern sector of the field has revealed high temperature $\left(>270^{\circ} \mathrm{C}\right)$ feed zones below the shallow reservoir. Limited data on the chemical composition of the fluids (specifically boron and chloride concentrations) suggests that the shallow geothermal fluids are a mixture of the deeper high temperature fluids and cold ground water. Therefore exploitation of the deeper reservoirs could accelerate the depletion of the shallow resources. However, due to a very limited data set it is difficult to evaluate (1) the potential of the deep resource and (2) the extent to which the deep and shallow resources are hydrologically connected. The heat source for the deeper reservoir is also an unknown. As an initial survey of the Yangbajing Field 10 samples were collected in late FY98 for noble gas analyses which have recently begun. The project is a collaboration with Dr. Zhao Ping, Institute of Geology, Chinese Academy of Sciences.

The Geysers: The source of steam, non-condensable gas, and the temporal evolution of the present day Geysers vapor-dominated reservoir is not well understood, complicating attempts to predict production induced changes in pressure, steam flow, gas content, and composition. Prior studies have shown that the high non-condensable gas component in the high-temperature vapor-dominated reservoir of the northwest Geysers is magmatic and that there is an active present day flux of magmatic gases into the Geysers system. High ${ }^{3} \mathrm{He} /{ }^{4} \mathrm{He}$ ratios in steam from the southeast Geysers suggest that the influence of this magmatic gas flux may extend underneath much of the geothermal field. Fluid inclusion studies have revealed the existence of a liquid-dominated geothermal system that pre-dates the present day vapordominated reservoir. In collaboration with J. N. Moore (EGI) and D. I. Norman (New Mexico Tech), we have continued our analyses of noble gases from fluid inclusions to study the evolution of the early liquid-dominated system as it evolved towards the vapor-dominated system that is presently being produced.

Temporal Evolution of Heat Sources in Volcanic Systems: Heat input and fluid chemistry in geothermal systems associated with young volcanic centers are strongly influenced by the state of the deep magma chambers that feed the volcanic system. Magma chambers evolve in time due to changing rates of magma recharge from the mantle, assimilation of crustal rocks, etc. and these changes will be reflected in the overlying shallow geothermal system and influence strategies for geothermal fluid production. For 
instance, recent studies suggest that steam composition in the High Temperature Reservoir in the Northwest Geysers is strongly influenced by active magma degassing, that the formation of the High Temperature Reservoir was probably related to a recent magmatic intrusion, and that the source magma chamber may be experiencing a high rate of recharge from the mantle.

Temporal variations in $\mathrm{Nd}$ isotopic compositions in erupted volcanics at a number of large volume silicic centers (Yellowstone, Long Valley, Timber Mountain) show a correlation with the volume of eruption. The variations in the isotopic composition of lavas reflect either a systematic change in the composition of the magma source or a change in the relative rates of physical processes such as crustal assimilation and magma recharge. The isotopic correlation with volume suggests that the temporal variations are caused by physical processes, and that these processes control the evolution of the magmatic system. Combined isotope and trace element data can be used to identify different sources involved in magma production. It should, therefore, be possible to differentiate between the effect of changing source composition, and the effect of changing relative contributions of recharge and assimilation on the isotopic signature of erupted magma. Temporal variations in isotopic ratios, if well understood, could therefore, be a useful tool in evaluating the state of a geothermal heat source and its influence on shallower geothermal production fluids. This may be particularly relevant in understanding the source and fate of acid fluids.

Three rhyolitic volcanic systems are being studied: the Clear Lake Volcanic Field, northern California, Long Valley Caldera, east-central California, and the Chalupas Caldera, Ecuador. Through an integrated approach, including field work, petrology, and isotope geochemistry the following will be addresses: (1) the causes of the observed temporal variations in isotopic compositions; (2) the correlation between eruption volume and isotopic signature in contrasting volcanic settings; and (3) the use of temporal variations in isotopic ratios to model the evolution of geothermal heat sources.

\section{PROJECT OBJECTIVES}

In general, this project is aimed at critically assessing the value of isotope ratio measurements for characterizing geothermal reservoirs. Our objective is to develop a set of isotopic parameters, based on measurements of fluids, fluid inclusions, and rocks and minerals, that will help to identify past and present fluid sources in geothermal systems and to estimate their extent, heat content, and lifetime.

\section{Technical Objectives}

- Dixie Valley: Development of a general and more thorough understanding of the reliability and limitations of various natural chemical tracers for injectate fluids in geothermal systems.

- The Coso Geothermal System: Provide a better understanding of the distribution and influence of potential magmatic fluid and heat sources.

- $\quad$ Philippine Geothermal Systems: Address the problem of acid reservoir fluids that are common to most geothermal fields associated with recent andesitic volcanoes, so as to better understand and anticipate their occurrence, thereby improving reservoir management.

- $\quad$ Yangbajing Field, Tibet: To develop a better understanding of the heat source for moderate to high temperature shallow geothermal reservoirs that are not closely associated with recent volcanism but are associated with deep faults or crustal sutures.

- The Geysers: Develop a more thorough understanding of how and when The Geysers evolved from a liquid-dominated to a vapor-dominated system and what role the present day flux of magmatic gases has played over the course of this evolution. 
- Temporal Evolution of Heat Sources in Volcanic Systems: Using temporal trends in the isotopic composition of erupted and intruded volcanics, to develop a model for the evolution of crustal magma chambers and how the evolving chamber will be reflected in overlying shallow geothermal systems.

\section{Expected Outcomes}

- Dixie Valley: A quantitative assessment of (1) the volume of injectate co-produced with indigenous reservoir fluid, (2) the rate at which injected fluids are replacing the original reservoir fluid and provide an estimate of (1) reservoir volume and (2) the relative fluxes of indigenous and injectate fluids into a production reservoir.

- The Coso Geothermal System: (1) The identification of heat and fluid source(s), particularly the fluids feeding the deep high temperature Coso reservoirs and (2) a determination of the spatial distribution of fluid types, their potential migration paths, and the connectivity within the geothermal reservoir.

- $\quad$ Philippine Geothermal Systems: Develop a better understanding of the origin, occurrence, and evolution of acidic fluids in andesite hosted geothermal systems.

- Yangbajing Field, Tibet: Characterize the heat source and the potential for developing a deeper higher temperature reservoir without adversely affecting a shallower resource presently under production. Evaluate the potential for finding additional potential geothermal resources related to the Tibetan Suture Zone.

- The Geysers: Better and more comprehensive models of the origin and evolution of the vapordominated Geysers reservoir will enable steam producers to more confidently predict the decline in steam flow, the future concentrations of non-condensable gases, the possible appearance of corrosive $\mathrm{HCl}$, and the positive or adverse effects of injection.

- Temporal Evolution of Heat Sources in Volcanic Systems: Determine the causes of observed temporal variations in the isotopic compositions of crustal magma systems. Quantitatively assess the correlation between eruption volume and isotopic signature in contrasting volcanic settings. And develop temporal variations in isotopic ratios to model the evolution of geothermal heat sources.

\section{APPROACH}

The isotopic compositions of elements in fluids provide a quantitative measure of material balance, therefore isotopes are extremely powerful in tracing fluid flow and history. We believe that a systematic study of the isotopic compositions of noble gases, $\mathrm{C}, \mathrm{O}, \mathrm{H}, \mathrm{N}, \mathrm{Sr}$, and $\mathrm{Nd}$ associated with geothermal reservoirs, associated volcanics, and local groundwaters will provide valuable information regarding fluid sources, migration pathways, fluid flow rates, and reservoir compartments which could not be obtained with any other methods. The isotopic composition of a fluid moving through the crust will be modified in space and time in response to varying chemical and physical parameters and/or by mixing. During these processes, elements will either be conserved, thus preserving isotopic information related to initial conditions and sources or modified in a fashion that is diagnostic of fluid transit times, chemical reactions, and mixing along a flow path. The isotopic data can also support the hydrologic models by providing complementary information about the fluid flow regime. 
The temporal evolution of geothermal fluids is investigated by comparing the compositions of fluid inclusions of different paragenetic histories with each other and with present day production fluids. The isotopes of the chemically inert noble gases $(\mathrm{He}, \mathrm{Ne}, \mathrm{Ar}, \mathrm{Kr}$, and $\mathrm{Xe}$ ) provide long-lasting tracers of fluid sources. These tracers include large ${ }^{3} \mathrm{He}$ enrichments of deep fluids originating in the mantle and introduced into crustal fluids through magma degassing or deep fluid circulation, enrichment in radiogenic ${ }^{4} \mathrm{He},{ }^{40^{*}} \mathrm{Ar}\left({ }^{40 *} \mathrm{Ar}=\right.$ radiogenic $\left.{ }^{40} \mathrm{Ar}\right)$ and nucleogenic components of crustal fluids and enrichment in ${ }^{36} \mathrm{Ar}$ of atmospheric fluids. Noble gases can be analyzed in fluid samples collected from producing wells, surface hydrothermal features, fluid inclusions, and in the rocks and minerals related to the geothermal system.

\section{RESEARCH RESULTS}

Dixie Valley: An aggressive injection policy has been in effect at the Dixie Valley Geothermal Field since 1988. Production and injection strategies rely on the ability to quantitatively asses and model the return of injectate and the potential for thermal breakthrough. Good agreement between the volume fraction of injectate in the production stream $\left(\mathrm{V}_{\text {inj }} / \mathrm{V}_{\text {lotal }}\right)$ determined using three independent natural tracers $(\mathrm{Cl}$, noble gases, and water isotopes) suggests that changing chloride can be used as a proxy for monitoring the return of injectate fluid. This is very important because chloride data for the production and injectate streams exists for the entire 1988-1998 production/injection period at Dixie Valley.

The estimated volume of injectate in the production streams from the northern section of the field (Section 33) increased from 1988 to a maximum value of $\sim 60 \%$ in mid-to-late 1992, and has steadily declined to a present value of $\sim 37 \%$. This pattern can not be identified with a similar change in the injectate composition and, therefore, is difficult to interpret. The continued decline may indicate that a change in the hydraulic connectivity occurred in mid 1992, perhaps induced by water table draw down isolating the Section 33 reservoir from a fracture or pathway supplying the injectate. Alternatively, the early rise in chloride concentration in the production stream that gives the apparent increase in $V_{\text {inj }}$ was driven not by high chloride injectate fluids but by the invasion of the Section 33 reservoir with a second high chloride indigenous reservoir fluid, like that known to exist in the Miocene basalt overlying the production reservoir.

There is definitive evidence for the presence of injectate in the production streams from the southern part of the field (Section 7). On average the Section 7 wells have experienced a linear increase in the volume fraction of co-produced injectate. The rate of increase is on the order of 5-7\% per year. Presently, the injectate fluid comprises $\sim 60-100 \%$ of the production stream. Assuming Section 7 wells produce from a closed reservoir with an average fracture porosity of $\sim 10 \%$, the total volume of fluid injected at Dixie Valley implies a Section 7 reservoir volume of $\sim 2.0-3.3 \mathrm{~km}^{3}$. Continued monitoring of the production and injectate fluid chloride and noble gas concentrations and water isotopic compositions could lead to a better estimate of the relative flux of the indigenous geothermal fluid into the reservoir and provide additional constraints on models predicting when a thermal breakthrough will occur and the rate reservoir temperatures will decline. The preliminary results of this study were presented at the 24th Workshop on Geothermal Reservoir Engineering, Stanford, University, 1999 and will appear in the workshop proceedings: Kennedy et al., 1999).

The Coso Geothermal System: To provide a better understanding of the distribution and influence of potential magmatic fluid and heat sources in the Coso Geothermal system 10 samples of production fluid and one of injectate were collect in late FY98. The samples have recently been analyzed for noble gas isotopic and relative abundances and $\mathrm{Sr}$ isotopic composition. Preliminary evaluation of the data confirms large enrichments of magmatic helium with moderate variation in the helium isotopic composition. We are working with Mike Adams, EGI, to map the variations into the physical and chemical structure of the field to assess the variation in magmatic influence. The relative abundances of the noble gases suggest 
field wide modification of the composition of non-condensable gases due to prior injection programs, including direct injection of atmospheric gases.

The Philippine Geothermal Systems: In December, 1998, three scientists from LBNL (Kennedy, Truesdell, and Shuster) traveled to the Philippines for 10 days as guests of the PNOC. While in the Philippines we conducted two workshops on isotope geochemistry in geothermal systems and we collected 7 gas and brine samples from the Mt Apo Geothermal Field in Mindanao (BOT with Oxbow Geothermal) and 13 gas and brine samples from the greater Tongonan (Mahanabong) Geothermal field in Leyte (BOT with CalEnergy). This represents the first comprehensive study of noble gas isotope systematics conducted in the Philippines. The primary goal is to help assess the origin of the geothermal fluids, which remains an open question for many of the Philippine systems, and to trace the connection between the acidic and neutral fluids that are characteristic of many of the production fields. For instance, at Mt. Apo the second phase of development is situated adjacent to a large zone of magmatic degassing, yet the primary production fluid is neutral. A similar situation exists in Tongonan, except the source of the acidity is not as well constrained as is the case for Mt. Apo. We anticipate that the sample analyses will be completed by April, 1999 and results will be presented at the upcoming World Geothermal Congress 2000.

Yangbajing Field, Tibet: As part of an initial survey of the Yangbajing Field, 10 samples were collected in late FY98 for noble gas analyses which are currently being analyzed. The project is a collaboration with Dr. Zhao Ping, Institute of Geology, Chinese Academy of Sciences. Dr. Ping collected the samples. Our preliminary results confirm earlier reports of low helium isotopic compositions suggesting very little, if any magmatic involvement, despite the presence of high temperature $\left(\sim 270{ }^{\circ} \mathrm{C}\right)$ reservoirs. This further suggests that the heat source for the Tibetan field may be deep circulation of meteoric waters along the Tibetan Suture, similar, in some ways, to one of the proposed heat sources for the Dixie Valley Geothermal Field and similar to fields of the Basin and Range Province in the United States. Or, alternatively, the geothermal field is influenced by an high advective flux of thermal fluids from the deep crust and/or mantle, similar to that proposed for the structural weakening of the San Andreas Fault (e.g. Kennedy et al., 1998). We plan to present the final results of this initial study at the upcoming World Geothermal Congress.

The Geysers: To establish a better understanding of the temporal evolution of The Geysers geothermal system, in collaboration with Joe Moore (EGI, University of Utah) and David Norman (New Mexico Tech.), we have analyzed noble gases extracted from fluid inclusions in hydrothermal minerals extracted from core samples (Moore et al., 1997).

The fluid inclusions record a zoned halo of decreasing temperature and salinity with distance away from the 1.3-1.4 Ma felsite intrusion and are, therefore. likely to be related to the intrusion of the felsite (Moore and Gunderson, 1995). In a suite of samples selected to provide a representative section of the temperature-salinity halo, the bulk gas chemistry of the fluid inclusions suggest mixing between three different fluids: one indistinguishable from air saturated water, a second that is strongly enriched in $\mathrm{N}_{2}$ and believed to be magmatic, and a third that is enriched in $\mathrm{CH}_{4}$ suggesting a crustal source. In all samples, except one, the fluid inclusions are enriched in magmatic helium with a nearly constant ${ }^{3} \mathrm{He} /{ }^{4} \mathrm{He}$ ratio of $\sim 6 \mathrm{Ra}$, significantly less than that observed in present day production steam ( $\sim 8 \mathrm{Ra}$, Kennedy and Truesdell, 1996). The enrichment in magmatic helium confirms the suspected influence that the felsite intrusion had on the evolution of the liquid system. The exception (L'esperance-2) is vein material from the margin of the high temperature reservoir in the Northwest Geysers. Noble gases in fluid inclusions from these veins are strongly enriched in He but with a low helium isotopic composition (0.5 Ra), suggesting overprinting of the magmatic signature by connate or metamorphic fluids or that these veins contain fluids that pre-date the felsite intrusion. The results of this project are presented in Moore et al. (1999). 
Temporal Evolution of Heat Sources in Volcanic Systems: A comprehensive suite of samples from the Clear Lake, California volcanic system have been collected to study the variations of $\mathrm{Rb}-\mathrm{Sr}$ and $\mathrm{Sm}-\mathrm{Nd}$ isotopic systems with major and trace element chemistry of the lavas, eruptive age, and flow volume. We are especially interested in modeling these variations so as to predict whether or not the Clear LakeGeysers region is still being supplied with magma and hence whether the geothermal system is being recharged with heat. There is independent evidence suggesting that the area is still active (long-period earthquakes at $25 \mathrm{~km}$ depth, gravity anomalies, mantle helium isotopic compositions and ${ }^{3} \mathrm{He} / \mathrm{CO}_{2}$ ratios in steam produced from The Geysers high temperature reservoir, etc.).

The collected suite of samples represent the four main periods of Clear Lake volcanic activity and cover the full compositional range of eruptions from each period. A second set of this suite of samples was collected for geochronological studies. The isotopic, chemical, and petrologic analyses of a large number of these samples has been completed. To date, the most interesting results are related to the $\mathrm{Nd}$ isotopic compositions which, in general, are high and similar to mantle values. In addition, the Nd ratios increase through time, suggesting that supply of fresh mantle magma to the volcanic system has also been increasing with time. This provides supporting evidence for a still active magmatic system beneath the Clear Lake-Geysers area. Results from the geochronological study should provide a more quantitative measure of the magma chamber recharge rate.

\section{FUTURE PLANS}

Several of the projects discussed above are new or in their early stage of activity: Coso Geothermal Field, Philippine geothermal fields, and the Yangbajing Field in Tibet. Therefore, the future plans for these projects consist primarily of sample analyses, data interpretation, and collection of additional samples, if necessary. In some cases, such as the study of Philippine and Tibetan systems, we anticipate that the projects will be expanded to include additional fields and/or prospective fields. Preliminary evidence for a change in the helium isotopic composition at the Coso Geothermal Field may lead to a monitoring program for a selection of wells.

Dixie Valley: (1) Continue monitoring chloride concentrations, noble gas abundances, and water isotopic compositions of the Dixie Valley production streams and injectate fluids to study the changing volume of co-produced injectate. (2) Model the changing proportion of co-produced injectate with time to obtain an estimate of reservoir volume, the flux of indigenous geothermal fluid into the production reservoirs, and to provide additional constraints for predicting when a thermal breakthrough will occur and the rate reservoir temperatures are likely to decline.

Fluid Inclusions and the Temporal Evolution of Geothermal Fluids: Due to our success in the study of noble gases in fluid inclusions from The Geysers, we plan to apply this technique to vein minerals in UNOCAL drilled core obtained from the Awibenkok Field, Indonesia and the Matalibong-25 well, Tiwi Field, Philippines. As with the Geysers fluid inclusion project, this work will be conducted in collaboration with J. N. Moore (EGI, petrographic and paragenetic characterization) and D. I. Norman (New Mexico Tech, bulk gas chemistry). The primary focus will be the temporal evolution of these fields, the transition zone from magmatic to geothermal fluid, the transition through the field cap, and there will be an additional emphasis on evaluating the degree of heterogeneity of fluid composition within individual compositional zones and a more quantitative correlation between bulk gas compositions and magmatic contributions.

Temporal Evolution of Heat Sources in Volcanic Systems: Future work will consist primarily of (1) completion of the isotopic, chemical, and petrologic analyses of existing samples from the Clear Lake, CA. and Chalupas Caldera, Ecuador volcanic systems, (2) complete the geochronological study of these samples, (3) select and analyze mineral separates from which helium isotopic data may be obtained 
magmatic fluid inclusions, and (4) begin the process of data interpretation. The early results from the Clear Lake volcanic system are very interesting and should become even more exciting as changes in major and trace element chemistry of the erupted volcanics and geochronological information are combined with the temporal trends in Nd isotopic composition. Although erupted volcanics tend to be very gas poor due to gas loss during eruption, it is hoped that mineral separates can be obtained that still contain helium isotope information related to the magma chamber ambient atmosphere. If so, then we will attempt to develop a model which can evaluate the heat content of an existing or potential geothermal system based upon a correlation between ${ }^{3} \mathrm{He}$ content of the reservoir fluids and the mass influx rate of asthenospheric melt to a magma chamber as derived from the observed correlations between $\mathrm{He}, \mathrm{Nd}$, and $\mathrm{Sr}$ isotopes of associated erupted volcanics.

\section{INDUSTRY INTEREST AND TECHNOLOGY TRANSFER}

\section{Organization}

Calpine Corporation

Unocal

Oxbow Energy Co.

Philippine National Oil Co. (PNOC)

\section{Type and Extent of Interest}

Origin of production gas, potential for production of corrosive steam in SE Geysers.

Sources and potential for production of chemically hostile fluids in geothermal systems closely associated with active volcanoes.

Origin of heat, size of resource, and injectate return.

Origin, distribution, and fate of acidic reservoir fluids.

\section{REFERENCES}

Benoit, D. (1992), A case history of injection through 1991 at Dixie Valley, Nevada. Geothermal Resources Council Trans., 16, p. 611-620.

Kennedy, B.M. and Truesdell, A.H. (1996), The Northwest Geysers high-temperature reservoir: evidence for active magmatic degassing and implications for the origin of The Geysers geothermal field. Geothermics, 25, p.365-387.

Kennedy, B.M., Janik, C., Benoit, D., and Shuster, D. (1999), Natural geochemical tracers for injectate fluids at Dixie Valley. Proc. 24th Workshop on Geothermal Reservoir Engineering, January 25-27, 1999, Stanford, CA (in press).

Kennedy, B.M., Kharaka, Y.K., Evans, W.C., Ellwood, A., DePaolo, D.J., Thordsen, J., Ambats, G., and Mariner, R.H. (1998), Mantle fluids in the San Andreas Fault system, California. Science, 278, p. 12781281.

Moore, J.N. and Gunderson, R.P. (1995), Fluid inclusion and isotopic systematics of an evolving magmatic-hydrothermal system. Geochim. Cosmochim. Acta, 59, p.3887-3907.

Moore, J.N., Norman, D.I., Kennedy, B.M., and Adams, M.C. (1997), Origin and chemical evolution of The Geysers, California, hydrothermal fluids: implications from fluid inclusion gas compositions, Geothermal Resources Council Trans., 21, p.635-641. 
Moore, J.N., Norman, D.I., and Kennedy, B.M. (1999), Fluid-inclusion gas composition from an active magmatic-hydrothermal system: A case študy of The Geysers, California geothermal field. Chemical Geology, (in press).
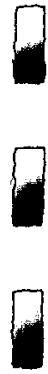


\title{
THERMODYNAMICS AND PHASE RELATIONS OF SYNTHETIC GRANITE MELTS AND ASSOCIATED AQUEOUS FLUIDS
}

\author{
J. G. Blencoe, L. M. Anovitz, D. R. Cole and J. Horita \\ Chemical and Analytical Sciences Division, Oak Ridge National Laboratory
}

\section{KEY WORDS}

silicate melts, geothermal fluids, fluid-rock interactions, thermodynamics, phase equilibria, modeling, granite

\section{PROJECT BACKGROUND AND STATUS}

Geothermal resources are genetically linked to silicic magmatism in numerous localities worldwide. Two important manifestations of this link are heat transfer from the magmas to superjacent geothermal systems, and mixing of magmatic fluids with meteoric waters. In mixed-fluid systems it is known that: (1) the initial chemical compositions of magmatic fluids are strongly influenced by the bulk composition and thermodynamic mixing properties of the magma, (2) incompatible melt components are preferentially partitioned into the aqueous fluids that separate from silicic magmas, and (3) geochemical reactions can potentially produce significant changes in the compositions of magmatic fluids prior to or during mixing with meteoric waters. These and other magma-hydrothermal processes have been understood semiquantitatively for many years; to characterize these systems more rigorously, new thermodynamic and kinetic models are needed.

A comprehensive thermodynamic model for granitic magmas would facilitate quantitative geochemical investigations of granite-hosted, magma-hydrothermal systems. With such a model, crystallization paths for the melts could be calculated. These paths correlate with release of latent heat, which is an important factor in the overall heat budget of the system. They also define both the P-T-X conditions at which an aqueous fluid begins separating from the magma, and the composition of that fluid.

Granitic magmas contain numerous minor and trace components. Consequently, it is impractical to experimentally quantify all of the thermodynamic characteristics of these melts. Fortunately, a great deal can be learned by investigating analog systems. The "haplogranite" system, $\mathrm{NaAlSi}_{3} \mathrm{O}_{8}$ (albite) $\mathrm{KAlSi}_{3} \mathrm{O}_{8}$ (sanidine) - $\mathrm{Si}_{4} \mathrm{O}_{8}$ (quartz) - $\mathrm{H}_{2} \mathrm{O}$ (water), is widely regarded as an excellent analog for granites and granitic pegmatites. Thus, we are conducting systematic investigations of the thermodynamics and phase relations of haplogranitic melts. Currently, our attention is focused on: 1) measuring the equilibrium $\mathrm{Na} / \mathrm{K}$ exchange between crystalline feldspars and melt, 2) measuring the mutual solubility of haplogranite melt and water, and 3) re-evaluating the available data for melting in the systems albitewater, silica-water and sanidine-water.

\section{PROJECT OBJECTIVES}

This project is part of the program "Physical Chemistry of Geothermal Systems" at the Oak Ridge National Laboratory (ORNL). The immediate goal of the research is to perform laboratory experiments that elucidate the phase relations and thermodynamic mixing properties of haplogranitic melts and associated aqueous fluids. The resulting fundamental thermochemical data can be applied in quantitative modeling of heat and fluid flow in geothermal systems associated with silicic magmas. The ultimate aim of the work is to develop thermodynamic models for silicic magmas and high-temperature geothermal fluids. 


\section{Technical Objectives}

- $\quad$ Measure the partitioning of $\mathrm{Na}$ and $\mathrm{K}$ between crystalline alkali feldspar(s) and haplogranitic melt as a function of the silica content and water content of the melt.

- Determine the alkali aluminosilicate composition of aqueous fluid in equilibrium with haplogranitic melt at $500-2500$ bars, $680-1000^{\circ} \mathrm{C}$.

- Determine the solubility of water in haplogranitic melts at $500-2500$ bars, $680-1000^{\circ} \mathrm{C}$.

- Re-evaluate the reliability of available thermodynamic data for the systems albite-water, silicawater and sanidine-water.

- Acquire new and more accurate data on the boundaries of melt-crystal phase fields in haplogranitic systems at $500-2500$ bars, $680-1000^{\circ} \mathrm{C}$.

\section{Expected Outcomes}

The new experimental data will be used to develop thermodynamic equations of state for: (1) calculating crystal-melt phase relations and water solubilities in silicic melts, and (2) predicting the solubility of granitic components in high-temperature geothermal fluids.

\section{APPROACH}

The integral thermodynamic mixing properties of hydrous haplogranitic melts can be determined if sufficient, accurate experimental data are obtained on: (1) the hypersolidus phase relations of haplogranitic systems, and (2) the free energies of fusion of stoichiometric silicate components $\left(\mathrm{NaAlSi}_{3} \mathrm{O}_{8}, \mathrm{KAlSi}_{3} \mathrm{O}_{8}, \mathrm{Si}_{4} \mathrm{O}_{8}\right)$. To obtain these data, experiments are being performed in an internallyheated pressure vessel, and in cold-seal hydrothermal apparatus. This equipment is part of the unique assemblage of laboratory devices at ORNL for studies of chemical equilibria, thermodynamics of brine systems, liquid-vapor molecular and isotopic partitioning, and other phase behavior. Literature data are also being evaluated to constrain the melting thermodynamics of the end-member silicate components.

\section{RESEARCH RESULTS AND VARIANCES}

\section{A. Haplogranite Melt-Feldspar Exchange Equilibria}

This year we conducted research to elucidate the equilibrium partitioning of $\mathrm{Na}$ and $\mathrm{K}$ between haplogranite melt and alkali feldspar, and the solubility of water in feldspar-rich haplogranitic melts. To date this work has focused on preparation of suitable starting materials and experimental design.

Our experimental method for determining feldspar-melt tie-lines is illustrated schematically in Figure 1. At a fixed pressure,

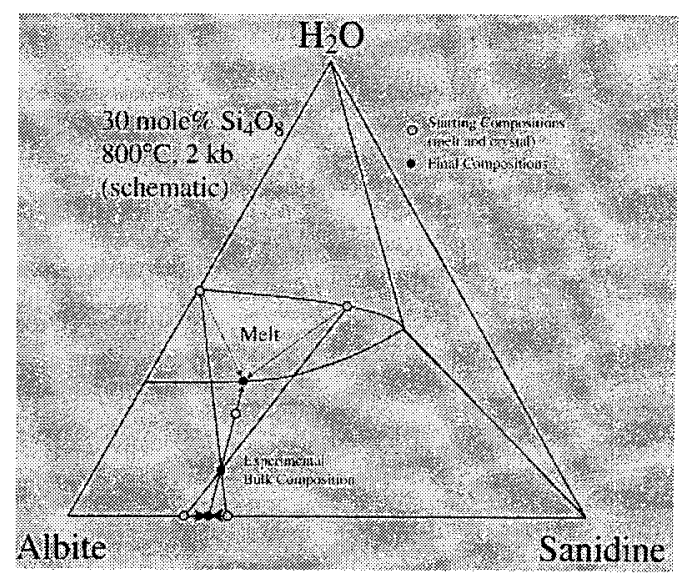


temperature and mole fraction $\mathrm{Si}_{4} \mathrm{O}_{8}$ a bulk composition is chosen for which the tie-line is to be determined. Two melt compositions and two feldspar compositions are then synthesized which, when mixed in the proper proportions, yield tie lines which cross at the bulk composition of interest and bracket the expected equilibrium feldspar and melt $\mathrm{Na} / \mathrm{K}$ ratios. During the experiment the $\mathrm{Na} / \mathrm{K}$ ratios of both the feldspars and melts will migrate toward, and ideally reach their equilibrium values. This constrains the equilibrium $\mathrm{Na} / \mathrm{K}$ compositions of the feldspar and the melt, but is only a half reversal on the water content of the melt.

A second experiment is performed with a crystal-free glass to reverse the water content of the melt in the water-increasing direction. The crystal-free glass has a bulk composition lying along the tie-line being investigated at a lower water content than the equilibrium value. It is prepared by reacting haplogranite starting materials in appropriate proportions at a pressure above that at which the tie line is to be determined. During the experiment at the pressure and temperature of interest, the crystal-free glass will partially crystallize, yielding a melt with a higher water content, thereby bracketing the equilibrium water content of the melt in the water-increasing direction. The above experiments will then be repeated for other mole fractions of $\mathrm{Si}_{4} \mathrm{O}_{8}$ to determine whether the concentration of this component affects $\mathrm{Na} / \mathrm{K}$ partitioning between feldspar and melt. Analyses of the initial and final $\mathrm{Na} / \mathrm{K}$ ratios will be performed using an electron microprobe, and water contents of the glasses will be measured by NIR spectroscopy or SIMS.

\section{B. $\quad$ Fluid-Composition Experiments}

A number of factors have limited the ability of previous researchers to determine the composition of aqueous fluid coexisting with haplogranitic melt. The most serious is that the high P-T composition of the fluid is not retained on quenching. Silicate materials precipitate as films and "quench roe" (amorphous silica-rich spheres). This prevents direct analysis of the high P-T fluid. The tendency of the silicate to precipitate on the glass further complicates the analysis.

We have developed a method that overcomes many of these difficulties. These experiments establish the $\mathrm{Na}, \mathrm{K}, \mathrm{Si}$, and Al composition, as well as $\delta \mathrm{D}$ and $\delta^{18} \mathrm{O}$, of an aqueous fluid coexisting with haplogranitic melt. The method uses a triple Pt capsule. Hydrous haplogranite glass is placed in two identical inner capsules, which are welded on the bottom only. The top of each capsule is filled with a ball of fine $\mathrm{Pt}$ mesh. These inner capsules are loaded, along with water, in a larger outer capsule. During the run the water has easy access to the melt through the mesh, but little water is actually in the inner capsule during quenching. Thus essentially all of the precipitate is found in the outer capsule, easily separable from the remaining glass after the run.

Hydrous haplogranitic glasses of known chemical and isotopic composition were synthesized as starting materials for the experiments. Nine compositions were prepared, five haplogranites, three on the bounding binaries ( $2.5 \mathrm{~kb}$ minimum melt compositions), and albite. In each, water-oversaturated and undersaturated glasses were prepared to allow reversal of the equilibrium water content of the melt. Experiments have been performed at $2.5 \mathrm{~kb}, 950^{\circ} \mathrm{C}$, for periods ranging from 1 to 35 days.

A major challenge in this project has been development of techniques for analyzing the experimental results. Several procedures are required: (1) opening the capsules, (2) processing the precipitate for analysis, (3) analysis of the precipitate, (4) dehydrating the glasses to measure the water content, and (5) isotopic measurements of both the free water and the glass. Capsules are opened by puncturing under vacuum. Heat tape on the puncturer prevents water precipitation in its upper section, and a heat gun is used sparingly to drive water out of the capsule and into a liquid nitrogen cooled break-seal tube. Special care is taken to ensure that excess heating does not partially dehydrate the experimental glass. The vacuum distillation process separates the water from the precipitate, and leaves any remaining dissolved 
material in the capsule. The break-seal tube is then sealed and the water stored for isotopic analysis. The difference in the weight of the capsule before and after puncturing gives the amount of free water present during the run.

To prepare the precipitate for analysis the inner capsules are removed and checked for precipitate. Comparison of the weight of the outer capsule to its initial weight yields one estimate of the amount of precipitate, and thus of the total solubility at $\mathrm{P}$ and $\mathrm{T}$. A second estimate is obtained by measuring the weight change in the inner capsules and correcting for absorbed water (the difference between the water added to the outer capsule and that recovered on puncturing) to obtain the amount of weight lost, which is assumed to be equal to the mass of precipitate. The capsule is then filled with Li-borate and heated to $1000^{\circ} \mathrm{C}$ to dissolve the silicate precipitate in the flux.

Analysis of the sample requires that it be dissolved. To do so, known amounts of $\mathrm{Ca}$ and $\mathrm{Mg}$ standards and $\mathrm{HNO}_{3}$ are weighed into small bottles. The capsules are then added, and the materials heated at $60^{\circ} \mathrm{C}$ for 2-3 weeks. The capsules are then removed and checked for complete sample dissolution. A third weight-change estimate of the total amount of precipitate is obtained at this stage by comparing the current weight of the capsule, with the flux and precipitate dissolved away, to its weight immediately after the inner capsules were removed. The dissolved samples are analyzed by ICP. Dilution factors calculated from the $\mathrm{Ca}$ and $\mathrm{Mg}$ analyses convert the $\mathrm{Na}, \mathrm{K}, \mathrm{Al}$, and $\mathrm{Si}$ analyses to amounts of material present to calculate the total amount of material in solution. The analysis of each element yields its relative solubility.

For each sample, glass in one of the two inner capsules can be dehydrated to determine its water content, thereby constraining the solubility of water in the melt (see below). The difficulty of analysis of the water content of hydrous glasses is well known. We have developed a dual method which avoids many of the pitfalls described by previous investigators. Dehydration tubes are evacuated and sealed before heating, and a single openable fitting minimizes leakage. Evolved water is trapped in a break-seal tube and analyzed with high precision by U-furnace manometry. Unfortunately, no technique based on heating to remove the water, regardless of the post-dehydration analysis technique, can separate dissolved water from that in trapped inclusions. For that reason, dehydration will only be used to make high precision standards for either SIMS or NIR analysis of experimental glasses.

To date, data have been obtained from samples reacted in two sets of otherwise duplicate experiments using two different waters that were performed to determine the solubility of a Si-poor haplogranite reacted at $950^{\circ} \mathrm{C}, 2500$ bars for $1,2,4,8$ and 11 days. Part of this work was reported at the annual meeting of the Geological Society of America, and was very well received (Anovitz and Blencoe, 1997b). These data suggest that: the total solubility of this haplogranite in water is $1.60 \pm 0.1 \mathrm{wt}$. \%; dissolution is incongruent, with a significant increase in $\mathrm{Si}$ in the fluid over that in the melt; $\mathrm{Al}$ is mobile in aqueous fluids, even in the absence of complexing anions; and significant $\mathrm{Na} / \mathrm{K}$ partitioning occurs between the water and melt.

Capsules have also been opened and processed for experiments at $950^{\circ} \mathrm{C}, 2500$ bars run for $1,2,4$, and 8 days for a eutectic melt with water W4 (capsules for water W6 are currently being processed), and for 35-day experiments for Si-poor, eutectic, quartz-orthoclase minimum and K-poor compositions. The 35-day experiment was completed earlier this year to ascertain whether the 11 day experiments had reached equilibrium. Preliminary results have been obtained from weight-change analysis, and chemical analysis will be performed during the next several months. 


\section{Water-Solubility Experiments}

The solubility of water in haplogranitic melts is being determined by reversing the bivariant reaction "melt = melt + vapor" in the same experiments as those conducted to determine the solubility of the melt in water. Reaction reversal is demonstrated by obtaining water-increasing and water-decreasing half reversals. A water-increasing half reversal is obtained by reacting water-undersaturated haplogranitic melt with an amount of water that is more than sufficient to saturate the melt. During the experiment, some of the "free" water dissolves in the melt. Afterwards, as described above, SIMS or NIR analysis can be used to measure the water content of the hydrous glass obtained from the reacted sample. This measurement yields a minimum solubility of water in the melt. A water-decreasing half-reversal is obtained by reacting water-oversaturated haplogranitic melt at experimental P-T conditions. During experimentation some of the water dissolved in the melt exsolves to form a separate aqueous fluid. Measuring the water content of this glass yields a maximum solubility of water in the melt.

In addition to the haplogranite experiments described above, we have measured the solubility of water in albite-water and albite-quartz-water melts. Solubilities for albite-water melts are slightly higher than those measured by previous investigators. Data for albite-quartz-water melts indicate that: (1) $\mathrm{H}_{2} \mathrm{O}$ solubility is nearly independent of albite/quartz ratio between 740 and $800^{\circ} \mathrm{C}$, but decreases slightly with decreasing albite/quartz ratio at $900^{\circ} \mathrm{C}$; and (2) $\mathrm{H}_{2} \mathrm{O}$ solubility decreases from $\sim 55$ mole $\%$ at $740^{\circ} \mathrm{C}$ to $\sim 50$ mole $\%$ at $900^{\circ} \mathrm{C}$. These results are in good agreement with data obtained by previous investigators, except at near-eutectic temperatures, where our data indicate that water solubilities are slightly higher than those measured by earlier investigators.

\section{Evaluation of Phase Equilibria for the Systems Albite - Water, SiO - Water and Sanidine-Water}

Any model of the thermodynamic properties of haplogranite melts needs to take into account the existing experimental database describing phase equilibria for haplogranites. In addition, it is especially critical that the melting thermodynamics of the end member binary systems albite-water, silica-water and sanidine--water be determined as accurately as possible. To begin this work, and to provide a basis for the expansion of the preliminary thermodynamic model developed by Blencoe et al. (1994), we are reanalyzing data for albite-water melts. This system has been extensively investigated, and work on it dates back to Goranson (1936).

Our analysis has revealed that, despite the copious amount of work completed, the system is, in fact, very poorly known. In the dry system neither the reversed experimental data, nor the thermodynamic data, strongly constrain the melting of albite as a function of pressure and temperature. Therefore, we have derived new thermodynamic data for this reaction, including realistic uncertainties for each parameter.

Our examination of the hydrous phase relations in the albite-water system has demonstrated the need for reversed experiments, of which there are very few in the literature. Many of the apparent inconsistencies amongst various experimental data sets disappear when only carefully reversed data are considered. Unfortunately, as happened in our examination of data for the dry albite system, this evaluation shows that knowledge of this system is far poorer than is commonly believed. Our work on the hydrous part of this system was reported to the American Geophysical Union (Anovitz and Blencoe, 1997a). A manuscript on the dry melting of albite was submitted to the American Mineralogist, and has been accepted for publication after minor revisions.

The above analysis is currently being extended by completing our work on the albite - water system to permit preparation of a companion paper to the first article we wrote, and by evaluating available data for the system silica-water. For the later system we have begun compiling the relevant literature, and will evaluate the data in a manner similar to that already done for albite-water. 


\section{FUTURE PLANS}

The immediate future goals of our research are to: (1) complete our work on the mutual solubility of haplogranite melt and water at $2.5 \mathrm{~kb}, 950-1000^{\circ} \mathrm{C}$, (2) initiate experiments on the partitioning of $\mathrm{Na}$ and $\mathrm{K}$ between coexisting haplogranite melt and feldspar, (3) make corrections to the paper we have prepared on the dry melting of albite, and (4) continue our evaluations of the albite-water and silica-water systems.

\section{INDUSTRY INTEREST AND TECHNOLOGY TRANSFER}

To perform our research, we have developed laboratory techniques for acquiring highly precise and accurate data on the volatile contents and bulk chemical compositions of very small masses of aluminosilicate material. These methods have numerous potential practical applications in geothermal R\&D. We have reported preliminary results of our work at technical meetings (e.g. Anovitz et al., 1995; Anovitz and Blencoe, 1997b). After further refinement, the methods will be described in detail in articles written for leading geochemical journals. Researchers and technologists interested in the progress of our research are encouraged to contact us for further information.

\section{REFERENCES}

Anovitz L. M., Blencoe J. G., Horita J., and Cole D. R., 1995, An Experimental Method for Determining Compositions of Aqueous Fluids Coexisting with Silicate Melts. U.S: Geol. Surv. Circ. 1129, p. 10-11.

Anovitz, L.M. and Blencoe, J.G., 1997a, Re-analysis of the albite-water system. EOS.

Anovitz, L.M. and Blencoe, J.G., 1997b, Experimental determination of the compositions of aqueous fluids coexisting with silicate melts. GSA Abst.w. Prog. 29, A394.

Anovitz, L.M. and Blencoe, J.G. (1999) The dry melting of high albite. Amer. Mineral.

Blencoe J. G., and Anovitz L. M., 1995, Methods for Determining the Thermodynamic Mixing Properties of Hydrous Haplogranitic Melts: Progress, Problems and Prospects. U.S. Geol. Surv. Circ. 1129, p. 24-25.

Blencoe, J. G., Anovitz, L. M., Joyce, D. B., and Burch, T. E., 1994, A new thermodynamic model for albite-water melts, Eos, v. 75, p. 693.

Goranson, R.W. (1936) Silicate-water: the solubility of water in albite melt. Amer. Geophys. Union Trans. 17, 257-259.

Ihinger, P. D., Hervig, R. L., and McMillan, P. F., 1994, Analytical methods for volatiles in glasses, In Carroll, M. R. and Holloway, J. R. (eds), Volatiles in Magmas (Reviews in Mineralogy, Volume 30), 67 121, Mineralogical Society of America, Washington, D.C. 


\title{
GEOTHERMAL CHEMISTRY, EXPLORATION and RESERVOIR PROCESSES
}

\author{
Cathy J. Janik \\ U.S. Geological Survey \\ Fraser Goff \\ Los Alamos National Laboratory
}

\section{KEY WORDS}

Fluid geochemistry, gas composition, water composition, isotope composition, Dixie Valley geothermal system, The Geysers-Clear Lake geothermal region, geochemical reservoir-modeling, scaling, recharge, $\mathrm{CO}_{2}$ flux.

\section{PROJECT BACKGROUND AND STATUS}

The current project is a modification of work funded annually since FY91 to provide chemical sampling expertise, chemical and isotopic analyses of fluids and minerals, and geochemical data interpretations for DOE efforts to understand the chemical evolution and behavior of geothermal systems in their natural and developed states. To date, analyses have been performed on samples for U.S. Geological Survey (USGS) projects at Cerro Prieto, Mexico; Steamboat Springs, Nevada; and Twin Falls, Idaho; for USGS/Los Alamos National Laboratory collaborative projects in The Geysers-Clear Lake region, California, and Dixie Valley, Nevada; for a University of Nevada-Reno project on Geothermal Modeling of Productive Geothermal Resources in Nevada; and for small private contractors concerned with resource assessments in the domestic and international geothermal arenas. We have routinely analyzed about 100 to 120 samples on an annual basis, but this total increased considerably in FY98 because of our extensive work on the Dixie Valley geothermal system.

In FY98, we completed a research project on carbon isotope systematics and carbon flux in The GeysersClear Lake geothermal region, and completed compilations of all gas and isotope analyses on samples collected from this region over the past 20 years. We also began an investigation in response to inquiries about increased activity in thermal manifestations at Anderson Springs, adjacent to the Southeast Geysers geothermal field. We became active in geothermal exploration and research aspects of selected areas in Latin America and the Caribbean for which we provided analyses and interpretive expertise. At Dixie Valley we continued a study of scaling in injection wells and pipelines, and began new investigations to 1) determine fluid origins and rate of recharge to the system, 2) monitor temporal geochemical changes in production fluids, and 3) determine origin, dimension, and growth-rate of a new fumarolic area north of the power plant (the "dead zone"). We organized a special session for the Annual Fall Meeting of the American Geophysical Union (FY99) on $\mathrm{CO}_{2}$ flux measurements in volcanic and geothermal environments. We continued to publish our results, and completed an invited chapter on geothermal systems for an upcoming reference book called Encyclopedia of Volcanoes.

\section{PROJECT OBJECTIVES}

This project produces and uses geochemical data to infer the structure of geothermal reservoirs, estimate subsurface temperatures, and identify processes that cause temporal changes in fluid compositions. Our primary objectives are to: 1) provide comprehensive major/trace element analyses, bulk gas analyses, and isotope analyses of fluids, dissolved constituents, and minerals on samples collected for geothermal 
projects sponsored by the U.S. Department of Energy; 2) provide geothermal/geochemical exploration, modeling, and monitoring expertise for the above projects as required.

\section{Technical Objectives}

- $\quad$ Provide high-quality analyses and data interpretations for DOE-sponsored geothermal projects listed below, plus newly identified sites of interest in Bolivia, Peru, and the Caribbean.

- Complete study on chemical scaling in injection wells at the Dixie Valley geothermal system, Nevada.

- Study temporal variations in production-fluid chemistry, Dixie Valley, Nevada.

The Dixie Valley geothermal field has been operational since 1988. Injection of spent brine began shortly after production commenced and has been continuing to present. Over the lifetime of the field, the production-fluid composition has significantly increased in chloride and heavy water isotopes and decreased in noncondensible gas concentrations, indicating co-production of injectate. Returning injectate will eventually cool the reservoir. It is therefore necessary to quantify the volume of injectate co-produced with the indigenous reservoir fluid and the rate at which this volume increases in order to predict the likelihood or onset of cooling. Fluid chemistry is more sensitive than temperature to the emergence of injectate in production fluids. In FY98 we collected fluids from production and injection wells and performed comprehensive chemical and isotopic analyses on the samples. Data obtained will be compared with data provided by Oxbow on samples collected from 1986 (pre-production) through 1996 in order to evaluate the present reservoir conditions. Continued monitoring of the production and injection fluids may also lead to a better understanding of the relative flux of indigenous geothermal fluid into the reservoir.

- Study regional recharge of Dixie Valley geothermal system, Nevada

Recharge to the Dixie Valley geothermal system is poorly understood. In addition to sampling the production and injection wells at the Dixie Valley geothermal field, we began a systematic collection of streams, cold and thermal springs, domestic wells, irrigation wells, and exploration wells in Dixie Valley, adjacent valleys, and surrounding mountains to determine sources and ages of reservoir fluids. We have completed the following analyses on two suites of samples from about 40 sites collected in November 1997 and April-May 1998: bulk chemistry, water isotopes, some tritium, ${ }^{18} \mathrm{O}$ of dissolved $\mathrm{SO}_{4},{ }^{13} \mathrm{C}$ of dissolved inorganic carbon (DIC), ${ }^{14} \mathrm{C} \mathrm{DIC},{ }^{36} \mathrm{Cl}, \mathrm{Sr}{ }^{87 / 86}$, and U-Th disequilibrium.

- Study $\mathrm{CO}_{2}$ flux and temperature distribution of the "dead zone" NNE of the Dixie Valley power plant.

In-situ measurements of soil $\mathrm{CO}_{2}$ have greatly progressed since the invention of portable devices that report real-time concentrations and fluxes of this important diagnostic gas. At Dixie Valley, new zone of fumarolic activity and plant kill formed in 1996, between the Stillwater Fault and the northern section of the geothermal field. In FY98 we began monitoring temperature, $\mathrm{CO}_{2}$ concentrations and flux in this zone to determine its dimension, growth-rate and seasonal variation. Discussions with other scientists and technical experts were initiated on the problem of $\mathrm{CO}_{2}$ flux measurements in geothermal and volcanic environments. We organized a Special Session for the December 1998 Fall Meeting of AGU (FY99) to bring together national and international scientists to explore this issue. 
- Write chapter on Geothermal Systems for upcoming Encyclopedia of Volcanoes to be published by Academic Press, Inc. (invited contribution).

\section{Expected Outcomes}

\section{General}

- $\quad$ Perform chemical and isotopic analyses for DOE-sponsored projects.

- Contribute to or conduct international geothermal exploration that may identify energy sources for under-developed countries in need of electricity.

- Add to knowledge of natural geothermal processes and manmade geothermal developments on ecosystems and drinking water.

- Publish databases and journal manuscripts for the geothermal community.

Specific FY98

- Completed about 400 chemical and isotopic analyses for several DOE-sponsored projects, including samples from Dixie Valley, The Geysers Clear-Lake, Steamboat Springs, South America, and the Caribbean.

- Advised Oxbow Power Services, Inc. on appropriate strategy to minimize silica-rich scaling in injection lines and wells (Bruton et al., 1997).

- $\quad$ Advised Oxbow Power Services, Inc. on the significance of the "dead zone" and its relation the Dixie Valley geothermal field, and published a preliminary report (Bergfeld et al., 1998b).

- Collaborated with USGS researchers to understand gas-driven geyser eruptions by providing knowledge and data from the Clear Lake region (Galloway et al., 1997)

- Contributed to a report on temperatures and origins of geothermal fluids in the Twin Falls, Idaho area (Mariner et al., 1997).

- Organized a Special Session on $\mathrm{CO}_{2}$ flux measurements in geothermal and volcanic regions for the 1998 Fall Meeting of AGU (primary convener: Deborah Bergfeld).

- Completed a book chapter on Geothermal Systems, summarizing our present knowledge of the subject for general public readership and wide circulation (Goff and Janik, in press). The editors regard this project as a unique opportunity for the entire earth science community to bring together in a single volume a detailed treatment of volcanism (and related topics), its causes, effects and societal impact. They have invited "the leading experts in each field" to contribute chapters.

\section{APPROACH}

General Statement: We explore for new geothermal systems and obtain basic knowledge of existing systems using geochemical methods. We collect and analyze fluids and minerals to characterize regional and reservoir fluid properties, define boundary conditions such as reservoir age and fluid sources, and determine if newly explored sites justify exploration drilling. In developed fields, we determine processes related to fluid extraction and injection, model scaling/corrosion potential, evaluate parameters that affect 
reservoir productivity and lifetime, and provide geochemical insights to help manage resources and improve reservoir performance (energy output). Our work provides the US geothermal community with data and interpretations that aid in making development and environmental policy decisions, increasing domestic profits and improving the competitive edge abroad.

Dixie Valley Investigations: Due to our rapid response to help solve injection-scaling problems (Bruton et al., 1997), we have been encouraged to conduct three new geochemical investigations at Dixie Valley: 1) monitor changes in chemical and isotopic compositions of production fluids to identify reservoir processes; 2) determine reservoir fluid origins, age, and rate of recharge; and 3) determine dimensions, growth-rate, and source of a zone of plant kill and fumarolic activity north of the power plant.

Note: We are working cooperatively with Oxbow Power Services, Inc., Lawrence Livermore National Laboratory, Lawrence Berkeley National Laboratory, and Energy Geosciences Institute on the Dixie Valley projects.

$\mathrm{CO}_{2}$ flux measurements: This is a new domain of research which uses portable instruments to obtain real-time data on $\mathrm{CO}_{2}$ concentration and flux. We have conducted a regional study at The Geysers-Clear Lake area (Bergfeld et al., 1997; Bergfeld et al., in press) and have begun a more focused study at Dixie Valley (Bergfeld et al., 1998a; 1998b) to determine the practicalities and potential of these methods for geothermal exploration and monitoring.

The Geysers-Clear Lake region: In late FY98, we received inquiries about possible changes in thermal manifestations around Anderson Springs, located near the Southeast Geysers geothermal field. We conducted a literature search and reviewed our own data files, which revealed that the temperature of Anderson Spring ranged from 42 to $63^{\circ} \mathrm{C}$ between 1889 and 1992 , but measured about $77^{\circ} \mathrm{C}$ in 1995 . When we returned in September 1998 to investigate the area, we measured boiling temperatures $\left(\leq 99^{\circ} \mathrm{C}\right)$, and collected samples for chemical and isotopic analysis. We initiated dialogue with local residents and contacted Calpine Corporation for further information to determine the cause and significance of these observations.

\section{RESEARCH RESULTS}

The Geysers-Clear Lake region: Three Geothermics manuscripts summarizing carbon isotope systematics, thermal modeling, and K-Ar dating of illites are in press (Bergfeld et al., Stimac et al., and WoldeGabriel et al., but the publication date is not yet determined).

Dixie Valley Scale: Modeling shows that low-pressure brine and injection fluids are saturated with respect to amorphous silica as determined by chemical analysis and XRD. Shallow groundwater near the power plant is a mixture of meteoric recharge and geothermal brine. This groundwater is supersaturated with respect to calcite, and modeling indicates the injection of this fluid would precipitate calcite in the reservoir. Mixing of existing injectate with reservoir fluid can have a variety of consequences depending on where and at what temperature mixing occurs (Bruton et al., 1997).

Dixie Valley Recharge: Since exploitation began in 1988, the Dixie Valley geothermal reservoir has experienced a systematic decline of water levels and pressures in production wells. This has created a need to more thoroughly evaluate recharge to the geothermal system. We are presently collaborating on a combined chemical and isotopic study of regional springs and aquifers to determine sources of the geothermal reservoir fluids and how fast recharge occurs. To date we have determined an equation for the local (Dixie Valley) meteoric water line, which is $\delta \mathrm{D}=7.42 \delta^{18} \mathrm{O}-8.91(\mathrm{n}=24, \mathrm{r}=0.91)$. Meteoric waters collected from the floor of Dixie Valley are isotopically depleted relative to those collected at higher elevations in the Stillwater and Clan Alpine ranges. The implication is that waters in Dixie Valley 
were either recharged at elevations higher than those we collected in the ranges, or originated from an earlier time when precipitation was isotopically different. The deuterium values of reservoir fluid from production wells most closely match those of meteoric waters within Dixie Valley, not those in adjacent ranges (Goff et al., 1998).

Dixie Valley "Dead Zone": A map of the $\mathrm{CO}_{2}$ flux across the newly formed area of plant kill and hot ground in the NW part of the Dixie Valley geothermal system was constructed to monitor potential growth of a fumarole field. Flux measurements were recorded using a LiCor infrared analyzer. Sample locations were restricted to areas within and near the dead zone. The data delineate two areas of high $\mathrm{CO}_{2}$ flux in different topographic settings. Older fumaroles along the Stillwater Range front produce large volumes of $\mathrm{CO}_{2}$ at temperatures near boiling. High $\mathrm{CO}_{2}$ flux values were also recorded at sites along a series of recently formed ground fractures at the base of the dead zone. The two areas are connected by a zone of partial plant kill, moderate $\mathrm{CO}_{2}$ flux, and elevated temperatures on an alluvial fan. Results from this study indicate a close association between the range front-fumaroles and the dead-zone fractures (Bergfeld et al., 1998a; 1998b).

\section{FUTURE PLANS}

In FY99 we will continue our various collaborative investigations of the Dixie Valley geothermal system, as described above. We will conduct field work to obtain new fluid/solid samples as required to meet our objectives, and will analyze samples for their chemical and isotopic composition. The data will be used to: 1) complete models of scaling processes and to offer solutions for preventing scaling and corrosion, 2) determine indigenous reservoir-fluid origins and age, and 3) evaluate the effects of injection and production (joint studies, LANL - USGS - LLL- LBL - EGI - Oxbow Power Services, Inc.). Data will be made available to collaborators; results and interpretations will be presented at appropriate scientific meetings and published in suitable journals.

In FY99 we will also: 1) analyze geothermal fluid samples from other DOE-sponsored geothermal sites in FY99, as required; 2) begin a study of mineralized hydrothermal breccias from cores of the Awebengkok geothermal system, Indonesia; 3) organize a special volume of Chemical Geology to publish research papers resulting from the 1998 AGU Fall Meeting Special Session on $\mathrm{CO}_{2}$ flux; 4) publish a report on The Geysers steam field database; and 5) complete a journal article summarizing geochemistry of magmatic, metamorphic, and connate fluids in The Geysers-Clear Lake region.

\section{INDUSTRY INTEREST AND TECHNOLOGY TRANSFER}

(1996 to present)

\section{Organization}

Union Geothermal Co. Environmental Protection Agency

Caithness Power, Inc.

Oxbow Power Services, Inc.

SB Geo, Inc.

California Energy Co.

Southwest Tech. Devel. Inst.

NRECA

Geothermal Manage. Co.

Calpine Corporation
Type and Extent of Interest

Land access; permission to use data/cores

Geochemistry of Sulphur Bank Mine

Samples for analysis, Nevada assessment

Active participation in Dixie Valley studies

System modeling (Steamboat); tracer studies

Information on Medicine Lake Highlands

Analyses for Fort Bliss geothermal project

Analyses for Bolivia and Peru sites

Analyses for Caribbean and Peru sites

The Geysers-Clear Lake studies 


\section{REFERENCES}

Bergfeld, D., Goff, F., and Janik, C.J., 1997, Carbon dioxide flux and carbon reservoirs in

The Geysers-Clear Lake geothermal region of northern California: Eos, Trans., 1997 Fall Meeting (Dec.), San Francisco, CA, American Geophysical Union, v. 78, p. F831.

Bergfeld, D., Goff, F., and Janik, C.J., 1998a, $\mathrm{CO}_{2}$ flux measurements at the Dixie Valley geothermal system, Nevada: Eos, Trans., 1998 Fall Meeting (Dec.), San Francisco, CA, American Geophysical Union, v. 79, p. F941.

Bergfeld, D., Goff, F., and Janik, C.J., in press, Carbon isotope systematics and $\mathrm{CO}_{2}$ sources in The Geysers-Clear Lake region, northern California: Geothermics (1999?).

Bergfeld, D., Goff, F., Janik, C.J., and Johnson, S.D., 1998b, $\mathrm{CO}_{2}$ flux measurements across portions of the Dixie Valley geothermal system, Nevada: Geothermal Resources Council Trans., v. 22, Sept. 1998, p. 107-111.

Bruton, C.J., Counce, D., Bergfeld, D., Goff, F., Johnson, S.D., Moore, J.N., and Nimz, G., 1997, Preliminary investigation of scale formation and fluid chemistry at the Dixie Valley geothermal field, Nevada: Geothermal Resources Council Trans., v. 21, Sept./Oct. 1997, p. 157-164.

Galloway, D.L., Ingebritsen, S.E., Lorenson, T.D., and Janik, C.J., 1997, Frequency behavior of a gasdriven "geyser" in northern California: Eos, Trans., 1997 Fall Meeting (Dec.), San Francisco, CA, American Geophysical Union, v. 78, p. F808.

Goff, F., and Janik, C.J., in press, Chapter 51: Geothermal Systems, in (B. Houghton, H. Rymer, J. Stix, and S. McNutt, eds.), Encyclopedia of Volcanoes: Academic Press, NY, 25 pp. (1999?).

Goff, F., Janik, C.J., Bergfeld, D., Counce, D., Bruton, C.J., and Nimz, G., 1998, Geothermal chemistry/exploration investigations at Dixie Valley, Nevada: Proceedings Geothermal Program - Review XVI, U.S. Department of Energy, April 1-3, 1998, Berkeley, CA, 7 pp.

Mariner, R.H., Young, H.W., Bullen, T.D., and Janik, C.J., 1997, Sulfate-water isotope geothermometry and lead isotope data for the regional geothermal system in the Twin Falls area, south-central Idaho: Geothermal Resources Council Trans., v. 21, Sept./Oct. 1997, p. 197-201.

Stimac, J.A., Goff, F., and Wohletz, K., in press, Thermal modeling of the Clear Lake magmahydrothermal system: Implications for conventional and hot dry rock geothermal development: Geothermics (1999?).

WoldeGabriel, G., Goff, F., and Aronson, in press, Mineralogical and K-Ar geochronology of mixedlayered illite/smectite from The Geysers coring project, California: Geothermics (1999?). 


\title{
THREE-DIMENSIONAL VISUALIZATION OF THE GEOLOGY, HYDROLOGY AND GEOCHEMISTRY OF THE MEDICINE LAKE HIGHLAND AND SURROUNDING REGION
}

\author{
Jacob B. Lowenstern and Robert H. Mariner \\ U.S. Geological Survey, Menlo Park
}

\section{KEY WORDS}

\author{
Medicine Lake Highland, Medicine Lake Volcano, EarthVision, Hydrogeology, geology, isotopes

\section{PROJECT BACKGROUND AND STATUS}

We have begun using EarthVision, a 3-D mapping, modelling and visualization tool to create an integrated spatial database for studies of the Medicine Lake highland and surrounding region. The database was initiated in 1998 and now includes topographic, geologic, hydrologic, geophysical and geochemical data collected by the USGS, industry and other government agencies. Our plan is to use this database as a tool to understand the regional hydrogeology of the Medicine Lake highland and Modoc Plateau as well as the geologic underpinnings of the volcano and related geothermal system. If geothermal development proceeds at Medicine Lake, we view this database as a framework upon which new geoscience data can be viewed and integrated.

\section{PROJECT OBJECTIVES}

Current research at the Medicine Lake highland includes many facets, including geothermal exploration, geologic mapping to unravel the complex volcanic history, geochemical sampling of springs and wells and lithologic sampling of rocks from drillcore. By placing these datasets within a single 3D database system, along with cultural and topographic information, we hope to provide a tool for visualization of the geology and hydrology of the Medicine Lake highland, and a data warehouse that researchers can use as development proceeds.

\section{Technical Objectives}

- Collect diverse data sets within the MacArthur and Tule Lake $100 \mathrm{~K}$ sheets including: digital elevation model, major roads, lakes, streams, springs and volcanic features, geology, well logs, spring chemistry, precipitation/recharge and gravity data. This information will be available to all researchers working within the study area.

- Divide the study area into hydrologic basins so that precipitation-derived recharge can be calculated for individual basins. Calculate the mean isotopic composition of rainfall for each basin by merging precipitation data with newly acquired information on the geographic variability of the isotopic composition of precipitation. The results can be used to assess the importance of various hydrologic basins as source regions to the large-discharge cold springs of the Fall River.

- Input heat flow data from geothermal drillholes (in collaboration with Colin Williams) to infer the direction and magnitude of groundwater flow in the Medicine Lake highland. Such information can be used to identify promising target areas for further exploration and injection of spent fluids, and can also identify areas where connections between the geothermal system and shallow groundwater system, if any, should exist. 
- Input lithologic information from geothermal drillholes to characterize the geological architecture of Medicine Lake volcano (e.g., the distribution of silicic volcanic rocks and granitic intrusions within the volcano, and areas of hydrothermal alteration). These data can be used to develop a model for the growth and development of the volcano and related geothermal system.

\section{Expected Outcomes}

- One or more journal papers on the hydrogeology of the Medicine Lake Highland.

- Construction of a database of vents, springs, lakes, streams, roads, and subsurface geology of the Medicine Lake highland that can be used by industry, academica and others interested in geologic, hydrologic and geothermal characteristics of the Medicine Lake region.

- One or more journal papers on the history of granitic intrusions at Medicine Lake and their role in the creation of the modern geothermal system.

\section{APPROACH}

With funds from the USGS Volcano Hazard Program, we are working on a variety of topics related to the geology and hydrogeology of Medicine Lake volcano. DOE funds have allowed us to work with a new GIS/data visualization tool called that has been useful in two primary ways.

1. It has allowed us to create 3-D views of the region, its geology and surficial features that aid the viewer in conceptualizing complex datasets. In Lowenstern et al. (1998), we presented numerous views of the Medicine Lake region that proved popular with land managers, environmental consultants and citizen groups that were trying to grasp complex environmental issues related to geothermal development.

2. The gridding and volumetrics functions of EarthVision allow us to perform complex calculations for the hydrogeologic model such as the potential recharge and isotopic composition of recharge to hydrologic basins.

3. It permits incorporation of downhole data into a 3D viewer so that one can create a $3 \mathrm{D}$ model of lithological, geochemical and geophysical properties of the subsurface units.

\section{RESEARCH RESULTS}

Starting in May '98, we started incorporating diverse data types into formats that are compatible with EarthVision. These included the following data: 1) the USGS Alturas West 1:250K DEM (of which we used the western half with the MacArthur and Tule Lake Quads), 2) the USGS DLG data for roads, springs, lakes, streams and wells, 3) a list of 488 volcanic vents, with their location, age and rock type, 4) raster files with the isostatic residual gravity anomalies and surficial geology, 5) the Rantz (1969) map of isohyetal precipitation contours for California, 6) a dataset of spring and well compositions (compiled by R. Mariner), 7) the isotopic composition of snow cores, and 8) lithology of cuttings from geothermal wells as a function of depth, as logged and analyzed by J. Donnelly-Nolan.

By turning the Rantz (1969) precipitation information into a gridded dataset, we were able to use EarthVision to calculate the volume of precipitation within a variety of pre-defined hydrologic basins. This allows estimation of the maximum potential recharge to any given geographic area, permitting assessment of the likely role of different areas as sources for large-discharge cold springs of the Fall River, $\sim 30 \mathrm{mi}$. to the south of the Medicine Lake highland. For example, these calculations imply that a 
maximum of $6 \%$ of the discharge of the Fall River Springs could originate in Medicine Lake caldera. Such calculations are useful to consultants working on the potential environmental impact of geothermal development and will be helpful for future efforts to develop a hydrogeologic model of the region. The results, and many images produced with EarthVision were published in Lowenstern et al. (1998a).

In a parallel project, we have been studying 40 samples of granitoid found as inclusions in Holocene lavas and $\sim 10$ similar rocks from geothermal drillholes to understand the history of granitic magmatism at Medicine Lake volcano. A poster and abstract were prepared for the 1998 meeting of the International Association for Volcanology (Lowenstern et al. 1998b) which presents the following conclusions: 1) most of the granitoid inclusions have shallow crystallization textures, 2) the trace-element and isotope geochemistry of the inclusions indicate that they are not subsurface equivalents of the lavas in which they are found, 3) granitoid inclusions in Holocene lavas are unaltered, as opposed to some inclusions in Pleistocene lavas and all granitoids in drillholes from the geothermal system, 4) it appears that the granitoid inclusions originated from intrusions emplaced at shallow depth, prior to development of the overlying Medicine Lake volcano and geothermal system. Since that time, these granitoids have been buried by recent volcanic materials and samples of them were dislodged and transported to the surface during Holocene eruptions. It is fully possible that the granodiorites present in geothermal drillholes are altered equivalents of the granitoid inclusions. Future geochronological studies and continued studies of the inclusions, as well as granitoids from drillholes will allow development of a model of granitic magmatism and geothermal-system evolution at Medicine Lake volcano.

\section{FUTURE PLANS}

We plan to continue to expand our accumulation of surface and downhole datasets from the Medicine Lake Highland. We will proceed on our modeling of the isotopic composition of precipitation as a function of latitude and elevation within the region. Collaboration with Dr. Colin Williams may allow us to work with heat flow data to model shallow groundwater flow as well as convective processes in the deeper geothermal system. Our focus on granitic magmatism at Medicine Lake volcano will continue and we plan to begin $\mathrm{U} / \mathrm{Pb}$ dating of granite clasts to provide new constraints on the age of intrusive events that contributed to the development of the geothermal system at Medicine Lake.

\section{INDUSTRY INTEREST AND TECHNOLOGY TRANSFER}

\author{
Organization \\ CalEnergy Corp. \\ Calpine Corp.
}

\author{
Type and Extent of Interest \\ Environmental and hydrological studies \\ Geochronology of silicic intrusions
}

Environmental and hydrological studies Geochronology of silicic intrusions

\section{REFERENCES}

Lowenstern, J.B., Killgore, M., Mariner, R., Blakely, R., Smith, J.G., Donnelly-Nolan, J., 1998a, 3dimensional visualization of the Medicine Lake Highland, CA: Topography, Geology, Geophysics and Hydrology, U.S. Geological Survey Open File Report 98-777 (URL http://caldera.wr.usgs.gov/OF98$\underline{777)}$.

This Open File Report consists of a poster, available only through the Web, with a variety of figures to show the capabilities of EarthVision for visualization and display of geological and other data. Included are calculations of the potential groundwater input through precipitation in various hydrologic basins throughout the highland. These calculations have been valuable to land managers and local citizen groups 
interested in the potential connection between the Fourmile Hill and Telephone Flat geothermal prospects and the Fall River Springs near MacArthur, CA.

Lowenstern, J.B., Donnelly-Nolan, J., Grove, T.L., 1998b, Granite Inclusions in Holocene lavas of Medicine Lake Volcano, California, USA: Clues to the Subsurface Geology. IAVCEI Abstracts, Capetown, South Africa July 1998, p. 36. 


\title{
Study of the Coso Formation
}

\author{
Diane L. Kamola and J. Douglas Walker \\ KU Center for Research, Inc. \\ and \\ Department of Geology \\ University of Kansas \\ Lawrence, KS 66049
}

\section{KEY WORDS}

Geologic studies, extensional basins, facies analysis, geochronology, Coso Range

\section{PROJECT BACKGROUND AND STATUS}

There have been great advances in the last 20 years in understanding the volcanic, structural, geophysical, and petrologic development of the Coso Range and Coso geothermal field. These studies have provided a wealth of knowledge concerning the geology of the area, including general structural characteristics and kinematic history of Tertiary deformation. One element missing from this dataset is an understanding of the sedimentology and stratigraphy of well-exposed Cenozoic sedimentary strata - the Coso Formation.

The Coso Formation is loosely defined to include all sedimentary and pyroclastic rocks between preTertiary basement and the voluminous Pliocene to recent volcanic rocks (Schultz, 1937). Sedimentary facies include lacustrine, fanglomerate, volcaniclastic and, locally, volcanic tuffs. The history of the Coso Formation has received limited treatment in the geologic literature (e.g., Bacon et al., 1982; Grant, 1986; Stinson, 1964; Duffield et al., 1986). The Coso Formation merits study for the following reasons: 1) it provides a look at events older than most of the volcanic rocks in the area, and 2) it can give detailed insights into paleogeographic and structural development on the local and regional scale.

The Coso Formation owes its present structural configuration to the tectonics of Rose and Owens valleys. Numerous folds and faults cut the Coso Formation in its various exposures (Stinson, 1977a, 1977b; Duffield and Bacon, 1981). Some of these faults may be syndepositional, controlling stratigraphic patterns. Other faults may be wholly post-Coso in age. Understanding these structures could give great insight into the relative roles of strike-slip and normal faulting in the development of the Rose-Owens Valley system, and give new knowledge about the late Miocene to present structural development of the area. This is only possible using the Coso Formation.

The study was initiated in cooperation with CalEnergy Company, Inc., the U.S. Navy Geothermal Program Office and DOE to better understand the geologic development of Basin and Range structure around the Coso geothermal field. This understanding of Coso and Basin and Range structure and kinematics should be useful in developing exploration models for the Coso region and Basin and Range.

\section{PROJECT OBJECTIVES}

The main aim of this study is to better understand the development of the Coso Range, east-central California. Pliocene to Holocene volcanic rocks of the area are fairly well understood. Recent work on the bedrock geology of the area (Whitmarsh, 1997) is complete. The last remaining unknown aspect of the Coso Range history is the latest Miocene to middle Pliocene ( $\sim 6$ to $3 \mathrm{Ma}$ ) structural and paleographic development of the area. A study of the Coso Formation will fill this gap in our knowledge. 


\section{Technical Objectives}

- Construct geologic maps of the Coso Formation to delineate the stratigraphy and structural configurations of the unit.

- Perform depositional analysis of the Coso Formation and establish stratigraphic relations across its exposures.

- Determine ages of various exposures of the Coso Formation to aid in correlation within the Coso Range and the Indian Wells Valley.

\section{Expected Outcomes}

- An understanding of the spatial and temporal variations in paleostructural and paleogeographic development of the Coso Formation. This will allow for a quantification of the relative amounts of extension and strike-slip deformation involved with construction of the Coso Formation basin.

- Elucidation of the position and formation of the Coso geothermal area in the context of the development of the southwestern Basin and Range Province. This may aid in developing models for exploration of geothermal resources in other areas of the Basin and Range.

\section{APPROACH}

Field work follows normal practices of geologic mapping and stratigraphic efforts. Geologic mapping is done by walking the area and employing topographic maps aided by photographic or satellite images to delineate important geologic features. Stratigraphic studies are conducted by preparing several carefully measured stratigraphic sections through the Coso Formation. These sections form the basis for a stratigraphic/paleogeographic framework for the unit. Samples are collected where needed for dating by the Ar/Ar method. Where available, fault zone structures such as slickenside lineations and fault grooves are used to determine fault motions.

Data collected will be compiled into an existing GIS database constructed at the University of Kansas for the Coso Range and Indian Well Valley area. This database contains many geologic maps, compilation of ages determined for various rocks, remote sensing data, and numerous other geologic datasets.

\section{RESEARCH RESULTS}

\section{Geologic Mapping and Structural Studies}

Five mappable units were identified based on the stratigraphic studies completed last year, and are listed from oldest to youngest: (1) basal conglomerate, (2) arkosic sandstone, (3) lacustrine suite, (4) upper ash, (5) upper sandstone/conglomerate. Previous geologic maps (i.e. Stinson, 1977a, 1977b; Duffield and Bacon, 1981) which include the Coso Formation are not based on an established stratigraphic framework of mappable units, but rather map lithofacies which are not defined or placed in stratigraphic hierarchy. These previous attempts often map the same stratigraphic unit as multiple units, and sometimes combined different aged stratigraphic units as the same mappable unit. Outcrops of the Coso Formation have been mapped from the Haiwee Ridge area to Vermillion Canyon. This mapping shows that the stratigraphic framework established can be carried regionally across this area.

Mapped structural features include a series of north-south trending faults with normal separation. Offset along these faults is limited to 30 meters, with many of the smaller faults displaying offsets of only 
5 meters. These smaller faults, however, are often within a fault series, which collectively show offsets of around 20-30 meters. A number of east-west trending, broad open folds were identified and mapped. Although sparsely distributed, grooves and ornamentation on fault surfaces are consistent with down-dip movement.

One large fault zone has been identified that runs from east of Haiwee Ridge through the Vermillion Canyon area. This fault zone is generally high-angle, and is has dominantly down-to-the-east separation in its southern portion. In addition, it appears to have served as a conduit for some of the later volcanic flows - the fault zone hosts dikes that feed some of the mid-Pliocene basalts. About $3 \mathrm{~km}$ south of Vermillion Canyon, however, the fault takes on a more complex character. It hosts a large anticline/syncline pair that has an amplitude of at least $500 \mathrm{~m}$. The fault zone itself widens and contains several large panels of breccia and gouge developed in vertically dipping strata. We interpret these features as part of a negative flower structure along a strike-slip fault. Unfortunately, slip on the fault zone is uncertain, but is probably at least $1 \mathrm{~km}$ or larger in a right-lateral sense based on regional considerations and the width of the zone.

Overall, the Coso Formation is cut by few faults or folds. Faults are either of strike-slip or normal character, and folds are mostly related to the faults. The amount of extension during and after deposition of the Coso Formation appears to be relatively minor. This indicates to us that the unit was deposited in a simple half graben developed off of the Sierran front. Uplift along the east-dipping Sierran frontal fault, therefore, began about about $6 \mathrm{Ma}$ (the approximate age of the oldest part of the Coso Formation). This is consistent with initiation of extension in the Nova Basin to the east (Coleman and Walker, 1990; Hodges et al., 1989).

\section{FUTURE PLANS}

Geologic mapping of the Coso Formation will be complete. These studies will rely on the stratigraphic framework established in this study. Age analyses will be completed on samples already collected. The geologic maps and stratigraphic information will be compiled into a series of paleogeographic and paleostructural maps. All of the geologic studies will be compiled and integrated with existing interpretations for the Coso Range.

\section{INDUSTRY INTEREST AND TECHNOLOGY TRANSFER}

\section{Organization}

CalEnergy Company

U.S. Navy Geothermal

Program Office, China Lake

\section{Type and Extent of Interest}

Geology and stratigraphy of the coso range

Geology and stratigraphy of the coso range

This project is supported by the Department of Energy (DOE) and the Geothermal Technology Organization (GTO). Funding is provided by GTO members (U.S. Navy and CalEnergy) and DOE.

\section{REFERENCES}

Bacon, C. R., Giovannetti, D. M., Duffield, W. A., Dalrymple, G. B., and Drake, R. E., 1982, Age of the Coso Formation, Inyo County, California: United States Geological Survey Bulletin 1527, 18 pp.

Coleman, D.S., and Walker, J.D., 1990, Geochemical and tectonic significance of Mio-Pliocene volcanic rocks in the northern Panamint Mountains, in, Wernicke, B.P., ed., Basin and Range extensional tectonics 
near the latitude of Las Vegas, Nevada: Boulder, Colorado, Geological Society of America Memoir 176, p. 391-411.

Duffield, W.A., and Bacon, C.R., 1981, Geologic map of the Coso volcanic field and adjacent areas, Inyo County, California: U.S. Geological Survey, Map I-1200.

Duffield, W. A., Bacon, C. R., and Delaney, P. T., 1986, Deformation of a poorly consolidated sediment during shallow emplacement of a basalt sill, Coso Range, California: Bulletin of Volcanology, v. 48, p. 97-107.

Hodges, K.V., McKenna, L.W., Stock, J.M., Knapp, J.H., and Walker, J.D., 1989, Structural relationships between Neogene extensional basins, Panamint Valley area, southeast California: New perspectives of Basin and Range topography: Tectonics, vol. 8, 453-467.

Schultz, J. R., 1937, A late Cenozoic vertebrate fauna from the Coso Mountains, Inyo County, California: Carnegie Institution of Washington Publication, v. 487, p. 75-109.

Stinson, M. C., 1964, A trip to a vertebrate fossil locality: California Division of Mines and Geology Mineral Information Service, v. 17, p. 160-163.

Stinson, M.C., 1977a, Geology of the Haiwee Reservoir 15' Quadrangle, Inyo County, California: California Division of Mines and Geology, Map Sheet 378.

Stinson, M.C., 1977b, Geology of the Keeler 15' Quadrangle, Inyo County, California: California Division of Mines and Geology, Map Sheet 38.

Whitmarsh, R.S., 1997, Structural development of the Coso Range and adjacent areas of eastern California [Ph.D. dissertation]: University of Kansas, Lawrence. 


\section{LIST OF CONTACTS FOR EXPLORATION TECHNOLOGY}

David D. Blackwell

Department of Geological Sciences

Southern Methodist University

Dallas, TX 75275-0395

Phone: (214) 768-2745

Fax: (214) 768-2701

Email: blackwel@passion.isem.smu.edu

James G. Blencoe Phone: (423) 574-7041

Lawrence M. Anovitz Phone: (423) 574-5034

David R. Cole Phone: (423) 574-5473

Juske Horita Phone: (423) 576-2750

Chemical and Analytical Sciences

Division Oak Ridge National Laboratory

P.O. Box 2008, MS 6110

Oak Ridge, TN 37831-6110

FAX: (423) 574-4961

Peggy Brookshier

Office of Program Management

U.S. Department of Energy

Idaho Operations Office

785 DOE Place, MS 1220

Idaho Falls, ID 83402

Phone: (208) 526-1403

Fax: (208) 526-6249

Email: BROOKSPA@INEL.GOV

Robert J. Creed Jr.

U.S. Department of Energy

Idaho Operations Office, MS 1220

850 Energy Drive

Idaho Falls, Idaho 83401

- Phone: (208) 526-9063

Fax: (208) 526-6249

email: creedri@id.doe.gov

Donald J. DePaolo

Department of Geology and Geophysics

University of California

Berkeley, CA 94720

Phone: (510) 643-5063

Fax: $\quad$ (510) 486-5496

E-mail: djdepaolo@lbl.gov

Mark A Feighner

Phone : (510) 486-6781

email: mafeighner@lbl.gov

Earth Science Division, Mail Stop 90-1116
Lawrence Berkeley National Laboratory

Berkeley CA, 94720

Fax: (510) 486-5035

Fraser Goff

EES-1, MS D 462

Los Alamos National Laboratory

Los Alamos, NM 87545

Tel: (505) 667-8060

Fax: (505) 665-3285

e-mail: fraser@lanl.gov

Lawrence J. Hutchings

Lawrence Livermore National Laboratory

P.O. Box 808, L-203

Livermore, CA 94551-0808

Phone: (925) 422-9739

Email: hutchings2@llnl.gov

Cathy J. Janik

MS 910

US Geological Survey

345 Middlefield Rd.

Menlo Park, CA 94025

Tel: (650) 329-5213

Fax: (650) 329-5203

e-mail: cjanik@usgs.gov

Diane L. Kamola

KU Center for Research, Inc. and Department of Geology

University of Kansas

Lawrence, KS 66045-2124

Phone: 785-864-7712

FAX: $\quad 785-864-7789$

Paul Kasameyer

Lawrence Livermore National Laboratory

P.O. Box 808, L-203

Livermore, CA 94551-0808

Phone: (925) 422-6487

Fax: (925) 422-3925

Email: kasameyer@llnl.gov

B. Mack Kennedy

Lawrence Berkeley National Laboratory

Earth Sciences Division, MS 70A-3363

1 Cyclotron Road

Berkeley, CA 94720 
Phone: (510) 486-6451

Fax: (510) 486-5496

E-mail: bmkennedy@lbl.gov

Ki Ha Lee

Earth Sciences Division, MS 90-1116

Lawrence Berkeley National Laboratory

One Cyclotron Road

Berkeley, CA 94720

Phone: (510) 486-7468

Fax: (510) 486-5686

e-mail: khlee@lbl.gov

Jacob B. Lowenstern

USGS/ Mail Stop 910

345 Middlefield Road

Menlo Park, CA 94025

Fax: 650-329-5203

jlwnstrn@usgs.gov

Ernie L. Majer

Phone: (510) 486-7316

e-mail: elmajer@lbl.gov

Thomas M Daley

Phone: (510) 486-7316

e-mail: tmdaley@lbl.gov

Gregory D. Nash

423 Wakara Way, Suite 300

Salt Lake City, Utah 84108

Phone: (801) 585-3889

FAX: (801) 585-3540

gnash@egi.utah.edu

William "Bill" Pickles

Lawrence Livermore National Laboratory

P.O. Box 808, L-182

Livermore, CA 94551-0808

Phone: (925) 422-7812

Fax: (925) 422-3821

Email: pickles1@llnl.gov

Marshall Reed

Office of Geothermal Technologies

U.S. Department of Energy, EE-12

1000 Independence Ave., SW

Washington, DC 20585

Phone: (202) 586-8076

Fax: (202) 585-8185
Joel Renner

Idaho National Engineering Laboratory

P.O. Box 1625

Idaho Falls, ID 83415-3830

Phone (208) 526-9824

Fax (208) 526-0969

Howard P. Ross

Energy \& Geoscience Institute

University of Utah

423 Wakara Way, Suite 300

Salt Lake City, Utah 84108

Phone: (801) 581-5184

Fax: (801) 585-3540

email: hross@egi.utah.edu

John H. Sass

Scientist Emeritus

U.S. Geological Survey

2255 N Gemini Dr

Flagstaff, AZ 86001-1698

Phone 5205567226

FAX 5205567169

Jsass@flagmail.wr.usgs.gov

Albert T. Smith

Lawrence Livermore National Laboratory

P.O. Box 808, L-205

Livermore, CA 94551-0808

Phone: (925) 422-9739

Email: smith16@llnl.gov

Alan C. Tripp

717 Browning Bldg.

Dept. of Geology and Geophysics

University of Utah

Salt Lake City, Utah 84112

Ph. 435-462-2112

Fax. 801-581-7065

e-mail: actripp@mines.utah.edu

Alfred $\mathrm{H}$. Truesdell

700 Hermosa Way

Menlo Park, CA 94025

Phone: (650) 322-6135

Fax: (650) 324-4009

E-mail: ahtruesdell@lbl.gov 
J. Douglas Walker

Department of Geology

University of Kansas

Lawrence, KS 66045-2124

Phone: 785-864-2735

FAX: $785-864-5276$
Philip E. Wannamaker

Energy \& Geoscience Institute

University of Utah

423 Wakara Way, Suite 300

Salt Lake City, UT 84108

Phone: (801) 581-3547

Fax: (801) 585-3540 


\title{
VOLATILITY OF CHLORIDES AND THE THERMODYNAMICS OF BRINES DURING BRINE DRYOUT
}

\author{
J. Michael Simonson, Donald A. Palmer, S. L. Marshall, P. C. Ho, and M. S. Gruszkiewicz \\ Chemical and Analytical Sciences Division, Oak Ridge National Laboratory
}

\section{KEYWORDS}

hydrochloric acid, volatility, corrosion, The Geysers, modeling, thermodynamics, acidity, chloride, brine, steam, steam caps

\section{PROJECT BACKGROUND AND STATUS}

Corrosive solutes in geothermal steam can limit or prevent economic production of steam from relatively high-temperature geothermal resources. Some wells in a high-temperature $\left(>300^{\circ} \mathrm{C}\right)$, vapor-dominated resource at the Northwest Geysers, California, have produced high levels of chloride at the wellhead, with observed levels greater than $100 \mathrm{ppm}$ in some cases. This chloride-bearing steam is extremely corrosive to piping and well casings, leading in severe cases to loss of production within a few days. In addition to the current problem, the question of potential production of acidic steam in older wells at The Geysers as the reservoir dries out with continued production is of great long-term significance in the operation of the resource. Questions of acid chloride partitioning from brines to steam have also been raised in conjunction with other geothermal systems. Examples include the observation of elevated chloride in steam on production of fluids with excess enthalpy (e.g., Los Azufres; Kakkondo), and the effects of surface processes ( $\mathrm{pH}$ modification through acid injection) at plants in the Salton Sea geothermal area.

The high volatility of hydrochloric acid and the observed nonstoichiometry of chloride with cations in steam (e.g., $\mathrm{Na}$ ) led to the hypothesis that the observed chloride at The Geysers is due to hydrochloric acid. A laboratory study of the partitioning of acid chlorides over both single electrolyte solutions and over brines likely to be encountered in the reservoir was undertaken to address the problem of acidic steam production, particularly in the deeper, hotter wells in the Northwest Geysers, and the projected behavior of the 'normal' reservoir with further production. Early results, including measurements of the partitioning of $\mathrm{HCl}$ from liquid to vapor in pure-acid solutions and $\mathrm{NaCl}(\mathrm{aq})$ brines, indicated that $\mathrm{HCl}$ was unlikely to be the sole source of chloride in steam due to the low brine $\mathrm{pH}$ required to give high $\mathrm{HCl}$ concentrations in steam. Calculations based on the results of these measurements, and on primary volatility data obtained for aqueous ammonium chloride in a program at this laboratory sponsored by the Electric Power Research Institute, indicate that $\mathrm{NH}_{4} \mathrm{Cl}(\mathrm{aq})$ volatility could give high chloride levels in steam over near-neutral high-temperature brines containing high concentrations of $\mathrm{NaCl}(\mathrm{aq})$. [Simonson et al., 1995, 1997] Furthermore, recent measurements have shown that, for temperatures $\leq 300^{\circ} \mathrm{C}$, the volatility of $\mathrm{NaCl}$ over very concentrated (to halite saturation) $\mathrm{NaCl}(\mathrm{aq})$ brines is significantly lower than predicted from recently-developed equations of state for $\mathrm{NaCl}+\mathrm{H}_{2} \mathrm{O}$. These new measurements are consistent with very low sodium ion concentrations found in wellhead condensate samples having high chloride as a result of $\mathrm{HCl}+\mathrm{NH}_{4} \mathrm{Cl}$ partitioning at high temperatures. Measurements have also been made of the partitioning of solutes to steam over $\mathrm{NaCl}(\mathrm{aq})$ brines in the presence of finely-ground samples of reservoir rocks (wells MLM-3 and L'Esperance \#2) from The Geysers. Analyses of these condensedsteam samples showed that the chloride concentration in steam was not significantly enhanced by the presence of the rock sample. Although the rock samples were treated with hydrochloric acid prior to beginning the volatility measurements, relatively high concentrations of ammonia have been found in these condensate samples. Other ions have also been found in significant quantities, indicating volatilization or exchange with minerals in the rock samples. Efforts to identify and fully quantify the other volatile species have been hindered by the high levels of ammonia found in the condensed vapor 
samples. It was clear that there was no enhancement of chloride in steam above those levels expected on the basis of $\mathrm{NaCl}$ partitioning for the MLM-3 samples, but a small enhancement has been noted for the steam equilibrated with L'Esperance \#2 samples.

\section{PROJECT OBJECTIVES}

The goals of this project are to determine likely sources of highly corrosive steam from hightemperature geothermal wells and to suggest appropriate mitigation procedures based on the thermodynamics of liquid-vapor partitioning of corrosive solutes. A further objective is to enable calculations to be made of the compositions of coexisting brines and steam over the full range of conditions (reservoir to surface equipment) of conditions encountered in the production of electricity from geothermal steam. This research is of particular importance to the control of chloride in the steam produced from the vapor-dominated reservoir at The Geysers geothermal field in California. However, the fundamental approach taken makes the results of this program generally applicable to a variety of operating problems including the onset of excess enthalpy (two-phase) fluid production from liquiddominated reservoirs and changes in fluid chemistry on steam flashing or condensation.

\section{Technical Objectives}

- Carry out precise laboratory measurements of the partitioning of corrosive solutes to steam over ranges of temperature and brine composition appropriate to geothermal reservoirs, including equilibrations of brine in contact with rock samples from geothermal reservoirs.

- Represent the experimental data quantitatively, using sound thermodynamic models, in order to provide the means for reliable calculation of the composition of coexisting brine and steam under both reservoir and surface (e.g., piping and turbine) conditions.

- $\quad$ Propose and validate methods for mitigation of the production of corrosive steam from geothermal reservoirs based on the experimental and modeling results.

\section{Expected Outcomes}

- The primary products of this research will be new data on the partitioning of potentially corrosive solutes between brine and steam over wide ranges of temperature and composition characteristic of various geothermal systems, and a quantitative method for calculating the composition of coexisting phases at various points in the geothermal steam cycle.

- In collaboration with personnel from companies operating geothermal power plants, these experimental results will be used to develop methods for the mitigation of problems (corrosion; solids deposition) encountered in energy production from geothermal resources.

\section{APPROACH}

The problem is addressed through laboratory measurements of liquid-vapor partitioning equilibria coupled with the development and application of quantitative thermodynamic models to represent and interpret the experimental results. The partitioning of chlorides to the vapor phase has been measured at temperatures to $350^{\circ} \mathrm{C}$ over pure $\mathrm{HCl}(\mathrm{aq})$, from aqueous mixed brines at concentrations ranging to salt saturation, and from brines in contact with rock samples from The Geysers.

This project is part of the program "Physical Chemistry of Geothermal Systems" at ORNL. Significant contributions to the general objectives of this program are provided by other closely-related programs in 
progress at ORNL, including research in fundamental aqueous chemistry at high temperatures and measurements of solute volatilities important in fossil-fired and nuclear steam cycle chemistry.

\section{RESEARCH RESULTS AND VARIANCES}

A special apparatus has been constructed for these measurements of the partitioning of chloride between liquid and vapor phases, using a thin platinum liner within a stainless-steel pressure vessel to permit studies to high temperatures on these very corrosive solutions. Samples of both the liquid and vapor phases are obtained at temperature through chemically-inert tubing and valves, with condensed vaporphase samples withdrawn at a precisely controlled rate in order to prevent disturbing equilibrium conditions and to minimize sample contamination by entrained liquid droplets. Sample compositions are determined quantitatively using methods appropriate for the solutes in a particular sample. Where practical, experiments are carried out over wide ranges of ionic strength and acidity/salinity ratios at each temperature, to insure that the correct thermodynamic equilibrium constant is obtained from the analysis of the results.

The thermodynamic equilibrium constant for the partitioning reaction may be written as $\mathrm{K}=$ $\mathrm{m}_{\mathrm{v}}(\mathrm{MCl}) /\left\{\mathrm{m}_{\mathrm{l}}(\mathrm{M}) \mathrm{m}_{\mathrm{l}}(\mathrm{Cl}) \gamma_{ \pm}^{2}(\mathrm{MCl})\right\}$, where $\mathrm{m}_{\mathrm{v}}$ and $\mathrm{m}_{\mathrm{l}}$ are molalities of the components in the vapor and liquid phases and $\gamma_{ \pm}$is the stoichiometric mean ionic activity coefficient for $\mathrm{MCl}$ in the liquid phase. These activity coefficients, which are significantly different from unity at the conditions investigated, are known or can be estimated reliably from studies in this Laboratory; the activity coefficient for the neutral $\mathrm{MCl}$ molecule in the vapor phase is assumed to be unity. The invariance of $\mathrm{K}$ with observed liquid and vapor phase compositions and sampling rates serves as a check for the absence of mechanical carryover of solute, and of the accuracy of the activity coefficients.

The values of $\mathrm{K}$ for $\mathrm{HCl}$ have been represented as a simple function of temperature and solvent (water) density for purposes of interpolation and extrapolation of the results to the solvent critical temperature $\left(374^{\circ} \mathrm{C}\right)$. However, activity coefficients for $\mathrm{HCl}$ in the liquid phase are strongly dependent on the identity and concentration of other solutes (e.g., $\mathrm{NaCl}$ ), and changing values of $\gamma$ lead directly to changes in the vapor-phase $\mathrm{HCl}$ concentration according to the equation given above. A full analysis of our experimental results for $\mathrm{HCl}$ partitioning from aqueous $\{\mathrm{HCl}+\mathrm{NaCl}\}$ brines gave measured values at high $\mathrm{NaCl}$ concentrations slightly higher than those predicted from our earlier model for this mixture. We have used the new partitioning results to refine the model for activity coefficients of $\mathrm{HCl}$ in concentrated $\mathrm{NaCl}$ brines, including determination of a parameter describing the specific interaction between sodium and hydrogen ion in concentrated chloride solutions. The revised treatment, which is based on the experimental results, predicts slightly higher $\mathrm{HCl}$ concentrations in steam equilibrated with $\mathrm{NaCl}(\mathrm{aq})$ brines at high concentrations and temperatures as compared with our earlier estimates from measurements at lower $\mathrm{NaCl}(\mathrm{aq})$ concentrations. The partitioning of $\mathrm{NaCl}$ is somewhat more complex: at constant temperature, values of $\mathrm{K}$ decrease with the decreasing density of steam as the brine becomes more concentrated. A full treatment of the extensive experimental results for this solute, leading to an improved capability to calculate the contribution of $\mathrm{NaCl}$ volatility to overall chloride transport, is in preparation.

Additional measurements of the compositions of coexisting phases have been made to $350^{\circ} \mathrm{C}$ for aqueous brines containing $\mathrm{MgCl}_{2}, \mathrm{MgCl}_{2}+\mathrm{NaCl}$, and $\mathrm{CaCl}_{2}$. It is clear from these experiments that while $\mathrm{HCl}$ is produced by hydrolysis of cations in these solutions, the total amounts of $\mathrm{HCl}$ generated are again too small to account for the high levels of chloride observed in steam from the high-temperature reservoir at The Geysers. However, it must be noted that these observations have been made in relatively dilute solutions. In a recent study of the activity of water over $\mathrm{CaCl}_{2}(\mathrm{aq})$ at very high concentrations and at temperatures to $250^{\circ} \mathrm{C}$ carried out in our isopiestic facility and sponsored by the DOE Division of Chemical Sciences, hydrolysis and subsequent $\mathrm{HCl}$ volatilization was noted which led to pronounced hysteresis in the vapor pressure curves as functions of concentration. These results, which are 
qualitatively consistent with the recent high-concentration results reported at higher temperatures by Bischoff and Rosenbauer [Geochim. Cosmochim. Acta 1996, 60, 7-16], may help to resolve the uncertainties in the generation of acidic steam through calcium hydrolysis. Further experiments toward a quantitative understanding of this process are outlined below.

Measurements of solute volatilities from brines in contact with Geysers reservoir rock samples (MLM-3; L'Esperance \#2) have been carried out at 250,300 , and $350^{\circ} \mathrm{C}$. Analyses of condensed-steam samples from equilibrations with $\mathrm{NaCl}(\mathrm{aq})$ in contact with samples of both of these reservoir rocks indicated the presence of significant concentrations of additional solutes (i.e., other than sodium, hydrogen ion, and chloride). Significant concentrations of ammonia were found in both sets of equilibrations; the MLM-3 studies indicated thiosulfate ion in steam condensate. The presence of these solutes also complicated the determination of sodium and chloride concentrations in the samples. While it was not possible to quantify fully the concentrations of all solutes in the condensed vapor samples from equilibrations with MLM-3, it was clear that no enhancement of the chloride concentration over that expected for $\mathrm{NaCl}$ partitioning was observed in these experiments. On the other hand, equilibrations carried out at 250 and $300^{\circ} \mathrm{C}$ for $\mathrm{NaCl}(\mathrm{aq})$ in contact with rock samples from L'Esperance \#2 showed small but reproducible enhancements of chloride over sodium concentrations condensate samples. As noted above, ammonia was observed in all vapor condensate samples, accounting for a portion of the apparent chloride enhancement by ammonium chloride partitioning. Further samples have been obtained for this system at temperatures through $350^{\circ} \mathrm{C}$. Analysis of the results will be carried out in the next period, taking advantage of the higher sensitivity and precision offered by the new ion chromatograph, to determine whether the enhanced chloride in the vapor samples arises from partitioning as $\mathrm{HCl}$ or $\mathrm{NH}_{4} \mathrm{Cl}$.

\section{FUTURE PLANS}

Measurements of the partitioning of chloride to steam over $\mathrm{NaCl}(\mathrm{aq})$ brines equilibrated with core samples from the Northwest Geysers are nearly complete. We expect that new information on a number of volatile components arising from the rocks, in addition to chloride, will be available from final analysis of the vapor-condensate samples. We anticipate that some further detailed mineralogy on the rock samples from L'Esperance \#2 will yield valuable additional information on the possible source minerals for these volatile components, with enhanced capabilities to predict fluid chemistry from analyses of mineral samples.

The establishment of the need for a mixing parameter of the ion-interaction treatment to describe quantitatively the partitioning of $\mathrm{HCl}$ from mixed $\{\mathrm{HCl}+\mathrm{NaCl}\}$ brines points out the need for some confirmatory measurements of the partitioning of chlorides from brine to steam in the system $\left\{\mathrm{NH}_{4} \mathrm{Cl}+\right.$ $\mathrm{NaCl}\}(\mathrm{aq})$. These experiments should demonstrate the reliability of the calculations carried out previously for ammonium chloride volatility in mixed brines at high temperatures, and lead directly to improvements in our ability to estimate the $\mathrm{pH}$ of brines in place based on measurements of the volatile components of produced fluids.

The experimental techniques and modeling approaches developed in this program and complementary programs in this Laboratory have applications to geothermal systems beyond the original problem of corrosive-steam production at The Geysers. A good example of this range of application is the investigation of the hydrolysis behavior of cations at high concentrations. It is clear from our volatility measurements that hydrolysis of $\mathrm{NaCl}$ is not sufficiently extensive at temperatures to $350^{\circ} \mathrm{C}$ to lead to significant partitioning of $\mathrm{HCl}$ from brine to steam, even at high $\mathrm{NaCl}$ concentrations. Similarly, relatively low concentrations of 'hydrolyzable' cations (e.g., $\mathrm{Ca}^{2+}, \mathrm{Mg}^{2+}$ ) also do not give high levels of $\mathrm{HCl}$ partitioning to steam. However, recent work in our laboratory at temperatures to $250^{\circ} \mathrm{C}$ and by Bischoff and Rosenbauer (op. cit.) at higher temperatures has shown that high acidity can be generated by $\mathrm{CaCl}_{2}$ (aq) at high concentrations. For geothermal brines with high calcium content (e.g., Salton Sea) this 
could represent an important mechanism for the generation of acidic steam on brine dryout. We anticipate beginning a quantitative study of the generation of acidic steam by concentrated $\mathrm{CaCl}_{2}(\mathrm{aq})$ at temperatures from 200 to $350^{\circ} \mathrm{C}$. Initial experiments will center on the [initially homogeneous] aqueous system. When the fundamental thermodynamics of calcium ion hydrolysis at high concentrations are available from the results of these experiments, subsequent equilibrations on systems including pure mineral phases (e.g., simple aluminosilicates) will be carried out to give indications of the efficacy of solid-brine reactions in removing hydroxide produced on hydrolysis of calcium ion. These experiments may require further modification of the volatility apparatus to insure appropriate contact of the solution with mineral surfaces during the equilibrations. This relatively simple system should give results which are much more appropriate for quantitative analysis than would be the case for the necessarily heterogeneous assemblages obtained from geothermal core samples.

A packed-column solubility apparatus has recently been constructed in our laboratory and tested successfully to $350^{\circ} \mathrm{C}$ over a wide range of pressures corresponding to liquid and steam phase conditions. Metal oxide solubilities in the 1 ppt range have been measured accurately and reproducibly after preconcentration steps by graphite furnace AA methods. This technique would be ideal for the study of $\mathrm{NaCl}$ and $\mathrm{NH}_{4} \mathrm{Cl}$ solubilities in steam, the $\mathrm{pH}$ of which could be buffered by ammonia if necessary. These measurements would complement and extend the "volatility" experiments in terms of the range of pressure (density) and temperature $\left(>350^{\circ} \mathrm{C}\right)$ that could be attained with the two-phase studies. An additional advantage of the flow method is that it produces large sample volumes that can be readily concentrated prior to analysis. Moreover, the design of this apparatus is such that accurate control of the pressure is readily achievable, which is essential for solubility measurements in low density steam. Measurements of $\mathrm{NH}_{4} \mathrm{Cl}$ solubility in dilute ammoniated steam should provide a precise and more direct measure of the volatility of the this salt than was previously possible previously due to the strong, preferential distribution of $\mathrm{NH}_{3}$ to the steam phase and its adverse effect of the analysis of chloride by ion chromatography. The thermodynamic information obtained from these measurements will give a clearer quantitative picture of the fate (in terms of maximum effects which correspond to equilibrium conditions) and speciation of chloride in steam produced at the Geysers as it rises up the production well while experiencing a large temperature gradient.

It is apparent that the application of measured equilibrium constants to the wide range of conditions (temperature, pressure, brine composition) encountered in geothermal systems requires a broad and accurate knowledge of the thermodynamic properties of solutes in brines at high temperatures, including homogeneous reactions (e.g., ion association) and excess properties (i.e., activity coefficients). We expect that further quantitative modeling of the volatility results, and applications to field observations from geothermal systems, will indicate that some closely-targeted experimental measurements of these properties under clearly defined conditions could contribute significantly to an overall understanding of liquid-vapor phase behavior of solutes in geothermal systems. In the longer term, isopiestic (vapor pressure) measurements aimed toward an understanding of the activity of carbonates in aqueous solutions at high temperature could give important new information related to the problem of carbonate scale formation in geothermal systems. Similarly, calorimetric experiments on $\left\{\mathrm{NaCl}+\mathrm{CO}_{2}\right\}$ aqueous mixtures, and on the less-basic carbonate and bicarbonate mixtures inaccessible to isopiestic measurements, could advance materially our understanding of the thermodynamics of $\mathrm{CO}_{2}$-containing fluids under both reservoir and surface-equipment conditions.

\section{INDUSTRY INTEREST AND TECHNOLOGY TRANSFER}

Technology transfer has been an integral component of this program from its inception. Results have been communicated frequently to the geothermal industry through both periodic, focused update meetings and participation in geothermal conferences of broader scope. Direct contact and consultation on the application of these results to problems arising from volatility of solutes are continuing with the 
organizations listed below. We intend to extend these contacts in the next year through direct discussions of the full results of the volatility and modeling studies of chloride transport with interested parties operating at The Geysers.

\section{Organization}

UNOCAL; other Geysers operators California Energy Company Electric Power Research Institute Pacific Gas and Electric Company

\section{Type and Extent of Interest}

Geysers geothermal field applications

Salton Sea geothermal field process applications

Fossil-fired and nuclear steam cycle applications

Guidelines for operation of corrosion-mitigation equipment

\section{REFERENCES}

Simonson, J. M. and Palmer, D. A. (1993) "Liquid-vapor partitioning of $\mathrm{HCl}(\mathrm{aq})$ to $623 \mathrm{~K}$," Geochim. Cosmochim. Acta, 57, 1-7.

Simonson, J. M., Palmer, D. A., and Carter, R. W. (1994) "Liquid-vapor partitioning of $\mathrm{NaCl}(\mathrm{aq})$ from concentrated brines at temperatures to $350^{\circ} \mathrm{C}$," Proceedings of the 19th Stanford Geothermal Reservoir Engineering Workshop, 19, 245-251.

Simonson, J. M. and Palmer, D. A. (1994) "Vapor-liquid equilibrium of chlorides in aqueous systems to high temperatures: Application to the Geysers geothermal field," Geothermal Resources Council Transactions, 18, 347-352.

Simonson, J. M. and Palmer, D. A. (1995) "Partitioning of solutes between liquid water and steam in the system $\left\{\mathrm{Na}-\mathrm{NH}_{4}-\mathrm{NH}_{3}-\mathrm{H}-\mathrm{Cl}\right\}$ to $350^{\circ} \mathrm{C}$," Physical Chemistry of Aqueous Systems: Meeting the Needs of Industry (Proceedings of the 12th International Conference on the Properties of Water and Steam), 677-684.

Simonson, J. M. and Palmer, D. A. (1995) "Liquid-vapor partitioning in the system Na-H-NH $\mathrm{N}_{4}-\mathrm{NH}_{3}-\mathrm{OH}-$ $\mathrm{Cl}-\mathrm{H}_{2} \mathrm{O}$ to $350^{\circ} \mathrm{C}$," Proceedings of the World Geothermal Congress 1995, 969-974.

Joyce, D. B., Simonson, J. M., and Palmer, D. A. (1995) "Vapor liquid partitioning of aqueous sodium chloride to $350^{\circ} \mathrm{C}$," Geological Society of America: Abstracts with Programs, v. 27.

Simonson, J. M. and Palmer, D. A. "Volatility of $\mathrm{HCl}$ and the thermodynamics of brines during brine dryout," Proceedings: Geothermal Program Review XV, "The Role of Research in the Changing World of Energy Supply." Springfield, VA: National Technical Information Service, 1997, pp. 2-25 - 2-31.

J. M. Simonson, D. A. Palmer, R. W. Carter and S. L. Marshall, "Vapor-liquid partitioning of solutes in aqueous $\mathrm{NaCl}-\mathrm{HCl}$ mixtures at high temperatures," Geothermics, submitted for publication (1998). 


\title{
GEOCHEMISTRY OF ALUMINUM IN HIGH TEMPERATURE BRINES
}

\author{
D. A. Palmer, P. Bénézeth, D. J. Wesolowski \\ Chemical and Analytical Sciences Division, Oak Ridge National Laboratory
}

\section{KEY WORDS}

aluminum, solubility, kinetics, potentiometry, permeability, alteration, aluminosilicates, modeling

\section{PROJECT OBJECTIVES}

The objective of this research is to provide quantitative data on the equilibrium and dynamic properties of aluminum minerals required to model changes in permeability and brine chemistry associated with fluid/rock interactions in the recharge, reservoir, and discharge zones of active geothermal systems. The empirical and semi-empirical treatments of the solubility/hydrolysis experimental results on single aluminum mineral phases for the basis for the ultimate investigation of the behavior of complex aluminosilicate minerals. These treatments will also be incorporated into existing code used by the geothermal industry to predict the chemistry of the reservoirs and will be tested for reliability against our laboratory results and field observations.

\section{Technical Objectives}

- Complete analysis of all thermodynamic data pertaining to the solubility of gibbsite and boehmite garnered in this program with appropriate, verified data taken from the literature. This treatment will provide a unified set of equilibrium constants and associated thermodynamic parameters from ambient conditions to $300^{\circ} \mathrm{C}$ and ionic strengths of up to five molal.

- Kinetic studies of the dissolution/precipitation of gibbsite and boehmite will be performed in the existing hydrogen-electrode concentration cells to gain unique rate data on these processes, instigated by small and large isothermal perturbations in $\mathrm{pH}$. These investigations will then extend to more complex aluminosilicate minerals using this method and perhaps conventional flowthrough reactors equipped with down-stream $\mathrm{pH}$ monitoring.

- The solubility quotients for gibbsite and boehmite obtained in this program will be substituted into the codes commonly used in the geothermal industry. In particular, the Pitzer ion-interaction model will be used to treat the solubility/hydrolysis quotients, $\mathrm{Q}_{\mathrm{s} 0}$ and $\mathrm{Q}_{\mathbf{5 4}}$, involving aluminum in high ionic strength solutions to temperatures in excess of $100^{\circ} \mathrm{C}$, which is the current limit of the EQ3-6 code, for example.

\section{Expected Outcomes}

- A consistent set of thermodynamic parameters will be generated which will define the prevalent aqueous aluminum species, as well as the chemical composition of solutions in equilibrium with rock-forming minerals, at geothermal reservoir conditions.

- The results will be treated to allow them to be readily incorporated into chemical reaction and transport computer codes in common use by the geothermal industry.

- The dissolution/precipitation kinetics and solubilities of aluminosilicates will be studied with the intent of addressing problems associated with brine reinjection, scaling, and corrosion in downhole and in-plant systems. 


\section{PROJECT BACKGROUND AND STATUS}

Accurate models for the thermodynamics and kinetics of processes at mineral-aqueous interfaces are essential to the prediction of corrosion and scale formation in geothermal systems. The effects of other activities, such as fluid extraction and spent fluid reinjection on reservoir porosity and permeability, can also benefit from model calculations based on sound fundamental data obtained in the laboratory.

The solubility of gibbsite in $\mathrm{NaC} 1$ solutions to 5 molal over a wide range of $\mathrm{pH}$ to $80^{\circ} \mathrm{C}$ was investigated in the initial phases of this program. These studies were performed using a batch technique, which involved either calculations of $\mathrm{pH}$ from the stoichiometric concentrations of initial acid or base and the measured concentration of aluminum in solution with a known speciation, or the use of $\mathrm{pH}$ buffering agents. The latter approach, which was essential in the intermediate $\mathrm{pH}$ region, required in most cases correction for the interaction of the buffer with the aluminum species in solution (Wesolowski et al., 1990; Palmer and Bell, 1994). The solubility studies (Wesolowski, 1992; Palmer and Wesolowski, 1992; Wesolowski and Palmer, 1994) were complemented by a potentiometric determination of the first hydrolysis quotient for $\mathrm{Al}^{3+}$, which was carried out to 5 molal ionic strength $(\mathrm{NaCl})$ and $125^{\circ} \mathrm{C}(\mathrm{Palmer}$ and Wesolowski, 1993). Combination of these results yielded solubility quotients for gibbsite to form $\mathrm{Al}^{3+}, \mathrm{Al}(\mathrm{OH})^{2+}, \mathrm{A} 1(\mathrm{OH})_{2}{ }^{+}$, and $\mathrm{A} 1(\mathrm{OH})_{4}{ }_{4}^{-}$. The stability of the neutral aluminum species, $\mathrm{Al}(\mathrm{OH})_{3}{ }^{0}$, could not be determined, despite the large number of data gathered at the solubility minimum of gibbsite, so that it was assumed that this species represented only a minor contribution to the overall aluminum inventory in solution at low temperatures. Additional solubility experiments in non-complexing sodium triflate solutions established that no detectable ion pairing occurred, at least at $50^{\circ} \mathrm{C}$, between $\mathrm{Al}^{3+}$ and $\mathrm{Cl}^{-}$, which was the dominant anion in the supporting electrolyte used throughout this entire investigation. Moreover, other experiments in sodium nitrate media with gibbsite that had never been exposed to chloride ion, established that chloride had no specific effect on this solid phase that could be detected as anomalous solubility.

The second stage of this research program involved a thorough study of the thermodynamics of aqueous aluminum at temperatures above $100^{\circ} \mathrm{C}$, which required a different approach, in that use of $\mathrm{pH}$ buffers is impractical due mainly to their limited thermal stabilities and to the likelihood that their interactions with dissolved aluminum species would become even stronger with increasing temperature. Furthermore, the batch method was considered too time-consuming to investigate not only the temperature dependencies of the solubility equilibria, but also the influence of salinity on speciation, which is substantial and most directly relevant to geothermal environments. Note that the effect of salinity has not been addressed in any of the previous high temperature studies. The current program focused on the solubility of beohmite in the $100-290^{\circ} \mathrm{C}$ range at ionic strengths of 0.03 to 5 molal $(27.5 \mathrm{wt} \%)$ using the hydrogen-electrode concentration cell, which allows continuous $\mathrm{pH}$ monitoring in conjunction with periodic sampling and analysis of aluminum in the aqueous phase.

This research program benefits substantially from three projects funded by the DOE Office of Basic Energy Sciences, namely two from the Geoscience Research Program entitled "Fundamental Geochemistry of Geothermal Systems", and "Experimental Studies of Hydrothermal Processes Employing In Situ pH Measurements", as well as the project entitled "Basic Aqueous Chemistry to High Temperatures and Pressures", funded by the Chemical Sciences Division. These programs permit more detailed, fundamental studies of certain aspects of aluminum chemistry, such as complexation by organic and inorganic ligands occurring in natural and experimental solutions.

\section{APPROACH}

Detailed laboratory-scale measurements of the solubility of gibbsite and boehmite have been made under controlled conditions of temperature and ionic strength. The technique of monitoring $\mathrm{pH}$ in situ during 
each solubility experiment was developed in this program and has proven invaluable at high temperatures by providing accurate, expedient and unique thermodynamic and kinetic results. This is particularly apparent at the solubility minima for boehmite which were found to be lower by almost a $\log$ unit at $300^{\circ} \mathrm{C}$ than previously acknowledged. Initial kinetic studies have been made on the dissolution/precipitation reactions of boehmite by monitoring the associated change in $\mathrm{pH}$ as a function of time. Modeling efforts were also initiated to establish the reliability of codes used by the geothermal community in regard to aluminum chemistry.

\section{RESEARCH RESULTS AND VARIANCES}

During this period the final experiments were performed to complete the study of the solubility of boehmite in brines from 100 to $290^{\circ} \mathrm{C}$ at concentrations from 0.03 to 5 molal. These final experiments involved four sets of solutions at 1 and 5 molal $(\mathrm{NaCl})$. For two sets the batch sampling mode was used as the $\mathrm{pH}$ was controlled with excess $\mathrm{HCl}$, so that the dominant aluminum species in solution was $\mathrm{Al}^{3+}$. The remaining experiments were performed in dilute $\mathrm{NaOH}$ where the aluminate anion predominates and it was therefore necessary to measure the $\mathrm{pH}$ in situ with the hydrogen-electrode concentration cell. The previous boehmite work focused on measuring the $\mathrm{pH}$ dependence of the solubility isothermally, mainly at lower ionic strengths. Each isothermal set of resulting "pH profiles", which in some cases comprised up to five individual experiments, has now been treated to yield the solubility quotients, $Q_{s n}(n=0-4)$, corresponding to the reaction: $\mathrm{AlOOH}+(3-n) \mathrm{H}^{+}-\mathrm{Al}(\mathrm{OH})_{n}{ }^{3-n}+(2-n) \mathrm{H}_{2} \mathrm{O}$. These quotients, together with those alluded to above for the end-member species and selected values from the literature, have each been fitted as functions of temperature and ionic strength, including the appropriate Debye-Hückel terms. Two manuscripts describing these results and the experimental approach are being prepared. Moreover, these functions have been used to generate new parameters for the Chiller and EQ3-6 commercial programs and these are now being tested against our most recent data.

Note that one solubility experiment was performed involving gibbsite in contact with an acidic saline solution in the hydrogen-electrode concentration cell at $70^{\circ} \mathrm{C}$. The solubility quotient, $\mathrm{Q}_{\mathrm{s} 0}$, obtained at these conditions was found to be in exact agreement with that obtained by the laborious batch method (Palmer and Wesolowski, 1992) using a different batch of purified gibbsite. This is not only very reassuring in terms of the intrinsic reliability of the results obtained in this long-standing research program, but also opens the door for future kinetic studies on gibbsite with this unique technique.

A logical extension of the solubility studies on boehmite in $\mathrm{NaCl}$ brines was to conduct a number of solubility studies in tetramethylammonium chloride (TMACl) solutions in moderately basic solutions at $200^{\circ} \mathrm{C}$. The large, singly-charged $\mathrm{TMA}^{+}$cation is known to form very weak ion pairs with singly-charged aqueous anions. We therefore attempted to use this approach to determine the extent of ion pairing between the aluminate anion $\mathrm{Al}(\mathrm{OH})_{4}{ }_{4}$ and $\mathrm{Na}^{+}$, by titration of a $\mathrm{NaCl} / \mathrm{NaOH}$ solution into the hydrogenelectrode concentration cell. Recent literature studies provide conflicting ion pair association constants for this interaction. However, we were unable to detect any increase in solubility with increasing sodium concentration and can therefore only place a possible minimum value on this constant at this time.

As yet unpublished isopiestic data on sodium aluminate solutions from 110 to $250^{\circ} \mathrm{C}$ are available from the work of Howard Holmes (retired) carried out in our laboratory for the geothermal program. Due to the restricted concentrations of aluminate that could be reached in these solutions, modeling of the resulting osmotic/activity coefficients according to the Pitzer ion-interaction model proved to be ambiguous. The cause of this problem rests with the pure $\mathrm{NaAl}(\mathrm{OH})_{4}$ parameters, which could not be uniquely specified without having data at high mole fractions of this salt. Although solubility data exist in the literature for boehmite in relatively high caustic solutions, it was decided to conduct some batch experiments to verify the accuracy of these results and to provide the needed "high aluminate concentrations" that would contribute to the modeling effort. A series of experiments was conducted from 100 to $200^{\circ} \mathrm{C}$ in a Teflon- 
lined autoclave up to approximately four molal total $\mathrm{NaOH}$ with aluminate concentrations up to 1.9 molal. Beyond this concentration, precipitation of an aluminate phase occurred in the sampling lines indicating the upper concentration limit for these experiments. We intend to remodel the entire solubility/isopiestic data sets with the Pitzer treatment and if the problem persists with the uncertainties in the pure $\mathrm{NaAl}(\mathrm{OH})_{4}$ parameters, then we will undertake further experiments in which the solid and liquid phases are separated at temperature before quenching. This technique is by nature laborious and time consuming and will only be instigated absolutely necessary.

By monitoring the change in $\mathrm{pH}$ with time, considerable kinetic information can be obtained without the need for sampling. Therefore studies of the dissolution/precipitation rates of boehmite were initiated in neutral to basic solutions at 100 to $290^{\circ} \mathrm{C}$ at 0.1 molal ionic strength. The equilibrium solubilities obtained after each addition of acid or base were in excellent agreement with our previous solubility measurements performed at the same conditions. The rates of both dissolution/precipitation reactions are extremely fast at high $\mathrm{pH}$, so that only the runs performed at $100^{\circ} \mathrm{C}$ have been analyzed in detail to extract the kinetics of these processes.

The rate of dissolution of boehmite was first converted from $\mathrm{pH}_{\mathrm{m}}$ versus time to total aluminum molality $\left[\mathrm{Al}(\mathrm{OH})_{4}{ }^{-}\right]$versus time based on the known stoichiometry of the reaction. Both plots followed an exponential dependence with time as equilibrium was approached. Applying "the principle of detailed balancing", the dissolution reaction, which was monitored following a small addition of base, seems to obey the following simple rate law:

$\mathrm{d}\left[\mathrm{Al}(\mathrm{OH})_{4}\right] / \mathrm{dt}=\mathrm{k}_{\mathrm{diss}} \mathrm{C}-\mathrm{k}_{\text {prec }} \mathrm{Cm}_{\mathrm{H}+} \mathrm{m}_{\mathrm{Al}(\mathrm{OH}) 4}$

where $\mathrm{C}$ stands for the ratio of total surface area of boehmite to the mass of solution, $\mathrm{k}_{\text {diss }}$ and $\mathrm{k}_{\mathrm{prec}}$ are the zero-order and second-order rate constants for dissolution and precipitation, respectively, and $\mathrm{m}_{\mathrm{x}}$ represents the appropriate molal concentrations. Thus plots of rate, $\mathrm{d}\left[\mathrm{Al}(\mathrm{OH})_{4}{ }_{4}\right] / \mathrm{dt}$, versus $\left[\mathrm{H}^{+}\right]\left[\mathrm{Al}(\mathrm{OH})_{4}^{-}\right]$ were linear with an intercept and slope proportional to the respective rate constants. Comparison of the rate constants extracted from these plots showed good agreement. The ratio of the forward and reverse rate constant ratios should be equal to the overall solubility quotient. For the two dissolution cases investigated, the ratios were in excellent agreement, within $0.1 \log$ units, with the corresponding equilibrium constants determined previously for the boehmite reaction on the basic side. The same simple rate law should be applicable to the precipitation reaction steps (i.e., those generated by the addition of acidic titrant), assuming that no other metastable phase is first formed on the surface of the boehmite crystals. The precipitation steps are currently being analyzed.

\section{FUTURE ACCOMPLISHMENTS}

The hydrogen-electrode concentration cell approach is entirely amenable to studies of the rates and equilibrium constants of mineral transformation reactions, such as the hydrolysis of feldspars via reactions like the alteration of potassium feldspar to muscovite and quartz:

$3 \mathrm{KAlSi}_{3} \mathrm{O}_{8}+2 \mathrm{H}^{+}-\mathrm{KAl}_{3} \mathrm{Si}_{3} \mathrm{O}_{10}(\mathrm{OH})_{2}+2 \mathrm{~K}^{+}+6 \mathrm{SiO}_{2}$

If these phases react sufficiently rapidly to achieve equilibrium in a few weeks at temperatures of 200$300^{\circ} \mathrm{C}$ in our cells, which are magnetically stirred with high efficiency promoting rapid attainment of solid/liquid equilibrium, the kinetics will be investigated in detail. This knowledge will aid in predicting, $\mathrm{pH}$, steam corrosivity and scale formation in geothermal systems. Furthermore, by first establishing an equilibrium $\mathrm{K}^{+} / \mathrm{H}^{+}$ratio, then quickly changing this ratio by titration of acid, base, or potassium into a solution in equilibrium with the mineral assemblage, and monitoring $\mathrm{pH}$ to a new equilibrium value, we 
can obtain the rates of reaction, both at near- and far-from- equilibrium conditions, as a function of temperature, $\mathrm{pH}$, salinity, and mineral grain size.

Future studies will involve equilibrium solubility and dissolution/precipitation rate determinations of gibbsite at low temperature $\left(50-70^{\circ} \mathrm{C}\right)$, and for a number of aluminosilicate phases prevalent in geothermal reservoirs at higher temperatures, using the hydrogen-electrode concentration cell. The only limiting factor in the use of these cells will be the formation of additional phases during the course of the experiments. Therefore, we will first initiate studies of gibbsite for which equilibrium data are available from earlier work in this program and we know that at least in the dissolution reaction, no other phases are formed. We will then undertake to investigate aluminosilicate solubility equilibria and kinetics by first determining the dissolution and precipitation kinetics of increasingly complex aluminosilicates, including kaolinite and dickite. Natural kaolinite from Decazeville, France, is already available and will be used after treatment to remove traces of iron oxide.

\section{REFERENCES}

D. J. Wesolowski, D. A. Palmer, and G. M. Begun, "Complexation of aluminate anion by Bis-Tris in aqueous media at 25-50C," J. Soln. Chem., 19, 159-173 (1990).

D. J. Wesolowski, "Aluminum speciation and equilibria in aqueous solution: I. The solubility of gibbsite in the system Na-K-Cl-OH-Al(OH) ${ }_{4}$ from 0-100 ${ }^{\circ}$ C," Geochim. Cosmochim. Acta, 56, 1065-1092 (1992).

D. A. Palmer and D. J. Wesolowski, "Aluminum speciation and equilibria in aqueous solution. II. The solubility of gibbsite in acidic sodium chloride solutions from 30 to 70C," Geochim. Cosmochim. Acta, 56, 1065-1091 (1992).

D. J. Wesolowski and D. A. Palmer, "Experimental studies of aluminum solubility and speciation in brines," in Water-Rock Interaction, Y. K. Kharaka and A. S. Maest, Eds., A. A. Balkema, p. 185-188, 1992.

D. A. Palmer and D. J. Wesolowski, "Aluminum speciation and equilibria in aqueous solution. III. Potentiometric determination of the first hydrolysis constant of aluminum(III) in sodium chloride solutions to 125C," Geochim. Cosmochim. Acta, 57, 2929-2938 (1993).

D. A. Palmer and J. L. S. Bell, "Aluminum speciation and equilibria in aqueous solution. IV. A potentiometric study of aluminum acetate complexation in acidic $\mathrm{NaCl}$ brines to $150 \mathrm{C}$, " Geochim. Cosmochim. Acta. 58, 651-659 (1994).

D. J. Wesolowski and D. A. Palmer, "Aluminum speciation and equilibria in aqueous solution. V. The solubility of gibbsite at $50 \mathrm{C}$ in 0.1 molal $\mathrm{NaCl}$ solutions at hydrogen ion concentrations ranging from $10^{-3}$ to $10^{-9}$ molal," Geochim. Cosmochim. Acta. 58, 2947-2969 (1994).

P. Benezeth, D. A. Palmer, and D. J. Wesolowski, "The aqueous chemistry of aluminum. A new approach to high temperature solubility measurements," Geothermics, 26, 465-481 (1997). 


\title{
STABLE ISOTOPE PARTITIONING IN BRINE-GAS-MINERAL SYSTEMS RELEVANT TO GEOTHERMAL RESOURCES
}

\author{
Juske Horita, David R. Cole, and David J. Wesolowski \\ Chemical and Analytical Sciences Division \\ Oak Ridge National Laboratory
}

\section{KEY WORDS}

isotope, oxygen, hydrogen, brine, steam, mineral, partitioning, tracers, geothermometer

\section{PROJECT BACKGROUND AND STATUS}

The distribution of the stable isotopes of oxygen, hydrogen, carbon, and other light elements, which partition as a function of temperature and the bonding characteristics of individual phases, has been widely studied in geothermal systems in order to constrain the time-temperature history of geothermal systems, the sources and fluxes of fluids, the extent of boiling and mineral deposition from the fluids, and the temporal relationship among alteration minerals. Numerous investigations of isotope partitioning at room temperature have demonstrated that there exist composition-dependent salt effects on the partitioning of $\mathrm{D} / \mathrm{H}$ and ${ }^{18} \mathrm{O} /{ }^{16} \mathrm{O}$ ratios between brines and coexisting phases, such as steam, other volatiles $\left(\mathrm{CO}_{2}, \mathrm{CH}_{4}\right)$, and alteration minerals. However, at elevated temperatures encountered in geothermal systems, there are insufficient experimental data or theoretical models to predict salt effects on isotope partitioning. The limited data available at elevated temperatures are conflicting, but indicate potentially significant isotope salt effects in the 100 to $300^{\circ} \mathrm{C}$ range, leading to large errors in calculated temperatures and gross misinterpretation of fluid sources and fluxes, particularly in highly saline geothermal systems such as the Salton Sea and the Guaymas Basin. Even in less-saline geothermal systems, boiling processes associated with steam separation and mineral precipitation can produce deepseated, highly saline fluid reservoirs. In order to model isotopic partitioning during boiling/condensation and mineral precipitation/alteration involving brines, accurate knowledge of the salt effect on isotope partitioning is required. In addition, recent theoretical work predicted that pressure may affect significantly isotope partitioning between water and coexisting phases at geothermal conditions. To date, pressure has been largely neglected as a potentially important variable in isotope partitioning. Experimental verification of the isotope pressure effect is needed.

The current project started several years ago, together with complementary experimental programs at Oak Ridge National Laboratory funded by DOE's Office of Basic Energy Sciences/Geosciences program. Recently, substantial progress has been made on liquid-vapor equilibration experiments of salt solutions up to $350^{\circ} \mathrm{C}$, and emphasis is being shifted toward hydrothermal experiments in mineral-water systems at temperatures up to $500^{\circ} \mathrm{C}$ to examine the isotope salt and pressure effects. An effort to model the isotopic behavior of geothermal systems has been initiated.

\section{PROJECT OBJECTIVES}

The objectives of this research are: (1) to provide precise experimental data on the partitioning of oxygen and hydrogen isotopes between geothermal waters and other phases (steam, gases, and alteration minerals formed in geothermal reservoirs) at elevated temperatures, and the effect of dissolved salts and pressure on the isotope partitioning, and (2) to investigate the importance of the salt and pressure effects on isotopic partitioning in geothermal systems through modeling of the isotopic evolution of fluids (steam and gases) and minerals at various physical and chemical conditions. 


\section{Technical Objectives}

- Determine precisely the effects of common dissolved salts $\left(\mathrm{NaCl}, \mathrm{KCl}, \mathrm{CaCl}_{2,}\right.$ etc.) and pressure on oxygen and hydrogen isotope partitioning in the systems water liquid-vapor and mineral-water at temperatures to $500^{\circ} \mathrm{C}$.

- Establish simple, empirical equations based on experimental results for calculating the isotope salt and pressure effects in natural, complex geothermal brines over wide ranges of temperature and chemical composition.

- Investigate the importance of the isotope salt and pressure effects for the interpretation of isotopic data from geothermal systems through modeling at various physical and chemical conditions.

\section{Expected Outcomes}

- A set of internally consistent, precise experimental results on the partitioning of oxygen and hydrogen isotopes among geothermal materials (waters, brines, steam, gases, and minerals) at elevated temperatures as a function of pressure and fluid composition, that can be directly used to better characterize geothermal reservoirs (temperatures, origin and residence time of fluids, phase separation, and water-rock interaction) and to trace injected fluids to production sites for estimating the quantity of production that is derived from injection.

- Isotopic models of geothermal systems, which can be used to investigate geochemical processes of geothermal fluids and rocks at various physical and chemical conditions.

\section{APPROACH}

Utilizing the unique experimental facilities and expertise at Oak Ridge National Laboratory, we measured salt and pressure effects on isotopic partitioning by means of salt solution-water vapor equilibration and salt solution-mineral exchange methods at temperatures up to $500^{\circ} \mathrm{C}$ at various pressures. Changes in the partitioning of $\mathrm{D} / \mathrm{H}$ and ${ }^{18} \mathrm{O} /{ }^{16} \mathrm{O}$ between liquid water, and water vapor or minerals as a function of the concentration of dissolved salts and pressure are modeled in terms of the activity coefficient ratios of the isotopic water molecules in the brines, in order to construct simple empirical equations for predicting the isotope salt and pressure effects in natural, complex brines over a wide range of temperature and pressure.

This project benefits substantially from the program "Fundamental Geochemistry of Geothermal Systems" funded by the Geosciences Program of the DOE Office of Basic Energy Sciences, in which more detailed, complementary studies and modeling are performed. This project is part of a program "Physical Chemistry of Geothermal Systems" at ORNL. The general objective of this program is to conduct laboratory experimental research utilizing unique facilities and expertise at ORNL for studies of selected chemical equilibria, thermodynamics of brine systems, liquid-vapor solute and isotopic partitioning, and other phase behavior.

\section{RESEARCH RESULTS AND VARIANCES}

A series of hydrothermal experiments quantifying the effects of pressure and dissolved $\mathrm{NaCl}$ on isotope partitioning for the systems brucite-water and epidote-water were conducted at the following conditions: (1) for brucite-pure water at $150,200,250,500,2000$, and 8000 bars, all at $380^{\circ} \mathrm{C}$; for brucite- 1 to 5 molal $\mathrm{NaCl}$ solutions at 200 and 250 bars, and at $380^{\circ} \mathrm{C}$, and (2) for epidote-pure water, at 100, 200, and 250 bars, and at $380^{\circ} \mathrm{C}$. These sets of experiments were specifically designed to determine, as well as differentiate, the effects of pressure and dissolved $\mathrm{NaCl}$ on equilibrium isotope partitioning. 
Approximately 15 to $20 \mathrm{mg}$ of brucite or $100-200 \mathrm{mg}$ of epidote and $50-200 \mathrm{mg}$ of water were loaded into Au capsules to maintain high water to mineral ratios. At each condition, four isotopically different waters, ranging in $\mathrm{D} / \mathrm{H}$ from -105 to $+107 \%$, were used, so that an equilibrium isotope fractionation factor can be calculated from partially exchanged mineral-water pairs, using the method developed by Northrop and Clayton (1996). Experiments were carried out with various pressure vessels, including cold-seal and piston cylinder. Run durations ranged from 12 to 73 days.

The grain size of brucite increased significantly, suggesting that dissolution-precipitation was a dominant process of isotope exchange. The $\mathrm{D} / \mathrm{H}$ ratios of brucite run product were determined by a procedure established in our laboratory. The $\mathrm{D} / \mathrm{H}$ ratios of the waters, which were nearly constant during the experiments due to large water to mineral ratios, were calculated based on an isotope mass-balance. The degree of isotopic exchange reached 91 to $98 \%$ of equilibrium, and these high exchange fractions yielded very precise results in the Northrop-Clayton partial exchange method. Our results show that measured $\mathrm{D} / \mathrm{H}$ fractionation factors between brucite and pure water systematically increased from $-31.4 \pm 0.8 \%(1 \sigma)$ at 150 bars to $-19.3 \pm 2.4 \%(1 \sigma)$ at 8000 bars, all at $380^{\circ} \mathrm{C}$. These results are, to our knowledge, the first experimental results which unambiguously demonstrated the effect of pressure on $\mathrm{D} / \mathrm{H}$ partitioning between mineral and water. The observed $12 \%$ pressure effect is in the same direction as predicted by the theoretical works of Polyakov and Kharlashina (1994) and Driesner (1997), but its magnitude is much smaller than calculations by Driesner (1997). A close examination of the results revealed that a positive linear relationship exists between the fractionation factor $(-31.4$ to $-19.3 \%$ ) and the density of water $(0.07$ to $\left.1.04 \mathrm{~g} / \mathrm{cm}^{3}\right)$ at the experimental conditions. It is reported in the literature that the density of water exhibits a linear correlation with the symmetric O-H and O-D stretching frequencies of pure water at a given temperature, which is a dominant factor in determining the isotopic fractionation of water.

We have conducted similar experiments on brucite-water isotope exchange at $200^{\circ} \mathrm{C}$ and 21 bars, $300^{\circ} \mathrm{C}$ and 100 bars, $400^{\circ} \mathrm{C}$ and 500 bars, and at $500^{\circ} \mathrm{C}$ and 800 bars. A comparison of our results with those of Satake and Matsuo (1984) at the same temperatures, but at higher pressures also show a positive relationship between the $\mathrm{D} / \mathrm{H}$ fractionation factor and the density of water. The $\mathrm{D} / \mathrm{H}$ pressure effect seems larger at $200-300^{\circ} \mathrm{C}$, based on these preliminary results.

The results of our epidote-water experiments at 100,200 , and 250 bars, and at $380^{\circ} \mathrm{C}$ are somewhat ambiguous. Microscopic observations indicate that the epidote run products did not change much in color (green), grain size (10-40 $\mu \mathrm{m}$ ), and shape (elongated with sharp edges). A few, very small brown crystals (alteration mineral magnetite?) were observed. These observations suggest that diffusion, rather than dissolution-precipitation, was the main mechanism of isotopic exchange. $\mathrm{D} / \mathrm{H}$ fractionation factors calculated from all of the three experiments using the partial isotope exchange technique show a similar non-linear pattern. These data suggest the same isotopic exchange reaction between epidote and water was not replicated within a set of experiments with different waters. It is possible that in diffusioncontrolled exchange as suggested by SEM observation, variations in trace species (pH, salinity, etc.) might have affected exchange kinetics substantially. Relatively low (8-40\%) overall isotope exchange shown by the $\mathrm{D} / \mathrm{H}$ analysis of the run products precludes precise determination of equilibrium $\mathrm{D} / \mathrm{H}$ fractionation between epidote and water, but some useful constrains can be obtained. At 250 bars, the estimated D/H fractionation is $-42 \%$, about $8-9 \%$ lower than that which Graham et al. (1980) obtained at 2 and 4 kbar. For the 200 and 100 bar runs, probable upper limits of the D/H fractionation are $-82 \pm 3$ and $-87 \pm 3 \%$, respectively. These preliminary results suggest substantial pressure effects on D/H isotope partitioning, consistent with the calculations of Driesner (1997).

The effect of 1-5 molal $\mathrm{NaCl}$ on $\mathrm{D} / \mathrm{H}$ fractionation factors between brucite and water at $200-500^{\circ} \mathrm{C}$ showed that dissolved $\mathrm{NaCl}$ slightly, but consistently, increased brucite-water $\mathrm{D} / \mathrm{H}$ fractionation at all the temperatures studied. Our results and the literature data obtained from the epidote-water system at much higher pressures are generally consistent with each other, although the latter show $\mathrm{D} / \mathrm{H}$ effects slightly 
larger than ours. Our results on the effect of dissolved $\mathrm{NaCl}$ on brucite-water $\mathrm{D} / \mathrm{H}$ partitioning at $380^{\circ} \mathrm{C}$, and at 200 and 250 bars suggest that the $\mathrm{NaCl}$ effects are pressure-dependent. These new results demonstrate that isotope fractionation is a function, not only of temperature, but also of pressure and fluid composition.

In order to enhance our experimental capabilities for mineral-fluid isotopic exchange experiments such as discussed above, six new cold-seal facilities were constructed. The new 1/2" ID cold-seal vessels, rated for temperatures to $800^{\circ} \mathrm{C}$ and pressures to $4 \mathrm{kbars}$, can easily accommodate multiple capsules at the same time. Temperature and pressure of the six vessels are controlled and monitored independently. These six new cold-seal vessels are currently in operation, together with our existing three cold-seal vessels (one $1 / 2$ " ID and two 1/4" ID). Our preparation line for oxygen isotope analyses of silicates and oxides, which became antiquated over the last decade, was also renovated.

A major objective in stable isotope studies of fossil geothermal systems and sedimentary basins is to estimate isotopic ratios of fluids from which mineral assemblages were precipitated. Isotopic data on minerals together with estimated temperatures from fluid inclusion microthermometry can yield the isotopic ratios of the fluid. In cases where the salinity exceeds about $5.5 \mathrm{wt} \%$, a correction for the "isotope salt effect" must be applied in order to obtain more accurate values for the fluid. We have used our experimental results to correct the oxygen isotope compositions of fluids responsible for quartz and calcite deposition in low-sulfidation epithermal systems from Mexico. These paleo-geothermal systems range in temperature from 170 to $320^{\circ} \mathrm{C}$ with salinities up to $20 \mathrm{wt} \%$ eq. $\mathrm{NaCl}$. Corrections of approximately $1 \% \circ$ are estimated for the highest temperature-highest salinity data.

\section{FUTURE PLANS}

Measurements of oxygen and hydrogen isotope partitioning between vapor and liquid water will be resumed and continued for the system Na-K-Mg-Ca-Cl-SO${ }_{4}$ to $350^{\circ} \mathrm{C}$, including several mixed salt solutions resembling natural geothermal brines (i.e., Salton Sea). Recently, hot $\left(500^{\circ} \mathrm{C}\right)$, hypersaline ( $40 \mathrm{wt} \%$ salinity) brines rich in $\mathrm{FeCl}_{2}$ were recovered from the Kakkonda geothermal field in Japan. It is very likely that $\mathrm{FeCl}_{2}$ has large isotope effects. Highly concentrated acid waters are encountered in mine drainages, crater lakes, volcanic emanations, and some andesitic geothermal systems. It is known that $\mathrm{HCl}$ and $\mathrm{H}_{2} \mathrm{SO}_{4}$ have large oxygen isotope effects at room temperature, and we plan to examine the effect of these acids at elevated temperatures. It is likely that there exist measurable effects of these salts and acids on liquid-vapor isotope partitioning as found for $\mathrm{NaCl}$ to $350^{\circ} \mathrm{C}$.

It has been noted above that isotopic partitioning between water and coexisting phase (minerals, gases) is substantially affected by pressure as well. Thus, isotope partitioning is determined not only by temperature (T) and the composition of aqueous fluids (X), but also by pressure (P). Isotopic pressure effects, which appear to be significant in the low-pressure range, are especially relevant to geothermal systems, where pressure is around that of vapor saturation. The demonstration of large pressure effects has significant implications for the interpretation of isotopic data obtained from geothermal systems. We will extend our experiments of the effect of pressure and dissolved salts on isotope partitioning between minerals and aqueous fluids to a wide range of P-T-X conditions encountered in geothermal systems. Within wide ranges of each variable, our efforts will be focused on the system brucite-pure water at $200-500^{\circ} \mathrm{C}$ and at $200-8000$ bars, in order to determine pressure effects systematically. Our preliminary results at $200-300^{\circ} \mathrm{C}$ suggest that pressure effects on $\mathrm{D} / \mathrm{H}$ partitioning are possibly larger than those obtained at $380^{\circ} \mathrm{C}$. Pressure effects on ${ }^{18} \mathrm{O} /{ }^{16} \mathrm{O}$ partitioning between brucite and water will also be investigated, using the run products from the experiments already conducted for $\mathrm{D} / \mathrm{H}$ partitioning. 
Experiments on mineral-water isotope exchange in the presence of salts $\left(\mathrm{NaCl}, \mathrm{CaCl}_{2}\right)$ will be extended, in order to investigate and differentiate the effects of pressure and dissolved salts on isotopic partitioning at elevated temperatures. In addition to temperature, pressure, and solution composition, minerals stable in the presence of dissolved salts at given pressures and temperatures will be identified. Calcite $\left(\mathrm{CaCO}_{3}\right)$, strontianite $\left(\mathrm{SrCO}_{3}\right)$, and portlandite $\left(\mathrm{Ca}(\mathrm{OH})_{2}\right)$ are good candidates for investigation based on our extensive experience in isotopic exchange between minerals and fluid. We plan to conduct a few experiments in the system mineral-water-salt to gain knowledge of the isotopic salt and pressure effects at select T-P-X conditions. Possible pressure effects on oxygen isotope partitioning will also be investigated with these minerals.

Aside from the salt and pressure effects on isotopic partitioning between water and other phases, fractionation factors for a number of important phases are simply lacking. The temperature dependence of stable isotope partitioning provides geochemists with a particularly large number of geothermometers, but most of the reliable equilibrium fractionation factors have been obtained experimentally at temperatures well above those appropriate for geothermal systems. We plan to investigate the equilibrium oxygen and hydrogen isotope partitioning between common hydrous minerals (e.g., kaolinite, chlorite, epidote) and water, and the carbon and hydrogen equilibrium exchange among $\mathrm{C}-\mathrm{O}-\mathrm{H}$ gas species at temperatures below $500^{\circ} \mathrm{C}$. These will be directly applicable to many problems encountered in geothermal systems.

\section{INDUSTRIAL INTEREST AND TECHNOLOGY TRANSFER}

\author{
Organization \\ UNOCAL \\ EGI, Univ. of Utah \\ JMC (Japan)
}

\section{Type and Extent of Interest}

Using our results to monitor injection

Using our results for the interpretation of geochemical data from the Geysers

Discussions on isotopic data of hot, hypersaline brines from Kakkonda geothermal field in Japan

\section{REFERENCES}

Horita J., Wesolowski D.J., and Cole D.R. (1993) The activity-composition relationship of oxygen and hydrogen isotopes in aqueous salt solutions: I. Vapor-liquid equilibration of single salt solutions from 50 to $100^{\circ} \mathrm{C}$, Geochimica et Cosmochimica Acta, 57, 2797-2817.

Horita J., Cole D.R., and Wesolowski D.J. (1993) The activity-composition relationship of oxygen and hydrogen isotopes in aqueous salt solutions: II. Vapor-liquid equilibration of mixed salt solutions from 50 to $100^{\circ} \mathrm{C}$ and geochemical implications, Geochimica et Cosmochimica Acta 57, 4703-4711.

Horita J. and Wesolowski D.J. (1994) Liquid-vapor fractionation of oxygen and hydrogen isotopes of water from the freezing to the critical temperature. Geochimica et Cosmochimica Acta 58, 3425-3437.

Horita J., Cole D.R., and Wesolowski D.J. (1994) Salt effects on stable isotope partitioning their geochemical implications for geothermal brines. Proceedings of the 19th Annual Workshop on Geothermal Reservoir Engineering, Stanford University, p285-290.

Horita J., Cole D.R., and Wesolowski D.J. (1995) The activity-composition relationship of oxygen and hydrogen isotopes in aqueous salt solutions: III. Vapor-liquid equilibration of $\mathrm{NaCl}$ salt solutions to $350^{\circ} \mathrm{C}$. Geochimica et Cosmochimica Acta 59, 1139-1151. 
Horita J., Cole D.R., Wesolowski D.J., and Fortier S.M. (1996) Salt effects on isotope partitioning and their geochemical implications: An overview. Proceedings of Todai International Symposium on Cosmochronology and Isotope Geoscience, p33-36.

Cole D.R., Riciputi L.R., Horita J. and Chacko T. (1998) Stable isotope exchange equilibria and kinetics in mineral-fluid systems. In: Proceedings of the 9th International Symposium on Water-Rock Interaction WRI-9, G.B. Arehart and J.R. Hulston, eds. A.A. Balkema Pub., pp827-830. 


\title{
LABORATORY INVESTIGATION OF FRACTURE CLOSURE UNDER HYDROTHERMAL CONDITIONS
}

\author{
Peter Persoff \\ Lawrence Berkeley National Laboratory
}

\begin{abstract}
KEY WORDS
pressure solution, creep, fracture closure, mineral precipitation
\end{abstract}

\section{PROJECT BACKGROUND AND STATUS}

This project continues our studies of the hydrologic properties of geothermal reservoir rocks, using samples obtained in scientific coring projects. In Geysers cores, we found more mineral-filled, impermeable veins than permeable ones. The prevalence of sealed veins (formerly permeable fractures) indicates that the productivity of natural fractures decrease with time as minerals precipitate. The "permeable lifetime" of fractures is especially important in evaluating the long-term effect of geothermal reservoir stimulation by hydro-fracturing with or without sand propping, and predicting the productivity of production and injection wells. We are now starting a study of fracture closure mechanisms under reservoir conditions, using core samples, obtained from a geothermal well in Awinbengkok, Indonesia, that contain natural fractures.

Fractures in the subsurface are held open by asperities, points of rock-to-rock contact. This is true both for small (millimeter-scale) fractures, having open spaces between imperfectly matched rough surfaces with isolated asperities, and for large (meter-scale) fractures or fracture zones that are partially filled with rubble. In general, the lithostatic stress on the rock is greater than the pore pressure, and this unbalanced force provides one of the driving forces for fracture closure. Several mechanisms can potentially cause fractures to close. One of the goals of this project is to identify which ones are important in geothermal reservoirs.

Within the rock itself, the rock may break or creep to close fractures. In addition to these phenomena, it is paradoxical that both dissolution and precipitation can cause fracture closure. Precipitated minerals can fill and close the pore space in the fractures. But dissolution can also close the fractures, if the asperities themselves are dissolved away.

Pressure solution (Rutter 1983) appears to be an important mechanism of fracture closure at geothermal reservoir conditions. Generally pore water is at lower pressure than the solid phase (hydrostatic vs. lithostatic pressure). But depending upon mineral surface charge density, a film of water up to 100 angstroms thick can be held between asperities, where the water pressure equals the solid phase pressure. Because of this elevated pressure, minerals are more soluble in this water film than in the bulk water.

Most previous studies of pressure solution phenomena have been done with pure compounds, and assuming simple geometries. We have assembled an apparatus to carry out the first experiment to investigate these phenomena in a natural fracture under reservoir conditions of temperature, pressure, and mineral heterogeneity.

Because the pressure solution mechanism only acts in water films held between asperities, dissolution is restricted to the asperities. As a result, dissolution of a minute amount of material decreases fracture aperture over a relatively large area. The resulting decrease in permeability is much greater than could be caused by an equivalent amount of mineral precipitation. 
During FY 1998, we completed the analysis of laboratory data from our earlier investigation of Geysers core rock properties. We designed and fabricated a new apparatus to study fracture closure under reservoir conditions. Samples for this study will come from the Awi 1-2 core recently obtained. A specially designed pressure vessel (rated for 23,000 psia at $800^{\circ} \mathrm{C}$ ) has been added to the pressure-pulsedecay permeameter used before for ambient-temperature measurements. The pressure vessel will be heated externally by a tube furnace which can reach $1200^{\circ} \mathrm{C}$.

In our experiments, 1 -inch $(2.5 \mathrm{~cm}) \times 2$-inch $(5 \mathrm{~cm})$ cylindrical samples, that contain natural fractures, will be fitted with endcaps, encased in a titanium membrane, and subjected to $400^{\circ} \mathrm{C}$ temperature and 20,250 psi confining pressure. A core-test system of computer-governed pumps controls confining pressure, pore pressure, and flow rates. Water flowing through the sample is pre-equilibrated with the solid phase at experimental conditions within the pressure vessel; flow direction is reversible to permit long flowing runs without undersatured water contacting the fracture walls. Pressure drop across the fracture is expected to be initially small, but will increase dramatically due to fracture closure. Measurement of a small differential pressure at high line pressures requires an extremely rugged but sensitive pressure transducer for permeability determinations. Water will be pumped through the sample at a lower pressure, at about $10,000 \mathrm{psi}$, to simulate hydrostatic pressure. Preliminary calculations have been done to check that, for water at this temperature and pressure, and for fractures of 1 to $100 \mu \mathrm{m}$ aperture, both the flow rate and pressure drop will be within easily measured ranges. Although we are simulating a geological process in the laboratory, the results of Moore et al. (1994) suggest that under these conditions measurable or even dramatic permeability decrease should be observable within one month.

Mineral samples will be examined by X-ray diffraction, scanning electron microscopy and electron microprobe analysis to identify the phases dissolved and precipitated. Water samples will be analyzed for appropriate constituents to measure dissolution rates. The data will be used to calculate kinetic constants for mineral dissolution and precipitation.

\section{PROJECT OBJECTIVES}

The objective of the project is to understand mechanisms that contribute to fracture closure in geothermal reservoirs in general and in Awibengkok, in particular.

\section{Technical Objectives}

- $\quad$ Construct a "map" of temperature-pressure space for a few important minerals (e.g. quartz) showing the areas in which various fracture closure mechanisms dominate.

- Construct a similar map for natural fractures in the Awibengkok 1-2 core and explain reasons for discrepancy from the pure-mineral map.

\section{Expected Outcomes}

- $\quad$ Kinetic data to predict rates of pressure solution of important minerals under geothermal reservoir conditions.

- Develop the ability to approximately predict fracture permeability changes as the result of geothermal reservoir exploitation. 


\section{APPROACH}

The project consists of controlled laboratory experiments using both ideal and natural fractures. Ideal fractures are machined from pure mineral with smooth parallel walls and uniform aperture, propped open at a few points. In natural fractures, the roughness of the fracture walls, the local and average aperture, and the mineralogy are "as received." Experiments will be done at reservoir-relevant conditions of temperature, (pore and confining) pressure, and mineralogy. Essentially, each experiment consists of flowing water through the fracture at a constant rate and observing pressure changes. In an ideal fracture, decrease in permeability can be precisely related to dissolution of the asperities, from which dissolution kinetics can be calculated. Experiments with natural fractures will test how far the theory could be applied to field conditions.

\section{RESEARCH RESULTS}

During FY 1998, the apparatus was under construction (see "Project Background and Status section) and no experiments have been conducted yet.

\section{FUTURE PLANS}

As indicated above, we will conduct several series of experiments on both ideal and natural systems. All results will be reported in reports and scientific papers. Feedback will be sought from industry and other researchers to guide in the selection of future experiment conditions.

\section{INDUSTRY INTEREST AND TECHNOLOGY TRANSFER}

Fracture closure is of great practical importance since aperture controls the amount of fluids allowed to flow through the fractures. The development of deep geothermal reservoirs will depend on the presence of open fractures with enough permeability to sustain commercial-scale fluid flow. .

All companies interested in exploiting geothermal resources located at more than $3-4 \mathrm{~km}$ depth, at temperatures and pressures higher than those encountered in presently developed reservoirs, would like to know how fractures behave under those conditions.

\section{REFERENCES}

Rutter, E.H. (1983). Pressure solution in nature, theory, and experiment. J. Geol. Soc. London, 140, 725740. (An excellent synthesis of the physical processes involved in fracture closure).

Moore, D.E., Lockner, D.A., and Byerlee, J.D. (1994). Reduction of permeability of granite at elevated temperatures. Science, 265, 1558-1561. ( This paper illustrates experimental techniques similar to those to be used in this project). 


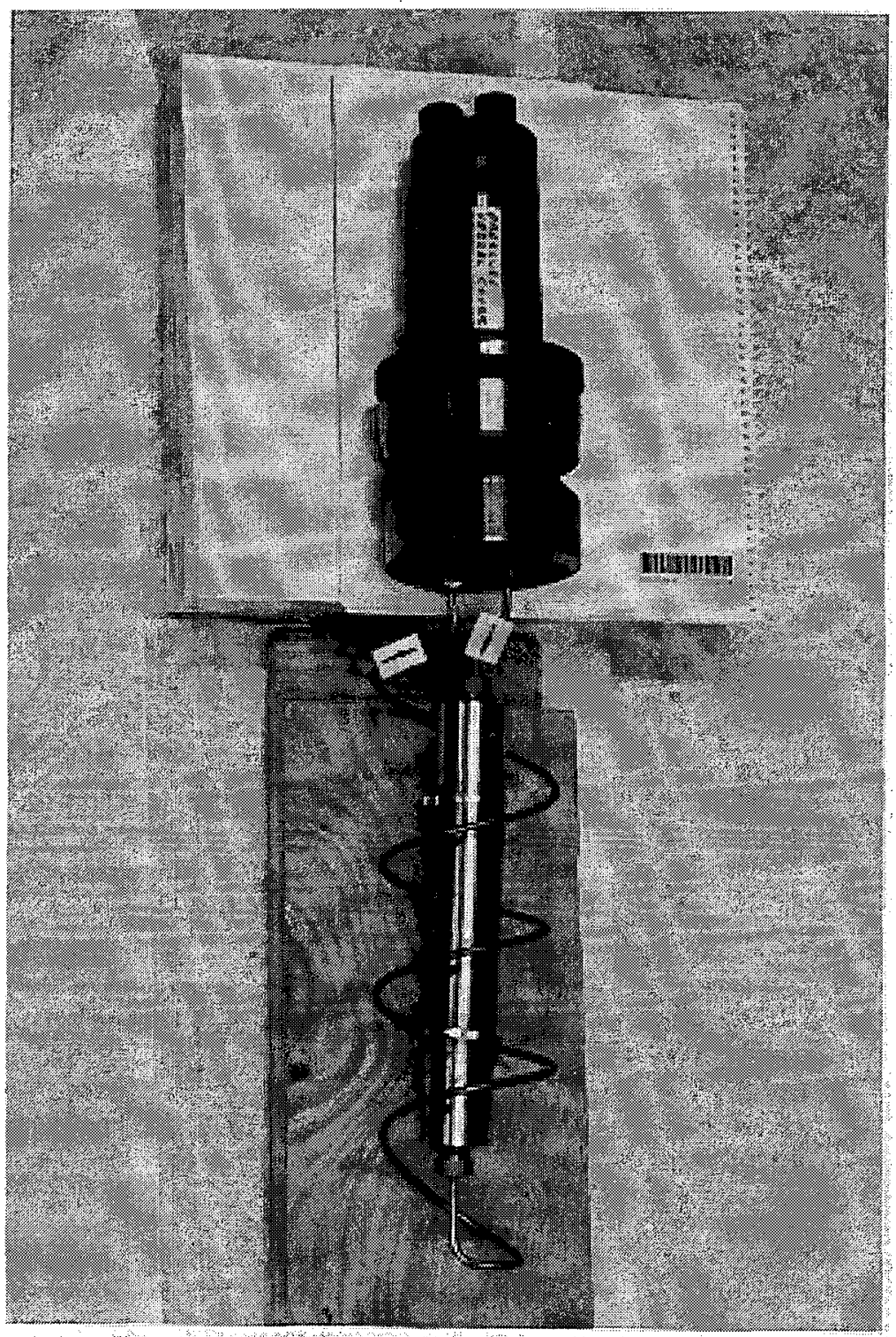

Figure 1. Test Sample, between endcaps inside a thin cylindrical titanium membrane. Pore fluid flows through coiled tubing and through the sample. The sample is attached in this manner to the cover of the pressure vessel. 
( $\therefore$

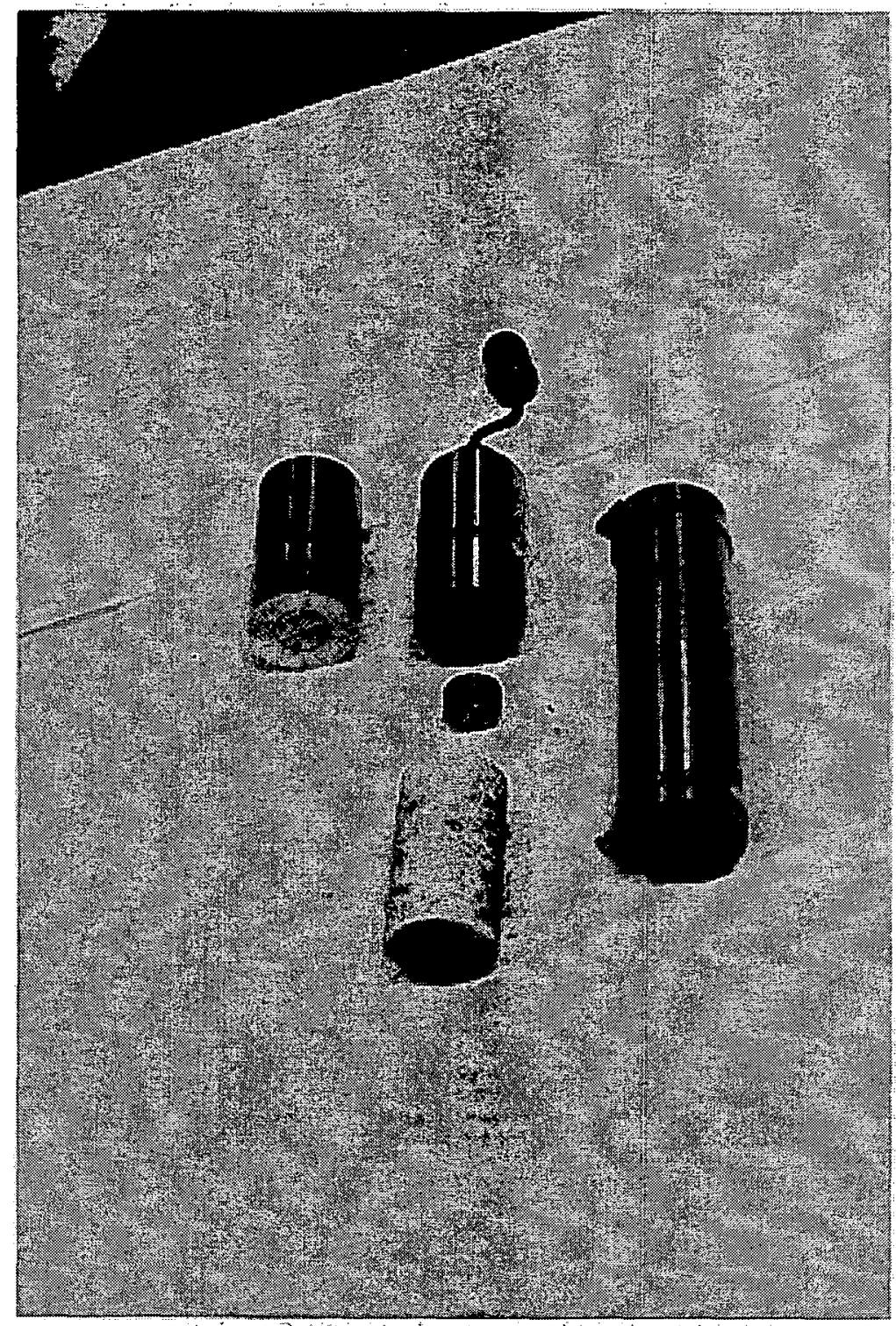

Figure 2. Sample with endcaps and cylindrical membrane. Left: endcap. Center, top to bottom: endcap, with retaining plug removed to expose presaturation chamber, unfractured sandstone sample. Right: Cylindrical titanium membrane, $1 / 200$ inch thick, with clamping rings. 


\title{
LABORATORY MEASUREMENTS ON CORE SAMPLES FROM THE AWIBENGKOK GEOTHERMAL FIELD, INDONESIA
}

\author{
G. N. Boitnott \\ New England Research, Inc.
}

\section{KEY WORDS}

Awibengkok, core measurements, physical properties, velocities, permeability, resistivity, tensile strength, fracture morphology, shear weakening

\section{PROJECT BACKGROUND AND STATUS}

The Awi 1-2 corehole has provided $1.1 \mathrm{~km}$ of continuous core from the Awibengkok geothermal field in Indonesia. The core is representative of volcanic hosted hydrothermal systems which are of increasing importance to the U.S. geothermal industry. A collaborative research effort has been initiated to study this core (see Hulen and Anderson, 1998). As part of this effort, this work has concentrated on making measurements on a representative set of core samples in order to develop a better understanding of the interrelationships between physical properties and petrograpic charateristics. This information will be used to improve interpretations of geophysical observations used for exploration and reservoir monitoring.

\section{PROJECT OBJECTIVES}

The project focuses on development and constraint of physical models to improve interpretations of geophysical observations in geothermal reservoirs. Laboratory measurements are being made to characterize the physical properties of representative core samples. The measurement suite includes porosity, permeability, electrical impedance, elastic constants, velocities, and tensile strength. The data are being used to relate the physical properties to primary rock type, the type and degree of alteration, and mineralogy.

\section{Technical Objectives}

- Make a suite of measurements on representative core samples from the Awibengkok geothermal field and integrate the results with mineralogic and petrographic characteristics.

- Develop and test physical models for rock properties based on the measured data.

\section{Expected Outcomes}

- Improved physical models of rock properties for interpretation of geophysical observations.

- Assessment of the potential value of field seismic observations at Awibengkok and related fields

\section{APPROACH}

A suite of laboratoy measurements are being made on core samples from the AWI 1-2 corehole in order to establish a data set with which to develop and constrain physical models of rock properties. The data set is being used to identify correlations and patterns among the physical properties and petrographic characteristics. The patterns and correlations are then used to guide the development of physical models for the rock properties. 


\section{RESEARCH RESULTS}

Sample Selection:

The AWI 1-2 core contains a wide variety of rock types, including lahars, tuffs, and dacitic and andesitic flow units. A thick microdiorite intrusive is also present. Sampling for this study has concentrated on the dominant lahars and flow units. Three dacite autobreccias, five andesites, and nine lahars were selected, spaning depths from $768 \mathrm{~m}$ to $1819 \mathrm{~m}$. One sample of the microdorite intrusive and one tuff sample were also selected. From these samples, 26 plugs were prepared for testing.

Velocites:

Ultrasonic velocities were meaured as a function of effective confining pressure. In general, the velocities are relatively fast and independent of pressure. Typical pressure dependence is less than $0.1 \%$ per MPa change in confining pressure. Measured shear velocities correlate reasonably well with compressional velocities (Figure 1). Lahars and andesites span an overlapping range of velocities while the dacites (all from similar depths) are slow in comparison. The tuff sample has similar velocities to the dacites and the microdiorite falls within the fast end of the observed values for lahars and andesites. There appears to be little systematics with depth. Correlation between velocities and porosity (not shown) is weak.

The effect of brine saturation on the velocities is characterized by a marked reduction in shear velocity and little effect on the compressional velocities (Figure 2). The results are similar to findings on cores from The Geysers, indicating that a common physical model for these widely different reservoir rocks is appropriate. Like The Geysers cores, the Awibengkok data is fit reasonably well using the modified BiotGassmann poroelastic model originally proposed by Boitnott [1995]. This theory involves the addition of a simple shear weakening term to standard Biot-Gassman theory. Shear weakening is operationally defined as the amount of shear modulus reduction upon saturation. The Awibengkok cores exhibit shear modulus reductions ranging from $1 \mathrm{GPa}$ to over $3 \mathrm{GPa}$, being of similar or slightly greater magnitude than that found for The Geysers cores. The shear weakening is dramatic enough to counteract poroelastic mechanisms which are acting to increase compressional velocities with saturation, resulting in little observed change in compressional velocity with saturation. This has important implications for the design of field seismic studies at Awibengkok and similar fields.

One lahar sample was tested saturated with kerosene as a test to further understand the poroelastic and chemo-mechanical effects of saturation on velocities. No shear weakening is observed upon saturation with kerosene (Figure 3). This suggests that the shear weakening effect is the result of a rock/water chemical interaction of some type. This is consistent with the observations from The Geysers core that shear weakening correlated with illite content. An alternative possibility is that the weakening may result from dissolution of salts upon saturation with brine.

Electrical Resistivity:

Electrical resistivity was measured on selected samples as a function of effective confining pressure and frequency. A systematic decrease in formation factor (sample resistivity divided by brine resistivity) with increasing porosity is observed, but the observed formation factors are relatively high in comparison with other rock-types (Figure 4). Considering the high clay contents of these samples (which should act to lower formation factors), the relatively high F may indicate a significant fraction of the pore space is not contributing to electrical conduction. This may reflect the heterogeneous nature of the cores. 
Permeability:

Brine saturated permeabilities were measured on 6 lahars and 1 andesite as a function of effective confining pressure. Despite the high porosities, the measured permeabilities are very low (on the order of 0.1 to 1 microdarcies), and exhibit little pressure dependence. One lahar sample (depth $1551.8 \mathrm{~m}$ ) exhibited a relatively high permeability ( 151 microdarcies) in comparison with the other samples. This sample exhibits a different alteration texture from the other samples tested.

Tensile Strength:

Tensile strength was measured using the Brazil method on three dry lahar samples. Tensile strengths are highly variable and apparently not correlated with porosity. Measured tensile strengths ranged from 3.6 $\mathrm{MPa}$ to $10.6 \mathrm{MPa}$, thus spanning values typical of Berea sandstone (3.5 $\mathrm{MPa}$ ) and Barre Granite $(10.3 \mathrm{MPa})$. Both the most porous (18.6\%) and least porous (12.2\%) samples had similar tensile strengths (10.6 and $9.9 \mathrm{MPa}$ respectively), while the sample with intermediate porosity (17.2\%) was considerably weaker (3.6 MPa).

Observations of fracture morphology indicate that fracture roughness is influenced by heterogeneity, but that visible heterogeneity does not always correspond to mechanical heterogeneity. In general the fractures propagate through (rather than around) the visible heterogeneities in the samples.

The results also suggest that lithology may be an important factor in controlling fracture morphology. One of the lahar samples contained a large andesite pebble which was split by the propagating tensile fracture. The fracture in the andesite pebble is very smooth and straight, in stark contrast to the rough, sinuous fracture plain in the lahar matrix. It is also interesting to note that the tensile fractures propagate around disseminated pyrite crystals, leaving euhedral crystals standing on the fracture plain. These types of observations are being used to develop and understanding of the variables important in controlling fracture generation, fracture growth, and fracture properties.

\section{FUTURE PLANS}

More work has been proposed, focusing on establishing a more complete data set, developing a physical understanding of the shear weakening phenomena, characterizing core scale heterogeneity of mechanical and electrical properties, and applying the results to field scalable models for interpretation of geophysical observations.

\section{INDUSTRY INTEREST AND TECHNOLOGY TRANSFER}

\section{Organization}

Unocal, Calpine etc

LLNL LBL

\section{Type and Extent of Interest}

General interpretation of geophysical measurements geothermal reservoirs

Support of geophysical research and development.

\section{REFERENCES}

Boitnott, G. N., Laboratory measurements on reservoir rocks from The Geysers geothermal field, in Proceedings $20^{\text {th }}$ Workshop on Geothermal Reservoir Engineering, Stanford University, Stanford, California, January 1995. 
Boitnott, G. N., and P. Boyd, Laboratory measurements in reseroir rocks from The Geysers geothermal field, in Proceedings $21^{\text {st }}$ Workshop on Geothermal Reservoir Engineering, Stanford University, Stanford, California, January 1996.

Hulen, J. B., and T. D. Anderson, The Awibengkok, Indonesia, geothermal research project, in Proceedings $23^{\text {rd }}$ Workshop on Geothermal Reservoir Engineering, Stanford University, Stanford, California, January 26-28, 1998. 

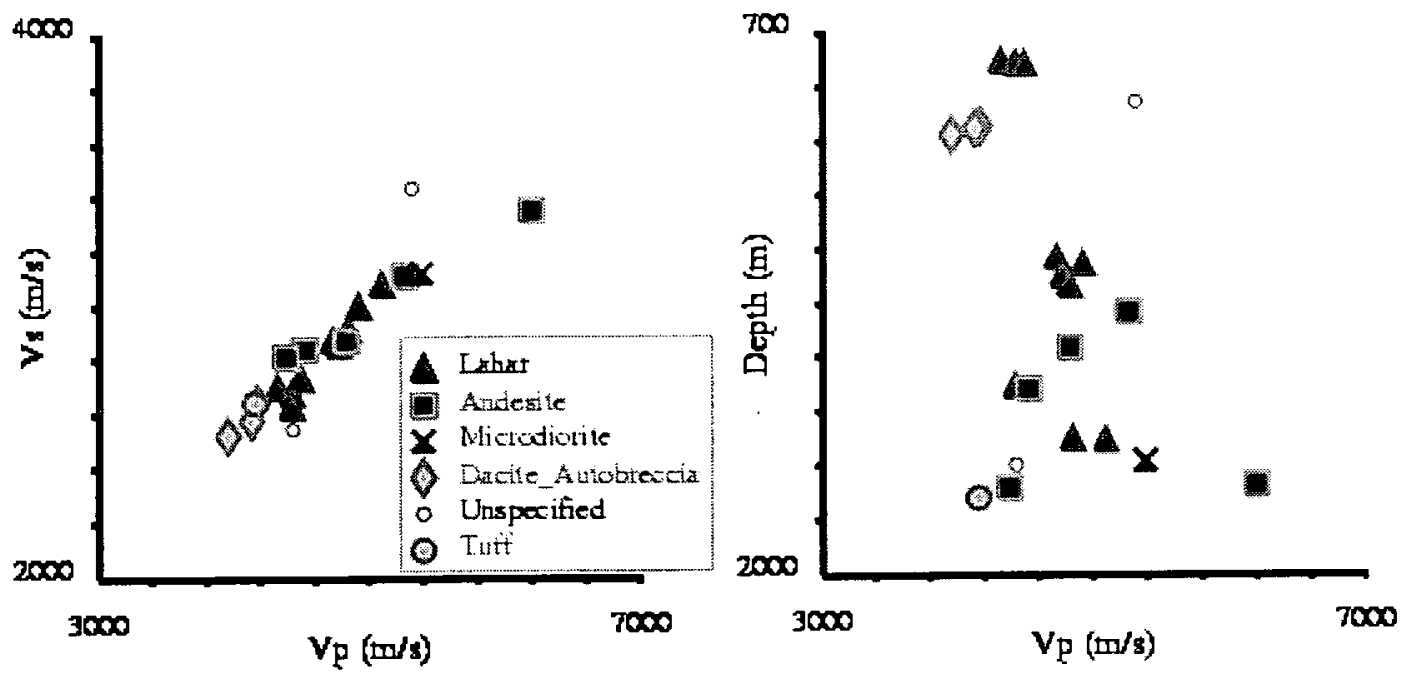

Figure 1. Summary of velocity data on AWI 1-2 samples. Vp correlates reasonably well with Vs, but there is no apparent trend in the velocities with depth. Lahars and andesites span similar variation in velocities.
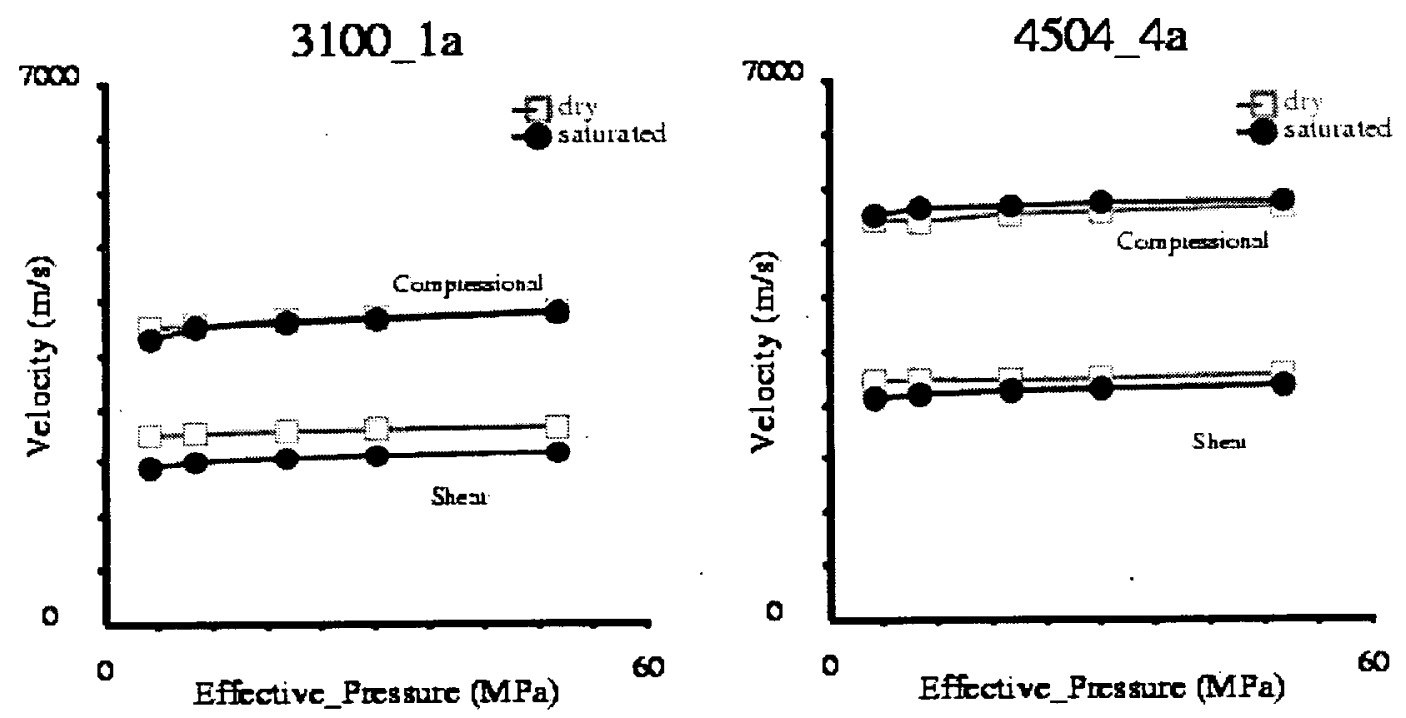

Figure 2. The effect pressure and brine saturation on two representative samples from AWI 1-2. There is little pressure effect on the velocities. Brine saturation leads to a modest reduction in shear velocities and little effect on the compressional velocities. 

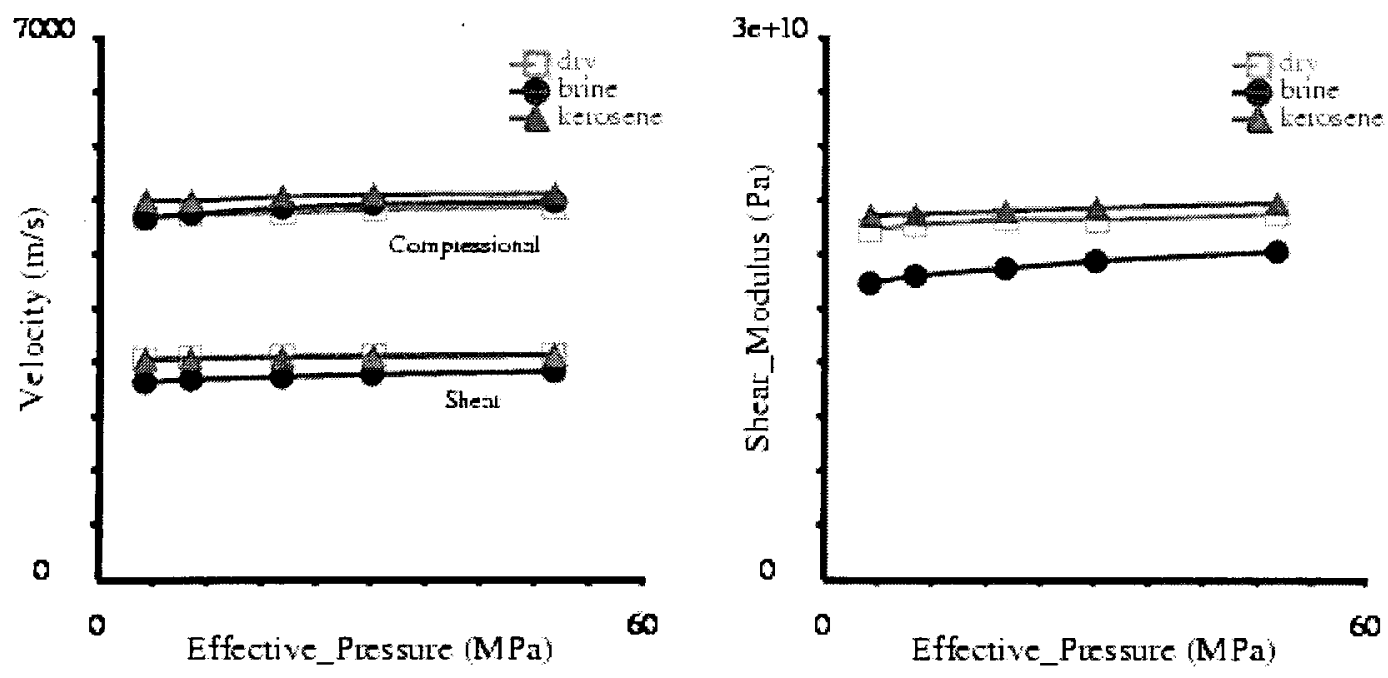

Figure 3. Comparison of dry, brine saturated, and kerosene saturated velocities and dynamic shear moduli for a lahar sample from AWI 1-2.

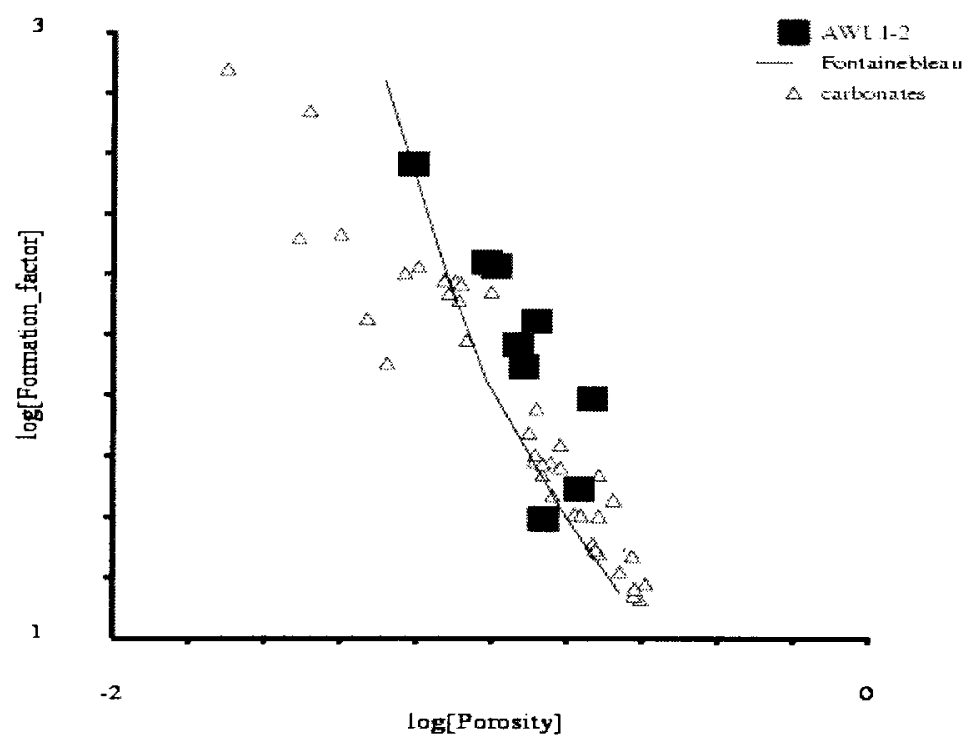

Figure 4. Formation Factor vs. porosity for selected AWI 1-2 samples compared with data for Fontainebleau sandstone and middle eastern carbonates. Note that the AWI 1-2 samples have relatively high formation factors for their porosities. 


\title{
STEAM-WATER RELATIVE PERMEABILITY IN GEOTHERMAL ROCKS
}

\author{
Roland N. Horne \\ Stanford University
}

\section{KEY WORDS}

Relative permeability, steam-water, phase change, X-ray CT scanner

\section{PROJECT BACKGROUND AND STATUS}

The reliable measurement of relative permeability functions for steam-water flows in porous media is of great importance for reservoir simulation in order to forecast production performance of geothermal reservoirs. Despite their importance, these functions are poorly known due to the lack of understanding of steam-water flows, and to the difficulty of making measurements. Traditionally, these functions are taken directly from isothermal, immiscible gas-liquid displacement processes. However, the use of such functions is not appropriate because these processes do not involve the two important phenomena pertinent to steam-water flows: heat transfer and phase change. Therefore, the objective of this research project is to determine the appropriate relative permeability functions for steam-water flows in geothermal reservoirs, as well as to investigate their properties as a function of temperature and flow rate.

In earlier stages of the project we have measured steam-water relative permeabilities successfully in high permeability rocks (Berea sandstone). These measurements demonstrated that relative permeability in boiling flow is distinctly different than in the flow of immiscible fluids (such as oil and water). In more recent experiments, we have been attempting to refine the experimental procedures and apparatus to verify repeatability of the results and to investigate the influence of temperature and flow rate on the relative permeability behavior. These new experiments are ongoing.

\section{PROJECT OBJECTIVES}

\section{Technical Objectives}

- To measure the steam-water relative permeabilities in rocks, in order to provide reasonable relationships for use in the simulation of actual reservoir performance.

- To determine the fundamental flow behavior of two-phase boiling flow in real rocks.

\section{Expected Outcomes}

- A set of experimental relative permeability curves that can be used in reservoir simulation. Applying the correct behavior in simulation could make a difference in the calculated performance by as much as $50 \%$ of total production -- hence the value in measuring relative permeability is a substantial increase in the certainty of prediction of reservoir performance.

- A set of relationships to determine the variation of relative permeability as a function of reservoir and flow conditions. Providing the correct relationships will improve the certainty of reservoir performance predictions. 


\section{APPROACH}

The relative permeability concept is used widely to describe multiphase fluid transport through the porous and fractured rocks that represent the main fabric of geothermal reservoirs. Relative permeability is a dimensionless measure of permeability to individual phases in the presence of other phases during multiphase flow in a porous medium. Typically, relative permeability to each phase is described in a functional form, traditionally as a function of one of the fluid saturations. Good literature reviews on the subject can be found in Satik et al. (1995) and Ambusso et al. (1996). These reviews indicate a wide range of discrepancy in the previous experimental results. The main reason for this has been identified as the difficulty in measuring saturations accurately and using incorrect pressure gradients to compute relative permeability (Ambusso et al., 1996). We have developed the capability to overcome these difficulties by using an X-ray CT (computer tomography) scanner to measure saturation accurately and by evaluating pressure gradients within the constant saturation regions only.

\section{RESEARCH RESULTS}

In 1996 we reported our first successful steam-water flow experiments where significant improvements were achieved in measuring saturations and collecting pressure data (Ambusso et al., 1996). The results obtained from the first experiment suggested a linear relationship for steam-water relative permeability. This result was presented at national technical meetings, and response from the industry was encouraging.

The difficulty with the 1996 results arose from the fact that mechanical problems with the nonmetallic core-holders meant that the rock samples were essentially destroyed during the course of the experiment. This made it impossible to undertake the standard scientific test of repeatability of the results. More recent improvements in the core-holder design have allowed us to make repeat measurements on the same core, however unfortunately the results of duplicated experiments revealed that the measured values were not in fact repeated. The source of the new difficulty was determined to lie in the problem of ascertaining the independent flow rates of steam and water, since the X-ray tomography is only able to measure the inplace (or static) saturation. The method used to estimate the steam and water flow rates required the careful monitoring of heat input and loss in the experimental apparatus in order to determine the flowing enthalpy of the fluid and hence the steam/water ratio. Cumulative inaccuracies in measuring the heat losses resulted in the ultimate uncertainty in the relative permeability values inferred from them.

\section{FUTURE PLANS}

Although the experimental challenges involved in measuring steam-water relative permeability are daunting, the experience of the Stanford Geothermal Program and the facilities available to us provide expectation that the difficulties will be overcome. Unlike oil-water relative permeability, which is measured routinely in the oil business, steam-water flow is rendered much more complicated by the fact that the two flowing fluids, steam and water, can and do interchange freely by the processes of boiling and condensation. Measuring the in-place saturation using the X-ray CT scanner and using the pressure measurements over the section of the core that shows constant saturation obviates the phase interchange problem. Accurate measurement of the flowing saturation is a new challenge, since it requires the estimation of the enthalpy. Although the determination of enthalpy has proven problematic, the use of thin-film guard heaters will alleviate this difficulty considerably since it will become possible to measure the enthalpy prior to injection into the core with the knowledge that the enthalpy will not change during transport. 
The targets of the project will be two:

(a) The measurement of steam-water relative permeability of a high permeability rock sample in an adiabatic flow apparatus. The experiments will examine repeatability of the values and will compare them to nonboiling multiphase flow (for example air and water) to isolate the effects of phase transfer on the relative permeability phenomenon. If time permits, we will also address the issue of the effects of temperature and flow rate on steam-water relative permeability.

(b) The measurement of end-point saturation values in a low permeability geothermal rock sample. This experiment will take place over a longer period of time, and will be a static (or pseudostatic) rather than a flowing experiment. The low end-point values will be estimated by reducing the water saturation in the rock to its irreducible value, with a direct measurement of the saturation using the X-ray CT scanner. The high end-point values will then be estimated by resaturating the rock with water to find the saturation at which no more steam can be removed. Again, the saturation will be measured directly using the X-ray CT scanner.

\section{INDUSTRY INTEREST AND TECHNOLOGY TRANSFER}

In a recent DOE research strategy meeting, one industry participant made the observation that he had not until that time had any confidence in the values of relative permeability that had been used in the industry and therefore that he considered the Stanford results to be very welcome.

Organization

Maxwell Technologies

\section{Type and Extent of Interest}

Proposed use of curves in reservoir simulations

\section{REFERENCES}

Ambusso, W.J., Satik , C. and Horne, R.N. (1996). Steam-water relative permeability. 1996 Geothermal Resources Council Transactions, Vol. 20, p. 783-795.

Finsterle S., Satik C., and Guerrero M., (1998). "Analysis of Boiling Experiments Using Inverse Modeling, Proc. of 1st ITOUGH2 Workshop, Berkeley, California.

Satik, C., Ambusso, W.J., Castanier L.M. and Horne, R.N., (1995). A Preliminary Study of Relative Permeability in Geothermal Rocks, Geothermal Resources Council Transactions. Vol. 19, p. 539-546.

Satik C. (1997), "A Study of Boiling in Porous Media", Proc. 19th New Zealand Geothermal Workshop, Auckland, NZ.

Satik C. (1998), “A Measurement of Steam-Water Relative Permeability”, Proc. of 23rd Workshop on Geothermal Reservoir Engineering, Stanford, Calif.

Tovar, R.A. (1997). Measurements of Relative Permeability for Steam-Water Flow in Porous Media. MS Thesis, Stanford University, Stanford, CA 


\title{
WATER ADSORPTION
}

\author{
Miroslaw S. Gruszkiewicz, Juske Horita, J. Michael Simonson, and Robert E. Mesmer \\ Oak Ridge National Laboratory
}

\section{KEY WORDS}

geothermal reservoir, adsorption, The Geysers, Awibengkok, rocks, porous materials

\section{PROJECT BACKGROUND AND STATUS}

Any reliable model of the behavior of vapor-dominated geothermal reservoirs must include information about the amount of water retained on the surface of the rocks by adsorption and by capillary forces. All porous materials, including rocks, can retain water as multi-layer adsorbate on all of their internal surfaces, as pore-filling adsorbate in the micropores (widths up to about $20 \mathrm{~A}$ ) and as multi-layer adsorbate and capillary condensate in the mesopores and macropores (widths up to about $1000 \mathrm{~A}$ ). This retained water has a density close to the density of bulk liquid even if the temperature and pressure in the reservoir are in the superheated steam region. To estimate the size of the available resource and to predict pressure changes during operation it is important to know what fraction of the water is present in the reservoir as adsorbed layers and as capillary condensate with an equilibrium vapor pressure lower than that of bulk water. In liquid-dominated reservoirs, such as the Awibengk geothermal field, West Java, Indonesia, vapor-dominated conditions may exist in native steam caps which expand during reservoir exploitation. Ideally, in such reservoirs, injection would be placed deep in the liquid zone, while the steam would be produced from the shallow steam and two-phase zones. Operating experience suggests that the water adsorbed in the pore system may act as either a source or a potential sink directly influencing the response to both production and reinjection. This response may be influenced by adsorption/desorption hysteresis. The same surface forces and pore system properties that cause vapor pressure lowering and water condensation on solid surfaces are also involved in the transport and separations of artificial tracers and natural components of geothermal fluids. Thus information obtained in studies of water adsorption can be useful in solving a wide range of issues where the solid-liquid interface plays an important role.

Since the physicochemical complexity of geothermal rocks makes it impossible to predict their water retention at different temperatures and pressures with a reasonable certainty, the most useful data would be those obtained at temperatures in the vicinity of the actual reservoir temperatures. The temperature in most of The Geysers reservoir is approximately $240^{\circ} \mathrm{C}$, and a higher temperature reservoir is found in the northwest area of the field. The temperatures measured in several Awibengkok wells range from $225^{\circ} \mathrm{C}$ to $285^{\circ} \mathrm{C}$. The experimental data on water adsorption/desorption published in the literature have been limited to about $150^{\circ} \mathrm{C}$, with most of the experiments conducted at $120^{\circ} \mathrm{C}$ or $130^{\circ} \mathrm{C}$ and below.

This project was undertaken in order to expand significantly our knowledge of the adsorption/desorption processes useful for operating geothermal reservoirs. The following work has been completed in this project:

- The Oak Ridge National Laboratory (ORNL) isopiestic apparatus was extensively overhauled and modifications were made to achieve the highest possible accuracy.

- The $150^{\circ} \mathrm{C}, 200^{\circ} \mathrm{C}$ and $250^{\circ} \mathrm{C}$ adsorption and desorption isotherms in the relative pressure range from vacuum to saturation were determined for 12 rock samples in three grain size fractions taken from three wells at the Geysers geothermal system, and for four pure mineral samples. 
- Mercury intrusion porosimetry and low temperature nitrogen adsorption/desorption analyses were performed on representative samples from The Geysers by Micromeritics laboratories. BET specific surface areas, pore size distributions and total porosities of the samples before and after high temperature adsorption measurements were obtained.

- The experimental data were reduced by fitting isotherms to empirical correlations of the amount of water retained as a function of relative pressure. Approximate pore size distributions were calculated from the water adsorption/desorption isotherms.

- A paper describing the results on The Geysers core samples was accepted for publication in Geothermics.

- The isopiestic apparatus was upgraded by installing new, very precise quartz pressure gauges.

- Samples were obtained for the next high-temperature adsorption run. These include mainly well core samples from the Awibengkok field.

\section{PROJECT OBJECTIVES}

\section{Technical Objectives}

- Experimental determination of water retention capacities on geothermal rocks as a function of vapor pressure at temperatures from $150^{\circ} \mathrm{C}$ to $250^{\circ} \mathrm{C}$ when pressure is increasing ('adsorption' isotherms) and decreasing ('desorption' isotherms).

- Characterization of the rocks using high-temperature water adsorption results, mineralogical descriptions, and low temperature nitrogen adsorption data.

- Correlation of the water retention phenomena in the reservoirs with rock characteristics and T-p conditions.

\section{Expected Outcomes}

- Obtain accurate and reliable water retention data for representative core samples at the reservoir temperature (for the first time). These data, including hysteresis behavior, will be available for use in reservoir models and in injection/production simulations.

- Resolve the issue of the temperature dependence of the amount of water retained.

- Determine the predominant water storage mechanism and the best way to model adsorption.

- Expand the available knowledge about the structure of the rocks and about rock-water interactions. Gain insights into both chemical and physical rock surface-water interactions that are present in geothermal reservoirs.

\section{APPROACH}

The ORNL high-temperature isopiestic apparatus is a unique facility capable of precise and accurate measurements of the change of mass of a sample under high temperature-high pressure conditions. This capability makes it suitable for measurements of adsorption by materials characterized by small specific surface areas. The parameter measured is the mass of the solid as a function of vapor pressure. The 
sorptometers that have been used most often rely on measurements of vapor pressure in a chamber of known volume containing the sample. The total volume of the instrument is kept small to increase its sensitivity to relative pressure changes, but the small volume also makes the instrument more sensitive to leaks, temperature variation, and errors in calibration of the internal volumes. In the isopiestic apparatus the mass is measured directly in situ by comparison with a set of standard weights placed inside the pressure vessel together with the samples. The densities of the samples, which must be known in order to correct the results for the effect of buoyancy, are measured inside the isopiestic apparatus by weighing the samples in vacuum and then in the atmosphere of a compressed gas (e.g. Ar) of known density. The large volume of the isopiestic vessel (about 28 liters) makes the method relatively insensitive to leaks. These characteristics make it relatively easy to evaluate the time needed for reaching equilibrium, as the samples may be left under the same vapor pressure for many days and the change of mass with time can be monitored. The isopiestic apparatus is capable of, and has been previously used for, measurements to $250^{\circ} \mathrm{C}$ and 40 bar.

In conjunction with the high temperature water adsorption measurements, multipoint BET surface area analyses using nitrogen adsorption measurements at $77 \mathrm{~K}$, and mercury porosimetry analyses were performed on the same rock samples by Micromeritics using state-of-the-art cryogenic sorptometers and high-pressure porosimeters in order to obtain information on specific surface area, total pore volume, and pore size distribution. With the pressure range from vacuum to 60,000 psia the mercury intrusion technique covers pores from $3 \mathrm{~nm}$ to over $100 \mu \mathrm{m}$, while low temperature adsorption is a well-developed standard method for determination of specific surfaces and provides the most accurate information about pores up to roughly $50 \mathrm{~nm}$.

Scanning electron microscopy is also used to examine the structure of the samples and detect possible changes in the structure and the composition of the samples caused by exposure to steam at high temperature. Such changes are expected to be found, since both nitrogen adsorption and mercury porosimetry results indicated that the pore structure had changed after water adsorption experiments.

\section{RESEARCH RESULTS AND VARIANCES}

Since the isopiestic facility is used on the time-share basis together with other programs sponsored by DOE, no high-temperature water adsorption measurements were made during 1998. A series of measurements of vapor pressure over concentrated brines including $\mathrm{CaCl}_{2}$ was carried out at temperatures between $100{ }^{\circ} \mathrm{C}$ and $250{ }^{\circ} \mathrm{C}$, and this work has significant implications for the partitioning of acid chlorides due to hydrolysis of calcium ion at high molalities. One of us participated in the inaugural workshop on the Awibengkok, Indonesia, geothermal research project in Salt Lake City. The meeting was an opportunity to present our planned experimental high-temperature water adsorption study, and learn about the Awibengkok reservoir and some of the characteristics of AWI 1-2 well core. After this meeting we selected and have now received all the samples necessary for the next series of water adsorption measurements.

The apparatus was further improved by installing several new components. The new pressure measurement system is at least an order of magnitude more accurate and much more reliable than the gauges used in our earlier water adsorption measurements. During the tests it was discovered that the new pressure gauges need to be protected from ambient temperature changes to assure the highest accuracy. A constant temperature oven is now being installed for this purpose. Voltage stabilization for the optical position detection device was also added. After completing the isopiestic and vapor pressure run, the electromagnetic balance was disassembled and tuned, and steel ribbon suspension was replaced.

The performance of the isopiestic apparatus during the last run and the new improvements lead us to expect even better results in future runs than obtained for The Geysers well core samples. 
The paper describing the final results for The Geysers samples was accepted for publication in a special issue of Geothermics.

\section{FUTURE PLANS}

We are now ready to start the next high-temperature water adsorption run focused on representative samples from the continuous core obtained by DOE from the Awibengkok (Indonesia) geothermal system operated by Unocal. The study of water adsorption on samples from this core will be a part of an extensive, multidisciplinary research program. Several samples from The Geysers will be included in order to resolve some interlaboratory discrepancies.

We are also planning to include a few naturally occurring zeolite samples as a collaboration with the group of Prof. Barnes at Pennsylvania State University. A pioneering study of adsorption of water on these materials at elevated temperatures is expected to provide valuable information on their fundamental properties and structure. Zeolitic materials (wairakite) were also found in the Awibengkok core.

\section{INDUSTRY INTEREST AND TECHNOLOGY TRANSFER}

Results of this study were presented at two Annual Stanford Geothermal Reservoir Engineering Workshops in Stanford, California (1996 and 1998). They were also presented during two DOE Geothermal Program Reviews. Papers were published in the proceedings of these meetings. The interest of the geothermal industry in continuing water adsorption studies was confirmed during the meeting of ORNL research staff with geothermal industry representatives in Santa Rosa, California in the end of January 1998. The knowledge of adsorption/desorption isotherms including hysteresis loops is considered essential in modeling the behavior of geothermal reservoirs and especially their response to reinjection.

\section{REFERENCES}

Gruszkiewicz, M. S., Horita, J., Simonson, J. M, Mesmer, R. E. (1996) "Measurements of water vapor adsorption on The Geysers rocks," Proceedings, Twenty-First Workshop on Geothermal Reservoir Engineering, Stanford University, Stanford, CA, January 22-24, 1996, 481-487

Gruszkiewicz, M. S., Horita, J., Simonson, J. M, Mesmer, R. E. (1997) "High temperature water adsorption on The Geysers rocks," Proceedings of the Geothermal Program Review XV, US DOE, Office of Geothermal Technologies, March 24-26, 1997, San Francisco, California, pp. 2-15 - 2-23.

Gruszkiewicz, M. S., Horita, J., Simonson, J. M, Mesmer, R. E. (1998) "Water adsorption at high temperature on core samples from The Geysers geothermal field," Proceedings, Twenty-Third Workshop on Geothermal Reservoir Engineering, Stanford University, Stanford, CA, January 26-28, 1998, 110-119

Gruszkiewicz, M. S., Horita, J., Simonson, J. M, Mesmer, R. E. (1998) "Water adsorption at high temperature on core samples from The Geysers geothermal field," Proceedings of the Geothermal Program Review XVI, US DOE, Office of Geothermal Technologies, April 1-2, 1998, Berkeley, California (in press).

Gruszkiewicz, M. S., Horita, J., Simonson, J. M, Mesmer, R. E., and Hulen, J. B. (1999) "Water adsorption at high temperature on core samples from The Geysers geothermal field, California," Geothermics, (in press) 


\title{
THE TWIN FALLS REGIONAL GEOTHERMAL SYSTEM: CHANGES DUE TO OVER UTILIZATION
}

\author{
R. H. Mariner \\ U.S. Geological Survey, Mail Stop 434, 345 Middlefield Road, Menlo Park, CA 94025 \\ H. W. Young \\ U.S. Geological Survey, 230 Collins Road, Boise, ID 83702-4520
}

\section{KEY WORDS}

geochemistry, stable isotopes, water composition, low-temperature geothermal, regional geothermal system

\section{PROJECT BACKGROUND AND STATUS}

Thermal fluids occur at many locations along virtually the entire length of the Snake River Plain in southern Idaho. In south-central Idaho, thermal waters occur principally between the Snake River and the mountains of northern Nevada. Topographically the area consists of a plain which slopes gently upwards from the river to the mountains. Numerous wells scattered over the plain draw thermal fluid from a geothermal system of regional extent. Wells in the northern part of the plain are drilled into Tertiary rhyolite (Idavada Volcanics). Wells in the southern part of the plain are drilled into Paleozoic limestone. Sodium-bicarbonate type waters of high $\mathrm{pH}$ are recovered from wells in rhyolite. These waters are also high in silica and fluoride. Calcium-bicarbonate and calcium-sodium-bicarbonate type waters of near neutral $\mathrm{pH}$ are recovered from wells in limestone. These waters are especially low in silica and fluoride (Lewis and Young, 1982; Mariner, and others, 1991). Although most waters range in temperature from $25^{\circ}$ to $50^{\circ} \mathrm{C}$, a few wells produce $70^{\circ} \mathrm{C}$ water. Well depths range from 350 to 2,200 feet (Lewis and Young, 1982). Mariner and Young (1995) used lead isotopes to prove that all thermal waters in the area circulate principally or entirely through one particular Paleozoic limestone. None of the waters have circulated solely in Tertiary rhyolite. The waters recovered from the rhyolite have reacted sufficiently with the Tertiary rock to achieve the chemical characteristics typical of thermal waters in rhyolitic/granitic rock. As a result of increased utilization, well-head pressures have declined as much as 25 pounds per square inch ( 60 feet of water head), and some previously flowing wells must now be pumped.

To determine if over utilization was causing changes in the chemical, isotopic, and thermal characteristics of the geothermal system, it was proposed that the same wells that we sampled in our 1991 report be resampled. A student from the University of Idaho was to do the water sampling as part of his Master's thesis and we (USGS) were to provide chemical and isotopic analyses. All analyses have been completed and the results transmitted to the student

\section{PROJECT OBJECTIVES}

\section{Technical Objectives:}

- Use new chemical, isotopic, and thermal data to detect systematic changes in the system.

\section{Expected outcomes:}

- Demonstrate that one or more constituents or variables are changing in systematic ways. 
- Document chemical, isotopic, and thermal changes in the system as it responds to stress.

- Provide a snapshot of the chemical, isotopic, and thermal characteristics of the system so that trends can be followed over the life of the system.

\section{APPROACH}

Obtain high quality chemical and isotopic data for waters collected from wells in south-central Idaho and north-central Nevada. Samples will be collected from sites which have been sampled previously. Chemical, isotopic, and thermal data can be used to detect changes in the system brought about by overproduction. Pressure declines could cause changes in the locations of boundaries between the different dominant water types (limestone water, rhyolite water, or shallow ground water). Also, temperature variations could result in changes in specific dissolved constituents.

\section{RESEARCH RESULTS AND VARIANCES}

New data are identical or virtually identical to older data at about $82 \%$ of the sites. The other five sites $(18 \%)$ generally show increases in several or all of the following: chloride, sulfate, nitrate, calcium, and sodium. Where the deuterium changes, it becomes less depleted. Less depleted deuterium and more nitrate and chloride are particularly characteristic of the shallow ground water. Sites with increased nitrate and chloride correspond to areas of greatest thermal water usage (in and near Twin Falls and Buhl). It appears that decreases in heads pressure in these areas have permitted shallow ground waters to mix with the thermal waters coming from greater depths. With time, it is anticipated that these trends will continue.

\section{FUTURE PLANS}

Documenting chemical changes associated with withdrawal rates would permit prediction of coming changes in the system. However, the state of Idaho does not currently collect the withdrawal rate data that is needed to interpret causes for the observed chemical changes.

\section{INDUSTRY INTEREST AND TECHNOLOGY TRANSFER}

University of Idaho

Moscow, ID

College of Southern Idaho

Twin Falls, ID

Aqua culture operations

Greenhouse operations (plants to cut flowers)
Graduate student obtained field experience

and data for Master's thesis.

This study documented changes in the system related to decreased head pressures which have required installation of turbine pumps to maintain production of sufficient water for space heating.

Continuing declines in head pressure will be detrimental to aqua culture that relies on artisan flows. Pumping costs make aqua culture noneconomic in this area.

Continuing decline will impact greenhouse operations which rely on both artisan flow and water temperatures.

\section{REFERENCES}

Lewis, R. E., and Young, H. W., 1989, The hydrothermal system in central Twin Falls County, Idaho:

U.S. Geological Survey Water-Resources Investigations Report 88-4152, p. 44. 
Mariner, R. H., Young, H. W., Evans, W. C., and Parliman, D. J., 1991 Chemical, isotopic, and dissolved gas compositions of the hydrothermal system in Twin Falls and Jerome counties, Idaho: Transactions of the 1991 Geothermal Resources Council Annual Meeting, v. 15, pp. 257-263.

Mariner, R. H., and Young, H. W., 1995, Lead and strontium isotope data for thermal

waters of the regional geothermal system in the Twin Falls and Oakley areas, south-central Idaho:

Transactions of the 1995 Geothermal Resources Council Annual Meeting, v. 19, pp. 207-210.

Young, H. W., and Lewis, R. E., 1982, Hydrology and geochemistry of thermal ground water in southeastern Idaho and north-central Nevada: U.S. Geological Survey Professional Paper 1044-J, p. 20. 


\title{
COVE FORT RESOURCE EVALUATION
}

\author{
K. K. Bloomfield \\ Idaho National Engineering and Environmental Laboratory \\ M. C. Adams \\ J. N. Moore \\ Energy and Geoscience Institute
}

\section{KEY WORDS}

tracers, numerical simulation

\section{PROJECT BACKGROUND AND STATUS}

The Cove Fort-Sulphurdale geothermal system consists of a small vapor-cap and an underlying liquiddominated system. Exploration of this system began in the 1970's by Unocal, but it was not until the late 1980 's that the field was brought into production. It is currently owned and operated by Utah Municipal Power Agency (UMPA) as a source of electricity for Utah municipalities. Essentially all of the production data on the field has been made available to DOE for their investigations. In addition, a significant geologic, geophysical and geochemical database developed by DOE researchers and private companies is available. Although a good conceptual understanding of the geothermal system has been developed, no detailed reservoir engineering models, which can be used for field development, are available.

A preliminary numerical model for the Cove Fort-Sulphurdale geothermal system was constructed. A successful production history match exercise was performed with limited reservoir measurements. The history match model was then used to examine tracer test design. The results of that study indicate that at least $400 \mathrm{lbm}$ of tracer would be required to exceed detection limits in producing wells, and that breakthrough is not expected in any well for at least 2 months. This is a working model that will be updated, as additional reservoir data becomes available. The tracer test was started January 1999.

One liquid tracer, fluorescein and one vapor phase tracer, R-134a were injected into well $42-7$. The two types of tracers were used because five of the wells in the field produce steam, and one produces water. Both compounds are stable enough to survive the long residence times, and have detection limits on the order of parts per trillion. UMPA personnel were trained to take full liquid samples, combined liquid/gas samples, and gas/steam samples.

\section{PROJECT OBJECTIVES}

The objectives of this project are to develop better understanding of Cove Fort-Sulphurdale geothermal resource, in particular, and the behavior of liquid geothermal systems with steam-dominated caps in general. An improved understanding of reservoir boundaries, communication between injector and production wells, and interaction between the liquid zone and steam cap must be developed before resource expansion can be considered. The numerical model will be calibrated using the tracer data to expand and improve the methods of reservoir characterization and reservoir management.

\section{Technical Objectives}

- Develop numerical simulation as a dependable method for estimating reservoir response to water injection projects. 
- Incorporate developed methods of defining reservoir tracer tests into numerical simulation techniques.

- Train resource operators to incorporate tracer testing in reservoir management.

\section{Expected Outcomes}

- Identify key parameters that reduce the risk and expense of expanding exploitation of the Cove Fort-Sulphurdale geothermal resource.

- Develop computationally efficient field scale models to validate project benefits.

- Improve our understanding of the behavior of liquid-dominated systems with exploitable vapordominated caps.

\section{APPROACH}

A three dimensional model was constructed of the Cove Fort-Sulphurdale, Utah geothermal resource. The areal size of the model is $7000 \mathrm{ft}$ by $7000 \mathrm{ft}$. The model was developed using data supplied by the Energy and Geoscience Institute (EGI), Mesquite Group Inc. and verbal communication with UMPA personnel. The data included well surface locations, depth to top of reservoir, and monthly power generation data. The reservoir was given a uniform thickness of 400 feet based on an estimate of the thickness of the Coconino Sandstone, which is the producing formation of the geothermal fluids. The study area was modeled areally by a 20 by 20 grid. This grid was selected in part to ensure that no grid block had more than one well. The vertical grid used was 5 layers of varying thickness. Although the boundaries in the Cove Fort-Sulphurdale resource are not well defined, it is believed that the model covers a large enough area for the boundary temperatures to be given by the normal temperature gradient and for pressures to be hydrostatic. It is also believed there is a regional mass flow from the Tushar Mountains, east of the reservoir, and that the heat source is associated with the Woodtick Volcano to the west. For the initial pass at modeling this area, however, no-flow boundaries were used on all sides of the domain. Exploitation simulations discussed below using that boundary condition suggested more mass and energy was needed to match the production history. Rock properties for the numerical simulation were those of typical sandstone. Permeability was estimated from the steady-state radial flow of incompressible fluid using production rate and drawdown pressure from the hot water well. The calculated permeability was 10 darcy, and was assumed constant field wide. Porosity was assumed to be a constant $5 \%$ based on drill cuttings of the Coconino Sandstone. Saturations were initialized to develop a 150-foot thick steam zone with an underlying liquid dominated zone. Heat flux of $50 \mathrm{~mW} / \mathrm{m}^{2}$ was added to the bottom of the model and heat was lost through the top of the model to develop a vertical temperature gradient. The model was then initialized for 100 years to develop a stable steam cap and appropriate temperature gradient in the underlying liquid dominated zone.

\section{RESEARCH RESULTS}

To calibrate the model, exploitation of the Cove Fort-Sulphurdale geothermal field was simulated between 1985 and 1997. Pressure data from each of the five steam zone producers was available for history matching. Steam production rate for each well was not available because steam is not metered at the wellhead. Therefore, the total fluid production was estimated using power generation and plant efficiency and then divided equally among the wells in the steam cap. In reality this is probably a not a true representation of the steam well performance but for the purpose of tracer detection we felt this approach was satisfactory. The water well is pumped by submersible pump and mass rate was attained using a low-pressure constraint. Preliminary simulations using no-flow boundaries were unable to match 
production data. Aquifers were then added on the east side of the reservoir, consistent with recharge from the Tushar Mountains. Aquifer influx was adjusted to achieve production and pressure history matches. After achieving a history match of production, the tracer test was simulated. Tracer was added to the injectate over a one-hour period. Injection was held constant at $720 \mathrm{kph}$; production wells were kept on a 40 psia pressure constraint. The breakthrough times of the tracer are consistent with individual wells' distance from the injector. Differences in peak concentrations are due to variations in completion depths of the wells, and variations in individual well production rates. The water well (P91-4) produced the largest fraction of the tracer because it is pumped at a high rate. Tracer breakthrough times and peak concentrations are given in Table 1. Results of the simulation are being used to calculate the volume of tracer needed for the tracer test and has helped to devise a sampling schedule. The tracer test was performed in January 1999. Field results from this tracer test will be used to refine this numerical model.

Table 1. Detection and breakthough time after start of tracer test.

\begin{tabular}{lcccccc}
\hline & P91-4 & Mary & Lorretta & Clara & Olga & Linda \\
\hline Breakthrough time in months & 13 & 12 & 11 & 8 & 5 & 2 \\
Peak concentrations in ppb & 43 & 34 & 32 & 24 & 21 & 34 \\
\hline
\end{tabular}

\section{FUTURE PLANS}

We plan to continue the model study and develop and implement techniques to characterize geothermal resources using tracers. We will:

- Identify methods of relaxing the boundary conditions to incorporate what is happening outside the study area.

- Incorporate tracer test results into the numerical simulation.

- $\quad$ Continue monitoring tracer returns

- $\quad$ Continue monitoring fluid compositions in the production wells;

- Characterize changes in composition over time and determine the reservoir conditions responsible for them;

- Incorporate these changing reservoir conditions into the numerical simulations being developed;

- Present the results to the geothermal industry

\section{INDUSTRY INTEREST AND TECHNOLOGY TRANSFER}

There is significant interest in this project from both UMPA and the industry in general because of the similarities between the Cove Fort-Sulphurdale geothermal systems and other systems in Indonesia with parasitic vapor caps. The initial numerical simulations were presented at the annual GRC meeting and have been provided to UMPA. 


\section{REFERENCES}

Bloomfield, K. K., Moore, J. N., Sperry, T. L., 1998, Cove Fort-Sulphurdale Reservoir Numerical Simulation: Geothermal Resources Council Transactions, v22, pp.149-152

Ross, H. P., Moore, J. N., 1985, Geophysical Investigations of the Cove Fort-Sulphurdale Geothermal System, Utah: Geophysics, v50, pp.1732-1745.

Ross, H. P., Blackett, R. E., Sperry, T. L., 1997, Self-Potential and Electrical Resistivity Studies of the Cove Fort-Sulphurdale Geothermal System, Utah: Geothermal Resource Council Transactions, v.21, pp. 255-261.

Nash, G. D., 1997, Preliminary Results from Two Spectral-Geobotanical Surveys Over Geothermal Areas: Cove Fort-Sulphurdale, Utah and Dixie Valley, Nevada: Geothermal Resource Council Transactions, v.21, pp. 203-209.

Huttrer, G. W., 1992, Geothermal exploration at Cove Fort-Sulphurdale, Utah 1972-1992: Geothermal Resource Council Transactions, v.16, pp. 89-95. 


\title{
THE SALTON SEA GEOTHERMAL FIELDS
}

\author{
Marcelo J. Lippmann \\ E.O. Lawrence Berkeley National Laboratory \\ Alfred H. Truesdell and George A. Frye \\ Consultants
}

\section{KEY WORDS}

Salton Trough, liquid-dominated geothermal systems, field case studies, geothermal power

\section{PROJECT BACKGROUND AND STATUS}

The Salton Trough contains the most prolific geothermal power production areas in North America. It includes the Imperial Valley of southern California (US) and the Mexicali Valley of Baja California (Mexico), where a number of high-temperature (above $180^{\circ} \mathrm{C}$ ) geothermal areas are under commercial production. The existence of these fields is due to the region's particular geologic environment.

The Trough is a large trans-tensional basin (Herzig and Jacob, 1994) that lies astride the Pacific-North American plate boundary over the $300 \mathrm{~km}$ distance between the southern end of the San Andreas fault near the Salton Sea and the northern end of the Gulf of California (Fig. 1). This broad structural trough, characterized by high heat flow, tectonic deformation and seismicity, as well as volcanism, resulted from tectonic activity that created a series of pull-apart basins and transform faults linking the East Pacific Rise to the San Andreas fault system (Fig. 2, Elders et al., 1972; Lachenbruch et al., 1985).

The first long-lived commercial developments of liquid-dominated geothermal systems in North America took place in this region; i.e., in the Cerro Prieto geothermal field (CPGF) of Baja California in 1973, and in the East Mesa geothermal field (EMGF) of California in 1980 (CFE, 1992; DOE, 1997). At present the installed electrical generation capacity in the Trough exceeds 1,000 MW (i.e., in Mexico $620 \mathrm{MW}$ at CPGF; and in California $248 \mathrm{MW}$ at the Salton Sea geothermal field (SSGF), $105 \mathrm{MW}$ at EMGF and $84 \mathrm{MW}$ at the Heber geothermal field). According to Brook et al. (1979; Tables 5 and 8), the identified accessible geothermal resource base for the U.S. part of the Salton Trough is $240 \times 10^{18}$ Joules (corresponding to about $6800 \mathrm{MW}$ electrical for 30 years), while the undiscovered base is estimated to be twice as much.

As is typical of all geologic systems, the Salton Trough geothermal areas have their own particular characteristics, however they also have some underlying similarities. The CPGF and SSGF were the first geothermal fields to be compared under this project, since they are the two largest and hottest (maximum reservoir temperatures around $350-370^{\circ} \mathrm{C}$ ) ones in the Trough.

The main purpose of the project's FY-1998 effort was to explore the similarities and differences between CPGF and SSGF from the earth sciences and developmental points of view (Lippmann et al., 1999).

\section{PROJECT OBJECTIVES}

The objective of the project is to study the basic differences and similarities among the Salton Trough geothermal systems. From the exploration and development point of view it is important to recognize these differences and understand the underlying causes. 


\section{Technical Objectives}

- Characterize the various geothermal systems in the Salton Trough from the geologic and geochemical points of view.

- If adequate open-file data are available, develop hydrological models for the various geothermal fiels in the region.

- Identify and document the similarities and differences among the Salton Trough fields.

\section{Expected Outcomes}

- Conference papers discussing the results of the comparison between a number of Imperial Valley geothermal fields.

- A paper in a refereed technical journal describing the particular characteristics of Salton Trough geothermal fields and their differences.

\section{APPROACH}

Information from published reports, conference articles and journal papers will be analyzed to establish the characteristics of the various Salton Trough geothermal fields. If possible, additional data will be collected from company files and from records maintained by the California Division of Oil, Gas and Geothermal Resources.

\section{RESEARCH RESULTS}

As described by Lippmann et al. (1999) paper, a comparison between the CPGF and SSGF showed that,

- Both fields have similar geologic frameworks and maximum measured temperatures (about $\left.350-370^{\circ} \mathrm{C}\right)$.

- They differ slightly in lithology (more continental, especially lacustrine sediments at the SSGF) and ultimate electrical generating capacity (more than $800 \mathrm{MW}$ at CPGF, more than $1000 \mathrm{MW}$ at SSGF).

- There are large differences in the chemistry of their geothermal fluids (Fig. 3) and in the amount of evaporites and sulfides in their sedimentary columns, both being higher at SSGF.

- The contrasting fluid chemistries may be explained by the positions of the fields with respect to the crest of the Colorado River delta (Fig. 1). The SSGF is below sea level in a closed basin that has accumulated continental brines since the Pliocene. In contrast, in the area of the CPGF groundwater derived from the Colorado River flows to the sea (i.e., to the Gulf of California), and most marine salts and brines have been flushed.

- The need to solve the problems of handling the higher salinity (and corrosivity) of the SSGF fluids, as well as differences in US public policy and economic considerations were the main factors that delayed the development of SSGF compared to that of CPGF in Mexico (Fig. 4). 


\section{FUTURE PLANS}

Data on other Salton Trough geothermal fields will be gathered and analyzed. On the basis of the amount and type of information available, the characteristics of individual fields will be compared against those of others in the region. The results will be published as described in the section "Expected Outcomes", given above.

\section{INDUSTRY INTEREST AND TECHNOLOGY TRANSFER}

U.S. companies interested in the development of the Salton Trough geothermal resources on both sides of the California-Baja California border, will benefit in the results of this study since it will be useful in their exploration, evaluation and development efforts.

\section{REFERENCES}

Brook, C.A. et al. (1979). Hydrothermal convection systems with reservoir temperatures $\geq 90^{\circ} \mathrm{C}$. In Assessment of Geothermal Resources of the United States-1978 (L.P.J.Muffler, ed.), USGS Geological Circular 790, pp. 18-85.

CFE (1992). Cerro Prieto geothermal field. Comisión Federal de Electricidad, Residencia General de Cerro Prieto brochure.

DOE (1997). Geothermal power plant tables. Geothermal Progress Monitor No.19, U.S. Department of Energy publication DOE/EE-0160, pp. 35-42.

Elders, W.A., Rex, R.W., Meidav, T., Robinson, P.T. and Bielher, S. (1972). Crustal spreading in southern California, Science, 178, 15-24.

Herzig, C.T. and Jacobs, D.C. (1994). Cenozoic volcanism and two-stage extension in the Salton trough, southern California and northern Baja California. Geology, 22, 991-994.

Lachenbruch, A.H., Sass, J.H. and Galanis, S.P., Jr. (1985). Heat flow in southernmost California and the origin of the Salton Trough. Journal Geophysical Research, 90, B8, 6709-6736.

Lippmann, M.J., Truesdell, A.H., and Frye, G.A. (1999). The Cerro Prieto and Salton Sea geothermal fields - Are they really alike? Proceedings, 24nd. Workshop on Geothermal Reservoir Engineering, Stanford, CA, January 25-27, 1999 (in press).

Palmer, T.D., Howard, J.H. and Lande, D.P. (1975). Geothermal development of the Salton Trough, California and Mexico. Lawrence Livermore Laboratory report UCRL-51775. 


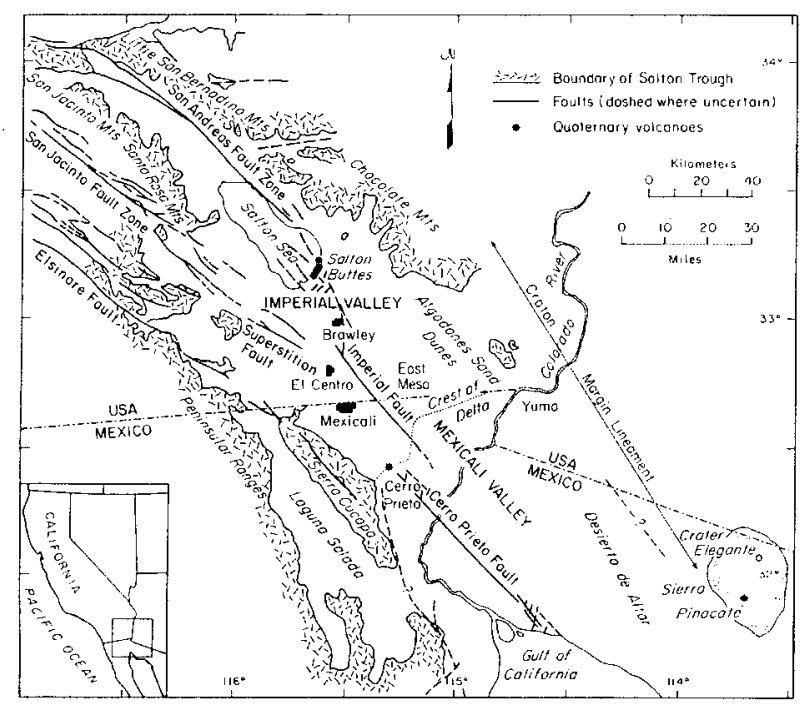

Figure 1. Generalized map showing the location of the Cerro Prieto (CPGF) and Salton Sea (SSGF) geothermal fields within the Salton Trough, Gulf of California and the East Pacific Rise tectonic regime (from Herzig and Jacobs, 1994).

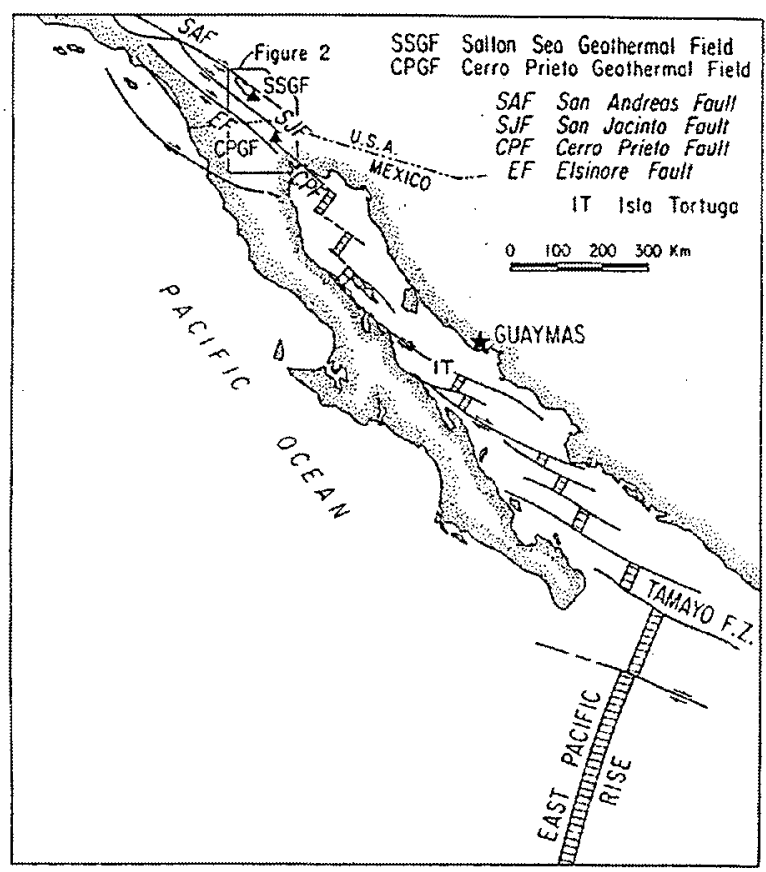

Figure 2. Chemical compositions of aquifer fluids from Cerro Prieto well M-5, and Salton Sea SSSDP well State 2-14 compared to those of normal seawater and Reykjanes well 8 (geothermal fluid compositions calculated for reservoir conditions). 


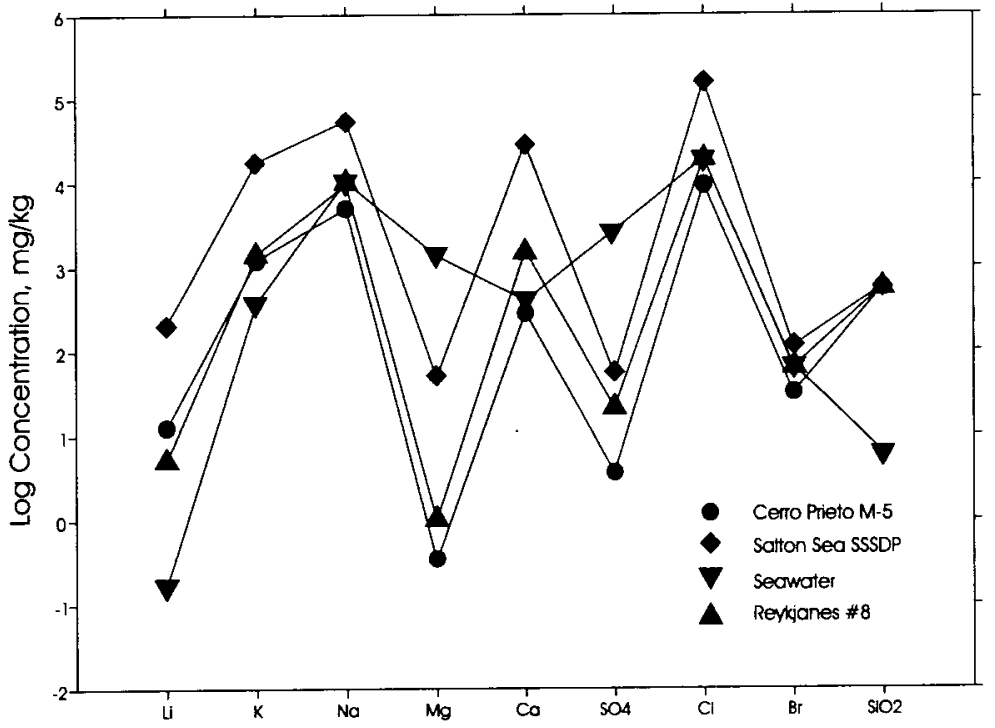

Figure 3. Regional geological model of the Salton Trough showing the location of the crest of the Colorado Delta (modified from Palmer et al., 1975).

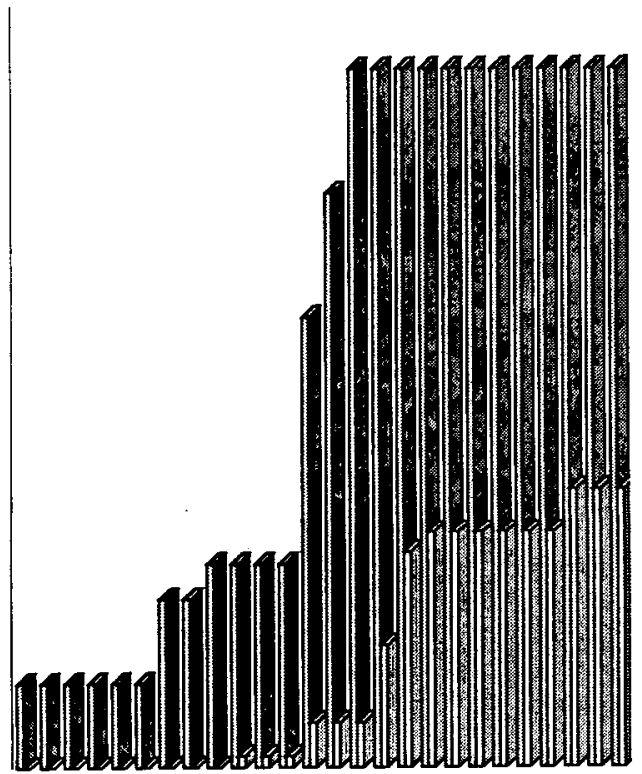




\title{
GEOLOGIC RESERVOIR CHARACTERIZATION OF THE TELEPHONE FLAT GEOTHERMAL SYSTEM, MEDICINE LAKE VOLCANO, CALIFORNIA
}

\author{
Jeffrey B. Hulen and Susan J. Lutz \\ Energy \& Geoscience Institute, University of Utah
}

\section{KEY WORDS}

Telephone Flat, geothermal system, Medicine Lake, California, volcanic stratigraphy, hydrothermal alteration, Quaternary volcanism

\section{PROJECT BACKGROUND AND STATUS}

Medicine Lake volcano (MLV), in northeastern California (Fig. 1), is the largest in or near the Cascade Range. The volcano's summit area, an enigmatic, elliptical basin ringed by a topographic high, coincides with a huge temperature anomaly, which has been explored for its obvious geothermal potential since the early 1980's, first by Occidental Petroleum, Phillips Petroleum, and Unocal Geothermal, and more recently by the present leaseholders, Calpine Corporation and California Energy Company (CEC). Numerous thermal-gradient boreholes and four deep production-scale wells have been completed in the MLV system (Fig. 1). Three of the wells, in the CEC Telephone Flat region, are capable of commercial, electrical-grade, thermal-fluid production, and CEC has proposed accordingly to install and operate a 48 MW geothermal plant on the property (Iovenitti and Hill, 1997).

Although Unocal and CEC have demonstrated the presence of a viable Telephone Flat geothermal resource, in the process assembling a voluminous geoscientific exploration database, additional work is desirable to develop an optimal geologic model of the system B a model to help guide future exploration and development efforts, and one which is tightly focused on elucidating the nature and configuration of the system $=\mathrm{s}$ all-important porosity and permeability network. One means of accomplishing this task is through cooperative investigation with Department of Energy geothermal researchers. This approach has been highly beneficial at such geothermal systems as The Geysers (Hulen et al., 1995), California, and Awibengkok, West Java, Indonesia (Hulen and Anderson, 1998). Through implementation of such a program, industry gains the services of a dedicated research team of a size and breadth of knowledge which most geothermal companies find impractical to maintain internally. Researchers are correspondingly able to work with talented industry personnel on incomparable research materials which would otherwise remain exclusively proprietary.

EGI has recently obtained the key documents, data sets, and petrographic thin sections accumulated by Unocal and CEC for their Medicine Lake/Telephone Flat geothermal exploration effort. Under the broader terms of a CEC-EGI technical data gathering agreement, these data, reports, and samples are considered confidential and proprietary, but can be used freely in support of EGI research projects. Results of these projects, by contractual obligation to the DOE Office of Geothermal Technologies, can be published with prior review by CEC.

CEC wishes to complete a cooperative scientific coring project at Telephone Flat in partnership with the DOE (Alexander Shchriener, Jr. and Mark Walters, CEC, personal communication, January 1999), and should it obtain the necessary co-funding for these efforts, the EGI geologic reservoir characterization briefly summarized in this volume will be critical in selection of coring sites with the highest potential to yield the maximum amount of information about the resource. EGI would also provide the Chief Scientist for the coring effort, and that individual would be responsible for assembling and coordinating a first-rate 
geoscientific research team to work on the core and obtain appropriate measurements in the borehole environment both during and following actual drilling operations. EGI scientists have successfully served in this capacity for The Geysers Coring Project (1994-present) and the Awibengkok geothermal research project (1995-present), and have also played similar roles in Continental Scientific Drilling Projects in theValles and Creede calderas, New Mexico and Colorado, respectively.

Acting on the assumption that CEC will go forward with this coring effort, we have begun to analyze the extensive data and sample collection furnished in support of the effort by CEC. In addition, we have completed preliminary petrographic and XRD analyses of key lithologic sections of the aforementioned thermal-gradient and production-scale wells, and have begun preparation of three-dimensional geologic models of the drilled portion of Medicine Lake volcano to guide the drill-site selection process. The results are and will be relevant not only for Telephone Flat, but for similar volcanic-hosted hydrothermal systems anywhere they are found.

\section{PROJECT OBJECTIVES}

\section{Technical Objectives}

- Evaluate the existing Telephone Flat and Medicine lake geological, geochemical, and geophysical database, including information obtained directly by CEC and its predecessors at the site as well as published accounts, in particular the landmark contributions of the U.S. Geological Survey (e.g. Donnelly-Nolan et al., 1990).

- Examine the existing documentation (lithologic logs, geophysical logs, XRD analyses, petrographic descriptions, etc.) for cores and cutting retrieved to date from the Medicine Lake volcano. Determine what further characterization would be beneficial to the overall research effort. Complete this additional work (e.g. fluid-inclusion, stable-isotopic, age-dating, petrographic investigations).

- Build conceptual models portraying possible 3-D configurations for the explored and outlying portions of the Telephone Flat system.

- Select coring sites in the system most likely to yield the maximum amount of useful subsurface information about the circulating geothermal system and its permeability and porosity network.

- (Contingent on project approval and co-funding): Hulen to participate in a Telephone Flat scientific coring effort in the capacity of Chief Scientist, discharging the duties of that position as for past such efforts including The Geysers Coring Project

\section{Expected Outcomes}

- Improved understanding, in three dimensions, of the stratigraphic, structural, alteration, mineralization, and permeability configurations of the Medicine Lake volcano and Telephone Flat geothermal system as well as similar such volcanic-geothermal settings around the world.

- Selection of the best possible Telephone Flat coring site to obtain the maximum amount of useful information about the circulating geothermal system, its enveloping hydrologic seal, and its youthful volcano-tectonic setting. 


\section{APPROACH}

Phillips and Occidental Petroleum and Unocal Geothermal assembled a rich database on the geology, geochemistry, alteration, hydrology, and structural setting of Telephone Flat as an essential part of their extensive exploration effort commencing in the mid-1980's. The Phillips and Occidental data were inherited by Calpine Corporation, and the Unocal data were acquired by CEC in 1993. Since then, CEC and Calpine have significantly augmented the database through new exploration and evaluation. The combined database includes, but is not limited to, borehole logs of all types, petrographic descriptions, fluid-inclusion microthermometry, downhole stable-isotope analyses, whole-rock geochemistry, volcanic stratigraphy, magnetotelluric survey results, gravity, magnetics, and surface and subsurface water chemistry and isotopic composition. It is a wonderful resource, obviating the need for extensive additional such work in the near term. We are absorbing, cataloguing, and utilizing the data sets in alternative ways to obtain a thorough understanding of the system as known by the geothermal companies, and doing a limited amount of supplemental petrographic and XRD analytical work to bridge gaps where we perceive them. A three-dimensional model of the volcano and geothermal field has not heretofore been prepared. We have begun work upon one because such models aid immeasurably in the visualizing of the subsurface geologic setting necessary for optimum corehole siting. With regard to the proposed scientific drilling efforts, we are of course in close contact with CEC geoscientists, who are the real experts on the Telephone Flat system, when the answers to specific questions are not immediately accessible from study of the database.

\section{RESEARCH RESULTS}

Because this project did not get underway until late in FY98, our efforts on its behalf have necessarily been preliminary and organizational in nature. The work has involved: (1) careful cataloguing and initial study of the valuable CEC database; (2) initial preparations for constructing a working 3-D geologic framework for Medicine Lake volcano and the Telephone Flat area; (3) limited petrographic and X-ray diffraction study of drill-core and cuttings samples from selected thermal-gradient boreholes completed on the volcano by Unocal.

Examination and reexamination of cores, cuttings, thin sections, and X-ray diffractograms from selected boreholes (Fig. 1) shows that the volcano is constructed of interstratified basalt, andesite, dacite, and rhyolite, with the latter two rock types more prevalent within and beneath the prominent summit depression.

The temperature profiles of wells and thermal-gradient boreholes completed though this sequence in the Telephone Flat area of MLV show, in downward progression: (1) a near-isothermal interval corresponding to a cool, shallow groundwater zone; (2) a steep, steadily-increasing, conductive profile which becomes more isothermal in its deeper reaches at temperatures approaching $250^{\circ} \mathrm{C}$ (A. Schriener, pers. comm., 1999). The deepest portions of the profiles remain proprietary at this writing. The steep conductive zone clearly corresponds directly with intense clay alteration.

Beneath an unaltered zone ranging in thickness up to a few hundred meters, the MLV/Telephone Flat volcanics are hydrothermally altered, with a well-defined vertical zonation. Directly below the unaltered zone B and wholly within the intense clay-alteration zone B is a subhorizontal zone in which all rocks, but particularly the more mafic varieties, have been altered dominantly to clay minerals. Chief among these is saponite, a swelling clay which is stable to very high temperatures, and which locally accounts for $50 \%$ of the altered rocks. This clay zone, also several hundred meters thick, provides a tight hydrologic seal on the underlying geothermal system, preventing the influx of cool groundwaters, and conversely, escape of the more buoyant thermal fluids below. The volcanic host rocks of the geothermal system itself 
are propylitically altered, with epidote and chlorite predominating. Quartz, albite, potassium feldspar, calcite, and pyrite are the subordinate phases.

The significance of the saponitic caprock, or hydrothermal seal, on the system, cannot be overstated. As a ductile horizon, it can conceptually withstand significant tectonic stresses without breaching, thereby preserving not only seal integrity, but also that of the entire geothermal system.

\section{FUTURE PLANS}

The level of effort directed toward our Telephone Flat geologic characterization will depend in part on the scope and pace of the envisioned, collaborative, DOE-CEC coring effort. Should CEC obtain the funding required for this effort, EGI's supporting geoscientific research will be accelerated. If plans to drill a deep scientific corehole are realized, EGI will participate fully in site selection, core characterization, scienceteam selection and coordination, and core curation. A comprehensive research program dedicated to the Telephone Flat core and borehole database-a program involving the best scientists from national laboratories, universities, and research institutes, and governmental agencies-would likely span 2-3 years after completion of the drilling effort.

In the meantime, EGI will continue its Telephone Flat research utilizing a combination of techniques including petrographic examination of the nearly 1000 thin sections supplied by CEC; semi-quantitative $\mathrm{X}$-ray diffraction analysis of cores and cuttings, to augment prior qualitative XRD performed for CEC by EGI predecessor UURI; whole-rock geochemistry; and stable-isotopic analysis. The resulting data will be used to refine the evolving 3-D geologic model of Medicine Lake volcano and associated hydrothermal phenomena, a model which will facilitate drill site selection when the planned deep coring efforts are ultimately initiated.

\section{INDUSTRY INTEREST AND TECHNOLOGY TRANSFER}

Our Telephone Flat work, based as it is upon a voluminous sample and database supplied by CEC, will clearly benefit that company most directly. As the research is publically funded, however, it will also be of use to other geothermal companies with interest in or leaseholdings on the Medicine Lake volcano (e.g. Calpine Corporation). As always, many of our findings will be not only site-specifically beneficial, but will be useful in exploration for, and characterization and development of, all such high-temperature hydrothermal systems on a global basis.

\section{REFERENCES}

Donnelly-Nolan, J.M., Champion, D.E., Miller, C.D., Grove, T.L., and Trimble, D.A., 1990, Post-11 Ka volcanism at Medicine Lake volcano, Cascade Range, northern California: Journal of Geophysical Research, v. 95, p. 19,693-19,704.

Hulen, J.B., Koenig, B.A., and Nielson, D.L., 1995, The Geysers Coring Project, Sonoma County, California B Summary and initial results: Proceedings, World Geothermal Congress, 1995, Florence, Italy, p. 1414-1420.

Hulen, J.B., and Anderson, T.A., 1998, The Awibengkok, Indonesia, geothermal research project: Califormia, Stanford University, Proceedings, $23^{\text {rd }}$ Workshop on Geothermal Reservoir Engineering, 8 p.

Iovenetti, J.L., and Hill, D.G., 1997, Baseline hydrogeology evaluation report for Telephone Flat geothermal project, Medicine Lake, California: Emeryville, California, Weiss Associates, Report prepared for CalEnergy Corporation (August 20, 1997), 34 p. (not including illustrations and appendices). 


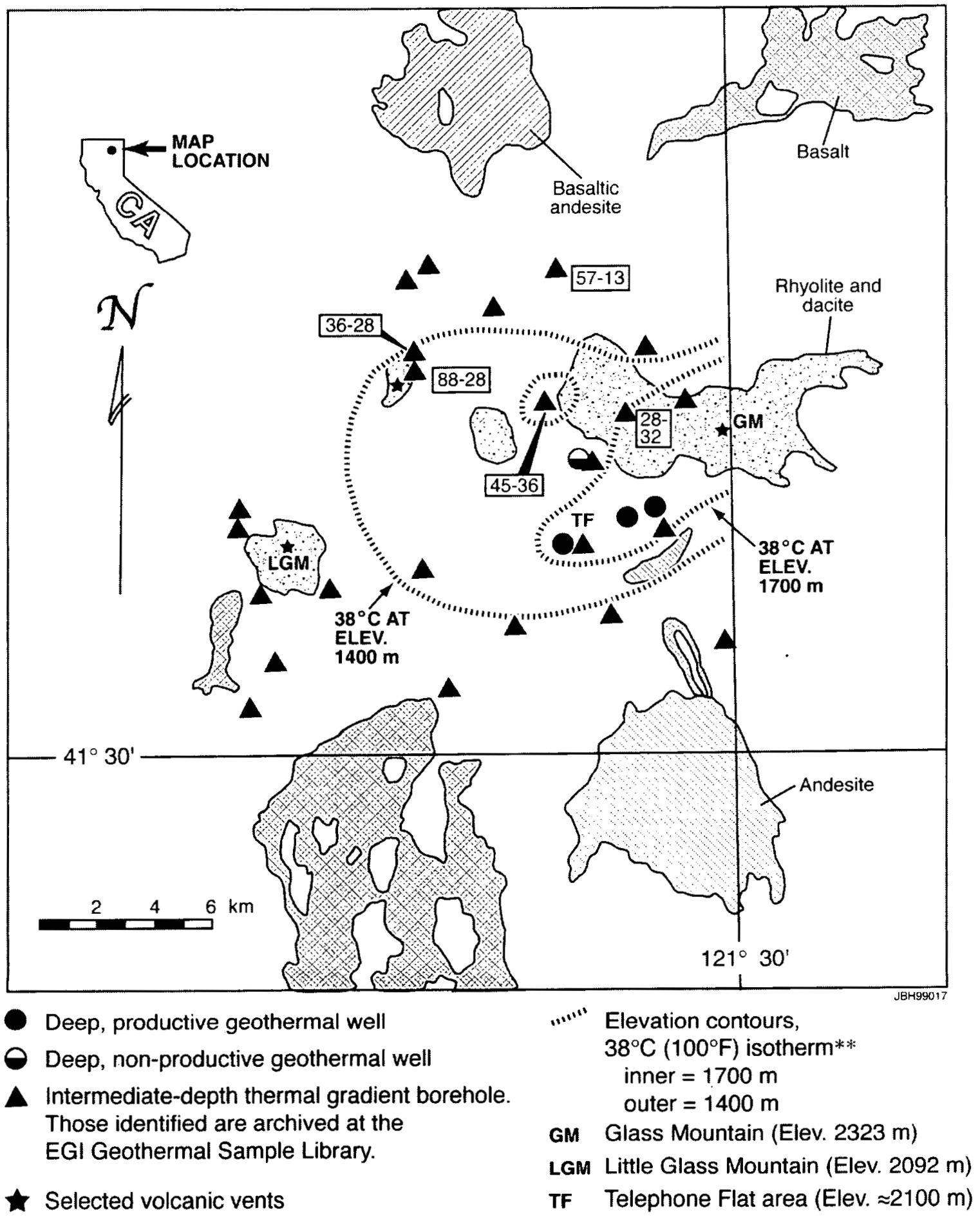

Figure 1. Location map showing a portion of the Medicine Lake volcano encompassing the summit depression* and Telephone Flat geothermal area. Patterned areas are Holocene volcanics, including the 10ka Glass Mountain flow. (From Donnelly-Nolan et al., 1990).

$*$ Rim of summit depression is just inside $38^{\circ} \mathrm{C}$-at- $1400 \mathrm{~m}$ contour

**From lovenetti and Hill. 1997 


\title{
THE AWIBENGKOK, INDONESIA, GEOTHERMAL RESEARCH PROJECT
}

\author{
Jeffrey B. Hulen \\ Energy \& Geoscience Institute \\ University of Utah
}

\section{KEY WORDS}

Awibengkok, Salak, West Java, Indonesia, core, high-temperature, volcano, geothermal system, porosity, permeability, fractures, breccias, dissolution, fluid migration and storage

\section{PROJECT BACKGROUND AND STATUS}

In March of 1998 the Energy \& Geoscience Institute (EGI) took possession of $1.1 \mathrm{~km}$ of continuous core from well Awi 1-2, completed in 1995 as a joint Department of Energy/Unocal Geothermal Indonesia (UGI) operation in the heart of the high-temperature, composite-volcanic-hosted, Awibengkok geothermal system in West Java, Indonesia. EGI personnel (J. Hulen and D. Nielson) were on site as the core was being collected to monitor the drilling and make a preliminary description of each $10-\mathrm{m}$ core section immediately upon its retrieval to the surface. Hulen returned to Java in November of 1997 to arrange for shipping of the core and to help ensure its proper labeling and boxing at the Unocal Geothermal Indonesia (UGI) warehouse complex in the Salak contract area, where Awibengkok is located. A variety of shipping and bureacratic delays prevented its arrival in the United States until the following March, but it arrived in perfect condition. Chief Scientist for the project, J. Hulen, then set about contacting prospective members of a dedicated research team to conduct a 2-3 year, multidisciplinary investigation of the retrieved core and measurements made in the borehole during and after drilling operations.

\section{PROJECT OBJECTIVES}

\section{Technical Objectives}

- (Governing) B Through detailed study of the continuous Awi 1-2 core and ancillary data, significantly improve understanding of reservoir controls in a large but otherwise probably typical, island-arc composite-volcanic-hosted, high-temperature geothermal system. Compare and contrast the new information obtained from this study with corresponding data from other such systems around the world.

- Determine the origins, measure and map the configurations, and establish the interrelationships of fractures, breccias, dissolution cavities, vesicles, and other voids which singly or in combination serve as geothermal fluid conduits or storage sites. Study the relative influence of regional vs local controls on development of these features. For example, to what extent are fractures and breccias formed in response to far-field stresses vs those of local origin (e.g. overpressured thermal fluids).

- Determine lithologic controls on configuration of the geothermal system=s key components (e.g. caprock vs productive reservoir, aquifers and aquicludes in the reservoir proper). In so doing, establish a detailed volcanic stratigraphy potentially of use in indirect three-dimensional mapping of discordant conduits such as fractures and pebble dikes. 
- Ascertain the effects of penetrated igneous intrusions on the geometry of the geothermal system, and on the compositions and textures of the reservoir rocks these igneous bodies invade.

- Map in detail hydrothermal alteration mineralogy and zoning, not only in a gross vertical sense with respect to the reservoir as a whole but also locally, for example selvages bordering veins as well as rims and rinds on clasts and phenocrysts. Examine this information for correlations with other rock and reservoir properties. For example, do certain alteration mineral assemblages and zoning sequences show a systematic relationship to active thermal-fluid-flow conduits? Are impermeable hydrothermal breccias differently altered than their permeable vuggy counterparts? Investigate the utility of secondary-mineral zoning and paragenetic sequences in targeting remotely, as well as mapping, potentially productive thermal-fluid conduits.

- Compare characteristics and controls of the Awibengkok system with those observed and inferred for several late Cenozoic volcanic-hosted precious-metal deposits in the immediate vicinity, especially the $2 \mathrm{M} \mathrm{oz}, 8 \mathrm{Myr}$-old Pongkor deposit (Basuki et al., 1994) just a few kilometers to the northwest of Awi.

- Reconstruct the hydrothermal history of the portion of the Awibengkok geothermal system penetrated by the corehole. If possible, utilize this information to help predict changes in reservoir characteristics with time and progressive depletion. As a particularly important module of this work, investigate the possibility that a noncondensible gas cap had accumulated above this shallowest portion of the geothermal reservoir.

- Measure multiple physical and mineralogic properties of the penetrated rocks, not only under ambient conditions but also under simulated reservoir pressures and temperatures. Examine the utility of this information in constraining interpretations of surface- and borehole-based geophysical surveys of these and similar geothermal-reservoir rocks and the fluids they contain.

\section{Expected Outcomes}

- With the new information obtained from this investigation: (1) improve the odds of finding similar volcanic-hosted geothermal systems in other volcanic provinces; (2) help reduce operators' costs in exploiting those systems already secured, including Awi itself; and (3) enable those operators to prolong the systems $=$ productive lives through more informed long-term development strategies.

- A detailed picture of the Awibengkok geothermal system's evolution since inception, especially: (1) the nature and timing of events specifically linked to the creation, enhancement, or occlusion of porosity and permeability; and (2) fluid sources, volumes, pathways, chemical transformations, and thermal histories.

\section{APPROACH}

The inaugural Awibengkok Workshop was held June 2, 1998, at the Marriott University Park Hotel in Salt Lake City. In attendance were the following individuals:

- Marshall Reed, Department of Energy (DOE), Office of Geothermal Technologies; Joel Renner and Mike Shook, Idaho National Engineering and Environmental Laboratory (INEL); Bob Creed, Department of Energy, Idaho Falls; Deb Bergfeld of Los Alamos National Laboratory (LANL); Brian Bonner, Carol Bruton, and Paul Kasameyer of Lawrence Livermore National Laboratory (LLNL); Greg Boitnott and Stephen Brown of New England Research, Inc. (NER); Peter Persoff of Lawrence Berkeley National Laboratory (LBL); Tom Powell of Unocal Geothermal; Dave Cole 
and Mirek Gruszkiewica, Oak Ridge National Laboratory (ORNL); and Rick Allis, Greg Nash, Bob Ehrlich, Hulen, Susan J. Lutz, and Dennis Nielson of EGI.

Following introductions by Hulen, Reed, and Powell, each researcher presented a brief summary of the work he or she has proposed or inititated to advance our understanding of the Awibenkok core, borehole environment, and geothermal system. Abbreviated accounts as follows:

Greg Nash B Organization of Awi data using state of the art GIS techniques. Spectral analysis of core, conceptually leading to rapid and reliable on-site characterization of alteration mineralogy. Creation and maintenance of the Awi project's world-wide-web site.

Dennis Nielson B Fracture systematics in the Awi 1-2 core. Direct measurement and description compared with FMS imagery. Discrimination, based on these logs and accompanying petrologic work, of productive fractures vs those which are porous at the core scale but clearly sealed at some distance away from the corehole.

Peter Persoff B Highly accurate measurement of permeability at the core scale (as low as 0.1 nanodarcies) utilizing sophisticated instrumentation adapted or invented by him specifically for the purpose. Utilizing this equipment, gauging the effect of changing reservoir pressures and fluid compositions on the permeabilities of fractures and partially open mineralized veins.

Bob Ehrlich B Assessment of porosity and permeability at the core scale utilizing computer-assisted imaging of petrographic thin sections. Investigation of geochemical controls on productive porosity and permeability by use of his patented unmixing algorithms.

Greg Boitnott-Determination of the influence of rock type, alteration, mineralization, porosity, permeability, and reservoir-fluid composition on electrical and acoustical properties of the Awi 1-2 cores. Extrapolation of results to surface- and borehole-based geophysical surveys designed for remote measurement of these properties in the

Mirek Gruszkiewicz-Investigation of the effects and potential effects of adsorption at high temperatures on present and future thermal-fluid production. Especially germane to potential development of steam cap above the Awibengkok geothermal

Dave Cole, speaking also on behalf of Mike Simonson and D.A. Palmer B Study on partitioning of solutes to steam, from equilibration of high-temperature brines with core samples. With Lee Riciputi: Analysis of stable isotopes of sulfur, carbon, oxgyen, and hydrogen in fluid inclusions as tracers to determine ultimate water sources and fluid evolution from the point of origin (work to be closely coordinated with that of EGI fluid-inclusionist Joe Moore).

Steven Brown-Evolution of fracture permeability under stress. Work to be carried out in collaboration with Ron Bruhn, structural geologist and professor at the University of Utah.

Carol Bruton, Jeff Roberts, Brian Bonner, and Paul Kasameyer B A joint project first of all aimed at measurment of electrical resistivity and compressional and shear velocity as a function of pressure. Secondly to measure permeability, to realistic pore fluids, of the Awi cores at elevated temperatures and pressures. Determination of the role of rock-water interactions on the creation and loss of permeability.

Deb Bergfeld, speaking on behalf of her colleagues Fraser Goff, Giday Woldegabriel, Kenneth Wohletz, and Jim Stimac. Goff and Woldegabriel will perform K-Ar age-dating of illitic clays in the Awi 1-2 core, as a complement to planned ${ }^{40} \mathrm{Ar}{ }^{39} \mathrm{Ar}$ age dating of adularia by Matt Heizler (New Mexico Tech.) and 
Jeff Hulen. Goff and Wohletz will investigate hydrothermal breccias in the core in order to help constrain the Awibengkok system's intricate hydrothermal history, and to better understand the nature and origin of fracture permeability.

Rick Allis-Interpretation of the large array of geophysical logs for the Awi 1-2 corehole and a companion, sidetrack production leg, Awi 1-2-ST. Development of interpretation strategies for reliable identification of rock types, alteration, mineralization, and favorable permeability using the logs alone in the absence of physical rock samples (cores and cuttings).

Joe Moore B Fluid-inclusion systematics. With Dave Norman of New Mexico Tech., measurement and interpretation of gas geochemistry of fluid inclusions, as tracers of fluid sources and hydrothermal histories. Work to be coordinated with Cole and Riciputi of Oak Ridge National Laboratory.

Richard Hervig and Lynda Williams (Arizona State University) B Not present but sent research summary. Boron and oxygen isotopes of clays and other secondary minerals. Determination of paleo-water chemistry, and how it differed from modern reservoir fluids.

\section{J. Hulen and Susan Lutz-Baseline geology, to be communicated regularly to the science team.}

It should be noted that also in support of this effort, UGI has made available a voluminous accompanying Awi 1-2 database including, but not limited to, stable-isotope analyses, whole-rock geochemistry, porosity, permeability, etc. These data greatly reduce the amount of basic measurement to be done on the core by the research team, and we are grateful to EGI for making the data available.

\section{RESEARCH RESULTS}

By common consent of the Workshop participants, extensive publication of research results will be withheld until the 1999 Geothermal Resources Council annual meeting in Reno, Nevada, where Hulen is chairing a special session devoted to the Awibengkok project.

\section{FUTURE PLANS}

Continue the research outlined above. Presentation of initial research results at the 1999 GRC annual meeting.

Hulen and Fransiskus Sugiaman (UGI) and/or Jim Stimac (Unocal Geothermal Philippines) will prepare and present a paper on Awibengkok at the World Geothermal Congress in 2000.

Greg Nash and his Geomatics staff have digitized the Unocal Awi database and made it available on the world-wide-web.

\section{INDUSTRY INTEREST AND TECHNOLOGY TRANSFER}

Obviously the field operator, UGI. In addition, however, Awi is a proxy for all such composite volcanichosted hydrothermal systems, and information gained from its detailed investigation will be nearuniversally applicable. 


\section{REFERENCE}

Basuki, A., Sumanagara, D.A., and Sinambela, D., 1994, the Gunung Pongkor gold-silver deposits, West Java, Indonesia: Journal of Geochemical Exploration, v. 50, p. 371-391. 


\title{
TRACING FLUID FLOW IN GEOTHERMAL RESERVOIRS
}

\author{
Peter E. Rose \\ Energy \& Geoscience Institute \\ University of Utah
}

\section{KEY WORDS}

tracers, tracer tests, geothermal, fluorescein, polyaromatic sulfonates, reservoir simulation

\section{PROJECT BACKGROUND AND STATUS}

Injection of produced fluids is essential to prudent geothermal reservoir-management strategies, both as a means of disposing of an environmental pollutant as well as a method of maintaining reservoir pressures. The location of the injection wells within the three-dimensional network of fractures that forms the reservoir is crucial to the successful exploitation of the field. Proper well location leads to increased power production due to enhanced pressures, less reservoir scaling from boiling around the production wells, and reduced thermal breakthrough. Introduction of tracers into the injection-production loops is the fastest and most effective method of obtaining data that reveal the flow patterns of injected fluids.

At the inception of the tracer development program in 1982, there were very few tracers in use by the geothermal industry. In addition, an insufficient knowledge of the thermal stability of these known tracers produced a lack of confidence in the results of tracer field tests. Surveys of the geothermal industry by the DOE indicated a strong belief that tracer research and development would be very valuable if stable geothermal tracers could be developed. It was on this basis that the tracer development project was founded. Several tracers have subsequently been developed and field-tested (Adams and Davis, 1991; Adams et al., 1992; Rose and Adams, 1994; Rose and McPherson, 1997; Rose et al., 1998; Rose, 1998; Rose et al., 1999). Laboratory and field testing continues in an effort to develop additional tracers that are detectable, thermally stable, environmentally benign, and affordable in order to facilitate the prodigious task of tracing the flow paths of injected geothermal fluids through hydrothermal systems.

\section{PROJECT OBJECTIVE}

The primary objective of this research project is to identify and test candidate compounds for use as tracers in geothermal reservoirs. An ideal tracer is nontoxic, environmentally benign, thermally stable (or possessing a quantifiable and reasonably slow rate of decay under geothermal conditions), detectable at very low concentrations, non-reactive with the reservoir rock and relatively inexpensive. As many of these compounds as possible should be identified because of the need for identifying individual injector/producer flow paths in reservoirs containing multiple injection wells. A secondary objective of this project is to develop improved methods for the design of tracer tests as well as for the interpretation of tracer return-curve data.

\section{Technical Objectives}

- Prove the stability of several candidate compounds for use as geothermal tracers. Use both laboratory and field-tests to provide the evidence of stability. As many of these compounds as possible should be identified because of the need for the simultaneous use of multiple tracers in reservoirs containing many injection wells and, as a result, multiple injection-production flow paths. 
- Develop numerical-simulation techniques for modeling the flow of tracers along injectionproduction pathways. A properly calibrated model can provide such valued test-design information as the appropriate amount of tracer needed for chemical breakthrough, as well as an indication of where and when tracer breakthrough is expected. And, by combining a model of the thermal-decay kinetics with a numerical-simulation flow model, candidate tracers can be screened in advance of the actual field test and eliminated from consideration if they are not sufficiently stable.

\section{Expected Outcomes}

- To provide a minimum of five affordable, easily detectable tracers that are stable in geothermal reservoirs with temperatures exceeding $300^{\circ} \mathrm{C}$.

- To develop numerical modeling techniques as a means of evaluating candidate tracers, improving tracer-test designs, and calibrating flow-models.

\section{APPROACH}

Our approach to the development of new tracers for the geothermal industry has been, first, to search the literature for promising candidates. Next, the candidate compounds are screened for thermal stability and adsorption, based upon thermodynamic and kinetic data found in the literature. Methods of chemical analysis are developed in order to determine whether the candidate compounds are sufficiently detectable to render them affordable for industrial application. The surviving candidates are then subjected to a series of laboratory experiments using high-pressure autoclaves to create an environment of temperature, pressure, and solution matrix that simulates the reservoir environment. Upon completion of the laboratory phase, the candidate tracers are field-tested in geothermal reservoirs. The results of the full-scale field tests are then compared to the results of the laboratory tests in order to refine the laboratory-derived parameters. Finally, the results of the laboratory experiments and field tests are published in the open literature. These methods provide for rapid evaluation of candidate compounds and immediate, up-to-date access of our results to the geothermal community.

\section{RESEARCH RESULTS AND VARIANCES}

\section{Liquid Phase Tracer Development}

In order for candidate tracers to qualify for use in the geothermal industry, they must be environmentally benign, affordable, detectable, thermally stable, and resistant to adsorption on reservoir rock. Unfortunately, very few non-radioactive compounds are both very detectable and thermally stable under the rigors of a hydrothermal environment at $300^{\circ} \mathrm{C}$. We are continuing a systematic approach to the identification of viable tracers by looking within a class of fluorescent compounds that is known to possess these qualities--the sulfonate derivatives of polyaromatic hydrocarbons.

The polyaromatic sulfonates possess excellent thermal stability due to their condensed aromatic ring structure possessing significant double-bond character. Likewise, this condensed aromatic ring structure accounts for their fluorescence, which, in turn explains their excellent detectability. Figure 1 shows the various sulfonate derivatives of the 2- and 4-ring polyaromatic hydrocarbons that we have evaluated in the laboratory and in field studies during the past year (Rose, 1998; Rose et al., 1998; Rose et al., 1999). Column 3 lists the extent of thermal decay observed for each compound upon exposure to laboratorysimulated geothermal reservoir conditions for one week at $300^{\circ} \mathrm{C}$. Since the experimental error was $5 \%$, only Crisotan R5 evidenced any measurable decay. In subsequent experiments, 1,5-naphthalene disulfonate showed only $20 \%$ decay upon exposure to geothermal conditions for one week at $330{ }^{\circ} \mathrm{C}$. 
Further studies were conducted with 1,5-naphthalene disulfonate to determine its Arrhenius decay rate constant as a function of temperature over the range $310^{\circ} \mathrm{C}$ to $330^{\circ} \mathrm{C}$ (Rose et al., 1999).

Figure 2 shows the relationship between half-life and temperature for 1,5-naphthalene disulfonate. Also shown in Figure 2 are the comparable half-life vs. temperature plots for two xanthene dyes rhodamine WT and fluorescein that have been studied in our laboratory (refs). Fluorescein has been used extensively as a tracer in hydrothermal environments, whereas rhodamine WT has been used only sparingly. It is evident that 1,5-naphthalene disulfonate, which can be used in geothermal reservoirs with temperatures approaching $340{ }^{\circ} \mathrm{C}$, is considerably more thermally stable than the xanthene dyes fluorescein and rhodamine WT, which are qualified for use as tracers in reservoirs with temperatures as high as $250{ }^{\circ} \mathrm{C}$ and $180^{\circ} \mathrm{C}$, respectively.

In order to sort out distinct flow paths in reservoirs containing many injection and production wells, a chemically distinct tracer is required for each injection well in the reservoir. To facilitate the task of simultaneously analyzing for multiple tracers, our laboratory recently obtained a high-performance liquid chromatograph (HPLC). Using this instrument, a mixture of compounds can be separated chromatographically as well as spectrally. We have developed methods for the simultaneous analysis of a large number of fluorescent tracers, including the polyaromatic sulfonates described above (Rose et al., 1998). With the HPLC, it is now possible to analyze many fluorescent compounds simultaneously and thereby determine the injection-production pathways in reservoirs containing many injection wells.

Whereas laboratory experimentation is required for testing candidate tracers under controlled conditions of time, temperature, pressure and solution chemistry, the tracer qualification process is incomplete without field-testing. The four compounds listed in Figure 1 were used in tracer tests at the Steamboat Hills, Nevada, and Dixie Valley, Nevada, geothermal reservoirs, which possess average fluid temperatures of approximately $160^{\circ} \mathrm{C}$ and $250{ }^{\circ} \mathrm{C}$, respectively. The field tests involving the compounds 1,5-naphthalene disulfonate (Rose et al., 1999), 1,3,6-naphthalene trisulfonate and 1,3,6,8-pyrene tetrasulfonate (Rose et al., 1998) were successful, as each tracer behaved conservatively and in accordance with laboratory predictions.

\section{PLANS FOR CONTINUING WORK}

Our plans for the forthcoming year include the continued evaluation of candidate geothermal tracers. Additional fluorescent compounds from among the polyaromatic sulfonates will be tested for thermal stability and detectability in the laboratory under conditions that simulate high-temperature liquid-

- dominated geothermal reservoirs. The Arrhenius decay rate constants for 1,3,6-naphthalene trisulfonate and 1,3,6,8-pyrene tetrasulfonate will be determined at appropriate temperatures. In addition, we will seek opportunities to test these tracers in high-temperature $\left(300^{\circ} \mathrm{C}\right.$ or hotter) liquid-dominated hydrothermal systems.

We will assist in the verification of the finite element reservoir modeling code GEOCRACK that is being developed by Daniel Swenson and co-workers at Kansas State University (Swenson and Hardeman, 1996). In this effort we will use field data obtained from our tracer testing at Dixie Valley, Nevada. In addition, we will develop a flow model of the Dixie Valley reservoir using the finite difference code TOUGH 2 that has been used extensively in geothermal reservoir modeling studies (Pruess, 1991). The TOUGH2 model will provide additional verification of the GEOCRACK model.

\section{INDUSTRY INTEREST AND TECHNOLOGY TRANSFER}

All of our field tests are designed to maximize the collection of reservoir information as well as data on tracer stability. Because of this balance between research and application, industry is willing to cost-share 
those tests. The following table lists the name of the company as well as the type and extent of interest that it has demonstrated:

\section{Organization}

CalEnergy Corporation

Calpine Corporation

Far West Capital Inc.

Northern California Power Agency

Oxbow Power Services

Oxbow Power Services

Pacific Gas and Electric

Unocal Energy Resources

Unocal Geothermal Inc.

\section{Type and Extent of Interest}

cost-shared tracer test at Coso, CA, geothermal reservoir cost-shared tracer test at The Geysers, CA, geothermal reservoir cost-shared tracer test at Steamboat Hills, NV, geothermal reservoir

cost-shared tracer test at The Geysers, CA, geothermal reservoir cost-shared tracer test at Dixie Valley, NV, geothermal reservoir cost-shared tracer test at Beowawe, NV, geothermal reservoir cost-shared tracer test at The Geysers, CA, geothermal reservoir cost-shared tracer test at The Geysers, CA, geothermal reservoir cost-shared tracer test at Awibengkok, Indonesia, geothermal reservoir

\section{REFERENCES}

Adams, M. C., 1995, Vapor, liquid, and two-phase tracers for geothermal systems: Proceedings of the World Geothermal Congress, 3, 1875-1880.

Adams, M. C., Moore, J. N., Fabry, L. and Ahn, A. H., 1992, Thermal stabilities of aromatic acids as geothermal tracers: Geothermics, 21, 323-339.

Adams, M.C., and Davis, J., 1991, Kinetics of fluorescein decay and its application as a geothermal tracer: Geothermics, 20, 53-66.

Pruess, K., 1991, TOUGH2--a general-purpose numerical simulator for multiphase fluid and heat flow. Lawrence Berkeley Laboratory, Earth Sciences Division, LBL-29400.

Rose, P.E., Adams, M.C., 1994, The application of rhodamine WT as a geothermal tracer: Geothermal Resources Council Transactions, 18, 237-240.

Rose, P.E., McPherson, P.A., 1997, New fluorescent tracers for use in geothermal reservoirs: Geothermal Resources Council Transactions, 21, 249-253.

Rose, P.E., Adams, M.C., and Benoit, W.R., 1998, Tracer testing at Dixie Valley, Nevada, using pyrene tetrasulfonate, amino G, and fluorescein: Geothermal Resources Council Transactions, 22, 583-587.

Rose, P.E., 1998, The use of polyaromatic sulfonates as tracers in high temperature geothermal reservoirs: Proceedings $20^{\text {th }}$ NZ Geothermal Workshop, 239-241.

Rose, P.E., Goranson, C., Salls, D., and Kilbourn, P., 1999, Tracer testing at Steamboat Hills, Nevada, using fluorescein and 1,5-naphthalene disulfonate: Proceedings, $24^{\text {th }}$ Workshop on Geothermal Reservoir Engineering, Stanford University, Stanford, California, SGP-TR-162. 
Swenson, D. and Hardeman, B., 1996, GEOCRACK: A coupled fluid flow/heat transfer/rock deformation program for analysis of fluid flow in jointed rock, Mechanical Engineering Department, Kansas State University, Manhattan, KS. 


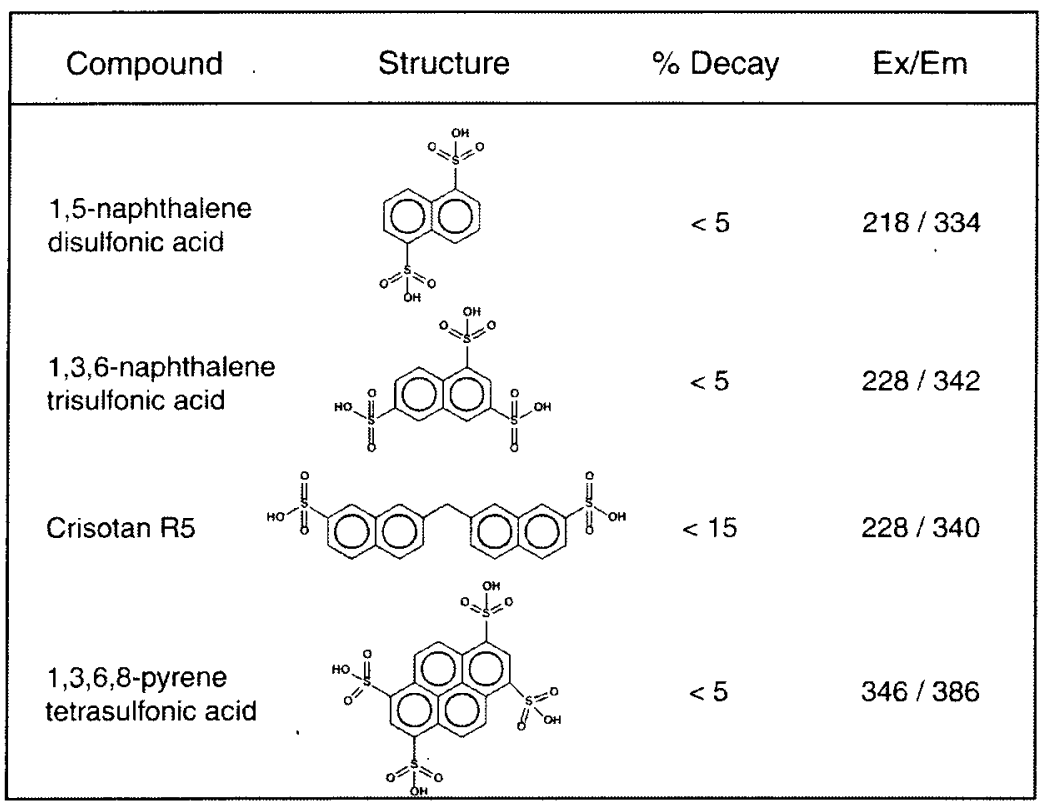

Figure 1. Chemical structures of the polyaromatic sulfonates tested in the laboratory and in the field. Column 3 shows the percent decay of each compound upon exposure to simulated reservoir conditions in laboratory batch reactors at $300^{\circ} \mathrm{C}$ for one week. Column 4 lists the excitation and emission maxima for each compound.

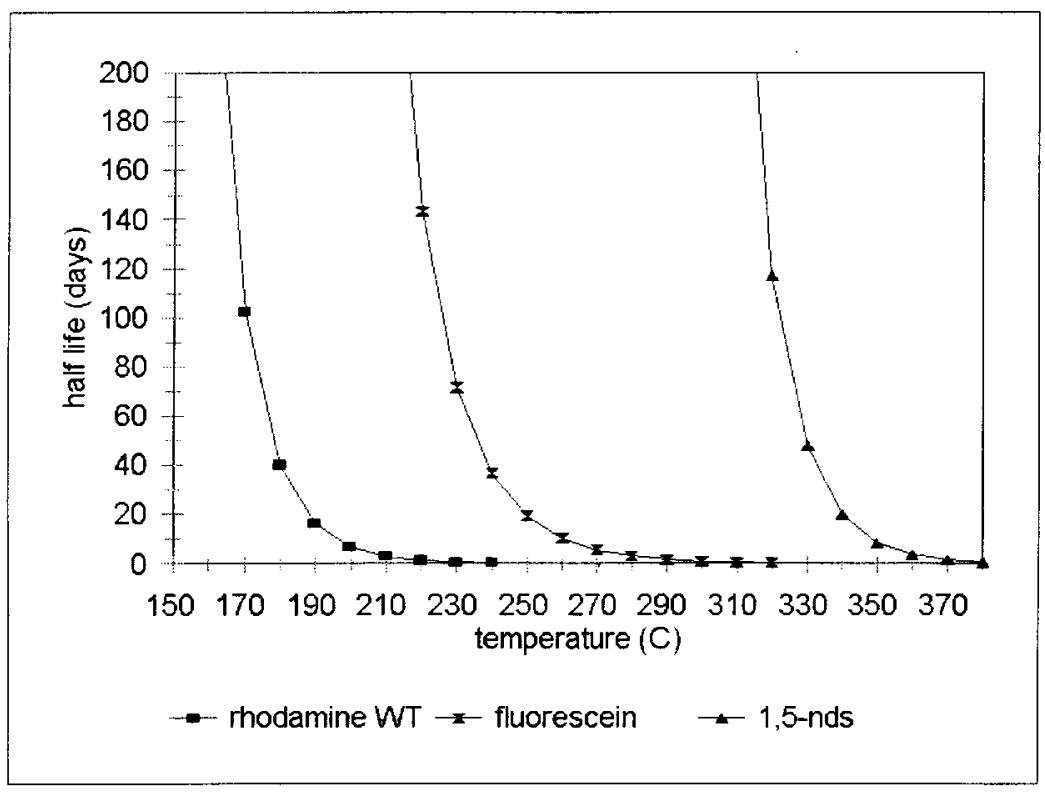

Figure 2. Half-life vs. temperature plotted for each of three fluorescent tracers based upon laboratorydetermined decay kinetics. Approximate maximum use temperatures were estimated to be $180^{\circ} \mathrm{C}, 250^{\circ} \mathrm{C}$, and $340^{\circ} \mathrm{C}$ for rhodamine WT, fluorescein, and 1,5-naphthalene disulfonate, respectively. 


\title{
TRACING FLUID SOURCES IN THE COSO GEOTHERMAL SYSTEM USING FLUID-INCLUSION GAS CHEMISTRY
}

\author{
Susan Juch Lutz, Joseph N. Moore, and Michael C. Adams \\ Energy \& Geoscience Institute, University of Utah
}

\section{KEY WORDS}

Fluid-inclusion gas chemistry, alteration mineralogy, vein assemblages, fluid evolution, geothermal system, quadrupole mass-spectrometry, Basin and Range

\section{PROJECT BACKGROUND AND STATUS}

In our previous work on the Coso geothermal system, we integrated petrographic observations, claymineral zoning, and fluid-inclusion studies into a conceptual model for alteration and mineral paragenesis during the history of the geothermal system (Moore et al., 1990; Lutz et al., 1996). Our recent study (Lutz et al., 1999) uses quadrupole-mass spectrometric analyses of fluid-inclusion gases trapped in vein and alteration minerals (Norman and Musgrave, 1995) to characterize the fluids that have circulated through the geothermal system through time.

Coso is one of several high-temperature geothermal systems associated with recent volcanic activity on the margins of the Basin and Range province. Rhyolite domes surround the productive portion of the field and the heat source for the present geothermal system is thought to be related to partially molten magma bodies at a depth of 5 to $20 \mathrm{~km}$. Like all modern geothermal systems, Coso production fluids are primarily meteoric water; however, the association with young volcanism allows the possibility of a magmatic component to the fluids. In this study, we examine the early evolution of the system as recorded by the fluid-inclusion gas compositions.

\section{PROJECT OBJECTIVES}

The overall objective of this study is to determine possible sources for the altering fluids, and the importance and distribution of magmatic, crustal, or meteoric-derived volatiles during the evolution of the geothermal system.

\section{Technical Objectives}

- Describe the occurrence and distribution of alteration minerals of selected samples from the Coso geothermal system and their relationship to permeable fracture zones.

- Characterize the gas compositions of specific alteration assemblages using the fluid-inclusion gas data obtained from the quadrupole mass spectrometric analyses.

- Compare the gas compositions of modern production fluids with fluid-inclusion gas compositions to determine which minerals are related to geochemical conditions in the present geothermal system, and which assemblages may be related to older alteration events. Compare the Coso fluidinclusion gas compositions with those from other Basin and Range geothermal systems, and other volcanic (andesitic or basaltic) systems around the world.

- Determine possible sources of altering fluids for characteristic vein or alteration assemblages at Coso. Interpret possible mechanisms (such as heating, mixing or boiling) for the deposition of the 
alteration minerals using the fluid-inclusion gas chemistry. Describe the roles of various kinds of fluids (magmatic, meteoric, or crustal) during the evolution of the Coso geothermal system.

\section{Expected Outcomes}

An understanding of the mineralogy and fluid chemistry of the deep fracture or fault zones is important in evaluation of the permeability structure of the modern geothermal reservoir. The fault zone mineralogy could be used as an exploration guide to distinguish older structures (Mesozoic fault zones or gouge zones) from younger active or reactivated fault or fractures zones that are permeable in the modern structural setting.

The gas chemistry and mineralogy of young alteration minerals may be used as a guide to pre-injection fluid chemistry where the initial (pre-injection) gas compositions of production fluids (for example, in a new well) are not known.

Knowing the source of fluids in the modern system is important compared to sources of fluids in the past. An increase in the amount of magmatic volatiles through time could signal an incipient eruption or tectonic activity, and may yield information about the periodicity of these events. This conceptual model can be related to other volcanic-hosted geothermal systems in the Philippines, Indonesia, Japan, Central America, and elsewhere.

\section{APPROACH}

Figure 1 presents our observations on the paragenesis of the alteration samples analyzed in this study. The general alteration history at Coso can be summarized as follows: 1 ) pregeothermal epidote mineralization; 2) initial heating to produce stilbite veins; 3 ) formation of clays (smectite at shallow depths, and sericite in upwelling areas) and carbonate veins as a result of mixing between thermal water and groundwater; 4) deposition of wairakite-bearing veins from fluids that were slightly more saline or carbon dioxide-rich than present production fluids; and 5) deposition of calcite veins with minor quartz, chlorite, pyrite and hematite.

The approach was to collect a variety of mineral samples from wells in the "Main Field" and "East Flank" portions of the geothermal area that represent a variety of depth intervals and types of alteration (Table 1). Four major types of secondary mineralization were sampled for analysis: 1) young calcite-hematite-pyrite veins; 2) wairakite or epidote veins and alteration that are spatially associated with deep reservoirs in the main field and eastern production wells; 3) older sericite-pyrite wallrock alteration; and 4) stilbite-calcite veins that are common in cooler or marginal portions of the geothermal area. Sixteen vein and alteration samples from eight Coso wells were selected from cuttings samples supplied by CalEnergy, and from cuttings and core stored at EGI's Geothermal Sample Library. A total of one hundred and twenty gas analyses were obtained from these samples.

\section{RESEARCH RESULTS}

The fluid-inclusion gas chemistry indicates that fluids of different origins were involved in the formation of a variety of alteration minerals during the evolution of the Coso geothermal system. Figures 1 and 2 record the changes in mineralogy and in gas chemistry through time. The samples are arranged with respect to their generalized paragenetic sequence from older (epidote assemblages) to younger (calcite assemblages).

The highest $\mathrm{N}_{2} / \mathrm{Ar}$ ratios are found in some calcite vein samples $\left(\mathrm{N}_{2} / \mathrm{Ar}\right.$ up to 5173) and in epidote assemblages $\left(\mathrm{N}_{2} / \mathrm{Ar}\right.$ ratios of 1000 to 1427 ). These high $\mathrm{N}_{2} / \mathrm{Ar}$ ratios suggest the presence of a magmatic 
component in the fluids that produced these assemblages. Sericite-pyrite altered samples, and stilbite and calcite-hematite veins have fluid-inclusion gas compositions with $\mathrm{N}_{2} / \mathrm{Ar}$ ratios less than 100 , indicating that these assemblages formed from meteoric fluids.

The epidote assemblage (Samples 1 and 2) is characterized by fluid-inclusion gases with high $\mathrm{N}_{2} / \mathrm{Ar}$ ratios and low He and $\mathrm{CH}_{4}$ contents. The epidote-chlorite-calcite assemblage appears to represent regional propylitic alteration that occurred before the formation of the present geothermal system. These gases may be associated with an andesitic magmatic system (Fig. 3; Giggenbach, 1992) related to an older subduction event.

Initiation of the present geothermal system is recorded by the formation of stilbite-calcite veins (Assemblage 1 in Figure 1, and Sample 3 in Figure 2). Low $\mathrm{CO}_{2} / \mathrm{CH}_{4}$ ratios of inclusions in stilbite veins indicate formation from crustal fluids. At Coso, we interpret the occurrence of stilbite to represent the presence of cool, dilute fluids either on the margin of the present geothermal system or during the initial heating of the system.

The high $\mathrm{CO}_{2}$ and low $\mathrm{H}_{2} \mathrm{O}$ contents of the sericite, pyrite, and wairakite assemblages (Assemblages 2 and 3 in Figure 2, and Samples 4-7 in Figure 3) suggest boiling. Wairakite veins are commonly observed to cut moderately-sericitized wallrock but generally these two assemblages appear to be spatially linked. The presence of quartz and calcite, and traces of adularia, pyrite and sphene in the wairakite veins is consistent with deposition resulting from boiling. Overall, the gas chemistry is consistent with our interpretation of the early formation of sericite from steam-heated groundwaters, and subsequent boiling to produce wairakite veins.

Calcite veining dominated the alteration mineralogy during later stages in the evolution of the Coso geothermal system (Assemblages 4 and 5 in Figure 1, and Samples 8-14 in Figures 2 and 3). These veins also contain some quartz, pyrite, hematite and chlorite. Calcite-hematite veins (Sample 8) have fluidinclusion gas compositions with meteoric $\mathrm{N}_{2} / \mathrm{Ar}$ ratios and low He contents. The presence of hematite in the calcite veins is consistent with deposition from oxygenated groundwaters that must have been present in the past (based on our previous fluid-inclusion studies).

The gas compositions of calcite vein Samples 13 and 14 from East Flank well 16 plot in the magmatic region on a $\mathrm{CH}_{4}-\mathrm{N}_{2}$-Ar ternary diagram (Fig. 3). The highest $\mathrm{N}_{2} / \mathrm{Ar}$ ratios of any of the study samples were found in the shallow samples collected from the upper cored portion of the well. It is intriguing that these samples are from the East Flank where we have previously documented recent heating based on the succession of alteration minerals (Lutz et al., 1996). Together, these two lines of evidence suggest that the eastern portion of the field may be undergoing heating as the result of recent magmatic activity. The high He contents (Fig. 3) of the calcite samples are consistent with a significant magmatic component. This signature is similar to the present-day gas analyses from steam samples taken from both the Devil's Kitchen fumarole area (Welhan et al.,1988) and from Coso production wells.

\section{FUTURE PLANS}

We plan to continue with the gas analyses of vein and mineral samples from the Coso well cuttings, and to extent this study to the analysis of surficial alteration samples (sinters, travertine, carbonate breccias). As part of understanding the alteration history, it would also be valuable to obtain some radiometric dates from one or more of the alteration assemblages. The hydrothermal sericite is an obvious candidate for either K-Ar or Ar-Ar dating. 


\section{INDUSTRY INTEREST AND TECHNOLOGY TRANSFER}

This study represents the combined efforts of CalEnergy, Caithness Corporation, and the Navy Geothermal Program Office and two research organizations, the Energy \& Geoscience Institute and New Mexico Technological University. CalEnergy and Caithness have recently completed a petrographic and whole-rock oxygen-isotopic study of selected cutting samples from the field. Their intent was to determine the extent of isotopic exchange between the rocks and the geothermal fluids at various locations throughout the field. Some of these samples were also analyzed in this study and together these two studies form a complementary investigation into the mineralogy and permeability of major structural features (fracture/fault zones, fluid entries) in the field. Barbara Bishop-Gollan of Caithness did her M.S. thesis on the sericite mineralogy of Coso reservoir rocks (Bishop, 1985), and has both a professional and academic interest in research concerning the sericite alteration. As part of monitoring the geochemistry of Coso geothermal system, the China Lake geothermal office is interested in comparing the gas chemistry of modern production fluids with the fluid-inclusion gas compositions and may use this information to refine their geochemical models for the system.

\section{REFERENCES}

Bishop, B.P., 1985, Correlation of hydrothermal sericite composition with temperature and permeability, Coso Hot Springs geothermal field, Inyo County, California: M.S. Thesis, Dept. of Geology, Stanford University.

Giggenbach, W.F., 1992, The composition of gases in geothermal and volcanic systems as a function of tectonic setting: in Kharaka and Maest, eds., Proceedings of the International Symposium of Water-Rock Interaction, Balkema, Rotterdam, v. 7, p. 873-878.

Lutz, S.J., Moore, J.N., and Copp, J.F., 1996, Integrated mineralogical and fluid-inclusion study of the Coso geothermal system, California: Proceedings, Twenty-first Workshop on Geothermal Reservoir Engineering, Stanford University, Stanford California, January 22-24, 1996, p. 187-194.

Lutz, S.J., Moore, J.N., Adams, M.C., and Norman, D.I., 1999, Tracing fluid sources in the Coso geothermal system using fluid-inclusion gas chemistry: Proceedings, Twenty-fourth Workshop on Geothermal Reservoir Engineering, Stanford University, Stanford California, January 25-27, 1999, in press.

Moore, J.N., Adams, M.C., Bishop-Gollan, B., Copp, J.F., and Hirtz, P., 1990, Geochemical structure of the Coso geothermal system, California: American Association of Petroleum Geologists Guidebook, Coso Field Trip, American Association of Petroleum Geologists EMD \#1, Moore, J.L. and Erskine, M., eds., p. 25-39.

Norman, D.I., and Musgrave, J., 1995, $\mathrm{N}_{2}$, Ar, and He in fluid inclusions: tracers of hydrothermal fluids: Geochimica et Cosmochimica Acta, v. 58, p. 119-131.

Welhan, J.A., Poreda, R.J., Rison, W., and Craig, H., 1988, Helium isotopes in geothermal and volcanic gases of the western United States, 1. Regional variability and magmatic origin: Journal of Volcanology and Geothermal Research, v. 34, p. 185-199. 
TABLE 1. Alteration Samples

\begin{tabular}{|c|c|c|c|}
\hline Sampla & viell & Destin ifi & Minerel \\
\hline 1 & 20 & 6550 & epidare \\
\hline$\overline{2}$ & 21 & 2846 & epidoss \\
\hline 3 & 22 & 6220 & etilbite-os \\
\hline 4 & 10 & 5080 & py+azricto \\
\hline 5 & 18 & 4600 & wakake \\
\hline 6 & 23 & 7950 & wair-qtz+cc.py \\
\hline 7 & 20 & 4970 & pyrits \\
\hline 8 & 20 & 4970 & cothem,pygtz \\
\hline 0 & 18 & 4630 & calcite \\
\hline 10 & 3 & 1810 & $\operatorname{cotal2}$ \\
\hline 11 & 10 & 5270 & $q 1 z \div c c$ \\
\hline 12 & 21 & 4940 & cotchl \\
\hline 13 & 16 & 5270 & Callite \\
\hline 14 & 16 & $331 \div 6.38$ & calvite \\
\hline
\end{tabular}

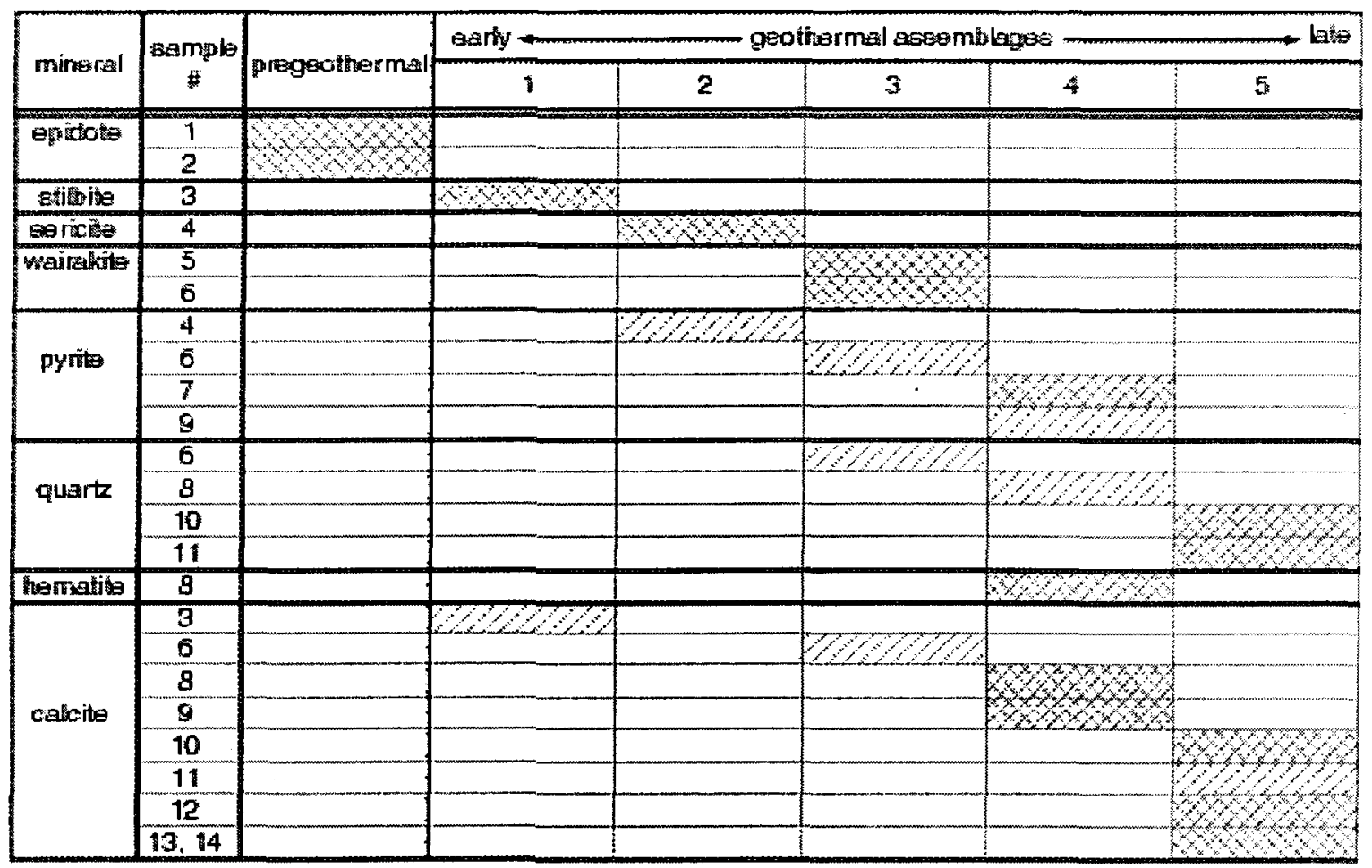

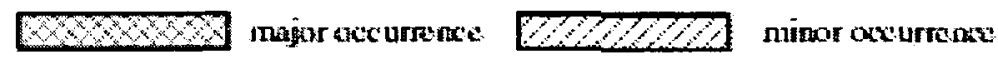

Fie. 1. Paragenetic scheme for allerution minerals associated with the Coso geothermal sy stan. See Tahle If for description of Samples 1-14. 


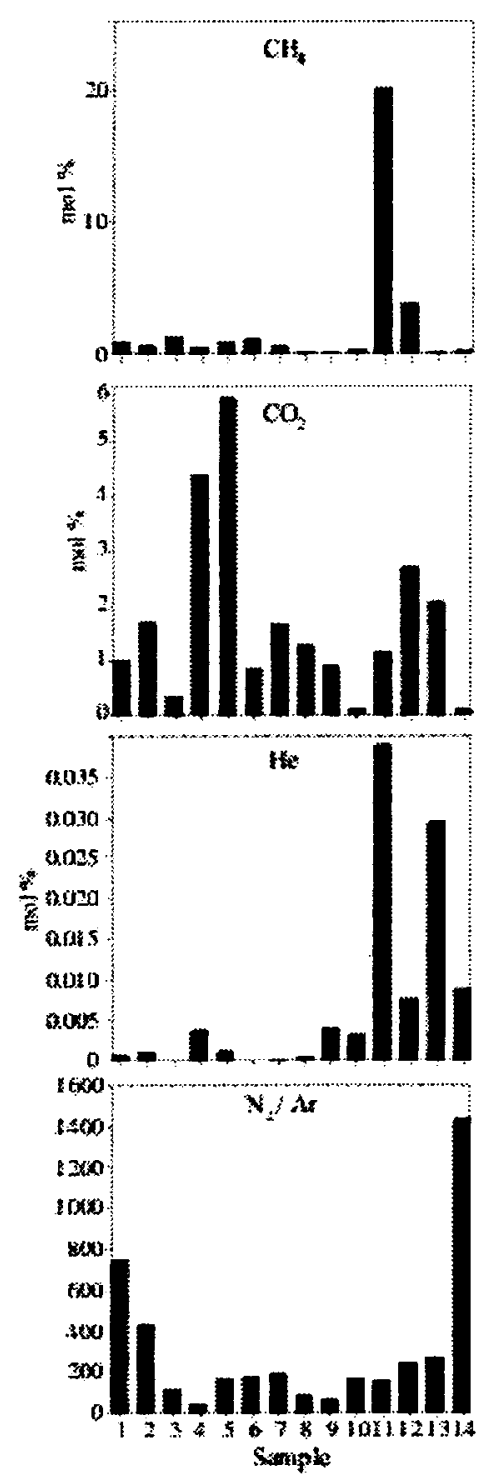

Fiz. 2. Arerage Buid-indusum

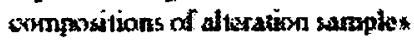
1- $\{4$, lisud in aerwel parazentic sexpus nce from older lepichto sumples ! and 2) ta yousacer foalcite samples 7 -14).
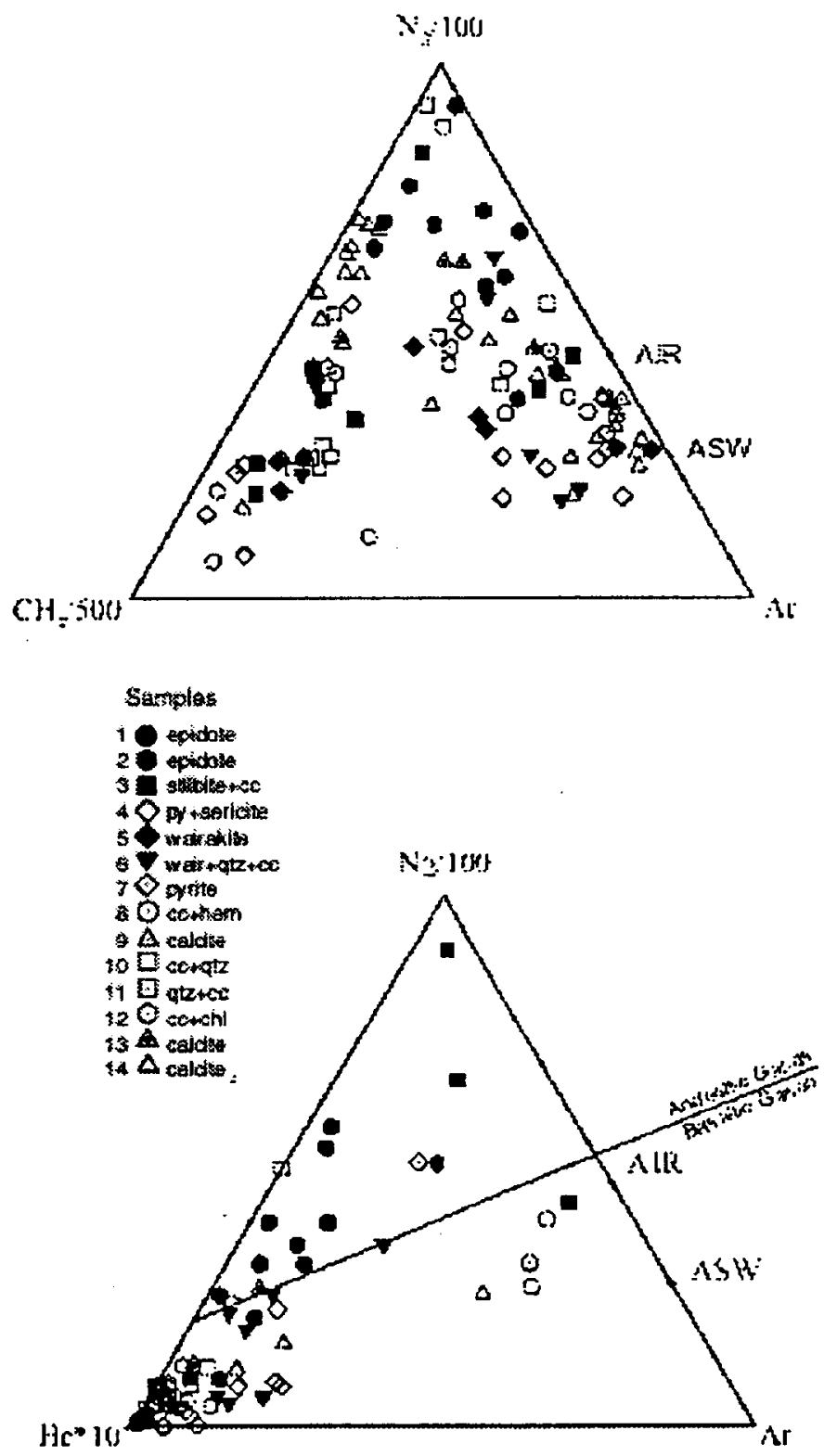

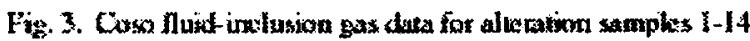

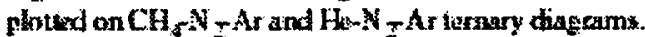
ASW = Air- Mturated water 


\title{
A COMPREHENSIVE STUDY OF FRACTURE PATTERNS AND DENSITIES IN THE GEYSERS GEOTHERMAL RESERVOIR USING MICROEARTHQUAKE SHEAR-WAVE SPLITTING
}

\author{
Peter E. Malin and Eylon Shalev, \\ Duke University
}

\section{KEY WORDS:}

The Geysers, microearthquakes

Project Purpose and FYs 1998 and 1999 Objectives: The purpose of this project is to produce threedimensional maps of crack-density and crack-orientation in fracture controlled geothermal or hydrocarbon reservoirs utilizing shear-wave splitting. Our 1998 and 1999 technical objectives are:

Determination of fracture pattern. Mapping the leading crack direction in two geothermal areas: The Geysers and Casa Diablo.

Detailed three-dimensional tomography for crack-density. To construct a crack-density map of the subsurface with $1 \mathrm{~km}$ resolution.

Develop a shear-wave splitting tomographic method to simultaneously invert for crack-density and crackorientation. This method may be employed in areas where the cracks are not align in the same direction.

FYs 1998 and 1999 Performance. We have made significant progress during 1998 and the first part of 1999. More than 2000 split shear-wave observations were collected from both The Geysers and Casa Diablo data. The polarization direction maps for both areas show consistent direction for fast shear-wave polarization, which enable us to perform crack-density inversion. Crack-density inversion in both geothermal fields point to several areas of high crack density. The development of simultaneous inversion for crack direction and density was not needed in the two geothermal fields we were working because of the uniform crack direction. A more careful experiment with complete knowledge of station orientation will be necessary for the simultaneous inversion.

A large number of the Casa Diablo earthquakes had unusual phases that were recorded by our network. The phases can be seen on many stations throughout the network, allowing the use of particle motions and differential travel times to examine their nature and points of origin. We used this data to image the locus of reflection points.

This project in not funded for 2000 .

\section{RESEARCH RESULTS}

POLARIZATION MAPS. Fast polarization maps (Figure 1) show that most of the stations in each geothermal area display consistent polarization directions, indicating uniform crack alignment. This direction is for The Geysers and for Casa Diablo. Some exceptions to uniform crack alignment can be seen at several stations, 9, 3, 13, and 14 at The Geysers, and M19, M25, M18, and M07 at Casa Diablo. It is possible that the horizontal component orientations of these stations are erroneous. If we treat the measurement of polarization direction as a statistical process, same as a depth of a layer interpretation, we can say that near the station we have uniformly aligned cracks. 
CRACK-DENSITY MAPS. Crack-density maps (Figure 2) show regions of high crack-density that may be used as drilling targets. There is a weak dependency between the crack-density and the choice of average crack orientation, but the changes are mainly in the size of the anomalies not in their locations. Since the amplitude of these anomalies depends mainly on the dumping parameters used in the inversion, exact average crack direction is not a critical parameter of the inversion. The maps show several zones of high crack-density in each geothermal area. The Geysers map (Figure 2a) suggests two zones of high crack-density at the top $1 \mathrm{~km}$, one near station 8 and the other between stations 6 and 5 . At greater depth these two areas converged to a single zone at depth of 1 to $2 \mathrm{~km}$. The Casa Diablo map (Figure 2a) suggests that there are two major zones of high crack-density: one near the junction of Highways 395 and 205, and one near the Mammoth airport. Both lie at depth of about 1.5 to $2.5 \mathrm{~km}$.

REFLECTION IMAGING: The results indicate that the reflecting zone is a curved, $1.5-\mathrm{km}$ by $2-\mathrm{km}$ surface $7.8 \mathrm{~km}$ below and $2.4 \mathrm{~km}$ west of Casa Diablo. For many events the reflections have the same directions of particle motion as direct P-waves, only with reversed polarities. The reversed polarity could result from reflection from a solid to partially molten rock contact. Unfortunately, the limited spatial extent of the reflecting zone and the relatively small number of stations at the right distances and azimuths make this possibility difficult to demonstrate. Yet, given the volcanic history of the caldera, its recent tectonic activity and other types of seismic evidence, the hypothesis, that the reflections come from a magmatic structure, such as a sill or the top of an intrusion, now seems likely.

Technology Integration: During the past two years, we worked in close cooperation with scientists from the University of North Carolina at Chapel Hill on the crack direction problem. We also cooperated with the California Energy Commission (Mr. Kelley Birkinshaw and Mr. Rodger Peak), the Mono Co. Office of Energy (Mr. Dan Lyster), UNOCAL (Mr. Tim Christiansen ), Mammoth Pacific Power Co. (Mr. Mike Walker), the Kenyan National Power Company, Limited lendash KenGen (Dr. Silas Simiyu), the Geothermal Program Office of the Naval Air Weapons Station at China Lake (Mr. Mike Hasting).

Presentations on this project were made in the fall 1997 and fall. 1998 AGU and the Twenty-Forth Workshop on Geothermal Reservoir Engineering in January 1999. One paper (Lou et. al. 1997) was published in a peer review journal and two papers are either submitted or in preparation. We also made several other presentations, including the Hydrologic Advisory Council of Mono Co. (HAC), and the United States Geological Survey.

\section{REFERENCES AND PRESENTATIONS}

Lou, M., E. Shalev, and P.E. Malin, 1997, Shear-wave splitting and fracture alignment at the Northwest Geysers, California: Geophysical Research Letters, v. 24, p.1895-1898.

Malin, P., A. Stroujkova, \& E. Shalev, 1998, Seismological witness to the birth of a dike: micro hybrid-, \& low frequency-earthquake activity at Mammoth, in 1997: EOS Fall Supplement, v. 79, p. F949.

Malin, P.E., and E. Shalev., 1999, Shear-wave splitting crack density maps for the Geysers and Mammoth: Proceedings, Twenty-Fourth Workshop on Geothermal Reservoir Engineering at Stanford University, Stanford, California, January 25-27, 1999, SGP-TR-162, p. 264-267.

Shalev, E., P. E. Malin, \& A. Dechkovovskaia, 1998, Fracture alignment \& crack-density in Long Valley Caldera, CA: EOS Fall Supplement, v.79, p. F622.

Duke University, Department of Civil and Environmental Engineering. Two examples of mechanical analysis of small-scale orogenic events. 1999 presentation University of North Carolina, Department of Geology. Two problems in crustal dynamics: Heinrich events and Mammoth intrusions. 1999 presentation 


\section{Geysers Polarization direction}

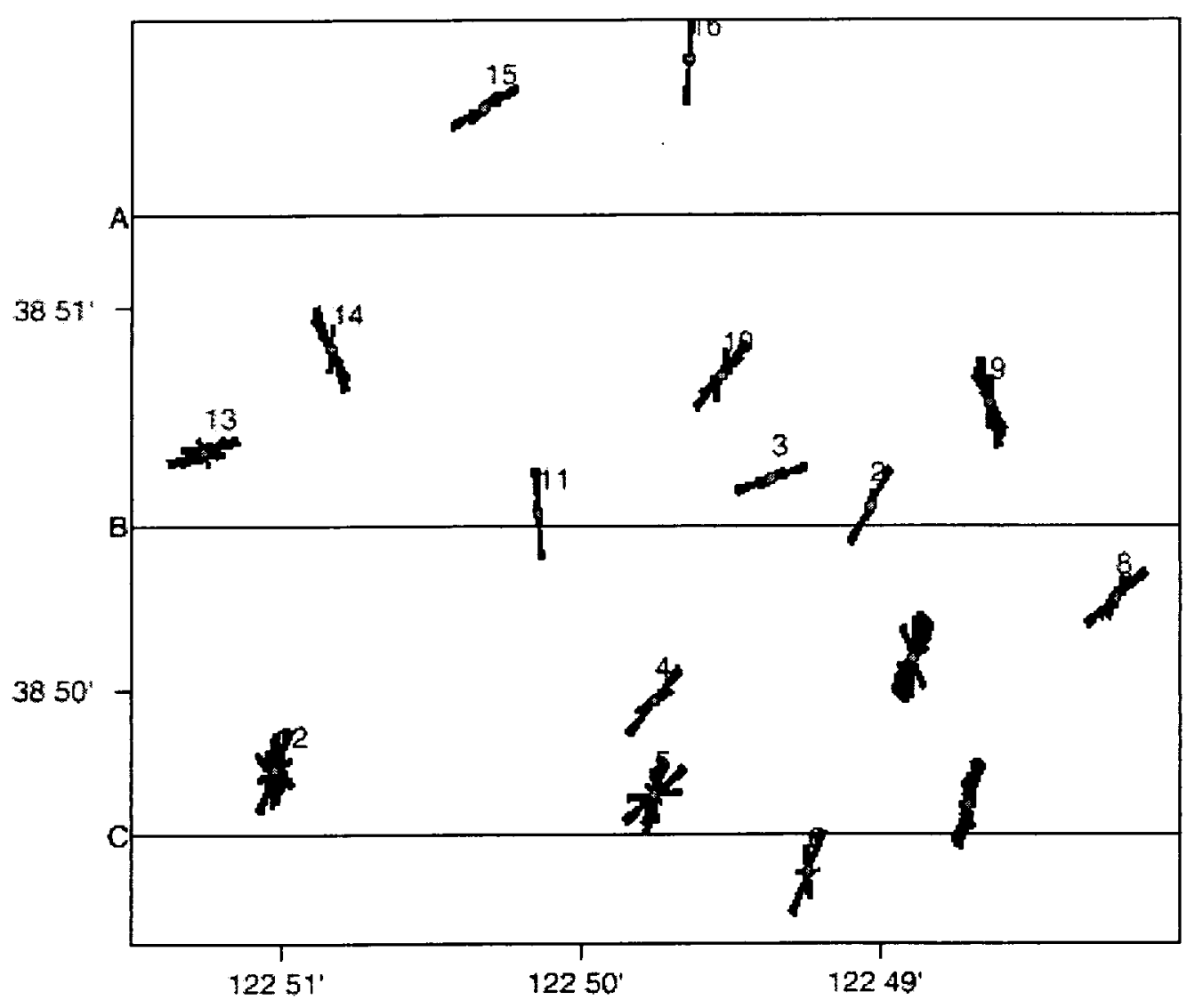

Figure 1. Geysers polarization direction. 

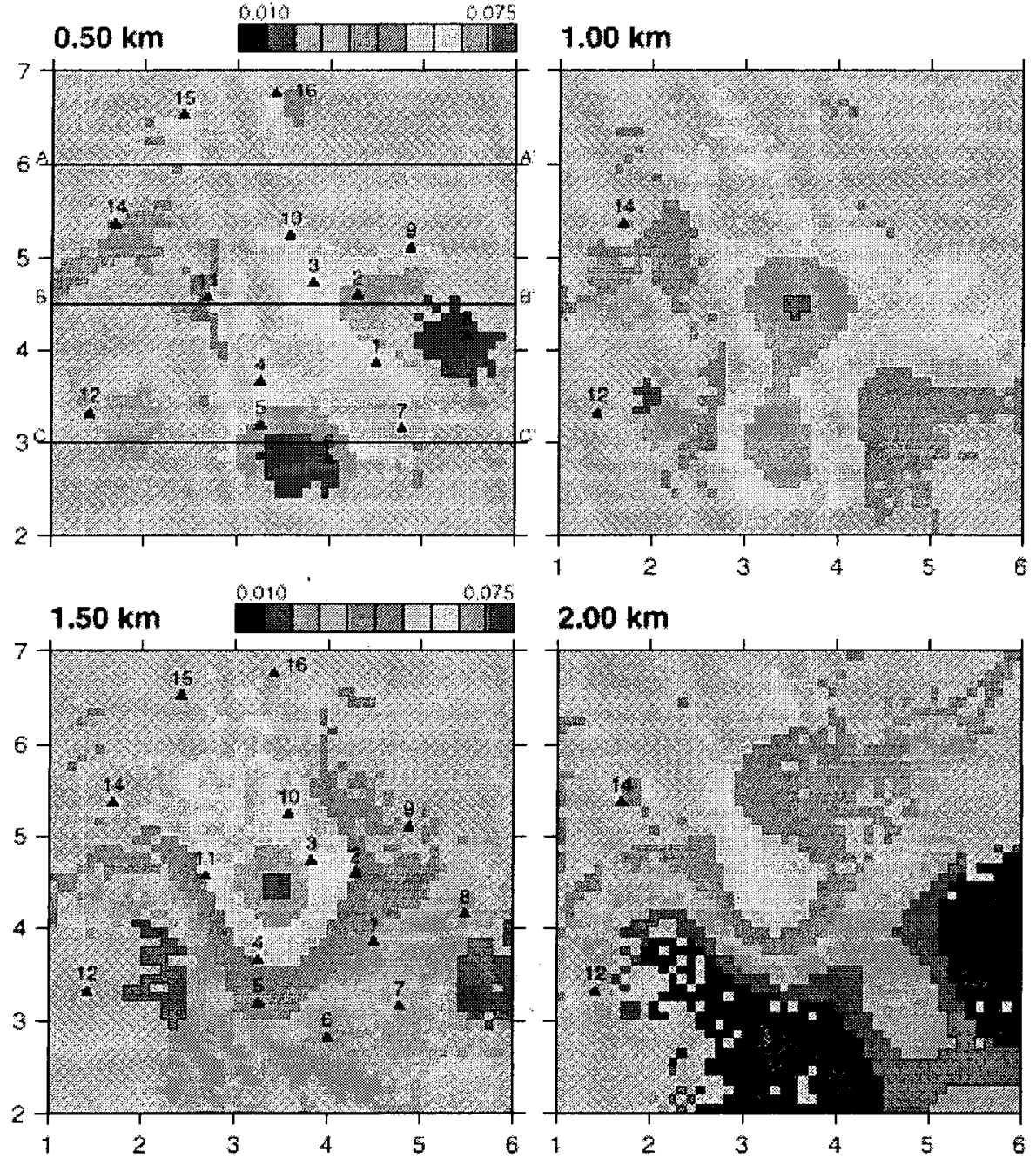

$2.00 \mathrm{~km}$

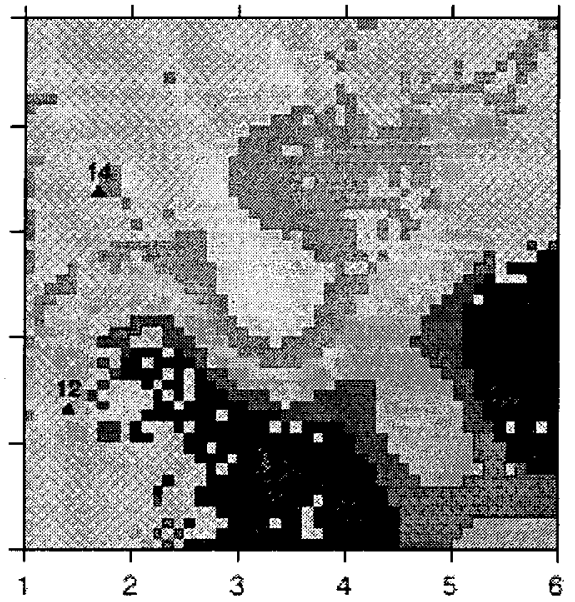

Figure 2. Crack density maps. 


\title{
INSTRUMENTATION DEVELOPMENT IN SUPPORT OF THE GEOTHERMAL INDUSTRY \\ High-Temperature Electronics Hardware and Software and Fiber Optics for Wellbore Temperature
}

\author{
Randy A. Normann and Joseph A. Henfling \\ Sandia National Laboratories
}

\section{KEY WORDS}

high-temperature electronics, distributed temperatures systems, downhole sample, wellbore sample

\section{PROJECT BACKGROUND AND STATUS}

Tools that provide data for characterizing the physical and chemical properties of a geothermal reservoir and can withstand the harsh geothermal environment are important for the geothermal industry. Indications of temperature gradients and/or changes in reservoir temperatures and levels enable the resource manager to better characterize the reservoir, leading to increased well life through optimized selection of injector wells and production management. Furthermore, detailed understanding of a producing reservoir is important for determining optimal locations for future wells.

In 1998, Sandia completed development of the pressure/temperature/spinner tool and worked with Thermochem Inc. to add a non-condensable gas capture option to the steam-sampler tool. Both of these tools are based on electronics housed within a heat shielding dewar (similar to a Thermos ${ }^{\mathrm{TM}}$ bottle). Sandia modified the tool and sample bottle to mate directly with a Thermochem-designed gas extraction system. With capture of both condensable and non-condensable gasses from the wellbore, a more complete chemical analysis of the wellbore could be performed. Following these modifications, the steam-sampler tool was successfully deployed in a production well at The Geysers.

Also in FY98, Sandia began a project on the use of fiber optics for monitoring wellbore temperatures. In this application, a single optical fiber placed along the length of a production well can provide a complete distributed temperature profile for the entire well very rapidly. Sandia's role was to evaluate the stability of fibers permanently installed within geothermal wells.

\section{- PROJECT OBJECTIVES}

Downhole measurement tools are used by the hydrocarbon industry to calibrate surface geophysical experiments, to establish reservoir parameters, and to provide engineering data for drilling and production. Such measurements are not as common to the geothermal industry because of its small market and harsh downhole conditions. Sandia's goal is to foster the development and commercial availability of suitable high-temperature logging tools for the geothermal industry.

\section{Technical Objectives}

Our overarching objective is to develop and transfer to industry tools and sensors for geothermal reservoir characterization.

In FY98, our goals were:

- To develop a non-condensable gas capture system for the steam-sampler. 
- To validate the performance of the new steam-sampler at The Geysers.

- To characterize the performance of fiber optic distributed temperature systems in geothermal wells.

\section{Expected Outcomes}

Ultimately, this research will lead to new, cost-effective reservoir characterization tools that are commercially available to the geothermal industry. Although the geothermal industry views hightemperature instrumentation as critical, it is difficult to characterize impact directly in terms of cost savings. The expected benefit of low-cost logging tools is the elimination of drilling one well in ten. This can be accomplished by developing tools that take dynamic measurements, such as the steam-sampler. This tool will enable direct measurement of well changes induced by production and re-injection within the reservoir. By monitoring these changes, the reservoir manager can correct unfavorable trends and/or make better initial assessments of expected performance.

\section{APPROACH}

Our approach to developing low-cost dewared tools for geothermal applications comprises the following steps (1) design electronics around common components, (2) develop hardware for simple manufacturing, (3) write software for easy use with Windows 95, (4) perform laboratory tests at Sandia; and (5) perform field tests in cooperation with industry. This approach allows first-hand field-operation feedback from industry to be incorporated directly into the hardware and software designs. We strive to keep our systems simple; hardware must be functional yet easy for the future operator to understand, fabricate and repair. Our software design has a simple interface and often includes software help and documentation.

Our approach to the development of Distributed Temperatures Systems (DTS) was to start with systems which had been successful in the oil and gas industry and deploy a fiber with a temperature rating of $300^{\circ} \mathrm{C}$ for geothermal applications. By working with industry on fiber deployment and calibration, we hope to expand the usefulness of DTS to include geothermal applications.

\section{RESEARCH RESULTS}

\section{Subsurface Steam-Sampler}

The steam sampler modified for capturing non-condensable gases was field tested in a production well at The Geysers. A number of samples were taken at various depths above different production zones. These samples demonstrated a working steam-sampler tool, and indicated variations of chemical composition with depth and production zone.

The gas sampler will enable producers to determine where and how unwanted elements are getting into the production stream ${ }^{2}$. This knowledge will be useful for developing strategies to mitigate the effects of harmful compounds (e.g., corrosive $\mathrm{HCl}$ ) entering into the production stream.

\section{Fiber-Optics Wellbore Installation}

Several polyamide fibers deployed in the low-temperature geothermal wells of Beowawe were monitored for stability. These fibers exhibited degradation, but continued to perform over a one-year period and eventually stabilized at a diminished level of performance. A spectrosopic analysis of the degraded fibers confirmed that hydrogen trapped within the fiber was largely responsible for the degradation. 
Degradation of the fibers prevents effective calibration, greatly limiting their value for quantitative determinations of well-bore temperature. Research is needed to overcome this difficulty. The successful approach will likely require field calibration once the fiber has equilibrated with the wellbore environment.

Fibers were also deployed in production wells at Dixie Valley, NV, which are $50^{\circ} \mathrm{C}$ hotter than the Beowawe wells. Because of the higher temperature, Dixie Valley fibers failed after only a few weeks of exposure'. We have analyzed and identified two failure mechanisms; one is hydrogen bonding within the fiber, thus changing their optical properties; and the second is the mechanical interaction between the protective stainless-steel tubing and the fiber-optic cable housed within. Work in progress is aimed at better understanding the degradation mechanisms so mitigation strategies can be developed.

\section{FUTURE PLANS}

Work will continue to transfer technology embodied in the existing tools to the industry for commercialization. We have applied for DOE Designated Capabilities status for our high-temperature capabilities for electronics over $200^{\circ} \mathrm{C}$. This designation will allow any company, large or small, to hire Sandia's Geothermal Research Department to aid in converting existing tools to higher temperature operation, and to test new high-temperature tools against Sandia standards.

We also plan to modify the steam sampler system to collect pristine samples of geothermal liquids and to begin a laboratory project to characterize the degradation mechanisms of fiber optics for distributed temperature measurement.

\section{INDUSTRY INTEREST}

\section{Organization}

Pruett Industries

Thermochem Inc.

Unocal, Calpine

Oxbow Geothermal

\section{Type and Extent of Interest}

Silicon-on-insulator electronics for future dewarless PTS tool; Life extension of fiber-optics within the wellbore

Steam-Sampler commercialization and the liquid sampling system

Steam-Sampler deployment at The Geysers

Optical-Fiber DTS for reservoir tracking. Temperature calibration methods for increased accuracy in reservoir tracking

\section{REFERENCES}

1. Colin Smithpeter, Randy Normann, James Krumhansl, Dick Benoit, Steve Thompson, "Evaluation of A Distributed Fiber-Optic Temperature Sensor For Logging WellBore Temperature", Proc. Twenty-Fourth Workshop on Geothermal Reservoir Engineering, Stanford University, Jan. 25-27, 1999

2. Peter Lysne, Brian Koenig, Paul Hirtz, Randy Normann, Joseph Henfling, "Subsurface Steam Sampling in the Geysers Wells", Trans. Geothermal Resources Council, 1997

3. Glowka, D.A., "The Role of R\&D in Geothermal Well Costs Reduction," (Oct. 1997), Trans. Geothermal Resources Council, 21, 405-410. 


\title{
Java Electronic Reporting System for California Geothermal Data
}

\author{
Jeff Wagoner \\ Lawrence Livermore National Laboratory (LLNL) \\ Stephanie Daveler \\ Lawrence Livermore National Laboratory (LLNL) \\ Richard Thomas \\ California Division of Oil and Gas and Geothermal Resources
}

\section{KEY WORDS}

database, geothermal production database, geothermal injection database, CADOGGR, electronic filing

\section{PROJECT BACKGROUND AND STATUS}

The California Division of Oil and Gas and Geothermal Resources (CADOGGR) has been the principal state regulatory agency for geothermal well drilling and field production activities since 1965. Records, consisting of notices, summaries, histories, and geophysical logs, have been filed and maintained in hardcopy form. Currently, there are an estimated 115,000 pages of records and 2500 geophysical well logs on file with CADOGGR.

The original CADOGGR electronic geothermal production and injection database was created in 1980, as part of a project to assess the geothermal resources at The Geysers in California. Staff entered data from hardcopy reports for all geothermal fields into a mainframe database maintained at the Teale Data Center.

In 1990, the entire production management system was changed. A PC-based system was developed, and the database was transferred to PCs in each district office. All of the data-integrity-checking programs written in COBOL were rewritten in Smart database programming code. The DOS Smart Database program is part of a suite of DOS programs developed by Innovated Software, Inc. This company ceased development and support of Smart in the early 1990s. Consequently, the entire system is dated and obsolete.

- Lawrence Livermore National Laboratory (LLNL) has reengineered CADOGGR's geothermal data processing programs by developing the Java Electronic Reporting System. These efforts will, in aggregate, cut costs, improve regulatory efforts, increase efficiencies, and serve as a 21 st Century model for other geothermal agencies and the geothermal industry. CADOGGR's engineers will be able to track geothermal production and injection, check data integrity, query the database, generate reports, and analyze statistics. Engineers will be able to electronically access virtually all of the geothermal production and injection data over the Internet. Engineers will also be able to access raster images of well file documents for the more than 1400 geothermal wells and temperature-gradient holes. Images will be stored on CD-ROM and will be updated periodically. Geothermal companies will have the option to electronically file the forms and required reports. This will decrease permit response time, which is an added benefit to well operators. 


\section{PROJECT OBJECTIVES}

\section{Technical Objectives}

- Convert hardcopy well files to Adobe Acrobat pdf files.

- $\quad$ Archive images on CD-ROM and computer hard drive.

- Populate a relational database with geothermal data.

- Develop an application to access data and images over the Internet.

- Redesign the existing Smart database system, using updated technology.

- Incorporate electronic filing.

\section{Expected Outcomes}

- An integrated data system that will help cut costs, improve regulatory efforts, increase efficiencies, and serve as a 21 st Century model for other geothermal agencies and the geothermal industry.

\section{APPROACH}

LLNL recently developed an inexpensive mechanism for on-line access to all of the nonconfidential oil and gas data currently available at CADOGGR. This project, called the Oil and Gas Data Infrastructure Project (OGDIP), provides cost-effective access through the existing Internet infrastructure. The current geothermal project has heavily leveraged the technology developed in OGDIP.

\section{RESEARCH RESULTS}

The Java Electronic Reporting System allows geothermal well operators and personnel from CADOGGR to report monthly production and injection data. In California, this information is required for every private, state, or federal well that is capable of producing or injecting geothermal fluids. A report is delinquent if not received by CADOGGR during the month following the reported values. Failure to file reports may result in civil penalties.

Previously, reports were submitted on a written form or by computer diskette. Written forms were mailed to the appropriate CADOGGR district, where they were hand entered by CADOGGR personnel. In contrast, the new Java Electronic Reporting System allows operators submitting reports by form to enter their information over the Web. Data are entered directly into temporary database tables, where CADOGGR personnel can validate the information. This saves CADOGGR employees from handentering data and allows them to change incorrect values.

CADOGGR personnel can also run this Applet as a standalone program. When run in this mode, CADOGGR employees can enter reports, read in diskette files, and view reports stored in the temporary database tables. CADOGGR personnel can view and change reports that contain suspected invalid data. Once validated, the reports can be moved from the temporary tables to the main database.

The main function of the Java Electronic Reporting System is to allow users to enter and validate geothermal well reports by accessing a Microsoft SQL server database over the Web. This reporting system was developed using Java, which is an object-oriented programming language developed by Sun 
Microsystems in 1991. Similar to $\mathrm{C}++$, it was designed to be small, simple, and portable across platforms and operating systems. Java has grown in popularity and has been incorporated into many browsers. Java can produce code that runs as a standalone program, an Applet within an HTML page, or both; this new system includes these Java features.

A graduate student from San Francisco State University scanned all of the geothermal well files at CADOGGR in Sacramento. All files are now stored on CD-ROMs and will soon be archived on a central computer hard drive at CADOGGR.

The current CADOGGR database, Smart, will soon be replaced by a Microsoft SQL server. This involves installing SQL server on the CADOGGR server, defining the tables, and migrating data from Smart to the new system.

\section{FUTURE PLANS}

The Java Electronic Reporting System will be implemented at CADOGGR in Sacramento during the third quarter of FY 1999.

\section{INDUSTRY INTEREST AND TECHNOLOGY TRANSFER}

The Java Electronic Reporting System will have applicability beyond the needs and use of CADOGGR's geothermal program. Special CD-ROMs containing the companies' production and injection data and the imaged well records that are not subject to confidentiality will be made available. Geothermal companies will be able to access production and injection data and the images as easily as CADOGGR. The public will be able to purchase CD-ROMs containing raster images of subsets of the nonconfidential data. District engineers will handle requests for data items, guaranteeing the confidentiality of proprietary data.

The Java code will also be made available to other interested state and federal agencies, such as the Nevada Bureau of Mines and the U.S. Bureau of Land Management. These agencies have expressed interest in and support for this project. Besides serving as a national geothermal standard, the computer programs developed will be very similar and will have the same functionality as projects being developed for the oil and gas industry and funded by the U.S. Department of Energy (DOE). Another attractive feature of this project is that it has leveraged previous DOE-funded projects and has resulted in major cost savings to the DOE.

Organization

\section{CADOGGR}

Nevada Bureau of Mines

U.S. Bureau of Land Management

\section{Type and Extent of Interest}

Will be implemented during the third quarter of FY 1999

Will have access to the Java code after implementation at CADOGGR

Will have access to the Java code after implementation at CADOGGR

\section{REFERENCES}

http://wildcat.llnl.gov

http://davelerpc.es.llnl.gov/jefs/ 


\title{
ADVANCES IN GEOTHERMAL RESERVOIR SIMULATION
}

\author{
Karsten Pruess, Curt Oldenburg, and George Moridis \\ E. O. Lawrence Berkeley National Laboratory
}

\section{KEY WORDS}

numerical modeling, coupled wellbore flow, multicomponent fluid mixtures, heterogeneous reservoirs

\section{PROJECT BACKGROUND AND STATUS}

Numerical reservoir simulation has matured to the point where it is now standard engineering practice in the assessment, development, and management of geothermal resources. Advances continue to be made to improve the description of reservoir fluids and processes, enhance numerical efficiency and enable solution of larger problems on smaller computers, and to increase the power of simulators as practical engineering tools.

\section{PROJECT OBJECTIVES}

The general objective of this research is to improve the realism, power and utility of geothermal reservoir simulation as a robust and accurate engineering tool, by developing enhanced process simulation capabilities, novel applications to reservoir problems, and improved user features. Recent work has focussed on assembling and documenting a new version 2.0 of our general-purpose reservoir simulator TOUGH2 (Pruess, 1991). Among the specific objectives of this new version are the following: (1) add significant capabilities for simulating flow and transport processes, that will be useful for engineering and geoscience applications; (2) add features to improve useability of the code, but avoid encumbering users with "feature creep;" (3) keep code changes to the minimum required to achieve desired capabilities; (4) remain as much as possible upward compatible with the earlier version; (5) stay with FORTRAN77 and publish source code; (6) facilitate code maintenance by minimizing the number of independent modules and "minor" variations among them; (7) increasingly emphasize solved problems and internal documentation as a way of communicating code features and use.

\section{Technical Objectives}

- Develop more comprehensive and accurate description of reservoir fluids and processes.

- Improve numerical algorithms, portability, and useability of reservoir simulators.

- Demonstrate novel applications of interest to the geothermal community.

- Accomplish technology transfer and provide technical support for users of the TOUGH/MULKOM family of codes.

\section{Expected Outcomes}

- Release of a fully documented version 2.0 of the widely used TOUGH2 simulator.

- More versatile and realistic descriptions of fluid mixtures containing dissolved solids and noncondensible gases, including water-soluble and volatile tracers.

- Improved modeling of fluid and heat flow in highly heterogeneous systems. 
- Capabilities for coupled modeling of reservoir and wellbore flow.

\section{APPROACH}

TOUGH2 program modules developed for various research projects are being integrated into the overall program structure. User documentation including templates for typical application problems and improved user features is being developed. Novel applications to difficult reservoir problems are being pursued. Technical information is being presented in laboratory reports and journal papers, at conferences, and on the TOUGH2 homepage on the WorldWideWeb, at URL: http://ccs.lbl.gov/TOUGH2/.

\section{RESEARCH RESULTS}

- Several new fluid property modules have been completed and integrated into the TOUGH2 framework, providing new capabilities for treating dissolved solids and non-condensible gases (Fig. 1), and water-soluble and volatile tracers.

- Simulations of thermohaline convection in a hypersaline system reproduced many of the features of the Salton Sea geothermal system (Oldenburg and Pruess, 1998).

- A capability for fully coupled simulation of reservoir and wellbore flow was implemented (Fig. 2; Pruess et al., 1998).

- A package of robust and efficient linear solvers for TOUGH2 was developed (Moridis and Pruess, 1998).

- Block-wise permeability modification with consistent scaling of capillary pressures was implemented for modeling flow in highly heterogeneous systems.

- A TOUGH Workshop '98 was held at the Berkeley Lab. It featured over 50 technical papers, with geothermal reservoir engineering having the largest share (Pruess, 1998).

- A fully documented version 2.0 of TOUGH2 is nearing completion.

\section{FUTURE PLANS}

We continue to improve process modeling capabilities and user features of TOUGH2. Emphasis will be placed on prediction of geophysical observables and on chemically reactive flows.

\section{INDUSTRY INTEREST AND TECHNOLOGY TRANSFER}

The TOUGH and TOUGH2 reservoir simulation programs are currently in use in approximately 150 organizations in 26 countries. The TOUGH Workshop '98 attracted over 80 participants from 12 countries. The International Groundwater Modeling Center (IGWMC) at the Colorado School of Mines has adopted TOUGH2 as a teaching tool and is planning short courses for users

\section{REFERENCES}

Hadgu, T., R.W. Zimmerman and G.S. Bodvarsson. Coupled Reservoir-Wellbore Simulation of Geothermal Reservoir Behavior. Geothermics, Vol. 24, No. 2, pp. 145-166, 1995. 
Moridis, G. and K. Pruess. T2SOLV: An Enhanced Package of Solvers for the TOUGH2 Family of Reservoir Simulation Codes, Geothermics, Vol. 27, No. 4, pp. 415 - 444, 1998.

Oldenburg, C.M. and K. Pruess. Layered Thermohaline Convection in Hypersaline Geothermal Systems, Transport in Porous Media, Vol. 33, pp. 29 - 63, 1998.

Pruess, K., TOUGH2 - A general-purpose numerical simulator for multiphase fluid and heat flow, Lawrence Berkeley Laboratory Report LBL-29400, May 1991.

Pruess K. (ed.) Proceedings of the TOUGH Workshop '98, Lawrence Berkeley National Laboratory Report LBNL-41995, Berkeley, CA, May 1998.

Pruess, K., C. Oldenburg and G. Moridis. Overview of TOUGH2, Version 2.0, in: K. Pruess (ed.), Proceedings of the TOUGH Workshop '98, pp. 307 - 314, Lawrence Berkeley National Laboratory Report LBNL-41995, Berkeley, CA, May 1998. 


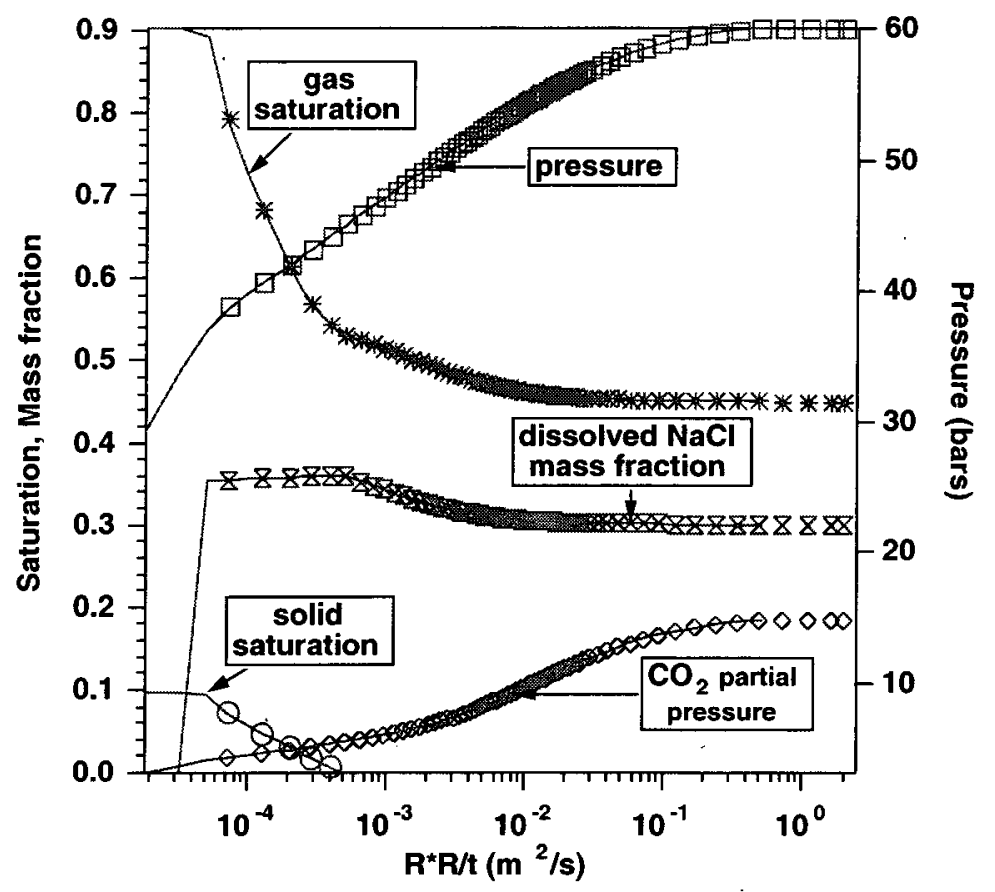

Figure 1. Simulated thermodynamic conditions for a 1-D radial flow problem with salinity and noncondensible gas, plotted as a function of the similarity variable $x=R^{2} / t$. Solids precipitation due to boiling and associated porosity and permability decline are included. Results at $2 \times 10^{6}$ seconds are shown as lines, while the data at $\mathrm{t}=5 \times 10^{5}$ seconds are given as symbols.

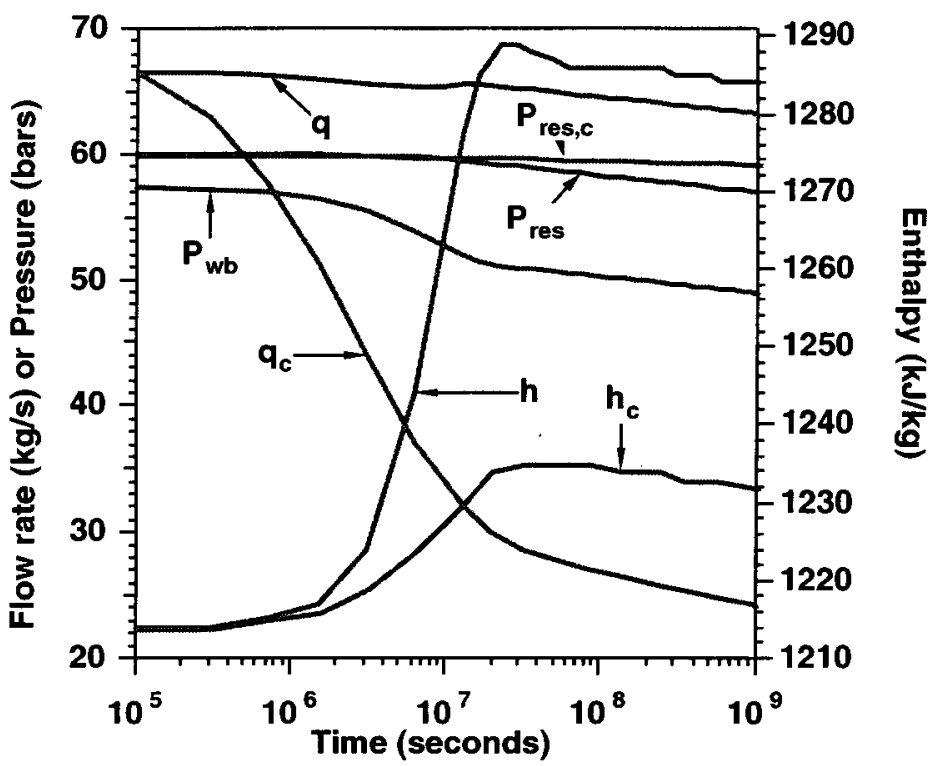

Figure 2. Simulated flow rate $(q)$, flowing enthalpy $(h)$, flowing bottomhole pressure $\left(P_{w b}\right)$ and reservoir pressure in well grid block $\left(\mathrm{P}_{\text {res }}\right)$ for a coupled reservoir-wellbore flow problem adapted from Hadgu et al. (1995). Results obtained for constant bottomhole pressure of $P_{w b}=57.37$ bars, labeled $q_{c}$, $h_{c}$, and $P_{\text {res,c, are also shown. }}$ 


\title{
ADVANCES IN MULTIPHASE INVERSE MODELING
}

\author{
Stefan Finsterle and Karsten Pruess \\ E. O. Lawrence Berkeley National Laboratory
}

\section{KEY WORDS}

inverse modeling, parameter estimation, parallelization, ITOUGH2

\section{PROJECT BACKGROUND AND STATUS}

The project aims at developing and improving parameter estimation techniques by automatically history matching the numerical model to laboratory and field data from geothermal reservoirs. If calibrating against production data, inverse modeling provides site-specific, model-related parameters on the scale of interest, making the subsequent model predictions more reliable.

The ITOUGH2 code (Finsterle, 1999a,b,c) provides inverse modeling capabilities for the general-purpose multiphase reservoir simulator TOUGH2 (Pruess, 1991). In theory, any TOUGH2 input parameter can be estimated in a joint inversion using any type of observed data, for which a corresponding TOUGH2 output can be calculated. This assumes that the conceptual model is sufficiently realistic; it must be able to represent the salient features of the reservoir. Furthermore, adequate and sensitive data of high quality must be available to enable independent and accurate estimation of the parameters of interest. Finally, the necessary computer resources must be available to efficiently run the many forward simulations required for the solution of the inverse problem.

ITOUGH 2 has been extensively tested, is fully documented, and ready to be released to the public. At the same time, the code is continually being revised and enhanced to incorporate improvements in the TOUGH2 simulator, which solves the forward problem. The efficiency and robustness of the optimization algorithms is also improved.

\section{PROJECT OBJECTIVES}

The general objective of this research is to adapt the ITOUGH2 code to specific needs of geothermal applications, and to demonstrate its usefulness for the determination of hydrogeologic and thermal properties. Furthermore, the code should be efficient enough to enable automatic calibration of large-scale reservoir models, making ITOUGH2 a powerful tool in geothermal engineering practice.

\section{Technical Objectives}

- Improve the efficiency of ITOUGH2 by allowing parallel execution of independent forward runs on a cluster of networked computers.

- Incorporate newly developed TOUGH2 modules into ITOUGH2.

- Analyze parameter correlations and investigate benefit from joint inversions.

- Implement robust estimators to reduce impact of outliers in the data and/or systematic modeling errors. 


\section{Expected Outcomes}

- Parallel version of ITOUGH2 for workstation clusters.

- Demonstration of robust estimation methodology.

- Demonstration of joint inversion capabilities.

- $\quad$ Full documentation of ITOUGH2 including a set of sample problems.

\section{APPROACH}

A suitable message passing concept was identified and implemented to parallelize ITOUGH2. We continue to adapt TOUGH2 modules to the architecture of ITOUGH2. Robust estimation concepts are implemented and tested using synthetic an laboratory data. Data of different types are analyzed in a joint inversion, and the resulting estimation error is examined. Technical information is being presented in laboratory reports and journal papers, at conferences, and on the ITOUGH 2 homepage on the World Wide Web, at URL http://www-esd.lbl.gov/ITOUGH2.

\section{RESEARCH RESULTS}

- A parallel version of ITOUGH2 has been developed based on the Parallel Virtual Machine (PVM) concept. The new capability has been tested and fully documented (Finsterle, 1998).

- Robust estimators have been implemented and applied to the gas-pressure-pulse-decay data from a graywacke core plug from The Geysers. A significant reduction in the estimation bias was observed (Finsterle and Najita, 1998).

- A laboratory boiling experiment was analyzed using inverse modeling to determine relative permeabilities and to study the impact of measurement errors (Guerrero et al., 1998; Finsterle et al., 1998).

- A joint inversion of multiple data types using the EWASG module (Battistelli et al., 1997) was performed. Production and tracer breakthrough data from a dual-porosity dual-permeability geothermal reservoir (Fig. 1) were used to infer hydrogeological, thermal, and geometrical parameters.

- Documentation of ITOUGH2 has been completed. Three reports are available which include a description of the theoretical background (Finsterle, 1999a), the ITOUGH2 command usage (Finsterle, 1999b), and a collection of sample problems (1999c).

\section{FUTURE PLANS}

We continue to improve process modeling capabilities and inversion algorithms as well as user features of ITOUGH2. Emphasis will be placed on prediction of geophysical observables and on chemically reactive flows, which can be used in a joint inversion along with hydrological data. ITOUGH2 will be transferred to the Energy Science and Technology Software Center for release. 


\section{INDUSTRY INTEREST AND TECHNOLOGY TRANSFER}

ITOUGH2 has been extensively tested by research laboratories and industry, and is ready to be released to the public through the ESTSC. ITOUGH2 has been used for the analysis of laboratory and field data, providing estimates of formation properties of geothermal reservoirs.

\section{REFERENCES}

Battistelli, A., C. Calore and K. Pruess, The simulator TOUGH2/EWASG for modeling geothermal reservoirs with brines and a non-condensible gas, Geothermics, Vol. 26, No. 4, 437-464, 1997.

Finsterle, S., Parallelization of ITOUGH2 Using PVM, Report LBNL-42261, Lawrence Berkeley National Laboratory, Berkeley, Calif., 1998.

Finsterle, S., ITOUGH2 User's Guide, Report LBNL-40040, Lawrence Berkeley National Laboratory, Berkeley, Calif., 1999a.

Finsterle, S., ITOUGH2 Command Reference, Report LBNL-40041 (updated reprint), Lawrence Berkeley National Laboratory, Berkeley, Calif., $1999 \mathrm{~b}$.

Finsterle, S., ITOUGH2 Sample Problems, Report LBNL-40042 (updated reprint), Lawrence Berkeley National Laboratory, Berkeley, Calif., 1999c.

Finsterle, S., and J. Najita, Robust estimation of hydrogeologic model parameters, Water Resour. Res., 34(11), 2939-2947, 1998.

Finsterle, S., C. Satik, and M. Guerrero, Analysis of boiling experiment using inverse modeling, Proceedings, TOUGH Workshop '98, Report LBNL- 41995, Lawrence Berkeley National Laboratory, Berkeley, Calif., pp. 281-287, 1998.

Guerrero, M. T., C. Satik, S. Finsterle, and R. Horne, Inferring relative permeability from dynamic boiling experiments, Proceedings, Twenty-Third Workshop on Geothermal Reservoir Engineering, Stanford University, Stanford, California, 389-396, January 26-28, 1998.

Pruess, K., TOUGH2-A General Purpose Numerical Simulator for Multiphase Fluid and Heat Flow, . Report LBL-29400, Lawrence Berkeley National Laboratory, Berkeley, Calif., 1991. 


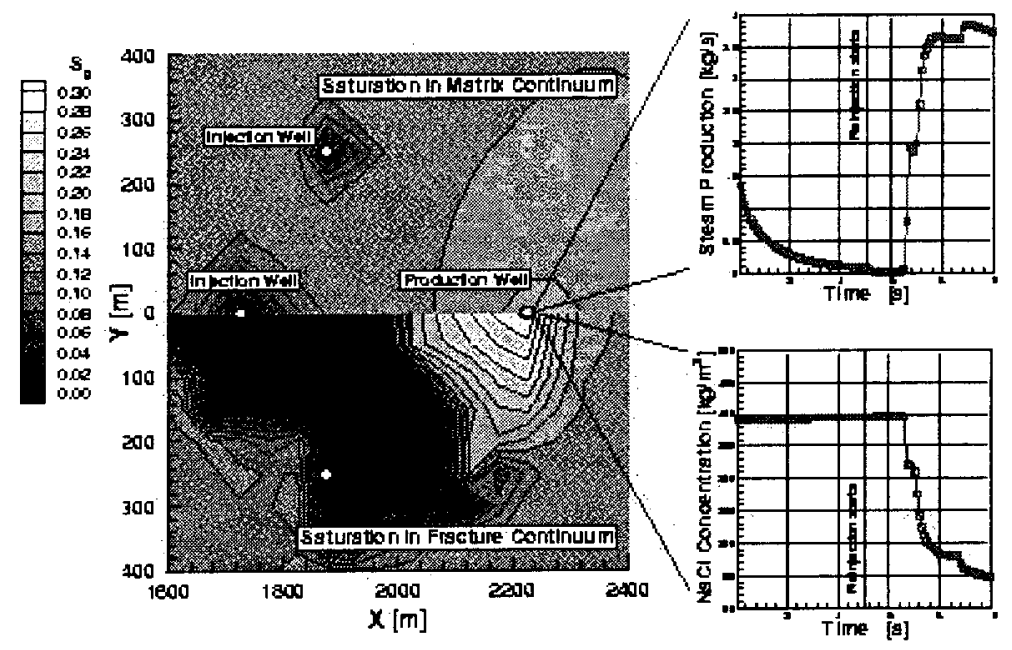

Figure 1. Saturation distribution in matrix (left, top) and fracture (left, bottom) continuum five years after reinjection of cold water into the geothermal reservoir. Steam production (right, top) and sodium chloride concentration in the production well (right, bottom) as a function of time. Simultaneous inversion of these data can be used to calibrate the numerical model. 


\title{
CHEMICAL MODELS FOR OPTIMIZING ENERGY PRODUCTION
}

\author{
CHEMICAL GEOLOGY GROUP: P.I., Nancy Mфller; Co P.I., John H. Weare \\ Chemistry Department (0340), University of California at San Diego, La Jolla, CA 92093
}

\section{KEYWORDS}

breakout, brines, chemistry, models, energy, enthalpy, EOS, equilibrium, gases, geothermal, pH, phase coexistence, reservoir, saturation, scaling, simulations, solubility, steam fraction, thermodynamic

\section{PROJECT BACKGROUND AND STATUS}

With support from the DOE Geothermal Program, the UCSD Chemical Geology Group has carried out a research program aimed at developing computer modeling technology to accurately characterize the chemistry of important geothermal systems and energy production processes. Using equilibrium thermodynamics and a free energy description, we have shown that it is possible to construct chemical models which can reliably reproduce downhole chemistry, chemical behaviors encountered during energy extraction operations (M $\phi$ ller et al. (1998)) and the high T,P chemistry (Duan et al. (1995)) associated with deep reservoirs. We have demonstrated that these models provide important assessment tools for predicting heat content, scaling, breakout, steam fractions, gas emission, phase co-existence, miscibility, $\mathrm{pH}$ and formation temperatures. Our present Pitzer-type models $\left(0-250^{\circ} \mathrm{C}\right)$ include the carbonate/silica scaling model, TEQUIL, and the comprehensive rock/water model for the seawater system, MTEQ. We are in the process of integrating these models and of expanding the compositional flexibility of the resulting model (see Project Results). Since the Pitzer electrolyte equations cannot be generalized to treat highly compressible phases, it was necessary to generate new equation of state (EOS) descriptions to model multiple phase geothermal processes such as flashing and miscibility. We now have a preliminary model of the important $\mathrm{NaCl}-\mathrm{CO}_{2}-\mathrm{CH}_{4}-\mathrm{H}_{2} \mathrm{O}$ system for $300^{\circ}$ to $1000^{\circ} \mathrm{C}$ and to 6000 bars (at lower temperatures GEOFLUIDS can be used), and have made considerable progress in adding new species to this model (see Project Results). We have also demonstrated that the free energy descriptions in both our subcritical and supercritical models can be differentiated to produce models of heat properties for both regions (see Project Results). These semi-empirical models summarize large amounts of experimental data in a concise, easily transferable format. For conditions with few data available, we have developed new simulation technology to generate, from first principle theory, reliable XPVT data. As we develop more theoretically based phenomenologies and better extrapolation techniques, the amount of required data will be reduced.

\section{PROJECT OBJECTIVES}

(1) To improve the productivity of geothermal operations and exploration by providing user-friendly computer models of the thermochemical/physical properties of geothermal brines and their associated noncondensible phases as well as reservoir behavior. (2) To develop methods to optimize the transfer of technology.

Technical Objectives: (1) To construct thermodynamic models for predicting energetic and chemical behaviors and reservoir degradation created by the extraction of energy from geothermal brines under a wide range of XTP conditions. (2) To develop new theoretically based modeling technology which reduces the dependency on experimental data and increases the understanding of rock/water interactions. (3) To develop application and visualization software which facilitate the use of our models.

Expected Outcomes: (1) Chemical modeling software for PC or mainframe use. (2) Modeling code application packages (transferred via diskette or the internet) designed to characterize the thermochemical 
behavior of various aspects of geothermal energy production and exploration. (3) A computer visualization postprocessing package (for internet use) which will aid in the interpretation of complex gas/liquid/solid phase relations under variable XTP conditions. (4) A summary of many geochemical data through model parameterizations. (5) Analysis and creation of more theoretically based modeling approaches to develop improved extrapolation capability and reduce the dependence on experimental data.

\section{APPROACH}

We develop semi-empirical computer models which calculate solubilities (Weare (1987)) in complex brines to high concentration and temperature $\left(\mathrm{T}<300^{\circ} \mathrm{C}\right)$ using the Pitzer (1987) electrolyte equations. These models describe a system's equilibrium chemistry via its free energy. With appropriate derivatives and reference state information, they are used to describe the heat properties of geothermal brines. Since the Pitzer equations cannot be generalized to treat the density variation of highly compressible phases, new equations of state (EOS) descriptions are generated to describe multiple phase geothermal processes, such as flashing and miscibility, and to accurately reproduce XPVT properties in solid-liquid-gas mixtures. Models of heat properties are produced from both the Pitzer and alternative EOS models. To achieve the high accuracy demanded for quantitative prediction, we utilize large amounts of laboratory and field data to parameterize and validate our models. In addition, we carry out first principles simulations (e.g., molecular dynamics) to construct more theoretically based descriptions of geothermal fluids and to generate needed thermodynamic "data" for model construction in both the sub- and supercritical regions. As our models are developed and validated, they are included in application software packages for PC or mainframe use. The TEQUIL package incorporates our rock/water models for temperatures below $300^{\circ} \mathrm{C}$. The GEOFLUIDS supercritical models calculate PVTX properties and two phase equilibria. The GEOHEAT package, under development, includes our heat models for calculating the specific heat, heat of solution and enthalpy of complex brines in both the subcritical and supercritical region. User interfaces are developed for these modeling codes. Our website will include a postprocessing package, GEOPHASES, for calculating and visualizing phase behavior. Publication of research results initiates feedback from the geothermal industry as well as from other industries and academic research groups.

\section{RESEARCH RESULTS AND VARIANCES}

Brine/Rock Water Models, $\mathbf{T}<\mathbf{3 0 0}^{\circ} \mathbf{C}$ Work was initiated to improve the acid/base description of the TEQUIL carbonate/silica scaling model. The previous parameterization of $\mathrm{H}^{+}$interactions in this model was based on $\mathrm{HCl}$ electrochemical data of Greeley et al. (1960), which suffer from increased solubility of $\mathrm{AgCl}$ in the electrodes at high temperatures. Comparison of model predictions with data in the $\mathrm{HCl}-\mathrm{H}_{2} \mathrm{O}$ system taken by the Holmes/Mesmer group (e.g., Holmes et al. (1987), Mesmer and Holmes (1992)) shows that the model fits low concentration data well to about $175^{\circ} \mathrm{C}$. Above this temperature and at higher concentrations ( $>2.5 \mathrm{~m}$ ), it diverges sharply from the experimental data (see Fig. 1). Agreement with the binary experimental data was improved significantly by adjusting the temperature dependent equations for the $\mathrm{HCl}$ binary parameters (Fig. 1). Agreement with activity and solubility data in the literature for the $\mathrm{NaCl}-\mathrm{HCl}-\mathrm{H}_{2} \mathrm{O}$ ternary system required adjustment of the $\psi_{\mathrm{Na}, \mathrm{H}, \mathrm{Cl}}$ mixing parameter. For more complete $\mathrm{pH}$ prediction, it is important to include the $\mathrm{H}_{2} \mathrm{SO}_{4}$ system in the TEQUIL model. The Holmes and Mesmer (1994) model of $\mathrm{H}_{2} \mathrm{SO}_{4}-\mathrm{NaHSO} 4-\mathrm{Na}_{2} \mathrm{SO} 4$ interactions has been implemented. We are now integrating the $\mathrm{Na}-\mathrm{HCl}$ and $\mathrm{Na}-\mathrm{H}_{2} \mathrm{SO}_{4}$ models and adding more cation interactions.

Since aluminum silicates are important components of reservoir rocks, inclusion of aluminum species in our models would greatly broaden their application. However, highly charged ions, such as $\mathrm{Al}^{3+}$ undergo complicated hydrolysis reactions. To model interactions between aluminum silicate rocks and hydrothermal brines, these reactions must be understood. Limited data are available for this process. We 
have started construction of an aluminum speciation model using available data in the literature and have also developed a new first principle simulation method designed to treat ion solvation reactions. Our simulation results show excellent agreement with the known aluminum hydrolysis behavior. We will continue these studies to further assess the accuracy of this approach.

We have also started to expand the carbonate scaling model prediction to systems with high carbonate concentrations using recently found data for $\mathrm{CaCO}_{3}$ and $\mathrm{MgCO}_{3}$ solubilities.

In preparation for adding pressure variability to TEQUIL and to fitting heat data, we have begun to program necessary changes in the model equations. The Pitzer free energy and activity equations include Debye-Huckel terms with density and static dielectric constant of water (D) variables, which are functions of temperature and pressure. Bradley and Pitzer's (1979) equation representing D from $0^{\circ}$ to $300^{\circ} \mathrm{C}$, for saturation pressure and higher has been programmed. Also, the Keenan-Keyes (Steam Tables, 1978) equation of state for water and their expression for determining saturation pressure as a function of temperature has been implemented.

Equations of State for High Temperature, Pressure A long range goal is to develop a supercritical model of the $\mathrm{NaCl}-\mathrm{KCl}-\mathrm{CaCl}_{2}-\mathrm{MgCl}_{2}-\mathrm{CO}_{2}-\mathrm{CH}_{4}-\mathrm{H}_{2} \mathrm{O}$ system which can be used to characterize high T,P reservoir rock/water behavior. We have completed an EOS for the $\mathrm{NaCl}-\mathrm{CO}_{2}-\mathrm{H}_{2} \mathrm{O}$ ternary and constructed a preliminary EOS for the $\mathrm{CH}_{4}$-containing quaternary subsystem. In this period, we concentrated on developing a reliable EOS for the $\mathrm{CaCl}_{2}-\mathrm{H}_{2} \mathrm{O}$ subsystem. This model must be able to describe the solution properties of polar $\left(\mathrm{H}_{2} \mathrm{O}\right)$ and quadrapolar $\left(\mathrm{CaCl}_{2}\right)$ species as well as be able to be incorporated into EOS with nonpolar species, such as $\mathrm{CH}_{4}$. Since data above $700^{\circ} \mathrm{C}$ are scarce for this system, this EOS must also have good extrapolation capabilities. Using the approach of Jiang and Pitzer (1996), an EOS was constructed which accurately fits both phase equilibria and XPVT data well from $250^{\circ} \mathrm{C}$ to $700^{\circ} \mathrm{C}$ and from 0 to 2000 bars. Parameterizing the EOS for the $\mathrm{MgCl}_{2}-\mathrm{H}_{2} \mathrm{O}$ binary subsystem, also accurately predicted available volumetric and phase data above the critical region to $973^{\circ} \mathrm{K}$ and 2000 bar. Vapor phase data in the critical region found for the $\mathrm{CaCl}_{2}$ system were poorly fit. As yet, we have not solved this problem which may reflect fundamental problems with the model equations in this T,P region.

In this project period we also further validated the EOS we developed for high T,P mixtures in the $\mathrm{H}_{2} \mathrm{O}$ $\mathrm{CO}_{2}-\mathrm{CH}_{4}-\mathrm{N}_{2}$ system. Then we developed activity and enthalpy models from this EOS. Predictions of these models agree within experimental uncertainty with the PVTX, activity, fluid/fluid coexistence and enthalpy data for supercritical T,P to $2000^{\circ} \mathrm{K}$ and $100 \mathrm{kbar}$.

Enthalpy Models We are developing models which can predict the heat properties of geothermal resources for a wide range of XTP conditions. Last year our progress in developing supercritical heat models was discussed. Since it is important to know the well head temperature and the the effect of dissolved salt on the breakout pressure in geothermal energy exploration, we have constructed a new model which predicts heat properties in brine systems. In Fig. 2, we show an enthalpy-pressure diagram for a Salton Sea-type brine calculated with this model. The subcritical brine enthalpies are shown to the left of the brine critical point and vapor enthalpies to the right. The solid lines indicate isotherms and dashed lines indicate steam ratios. The arrow indicates the expansion path of a brine originally at $300^{\circ} \mathrm{C}$ and 120 bar (liquid region) in the formation. In a constant enthalpy process, this brine would flash at about 50 bars in the well bore. Continued pressure reduction would lead to further evaporation and an increase in the steam ratio. At roughly $20 \mathrm{bar}$, solid $\mathrm{NaCl}$ scale would appear in the well bore. Here, we assume that evaporation proceeds as the pressure decreases to the well head pressure of $10 \mathrm{bar}$. From the diagram, we can see that at this pressure the steam ratio would be $23 \%$. This compares with $29 \%$ for a pure water system (see asterisk). Because the lower vapor pressure of the concentrated brine results in 
less fluid evaporation, the well head temperature is higher $\left(370^{\circ} \mathrm{F}\right)$ for the brine system than that predicted for a similar expansion of the pure water system $\left(345^{\circ} \mathrm{F}\right)$.

Theoretical Descriptions and Simulations Parameterizing empirical models can require considerable amounts of experimental data; however processes of interest to the geothermal community can occur in XTPV space where few, if any, data are available. Therefore we have developed reliable first principle simulations (e.g., using molecular dynamics methods) to generate needed XPTV information for high T,P conditions (see above). Preliminary molecular dynamics studies of the $\mathrm{NaCl}-, \mathrm{KCl}-, \mathrm{CaCl}_{2}-$ and $\mathrm{MgCl}_{2}-\mathrm{H}_{2} \mathrm{O}$ binaries and of the free energy surface of water have been carried out. The $\mathrm{CaCl}_{2}-\mathrm{H}_{2} \mathrm{O}$ subsystem is important because its potentially very high concentration can lead to much greater volume changes with changing T,P than found in the $\mathrm{NaCl}$ and $\mathrm{KCl}$ subsystems. Our early MD simulations of the $\mathrm{CaCl}_{2}-\mathrm{H}_{2} \mathrm{O}$ system yielded correct PVTX behavior. Recently new simulation methods we have developed have yielded important information about such complicated thermodynamic processes as aluminum hydrolysis (see above). We are now exploring other theoretically based methods (e.g., Mean Spherical Model) of predicting brine activities. Even semi-quantitative theoretical models would provide important estimates of scaling behavior in poorly characterized systems such as the sulfide system.

User Interface Improvements Work on phase diagram visualization software, GEOPHASES, continued. Our progress on this project and other user interfaces were demonstrated at the April 1998 Program Review. The new web-based capabilities demonstrated included: interactive viewing of (1) 3-D calcite saturation surfaces as functions of composition and T, (2) 3-D gas-liquid coexistence curves as functions of composition, $\mathrm{T}$ and $\mathrm{P}$ and (3) complex brine/solid phase equilibria as functions of composition and $\mathrm{T}$. Other improvements to the web-based TEQUIL application package developed this year included changes to enhance user security, the ability to save and restore input files and a TEQUIL tutorial, which guides users through the process of calculating calcite scale formation.

\section{FUTURE PLANS}

Our future plans include developing thermochemical models for the geothermal energy industry which address new long range problems, such as those arising from the exploitation of deep high T,P resources and low fluid reservoirs, as well present problems. We will continue expanding the compositional flexibility of our rock/water Pitzer-type models for temperatures below $300^{\circ} \mathrm{C}$. The sulfuric acid, aluminum hydroxide, aluminum silicate and sulfide systems and pressure variability will be added as well as important thermochemical assessment tools, such as heat content, $\mathrm{pH}$ prediction. We will complete a supercritical thermodynamic model for the $\mathrm{NaCl}-\mathrm{KCl}-\mathrm{CaCl}_{2}-\mathrm{MgCl}_{2}-\mathrm{H}_{2} \mathrm{O}$, targeted for $300^{\circ}-1000^{\circ} \mathrm{C}$ and to 6000 bars. This model will be useful to characterize the chemistry of very high T,P reservoirs and to describe important geothermal processes such as flashing, phase co-existence and miscibility. This model can also be used as a foundation for a heat property model for supercritical conditions. We will also explore more theoretically based modeling approaches in order to develop analytical forms for brine activity expressions $\left(\mathrm{T}<300^{\circ} \mathrm{C}\right)$ and free energy descriptions which are accurate through the critical range from subcritical to supercritical conditions. Positive results will reduce the dependency on experimental data as well as increase our understanding. We will continue to incorporate our modeling software into application packages with interfaces that facilitate their use. We will expand our TEQUIL and GEOFLUIDS models as described above. The present preliminary GEOHEAT will be substantially expanded and a new packages, GEOTHERM, containing geothermometry software will be developed. Our postprocessing visualization package, GEOPHASES, for internet use will be expanded. 


\section{TECHNOLOGY TRANSFER}

\section{Geothermal Related Contacts, FY98}

CFTA, Palermo Italy: Mario Nuccio requested GEOFLUIDS.

DOW CHEMICAL Co.: Requested copy of lecture (JW), "Modeling Hydrothermal Solutions to High Temperature and Pressures.

GEOSCIENCE, LTD., UK: Ross McCartney requested references about our models on website.

GEOTHERMAL RESOURCE CENTER, Miravalles Geothermal Field: Yalile Torres requested information about our models seen on our website.

INDUSTRIAL RESEARCH, LTD., New Zealand: Graham Weir requested TEQUIL and GEOFLUIDS.

LEYTE GEOTHERMAL POWER PROJECT, Philippines: A. Troy Salazar requested information about our models seen on our website.

MANCHESTER UN.: Paddy Hill, Earth Science Dept., requested TEQUIL and GEOFLUIDS.

McGILL Un., CANADA: David Palmer, Geosciences Dept., requested GEOFLUIDS.

OAK RIDGE NAT'L LAB.: James Blancoe requested GEOFLUIDS.

OBSERVATORIA NACIONAL-CNPQ (Brazil): Valiya Hamza requested copies of TEQUIL, GEOFLUIDS, GEOHEAT.

PG\&E: Dave Hutte requested information about the thermodynamic properties (enthalpy, energy storage) of brines.

ST. FRANCIS UN., CANADA: Allan Anderson requested information about first principle simulations of supercritical fluids.

TRUESDELL, AL, geothermal consultant: Requested TEQUIL and GEOFLUIDS.

UNIVERSITY OF AUCKLAND, New Zealand: Kevin Brown requested TEQUIL and GEOFLUIDS.

UC BERKELEY: W. McKenzie, Dept. Geol. and Geophys., requested TEQUIL and GEOFLUIDS.

UNIVERSITY OF CHICAGO: Leonid Aranovich, Dept. Geophysical Sciences, used GEOFLUIDS and requested information about $\mathrm{CO}_{2}-\mathrm{H}_{2} \mathrm{O}$ mixtures.

UNIVERSITY OF GUANAJUATO, Mexico: Panchito Lopez requested TEQUIL and GEOFLUIDS.

UNIVERSITY OF MICHIGAN: Youxue Zhang requested GEOFLUIDS.

\section{Technical Papers, FY98}

Duan, Z. Mфller, N. and Weare, J. "Accurate Prediction of the Thermodynamic Properties of Fluids in the System $\mathrm{H}_{2} \mathrm{O}-\mathrm{CO}_{2}-\mathrm{CH}_{4}-\mathrm{N}_{2}$ up to $2000^{\circ} \mathrm{K}$ and $100 \mathrm{kbar}$ from a Corresponding States/One Fluid Equation of State." In preparation. 
Lubin, M. and Weare, J. "First Principles Simulation of Aluminum Solvation in Aqueous Solutions." Goldschmidt Conference 1998, Toulouse, France. Minerol. Mag. 62A, (Part 3) 915 (1998).

Mфller, N., Greenberg, J. and Weare J. "Computer Modeling for Geothermal Systems." Transport in Porous Media 33(1-2), 173-204, (1998).

Mфller, N., Weare, J., Greenberg J. and Duan Z. "Chemical Models for Optimizing Geothermal Energy Production.” DOE Geothermal Program Review XVI, April 1-2, San Francisco, CA.

Weare, J., Duan, Z., and Mфller, N. "Supercritical thermodynamics and fluid/fluid phase coexistence in thermodynamic systems." Goldschmidt Conference 1998, Toulouse France, Minerol. Mag 62A, (Part 3) 1637 (1998).

Mфller, N., Weare, J. and Greenberg, J. "Solving Geothermal Chemistry Problems on the Web." submitted to GRC Bulletin

\section{REFERENCES}

Bradley, D. J. and Pitzer, K. S., J. Phys. Chem. 85, 1599 (1979)

Duan, Z., Mфller, N. and Weare, J., Geochim. Cosmochim. Acta 59, 2869 (1995).

Greeley, R.S., Smith, W.T., Stoughton, R.W. and Lietzke, M.H., J. Phys. Chem. 61, 652 (1960).

Holmes, H. F. and Mesmer, R.E., J. Chem. Thermodynamics 26, 581 (1994).

Holmes, H.F., Busey, R.H., Simonson, J.M., Mesmer, R.E., Archer, D.G. and Wood, R. H. J. Chem. Thermodynamics 19, 863 (1987)

Jiang S., and Pitzer K.S., AiChE J., 42, 585 (1996).

Keenan and Keyes, Steam Tables, John-Wiley \& Sons, Inc. (New York), pp 162 (1978).

Mesmer, R.E. and Holmes, H.F., J. Sol'n Chem. 21, 725 (1992).

Mфller, N., Greenberg, J. and Weare J. Transport in Porous Media 33 (1-2), 173 (1998).

Pitzer, K.S. Reviews in Mineralogy 17, 97 (1987)

Weare, J. H., Reviews in Mineralogy 17, 143 (1987). 

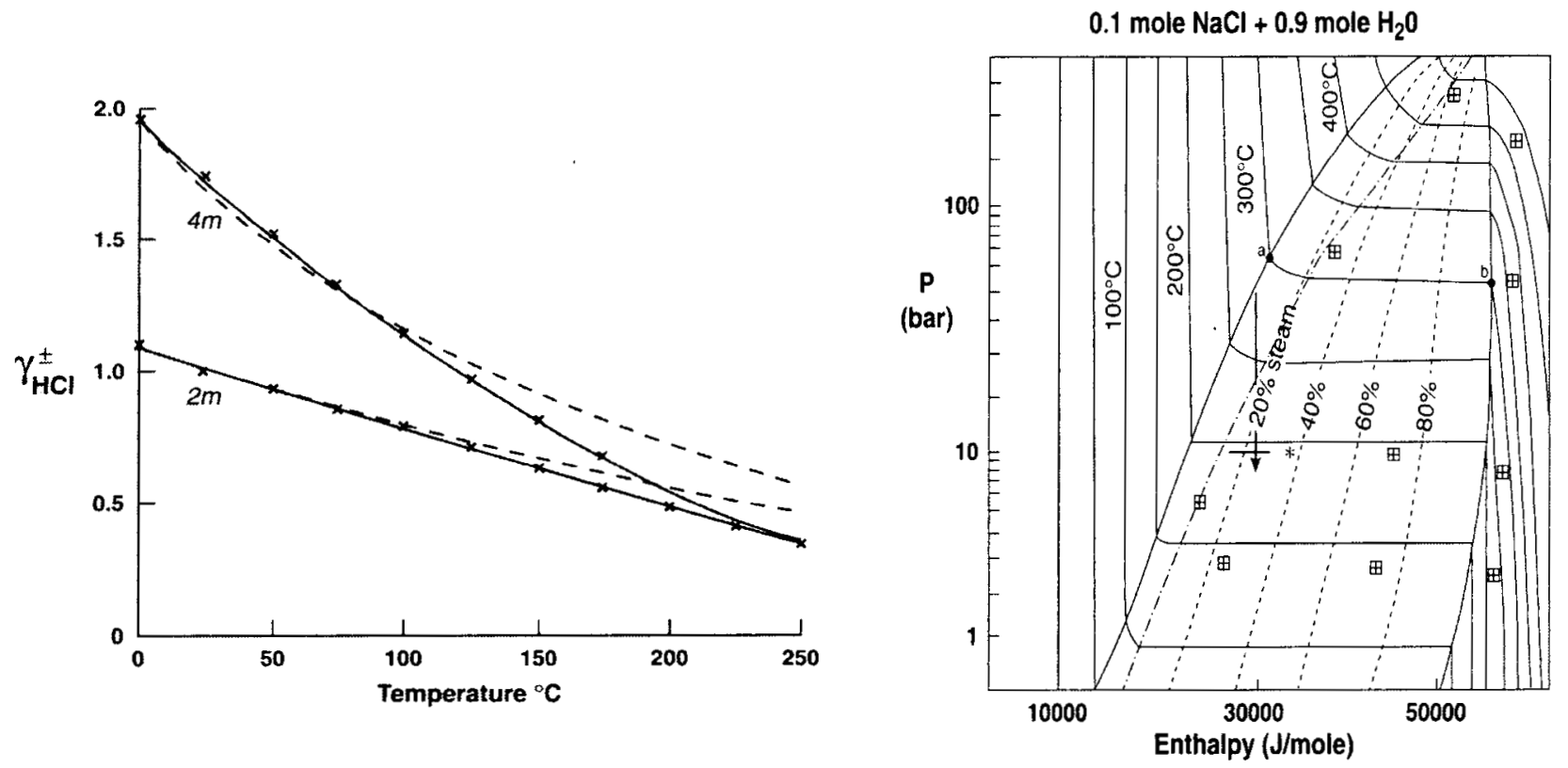

Figure 1. Comparison of TEQUIL model predictions (original, dashed line; revised, solid line) with experimental data (crosses) of Holmes et al. (1987) and Mesmer and Holmes (1992).

Figure 2. Predicted Enthalpy-Pressure diagram for a Salton Sea-like brine (see text). 


\title{
INVESTIGATION OF REINJECTION STRATEGIES
}

\author{
Roland N. Horne \\ Stanford University
}

\section{KEY WORDS}

reinjection, optimization, wavelet analysis

\section{PROJECT BACKGROUND AND STATUS}

In earlier years, the Stanford Geothermal Program has undertaken a project to develop techniques for the optimization of reinjection schemes in both liquid-dominated (Macario and Horne, 1992) and vapordominated geothermal reservoirs (Santa Maria and Pingol, 1996). These studies concentrated on determining the influence of fractures in the case of liquid-dominated reservoirs, and the influence of adsorption in the case of vapor-dominated reservoirs. The first study was completed in 1992, and the second was completed in FY'96.

In the current year we examined large production data sets from two producing geothermal fields, Dixie Valley in Nevada and Palinpinon in the Philippines, and refined the representation of the transport mechanisms governing injectate transport in the reservoir by using the wavelet transform method to relate injection and its influence on production.

\section{PROJECT OBJECTIVES}

\section{Technical Objectives}

- To develop methodologies to optimize geothermal reinjection strategy by analyzing the connectivity of reservoirs by correlating injection returns.

- To demonstrate these methods on operating geothermal fields.

\section{Expected Outcomes}

- A procedure to use routine chloride monitoring data to infer reservoir connections and thereby optimize reinjection strategy. Optimizing reinjection strategy has the potential to improve overall reservoir productivity by $30-50 \%$

- A set of field cases to demonstrate the application of the technique to field cases.

\section{APPROACH}

Reservoir chloride concentration and injection rate data have been used to identify injection return flow paths in the reservoir. General trends of chloride and injection rate with time were isolated from their respective short-term variations using the wavelet transformation appraoch. Multiple regression techniques were then used to correlate the isolated short-term variations in chloride with corresponding short-term fluctuations in injection rates; and, subsequently to quantify the degree of connectivity between injectors and producers. Data from Palinpinon-I field in the Philippines were analyzed using this method and results were successfully verified against tracer test data and qualitative field observations. 


\section{RESEARCH RESULTS}

Based on the results of regression analysis of chloride and injection rate data from Dixie Valley, we concluded that earlier multilinear modeling approaches (as developed by Macario and Horne, 1992) are not suitable for analyzing data sets which lack sufficient time variability or "texture". A closer look at multiple regression techniques showed that what seemed to be highly encouraging results from prior multilinear modeling were only effects of the scarcity of data used in the correlation; hence, no meaningful physical interpretation should be drawn from them. Moreover, it showed that care should be taken not to base the interpretation of multiple regression results on straightforward comparison of coefficients alone.

Wavelet analysis has provided more useful results. Qualitative field observations and tracer test data agreed best with the results of regression on level 3 detail of chloride concentration and injection rates in Palinpinon-I: wells identified by tracer tests to be strongly connected had high positive coefficients and weak connections were indicated by negative and low positive coefficients at level 3 regression (see Figure 1). This suggests that producer-injector interactions are best detected by correlating changes in chloride concentration over periods of four months (corresponding to level 3 resolution) with corresponding four-month fluctuations in injection rates. While the good correlation at such a relatively low level of time resolution may be explained as the result of the natural dispersion of chloride and injection rate signals as they propagate through the reservoir, it is also possible that this is due to the loss of information brought about by the use of monthly averaged data values in the analysis. It is possible that the Haar wavelet that was used in signal decomposition was too coarse in that it contributed to the loss of texture in the data, hence further investigation of the effects of using smoother wavelets is recommended.

\section{FUTURE PLANS}

A possible improvement to consider in future regression analyses is to take into account possible nonlinearity in the variation of chloride with injection rates. While nonlinearity does not invalidate the analysis, it certainly weakens it as the relationship between chloride concentration and injection rates is not completely captured by the coefficients of the linear model. Although regression analysis uses a linear model, effects of nonlinearity in the variation of chloride with injection rates may be incorporated into the model by using nonlinear terms: the model is kept linear even though the individual terms are not. Results of this modified analysis will be more difficult to interpret however, because the strength of interaction between producers and injectors will be measured not only by the magnitude of the coefficients but also by the exponent of each term.

\section{INDUSTRY INTEREST AND TECHNOLOGY TRANSFER}

Industrial developers of geothermal energy have take an interest in this project and the possibility of improving reinjection efficiency.

\section{Organization}

Oxbow Geothermal

PNOC

\section{Type and Extent of Interest}

Provided data from Dixie Valley field

Provided data and received algorithms

\section{REFERENCES}

Macario, M.E., and Horne, R.N. (1992) "Optimizing Reinjection Strategy at Palinpinon, Philippines, Based on Chloride Data," Proceedings, 17th Stanford Geothermal Workshop, Jan. 1992, Stanford, CA. 
Santa Maria, R., and Pingol, A.S. (1996) "Simulating the Effects of Adsorption and Capillary Forces in Geothermal Reservoirs," Proceedings, 21 st Stanford Geothermal Workshop, Jan. 1996, Stanford, CA.

Sullera, M.M. (1998), "Inferring Injection Returns from Chloride Monitoring Data", M.S. report, Stanford University, Stanford, CA. 
PN-6RD

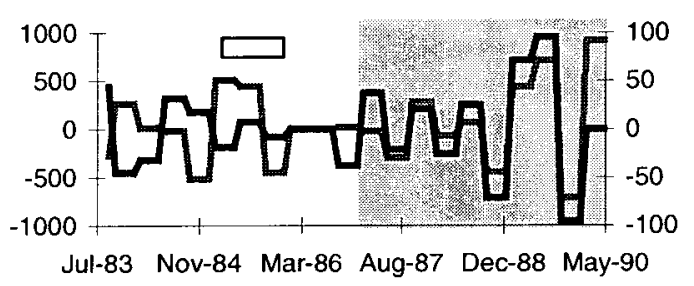

(a)

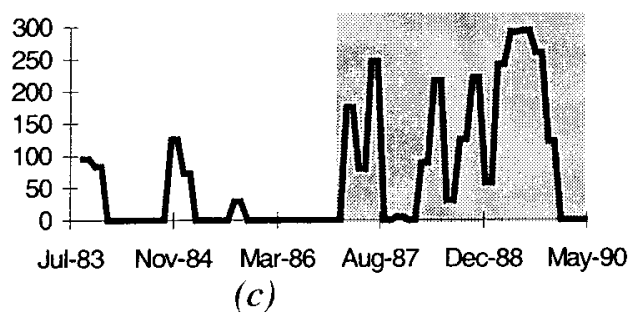

PN-9RD

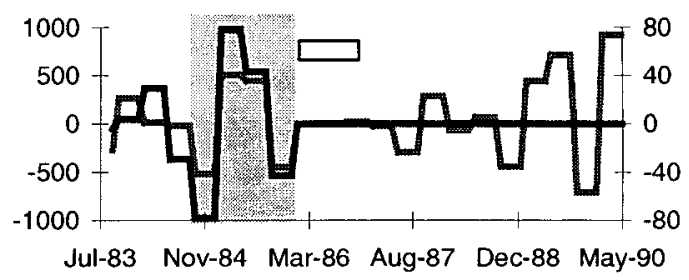

(b)

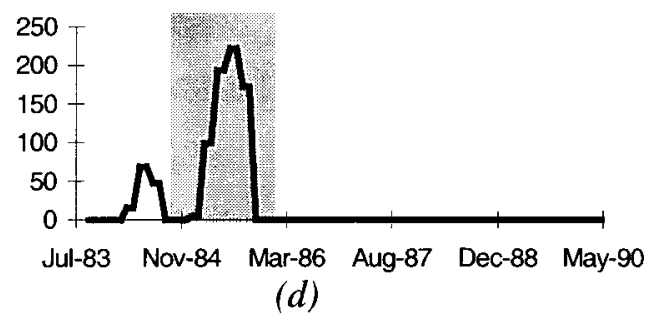

Figure 1. (a) Level 3 detail of OK-7D chloride - red; level 3 detail of PN-6RD injection rate - blue. (b) Level 3 detail of OK-7D chloride - red; level 3 detail of PN-9RD injection rate -blue. (c) PN-6RD injection rate. (d) PN-9RD injection rate. 


\title{
OPTIMIZING INJECTION USING TRACERS
}

\author{
G. Michel Shook \\ Idaho National Engineering and Environmental Laboratory
}

\section{KEY WORDS}

tracers, injection, swept volume, moment analysis, thermal breakthrough

\section{PROJECT BACKGROUND AND STATUS}

Injection of spent geothermal fluids has become a standard reservoir management tool over the past decade. Injection serves not only to maintain reservoir pressure, but also to increase energy extraction efficiency over the producing life of the resource. Because the injected fluid is frequently much cooler than in-situ fluid, these benefits depend strongly on locating injection wells in such a fashion so as to delay the breakthrough of the cooler injectate. Proper design of injection requires knowledge of the volume of rock and pore space the fluids contact in moving between injection and extraction wells. This volume can be estimated through an appropriately designed and analyzed tracer test. However, even when injection wells are optimally located, thermal breakthrough from injectate can only be delayed, not eliminated. Therefore, operators need to predict the time at which thermal breakthrough is expected. These data, both the pore volume "serviced" by an injection well and the time at which thermal breakthrough is expected, can be used to design an optimal injection strategy.

Work began during FY-1998 to develop the tools necessary to measure the pore volume serviced by an injection well, and to predict the onset of cooling at the production well. The work conducted to date has been restricted to single phase, heterogeneous porous media, but will be expanded to include multi-phase fractured media in the coming year.

\section{PROJECT OBJECTIVES}

The overall goal of this project is to develop the tools necessary to optimize an injection strategy. Because tracer testing has become a standard tool for tracing flow paths in geothermal reservoirs, the work has been focused on analysis of tracer test results (effluent analysis). The tools being developed include measurement of reservoir pore volume swept by a tracer and the prediction of thermal breakthrough through tracer test analysis. Work to date has been restricted to single phase porous media. Specific details of these objectives are given below.

\section{Technical Objectives}

- Develop a tracer test analysis method to predict reservoir pore volume from a tracer test.

- $\quad$ Predict the propagation of a thermal front arising from injection of cooler fluids.

\section{Expected Outcomes}

The successful conclusion to this project will allow the geothermal operator to design and implement a tracer test and use the results of the test to:

- Estimate the volume of reservoir associated with a given well pair. This can help identify thief zones or primary flow paths that result in short-circuiting of injected fluids. 
- Estimate from tracer test results the timing of expected thermal breakthrough arising from injection. This allows the operator lead time to either modify the injection strategy or drill makeup wells.

\section{APPROACH}

The approach taken in this project is to first develop the theory that governs estimating the desired quantity (pore volume or thermal breakthrough time), and then to compare predictions with numerical simulation results. As results for more complex reservoir conditions are developed, we will solicit interest from a geothermal operator to apply the predictive tools to a field tracer test.

\section{RESEARCH RESULTS}

A conventional slug tracer test can be analyzed and pore volume measured using the mean residence time of the tracer. The first temporal moment (mean residence time) of a tracer in single phase flow is given as (Shook, 1998):

$$
\bar{t}=\frac{\int_{0}^{\infty} C t d t}{\int_{0}^{\infty} C d t}-\frac{t_{s}}{2}
$$

where $C$ is tracer concentration in the effluent, $t$ is time, and $t_{s}$ is the tracer injection time. Pore volume swept by that tracer is calculated from the injection rate, $q$, and the first moment as shown below.

$$
V_{p}=q \bar{t}
$$

Thus, a conventional tracer test can be conducted and the reservoir pore volume readily calculated from analysis of the effluent.

The velocity of a thermal front, $v_{\mathrm{T}}$, can be estimated from the combined mass and energy conservation equations (Shook, 1999). The ratio of the velocity of isotherms relative to fluid velocity, $v_{w}$, is given as:

$$
\frac{v_{T}}{v_{w}}=\frac{v_{T}}{u_{w} / \varphi}=\left(\frac{\varphi \rho_{w} C_{p w}}{\varphi \rho_{w} C_{p w}+(1-\varphi) \rho_{r} C_{p r}}\right)
$$

where $\mathrm{u}$ is Darcy velocity, $\varphi$ is porosity, $\rho$ is density $(\mathrm{r}=\mathrm{rock}, \mathrm{w}=$ liquid water), and $\mathrm{Cp}$ is thermal heat capacity. Therefore, if one can estimate the fluid velocity, one can then predict the onset of cooling. The fluid velocity is given from the mean residence time above. In order to make use of the tracer data, however, we require variable transforms so that tracer data and temperature data exhibit similar behavior. The following variable transformations provide convenient comparison between the two data types.

For the predicted temperature histories, plot normalized tracer recovery (predicted dimensionless temperature, $\left.T_{P}\right)$ vs. pseudotime $\left(t^{*}\right)$ : 


$$
\begin{gathered}
T_{p}(t)=\frac{\int_{0}^{t} q(\tau) C(\tau) d \tau}{\int_{0}^{\infty} q(\tau) C(\tau) d \tau} \\
t^{*}=t\left(1+\frac{(1-\varphi) \rho_{r} C_{p r}}{\varphi \rho_{w} C_{p w}}\right)
\end{gathered}
$$

For observed temperature histories, plot dimensionless temperature $\left(T_{D}\right)$ vs. time $(t)$ :

$T_{D}=\frac{T(t)-T_{1}}{T_{J}-T_{I}}$

An example of these methods (and a more complete description of the example problem) is given by Shook $(1998 ; 1999)$. A tracer test was numerically simulated in a 2-D heterogeneous porous media. A random permeability field was generated, and four extraction wells were placed randomly in the field. A slug of tracer was injected from an injection well in about the middle of the reservoir, and the tracer test was simulated until thermal breakthrough was observed in each of the production wells (greater than 4500 days). The simulated tracer effluent concentrations were then analyzed to estimate pore volume and to predict the timing of thermal breakthrough. Drainage volume estimates were compared with volumes calculated from fluid velocity profiles; thermal breakthrough predictions were then compared with simulated temperature histories. Results of the analyses are summarized in the table below. For all cases, predicted results are nearly identical to the known (simulated) properties.

\begin{tabular}{lcccccc}
\hline Well Name & \multicolumn{2}{c}{ Pore Volume Estimates } & \multicolumn{3}{c}{$\begin{array}{c}\text { Thermal Breakthrough Time } \\
\text { (10\% change in temperature) }\end{array}$} \\
& $\begin{array}{l}\text { Method of } \\
\text { Moments }\end{array}$ & $\begin{array}{c}\text { Velocity } \\
\text { field }\end{array}$ & Error & $\begin{array}{c}\text { From tracer } \\
\text { data }\end{array}$ & $\begin{array}{c}\text { Simulated } \\
\text { Temps }\end{array}$ & Error \\
\hline P1 & 2267 & 2260 & 0.003 & $>4500 \mathrm{~d}$ & $>4500 \mathrm{~d}$ & NA \\
P2 & 2902 & 3007 & .035 & $3200 \mathrm{~d}$ & 3180 & .006 \\
P3 & 2618 & 2550 & .027 & 614 & 608 & .01 \\
P4 & 2140 & 2183 & .018 & 2297 & 2304 & .003 \\
Total & 9928 & 10,000 & .007 & NA & NA & NA \\
\hline
\end{tabular}

\section{FUTURE PLANS}

Work to date on this project has been restricted to single phase cases in heterogeneous, but porous, media. In the coming year, the method will be expanded to multi-phase conditions, and then to fractured media. After development of the appropriate analysis methods, interest in a field demonstration will be solicited from the geothermal community 


\section{INDUSTRY INTEREST AND TECHNOLOGY TRANSFER}

Presentations have been made at the Geothermal Resources Council annual meeting (Shook 1998) and the Stanford workshop (Shook, 1999). Additional discussions have been held with Oxbow Geothermal and USGS workers. Given the current status of this project, few concrete discussions have been held, though it is believed that a site will be readily available when a field demonstration is appropriate.

\section{REFERENCES}

Shook, G.M., "Prediction of Reservoir Pore Volume from Conservative Tracer Tests," Geothermal Resources Council Transactions, Vol. 22, p. 477-489.

Shook G.M., "Prediction of Thermal Breakthrough from Tracer Tests," Proceedings, Twenty-Fourth Workshop on Geothermal Reservoir Engineering, Stanford University, Stanford, CA, Jan. 1999, in press. 


\title{
PHASE-FRONT PROPAGATION IN GEOTHERMAL SYSTEMS USING HIGHER-ORDER DIFFERENCING SCHEMES
}

\author{
Curtis M. Oldenburg and Karsten Pruess \\ Lawrence Berkeley National Laboratory
}

\section{KEY WORDS}

higher-order differencing, phase front, boiling, numerical dispersion, TVD, simulation.

\section{PROJECT BACKGROUND AND STATUS}

In this project, we use higher-order differencing total variation diminishing (TVD) schemes to reduce numerical dispersion in simulations of phase front propagation in geothermal flow problems. Full upstream weighting is the accepted method to handle phase front propagation problems. However, full upstream weighting causes numerical dispersion, which manifests itself as smearing of the phase front. Numerical dispersion can be diminished by the use of finer discretization, but improvements come at the cost of increased memory and execution times. Numerical dispersion can also be decreased by the use of higher-order differencing schemes. We have coded and tested TVD schemes for simulation of phase fronts in the reservoir simulator TOUGH2 (Pruess, 1987; Pruess, 1991). In the geothermal reservoir flow problem investigated, the total variation of saturation increases with time as induced boiling occurs due to fluid production. The increase in variation of saturation would appear to be at odds with the underpinnings of the TVD methods. Results presented below demonstrate the effectiveness of the TVD schemes for phase front propagation even in cases where the total variation in saturation increases.

\section{PROJECT OBJECTIVES}

The objective of the project is to implement and test higher-order differencing schemes for phase front propagation in TOUGH2.

\section{Technical Objectives}

- Implement higher-order differencing schemes for relative permeability weighting into TOUGH2.

- Investigate the effectiveness of the new schemes in reducing numerical dispersion in the propagation of phase fronts in situations that are not physically total variation diminishing.

\section{Expected Outcomes}

- User-specified option in TOUGH2 of using higher-order differencing schemes for either concentration fronts, phase fronts, or both.

- Understand the effects of numerical dispersion on boiling front propagation.

- Draft research paper submitted to peer-reviewed journal.

\section{APPROACH}

In prior work, we identified the total variation diminishing (TVD) schemes as the most appropriate higher-order differencing schemes to implement in TOUGH2 (Oldenburg and Pruess, 1997). Although most of the prior work on higher-order schemes is for explicit methods, we have implemented the 
schemes into the fully implicit TOUGH 2 code. To calculate the flux across an interface between two gridblocks, the standard integral finite difference method in TOUGH2 only uses information from these two connected gridblocks. Therefore TOUGH2 keeps track of the locations of the two gridblocks comprising each connection. Because the higher-order schemes require that we know the location of an additional gridblock upstream, we currently limit application of the methods to rectangular twodimensional domains with regularly ordered gridblocks.

\section{RESEARCH RESULTS}

Verification of the higher-order differencing schemes by comparison to analytical solutions for solute transport was demonstrated in prior work (Oldenburg and Pruess, 1997). The present research focused on the propagation of phase fronts as occurs during reinjection with induced boiling (Oldenburg and Pruess, $1998 ; 1999)$. In these situations, the total variation of saturation increases with time. We investigated whether the TVD approach can be used in situations where the total variation of saturation increases during the flow process. The EOS7R module (Oldenburg and Pruess, 1995) with added higher-order schemes is used for these calculations. We show in Fig. 1 the domain and boundary conditions for onedimensional reinjection problem where cold water $\left(\mathrm{T}=30^{\circ} \mathrm{C}\right)$ is injected on the left-hand side into a hot column $\left(\mathrm{T}=300^{\circ} \mathrm{C}\right)$ with production on the right-hand side. Shown in Figs. 2 and 3 are temperature and saturation profiles at four times for full upstream weighting and for the Leonard TVD (LTVD) scheme, respectively, where the weighting is applied to both the phase and thermal energy transport equations. As shown, both schemes produce plausible results, although the upstream-weighted front is more than $10 \mathrm{~m}$ farther to the right-hand side after 6 mos. Through numerical experiments where LTVD was applied only to the thermal energy equation, we determined that numerical dispersion of the temperature field causes the boiling front to propagate faster. When this numerical dispersion is decreased as in the LTVD results of Fig. 3, the boiling front advances more slowly. The locations of the phase front after 6 mos. are summarized in Fig. 4 for several different discretizations. As shown in Fig. 4, the LTVD scheme produces much more accurate results with fewer gridblocks than full upstream weighting.

\section{FUTURE PLANS}

We plan to modify the higher-order differencing algorithms to handle more general grid systems and prepare them for release in future versions of TOUGH 2.

\section{INDUSTRY INTEREST AND TECHNOLOGY TRANSFER}

Higher-order differencing schemes may significantly improve numerical simulation of sharp fronts in concentration and phase saturation and therefore be of interest to all TOUGH2 users.

Improved simulation capabilities will be made available through DOE's Energy Science and Technology Software Center (ESTSC).

\section{REFERENCES}

Oldenburg, C.M., and K. Pruess, Higher-order differencing for geothermal reservoir simulation, Proceedings of the Twenty-Second Workshop on Geothermal Reservoir Engineering, Stanford University, Jan. 27-29, 1997, p. 303-308.

Oldenburg, C.M., and K. Pruess, Higher-order differencing for phase-front propagation in geothermal systems, Proceedings of the Twenty-Third Workshop on Geothermal Reservoir Engineering, Stanford University, Jan. 26-28, 1998, p. 127-134. 
Oldenburg, C.M., and K. Pruess, EOS7R: Radionuclide transport for TOUGH2, Lawrence Berkeley National Laboratory Report LBL-34868, November 1995.

Oldenburg, C.M., and K. Pruess, Simulation of propagating fronts in geothermal reservoirs with the implicit Leonard total variation diminishing scheme, Geothermics, submitted, 1999.

Pruess, K., TOUGH User's Guide, Nuclear Regulatory Commission, Report NUREG/CR-4645, June 1987 (also Lawrence Berkeley Laboratory Report LBL-20700, June 1987).

Pruess, K., TOUGH2 - A General Purpose Numerical Simulator for Multiphase Fluid and Heat Flow, Lawrence Berkeley Laboratory Report LBL-29400, May 1991. 


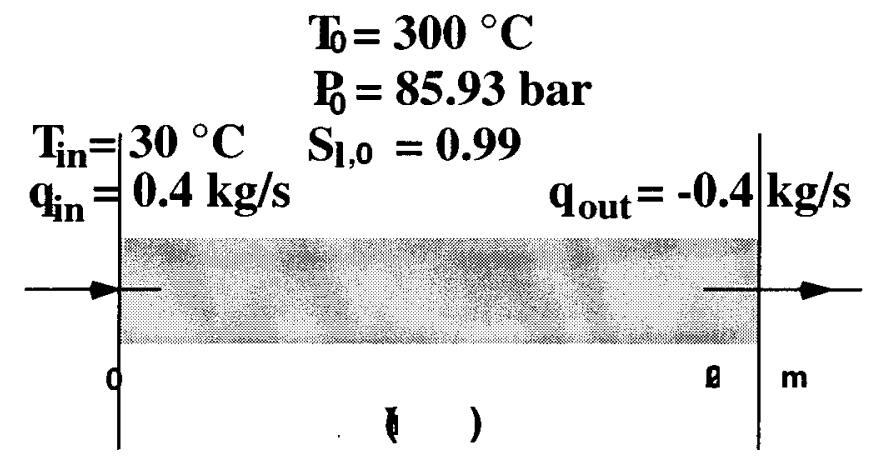

Figure 1. Boundary and initial conditions for the one-dimensional injection and production problem.

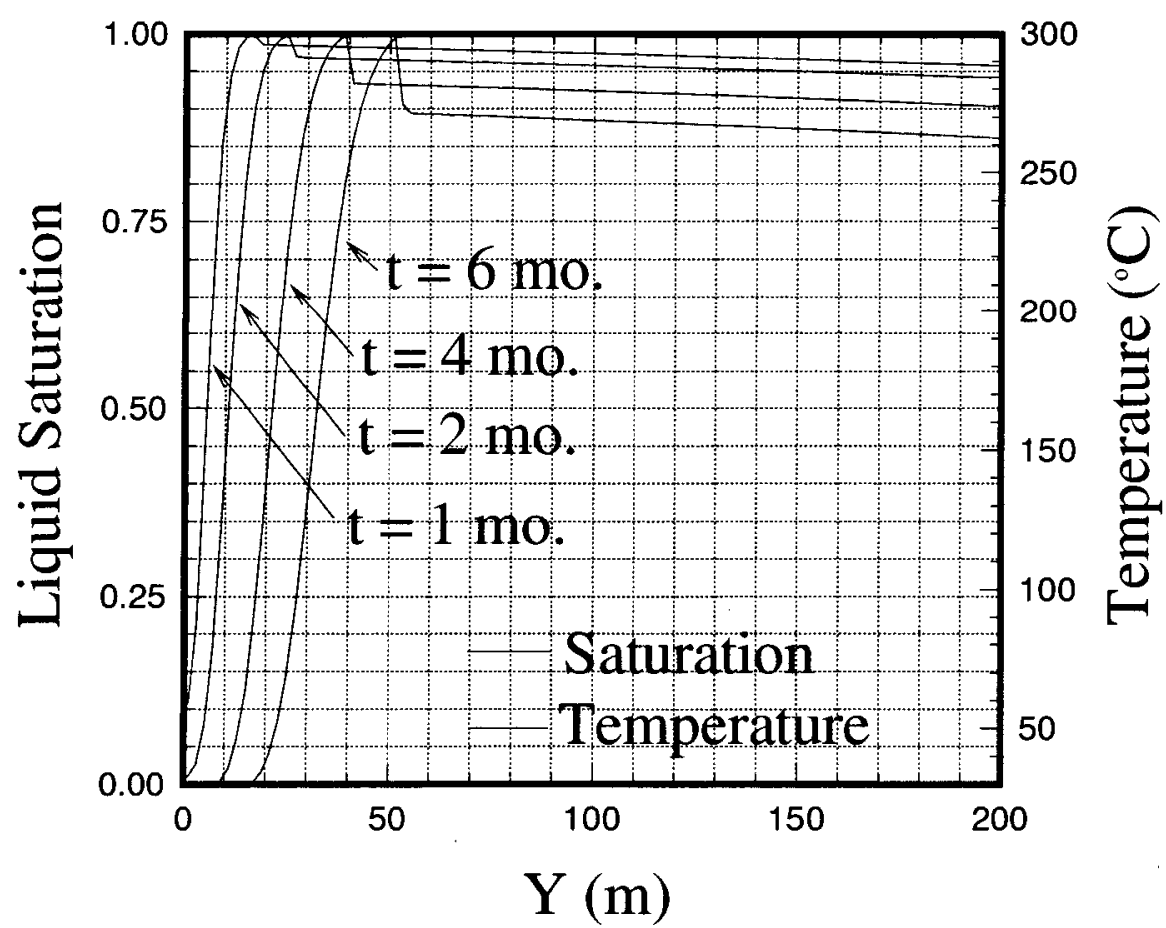

Figure 2. Liquid saturation and temperature for the geothermal injection and production problem with upstream weighting. 


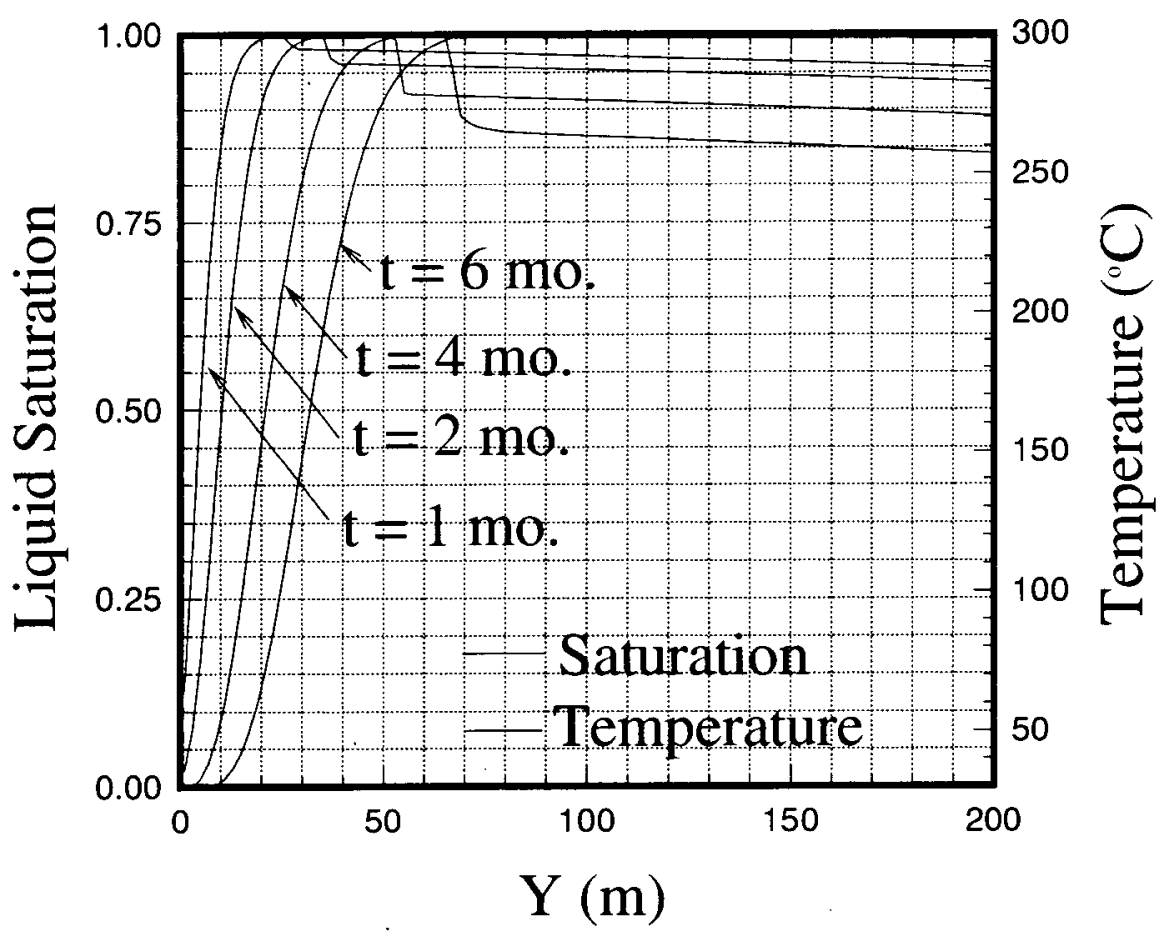

Figure 3. Liquid saturation and temperature for the geothermal injection and production problem with LTVD.

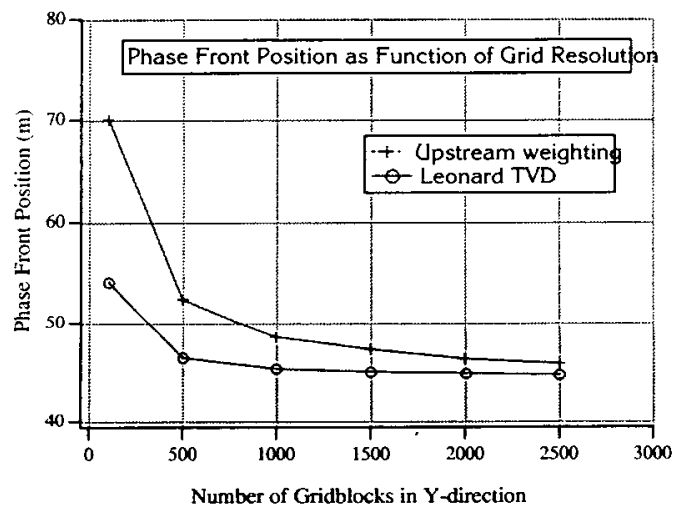

Figure 4. Phase front location vs. grid resolution for upstream weighting and Leonard TVD schemes at $t$ $=6$ months. 


\title{
Tracer Matching and Production/Injection Strategies for Fault Dominated Geothermal Reservoirs
}

\author{
Daniel Swenson \\ Mechanical Engineering Department \\ Kansas State University, Manhattan, KS 66506 \\ 785-532-2320, swenson@ksu.edu
}

\section{KEY WORDS}

Geothermal Reservoirs, modeling, flow, tracers, faults, fractures

\section{PROJECT BACKGROUND AND STATUS}

The goal of this project is to improve modeling of flow in fracture-dominated reservoirs. Realistic models of fractured reservoirs are needed because long-term, economic operation of geothermal reservoirs requires that re-injection be used to recharge fluid and recover additional thermal energy. However, flow on fractures can cause short-circuits and prematurely cool the produced fluid. In addition, there is increasing recognition that fractures will often be encountered at commercial reservoir scales and that these fractures will significantly affect flow. Realistic fracture models can help both in designing reinjection strategies and in operation of fractured reservoirs.

As part of previous work in support of geothermal technology, Kansas State University developed the Geocrack2D reservoir simulation program (Swenson, 1997). Geocrack2D includes the complex interactions between rock deformation, fluid flow, and heat transfer, where flow paths and reservoir pressures change as a result of heat removal. This project will develop similar capability in three dimensions.

The three-dimensional model (Geocrack3D) under development will explicitly represent the fractures. It will treat flow in fractures directly, rather than as flow through a thin layer of porous media. In addition, it will be based on a higher level geometric representation of the reservoir, rather than the traditional meshfocused representation. That is, the user will interactively define geometric features (the boundaries, wellbores, and fractures) of the reservoir. Geocrack3D will automatically store a valid geometric model and will mesh the features. This will be accomplished using a topological representation of geometry and object oriented programming.

The project includes numerical model development at Kansas State University, tracer and reservoir analyses at the Energy \& Geoscience Institute at the University of Utah, and oversight and industrial collaboration with Oxbow Power Services. The three year project started March 1 of 1998. At the end of fiscal year 1998, the project was 8 months into a 36 month project. However, since the project was building on previous work, significant progress has already been made.

\section{PROJECT OBJECTIVES}

This is a three year project with the objective of developing analysis capability to realistically simulate flow in fractured reservoirs. Geocrack3D will focus on fractured, liquid-dominated systems. It will include flow, heat transfer, and rock deformation effects, as well as tracer simulation capability.

In a larger sense, the goal of the project is help move fractured reservoir simulation capability forward in parallel with advances in diagnostic technologies. Significant effort is being applied to borehole imaging, improved tracer data, tomographic imaging (such as Electrical Resistance Tomography), and micro- 
seismic data analysis. All of these technologies are beginning to make it possible to map major features in a reservoir. When these technologies come to fruition, it will be possible to create a model that incorporates the major features of a reservoir before the reservoir is brought into production. At the same time, future computer power will make it possible to perform complex calculations in a much more routine manner than is now possible. Our goal is to make future reservoir modeling have the same engineering usefulness that structural analysis has today.

\section{TECHNICAL OBJECTIVES}

The objectives of this project are to:

- Develop capability for modeling fluid flow on 3D planar fractures. The model will provide a simultaneous solution of planar flow in fractures, porous flow through rock, deformation of the rock and fractures, and heat transfer through the reservoir, including all coupling effects. To better characterize flow along fractures, the capability to specify a variation of fracture aperture over surfaces will be included. Fracture contact behavior will be modeled through the use of contact elements with a nonlinear stiffness behavior.

- Include tracer simulation with thermal degradation and adsorption. The tracer model will be used to simulate existing tracer data in Dixie Valley.

- Implement the model in a modern interactive user interface that will allow the user to work at the reservoir feature level (boundaries, fractures, wells, etc.) when developing a model. By using a topological representation of the geometry and automatic meshing, the user will be free to focus on the problem, not the details of how it is solved numerically.

- Apply the model to the Dixie Valley reservoir, including simulation of tracer and production data. The development of this model will be an iterative process. By the end of the project, a fully coupled fluid flow/heat transfer/rock deformation analysis will be performed. This will include the effects of thermal cool-down on reservoir permeability.

\section{EXPECTED OUTCOMES}

Expected outcomes of the project include:

- The delivery of an analysis tool that will allow realistic modeling of flow in fractured reservoirs. Such analysis capability will be useful because of the increasing recognition of the importance of fractures both on production and during reinjection.

- Demonstration of a geometric framework for developing reservoir models using the features of the reservoirs, rather than focusing on the meshing used for the numerical solution. This more natural interface offers the possibility of extension to provide an interface to other reservoir simulators, such as TOUGH 2 and TETRAD.

- Demonstration of the use of the model on an actual reservoir at Dixie Valley, including tracer and flow analyses.

\section{APPROACH}

There are two primary aspects to our modeling approach: a description of the problem using a geometric database and the method used to solve the physics of the simulation. 
Geocrack3D uses a vertex-use based, non-manifold topological database as the modeling framework for representation of the problem domain (Mantyla, 1988; Weiler, 1986; Martha, 1997). Topology provides a rigorous framework for geometry description. The topology used in Geocrack3D includes vertices, edges, faces, and volumes. By defining a set of consistent Euler operators, and using only those operators during geometry construction, one can be guaranteed that the geometry created is physically meaningful. This approach makes it possible to describe the reservoir independent of any particular method to be used to solve the problem.

The finite element method will be used to discretize the problem and solve equations for fluid flow, heat transfer, and rock deformation. The approach is to use object-oriented software methods to design a finite element program framework applicable to the coupled hydro-thermal-structure problem, while allowing extension and application to other problems. A draft design document has been completed and is being followed as we write the actual code to implement the solution.

The coupled physics of the problem provides a challenge, since we solve the structure, fluid, and heat transfer problems simultaneously. In traditional finite element implementations, where there are many different modeling capabilities, an element such as a T6 may have multiple implementations. For instance, there may be both plane stress and plane strain elements that are implemented using the same shape functions.

Our approach emphasizes that the main purpose of an element is discretization and interpolation. The underlying element physics are independent of the element functionality, except that the integration scheme must be able to capture adequately the physics. The underlying physics, called the element behavior, is separated from the element interpolation functionality. Then, a T6 element can contain either plane stress or plane strain functionality by only changing the behavior, not the element.

\section{RESEARCH RESULTS}

The current status of the project is that we have completed the initial implementation of the geometric database and the finite element solution for fluid flow on fractures (heat transfer is scheduled for addition in the second year and rock deformation is scheduled for the third year).

Figure 1 shows an example problem where several fractures have been defined in a reservoir volume. Three wells (indicated as lines intersecting the fracture planes) are included in the model. To create this model, the user defined a point and normal to each plane-all intersections with existing planes were automatically calculated as each new feature was added.

After applying boundary conditions and meshing the fractures a finite element solution for flow on the fractures was obtained. The pressure contours on the fractures are shown in Figure 2.

\section{FUTURE PLANS}

Significant work still remains on model development. Tracer calculations are being implemented in the fluid flow model. Heat transfer (which requires volume meshing), porous flow, and rock deformation will be implemented in the two remaining years of the project.

An initial Dixie Valley model is being developed using the flow on fractures capability. Results from this model will be compared to tracer data. This model will be refined as new capabilities are added to Geocrack3D. 


\section{INDUSTRY INTEREST AND TECHNOLOGY TRANSFER}

\section{Organization}

Oxbow Power Services

Energy \& Geoscience Inst.

GeothermEx

Maxwell Technologies

\section{Type and Extent of Interest}

Providing Dixie Valley data and oversight

Using Geocrack3D for analysis Interested in analysis approach Interested in analysis approach

\section{REFERENCES}

Swenson, D. V., 1997, "User's Manual for GEOCRACK: A Coupled Fluid Flow/Heat Transfer, Rock Deformation Program for Analysis of Fluid Flow in Fractured Rock," Mechanical Engineering Department, Kansas State University, Manhattan, KS, 66505, available for download at: http://www.engg.ksu.edu/ geocrack.

Hardeman, Brian, Daniel Swenson, 1998, "A Geometric Modeling Framework for Numerical Analysis of Geothermal Reservoirs," presented at 23rd Workshop on Geothermal Reservoir Engineering, Stanford Geothermal Program, Stanford University, Stanford, CA.

Mantyla, Martti, 1988, An Introduction to Solid Modeling, Computer Science Press.

Martha, Luiz and A. R. Ingraffea, 1989, "Topological and Geometrical Modeling Approach to Numerical Discretization and Arbitrary Fracture Simulation in Three-Dimensions," Report 89-9, School of Civila nd Environmental Engineering, Cornell University, Ithaca, NY.

Weiler, Kevin, 1986, "Topological Structures for Geometric Modeling." Ph.D. Thesis, Rensselaer Polytechnic Institute. 


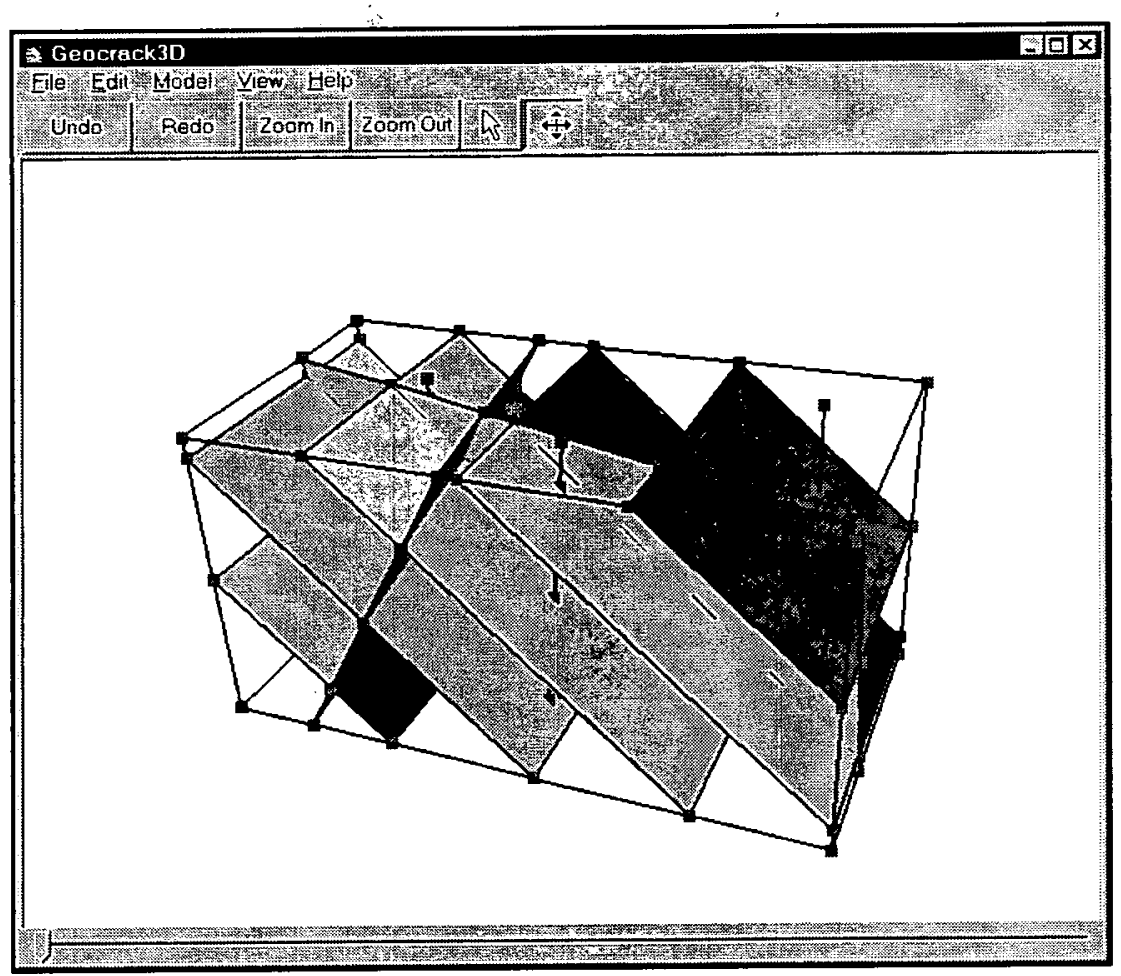

Figure 1. Geometric description of example reservoir, showing fractures and wells. Colors indicate volumes that will be meshed.

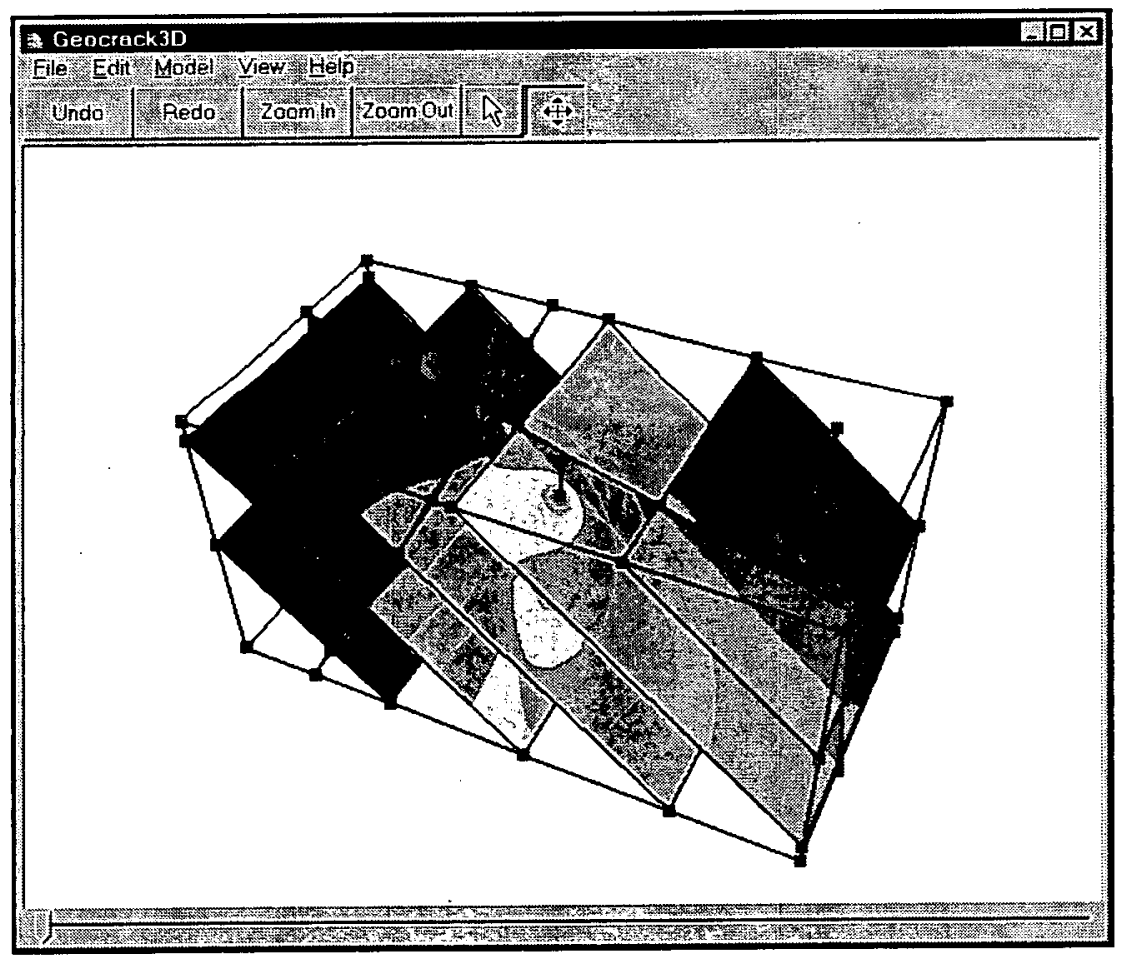

Figure 2. Pressure contours on reservoir. Injection into center well, production from two adjacent wells. 


\title{
LOWER LIMITS OF HYDROTHERMAL CIRCULATION AND CONDUCTIVE HEAT TRANSFER
}

\author{
Dennis L. Nielson and Joseph N. Moore \\ Energy \& Geoscience Institute \\ University of Utah
}

\section{KEY WORDS}

Intrusive, heat conduction, hydrothermal circulation, fractures, Ar-Ar age spectra

\section{PROJECT BACKGROUND AND STATUS}

High-temperature geothermal systems are supported by heat transfer from underlying magma chambers (Smith and Shaw, 1975). The transfer of heat to the convective volume is governed by conduction. The transition from a conductive to convective regime can be influenced by several factors. Perhaps the most discussed is the transition from brittle to ductile behavior of the rocks (Fournier, 1991; Nielson, 1996). Termination of permeability at the brittle-ductile transition is important in fields such as Larderello (Manzella et al., 1995) and Kakkonda (Yagi et al., 1995) where high temperatures $\left(370^{\circ}-400^{\circ} \mathrm{C}\right.$ ) are associated with pressures exceeding hydrostatic. At lower temperatures, the presence of lithologies that are not able to support open fracturing under hydrostatic pressures may contribute to decreased permeability. The thick section of Mesozoic shale in the Valles caldera which separates two major zones of hydrothermal circulation is an example (Nielson and Hulen, 1984).

The transition from conductive to convective thermal regimes can occur over very short distances and will be marked by steep temperature gradients. Within the convective zone, temperature will be limited by the boiling point to depth curve (e.g. Henley, 1985). If the temperature at the conductive-convective (c-c) interface is greater than the boiling point at that depth, the system will boil. If the temperature at the c-c interface is lower than boiling for that depth, the system will not boil unless there is very good vertical permeability or there are dilational events that will locally allow pressure drops to intersect the boiling point curve.

The hydrothermal history of the rocks can be established by combining the succession of hydrothermal alteration assemblages with ${ }^{40} \mathrm{Ar} /{ }^{39} \mathrm{Ar}$ age spectra on secondary adularia and fluid-inclusion homogenization temperatures (Moore et al., 1997,1998). This type of data has been established for both the Tiwi and Geysers geothermal systems. These time-temperature relationships provide constraints on numerical models.

Although research has focused on the upper parts of the hydrothermal circulation volume where permeability is highest, the lower parts are of interest because they will determine how the systems will naturally evolve. As technology improves, more developers will be interested in the recovery of heat from the lower parts of active hydrothermal systems (Nielson, 1996).

\section{PROJECT OBJECTIVES}

\section{Technical Objectives}

- Determine the character of the lower limits of hydrothermal circulation.

- Analyze the utility of heat conduction equations for describing the transfer of heat from underlying intrusive bodies to the hydrothermal circulation volume. 
- Study the relationships between the size and the temperature of geothermal systems.

\section{Expected Outcomes}

- Criteria for determining the reason for the termination of permeability in different systems.

- Develop models for Enhanced Heat Recovery through injection into the lower parts of geothermal systems.

\section{APPROACH}

A recent publication on the Tiwi geothermal system in the Philippines (Nielson and Moore, 1999) shows the approach for this project. The Tiwi geothermal field is a hot-water dominated system located in southern Luzon, Philippines. The thermal structure of the field and its main features have been described by Gambill and Beraquit (1993). Information on the thermal history of the system and the fracture distribution in the reservoir have come mainly from studies of core from Matalibong-25 (Nielson et al., 1996). This well was continuously cored from depths of 789 to $2439 \mathrm{~m}$. Matalibong-25 is located in the western portion of the field, and has a maximum measured temperature of $275^{\circ} \mathrm{C}$.

The hydrothermal history of the rocks in Matalibong-25 was established by combining the succession of hydrothermal alteration assemblages with ${ }^{40} \mathrm{Ar} /{ }^{39} \mathrm{Ar}$ age spectra on secondary adularia and fluid-inclusion homogenization temperatures (Moore et al., 1997,1998). Six stages of alteration and vein mineralization were documented in the cored portion of the well.

${ }^{40} \mathrm{Ar} /{ }^{39} \mathrm{Ar}$ age spectra were obtained on adularia from three depths between 1808 and $1851 \mathrm{~m}$. These data constrain the formation of adularia to the period between 314 and $279 \mathrm{ka}$. Subsequent alteration included the formation of wairakite and epidote, followed by calcite and then actinolite. The presence of actinolite indicates that temperatures in the lower part of the well must have exceeded $300^{\circ} \mathrm{C}$ at the end of the main stage of mineralization. ${ }^{40} \mathrm{Ar} /{ }^{39} \mathrm{Ar}$ age spectra indicate that these temperatures could have persisted until about $200 \mathrm{ka}$ when the system underwent significant and rapid cooling. Secondary fluid inclusions suggest that minimum temperatures stabilized at about $235^{\circ} \mathrm{C}$, although inclusions record temperatures as low as $191^{\circ} \mathrm{C}$. The present temperature of $275^{\circ} \mathrm{C}$ implies reheating by recent subvolcanic intrusions. Modeling of the ${ }^{40} \mathrm{Ar} /{ }^{39} \mathrm{Ar}$ age spectra suggests that the present temperature profile is not likely to have persisted for more than the last 50,000 years. Figure 1 presents a thermal model that is compatible with the measured adularia age spectra and the petrologic data.

An important feature of the Tiwi system is an apparent termination of permeability with depth. Gambill and Beraquit (1993) reported that the basement rocks beneath the field reach temperatures of more than $315^{\circ} \mathrm{C}$, but are relatively impermeable and unproductive. This reservoir bottom in the Naglagbong area is reported by them to be at an elevation of about $1500 \mathrm{~m}$ below sea level.

Nielson et al. (1996) documented the lithologic and fracture distributions in Matalibong-25. That paper concluded that the fractures controlling permeability are predominantly steeply dipping. It was also found that both fracturing and permeability decreased markedly in the lower part of the well. It appears that both the permeability and the frequency of veins decrease below about $2194 \mathrm{~m}$ (1643 m below sea level) depth. There are a number of possible explanations for this. The first possibility would be a brittle-ductile transition. However, measured temperatures are too cool and analysis of fluid inclusions suggests that the rocks were never hot enough for this explanation to be valid. The second possibility would be a lithologic effect. However, no major lithologic changes were observed in the lower part of the core, and permeability decreases related to rock type are unlikely. Within Matalibong-25, below depths of $1600 \mathrm{~m}$, the rocks consist mainly of volcanic sandstones. At greater depths, limestones, shales, and metamorphic 
basement are expected (Gambill and Beraquit, 1993). The third possibility would be a change in stress from extension above to compression below.

The transfer of heat from the underlying intrusive to the convective volume is governed by conductive heat transfer. To support this statement, we offer these observations. First, meteoric water will not circulate within an intrusive until it has crystallized and cooled to a temperature of less than approximately $400^{\circ} \mathrm{C}$ where open fractures can be maintained. Second, an intrusive will elevate the temperature of its wall rocks to above $400^{\circ} \mathrm{C}$ for some period of time during which these rocks will not be capable of supporting fracturing and convective heat transfer. This was demonstrated by Fournier (1991), and similar conclusions have been reached by Marsh et al. (1997). As argued by Nielson (1996), cooling of the wall rocks and the intrusive with time will lead to the eventual collapse of the convective regime into the magmatic heat source.

The interface between the conductive and convective zone is very important in the thermal budget of the geothermal system. In a system that is lithologically and structurally homogeneous, this boundary will coincide with the brittle-ductile boundary at a temperature of about $400^{\circ} \mathrm{C}$. In the Tiwi system, this boundary is found at $\mathrm{T}<400^{\circ} \mathrm{C}$, and we suggest that it is related to a change in the state of stress. The thermal energy delivered to the boundary by conduction will determine the behavior of the overlying convective volume with respect to the boiling point curve. If the temperature at the boundary is equivalent to the boiling-point at that depth, the boiling will be supported throughout the convective volume (barring influx of cold water into the system). If the temperature is less than the boiling-point at the interface, temperatures in the lower portion of the hydrothermal system will be less than boiling. If the temperature at the interface is greater than the boiling point curve, the hydrothermal system will boil, and vigorous boiling and the formation of hydrothermal breccias are expected.

Modeling of heat transfer can be useful for placing constraints on the size and age of intrusive events that are responsible for the observed thermal history of a geothermal system. Although we recognize that convection is important at Tiwi, particularly in its upper parts, the data suggest that conductive heat transfer dominates below about 1500 to $1650 \mathrm{~m}$ below sea level. The use of conductive cooling models has been discussed by Lovering (1935) and Carslaw and Jaeger (1959), and we are using heat conduction equations from those papers in this study. The geothermal reservoir at Tiwi underlies an area of approximately 1800 hectares and has dimensions of about $5 \mathrm{~km} \mathrm{x} 3.6 \mathrm{~km}$ (Gambill and Beraquit, 1993).

\section{RESEARCH RESULTS}

The intrusive in the model was assigned a thickness of $10 \mathrm{~km}$, a length of $5 \mathrm{~km}$, and a width of $3.6 \mathrm{~km}$. Initial simulations were run at a wall rock temperature of $150^{\circ} \mathrm{C}$ (based on mineralogical data) and intrusive temperatures of up to $1000^{\circ} \mathrm{C}$. Given our initial assumptions, these simulations were not able to produce temperatures at the interface between the ductile and convective zone high enough to fit the assumptions of the domed model. Through trial and error, it appeared that the intrusive had to have been hotter and the distance from the intrusive less than was originally assumed. The distance was modified to $500 \mathrm{~m}$ and the intrusive temperature increased to $1200^{\circ} \mathrm{C}$.

By rearranging the heat conduction equation, a time-temperature history at $500 \mathrm{~m}$ from the contact can be constructed (Fig. 2). This calculation shows a rapid increase in temperature within the first 5,000 years following the intrusive event; a temperature peak at about 10,000 years, and then gradual cooling.

Although temperatures exceeding $300^{\circ} \mathrm{C}$ between 314 and $200 \mathrm{ka}$ could be achieved by increasing the size of the intrusion or its temperature (such a model is not spiscifically precluded by the ${ }^{40} \mathrm{Ar} /{ }^{39} \mathrm{Ar}$ age spectra), the presence of wairakite, epidote, and calcite prior to the formation of actinolite implies that 
temperatures first declined below $300^{\circ} \mathrm{C}$ and then increased. Figure 2 shows the effects of a second intrusion emplaced at $225 \mathrm{ka}$.

A third intrusive event is required to raise temperature to that presently observed at $1800 \mathrm{~m}$ depth $\left(275^{\circ} \mathrm{C}\right)$. In formulating Model 3, we found it necessary to introduce a third intrusive event 41,000 years ago that increased the temperature of the intrusive body to $500^{\circ} \mathrm{C}$ to obtain the results shown in Fig. 2 .

The time-temperature profile determined from conductive cooling models suggests that intrusive events are associated with a rapid increase in temperature followed by gradual cooling. This suggests an episodic behavior of geothermal systems where intrusive events are manifested by active convection (perhaps boiling) and deposition of hydrothermal minerals followed by cooling and stagnation of the convective volume. Another implication of the models presented here is that long-lived geothermal systems, such as Tiwi, require multiple episodes of igneous activity to sustain high temperature.

\section{FUTURE PLANS}

We have already initiated thermal conduction modeling of The Geysers magmatic-hydrothermal system. At The Geysers, there is information on both the intrusive composition and age, and hydrothermal temperatures.

\section{INDUSTRY INTEREST AND TECHNOLOGY TRANSFER}

\section{Company Type and Extent of Interest}

Unocal Alteration Mineralogy and thermal modeling

\section{REFERENCES}

Carslaw, H. S. and Jaeger, J. C., 1959, Conduction of heat in solids, Oxford University Press, 510 p.

Gambill, D. T. and Beraquit, D. B., 1993, Development history of the Tiwi geothermal field, Philippines: Geothermics, v. 22, p. 403-416.

Fournier, R. O., 1991, The transition from hydrostatic to greater than hydrostatic fluid pressure in presently active continental hydrothermal systems in crystalline rock: Geophysical Research Letters, v. 18 , p.955-958.

Lovering, T. S., 1935, Theory of heat conduction applied to geological problems: Geological Society of America, v. 46, p. 69-94.

Manzella, A., Gianelli, G. and Puxeddu, M., 1995, Possible models of the deepest part of the Larderello geothermal field: Proceedings of the World Geothermal Congress, Florence, Italy, v. 2, p. 1279-1282.

Marsh, T. M., Einaudi, M. T. and McWilliams, M., 1997, ${ }^{40} \mathrm{Ar} /{ }^{39} \mathrm{Ar}$ geochronology of $\mathrm{Cu}-\mathrm{Au}$ and $\mathrm{Au}-\mathrm{Ag}$ mineralization in the Potrerillos district, Chile: Economic Geology, v.92, p.784-806.

Moore, J. N. and Gunderson, R. P., 1995, Fluid inclusion and isotopic systematics of an evolving magmatic-hydrothermal system: Geochimica et Cosmochimica Acta, v. 59, p. 3887-3907.

Moore, J. N., Powell, T. S., Bruton, C. J., Norman, D. I. and Heizler, M. T., 1998, Thermal and chemical evolution of the Tiwi geothermal system, Philippines: $9^{\text {th }}$ International Conference on Water-Rock Interaction, Taupo, N. Z., p. 565-568. 
Moore, J. N., Powell, T. S., Norman, D. I. and Johnson, G., 1997, Hydrothermal alteration and fluidinclusion systematics of the reservoir rocks in Matalibong-25, Tiwi, Philippines: Twenty-second Workshop on Geothermal Reservoir Engineering, Stanford University, p. 447-456.

Nielson, D. L., 1996, Natural analogs for enhanced heat recovery from geothermal systems: Proceedings, Twenty-first Workshop on Geothermal Reservoir Engineering, Stanford University, p. 43-49.

Nielson, D. L., Clemente, W. C., Moore, J. N. and Powell, T. S., 1996, Fracture permeability in the Matalibong-25 corehole, Tiwi geothermal field, Philippines: lroceedings, Twenty-first Workshop on Geothermal Reservoir Engineering, Stanford University, p. 209-:_16.

Nielson, D. L. and Moore, J. N., 1999, Lower limits of hydrothermal circulation in the Tiwi geothermal field, Luzon: Proceedings, Twenty-fourth Workshop on Geothermal Reservoir Engineering, Stanford University, in press.

Smith, R. L. and Shaw, H. R., 1975, Igneous-related geothermal systems, in White, D. E. and Williams, D. L., Assessment of geothermal resources of the United States * 1975: U. S. Geological Survey Circular 726, p. 58-83.

Yagi, M., Muraoka, H., Doi, N. and Miyazaki, S., 1995, NE:DO "deep-seated geothermal resources survey” overview: Geothermal Resources Council Transactions, v. 19, p.377-382. 

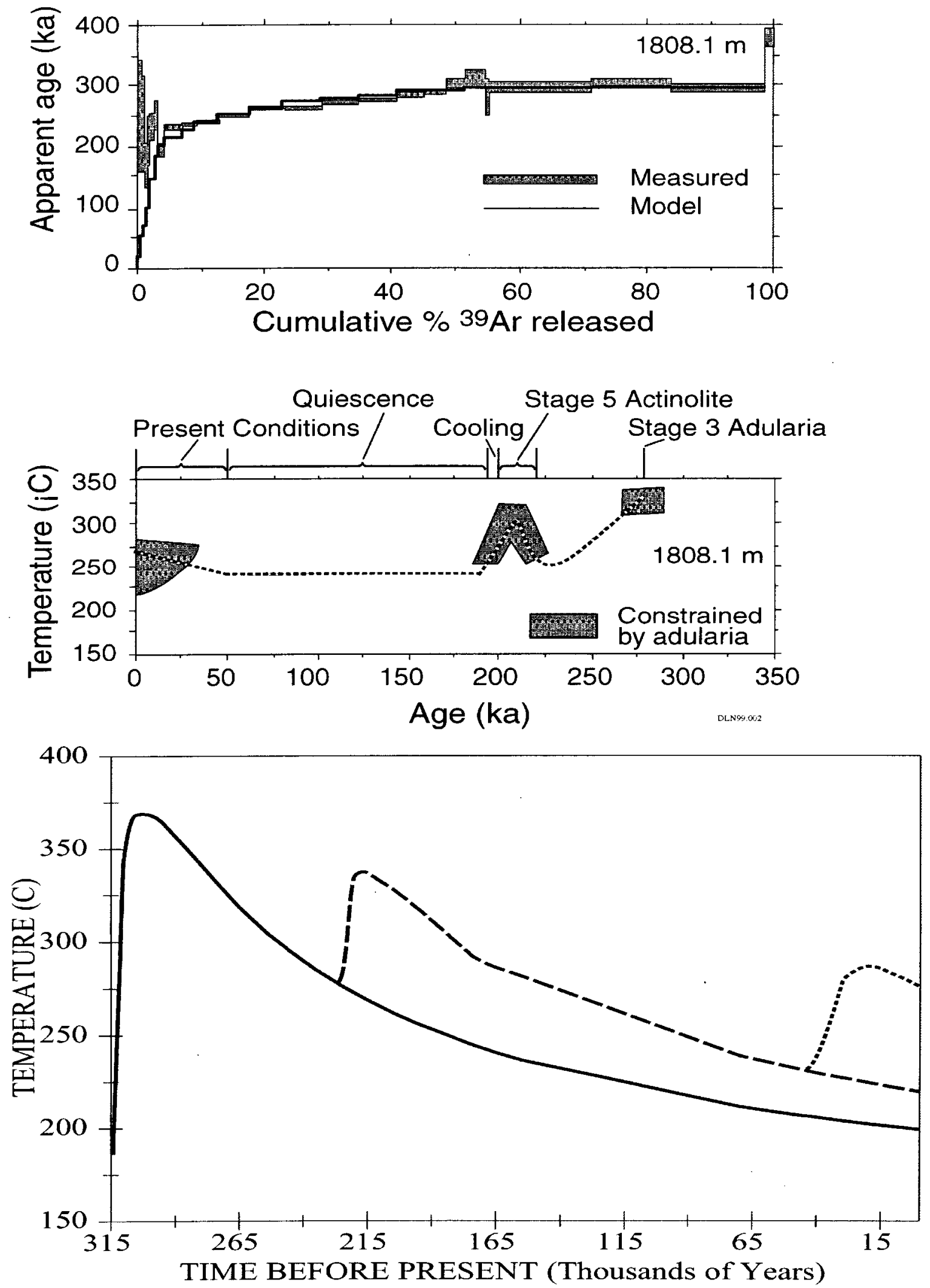

- Intrusive 1 - Intrusive 2 ..... Intrusive 3 


\title{
ON THE EFFECTIVE CONTINUUM ME'THOD FOR MODELING MULTIPHASE FLOW, MULTICOMPONEN $\rceil$ TRANSPORT AND HEAT TRANSFER IN FRACTURED ROCK
}

\author{
Yu-Shu Wu \\ Lawrence Berkeley National Laboratory
}

\section{KEY WORDS}

Fractured reservoirs, fracture and matrix interaction, numerical reservoir simulation, multiphase flow, tracer transport, heat transfer, effective continuum approach (ECM).

\section{PROJECT BACKGROUND AND STATUS}

Flow and transport through fractured porous media occurs in many subsurface systems and has received considerable attention in recent years due to the importance in the areas of energy resource recovery, waste storage, and environmental remediation schemes. Since the 1960's, significant progress has been made in understanding and modeling fracture flow phenomena in porous media (Barenblatt et al., 1960; Warren and Root, 1963; Kazemi, 1969; Pruess and Narasimhan, 1985). Despite these advances, modeling the coupled processes of multiphase fluid flow, heat transfer, and chemical migration in a fractured porous medium remains a challenge conceptually and mathematically. This is primarily due to the nature of inherent heterogeneity and uncertainties associated with fracture/matrix systems for any given field problem, as well as the computational intensity required. Numerical modeling approaches currently used for simulating multiphase fluid flow, heat transfer, and chemical transport processes are generally based on methodologies developed for geothermal and petroleum resirvoir simulations. They involve solving coupled multiphase fluid and heat flow, multi-chemical component migration formulations based on finite difference or finite element schemes with a volume averaging approach.

A key issue for simulating fluid and heat flow and chemical transport in the fractured porous rocks is how to handle fracture and matrix interactions under multiphase, non-isothermal conditions. The available methods for treatment of fracture and porous matrix interactions using a numerical model include: (1) an explicit, discrete fracture and matrix model (Sudicky and McLaren, 1992); (2) the dual-continua method including double- and multi-porosity, dual-permeability, or the more general "multiple interacting continua" (MINC) method (Pruess and Narasimhan, 1985); and (3) the effective continuum method (ECM) (Wu et al., 1996).

The ECM approximation has long been used for modeling fracture/matrix flow problems. However, there is a lack, in the literature and in applications, on the clear definition of the effective continuum or equivalent porous medium approach. Many different types of ECM models have been presented and used, based on different assumptions and approximations, such as for isothermal, unsaturated flow (Peters and Klavetter, 1988), for coupled fluid and heat flow (Pruess et al. 1988; 1990; Nitao, 1989), for single phase flow and transport (Berkowitz et al., 1988; Kool and Wu, 1991), and for coupled multi-phase fluid and heat flow and solute transport (Wu et al., 1996).

\section{PROJECT OBJECTIVES}

The objective of this research is to present a generalized, rigorous ECM formulation for modeling multiphase, non-isothermal flow and solute transport $(\mathrm{Wu}, 1999)$. The focus of this work is to develop the theoretical basis for the ECM methodology and the procedures to estimate effective parameters and constitutive relations needed for its application. 


\section{Technical Objectives}

- To rigorously derive a set of generalized effective continuum formulation for evaluation of the effective parameters and correlations for multiphase fluid flow, multicomponent transport and heat transfer in fractured reservoirs.

- To implement of the ECM formulation into the TOUGH2 code (Pruess, 1991) for modeling multiphase, multicomponent, non-isothermal flow and transport in fractured rocks.

- To present application and verification examples to demonstrate the usefulness of the ECM method in geothermal reservoir engineering.

\section{Expected Outcomes}

An alternative ECM numerical approach for modeling fluid and heat flow and tracer transport in geothermal reservoirs will be developed. The new ECM formulation will be implemented into existing reservoir simulators to significantly improve the modeling of large-scale field problems, both in computational efficiency and in simplification in data requirements. This has already been done for the TOUGH 2 codes.

\section{APPROACH}

When compared with conventional dual-continua modeling approaches, the ECM relies on an additional but critical assumption, i.e., that locally in the formation and at all times there is approximate thermodynamic equilibrium between fracture and matrix. This implies that the local fracture/matrix interactions (mass and heat exchanges) are simultaneously completed in a time scale relative to the time needed for the global flow and transport occurring through surrounding fracture-fracture/matrix-matrix connections. This results in a set of partial differential equations in the ECM formulation for flow and transport in fractured media, as follows.

For compositional transport equation of each species $\kappa$ :

$$
\begin{aligned}
& \frac{\partial}{\partial \mathrm{t}}\left\{\phi \sum_{\beta}\left(\rho_{\beta} \mathrm{S}_{\beta} \mathrm{X}_{\beta}^{\mathrm{k}}\right)+(1-\phi) \rho_{\mathrm{s}} \rho_{\mathrm{w}} \mathrm{X}_{\mathrm{w}}^{\mathrm{\kappa}} \mathrm{K}_{\mathrm{d}}^{\mathrm{\kappa}}\right\}+\lambda_{\mathrm{\kappa}}\left\{\phi \sum_{\beta}\left(\rho_{\beta} \mathrm{S}_{\beta} \mathrm{X}_{\beta}^{\mathrm{\kappa}}\right)+(1-\phi) \rho_{\mathrm{s}} \rho_{\mathrm{w}} \mathrm{X}_{\mathrm{w}}^{\mathrm{k}} \mathrm{K}_{\mathrm{d}}^{\mathrm{k}}\right\} \\
& =-\sum_{\beta} \nabla \bullet\left(\rho_{\beta} \mathrm{X}_{\beta}^{\mathrm{k}} \overrightarrow{\mathrm{v}}_{\beta}\right)+\sum_{\beta} \nabla \bullet\left(\rho_{\beta} \underline{D}^{\mathrm{k}} \bullet \nabla \mathrm{X}_{\beta}^{\mathrm{k}}\right)+\mathrm{q}^{\mathrm{\kappa}}
\end{aligned}
$$

The energy conservation equation is

$$
\begin{aligned}
& \frac{\partial}{\partial \mathrm{t}}\left\{\sum_{\beta}\left(\phi \rho_{\beta} \mathrm{S}_{\beta} \mathrm{U}_{\beta}\right)+(1-\phi) \rho_{\mathrm{s}} \mathrm{U}_{\mathrm{s}}\right\}=-\sum_{\beta} \nabla \bullet\left(\mathrm{h}_{\beta} \rho_{\beta} \overrightarrow{\mathrm{v}}_{\beta}\right) \\
& +\sum_{\beta} \sum_{\mathrm{\kappa}} \nabla \bullet\left(\rho_{\beta} \mathrm{h}_{\beta}^{\mathrm{K}} \underline{D}^{\mathrm{\kappa}} \bullet \nabla \mathrm{X}_{\beta}^{\mathrm{K}}\right)+\nabla \bullet\left(\mathrm{K}_{\mathrm{th}} \nabla \mathrm{T}\right)+\mathrm{q}^{\mathrm{E}}
\end{aligned}
$$

The notations and symbols in the equations above and below are standards as in literature and are defined in detail in $\mathrm{Wu}(1999)$.

Effective Parameters and Constitutive Relations needed for solving (1) and (2) are defined as follows: 
Effective saturation of fluid $\beta$,

$$
S_{\beta}=\frac{S_{\beta . f} \phi_{\mathrm{f}}+S_{\beta, m} \phi_{m}}{\phi_{\mathrm{f}}+\phi_{\mathrm{m}}}
$$

Effective distribution coefficient

$$
K_{d}^{\kappa}=\frac{A_{s} K_{d}^{f}+\left(1-\phi_{m}-\phi_{f}\right) K_{d}^{m}}{1-\phi}
$$

Effective Darcy velocity of fluid $\beta$,

$$
\overrightarrow{\mathrm{v}}_{\beta}=-\frac{\mathrm{kk}_{\beta}}{\mu_{\beta}}\left(\nabla \mathrm{P}_{\beta}-\rho_{\beta} \overrightarrow{\mathrm{g}}\right)
$$

Effective relative permeability to fluid phase $\beta$,

$k_{\beta}=\frac{k_{f} k_{\beta . f}+k_{m} k_{\beta . m}}{k_{f}+k_{m}}$

Effective fracture/matrix, diffusion-dispersion tensor accounting for both molecular diffusion and hydrodynamic dispersion,

$$
\underline{D}^{\kappa}=\frac{\phi_{\mathrm{f}} \underline{\mathrm{D}}_{\mathrm{f}}^{\kappa}+\phi_{\mathrm{m}} \underline{\mathrm{D}}_{\mathrm{m}}^{\kappa}}{\phi_{\mathrm{f}}+\phi_{\mathrm{m}}}
$$

where the fracture diffusion-dispersion tensor is,

$$
\underline{D}_{f}^{\kappa}=\left(\alpha_{T, f}\left|\vec{v}_{\beta, f}\right|\right) \delta_{i j}+\left(\alpha_{L, f}-\alpha_{T, f}\right) \vec{v}_{\beta, f} \vec{v}_{\beta, f} /\left|\vec{v}_{\beta, f}\right|+\left(\phi_{f} S_{\beta, f} \tau_{f} d_{f}\right) \delta_{i j}
$$

and the matrix diffusion-dispersion tensor is,

$$
\underline{D}_{m}^{k}=\left(\alpha_{T, m}\left|\vec{v}_{\beta, m}\right|\right) \delta_{i j}+\left(\alpha_{L, m}-\alpha_{T, m}\right) \vec{v}_{\beta, m} \vec{v}_{\beta, m} /\left|\vec{v}_{\beta, m}\right|+\left(\phi_{m} S_{\beta, m} \tau_{m} d_{m}\right) \delta_{i j}
$$

Effective thermal conductivity,

$$
\mathrm{K}_{\mathrm{th}}=\frac{\phi_{\mathrm{f}} \mathrm{K}_{\mathrm{th} . \mathrm{f}}+\phi_{\mathrm{m}} \mathrm{K}_{\mathrm{th}, \mathrm{m}}}{\phi_{\mathrm{f}}+\phi_{\mathrm{m}}}
$$

In solving the governing equations (1) and (2) with the ECM approach, the primary variables selected in a numerical solution are normally fluid pressures, $P_{\beta}$, effective saturations, $S_{\beta}$, temperature, $T$, and mass 
fraction, $X_{\beta}^{\kappa}$. Once the primary variables are chosen, all the secondary variables must be evaluated using the primary variables, effective parameters and correlations in order to set up a set of solvable numerical equations. In this process special attention needs to be paid to evaluating the secondary variables, effective constitutive relations and parameters. Many rock and fluid properties, such as porosities, absolute permeability, dispersivities, thermal conductivities, tortuosities, and diffusion coefficients of fracture and matrix continua, fluid viscosities and densities, should be determined from field and/or laboratory studies.

\section{RESEARCH RESULTS}

The ECM formulation has been implemented into the TOUGH 2 code, a multiphase, multicomponent, nonisothermal reservoir simulator (Pruess, 1991). It includes (a) the EOS3 and EOS4 modules for twophase (water and gas), two components (water and air) and heat; (b) the EOS9 module for two-phase, isothermal flow by solving Richards' equation; and (c) the EOS1G module for single gas flow in a twophase condition with aqueous phase as a passive phase (Wu et al., 1996). In addition, a two-phase, threecomponent and non-isothermal version is implemented into a solute transport code, T2R3D (Wu and Pruess, 1998). Because of computational efficiency and simplicity in data requirement with the ECM method, the implemented modules of the TOUGH 2 code and the T2R3D code have found a wide range of applications in field studies (Wu et al., 1998).

\section{FUTURE PLANS}

Derivation and implementation of the ECM approach have been completed. Future plans will focus on applications of the ECM methodology to field studies, especially to geothermal systems.

\section{INDUSTRY INTEREST AND TECHNOLOGY TRANSFER}

The ECM method has been incorporated into the TOUGH2 reservoir simulation codes, which are available to industry, university and national laboratory researchers worldwide.

\section{REFERENCES}

Barenblatt, G. I., I.P. Zheltov, and I.N. Kochina. Basic Concepts in the Theory of Seepage of Homogeneous Liquids in Fissured Rocks, PMM, Sov. Appl. Math. Mech., 24(5), 852-864, 1960.

Berkowitz, B., J. Bear, and C. Braester. Continuum Models for Contaminant Transport in Fractured Porous Formations, Water Resour. Res., 24(8), 1225-1236, 1988

Kazemi, H.. Pressure Transient Analysis of Naturally Fractured Reservoirs with Uniform Fracture Distribution, SPEJ, 451-62. Trans., AIME, 246, 1969.

Kool J.B. and Y.S. Wu. Validation and Testing of the VAM2D Computer Code, NUREG/CR-5795, HydroGeoloGic, Inc., Prepared for U. S. Nuclear Regulatory Commission, 1991.

Nitao, J.J. V-TOUGH - An Enhanced Version of the TOUGH Code for the Thermal and Hydrologic Simulation of Large-scale Problems in Nuclear Waste Isolation, Lawrence Livermore National Laboratory report UCID-2 1954, 1989.

Peters, R.R. and E.A. Klavetter. A Continuum Model for Water Movement in an Unsaturated Fractured Rock Mass, Water Resour. Res., 24(3), 416-430, 1988. 
Pruess K. TOUGH2-A General Purpose Numerical Simulator for Multiphase Fluid and Heat Flow, Lawrence Berkeley Laboratory report LBL-29400, 1991.

Pruess, K., and Narasimhan, T.N A Practical Method for Modeling Fluid and Heat Flow in Fractured Porous Media, Soc. Pet. Eng. J., 25, pp. 14-26, 1985.

Pruess, K., J.S.Y. Wang, and Y.W. Tsang. Effective Continuum Approximation for Modeling Fluid and Heat Flow in Fractured Porous Tuff. Sandia National Laboratories report SAND86-7000, 1988.

Pruess, K., J.S.Y. Wang, and Y.W. Tsang. On the thermohydrologic conditions near high-level nuclear wastes emplaced in partially saturated fractured tuff, Part 2. Effective continuum approximation, Water Resources Res., 26(6), 1249-1261, 1990.

Sudicky, E.A. and R.G. McLaren. Users's Guide for Fractran: An Efficient Simulators for Twodimensional, Saturated Groundwater Flow and Solute Transport in Porous or Discretely-fractured Porous Formations, Groundwater Simulations Group, Institute for Groundwater Research, University of Waterloo, Canada, 1992.

Warren, J.E., and P.J. Root. The Behavior of Naturally Fractured Reservoirs, Soc. Pet. Eng. J., pp. 245255, Transactions, AIME, 228, 1963.

Wu, Y. S. On the Effective Continuum Method for Modeling Multiphase Flow, Multicomponent Transport and Heat Transfer in Fractured Rock, paper submitted to the International Symposium on "Dynamics of Fluids in Fractured Rocks: Concepts and Recent Advances", organized in Honor of the $80^{\text {th }}$ birthday of Paul A. Witherspoon, Berkeley, CA, February 10-12, 1999, Lawrence Berkeley National Laboratory report LBNL-42720.

Wu, Y.S and K. Pruess. A 3-D Hydrodynamic Dispersion Model for Modeling Tracer Transport in Geothermal Reservoirs, Proceedings Twenty-third Workshop Geothermal Reservoir Engineering, Stanford, CA, 139-146, 1998.

Wu, Y.S., Ritcey, A.C., Ahlers, C.F., Hinds, J.J., Mishra, A.K.. Haukwa, C., Liu, H.H., Sonnenthal, E.L., and Bodvarsson, G.S., 3-D UZ Site-Scale Model for Abstraction in TSPA-VA. Yucca Mountain Project Level 4 Milestone Report SLX01LB3, 1998.

Wu, Y. S., C. F. Ahlers, P. Fraser, A. Simmons, and K. Pruess. Software qualification of selected TOUGH2 modules, Lawrence Berkeley National Laboratory report LBNL-39490, 1996. 


\title{
INVESTIGATION OF INDUCED SEISMICITY AND SURFACE DEFORMATION AT THE GEYSERS GEOTHERMAL FIELD, $\mathbf{N}$. CALIFORNIA
}

\author{
Paul Segall and Antony Mossop (*) \\ Geophysics Department \\ Stanford University \\ CA 94305 \\ (*) Now at:- \\ IPGP \\ 4, Place Jussieu (Tour 14-24) \\ 75252 Paris cedex 05 \\ France
}

\section{KEY WORDS}

induced seismicity, deformation, The Geysers, thermo-hydro mechanical modeling, injection correlated seismicity, production correlated seismicity

\section{PROJECT BACKGROUND}

The development of large scale geothermal energy extraction at The Geysers geothermal field in the 1970 's, prompted the USGS to perform a series of geodetic surveys, to monitor possible ground deformation. Survey results up to 1977 were published [Lofgren, 1981], the main results were that up to $0.192 \mathrm{~m}$ of subsidence were observed between 1973-1977 and horizontal displacements of as much as $0.095 \mathrm{~m}$ were observed for the period 1972--1977. The general trend of horizontal movement was towards the center of the field where fluid extraction operations were most intense. The results indicated a contracting reservoir. Lofgren [1981] suggested the contraction was a poroelastic process. This was refuted by Denlinger et. al. [1981] who noted that elastic parameters inferred from seismic data were inconsistent with a poroelastic mechanism they suggested that thermoelastic contraction due to reservoir cooling was a better explanation. The geodetic monitoring program ceased in 1981. None of the survey results subsequent to 1977 were published.

As power production grew at The Geysers there was also an apparent increase in seismic activity in the region [Majer and McEvilly, 1979]. Statistical studies initially indicated that the local seismicity had no significant correlation with water injection operations but some significant correlation was observed between steam withdrawal and seismicity [Eberhart-Phillips and Oppenheimer, 1984]. However, later work by Stark [1992] found that about half the seismicity at The Geysers showed strong spatial and temporal correlation with water injection, the correlation increased if only deeper earthquakes were considered.

Subsidence at The Geysers and at other geothermal fields is of concern. There are substantial problems associated with the damage to infrastructure such as roads, pipelines and cables due to ground movement. There is also the danger of land sliding in locations that are frequently characterized by weak thermally altered rock and high relief.

The study of induced seismicity in geothermal fields is of growing importance to the geothermal industry, not just because of concerns related to environmental hazard but also recognition that induced seismicity may contain information on fluid flow paths and hence be useful for the efficient exploitation of 
geothermal reservoirs. However, predictions and interpretations based on induced seismicity data must rely, to some extent, on the mechanics of how they occur and this is not well understood. As earthquakes are generally assumed to be stress release phenomena in deforming rock, it is important that any study should pay attention to regional deformation.

There would appear to be a need to resurvey The Geysers to find out how deformation has progressed over the past 20 years, and for repeat surveys to determine present deformation rates. Furthermore the surface deformation data should be analyzed to determine strain distribution within the volume of the crust and if possible identify the processes controlling deformation of the geothermal reservoir.

The mechanics of induced seismicity needs to be determined. At least in as far as to whether seismicity is controlled by water injection, fluid production or a combination of both. There is also the question as to whether the stress perturbations that lead to earthquake nucleation are controlled by pore pressure or temperature changes.

\section{PROJECT STATUS}

Started 7/1/97. Final Report written 9/22/98.

\section{PROJECT OBJECTIVES}

To gain a better understanding of the stresses, strains and seismicity induced in geothermal fields by power production operations, with special emphasis on The Geysers geothermal field. The goal is to identify the processes controlling deformation within the geothermal field and those that trigger the observed induced seismicity. In addition the project provided part of the research training for A.M. in pursuit of Ph.D. degree.

\section{Technical Objectives}

- Verify seismicity significantly correlates with industrial activity with formal estimate of significance.

- Determine surface deformation since 1977.

- $\quad$ Determine present deformation rates.

- Determine subsurface strain within the reservoir.

- Identify processes controlling reservoir strain.

- Model mechanics of poroelastic and thermoelastic stresses associated with fluid production and water injection.

- Identify processes controlling induced seismicity.

\section{Expected Outcomes}

- Improved understanding of processes controlling surface deformation in Geothermal fields with ability to predict effected areas. 
- Improved understanding of induced seismicity in geothermal fields allowing interpretation of reservoir properties from earthquake data.

\section{APPROACH}

The old survey monuments used in the USGS geodetic surveys of the 1970-80's were searched for, a substantial number were found to still survive. These were resurveyed in 1994, 1995 and 1996 using survey grade Global Positioning System receivers. The results were combined with the earlier USGS survey data after correcting for geoid variations. The monument displacements were used to invert for volume change and volume strain within the reservoir for various time intervals (1975-80, 1980-94, 199496, 1977-96). The results were interpreted to gain insight into the processes controlling deformation.

A model was developed of the thermoelastic stresses developed about a fracture, in a hot rock body, into which cold water is being injected. The flow rate is controlled by pressure gradients within the fracture. The reduction in compressive stress across the fracture due to fluid pressure and thermal stressing can then be directly compared. The reason for considering the fracture normal component is that we assume that the main deviatoric stress across a fracture in the reservoir is dictated by the ambient stress field. A reduction in fracture normal compressive stresses will drive it towards shear failure and hence the nucleation of an earthquake. The model takes an analytic approach and closed form solutions are found.

A similar model was developed to determine the pressure drop about a fracture from which steam is being extracted. As the pressure drops the water in the bulk rock porosity (the small pores in the bulk rock are initially full of hot liquid water) turn to steam. This leads to evaporative cooling of the rock surrounding the production fracture and again thermoelastic stresses are induced. A statistical analysis of the seismicity at The Geysers was carried out. The seismic data was taken from the Berkeley archives as recorded on CALNET. This network provides the longest time span of reasonably stationary coverage. For cross-correlation purposes the longest time span with the most events and greatest signal variation are the most desirable traits of a time series. A magnitude cutoff of $M>1.3$ was applied to ensure uniform recording coverage of The Geysers field. The seismic data were cross-correlated with steam production and water injection data. Various spatial and temporal subsets of data were similarly treated.

\section{RESULTS}

The most recent work was the statistical analysis. The results were that shallow seismicity at The Geysers, those events that locate above the reservoir, significantly correlate with steam production; there is no significant correlation between shallow seismicity and water injection. The time lag of the peak crosscorrelation about $\mathbf{5 0 0}$ days, this is consistent with the time delay for pressure to diffuse over the average distance between productive fracture. The indication is that the reservoir is contracting poroelastically, increasing shear stresses across fractures in the rocks above the reservoir, causing shear failure and earthquake nucleation.

Reservoir depth seismicity is found to correlate significantly with both injection and production for the 20 years 1976-1996. However, if only the first 12 years are analyzed then the correlation between seismicity and steam production increases. If the last 10 years are analyzed, then a significant correlation only exists between injection and seismicity, the cross-correlation between production and seismicity drops to an insignificant level. The production correlated seismicity is consistent with thermoelastic stressing due to evaporative cooling causing earthquakes to nucleate. As the steam front about the fracture is pushed further into the rock this effect becomes smaller. By the mid-1980's steam produced at The Geysers began to become superheated [Truesdel et. al, 1992], indicating that the majority of steam is being extracted from pores that already have boiled and are inside the steam front. Evaporative cooling 
requires a phase change to occur and ceases to be effective when the reservoir becomes superheated. Consistent with the disappearance of production correlated seismicity after the mid 1980's.

Cross-correlation at the well scale shows that significant correlations are seen between water flow into injection wells and seismicity. However, in wells where injection is switched off seismicity is observed to initially increase. This is inconsistent with the majority of injection correlated earthquakes being nucleated by the injected water pressure. However, it is consistent with thermal stressing due to advective cooling being the cause of earthquake nucleation. Similarly, injection pressures only grow slowly with time (logarithmic for stable flow conditions). Hence if earthquakes are triggered by increases in fluid pressure we'd expect a burst of seismicity when injection begins that drops off rapidly. Observed behavior though shows a slower drop off of injection correlated seismicity with time for a steady injector. A result more consistent with the $t^{\wedge}\{1 / 4\}$ behavior predicted for thermal stresses due to advective cooling.

\section{Earlier results have shown:}

- That seismicity at The Geysers is significantly correlated with industrial fluid flows.

- That the Geysers has subsided almost $1 \mathrm{~m}$ in it's most active region over the period 1975-1996.

- That volume change and volume strain within the reservoir closely match maps of pressure reduction inferred from measurements taken in production wells.

- That volume change and volume strain are inconsistent with a dominant themoelastic contraction mechanism but are consistent with a poroelastic mechanism. Account must be made for the frequency dependence of elastic modula so that the reservoir appears stiff at seismic frequencies but compliant for quasi-static deformation.

- That the reduction in compressive stress across a conductive fracture intersected by an injection well is dominated by thermal stresses rather than water pressure for conditions typical of a geothermal field.

\section{INDUSTRY INTEREST}
Organization
Type and Extent of Interest
Unocal
Assistance in field survey
NCPA
Assistance in field survey
Calpine
Assistance in field survey
CCPA
Assistance in field survey

A. M. gave presentation of results to a meeting of representatives of Unocal, NCPA and Calpine at a meeting held at Unocal's Santa Rosa offices in April 1998.

A. M. gave presentation of results to representatives of Shell's special projects department at Stanford in April 1998.

A. M. gave presentation of results to representative of Mitsubushi Corp. at IPGP in September 1998. 


\section{REFERENCES}

R. P. Denlinger, W. P. Isherwood, and R. L. Kovach. Inewblock Geodetic analysis of reservoir depletion at The Geysers steam field in northern California. Inewblock \{lem Journal of Geophysical Research\}, 86:6091--6096, 1981.

D. Eberhart-Phillips and D. H. Oppenheimer. Inewblock Induced seismicity in The Geysers geothermal area, California. Inewblock \{lem Journal of Geophysical Research\}, 89:1191--1207, 1984.

B. E. Lofgren. Inewblock Monitoring crustal deformation in the geyser-clear lake region. Inewblock In \{lem Research in The Geysers-Clear Lake geothermal area, northern California\}. Geological survey professional paper 1141, United States Government printing office, 1981.

M. A. Stark. Inewblock Microearthquakes -- a tool to track injected water in The Geysers reservoir. Inewblock In \{lem Monograph on The Geysers geothermal field, $\{S\}$ pecial report no. 17\}, pages 111 -117. Geothermal Resources Council, 1992.

A. H. Truesdell, J. R. Haizlip, W. T. Box, and F. D'Amore. Inewblock A geochemical overview of The Geysers geothermal reservoir. Inewblock In \{lem Monograph onThe Geysers geothermal field, $\{\mathrm{S}\}$ pecial report no. 17\}, pages 121--132. Geothermal Resources Council, 1992. 


\title{
ALTERATION/PARAGENETIC STUDIES AND ADULARIA AGE-DATING TO CONSTRAIN THE NATURE AND TIMING OF THE TRANSITION FROM LIQUID-TO VAPOR-DOMINATED CONDTIONS AT THE GEYSERS, CALIFORNIA
}

\author{
Jeffrey B. Hulen and Joseph N. Moore \\ Energy \& Geoscience Institute, University of Utah, Salt Lake City, Utah \\ Matthew T. Heizler \\ New Mexico Geochron. Research Institute, Socorro, New Mexico
}

\section{KEY WORDS}

The Geysers, mineralization, veins, hydrothermal alteration, paragenesis, ${ }^{40} \mathrm{Ar} /{ }^{39} \mathrm{Ar}$, age-dating, thermalhistory modeling, liquid-to-vapor-dominated

\section{PROJECT BACKGROUND AND STATUS}

At the $22^{\text {nd }}$ Workshop on Geothermal Reservoir Engineering at Stanford University, Hulen et al., (1997) presented the first strong evidence for the nature and timing of the transition from liquid to vapordominated conditions in The Geysers hydrothermal system. That work was based on careful paragenetic studies of vein mineralization in core from The Geysers Coring Project, on detailed fluid-inclusion work, and on ${ }^{40} \mathrm{Ar} /{ }^{39} \mathrm{Ar}$ incremental-heating age-dating and thermal-history modeling of vein adularia from a depth of $1548 \mathrm{ft}$ in corehole SB-15-D (Fig. 1). Important to this study was organic-matter geothermometry (done by Jeff Quick of the Utah Geological Survey), based on the reflectance of vitrinite (VR) in the Franciscan Assemblage metagraywacke which hosts the adularia-bearing veins. The reflectance was converted to peak paleotemperature using an empirical, hydrothermal-heating reflectanceto-temperature conversion developed by Barker and Pawlewicz (1994). Using this approach, we were able to show that the rock had not been heated to more than about $330^{\circ} \mathrm{C}$. One of us (Heizler) determined that the blocking temperature for the dated adularia was $375^{\circ} \mathrm{C}$, which in combination with the VR paleotemperature allowed unusually detailed temperature-constrained thermal-history modeling.

In short, the thermal modeling revealed that the adularia was deposited at about $0.57 \mathrm{Ma}$, at or below a temperature of $330^{\circ} \mathrm{C}$, then experienced a dramatic deline in temperature from about $300^{\circ} \mathrm{C}$ to $260^{\circ} \mathrm{C}$ between 0.28 and $0.25 \mathrm{Ma}$. Fluid inclusion systematics showed that the system changed from liquid- to vapor-dominated at about $290^{\circ} \mathrm{C}$. Since the thermal modeling indicated that this temperature prevailed only during the steep temperature decline, we concluded that (at least in the immediate area) The Geysers transformed from a liquid- to vapor-dominated system about a quarter of a million years ago.

These results were unprecedented and intriguing, but we still needed to know if the same thermal history occurred elsewhere in the field. Accordingly, we received permission from Unocal Geothermal to collect additional vein material from their collection of Geysers cores. About a third of these vein samples yielded reliable dates and corresponding thermal-history models. The results confirm a consistent timing for the liquid- to vapor-dominated transition in a broad area of the north-central Geysers (Fig. 1) and possibly at the top of The Geysers felsite where cored by well DV-2 (Fig. 1). 


\section{PROJECT OBJECTIVES}

\section{Technical Objectives}

- Analyze, mineralogically and paragenetically, vein mineralization and hydrothermal alteration in selected cores collected from The Geysers steam field. Focus particularly on the position of secondary potassium feldspar in the paragenetic sequence. Select vein samples with enough K-spar to permit effective concentration of the mineral in a sufficiently pure form for reliable dating efforts.

- Age-date the separated feldspars by ${ }^{40} \mathrm{Ar} /{ }^{39} \mathrm{Ar}$ incremental-heating methods, followed by geothermometer-constrained numerical thermal-history modeling of the resulting age spectra.

- With the aid of fluid-inclusion systematics (Moore and Gunderson, 1995) previously published for the dated cores, determine when in the paragenesis the system likely transformed from liquid- to vapor-dominated.

- Investigate and compare likely mechanisms which may have triggered the transformation.

\section{Expected Outcome}

- Quantification and clear undestanding of the nature and timing of the transition from the liquid- to the vapor-dominant state at The Geysers.

\section{APPROACH}

Much of the work for this project has been done gradually over the past few years in support of other Geysers research efforts (for example, Hulen and Norton's study of The Geysers felsite-see elsewhere in this volume). It remained only to refine earlier descriptions and mineralogical identifications of the cores, and to perform supplemental fluid-inclusion work prior to submitting the samples for age-dating. Collection of the samples involved a trip to Santa Rosa and The Geysers, and a full day examining and carefully selecting likely, adularia-bearing veins from a dozen core samples.

For a number of reasons, only four cores yielded enough and sufficiently pure adularia for the age-dating efforts B SB-15-D (dated previously), DX-84, GDHS-7, and DV-2 (Fig. 1). The latter two cores, however, produced two good samples apiece, and those from DV-2 surprisingly produced two different ages of adularia veins.

\section{RESEARCH RESULTS}

As an example of the temporal position of the dated adularia in the paragenetic sequence, please refer to Figure 1. Core DX-84, from deep in the steam reservoir, has a more complex and apparently initially higher-temperature mineralization history, with tourmaline being deposited during the first three hydrothermal veining events (the earliest veins in the core are inherited from Franciscan metamorphism). Tourmaline is absent from the GDHS-7 core, but the earliest vein here contains actinolite, placing it tentatively at the same paragenetic stage as the second veining event in the DX-84 core. In both cases, relatively coarse feldspar from late-stage veins was collected for the age-dating. These are translucent, whitish-appearing veins in GDHS-7; greenish-colored veins with abundant epidote and chlorite in the DX-84 core. 
The GDHS-7 adularia, though collected much deeper than the one from SB-15-D, produced a virtually identical precipitation age and subsequent thermal-history profile. The feldspar from DX-84 was apparently precipitated about a hundred thousand years later (as the cooling front retreated downward?). Its thermal-history profile, however, shows the same "steep" temperature decline at about $25 \mathrm{Ka}$. Results from DV-2 are ambiguous and require further analysis, but one of the two adularias in the rock appears to have been precipitated earlier in The Geysers overall hydrothermal history.

These exciting results suggest that the transition from liquid- to vapor-dominant conditions may have taken place over a very broad span of the field at about the same time, regardless of when the secondary feldspar recording the event was initially precipitated.

\section{FUTURE PLANS}

Carefully analyze the age-dating results in the light of all available geologic constraints to arrive at the most plausible precipitation ages and subsequent thermal histories for each of the dated feldspars. Obtain new mineralogic, paragenetic, fluid-inclusion, and vitrinite-reflectance information where warranted. Arrive at an integrated model for the liquid- to vapor transition. Publish the results, possibly in the Geothermics special issue on The Geysers in 1999.

\section{INDUSTRY INTEREST}

Obviously these results are of academic interest from the standpoint of the evolution of magmatichydrothermal systems in general, but the research also has a practical payoff. It bears directly on determination of the origin, character, and geometry of fractures in what ultimately became the productive steam reservoir. The fractures are essential for the field's permeability, and the more that is know about them, the better able steamfield operators like Calpine, Unocal, Florida Power and Light, and NCPA will be to cut production costs and augment future steam production through injection.

\section{REFERENCES}

Barker, C.E., and Pawlewicz, M.J., 1994, Calculation of vitrinite reflectance from thermal histories and peak temperatures B A comparison of methods in Vitrinite reflectance as a maturity parameter (W.G. Dow and P.K. Mukhopadhyay, editors): American Chemical Society, Symposium Series, p. 216-219.

Hulen, J.B., Heizler, M.T., Stimac, J.A., Moore, J.N., and Quick, J.C., 1997, New constraints on the timing of magmatism, volcanism, and the onset of vapor-dominated conditions at The Geysers steam field, California: Stanford University, $22^{\text {nd }}$ Workshop on Geothermal Reservoir Engineering, Proceedings, p. 344-351.

Moore, J.N., and Gunderson, R.P., 1995, Fluid-inclusion and oxygen-isotopic systematics of an evolving magmatic-hydrothermal system B The Geysers, California: Geochimica et Cosmochimica Acta, v. 59, p. 3887-3907. 


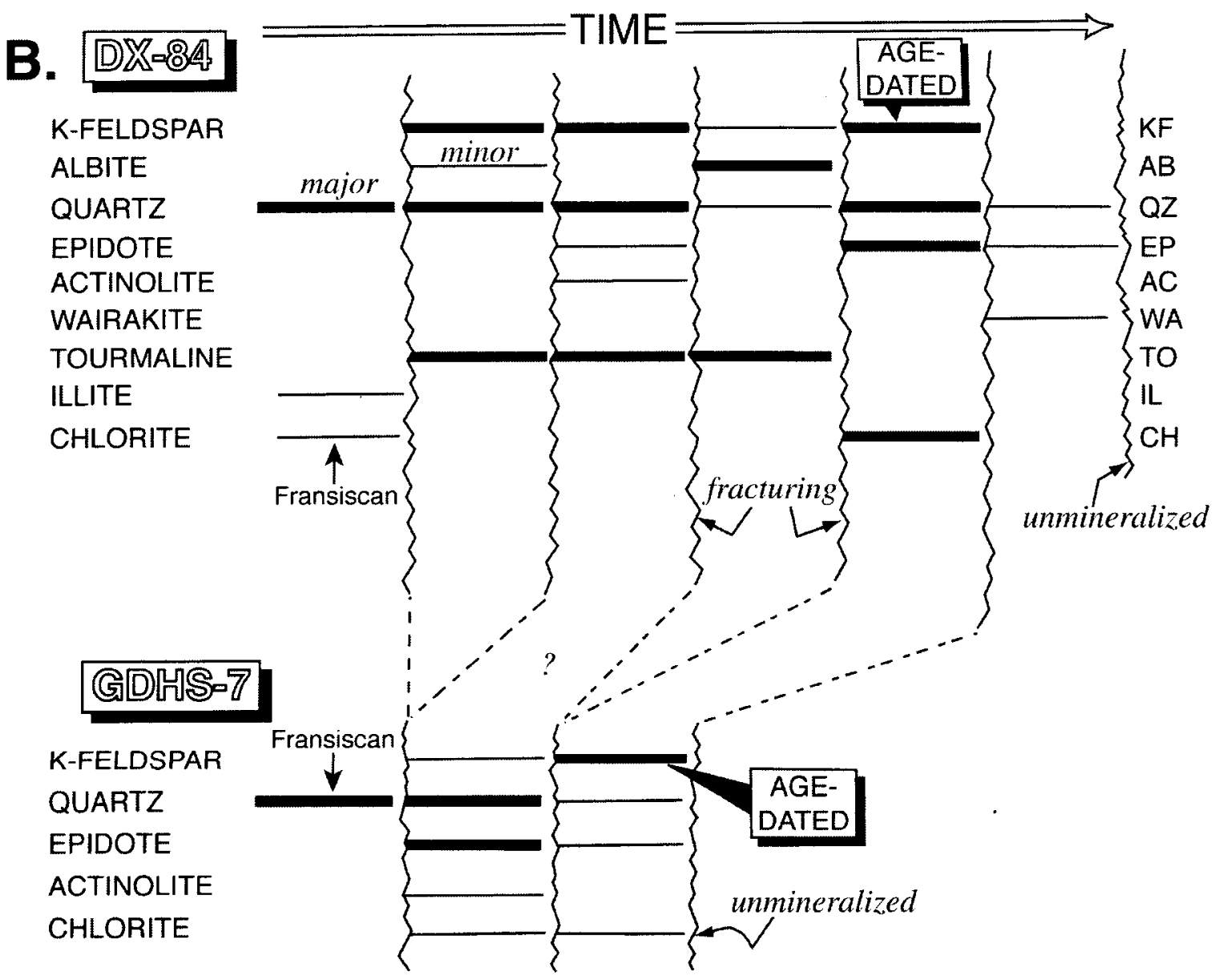

Figure 1. A $(\rightarrow)$ Location map. B $(\uparrow)$ Generalized vein-mineral paragenetic sequences for metagraywacke cores from wells GDHS-7 and DX-84, The Geysers steam field.

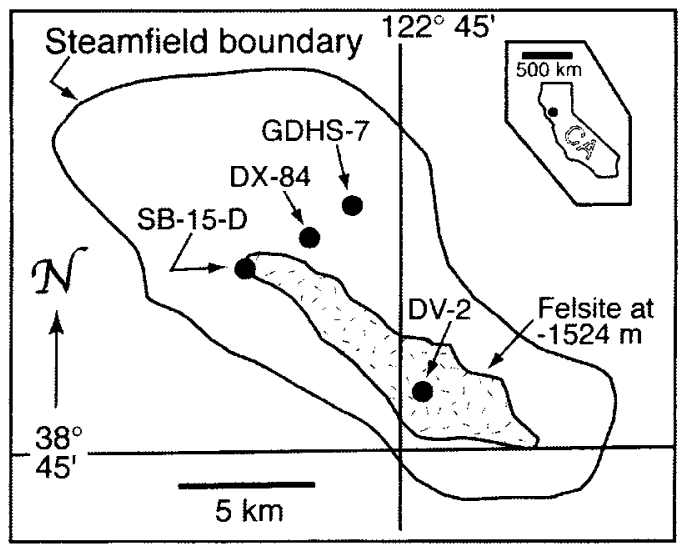




\title{
FIELD STUDIES USING NUMERICAL MODELING
}

\author{
K. K. Bloomfield \\ Idaho National Engineering and Environmental Laboratory
}

\section{KEY WORDS}

injection, The Geysers, numerical simulation

\section{PROJECT BACKGROUND AND STATUS}

Reservoir simulation is used to estimate energy recovery for a given producing scheme and to evaluate the effects on recovery of altered operating conditions.

Due to pressure declines at The Geysers, efforts have focused on improving our understanding of production response to injection. By using a numerical model to simulate the effects of water injection, we are able to identify key parameters that influence production. This will ultimately enable us to identify areas (zones?) that would most rapidly benefit from injection. With the recent startup of the SE Geysers Effluent Pipeline Project, and a future Santa Rosa Wastewater Project, a better understanding of the mechanisms for reservoir recharge/pressure support becomes critical.

\section{PROJECT OBJECTIVES}

The objective of this project is to develop better understanding of injection behavior using a numerical model. This model will be continuously expanded and refined, and will be used to improve methods of reservoir characterization and utilization of injectate.

\section{Technical Objectives}

- Develop numerical simulation as a dependable method for estimating reservoir response to water injection projects.

- Evaluate various injection scenarios in order to develop an improved understanding of optimizing use of injectate.

\section{Expected Outcomes}

- Develop computationally efficient field scale models to validate project benefits.

- Identify key parameters that reduce the risk and expense of expanding water injection into more areas of The Geysers.

\section{APPROACH}

A numerical model was constructed that included the Unit 18 injection project area. The model was developed using data supplied by Geysers operators UNOCAL, NCPA, and Calpine Corp. The data included deviated well surveys, steam entry data, and production data. Maps for top of steam and top of felsite published in the Monograph on The Geysers Geothermal Field were used as proxies for top and bottom of reservoir, respectively. The study area (see Figure 1) was $9000 \mathrm{ft}$. by $9000 \mathrm{ft}$., and was modeled areally by a 20 by 20 grid. Model thickness was $5000 \mathrm{ft}$. The vertical grid used was 6 layers of varying thickness. For the initial pass at modeling this area, no-flow boundaries were used on all sides of the 
domain (the north and west sides of the domain should be flow boundaries). Attempts at relaxing this assumption indicate that additional production across those boundaries must also be accounted for in order to use more realistic boundary conditions. This will be done in coming years.

Dual porosity, with uniform permeability and porosity in both fractures and matrix was used in the study. Fracture spacing was assumed to be $150 \mathrm{ft}$. A uniform initial liquid saturation was established, and the model was initialized for 20 years prior to exploitation to adjust to vapor-static conditions. The nonuniform structure in the study area resulted in non-uniform initial liquid saturations, with a small amount of mobil liquid ponding in the bottom of the domain. Sensitivity studies were conducted on the initial saturations in order to minimize mobil liquid in the lower layers. Average initial liquid saturations in the study area were $75 \%$ in the matrix and $6 \%$ in the fracture domain.

The model was then calibrated to match observed production in the 43 wells within the study area through well productivity index manipulation. After obtaining a successful history match of the production, the injection well was turned off in the model and a comparison was made in simulated production between the base case and a "no injection" scenario.

\section{RESEARCH RESULTS}

The Geysers Unit 18 injection study area model has been constructed using data from steam producers. Production rates and wellhead pressures were successfully matched for all 43 wells in the study area. In particular, early response to injection - in both timing and magnitude of response - was matched very well for all wells. Later response to injection was overpredicted to some extent, probably due to the boundary conditions used.

By comparing the base case simulation with the "no injection" case, and converting steam production to power generation $(20 \mathrm{klb} / \mathrm{hr}=1 \mathrm{MWe})$, we can also compare observed response to injection with simulated response. The results of this, reduced to a per-operator basis are given below.

$\begin{array}{lcc}\text { OPERATOR } & \text { Observed Response Mwe } & \text { Simulated Response Mwe } \\ \text { UNOCAL } & 2.0 & 2.8 \\ \text { NCPA } & 1.0 & 0.8 \\ \text { Calpine Corp } & 0.0 & 0.7\end{array}$

\section{FUTURE PLANS}

We plan to continue the model study by developing and implementing techniques to characterize the study area. The techniques are:

- Identify methods of relaxing the boundary conditions to incorporate what is happening outside the study area.

- Incorporate tracer tests results into the numerical simulation.

The study area is a candidate to receive water from the Lake County Waste Water Project. A study of long term steady state injection into a detailed reservoir description will help develop a better understanding of fluid flow and heat transfer processes during water injection. 


\section{INDUSTRY INTEREST AND TECHNOLOGY TRANSFER}

This project results are presented at conferences and data sets are shared with the GTO participants for review.

\section{REFERENCES}

Bloomfield K. K., et al, 1997, "Progress presentation of Numerical Modeling of The Geysers Unit 18 Cooperative Injection Project" Geothermal Resource Conference. 


\title{
GEOLOGIC ANALYSIS AND THERMAL-HISTORY MODELING OF THE GEYSERS HYDROTHERMAL SYSTEM, CALIFORNIA
}

\author{
'Denis L. Norton and ${ }^{2}$ Jeffrey B. Hulen \\ ${ }^{1}$ Independent Geologist-Geochemist, Stanley, Idaho \\ ${ }^{2}$ Energy \& Geoscience Institute, University of Utah
}

\section{KEY WORDS}

The Geysers, thermal-history modeling, felsite, igneous intrusion, geothermometry, vitrinite reflectance, age-dating, hydrothermal alteration, fluid inclusions, hydraulic fracturing

\section{PROJECT BACKGROUND AND STATUS}

It is has long been established that the modern Geysers geothermal system evolved from a hightemperature, hot-water-dominated precursor (e.g. Sternfeld, 1981). The transition may have taken place about 250,000 years ago (Hulen et al., 1997), and this timing presents a quandary. The reason? The likely magmatic heat engine for The Geysers, a large hypabyssal pluton know colloquially as "the felsite" (Schriener and Suemnicht, 1981) has so far yielded only much older radiometric age dates, clustering at about 1.1 Ma (Dalrymple, 1992; Hulen et al., 1997). It is generally thought that even very large magmatic bodies will cool to ambient temperatures within a few hundred thousand years, especially when that cooling is accelerated by convecting hydrothermal fluids set in motion by the plutons themselves (few cool by conduction alone; Norton, 1989). Yet The Geysers is still decidedly hot. Temperatures range from about $235^{\circ} \mathrm{C}$ in the "typical" vapor-dominated reservoir, and reach at least $342^{\circ} \mathrm{C}$ beneath the subjacent "high-temperature" reservoir (Walters et al., 1988). Thus, either (1) conventional cooling-pluton concepts do not apply here (highly unlikely), or (2) the felsite has undergone a much more complex and prolonged intrusive and hydrothermal history than so far indicated by the age-dating.

To help resolve these issues, we have completed preliminary numerical thermal-history modeling of The Geysers felsite and hydrothermal system assuming (1) that the igneous body, however unlikely, was intruded en masse; and (2) that maximum associated paleotemperatures in the pluton and its host rocks are recorded with reasonable accuracy by fluid inclusions, temperature-sensitive secondary minerals, and (in the host rocks only) the reflectance of indigenous and introduced organic matter. Even preliminary results of this approach have strong and clear implications for the nature and timing of development of The Geysers hydrothermal system.

\section{PROJECT OBJECTIVES}

\section{Technical Objectives}

- Numerically model the hydrothermal history of The Geysers felsite and its host rocks, utilizing methods developed by Norton to investigate the cooling histories of diverse plutons worldwide.

- $\quad$ Match the modeled 2-D isothermal configurations at various times post-intrusion to various peak paleotemperature indicators measured at multiple depths and locations throughout the geothermal field.

- Assess the probability, magnitude, and configuration of permeability-enhancing, natural hydraulic fracturing events in different sectors and depths of The Geysers steam reservoir. Determine the likelihood (and timing if feasible) of past catastrophic venting episodes, wherein large volumes of fluid could have been transferred from the hydrothermal system to the atmosphere. Such venting is 
believed crucial to the formation of a vapor-dominated system from a liquid-dominated precursor (Pruess, 1985; Shook, 1995; Hulen et al., 1997).

- Investigate natural processes leading to the formation of the Ahigh-temperature $\cong$ steam reservoir in the northwestern part of the field.

\section{Expected Outcomes}

- Improved understanding, in four dimensions, of the processes relevant to and ensuing from heat and mass transfer within, around, and above The Geysers felsite.

- $\quad$ Refined estimation of the time necessary, throughout The Geysers, to reach peak paleotemperatures within and around the felsite following its intrusion.

- Mapping of areas and volumes of The Geysers more likely to have experienced natural hydraulic fracturing as a permeability-enhancing mechanism.

- New insight into the mechanisms of natural hydrothermal reservoir formation, particularly with respect to: (1) the formation of fractures and sealing of fractures during dissipation of thermal energy from the pluton; and (2) the natural evolution of the fluid system to deep, "hightemperature" vapor-dominant conditions.

\section{APPROACH}

The heating and cooling histories of numerous and varied, actual and hypothetical (composite) magmatichydrothermal systems of all shapes and sizes have been modeled mathematically since the mid 1970's by Norton and colleagues (e.g. Norton, 1984; Brickowski and Norton, 1989). The work has focused on pluton environments ranging from porphyry copper stocks to batholiths. In most cases, many of the intrinsic fluid and rock properties use for these models by necessity have been inferred since the subject plutons and associated hydrothermal systems have long since cooled to ambient temperatures.

The Geysers presents a unique opportunity to apply this very effective approach to a magmatichydrothermal system which is still very hot, but which, by virtue of generous DOE financial support since the late 1980 's, boasts a voluminous and detailed geoscientific and reservoir-engineering database. This information can be used to constrain the models to an unprecedented degree.

The Geysers numerical thermal-history modeling, like that employed for the fossil systems, is based first of all upon measured or geologically reasonable and approximated initial magma and rock properties. At the Geysers, for example, petrologic, petrographic, geochemical, and mineralogical study of the full drilled extent of the felsite by Hulen has constrained its likely intrusion temperature (about $950^{\circ} \mathrm{C}$ ); volatile content (low), and viscosity (high). In like fashion, the bulk permeability of the volume of intrusive and overlying metagraywacke destined to host the steam reservoir is constrained reasonably to be on the order of 50 microdarcies. This value is consistent with fracture distributions in the carapace and lithocap of fossil magmatic-hydrothermal systems: an ensemble of numerical models of pluton thermal histories assembled by Norton and students; and from Williamson's (1992) estimate based on reservoirengineering considerations.

With guidance established by these initial properties, the model simulates the transport of thermal, chemical, and mechanical energy by fluid flow and molecular diffusion utilizing a coupled set of partial differential equations (Norton, 1984). A key provision of the model is a series of Afeedback loops $\cong$ by 
which the consequences of hydrothermal processes (e.g. microfracturing) modify the processes themselves in an intricate interplay sensitive to slight changes in single parameters.

These constraints and interactions are analyzed using computational methods that approximate the systematics of these events following intrusion of magma into the crust. The technique estimates the temperature, pressure, and fluid velocity within the pluton and its host rocks in a 2-D section of the system at various times following igneous intrusion.

\section{RESEARCH RESULTS}

As an example of our intriguing research results to date, Figure 1 shows modeled paleotemperature profiles at The Geysers 55,000 years after intrusion of the felsite (again, assuming it was emplaced en masse) at two different locations: (1) the site of Geysers Coring Project corehole SB-15-D, which passed through a relatively impermeable caprock into the topmost "normal" vapor-dominated geothermal reservoir; and (2) an arbitrarily selected site at which deep geothermal wells now penetrate the Ahigh-

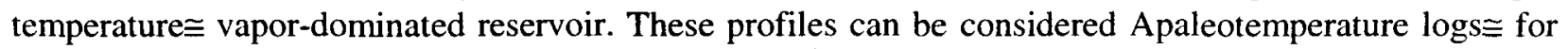
hypothetical geothermal wells completed at $55 \mathrm{Ka}$ into the two reservoir sectors. For both sites, modern static-temperature profiles are superimposed for comparison.

The rationale for choosing the SB-15-D site for the modeling was to attempt to match maximum paleotemperatures obtained for the corehole from fluid-inclusion microthermometry and vitrinite reflectance, the latter index believed to be a measure of the absolute maximum temperature ever to be reached in the affected rocks. Note that the VR temperatures are closely matched by the model temperatures only $55 \mathrm{Ka}$ after felsite intrusion, even though these rocks are $1.4 \mathrm{~km}$ above the top of the intrusive body.

This relationship would appear irreconcilable with the base assumption that the felsite was intruded as a single body about 1.1 Myr ago. It would mean not only that peak paleotemperatures at this elevation beneath the SB-15-D site were achieved more than a million years ago, but that temperatures have cooled here since that time by only about $70^{\circ} \mathrm{C}\left(0.00007^{\circ} \mathrm{C}\right.$ per year!). Additional, post-1.1 Ma magmatic input would seem to be an absolute requirement for at least this sector of The Geysers. At least two scenarios are plausible: (1) younger intrusions emplaced into the larger body intruded en masse at $1.1 \mathrm{Ma}$; (2) emplacement of the felsite as a sequence of smaller intrusions, coalescence of which through time produced the overall form of the igneous body as observed today. In view of the paucity (one) of felsite age dates younger than 1.1 Ma, this latter mechanism is problematical and the former preferred.

\section{FUTURE PLANS}

- Complete the preliminary thermal-history modeling summarized above, taking it to a point in time, following intrusion, at which the pluton and hydrothermal system would have cooled to ambient conditions in the absence of additional magmatic input.

- Plot, at equivalent, appropriate positions relative to the felsite in the models, fluid-inclusion and organic-matter-reflectance peak paleotemperatures obtained for cores from throughout The Geysers (Hulen et al., 1997 and unpublished data). Compare with modeled thermal configurations at various post-intrusion times to gauge when, at various elevations, thermal maxima were theoretically achieved. Investigate whether these maxima were reached contemporaneously, or whether they were attained at different times in The Geysers hydrothermal history.

- Publish results of this preliminary work, complete with the relevant geological and geochemical (organic and inorganic) constraints. Emphasize implications of the findings for the magmatic- 
hydrothermal history of The Geysers, particularly (1) aspects of that history fostering development and maintenance of superior reservoir permeability; (2) geological and geochemical means by which these "sweet zones" can be cost-effectively targeted and developed. Improved understanding of the nature, origin, configuration, and magnitude of reservoir permeability will help steamfield operators select optimum sites at which to inject steam condensates, purified wastewaters (as from Lake County and perhaps Santa Rosa) or other waters to replace or enhance steam production for decades to come.

\section{INDUSTRY INTEREST}

Understanding the present permeability and thermal structure of The Geysers requires improved knowledge of the evolution of the causative magma-hydrothermal system(s) from inception to present day. We are at a stage in Geysers research where a vast and incomparable geoscientific database provides the requisite framework for the detailed, field-wide, numerical magma-cooling and thermal-history modeling being carried out for this investigation. In illuminating the locations, configurations, and origins of optimally hot, permeable, and productive portions of the geothermal reservoir, results of this investigation are of value first and foremost to The Geysers steamfield operators B Unocal, Calpine, NCPA, and Florida Power and Light $\mathrm{B}$ but also industry-wide wherever hydrothermal systems are utilized for electric power production.

\section{REFERENCES}

Brikowski, T., and Norton, D., 1989, Influence of magma-chamber geometry on hydrothermal activity at mid-ocean ridges: Earth and Planetary Science Letters, v. 93, p. 241-255.

Dalrymple, G.B., 1992, Preliminary report on ${ }^{40} \mathrm{Ar} /{ }^{39} \mathrm{Ar}$ incremental-heating experiments on feldspar samples from the felsite unit, Geysers geothermal field: U.S. Geological Survey, Open-File Report 92$407,15 \mathrm{p}$.

Hulen, J.B., Heizler, M.T., Stimac, J.A., Moore, J.N., and Quick, J.C., 1997, New constraints on the timing of magmatism, volcanism, and the onset of vapor-dominated conditions at The Geysers steam field, California: Stanford University, $22^{\text {nd }}$ Workshop on Geothermal Reservoir Engineering, Proceedings, p. 75-82.

Norton, D.L., 1984, Theory of hydrothermal systems: Annual Review of Earth and Planetary Sciences, v. 12, p. 155-177.

Pruess, K., 1985, A quantitative model of vapor-dominated geothermal reservoirs as heat pipes in fractured, porous rock: Geothermal Resources Council, Transactions, v. 9, pt. 2, p. 353-361.

Schriener, A. Jr., and Suemnicht, G.A., 1981, Subsurface intrusive rocks at The Geysers geothermal area, California in Proceedings of the symposium on mineral deposits of the Pacific Northwest (M.L. Silberman, C.W. Field, and A.L. Berry, editors): U.S. Geological Survey, Open-File Report 81-355, p. 295-302.

Shook, M., 1995, Development of a vapor-dominated reservoir with a Ahigh-temperature $\cong$ component: Geothermics, v. 24, p. 489-505.

Sternfeld, J.N., 1981, The hydrothermal petrology and stable-isotope geochemistry of two wells in The Geysers geothermal field, California: University of Calif. at Riverside, M.S. Thesis, 202 p. 
Walters, M.A., Sternfeld, J.N., Haizlip, J:R. Drenick, A.F., and Combs, J., 1988, A vapor-dominated geothermal reservoir exceeding $600^{\circ} \mathrm{F}$ at The Geysers, California: Stanford University, $13^{\text {th }}$ Workshop on Geothermal Reservoir Engineering, Proceedings, p. 73-81.

Williamson, K.H., 1992, Development of a reservoir model for the Geysers geothermal field: Geothermal Resources Council, Special Report 17, p. 59-64. 


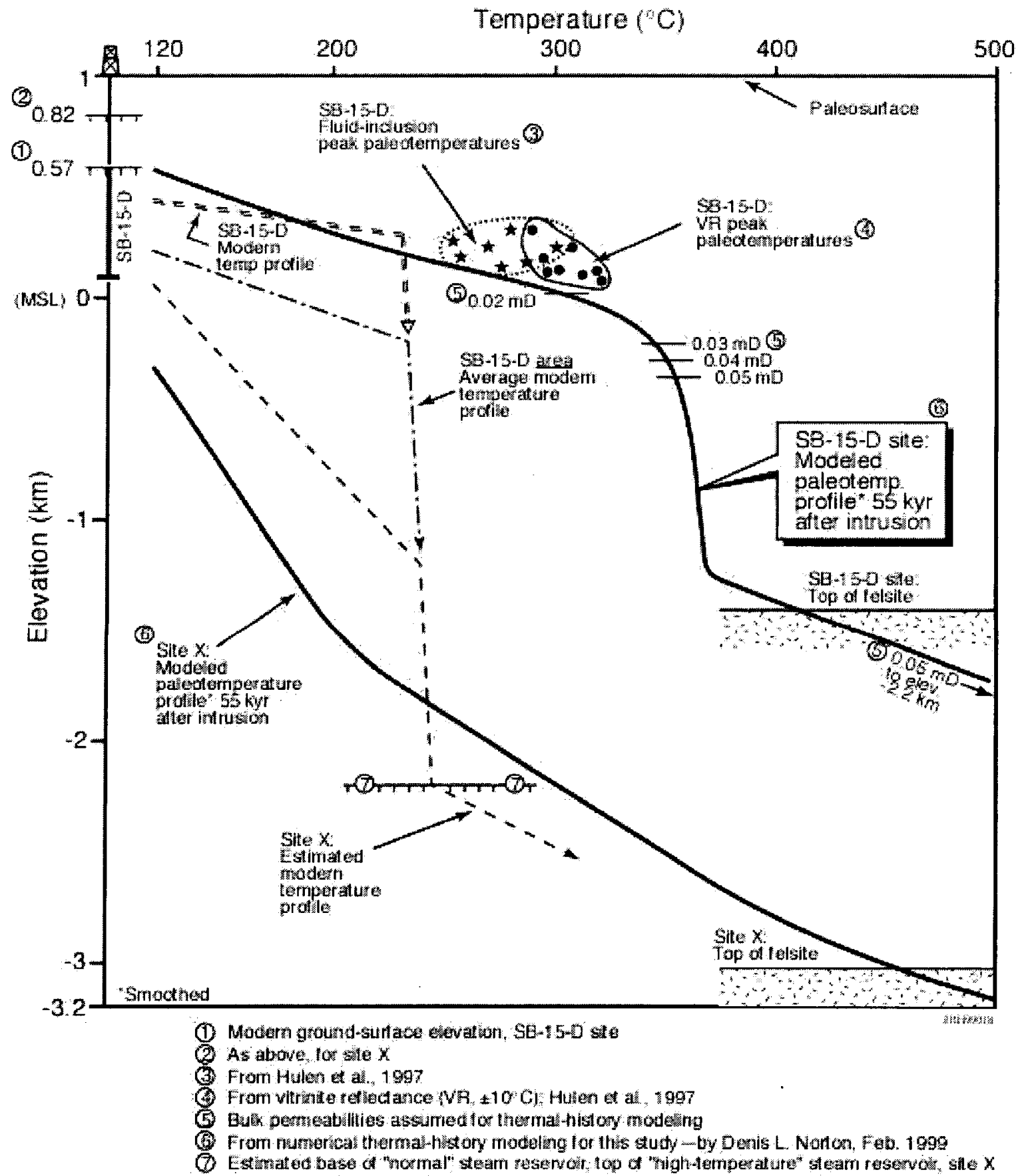

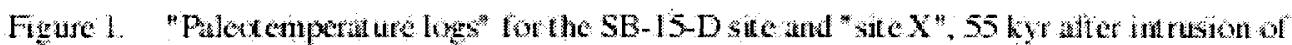
The Geysers felste. 


\title{
MICROSEISMIC MONITORING AT THE GEYSERS
}

\author{
A. Kirkpatrick, E.L. Majer and J.E. Peterson, Jr. \\ E.O. Lawrence Berkeley National Laboratory
}

\section{KEY WORDS}

microearthquakes, seismicity, seismic velocity, injection, geothermal monitoring

\section{PROJECT BACKGROUND AND STATUS}

It has been demonstrated by several investigators that microearthquake occurrence at the Geysers geothermal area is associated with both water injection and steam extraction (e.g., Eberhart-Phillips and Oppenheimer, 1984). However, the relevant changes in subsurface conditions caused by these activities, and the mechanisms by which these changes cause MEQs remain unknown. If more were understood about the relationships between these processes, then MEQ occurrence and characteristics could possibly serve as indicators of reservoir conditions, and thus be used as a reservoir management tool.

In order to collect data to address these questions, Lawrence Berkeley National Laboratory (LBNL) installed a network of digital seismometers at the SE Geysers in 1993. This network, and results of several studies utilizing data obtained from the network, have been described in previous reports (Kirkpatrick et al., 1995, 1996, 1997). In addition, Unocal operates a network of analog seismometers over a larger area of the Geysers, and provides a catalog of MEQs hypocenters in the SE Geysers to LBNL. The locations of both networks are shown in Figure 1. While the LBNL network is capable of locating events more accurately than the Unocal network, and can be used for more sophisticated source mechanism analysis, the Unocal network has operated for a long period of time with great reliability and is thus invaluable for studies of MEQ rate variations over time.

In addition to continued monitoring in the SE Geysers area, in 1998 microearthquake (MEQ) occurrence surrounding the injection well DV-11 in Unit 18 of the Southeast (SE) Geysers was investigated. Seismicity rates were compared to the injection rate, and to flow rates in nearby steam extraction wells, which were monitored during the Unit 18 Cooperative Injection Test in 1994 and 1995.

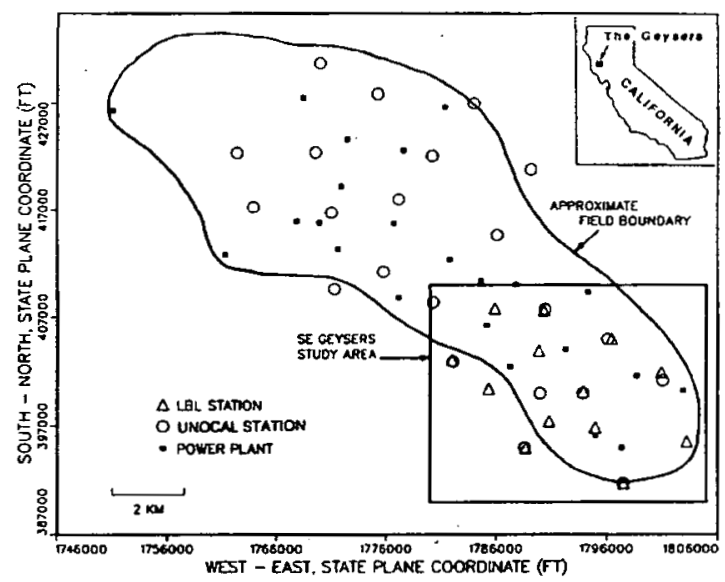

Figure 1. MEQ monitoring networks at The Geysers. The SE Geysers study area is shown in detail in Figure 2. 


\section{PROJECT OBJECTIVES}

The general objective of the project is to evaluate the utility of high-resolution MEQ monitoring as a reservoir management tool. Understanding the relationship between reservoir production activities and MEQ generation and occurrence, may help elucidate the effects of these activities on the reservoir and provide information useful for optimal management of the geothermal resource.

\section{Technical Objectives}

- Develop three-dimensional P- and S-wave seismic velocity and attenuation models for the SE Geysers.

- Locate hypocenters of MEQs occurring within the SE Geysers and characterize seismicity patterns.

- $\quad$ Determine MEQ source parameters such as size (magnitude, moment), stress drop, and focal mechanisms (moment tensors).

- Relate all of the above to reservoir parameters and processes such as lithology, location and nature of fracturing, steam occurrence, steam withdrawal, liquid injection, and reservoir pressure, temperature and degree of saturation.

\section{Expected Outcomes}

- Velocity structure and seismicity patterns to be used to characterize the subsurface in areas not sampled by other means, and to evaluate these areas as possible drilling targets.

- Monitoring changes in velocity structure, seismicity patterns, and source mechanisms through time to be used to devise optimal withdrawal and injection strategies.

- Greater understanding of the nature of seismicity in vapor-dominated geothermal systems, and of the physical effects of steam withdrawal and liquid injection .

\section{APPROACH}

In 1994 and 1995, the MEQ array at the SE Geysers consisted of 13 stations located over a $7 \mathrm{~km}$ by $4 \mathrm{~km}$ area. Vertical and horizontal ground velocity was continuously monitored at each station by threecomponent, $4.5 \mathrm{~Hz}$ geophones installed on the surface, and digitized at $480 \mathrm{samples} / \mathrm{s}$. The data were telemetered to a central site where the full waveform data for triggered events were recorded on tape, and later brought to LBNL for processing. Starting August 1997, data have been collected at 12 stations, and a switch to new, $8-\mathrm{Hz}$ geophones is planned. The new geophones are more watertight and will reduce station downtime during the winter due to moisture problems.

Automatic picking and locating is applied to all triggered events; $\mathrm{P}$ - and S-wave arrival times are then manually picked for all events so located within the SE Geysers study area. The events are then re-located using the hand-picked arrival times and a three-dimensional Vp and Vs model. Source parameters are obtained from the amplitudes and polarities of the $\mathrm{P}$ - and $\mathrm{S}$-wave pulses, using a moment tensor inversion procedure. Summaries of these results are sent to representatives of The Geysers operators (Unocal, Calpine, and NCPA) and collaborative work is performed in relating the information to reservoir parameters. 


\section{RESEARCH RESULTS}

The Unit 18 Cooperative Injection Project was a cooperative program between Unocal Corp., PG\&E., Northern California Power Agency (NCPA), Calpine Corp., and the U.S. Dept. of Energy whose purpose was to monitor and define the reservoir response to water injection into steam-production intervals at The Geysers. Well DV-11 in Unit 18 of the Unocal lease was chosen as the injector for this project, due partly to its proximity to producing wells in the Unocal, NCPA, and Calpine lease areas. Injection began in late December 1993, and continued through January 1995. During this time, flow rates, well-head pressures, and well-head temperatures were monitored daily in the surrounding wells, and were made publiclyavailable. Also made available were the 3-D well courses, and steam entry and top of felsite information. After the end of the Unit 18 project, injection into DV-11 was intermittent until the start-up of the SE Geysers Effluent Pipeline project in September 1997. At that time, treated sewage effluent from the Lake County began to be piped to the SE Geysers, and has provided a steady source of injectate into DV-11 as well as other Unocal, Calpine, and NCPA injection wells.

\section{SPATIAL SEISMICITY PATTERNS}

The general pattern of seismicity over the entire SE Geysers study area is shown in Figure 2. Shown are MEQ hypocenters detected by the LBNL array for a 3-month time period in 1998. This general pattern has been noted in the data from 1994-1995, and has been discussed in previous work (Kirkpatrick et. al., 1996). The events occur in both clusters and in more diffuse patterns. Some of the clusters surround injection wells, while others surround particular steam extraction wells. Not all injection wells have associated seismicity, nor do all areas of steam extraction. The depths of almost all of the events range from about the top of the producing reservoir to at least the total depths of the deepest wells.

Figure 3 shows MEQ hypocenters located in the DV-11 area from January 1994 to October 1995. The well traces for the injector DV-11 and the surrounding production wells are also shown.

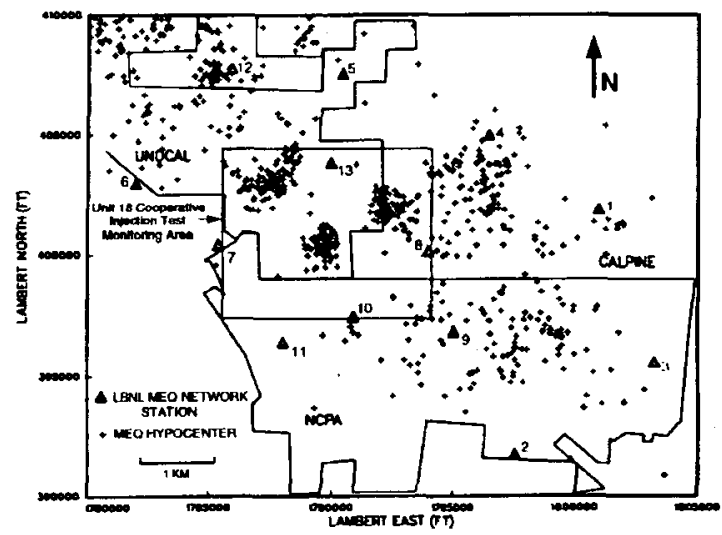

Figure 2. MEQ hypocenters detected by the LBNL MEQ Network in the SE Geysers study area, for the time period 7/1/98 to $9 / 30 / 98$. The Unit 18 Cooperative Injection Test Monitoring Area is shown in detail in Figure 3.

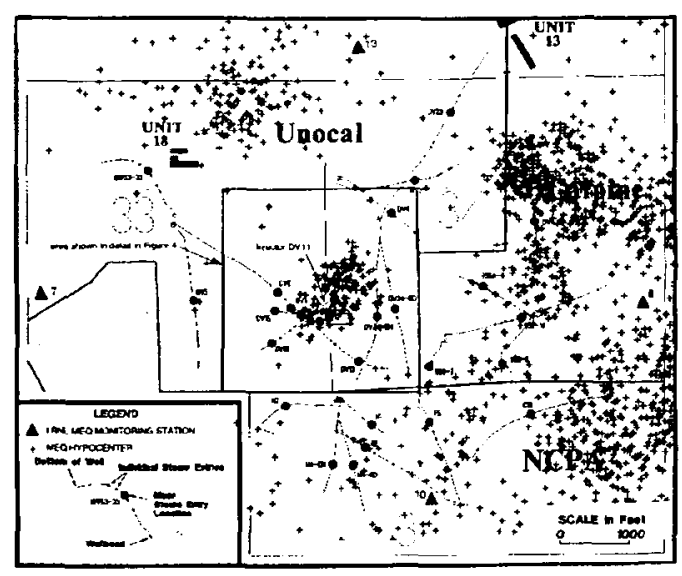

Figure 3. MEQ hypocenters in the Unit 18 Cooperative Injection Test Monitoring Area during and after the injection test (January 1994 during 1995), and the locations of the wells monitored. The cloud of seismicity immediately surrounding the injector DV-11 is shown in detail in Figure 4. 
The cloud of events immediately surrounding DV-11 is shown in both plan and depth section in Figure 4 . Interestingly, the wells to the west and south of DV-11, in both the Unocal and Calpine lease areas, showed the greatest increases in flow rate due to the injection (Voge et. al., 1994) The DV wells to the east and northeast showed less response to the injection, and the Calpine wells did not appear to respond at all.
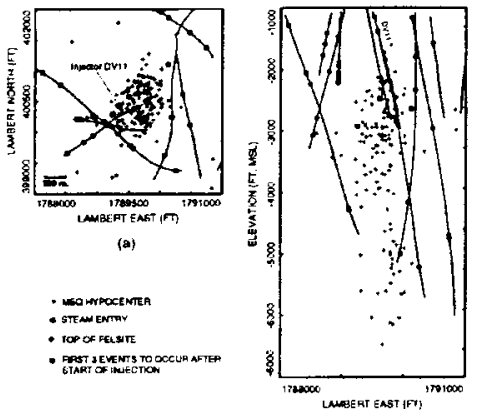

(b)

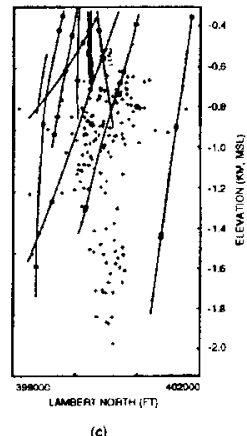

(c)

Figure 4. MEQ hypocenters in the DV-11 injection area, January 1994 to October 1995 . The locations differ slightly from those shown in Figure 3 because the data were filtered, the arrival times re-picked, and the events re-located. (a) plan view, (b) east-west cross-section, (c) south-north cross-section.

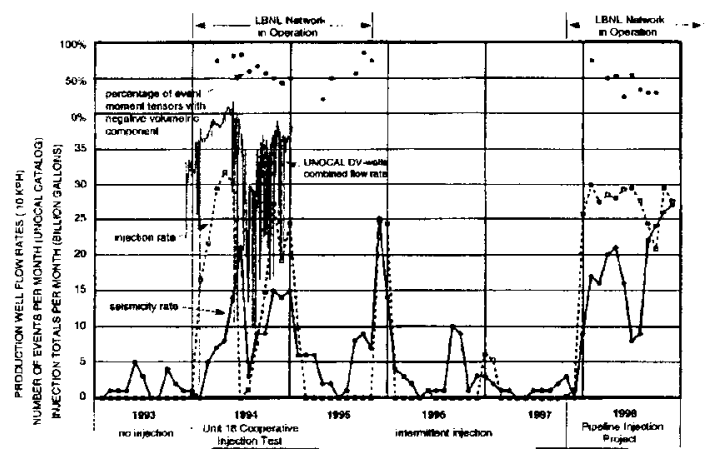

Figure 5. Injection rate into DV-11 and seismicity rate in the surrounding area for January 1993 through November 1998. The flow rate for all the Unocal DV-wells combined is shown for the Unit 18 Cooperative Injection Test period. The circles at the top of the plot represent the percentage of events for each month, whose moment tensors had a negative volumetric component. By definition, the remaining percentage had a positive volumetric component.

The cloud of events extends in a tube downwards. The tube is centered below the one steam entry in DV11; the top of the cloud is about $300 \mathrm{~m}$ below that steam entry. The events occur mainly in the felsite, with virtually none in the unit above the felsite contact. Steam entries, in contrast, occur in the wells in both the felsite and the overlying unit.

\section{TEMPORAL SEISMICITY PATTERNS}

The injection rates for DV-11 are graphed in Figure 5. The total volume injected for each month is plotted; daily flow rates reported ranged up to $848 \mathrm{gpm}$ during the Unit 18 Cooperative Injection Test. Injection began in late December 1993; prior to that time DV-11 was a producing well. Injection for the test ceased in February 1995; from that date to late September 1997 water was injected into DV-11 only intermittently. In October 1997 DV-11 began to accept injectate from the SE Geysers Effluent Pipeline, and in December 1997 injection rates reached a steady level which continue through 1998. The combined production rate for the DV wells in the Unocal lease area, provided during the Unit 18 Cooperative Injection Test, is also shown in Figure 5. Immediate increases in production followed injection, and decreases in injection were followed by decreases in flow rates.

An increase in seismicity is also observed starting in December 1997, simultaneously with the increase in injection due to the SE Geysers Effluent Pipeline Project. The overall seismicity rate remained high in 1998 at the same time as the injection rate remained high; however, there were fluctuations in seismicity rate that were not reflected in variations in the injection rate. In addition, the overall trend of the seismicity rate increased in 1998 while the injection rate was fairly constant. 


\section{WAVEFORM CROSS-CORRELATION ANALYSIS}

We used the waveform cross-correlation techniques on 149 events developed by Nadeau et. al. (1995), which they applied to MEQs detected by a network installed at Parkfield on the San Andreas fault, similar to the SE Geysers MEQ network.

Applying this procedure resulted in the identification of several groups of events that have similar waveforms, that we will term "clusters." Figure 6 and Figure 7 show the dramatic improvement in location when this is applied.
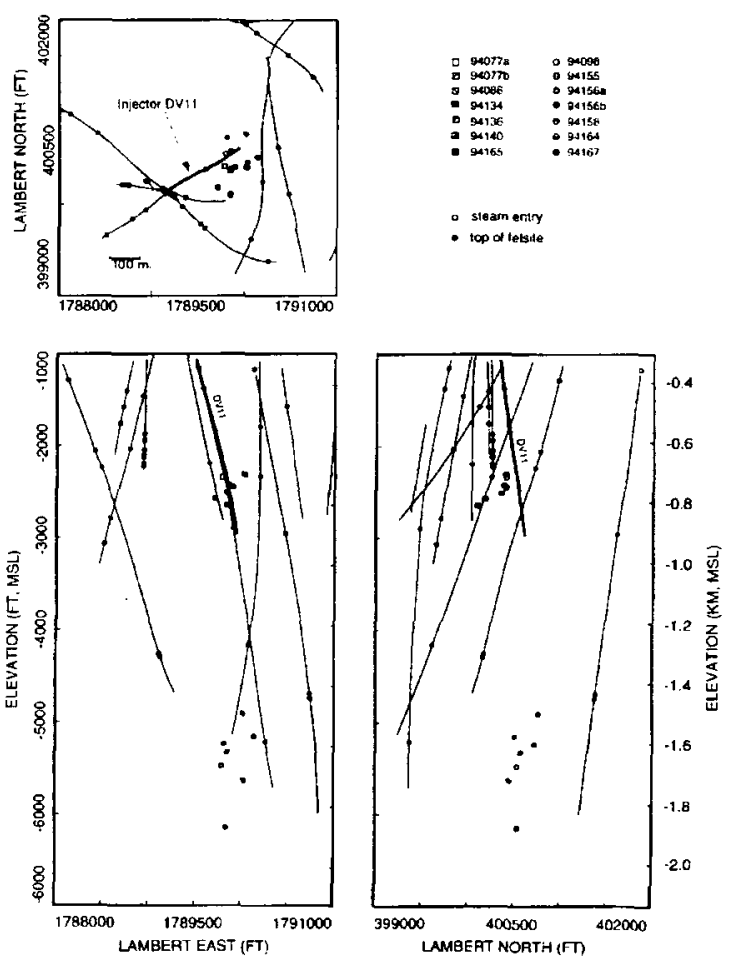

Figure 6. Hypocentral locations for the two clusters identified in the DV-11 area that are discussed in the text. The arrival time picks determined using first break are used in the location routine.
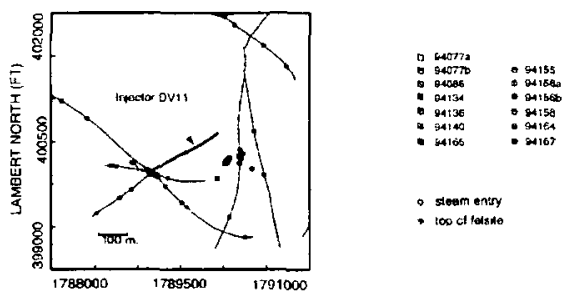

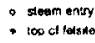
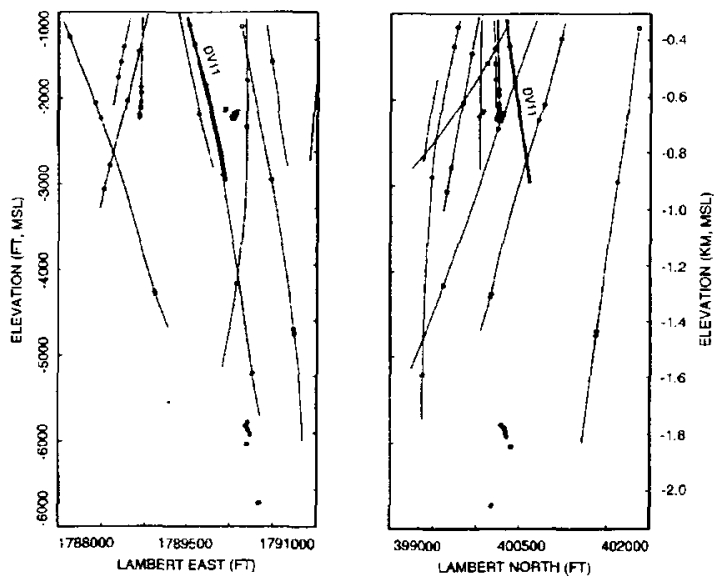

Figure 7. Relocated hypocenters for the two clusters shown in Figure 7. The arrival time picks are determined using waveform crosscorrelation as described in the text.

\section{DISCUSSION AND CONCLUSIONS}

In general, injection at DV-11 resulted in increased levels of seismicity. However, the increased seismicity also corresponded to increased flow rates in the production wells. It should also be noted that while there was not a lag time between injection and steam production rates, there was up to a several month lag time between injection and increased seismicity. In addition, it appears that there was a threshold of injection which caused increased seismicity, but once the system is primed, lower injection rates also increased the seismicity, i.e. as injection continued, the lag time between injection and seismicity decreased.

In terms of event attributes, it appears that event clusters are located tightly around and beneath DV-11, and do not, in general, extend to production wells. However, the broader seismicity pattern defined by all of the events indicate that the events extend toward the wells with the highest production rate increases. 
At this point we do not have independent evidence of the location of the injected fluid, but if the earthquake locations are indicative of the fluid path, it appears that the fluid does not travel a direct route to the production well, i.e. flow is fracture and/or fault controlled. The MEQ pattern also suggests that some fluid may be lost out of the bottom of the reservoir (may be only temporarily).

The "cluster" patterns indicate that for a portion of the events they repeat locations in very small ( $25 \mathrm{~m})$ volumes. They also have linear features, indicating occurrence on single planes. Improved locations on all events may reveal much more of a linear nature to the "clouds" of events rather than the "tubes" of events. Last, but not least, the source mechanisms are mainly negative volumetric (closing) possibly indicating cooling due to injection. This is in contrast to our past work where up to $60 \%$ of events were opening types where one includes a field-wide sample. Therefore, by looking at an area dominated by injection (DV-11), we are beginning to understand the mechanics of the events.

\section{FUTURE PLANS}

Future work will focus on including more events in the cluster analysis approach, expanding to production areas as well as injection areas defined by the 1997 injection from Lake County. Also, different time scales and magnitude scales will be examined by investigating the correlation between rate, location, size and nature (source mechanism) of seismicity as a function of injection and production parameters.

The sale of Unocal property to Calpine may affect The Geysers-wide MEQ monitoring strategy. We are working with NCPA and Calpine to develop a strategy for short term monitoring as well as long term monitoring.

\section{INDUSTRY AND TECHNOLOGY TRANSFER}

The project is a joint DOE-Industry (Unocal, Calpine, and NCPA) project. The companies provide field support, injection and production data, as well as a list of MEQs recorded by the Unocal network. Meetings are held periodically to discuss research results, directions, and priorities.

\section{REFERENCES}

Eberhart-Phillips, D., and D. H. Oppenheimer (1984), "Induced seismicity in The Geysers geothermal area, California, J. Geophys. Res., 89, 1191-1207.

Kirkpatrick, A., J. E. Peterson, Jr., and E. L. Majer (1995), "Microearthquake monitoring at the Southeast Geysers using a high-resolution digital array," Proc. 20th Workshop Geotherm Res. Eng., Stanford, CA, 79-89.

Kirkpatrick, A., J. E. Peterson, Jr., and E. L. Majer (1996), "Source mechanisms of microearthquakes at the Southeast Geysers geothermal field, California," Proc. 21st Workshop Geotherm Res. Eng., Stanford, CA, 359-366.

Kirkpatrick, A., J. E. Peterson, Jr., and E. L. Majer (1997), "Three-dimensional compressional- and shearwave seismic velocity models for the Southeast Geysers Geothermal Field, California," Proc. 22nd Workshop Geotherm Res. Eng., Stanford , CA, 399-410.

Nadeau, R. M., W. Foxall, and T. V. McEvilly (1995), "Clustering and periodic recurrence of microearthquakes on the San Andreas fault at Parkfield California," Science, 267, 503-507. 
Voge, E., B. Koenig, J. L. Smith, S. Enedy, J. J. Beall, M.C Adams, and J. Haizlip (1994), "Initial

findings of The Geysers Unit 18 Cooperative Injection Project," Geotherm. Resour. Counc. Trans., 18, 353-357. 


\title{
Monitoring $\mathrm{H}_{2} \mathrm{~S}$ at The Geysers by Cross-Dispersion Infrared Spectrometry
}

\author{
Charles Stevens, Jim Curry, and Carol Bruton \\ Lawrence Livermore National Laboratory (LLNL) \\ J M. Henderson \\ Technical and Ecological Services \\ Pacific Gas \& Electric Company
}

\section{KEY WORDS}

The Geysers, cross-dispersion infrared spectrometry, $\mathrm{H}_{2} \mathrm{~S}$, geothermal, echelle grating spectrometer

\section{PROJECT BACKGROUND AND STATUS}

To reduce chemical costs at geothermal power plants, we are investigating the use of a new type of infrared (IR) field spectrometer under development at LLNL (Stevens et al., 1995). This instrument is referred to as the echelle grating spectrometer (EGS), has no moving parts, and is based on crossdispersive infrared spectrometry, which provides spectral snapshots of an entire infrared spectral region. The EGS uses a very coarse echelle grating operating in high order to yield high spectral resolution in a small package. It is intrinsically robust for field operation and, when coupled with modern infrared (IR) detector arrays, can be more than 100 times more sensitive than existing IR instruments. This increase in sensitivity allows us to accurately, reliably, and continuously monitor $\mathrm{H}_{2} \mathrm{~S}$ emissions.

After calibrating this spectrometer in the laboratory to determine the infrared absorption of $\mathrm{H}_{2} \mathrm{~S}$, we field tested it at a geothermal power plant then operated by Pacific Gas \& Electric Company (now operated by Calpine) in The Geysers Geothermal Field in California. To meet air quality requirements, $\mathrm{H}_{2} \mathrm{~S}$ emissions from this power plant must be limited to less than $22 \mathrm{~kg} / \mathrm{h}$. Following power generation, $\mathrm{H}_{2} \mathrm{~S}$ is present in the Geysers steam at highly variable levels ranging from $\sim 150$ to $>2000$ ppmw (Truesdell et al., 1992). Processes based on oxidizing sulfur to less toxic forms are used to abate the $\mathrm{H}_{2} \mathrm{~S}$. In one process, an iron chelate (FeHEDTA, where HEDTA = hydroxy-ethylethylenediaminetriacetic acid) is used to oxidize $\mathrm{H}_{2} \mathrm{~S}$. Portable analyzers are used to measure $\mathrm{H}_{2} \mathrm{~S}$ emissions at 36 sample points per cooling-tower cell. The amount of reagent added to the condensed steam is based on the amount of $\mathrm{H}_{2} \mathrm{~S}$ measured in the incoming steam. Given the wide variability of $\mathrm{H}_{2} \mathrm{~S}$ content and the noncontinuous nature of the sampling, the power plant operator. must use enough iron chelate to oxidize the highest level of $\mathrm{H}_{2} \mathrm{~S}$ measured. Because iron chelate is an expensive oxidizing agent, the power company could reduce reagent use and thus cost if continuous $\mathrm{H}_{2} \mathrm{~S}$. monitoring were available to help determine precise iron chelate requirements.

During this field test, we also used the EGS to measure the $\mathrm{H}_{2} \mathrm{~S}$ concentration in the plant steam condensate. The results of these measurements demonstrate that this instrument has the sensitivity to monitor the $\mathrm{H}_{2} \mathrm{~S}$ concentration of the incoming steam.

There is currently no satisfactory way to continuously and accurately monitor the $\mathrm{H}_{2} \mathrm{~S}$ content in the various streams. Contact measurement such as thin film resistance is subject to corrosion and fouling in extended operation. A noncontact optical device, such as the EGS, has the potential to meet the requirements for continuous and reliable operation. 


\section{PROJECT OBJECTIVES}

\section{Technical Objectives}

- Develop an IR spectrometer capable of monitoring $\mathrm{H}_{2} \mathrm{~S}$ emissions accurately, reliably, and continuously.

- $\quad$ Conduct laboratory experiments with the EGS to measure the IR absorbance spectrum of $\mathrm{H}_{2} \mathrm{~S}$ and to determine the signal-to-noise ratio achievable with this instrument.

- Field test the EGS at a power plant in The Geysers Geothermal Field in California.

\section{Expected Outcomes}

- Reduce chemical costs at geothermal power plants by deploying a new type of IR field spectrometer under development at LLNL.

\section{APPROACH}

\section{Laboratory Experiments}

A series of laboratory experiments were conducted to measure the infrared absorbance spectrum of $\mathrm{H}_{2} \mathrm{~S}$ and to determine the signal-to-noise ratio achievable in anticipation of our field studies at the Geysers. $\mathrm{H}_{2} \mathrm{~S}$ has been the subject of several high resolution mid-infrared studies (Brown et al., 1996), and transition frequencies and strengths are now well established. Our laboratory efforts centered on establishing absorbance levels as a function of $\mathrm{H}_{2} \mathrm{~S}$ pressure at the spectral resolution of our instrument. A second effort sought to establish signal-to-noise performance under conditions approximating those anticipated in the field.

\section{Field Experiments}

A schematic layout of The Geysers Power Plant Unit 11 is shown in Figure 1. We considered three options for monitoring $\mathrm{H}_{2} \mathrm{~S}$. The most straightforward approach is to directly monitor the steam exiting the cooling towers (location 14) for $\mathrm{H}_{2} \mathrm{~S}_{\text {p }}$ content. These cooling-tower cells are approximately $28 \mathrm{ft}$ in diameter and, at each power plant, there are about ten cells. Several issues must be addressed to successfully monitor cooling-tower steam. First, the steam visibility at this location strongly depends on ambient weather conditions, ranging from transparent to very heavily fogged. Second, the $\mathrm{H}_{2} \mathrm{~S}$ concentration in the towers is nonuniformly distributed, and a representative measurement using the lineof-sight nature of optical interrogation depends on the stability of the $\mathrm{H}_{2} \mathrm{~S}$ spatial distribution. If the distribution is stable, then a calibration using point samplers is possible. Third, the $\mathrm{H}_{2} \mathrm{~S}$ concentration changes from cell to cell as the steam condensate remains in contact with the iron chelate for varying lengths of time for each cell; in principle, this could be calibrated. Finally, the concentration of $\mathrm{H}_{2} \mathrm{~S}$ at the tower exit point is low and requires the highest measurement precision at that point. Concentration levels in the older units generally range from 1 to $5 \mathrm{ppm}$. This corresponds to 10 to $50 \mathrm{ppm}-\mathrm{m}$ concentrationpathlength across the $\sim 10$-m-high tower. This is just above our current laboratory-measured detection threshold.

Another monitoring option is to measure the $\mathrm{H}_{2} \mathrm{~S}$ content in the headspace of the steam condensate at location 1. The amount of $\mathrm{H}_{2} \mathrm{~S}$ in the vapor above the steam condensate is proportional to the amount of $\mathrm{H}_{2} \mathrm{~S}$ in solution with a proportionality constant of $0.3 \mathrm{Torr} / \mathrm{ppmw}$ (Shih et al., 1967) at pH values near 5. 
The steam generally has $\mathrm{H}_{2} \mathrm{~S}$ content around 1 to 3 ppmw, generating $\sim 1$ Torr or $\sim 1000 \mathrm{ppm}$ of vapor. This is considerably above our laboratory detection threshold for a $1-\mathrm{m}$ cell. To successfully implement this approach, the amount of $\mathrm{H}_{2} \mathrm{~S}$ that has been removed in the headspace extraction step (Step 13 in the facility diagram) must also be determined. The amount to be treated is the difference between these two quantities.

The third option is to monitor the condensate in path 5, traveling from the power generator to the cooling towers. In this case, the concentration is reduced by the action of the iron chelate enroute to the tower. Calibration of the measurements with cooling-tower point sampling are required for this option.

\section{RESEARCH RESULTS}

\section{Laboratory Experiments}

Two sets of laboratory experiments were performed. In one, the absorption of $\mathrm{H}_{2} \mathrm{~S}$ was measured as a function of $\mathrm{H}_{2} \mathrm{~S}$ vapor pressure at a constant overall air pressure of one atmosphere in a $10-\mathrm{cm}$ cell. An example of an "echellogram" generated by the instrument is shown in Figure 2(a). This particular spectrum exhibits six spectral orders ranging from 2660 to $3100 \mathrm{~cm}^{-1}$ in spectral bites of $\sim 60 \mathrm{~cm}^{-1}$ each. The characteristic $\mathrm{H}_{2} \mathrm{~S}$ transitions are seen as a line series in the region between 2606 and $2720 \mathrm{~cm}^{-1}$. A spectrum generated by summing intensity across the width of the band is shown in Figure 2(b). The $\mathrm{H}_{2} \mathrm{~S}$ fill pressure in this example was 79 Torr $(10,400 \mathrm{ppm}-\mathrm{m})$, yielding a peak absorption coefficient for the transition at $2690 \mathrm{~cm}^{-1}$ of $8 \times 10^{-7}(\mathrm{ppm}-\mathrm{m})^{-1}$. This is not the intrinsic absorption coefficient but is rather the result of convolving the spectral features with the $0.5-\mathrm{cm}^{-1}$ bandwidth of the EGS spectrometer. This is a very low IR absorption coefficient. This low value presents the greatest challenge to the implementation of a noncontact infrared monitor for $\mathrm{H}_{2} \mathrm{~S}$. Figure 3 shows the results of our measurement of $\mathrm{H}_{2} \mathrm{~S}$ absorption signal-to-noise as a function of $\mathrm{H}_{2} \mathrm{~S}$ pressure. The overall air pressure was kept at 760 Torr.

The signal-to noise is defined by comparing the peak value at $2690 \mathrm{~cm}^{-1}$ with the rms noise level. The resulting detection limit (defined as a signal to noise of 1) for a 1-min integration time under these laboratory conditions is 0.22 Torr. This is equivalent to a $30 \mathrm{ppm}-\mathrm{m}$ detection limit. Averaging the data using all the absorption bands reduces the detection limit to approximately $11 \mathrm{ppm}-\mathrm{m}$, provided there are no strong optical interferences from other molecules such as water and methane.

\section{Field Experiments}

Following several preliminary orientation and facility assessment visits, we conducted a series of experiments over two days in September 1997 at Unit 11 at The Geysers. During these experiments, we measured the $\mathrm{H}_{2} \mathrm{~S}$ content in the incoming steam at location 1 in the diagram. Steam was condensed by means of 1/8-in.-diam aluminum tubing that was coiled within a tank of water; the condensate was collected in a polyethylene carboy. Headspace vapor was pumped from the container through a glass fiber filter, through either a 1- or 2-m optical cell and returned to the container. An alternate circulation route allowing the vapor to bubble through a volume of iron chelate solution was designed to remove the $\mathrm{H}_{2} \mathrm{~S}$ from the vapor; this provided a comparison background sample.

Typical of the spectra obtained during this campaign, the absorption spectrum of the headspace vapor taken with a 2-m cell using a humid air sample as background is dominated by methane lines. All of the evident spectral features are due to the presence of this molecule. A least-squares multivariate-spectralfitting routine was used to fit the observed spectrum using methane as the sole variable. The best-fit concentration of methane in this sample is $388 \pm 13 \mathrm{ppm}$. The presence of these absorption features at 
intensity levels considerably higher than the expected $\mathrm{H}_{2} \mathrm{~S}$ absorption makes a direct determination of $\mathrm{H}_{2} \mathrm{~S}$ somewhat uncertain. To remove the effects of methane, the vapor was circulated through a concentrated iron chelate solution to remove $\mathrm{H}_{2} \mathrm{~S}$. This vapor was then used as the background sample. The resulting spectrum is shown in Figure 4.

A residual of the methane spectrum is still in evidence, but is reduced sufficiently to reveal the presence of the $\mathrm{H}_{2} \mathrm{~S}$ peaks. A multivariate least squares fit to the spectrum was applied using methane and $\mathrm{H}_{2} \mathrm{~S}$ spectra as variables. The result is shown in Figure 5, where the best-fit combination of $\mathrm{H}_{2} \mathrm{~S}$ and methane is shown along with the residual. The concentration estimate for $\mathrm{H}_{2} \mathrm{~S}$ from this data is $350 \pm 30 \mathrm{ppm}$. These data are the result of integrating for $30 \mathrm{~min}$ through a $2-\mathrm{m}$ cell. The random noise floor is estimated at $0.005 \%$ absorption rms. The multivariable fit to all the peaks improves the detection limit by a factor of $\sim 2$. The presence of residual unknown spectral features apparently is limiting the improvement in estimation. A factor of 3 is expected for pure random noise considerations. This field result is equivalent to a $60-\mathrm{ppm}-\mathrm{m}$ detection limit. Accounting for the increased integration time, this represents a reduction in signal-to-noise performance of $\sim 30$ times with respect to the laboratory performance.

\section{FUTURE PLANS}

Our field studies have demonstrated that the echelle grating spectrometer approach has sufficient sensitivity to monitor $\mathrm{H}_{2} \mathrm{~S}$ content in the incoming steam condensate at a typical steam line at The Geysers. This sensitivity, obtained on a half-hourly basis, provides an accuracy of $\pm 0.2 \mathrm{ppm}$ by weight in the steam. Some question remains as to the required sampling time to fully monitor the $\mathrm{H}_{2} \mathrm{~S}$ concentration fluctuations at The Geysers. Our integration time can be reduced by a factor of 3 simply by reducing the ratio of the headspace vapor volume with respect to the condensate volume. The Henry's law proportionality constant holds only if the amount of $\mathrm{H}_{2} \mathrm{~S}$ in the headspace is negligible compared to the amount in the condensed phase. In our tests, the headspace volume was approximately 7 times that of the liquid, a factor that can easily be reduced by careful design. Further, we need to understand the origin of the diminished signal-to-noise values seen in our field experiments compared to the laboratory values. Unknown, low-level spectral interferences clearly play a role in this problem. We are planning experiments designed to understand the nature of these steam impurities and incorporate their spectra into the multivariate analysis.

Further on-site tests should examine the headspace vapor above the condensate at location 5 in Figure 1. The $\mathrm{H}_{2} \mathrm{~S}$ determination in that line can then be compared with point sampling measurements in the cooling towers. The degree of correlation between these two measurements can establish the viability of using cross-dispersion infrared spectrometry to continuously monitor $\mathrm{H}_{2} \mathrm{~S}$.

\section{INDUSTRY INTEREST AND TECHNOLOGY TRANSFER}

\section{Organization}

Pacific Gas and Electric Company (PG\&E)

\section{Type and Extent of Interest}

Tests of the EGS at a PG\&E geothermal power plant at The Geysers in 1997

\section{REFERENCES}

Brown, L.R., J.A. Crisp, D. Crisp, and A. Perrin (1997), "High-Resolution Fourier-Transform Spectrum of $\mathrm{H}_{2} \mathrm{~S}$ in the $2150-4260 \mathrm{~cm}^{-1}$ Region," Proc. SPIE 3090, 108-110. 
Shih, T.C., B.F. Hrutfiord, K.V. Sarkanen, and L.N. Johanson (1967), "Hydrogen Sulfide Vapor-Liquid Equilibrium in Aqueous Systems as a Function of Temperature and pH," TAPPI, 50(12), 630-634.

Stevens, C.G., P. Kuzmenko, W.E. Conaway, F. Magnotta, N. Thomas, J. Galkowski, I. Lewis, and T. Alger (1995), "Cross Dispersion Infrared Spectrometer (CDIRS) for Remote Chemical Sensing," Proc. SPIE, Int. Soc. Opt. Eng. 2552, 284-291.

Truesdell, A.H., W.T. Box Jr., J.R. Haizlip, and F. D'Amore (1992), "A Geochemical Overview of The Geysers Geothermal Reservoir," Monograph on The Geysers Geothermal Field, Claudia Stone, Ed., Geothermal Resource Council, pg. 127.

Ulenikov, O.N., A.B. Malikova, M. Koivusaari, and S. Alanko (1996), "High Resolution VibrationalRotational Spectrum of $\mathrm{H}_{2} \mathrm{~S}$ in the Region of the $\mathrm{v}_{2}$ Fundamental Band," J. Molecular Spectroscopy 176(2), 229-235.

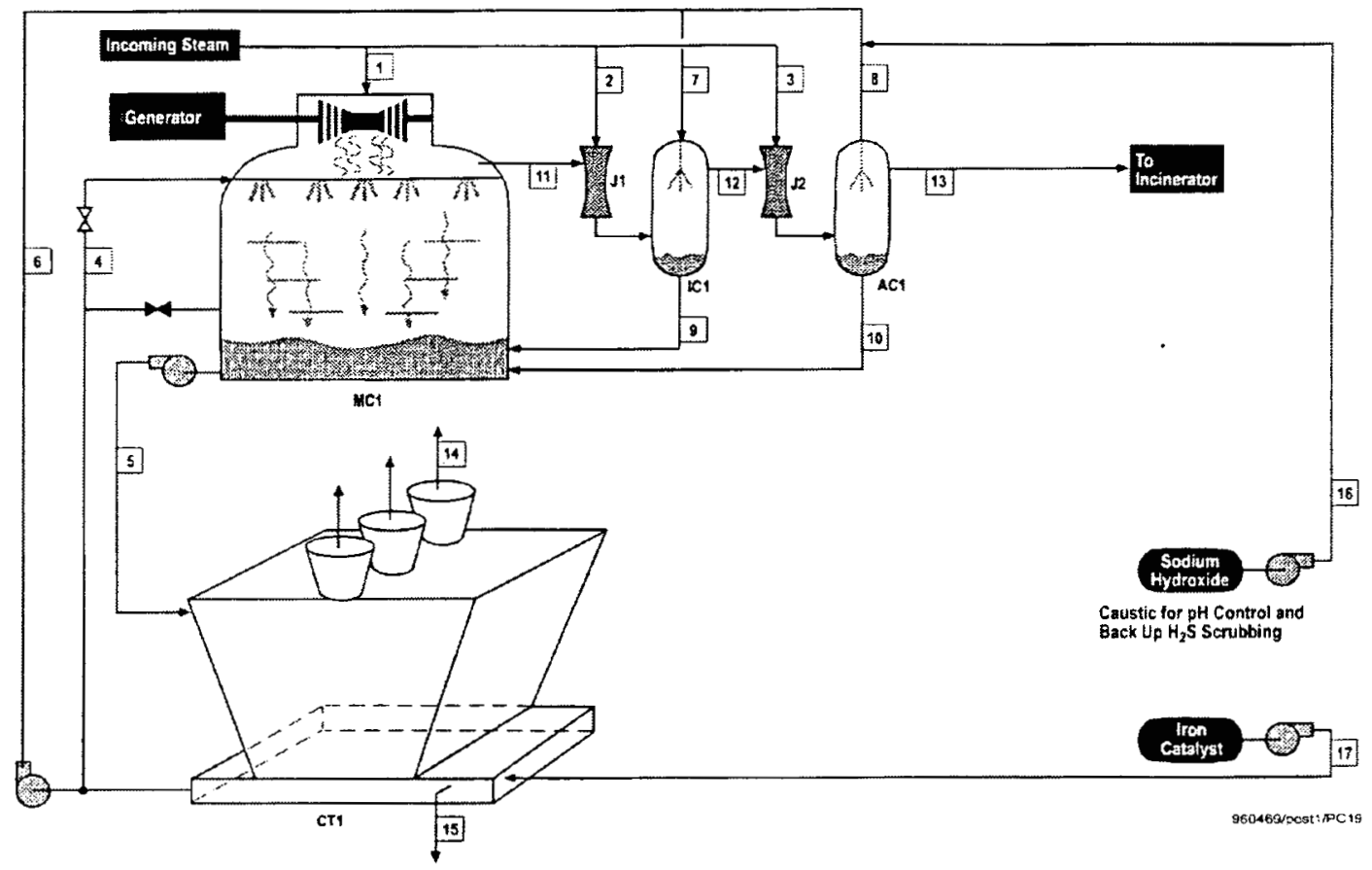

Figure 1. Schematic drawing of The Geysers Power Plant Unit 11.

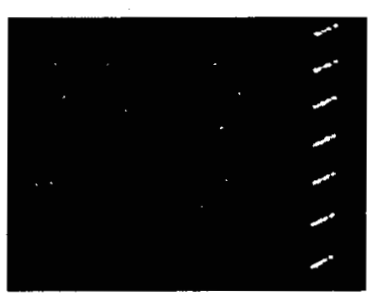

(a)

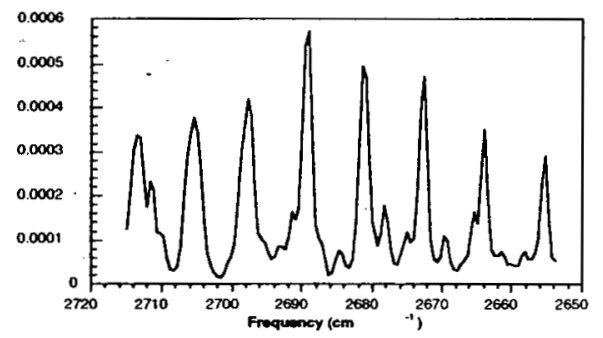

(b)

Figure 2. (a) An echellogram showing characteristic $\mathrm{H}_{2} \mathrm{~S}$ absorption features between 2660 and $2710 \mathrm{~cm}^{-}$ ${ }^{1}$, and (b) the absorption spectrum generated from the echellogram for 79 Torr in a 10-cm cell. 


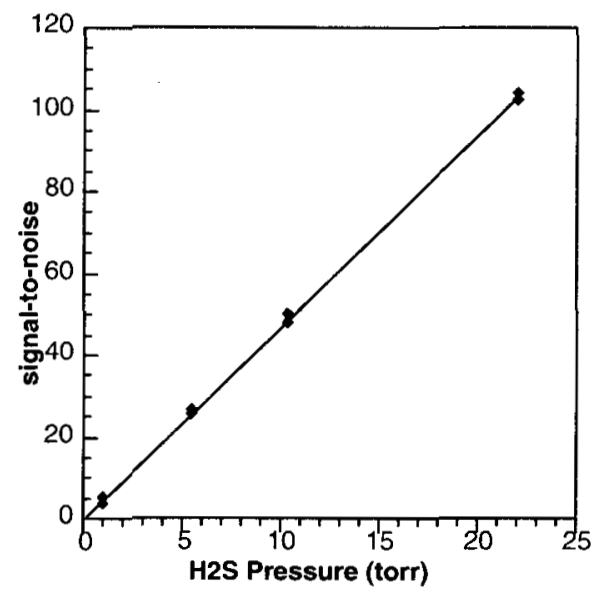

Figure 3. Signal-to-noise ratio for the $2690 \mathrm{~cm}^{-1}$ transition as a function of $\mathrm{H}_{2} \mathrm{~S}$ vapor pressure. A $30 \mathrm{ppm}-\mathrm{m}$ detection limit for this peak is estimated from these data.

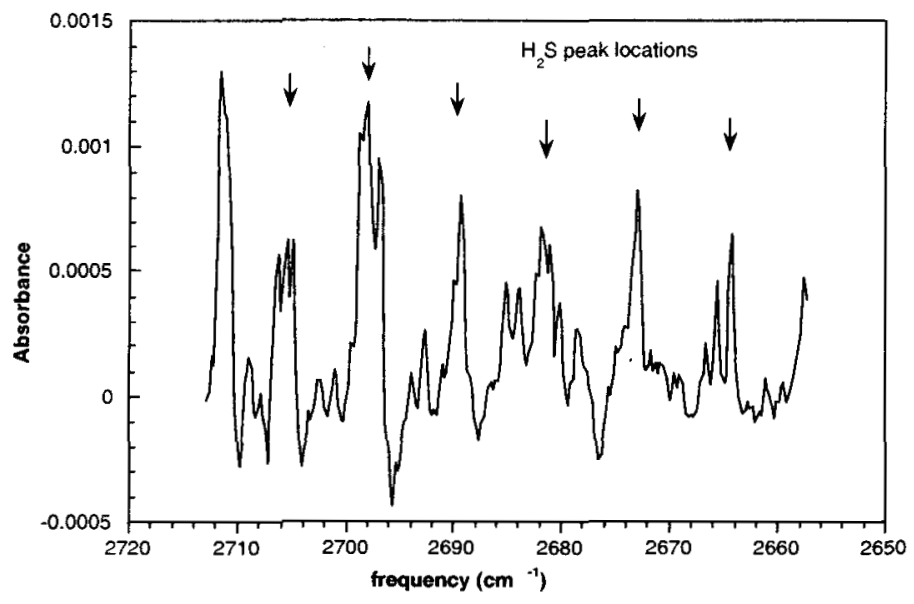

Figure 4. Absorption spectrum of geysers steam condensate vapor obtained by chemically removing $\mathrm{H}_{2} \mathrm{~S}$ from the sample. The $\mathrm{H}_{2} \mathrm{~S}$ peaks are now apparent along with residual methane features.

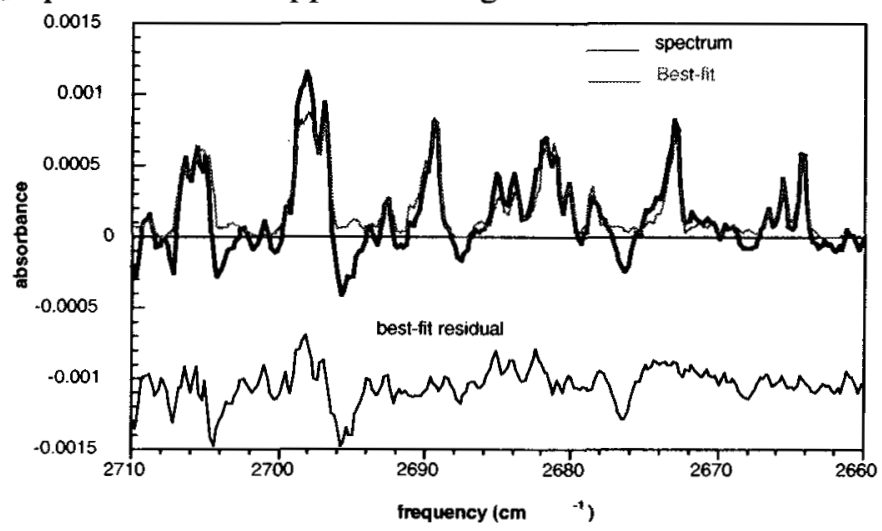

Figure 5. Best-fit spectrum and residual resulting from multivariate least-squares analysis of geysers steam condensate vapor. Best $\mathrm{H}_{2} \mathrm{~S}$ concentration estimate is $350 \pm 30 \mathrm{ppm}$ in this sample. 


\title{
TRACING THE FLOW OF EFFLUENT INTO THE GEYSERS STEAM FIELD
}

\author{
Michael C. Adams \\ Energy \& Geoscience Institute \\ University of Utah
}

\section{KEY WORKS}

vapor-phase tracers, tracer tests, geothermal, R-134a, R-23, tetrafluoroethane, trifluoromethane, fluoroform, The Geysers

\section{PROJECT BACKGROUND AND STATUS}

Tracing the flow of steam through a vapor-dominated reservoir is one of the more challenging tasks that the Tracer Development Laboratory at the Earth and Geoscience Institute (EGI) has undertaken. Unlike liquid tracers, which are added to injection water and flow through the reservoir as a liquid, vapor-phase tracers are added to the liquid injectate but boil before entering the steam reservoir. This means that the tracers must be soluble in both the liquid and vapor phases as well as stable at high temperatures, highly detectable, and nontoxic (Adams, 1995).

The predominant vapor-phase reservoir is, of course, The Geysers. These types of reservoirs produce only steam. The lack of produced liquid lowers the amount of water available to be injected back into the reservoir. Injection is a crucial factor in extending the power-producing lifetime of the reservoir because there is much more heat than water in geothermal systems. Industry has expended considerable effort to increase the amount of injected water, including power-plant modifications and the injection of outside sources of water from creeks. Recently, lake water and treated sewage effluent from Lake County have become important sources of injection water for the Southeast Geysers. Both DOE and industry sponsored this project, the Southeast Geysers Effluent Pipeline. It brings nearly 5,000 gpm of water from the Lake County Wastewater Treatment Plant and Clear Lake. The new injectate will feed about a dozen injection wells, and new tracers will be needed to quantify the benefits of this $\$ 45$ million cooperative venture of DOE and industry. The need for new tracers will be even greater when the Sonoma County pipeline is built, which will more than double the rate of effluent delivery to The Geysers.

Injection at The Geysers was not recognized as a significant factor in the lifetime of the reservoir until pressure declines began to accelerate during the 1980's. Industry appeals to the Department of Energy (DOE) in 1989 resulted in a broadening of focus of the DOE's Tracer Development program at EGI to include the development of vapor-phase tracers capable of tracking steam at The Geysers. During the next two years several potential tracers were identified (Adams et al., 1991b) and a field test of two of the candidate tracers (Adams et al., 1991a) was cooperatively funded and performed by DOE and its industry partners Calpine Geothermal Corp., Northern California Power Agency (NCPA), Unocal Geothermal, and Thermochem through the Geothermal Technology Organization. The test was a tremendous success. The tracers were detected in over 40 production wells within a few days at concentrations as low as 3 parts per trillion (million-million). One of the tracers, R-13, has been used in many tracer tests since 1991 (Beall et al., 1994).

Unfortunately, R-13 is now unavailable because of its potential to cause ozone depletion in the upper atmosphere, just when it is needed to evaluate the flow paths of the effluent injected into The Geysers. The cause of the ozone depletion by R-13 is the chlorine atom. Our solution is to substitute hydrogen for chlorine in these types of molecules, which not only eliminates the potential for ozone depletion but also increases the solubility in water, a beneficial effect for a tracer at The Geysers. In last year's summary we 
reported that several of these compounds had been identified and were being examined for use as geothermal tracers. In this year's report we discuss R-134a and R-23, the two compounds that seem most suitable, and the laboratory and field tests that have been performed on these tracers.

\section{PROJECT OBJECTIVES}

\section{Technical Objectives}

- Evaluate the cost, availability, toxicity, detectability, and solubility of the hydrofluorocarbons.

- Test their stability in the laboratory at temperatures typical of geothermal systems.

- Test their interactions with rock and some common geothermal gases at temperatures typical of geothermal systems.

- Perform field tests in conjunction with industry to determine their efficacy under actual field conditions.

- Inject them simultaneously with tritium to evaluate their performance.

- Compare the results of tracer tests performed in identical locations but using tritium, chlorofluorocarbons, or hydrofluorocarbons separately.

\section{Expected Outcomes}

- $\quad$ Provide as many proven vapor-phase tracers for The Geysers as possible. Only a few of these will be inexpensive enough to use routinely. The rest will be used for special cases when multiple tracers are needed. This will allow industry to:

1. Plan and change injection-well flow rates and locations.

2. Calculate injection recycling.

3. Calculate increased power output or increased reserves due to effluent injection projects.

- Evaluate the effects of tracer volatility on the calculation of injection recovery.

\section{APPROACH}

- Contact manufacturers and vendors to determine species, cost, and availability of volatile hydrofluorocarbons.

- Evaluate detectability in conjunction with commercial analytic laboratories to determine routine analysis procedures.

- Perform preliminary laboratory tests to determine thermal stability. The procedures used are described on our web site (http://www.egi.utah.edu: Choose Research and then Center for Tracer Development) and in our previous publications.

- $\quad$ Perform field tests to qualitatively determine stability under actual conditions. 
- Perform detailed laboratory tests to quantitatively determine stability under conditions that include some geothermal gases and rock.

\section{RESEARCH RESULTS}

Our search indicated that the most affordable species of hydrofluorocarbon is R-134a, or tetrafluoroethane. An analogous compound, R-23, or fluoroform, is more expensive but still economic for a tracer test at The Geysers. R-23 and R-134a are more soluble in water than their respective chlorofluorocarbons. At one bar of gas pressure the solubility of R-23 and R-134a are $0.1 \%$ and $0.15 \%$, respectively. Preliminary laboratory experiments have been used to predict the time-temperature-decay rate relationships of R-134a, which are shown in Figure 1. Our laboratory experiments indicate that R134a has a half-life of 153 days at $240^{\circ} \mathrm{C}$, a typical temperature at The Geysers. A typical Geysers tracer test lasts 60 to 90 days.

Seven field tests of the hydrofluorocarbon were conducted at The Geysers during 1998 (Table 1). The first of these is discussed in Beall et al. (1998). Six of the seven tests were cost-shared by DOE and industry during 1998. The tests were considered a success by the industry participants. The criteria used to determine success were: 1) mass recovery of the tracer, 2) similarity with previous R-13 or tritium tests, and 3) similarity of tritium, R-134a, and R-23 curves in simultaneous injection experiments. However, a detailed analysis shows that the using the gas tracers to calculate recoveries induces a bias that results from fractionation of the tracers to the steam phase early in the boiling process. This can be shown by comparing the recovery fractions obtained from gas tracers to those calculated from tritium concentrations in the one test that used both types of tracers. These data are listed in Table 2.

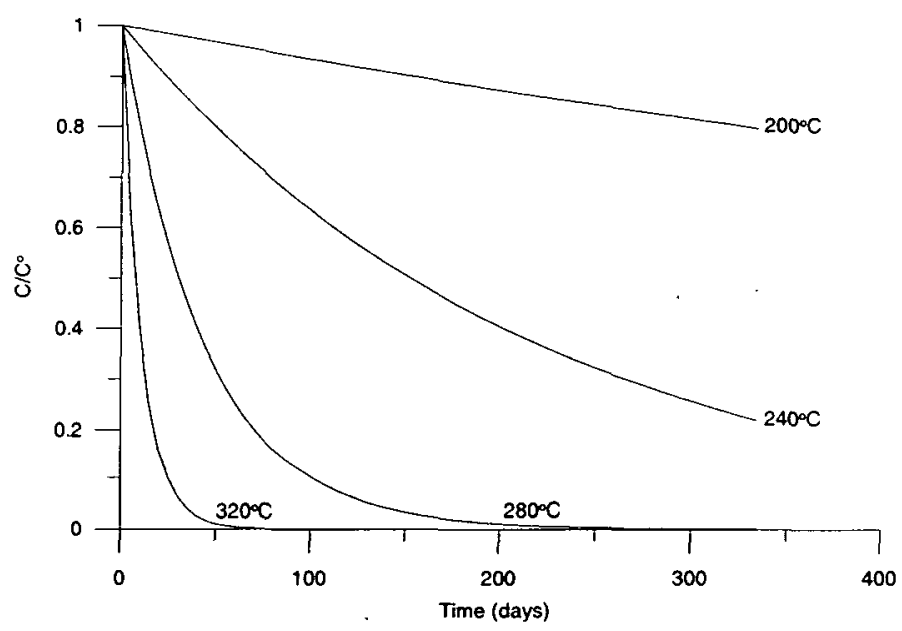

Figure 1. Time-temperature decay relationships of $\mathrm{R}-134 \mathrm{a} . \mathrm{C} / \mathrm{C}^{\circ}=$ fraction remaining after the specified time at a given temperature. 
Table 1. Summary of tracer tests at The Geysers that have used hydrofluorocarbons.

\begin{tabular}{|c|c|c|c|c|c|}
\hline & Injection Date & Fie Id & Wells Monitored & Tracer & Injection We II \\
\cline { 2 - 6 } & January, 1998 & Calpine & 10 & 245 Ibs R-134A & MLM-1 \\
\cline { 2 - 7 } & April, 1998 & Calpine & 5 & 244 lbs R-134A & Aidlin-8 \\
\cline { 2 - 7 } & April, 1998 & Calpine & 20 & 121 lbs R-134A & McKinley-4 \\
\hline August, 1998 & NCPA & 40 & 245 lbs R-134a, & P-1 \\
\hline & & & & 209 lbs R-23 & \\
\hline
\end{tabular}

The data listed in Table 2 show that the gas-tracer recovery-estimates range from much lower to much higher than tritium. There is a distinct geographic relationship to the recovery ratio, as shown in Figure 2. This relationship could arise from different fracture sets being sequentially encountered as the injectate boils. Alternatively, one fracture set could be filled with liquid, reducing its permeability to steam. This would direct the steam flow to the fracture set not filled by liquid.

Table 2. Recovery percentages and ratios for both types of tracers used in the NCPA tracer test. The injection well was P-1. Only wells for which analyses of both types of tracers are equally distributed over time are shown.

\begin{tabular}{|c|c|c|c|c|c|c|}
\hline Production & R-134a & $\mathbf{R}-23$ & Tritium & Earliest & Dominant Peak & R-134a/Tritium \\
\hline Well & Recovery (\%) & Recovery (\%) & Recovery (\%) & Peak & & Recovery Ratio \\
\hline$E-4$ & 0.02 & 0.01 & 7 & gas & trit & 0.00 \\
\hline$B-2$ & 0.3 & 0.2 & 6 & gas & trit & 0.05 \\
\hline B-6 & 0.8 & 0.7 & 4 & gas & tie & 0.20 \\
\hline B-5 & 4 & 4 & 8 & tie(trit) & tie(gas) & 0.50 \\
\hline D-7 & 0.3 & 0.2 & 0.5 & tie & gas & 0.60 \\
\hline$B-3$ & 6 & 5 & 7 & tie & tie(gas) & 0.86 \\
\hline $\mathrm{N}-6$ & 1.4 & 0.92 & 1.6 & tie & tie & 0.88 \\
\hline $\mathrm{P}-4$ & 8 & 8 & 8 & trit & tie(gas) & 1.00 \\
\hline Q-4 & 0.4 & 0.3 & 0.3 & tie & tie(gas) & 1.33 \\
\hline Q-8 & 14 & 15 & 10 & tie & gas & 1.40 \\
\hline Q-3 & 4 & 3 & 2 & tie & tie(gas) & 2.00 \\
\hline B-4 & 45 & 46 & 13 & tie(trit) & tie(gas) & 3.46 \\
\hline $\mathrm{P}-7$ & 14 & 17 & 2 & tie(trit) & gas & 7.00 \\
\hline
\end{tabular}




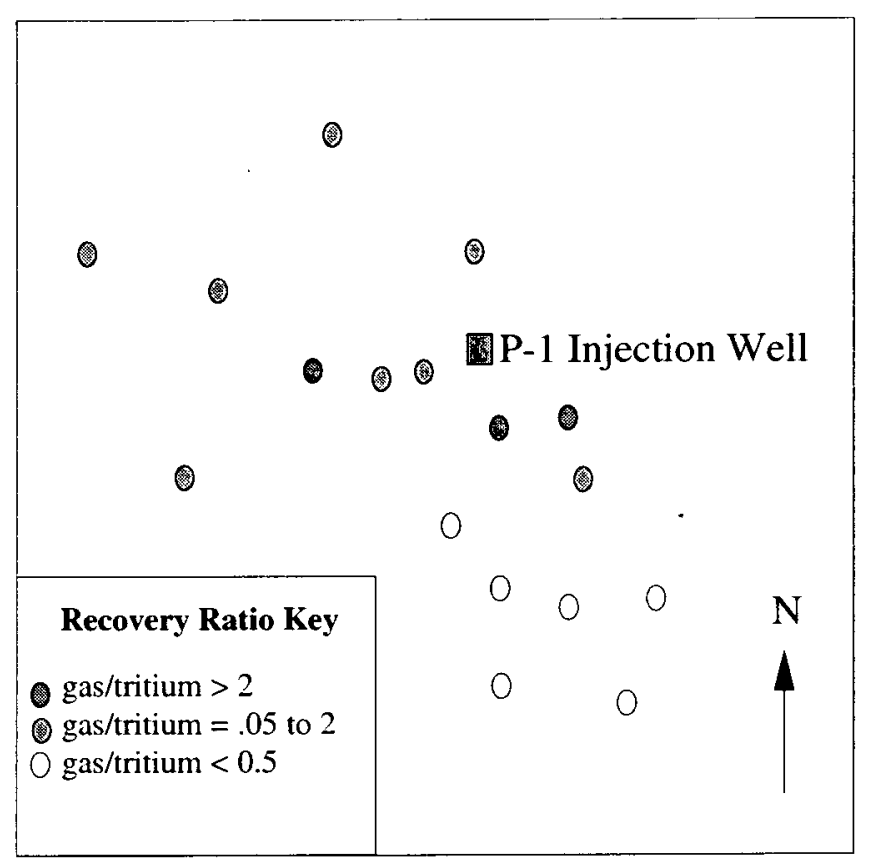

Figure 2. Relationship of the downhole location (center of steam) of the production wells to the gas/tritium recovery ratio.

\section{FUTURE PLANS}

Several more laboratory and field tests are planned for 1999 to continue our evaluation of the hydrofluorocarbons. DOE and industry will jointly fund these tests. Other, more soluble tracers will be examined to try and develop steam-phase tracers that will boil at the same rate as water. For example, some of the alcohols would be suitable if a more sensitive analytical method were developed (Adams, 1995). The equation-of-state for the perfluorinated methylcycloalkanes currently being developed by Robert Fox at INEEL will be used to examine the suitability of these compounds as geothermal steam or liquid tracers.

\section{INDUSTRY INTEREST AND TECHNOLOGY TRANSFER}

\section{Organization}

Calpine Corporation

Unocal Geothermal Inc.

Northern California Power Agency

Utah Municipal Power Agency

\section{Type and Extent of Interest}

Cost-shared tracer tests at The Geysers CA

Cost-shared tracer tests at The Geysers CA

Cost-shared tracer tests at The Geysers CA

Cost-shared tracer tests at Cove Fort

\section{REFERENCES}

Adams, M. C., 1995, Vapor, liquid, and two-phase tracers for geothermal systems: International Geothermal Congress, 1995, p. 1875-1880. 
Adams, M. C., Beall, J. J., Enedy, S. L., and Hirtz, P., 1991a, The application of halogenated alkanes as vapor-phase tracers: A field test in the Southeast Geysers: Transactions, Geothermal Resources Council, 1991a, p. 457-463.

Adams, M. C., Moore, J. M., and Hirtz, P., 1991b, Preliminary assessment of halogenated alkanes as vapor-phase tracers: Sixteenth Workshop on Geothermal Reservoir Engineering, Stanford University, Stanford CA, 1991b, p. 57-62.

Beall, J. J., Adams, M. C., and Hirtz, P. N., 1994, R-13 tracing of injection in The Geysers: Transactions, Geothermal Resources Council, 1994, p. 151-159.

Beall, J. J., Adams, M. C., and Hirtz, P. N., 1998, Evaluation of R-134a as an injection tracer in the Southeast Geysers: Geothermal Resources Council, 1998. 


\title{
THE MINERALOGIC AND FLUID-INCLUSION RECORD OF THE TRANSITION FROM LIQUID- TO VAPOR-DOMINATED CONDITIONS AT THE GEYSERS CALIFORNIA
}

\author{
J.N. Moore', M.C. Adams ${ }^{1}$, and A.J. Anderson ${ }^{2}$ \\ 1. Energy \& Geoscience Institute, University of Utah \\ 2. St. Francis Xavier University, Antigonish, Nova Scotia, Canada BG2 2W5
}

\section{KEY WORDS}

The Geysers, fluid inclusions, boiling

\section{PROJECT BACKGROUND AND STATUS}

During the past 5 years, significant progress has been made in our understanding of the evolution of The Geysers' geothermal system and its transition from a liquid- to vapor-dominated system. The temperatures, salinities, and gas compositions of the early hydrothermal fluids were established by Moore and Gunderson (1995) and Moore et al. (1997). They found that temperatures decreased from $>400^{\circ} \mathrm{C}$ near the intrusive contact to $300^{\circ} \mathrm{C}$ at distances of about $1700 \mathrm{~m}$ and that salinities indicative of a magmatic fluid ( $>26$ weight percent $\mathrm{NaCl}$ equivalent) occurred only within high-temperature veins in the plutonic rocks and surrounding biotite-hornfels. The gas compositions of these early fluids, however, were found to contain both magmatic and crustal components, irrespective of the distance from the intrusive.

Although it was generally thought that the transformation from a liquid- to a vapor-dominated regime would leave an obvious record within the reservoir rocks, the mineralogic and chemical signatures of this event were not well characterized.. Sternfeld and Walters (1989) had observed the presence of Aboiling assemblages $\cong$ consisting of calcite + quartz + clays in the northwest Geysers. Subsequent work by Hulen (e.g. Hulen et al., 1991) added additional insight into the importance of this mineral assemblage, but it was not until the drilling of SB-15-D, a cooperative DOE-Unocal core hole, that samples containing a detailed record of the transition from liquid-to vapor dominated conditions became available. Preliminary data on the temperatures of mineral deposition and on the compositions of the hydrothermal fluids were presented by Hulen et al. (1997) and Moore et al. (1998). By combining the temperature data and evidence of boiling with thermal models based on ${ }^{40} \mathrm{Ar}{ }^{39} \mathrm{Ar}$ age spectra of vein adularia, Hulen et al. (1997) were able to show that vapor-dominated conditions developed between 0.28 and $0.25 \mathrm{Ma}$. Our current studies build on the results of these earlier investigations.

\section{PROJECT OBJECTIVES}

Although The Geysers is the best known of the vapor-dominated resources, others are currently under production in Japan and Indonesia, and the discovery of new systems is likely. Conceptual models based on actual geologic and geochemical data remain an important component of exploration and development programs.

\section{Technical Objectives}

- The major objective of this work is to develop a detailed conceptual model of a vapor-dominated resource that includes its characteristics and evolution. 
- The secondary objective is to provide new information on the chemical changes that geothermal systems undergo as they evolve.

\section{Expected Outcomes}

- The results of this study will assist in the recognition of past or modern vapor-dominated regimes.

- Temperature and compositional data will help constrain numerical models that are currently being developed to describe reservoir characteristics of The Geysers and other vapor-dominated systems.

\section{APPROACH}

In this investigation, we have systematically characterized and documented samples and relationships found in core and cuttings samples. The majority of the samples were taken from SB-15-D. The investigators utilized a variety of techniques. Fluid-inclusion measurements and petrographic studies were performed at EGI by J. Moore. M. Adams of EGI modeled the isotopic and geochemical data. A. Anderson of St. Francis Xavier University determined the orientations and origins of the fluid inclusions. D. Norman of New Mexico Tech performed additional fluid-inclusion gas analyses using improved methods. These data were used to establish the compositional changes that occurred as The Geysers evolved.

\section{RESEARCH RESULTS}

The development of vapor-dominated conditions at The Geysers is illustrated schematically in Figure 1. The system was considered to be liquid-dominated from its inception until $0.28 \mathrm{Ma}$ (Hulen et al., 1997). Prior to this time, mineralization resulted from cooling or intermittent and local boiling that accompanied faulting (Fig. 1a). Quartz and adularia formed during episodes of boiling; other minerals including actinolite, epidote, and chlorite may have formed by cooling. At approximately $0.28 \mathrm{Ma}$, venting of the hydrothermal fluids occurred. The initial response of the hydrothermal system was a drop in pressure and a subsequent drop in the water level as the liquid boiled away (Fig. 1b). Fluid-inclusion homogenization temperatures suggest that bladed calcite and quartz were deposited by the boiling fluids between $300^{\circ}$ and $265^{\circ} \mathrm{C}$. A static or slowly migrating boiling water table can lead to intense mineralization and partial to complete sealing of the fractures. Subsequent venting produced a further lowering of the water table (Fig. 1c) and additional mineralization. Because the rock is left with a considerable amount of heat, the fracture may remain above the saturation temperature for a period of time. The difference between the rock temperature and the saturation temperature will increase downward since the temperature-depth gradient in a vapor-dominated system is much less than that of a liquid-dominated system. Liquid that results from steam condensation at the reservoir-cap interface (shown as a mineralogic seal) will flow downward until the rock temperature becomes higher than the saturation temperature and the liquid boils, removing heat and cooling the rock back to the saturation temperature (Fig. 1d).

The condensate that forms at the top of the developing heat pipe is essentially a distilled, slightly acidic water that contains variable concentrations of dissolved gases. These fluids are highly reactive and strongly undersaturated in silica and carbonate. Downward percolation of the condensate resulted in corrosion of calcite and quartz and the formation of clay minerals, which further sealed the fractures. Because quartz saturation is readily achieved, it follows that the circulation paths of the undersaturated, acidic fluids must be relatively short and that dissolution of quartz will occur close to the site of condensate formation.

Salinities of liquids in the primary liquid- and vapor-rich inclusions demonstrate that quartz and calcite were deposited by both condensate and mixtures of condensate and boiled hydrothermal fluids. Thus at 
times, the condensate was undersaturated with respect to these minerals while at other times, and in identical parts of the fracture, it was either in equilibirum with quartz and calcite or supersaturated. Supersaturation and mineral precipitation occurred as the downward percolating waters evaporated upon entering portions of the fractures that were still superheated (Fig. 1d) or during periods of venting that were accompanied by further pressure decreases (Fig. 1e). Quartz deposition occurred throughout the transition to vapor-dominated conditions, as demonstrated by the broad range of temperatures recorded by primary liquid-rich inclusions in individual crystals. Periods of rapid growth of the quartz crystals would have been triggered by intermittent venting whereas slower growth could reflect the progressive loss of superheat.

As steam was lost from the system, the salinity of the remaining liquid increased with time. In the central Geysers, salinities increased from approximately 2 to 4 weight percent $\mathrm{NaCl}$ equivalent as the fluid boiled from $300^{\circ}$ to $270^{\circ} \mathrm{C}$. Although water levels in the main fracture will drop rapidly, liquids can persist in subsidiary fractures due to capillary forces. Mixing of the condensate and reservoir fluids occurred as condensate was imbibed into the fracture network surrounding the heat pipe and as the residual boiled fluids leak into the main fracture (Figs. $1 \mathrm{~d}$ and $\mathrm{f}$ ). Salinity-temperature relationships indicate that the trapping of highly mixed fluids increased dramatically during the final stages of heat pipe development, and it is likely that the meteoric waters found in inclusions from the central and southeast Geysers were also drawn into the fractures at this time. The driving mechanism behind this fluid circulation was the steep pressure gradients that formed and spread outward from the underpressured fractures, where the fluids were boiling off, to the still partially saturated surrounding rocks. These pressure gradients may have intensified in response to a period of renewed venting and pressure drawdown. The effects of this event are reflected in the rapid but episodic growth of skeletal quartz crystals, the trapping of large vaporrich fluid inclusions, and the deposition of rhombohedral calcite and chlorite rosettes. Fluid circulation, however, was complex with both condensate and mixtures of condensate and the residual boiled fluids contributing to quartz growth. Mixed fluids that reentered superheated portions of the main fracture and boiled were accidentally trapped in primary vapor-rich inclusions in quartz from well Prati-14. As the superheat dissipated, the incursion of cooler mixtures of condensate, boiled hydrothermal fluid, and locally, meteoric water into different parts of the heat pipe resulted in thermal cracking of the quartz crystals and the formation of secondary liquid-rich inclusions.

As the fluids vented and boiled, there was a redistribution of volatile species, ${ }^{16} \mathrm{O}$, and deuterium. Loss of volatiles occurred in portions of the heat pipe that were directly connected to vents. The low concentrations of $\mathrm{CO}_{2}$ in SB-15-D are consistent with its position near the intensely altered Sulphur Creek Fault where some fumarolic activity continues today. Volatile species can concentrate in other portions of

the heat pipe as the water condenses and drains downward. The high concentrations of $\mathrm{CO}_{2}$ trapped in quartz from the Prati wells may be indicative of a gas cap that developed over parts of the system where limited venting occurred.

Self-sealing of the fractures and the downward migration of the cap rock occurred as the heat pipe evolved. These seals are represented by bleached zones above the modern steam reservoir where acidic condensate deposited late-stage clay minerals. The present conditions are shown in Figure 1g. The fracture is now at its saturation temperature throughout its length. Downward percolating condensate formed at the base of the cap is imbibed into the wall rocks or boils at the base of the heat pipe.

\section{FUTURE PLANS}

The results of this investigation and of the complimentary studies we are conducting have led to new approaches in the interpretation of fluid-inclusion microthermometic and gas data. We will apply these results to investigations of other geothermal fields. Emphasis will be place on systems in Indonesia and the Philippines. 


\section{INDUSTRY INTEREST AND TECHNOLOGY TRANSFER}

Our studies of The Geysers represent joint projects with Unocal and Calpine, who have provided samples, steam analyses, and other data. Unocal, Calpine, CalEnergy Inc. and Caithness have demonstrated a continuing interest in the application of fluid-inclusion data by providing samples and information on other fields. Discussions with researchers from New New Zealand, Japan, and Italy have demonstrated their interest in developing similar capabilities and joint projects are likely in the future. Preliminary results of this work have been presented at the Stanford Reservoir Engineering Meeting (Moore et al., 1998).

\section{REFERENCES}

Hulen, J.B., Heizler, M.T., Stimac, J.A., Moore, J.N., and Quick, J.C., 1997, New constraints on the timing of magmatism, volcanism, and the onset of vapor-dominated conditions at The Geysers steam field, California. Proc. $22^{\text {nd }}$ Wkshp. on Geotherm. Reservoir Eng., Stanford Univ., p. 75-82.

Hulen, J.B., Walters, M.A., Nielson, D.L., 1991. Comparison of reservoir and caprock core from the Northwest Geysers steam field, California. Geotherm. Resources Council Trans., 15, 11-18.

Moore, J.N., Anderson, A.J., Adams, M.C., Aines, R.D., Norman, D.I., Walters, M.A., 1998. The fluidinclusion and mineralogic record of the transition from liquid- to vapor-dominated conditions in The Geysers geothermal system, California. Proc. $23^{\text {rd }}$ Wkshp. on Geotherm. Reservoir Eng., Stanford Univ., pp. 211-218.

Moore, J. N. and Gunderson, R.P., 1995. Fluid inclusion and isotope systematics of an evolving magmatic-hydrothermal system. Geochem. Cosmochim. Acta., 59, 3887-3907.

Moore, J.N., Norman, D.I., Kennedy, B.M., and Adams, M.C., 1997, Origin and chemical evolution of The Geysers, California, hydrothermal fluids: Implications from fluid-inclusion gas compositions. Geotherm. Resources Council Trans. 21, 635-641.

Sternfeld, J., and Walters, M., 1989, The occurrence of acid-leached graywacke at The Geysers, Sonoma County, California. Proc. 14 ${ }^{\text {th }}$ Wkshp. on Geotherm. Reservoir Eng., Stanford Univ., p. 181-187. 


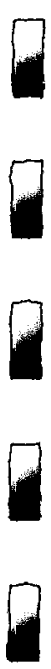

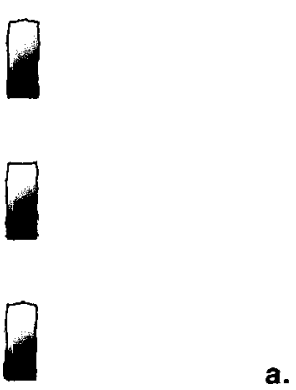

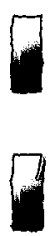

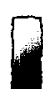

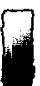

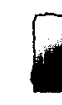

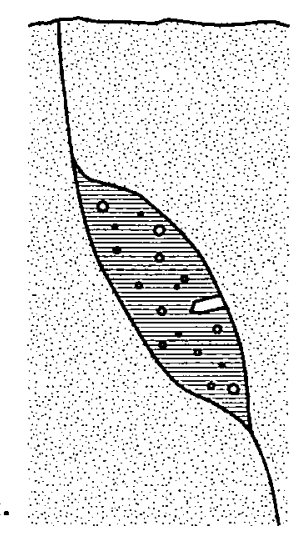

1.2-0.28 Ma

O Steam

管 Liquid Water

올 Superheated Region

Bladed Calcite

Quartz

Fracture

Metagraywacke

e.

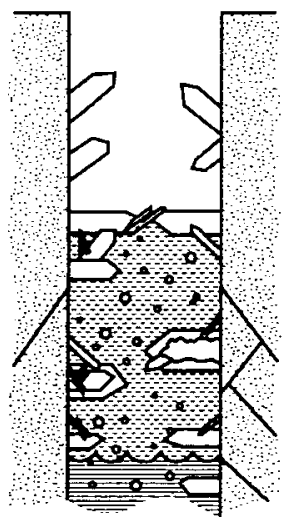

Figure 1 c.

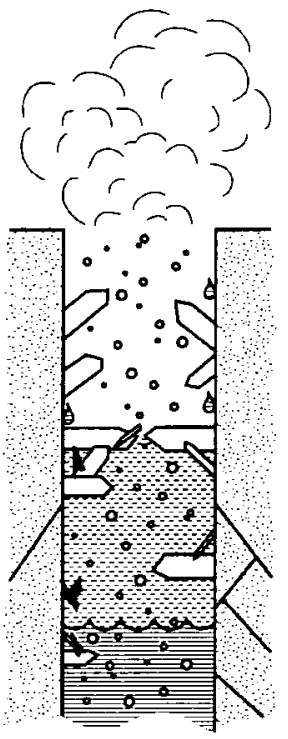

0.28-0.25 Ma

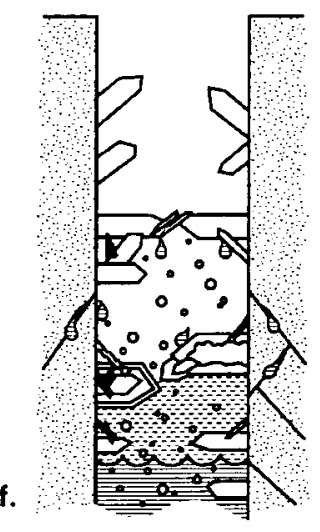

d.

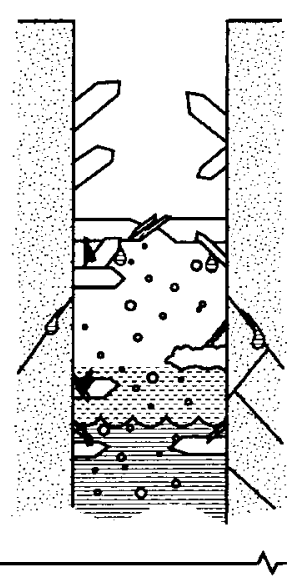

g.

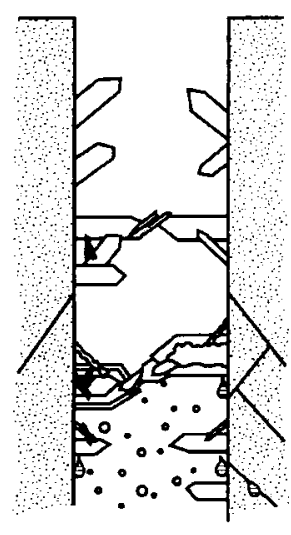

Present 


\title{
Federal Geothermal Research Program Update Fiscal Year 1998 Downhole Microseismic Monitoring
}

\author{
James Rutledge and James Albright \\ Los Alamos National Laboratory, GeoEngineering Group, Mail Stop D443 \\ Los Alamos, NM 87545 \\ 505-667-4318 \\ jrutledge@lanl.gov,j_albright@lanl.gov
}

\section{KEYWORDS}

induced seismicity, fracture imaging, reservoir characterization, temperature-hardened downhole seismic receivers

\section{PROJECT BACKGROUND AND STATUS}

This Project began in the fall of 1996 and has demonstrated downhole microseismic monitoring at The Geysers and Dixie Valley geothermal fields using retrievable geophone tools and the fabrication and installation of a permanent downhole geophone arrays at The Geysers for long- term monitoring. The Project is currently scheduled for completion in April, 1999.

Downhole microseismic mapping provides the most powerful technique for imaging reservoir fractures/faults at large distances from boreholes (100s of meters). Borehole microseismic mapping began in response to reservoir engineering needs to identify and locate both hydraulic fractures and naturallyoccurring reservoir fractures. The technique involves placing seismic sensors downhole to detect and locate small earthquakes occurring along conductive reservoir fractures and to directly image fracture geometry by delineating planar clusters of microearthquake event locations. Through numerous field studies, Los Alamos has shown that reservoir microseismicity is fairly ubiquitous. This can be attributed to crustal earth stresses invariably being anisotropic, which results in shear stress build up on pre-existing fractures. In subsurface reservoirs, discrete shear slip, that is, microearthquakes, can easily be induced along fractures by pressure changes accompanying both injection and production operations. Typical reservoir event magnitudes range from -3 to 0 with source dimension on the order of only a few meters, two to three orders of magnitude smaller than can be detected using surface-deployed instrumentation. To - detect and map such low-energy, high-frequency signals, requires the placement of sensors downhole at or near reservoir depth.

Los Alamos produced the first demonstration of reservoir microseismic mapping and has played a leading role in transferring the technique to the oil and gas industry via successful collaborations with major and independent operators alike. Mappable reservoir microseismicity is associated with numerous production processes under control of the reservoir engineer, including, hydraulic fracturing, primary production, water floods, acid treatments and re-injection. Applications involving production-related microseismicity requires downhole instrumentation that can survive monitoring periods up to months to 1) acquire sufficient amounts of high quality data and 2) to correlate the reservoir seismicity with production operation changes. Commercial applications in the oil and gas industry are just starting to take hold. However, the outstanding hurdle to widespread application are the high-costs associated with instrumentation of boreholes and the concomitant disruption to normal production operations. Los Alamos has made progress in reducing deployment costs through the development of new borehole seismic instrumentation. This was highlighted during the years 1994-1997 by the Los Alamos cooperative development with Schlumberger Wireline Services that resulted in a new high performance 1-11/16-inch 
OD (outside diameter) and now a 0.5 -inch OD borehole instrumentation packages developed in collaboration with Mark Products. These small diameter tools can be deployed within or outside of production tubing, thus dramatically reducing the costs of well preparation and loss production time. Further, Los Alamos is pursuing the development of a capability to drill and instrument very deep, smalldiameter boreholes, on the order of $35 \mathrm{~mm}$ at terminal depth. This so-called microhole drilling and instrumentation technology promises improved measurements, no disruption in production, and greatly reduced costs.

\section{PROJECT OBJECTIVES}

To demonstrate the value of the downhole monitoring of reservoir seismicity in geothermal fields and to provide a commercialization path for developing operationally efficient, borehole seismic instrumentation that can sustain deployment in high temperature wells for indefinite periods of time, be it permanentlyinstalled or retrievable.

\section{Technical Objectives}

- Quantify the sensitivity and detection rate of downhole monitoring in comparison to surfacedeployed instrumentation.

- Demonstrate the effectiveness with which productive fractures in geothermal systems can be mapped.

- Build and evaluate the next generation of retrievable and permanent borehole instrumentation for high-temperature service.

- Ensure that this equipment becomes commercially available to the geothermal industry.

\section{Expected Outcome}

- Characterization of near-surface deformation affecting borehole integrity at The Geysers, including fracture/fault maps, fault plane solutions, temporal variation in deformation (episodic or continuous) and association of observed microseismic deformation with production/ injection operations.

- Evaluation of the long-term performance of the permanent downhole geophone sensors deployed at The Geysers.

\section{APPROACH}

This Project has been a collaborative effort between Los Alamos, and geothermal field operators (Unocal and Oxbow) as well as Petroleum GeoServices (PGS), a world leader in marine and borehole seismic arrays. Microseismic mapping technology is to be transferred to the geothermal industry by way of field demonstrations and specification, fabrication and evaluation of new borehole seismic instrumentation, conducted in partnership with geothermal operators and field service companies.

To realize the full potential of microseismic mapping (1) long term measurements with permanently installed downhole instruments are necessary; and (2) instruments should be placed within or as close to production zones as possible. An ideal array should be capable of operating at geothermal temperatures with non-exotic, reasonably-priced fabrication materials and components. Our goal is to insure that such a capability is developed. 


\section{RESEARCH RESULTS}

During the period FY97-99 this Project completed substantial milestones toward demonstrating longterm, downhole microseismic monitoring at The Geysers. This work included a preliminary study using retrievable wireline geophone packages; the design, fabrication and installation of a $150 \mathrm{C}$ geophone array (Figure 1); and 9 months of recording and analysis of the array data. Analysis to date have shown that high-frequency events can be detected at magnitudes 2 to 3 levels below current surface array detection thresholds (Albright et al., 1998). The downhole array is placed at fairly shallow depths $(<800 \mathrm{ft})$. Downhole detection sensitivity will further improve with the capability to get deep within the reservoir. Still, one of the immediate objective of the shallow Geysers array was the monitoring and mapping of near-surface deformation induced by production operations. A fault projecting to at least 800 $\mathrm{ft}$ depth has been implicated as causing the progressive wellbore collapse in the monitor well and other surrounding wells. In fact, the monitor well, GDCF $63-29$, was abandoned and available for array deployment because of this shallow deformation. The events detected within $2000 \mathrm{ft}$ of the array are distinct from surfaced monitored seismicity in that they all occur above the reservoir, at depths ranging from about 1200 to $2200 \mathrm{ft}$ depth. This is partly due to increased sensitivity of the downhole sensors, but can also be attributed to array geometry. Surface stations are generally too far apart to achieve common detection of the shallow, low-magnitude, high-frequency events. The events mapped over the first 9 months of monitoring shows a low-angle feature that is associated with a lithologic boundary at about $1600 \mathrm{ft}$ depth.

A 3-component surface receiver was deployed in mid-November, 1998 to test if a surfaced-based instrument could be used to supplement the downhole data and improve location precision which is currently limited by hodogram azimuthal data. Indeed, common downhole-surface detection and phase identification of the shallow, high-frequency seismicity is possible. Supplementing the downhole array with just a few surface receivers will allow unique, 3-dimensional location to be determined from the arrival time data alone. In addition, location errors should be reduced and high-precision relative mapping techniques can be applied, allowing resolution of discrete fault surface geometries and focal mechanisms. Map and depth section views of the shallow seismicity detected since mid-November show a trend of steeply dipping seismicity projecting close to the $800 \mathrm{ft}$ deformation zone (Figures 2 and 3). Two additional 3-component surface geophone receivers were fabricated and deployed in early January, 1999.

\section{FUTURE PLANS}

Complete data analysis of The Geysers array data collected over a continuous one-year period (April, 1998 through April, 1999) and complete the final report on the Project.

\section{INDUSTRY INTEREST AND TECHNOLOGY TRANSFER}

Organization

Unocal

Oxbow

Petroleum GeoServices

\section{Type and Extent of Interest}

Industry Partner, Operator of The Geysers

Industry Partner, Operator of Dixie Valley

Subcontracted to fabricate high-temperture geophone array

\section{REFERENCES}

Albright, J. N., Rutledge, J.T., Fairbanks, T.D., Thomson, J.C., and Stevenson, M.A., 1998, "Vertical Arrays for Fracture Mapping in Geothermal Systems", Geothermal Resources Council Transactions, Vol. 22, p. 459-463. 


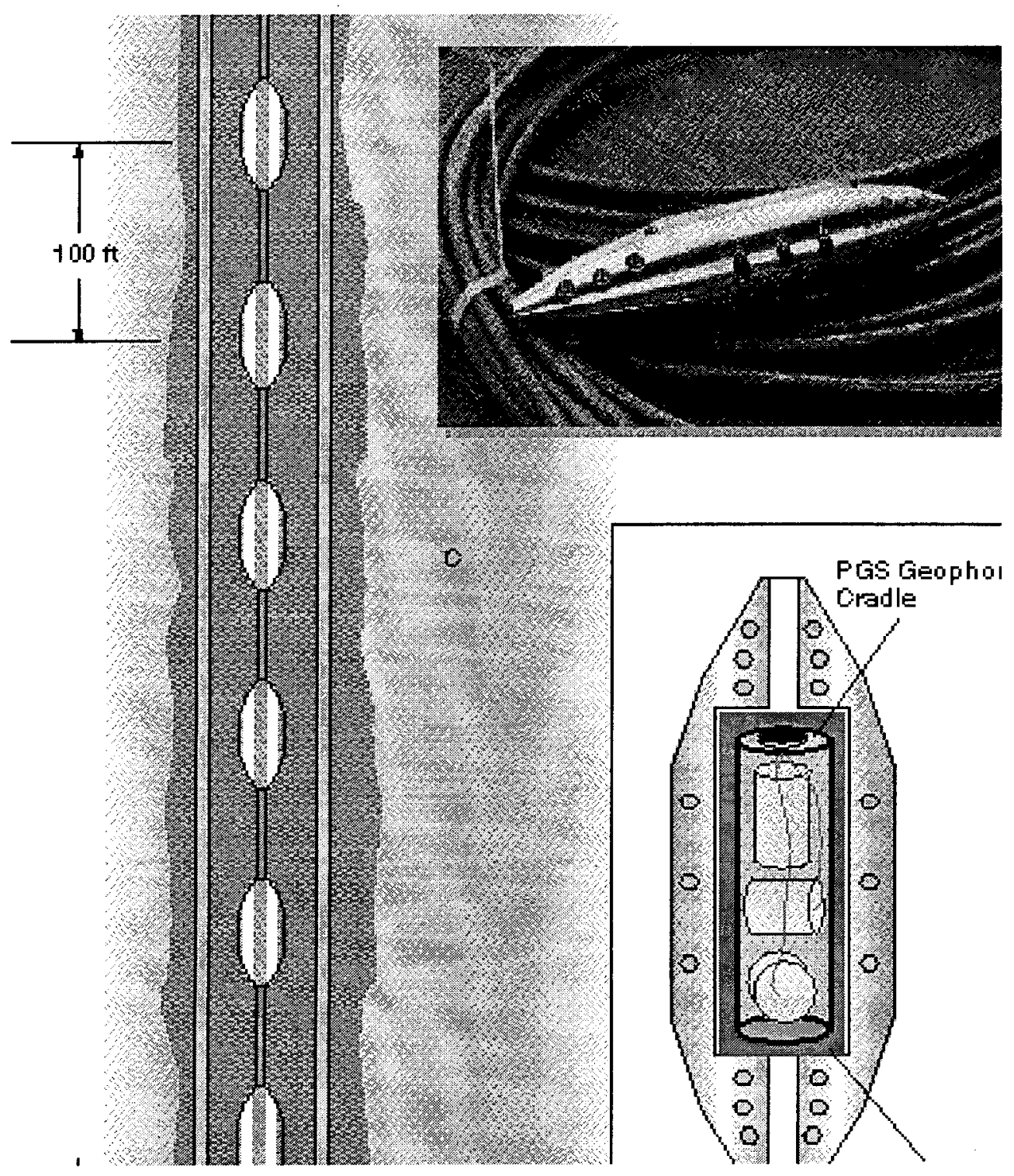

Figure 1. Downhole geophone array deployed during final abandonment of Unocal's production well GDCF 63-29. April, 1998. 
testno_hod.i225

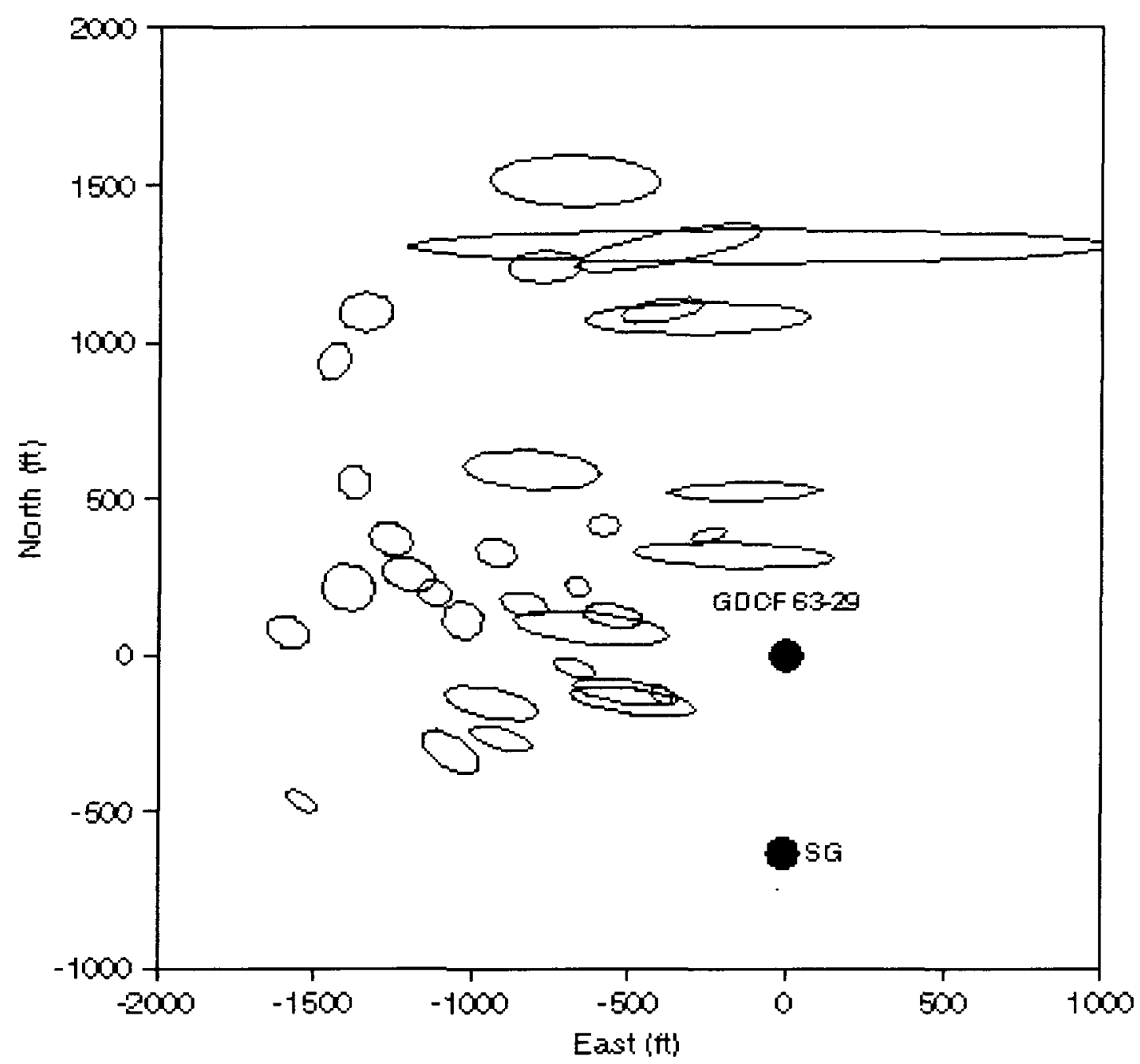

Figure 2. Map view location error ellipses for some near-array events detected on downhole array (63-29) and the first surface geophone deployed (SG). 
testno_hod.i225

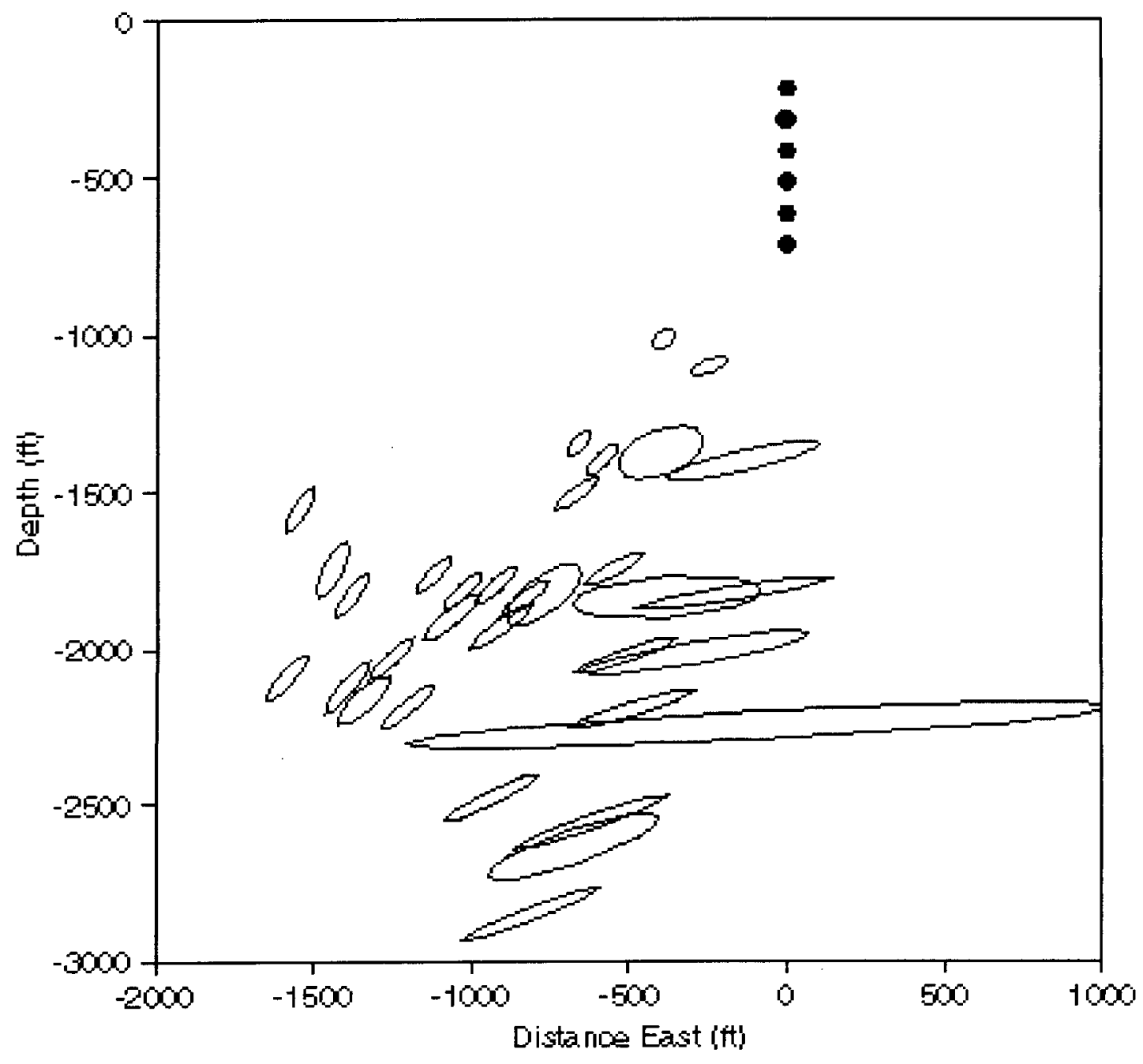

Figure 3. Depth view location error ellipses for events shown in Figure 2. The solid circles are the 63-29 downhole geophone stations. 


\title{
INDIGENOUS OIL IN THE DIXIE VALLEY GEOTHERMAL SYSTEM, NEVADA, AS A POTENTIAL TRACER OF NATURAL AND PRODUCTION-INDUCED RESERVOIR PROCESSES
}

\author{
'Jeffrey B. Hulen, ' James W. Collister, and ${ }^{2}$ Stuart D. Johnson \\ ${ }^{1}$ Energy \& Geoscience Institute, University of Utah \\ 'Oxbow Power Services
}

\section{KEY WORDS}

Dixie Valley, geothermal, hydrocarbons, biomarkers, natural tracer, geothermal scale, fluid inclusions, thermal history, reservoir processes

\section{PROJECT BACKGROUND AND STATUS}

In mid-1998, one of us (Johnson) discovered traces of oil in a wellhead-bleed wing valve atop Dixie Valley geothermal production well 37-33. The occurrence was a surprise to say the least, since conventional wisdom has it that oil cannot long survive, in the liquid state, at the high temperatures (up to $250^{\circ} \mathrm{C}$ ) encountered at depth in the Dixie Valley geothermal system. Accordingly, the oil was analyzed at the Energy \& Geoscience Institute (EGI) Organic Geochemical Laboratory. Its low thermal maturity was noted, and it was set aside for a time as an isolated curiosity. Then later in the year, we discovered additional oil traces encapsulated in and impregnating geothermal scales from three other production wells whose locations spanned the entire field. It seemed advisable at that point to make a preliminary investigation to determine the origin and significance of this hydrocarbon occurrence. As a delicate mixture of intricate organic compounds, the oil seemed to have good potential as a recorder of both natural thermal processes and those induced by reservoir production. In short, the oil was viewed as a possible natural tracer, which might be called upon to provide additional information in supplement to that furnished by sophisticated, manufactured tracers introduced into the reservoir. Preliminary results of this investigation suggest (but by no means prove at this point) that thermal-fluid flow stimulated by production is likely to be several orders of magnitude greater than that prevailing in the bulk of the geothermal system in its pre-production state.

\section{PROJECT OBJECTIVES}

\section{Technical Objectives}

- Characterize all known oil occurrences in the Dixie Valley geothermal system, noting such critical points as depth in wellbores; temperatures at collection depths; coexisting thermal-water chemistry; mineralogy and chemical composition of encapsulating geothermal scales; and the paragenetic sequence of scale formation at each site.

- Complete detailed organic-geochemical analyses of the oils, with particular attention to biomarkers (organic molecules which in combination are highly diagnostic of source-rock characteristics and facies); ages of these source rocks; and thermal maturation histories of the analyzed oils.

- Identify potential hydrocarbon source rocks at depth and distal to the Dixie Valley geothermal system and in outcrops in flanking mountain ranges. Obtain bitumen extracts from these rocks and compare the geochemical signatures of those extracts with those of the geothermal-system oils. In other words, investigate potential source-rock/oil correlations. 
- Collect and perform organic geochemical analysis on any refined, petroleum-based manufactured products utilized for drilling or wellhead maintenance so that any contamination arising from these can be subtracted from the signatures of the clearly natural crude oils.

- Complete numerical thermal-history modeling, employing appropriate Arrhenius equations, to determine the likely durations that already-existing oils could survive at a range of temperatures up to and exceeding the modern reservoir temperature of $250^{\circ} \mathrm{C}$.

- Assuming sufficient quantities of the oil can be collected, perform carefully controlled, closedtube, hydrous pyrolysis of the oils at a range of temperatures corresponding to those employed for the thermal modeling described above. These experiments have great potential to constrain the thermal stability of the oil, and monitor changes in its biomarker transformations (another gauge of thermal maturation) with increasing thermal stress.

- Knowing the likely life-span of the oil from results of the foregoing two tasks, along with the locations of potential source rocks with respect to actual oil occurrences, calculate maximum flow rates from the sources to the entrapment sites. Compare these rates with those inferred to apply to natural, undisturbed, high-temperature hydrothermal systems.

- From the foregoing, deduce the extent to which the presence of the oil in the heart of the geothermal system is due to production-induced reservoir changes.

\section{Expected Outcomes}

- Determination of the utility of natural oil as a semi-quantitative natural tracer and as a sensitive recorder of accumulated thermal stresses in the Dixie Valley geothermal system.

- Establishment of the likely rate at which oil-bearing thermal fluids traveled to their present accumulation sites at wellheads or in geothermal scales.

- Development of a new tool for mapping preferred fluid pathways in the reservoir. This application could augment sophisticated permeability mapping utilizing manufactured-tracer techniques (see Rose; Adams, this Program Update).

\section{APPROACH}

The critical initial step in this investigation was recognition of the Dixie Valley oil at the wellhead by Johnson. Additional oils were subsequently recognized in subsurface geothermal scales from throughout the field. Collection parameters of the scales (depths, temperatures of formation, position above "flash points") were noted, and the scales described in detail both megascopically and petrographically, the latter with particular emphasis on the sequence in which particular scale minerals were precipitated, and the distribution of oil with respect to those minerals. The oils were extracted from the scales in Sohxlet apparatus, and analyzed by gas chromatography-flame ionization detection (GC-FID) and by gas chromatography-mass spectrometry (GC-MS). The hypothetical maximum longevity of the oil under the most ideal of geologic conditions was modeled in preliminary fashion utilizing the aforementioned Arrhenius relationships. 


\section{RESEARCH RESULTS (Summarized from Hulen Et Al., 1999)}

Figure 1 schematically shows the sites in the Dixie Valley production wells at which natural oils have been identified. Live oil is found in traces in the 37-33 wellhead (pictured), and geothermal scales form above the flash points as the thermal waters depressurize and boil in transit to the surface.

The geothermal scales consist predominantly of the calcium carbonates aragonite and calcite, and the magnesium-rich swelling clay saponite, in association with minor magnetite, goethite (which possibly formed after scale extraction), and electrum, a natural gold-silver alloy. Oil occurs in the carbonates as fluid inclusions and as transparent brownish veils along healed microfractures, and in saponite as an impregnation.

The two calcium carbonate in the scales are typical of geothermal scales, but the saponite is distinctly unusual. It is a trioctahedral smectite, one important characteristic of which is it stability at temperatures up to at least $300^{\circ} \mathrm{C}$. An analysis of the smectite-rich portion of one of the oil-saturated saponites shows that it is unusually iron rich, so perhaps it is a hybrid between saponite and its iron analogue nontronite. In any event, a magnesium-rich mineral like this would seem at odds with the composition of the pristine modern reservoir fluid, which contains only a few ppb magnesium (Bruton et al., 1997). The presence of the magnesium can be linked with that of the oil to infer certain conditions likely imposed upon the reservoir by production.

The free (wellhead) and fluid-inclusion oils are shown by organic-geochemical analysis to be partially degraded "typical" crude oils with no evidence of advance thermal stress. Biomarker abundances and ratios in the oils show that they are derived form Cretaceous or younger source rocks, which in this part of the Basin and Range means that the source rocks are Tertiary in age. Temperature-sensitive biomarkertransformation ratios, considered in aggregate, indicate that the oils have not experienced temperatures above about $120^{\circ} \mathrm{C}$. It is likely, however, that they have experienced the $250^{\circ} \mathrm{C}$ Dixie Valley reservoir temperatures. The only way to resolve this discrepancy is to assume that the oils have had very brief residence times in the geothermal system. We have not yet established a firm estimate for the maximum duration of the oils' residence times, but Arrhenius relationships mandate an upper limit for this figure. They indicate that $50 \%$ of the oil would have been destroyed within 800 years at $250^{\circ} \mathrm{C}$. They do not address the biomarker transformation ratios of the residual oil, but we can be reasonably certain that they would not retain their original, pregeothermal values.

Our preferred explanation at this point is that the free and scale-hosted Dixie Valley oils have survived in the system not for hundreds of years, but for only a few years if not months. In support of this contention is the association of the oil with abundant magnesium-rich scale. The Dixie Valley reservoir waters contain only about $32 \mathrm{ppb} \mathrm{Mg}$, but ground waters flanking the system contain up to $3200 \mathrm{ppb}$ (Bruton et al., 1997). We conclude tentatively that the magnesium-rich groundwaters have been drawn into the system in response to a production-induced pressure sink.

If this proves to be the case, and if we can find the subsurface source of the oil at the margin of the field, we can define preferred (more permeable) pathways along which the oil was ingested into the system. Knowing this, in combination with refined estimates of the maximum lifespan of the oil at reservoir temperatures, we can then arrive at an approximate travel time for the oil to reach its entrapment sites. Such an analysis could prove to be another (if less precise) means than manufactured-tracer studies (e.g. Rose et al., 1998) to map out subsurface permeability configurations as a benefit to reservoir production and injection strategies.

A final point to be mad is that all of western Nevada's potential Tertiary hydrocarbon source rocks are quite immature, well-below the so-called oil-generation "window" (Bortz, 1983). In order to generate oil, 
they absolutely require geothermal heating. The common occurrence of geothermal systems in this part of the Basin and Range makes it quite likely that these otherwise immature source rocks instead have yielded significant quantities of liquid hydrocarbon.

\section{FUTURE PLANS}

This pilot study arose from the surprising discovery of oil in the Dixie Valley system in 1998, and was not part of EGI's initial geothermal research plan. Nonetheless, its potential significance at Dixie Valley is obvious, and accordingly we have conducted the above-described, low-intensity investigation to begin understanding its true significance. We plan similar efforts (collection of more oil samples; examination, characterization, and sampling of additional geothermal scales) during FY 1999. More intensive research is clearly called for, and that research could encompass the following tasks: (1) Comparison of the Dixie Valley oil occurrence with the more famous one documented at Kyle Hot Springs in nearby Buena Vista Valley; (2) hydrocarbon soil-gas surveys; (3) study of the nearby Dixie Comstock hot-spring gold deposit with emphasis on hydrocarbons and the search for clues to subsurface hydrothermal processes in the Dixie Valley geothermal system; (4) numerical modeling to reconcile hydrocarbon compositions and biomarker characteristics with temperatures and fluid chemistries encountered at depth; (6) hydrous pyrolysis experiments at a wide range of temperatures to quantify the relative effects of time and temperature on thermal maturation.

\section{INDUSTRY INTEREST}

Oxbow Power Services most directly. Other geothermal companies producing systems which might well contain oil in the hydrocarbon-source-rock-rich Basin and Range province.

\section{REFERENCES}

Bortz, L., 1983, Hydrocarbons in the northern Basin and Range, Nevada and Utah: Geothermal Resources Council, Special Report 13, p. 179-197.

Bruton, C.J., Counce, D., Bergfeld, D., Goff, F., Johnson, S.D., Moore, J.N., and Nimz, G., 1997, Preliminary investigation of scale formation and fluid chemistry at the Dixie Valley geothermal field, Nevada: Geothermal Resources Council, Transactions, v. 21, p. 157-164.

Hulen, J.B. Collister, J.W., Johnson, S.D., and Allis, R., 1999, Oils in the Dixie Valley and Kyle Hot Springs geothermal systems, Nevada B Potentially sensitive indicators of natural and induced reservoir processes: Stanford University, $24^{\text {th }}$ Workshop on Geothermal Reservoir Engineering, Preprint, 17 p.

Lutz, S.J., Moore, J.N., and Benoit, D., 1998, Integrated alteration mineralogy and fluid-inclusion study at the Dixie Valley geothermal field, Nevada: Stanford University, $23^{\text {rd }}$ Workshop on Geothermal Reservoir Engineering, Preprint, 8 p.

Rose, P.E., Benoit, W.R., and Adams, M.C., 1998, Tracer testing at Dixie Valley, Nevada, using pyrene tetrasulfonate, amino-G, and fluorescein: Geothermal Resources Council, Transactions, v. 22, p. 583-587. 


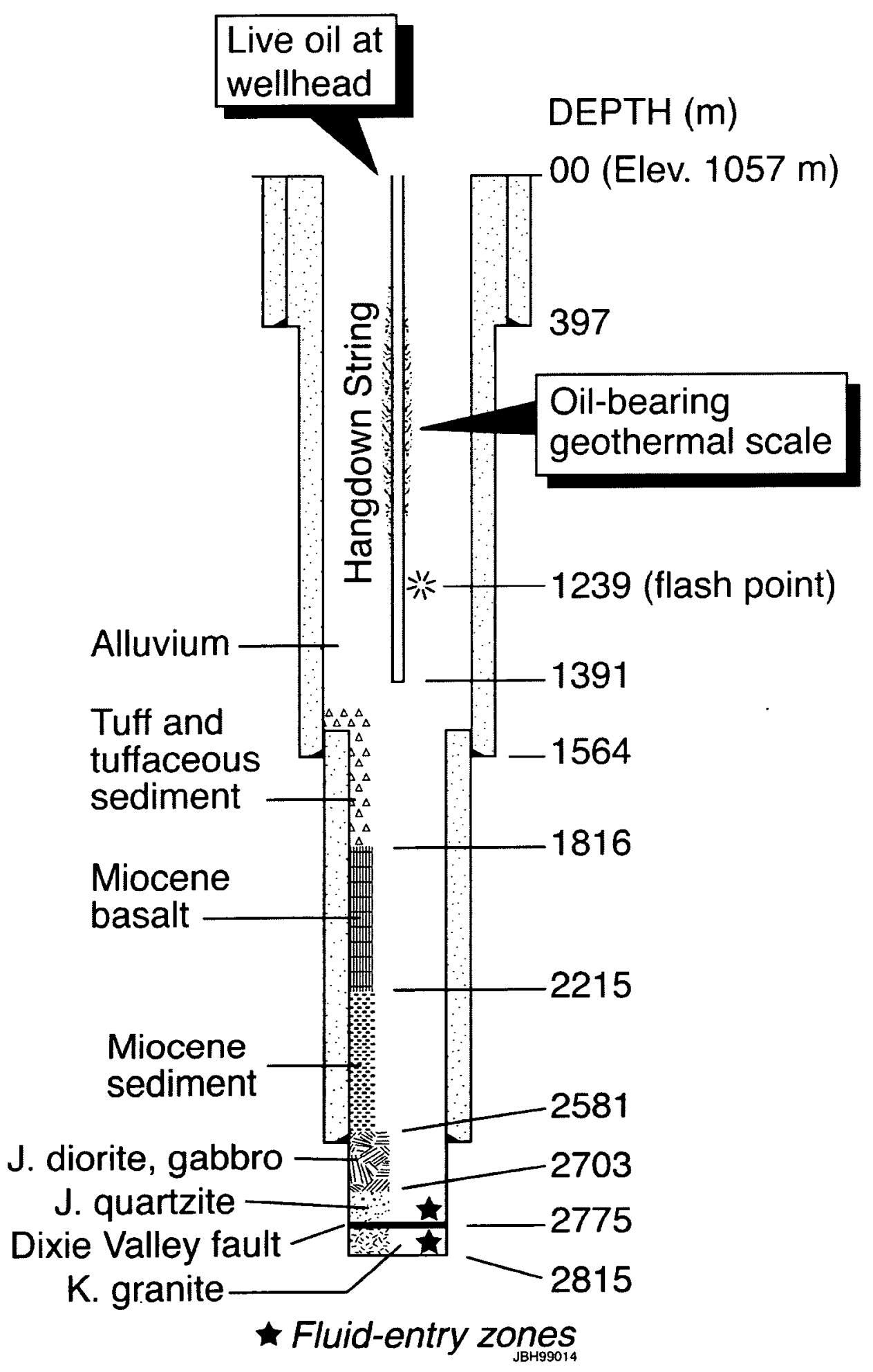

Figure 1. Completion diagram for a Dixie Valley geothermal production well, showing sites of accumulation of live oil. 


\title{
Alteration Mineralogy and Mapping of Outcrops Adjacent to the Dixie Valley Geothermal Field, Nevada
}

\author{
Susan Juch Lutz and Joseph N. Moore \\ Energy \& Geoscience Institute, University of Utah
}

\section{KEY WORDS}

Hydrothermal alteration, vein assemblages, stable isotopes, fumaroles, travertine, hot springs, Stillwater Range, Dixie Comstock gold mine, Basin and Range normal faults

\section{PROJECT BACKGROUND AND STATUS}

Our studies have focussed on the post-Oligocene alteration of the Jurassic reservoir rocks at Dixie Valley and the relationship and cumulative effect of these alteration events upon the permeability of the current geothermal reservoir. Based on these studies, a general alteration history for the reservoir rocks has been established (Lutz et al., 1996; 1997; 1998). In the well cuttings, much of the secondary mineralization (i.e., wairakite veining and sericitization) appears to represent Miocene hydrothermal events associated with andesitic dike intrusion and the early stages of Basin and Range extensional faulting, rather than present-day geothermal activity. Our recent efforts have concentrated on outcrops along the Stillwater rangefront immediately adjacent to the geothermal field, where splays of the Dixie Valley fault are exposed in the footwall of the main rangefront fault, and where other surficial manifestations of the present geothermal system (fumaroles and travertine deposits) are present.

\section{PROJECT OBJECTIVES}

The overall objective of this study is to develop better conceptual models for geothermal reservoirs associated with normal faults in extensional terrains.

\section{Technical Objectives}

- Describe the occurrence and distribution of alteration minerals from outcrops in the Stillwater Range adjacent to the Dixie Valley geothermal field, and their relationship to the present geothermal system.

- Characterize the fluids that produced these alteration minerals. Determine their temperatures and salinities, and geochemical and isotopic signatures.

- Relate the characteristics of the alteration minerals and altering fluids to major structural features (Miocene dikes, low-angle normal faults, high-angle rangefront faults) in order to understand the history of fluid flow in the area.

\section{Expected Outcomes}

- Assist explorationists and developers in targeting geothermal wells along large-scale normal faults common to the Basin and Range province. The fault zone mineralogy could be used as an exploration guide to distinguish older structures and alteration from younger active or reactivated fault zones that are more likely to be permeable in the modern structural setting.

- Develop an improved understanding of the distribution and evolution of permeability through time at Dixie Valley. 


\section{APPROACH}

As part of understanding the plumbing of the Dixie Valley geothermal system, we have started to map the alteration mineralogy and zoning in the Stillwater Range adjacent to the geothermal field. A variety of materials have been sampled and analyzed: vein minerals along splays of the rangefront fault; fumarole deposits at the north end of the field; travertine and calcite veins from Cottonwood Canyon; intensely altered rocks in an area of fault intersections just south of the field; and cuttings from well 45-15 located near the Dixie Comstock gold mine. A variety of geochemical techniques were employed to characterize these samples: X-ray diffraction and petrographic analyses to identify the mineralogy of fine-grained materials; fluid-inclusion analyses to determine the formation temperatures and salinities of the altering fluids; and oxygen stable isotopes to investigate the sources (meteoric, crustal or magmatic) of fluids that deposited the secondary minerals.

\section{RESEARCH RESULTS}

\section{$X$-ray diffraction and petrographic studies}

Alteration studies were conducted in two outcrop areas along the eastern escarpment of the Stillwater Range. In the northern part of the geothermal field, colorful alteration banding can be observed along splays of the rangefront fault near Senator Fumarole. The mineralization and zoning around the active fumaroles and fault splays appears to represent recent surficial alteration associated with the Dixie Valley geothermal system. Just south of the field is an area of intensely altered rocks that occur at the intersection of a north-trending fault, a low-angle normal fault (the Boyer fault; Plank, 1999), and the northeast-trending rangefront fault (the Dixie Valley fault). The hydrothermal alteration in these rocks appears to record fossil hot spring and fumarolic activity along the rangefront.

X-ray diffraction (XRD) analyses indicate that green fault material along splays of the Dixie Valley fault is composed predominantly of corrensite, a mixed-layer chlorite-smectite. Fibrous dolomite veins cut, and presumably postdate, the green fault gouge. Carbonate veins collected in a red-colored alteration band consist predominantly of calcite. The red mineralization is X-ray amorphous and probably consists of poorly crystalline iron oxides-hydroxides. Yellow-white crust forming along linear cracks in the soil at the new fumarole area is composed of gypsum, with minor anhydrite and traces of halite.

Triassic siltstone at the area of fault intersections south of the field appears bleached and is altered to a yellow-green color. Fossil fumarole activity is recorded by the presence of chalcedonic quartz and traces of alunite, jarosite, barite, anhydrite, goethite, hematite and kaolin in these rocks. This mineral assemblage suggests acidic, supergene alteration that formed above a boiling hot spring as steam moved upward along the high-angle rangefront fault. Present-day venting of steam and soil mercury anomalies suggest ongoing, albeit weak, fumarolic activity in the area.

Red-black mineralization and veining in breccia along the base of the siltstone exposure at the rangefront fault appears to be younger than the fumarole deposits, but older than landslide material that mantles it. $\mathrm{XRD}$ analyses indicate that the breccia is cemented with quartz, halite, sylvite, and poorly crystalline iron and manganese oxides. These deposits are interpreted to represent an older episode of hot spring activity along the rangefront fault. Parry et al. (1991) mention halite-cemented breccias in the Dixie Valley fault in the vicinity of the Dixie Meadow hot springs and suggest dissolution of basinal evaporites (by cold water and mixing with the low salinity hot water) as a source for the salt. 


\section{Fluid-inclusion studies}

Fluid inclusion analyses were performed on selected outcropping vein samples in an attempt to distinguish geothermal veins from older veins. Older hydrothermal fluids associated with the intrusion of Miocene dikes are characterized by fluid inclusions from two outcrop areas; one from Little Cottonwood Canyon in the Stillwater Range adjacent to the field, and the other in an area north of the geothermal field where a large Miocene intrusive complex is present from which andesitic dikes emanate into the surrounding Triassic carbonate rocks.

Fluid inclusions were analyzed from a quartz vein collected at the contact between Triassic phyllite and a fine-grained hornblende-biotite dike in Little Cottonwood Canyon that has returned a Miocene age (Dilek et al., 1995; Plank, 1999). Two populations of inclusions are identified, one with homogenization temperatures of $240^{\circ}$ to $277^{\circ} \mathrm{C}$ and melting temperatures of ice at $-4.2^{\circ}$ (about $7 \mathrm{wt} \% \mathrm{NaCl}$ equivalent), and the other with homogenization temperatures of $320^{\circ}$ to $327^{\circ} \mathrm{C}$ and melting temperatures of $-5.7^{\circ} \mathrm{C}$ (or $8.7 \mathrm{wt} \% \mathrm{NaCl}$ equivalent). These apparent salinity values are much higher than those measured in fluid inclusions from veins in the geothermal reservoir.

Fluid inclusions from quartz-calcite-actinolite veins in carbonate rocks adjacent to the northern dike complex have a range of homogenization temperatures (Th) and ice-melting temperatures (Tm-ice). The Ths ranged from $258^{\circ}$ to $387^{\circ} \mathrm{C}$, and ice-melting temperatures ranged from about zero down to $-9.2^{\circ} \mathrm{C}$ (or about $13.1 \mathrm{wt} \% \mathrm{NaCl}$ equivalent). There appears to be one population of fluid inclusions with Ths of about $300^{\circ} \mathrm{C}$ with $\mathrm{Tm}$-ices of about $-0.1{ }^{\circ} \mathrm{C}$, and another population with Ths of about $330^{\circ} \mathrm{C}$ and $\mathrm{Tm}$-ices of about $-1.6^{\circ} \mathrm{C}$.

One of the most significant results of our outcrop work to date is that the alteration mineralogy in the present footwall of the Dixie Valley fault (the Stillwater Range) appears to be different than that in the hanging wall of the fault (the Dixie Valley geothermal reservoir). In the hanging wall, there is an abundance of veins and vein types, only some of which are related to the present geothermal system. The presence of wairakite veins, in particular, appear to represent hydrothermal alteration associated with Miocene dikes in the Jurassic and Triassic reservoir rocks. The fluid inclusions associated with these hanging wall wairakite veins have homogenization temperatures of about $235^{\circ} \mathrm{C}$ and apparent salinities of about $1.2 \mathrm{wt} \% \mathrm{NaCl}$ equivalent (Lutz et al., 1998). In the footwall where similar andesitic dikes are fully exposed, there is very little associated alteration and a few actinolite-calcite-quartz veins. Fluid-inclusions associated with these actinolite veins have homogenization temperatures that range from $240^{\circ}$ to $390^{\circ} \mathrm{C}$ and apparent salinities up to $13.1 \mathrm{wt} \% \mathrm{NaCl}$ equivalent:

In summary, it is apparent that the rocks that now occur in the hanging wall of the Dixie Valley fault have undergone a different structural and alteration history from the rocks in the present-day footwall. The rocks in the hanging wall are much more fractured and veined and were altered by lower temperature and lower salinity fluids than the footwall rocks. It is possible that the dikes on either side of the Dixie Valley fault were not contemporaneous, or that they were emplaced at different paleodepths within the crust.

\section{Oxygen Isotope Analyses}

The stable isotope signatures of a variety of calcite vein and travertine samples were determined in order to determine the source of the fluids that produced these samples. Veins produced by the modern geothermal system should exhibit a meteoric signature similar to the present production fluids, whereas fluids associated with older hydrothermal events (Miocene dike intrusion and volcanism) may exhibit a magmatic or crustal character. 
Where available, homogenization temperatures from our previous fluid-inclusion analyses were used to calculate $\delta^{18} \mathrm{O}$ values of the water in equilibrium with the calcite. Most of the rangefront calcite veins have very few fluid inclusions, and most of these are all liquid. Where small vapor bubbles are found, the homogenization temperatures were generally about $110-115^{\circ} \mathrm{C}$. The results of the isotope analyses indicate that the fluids that produced the rangefront veins were predominantly meteoric in origin with $\delta$ ${ }^{18} \mathrm{O}$ water values of -10.2 to $-14.3 \%$. Dixie Valley geothermal waters have $\delta{ }^{18} \mathrm{O}$ water of -10.6 to -14.8 $\%$. Vikre (1994) obtained quartz and calcite vein fluids of $\delta{ }^{18} \mathrm{O}=-12$ to $-14.5 \%$ o for the Dixie Comstock hot-spring type gold mine samples. In his study, Vikre concluded that the isotopic similarities between the quartz breccia meteoric water and the calcite vein meteoric water at the Dixie Comstock mine, and the modern deep geothermal water in Dixie Valley indicated that the hydothermal phases at the mine were deposited from nearly unexchanged meteoric water.

Vein calcite from the Miocene-age dike complex north of the geothermal field was also analyzed. Based on fluid-inclusion homogenization temperatures of about $320^{\circ} \mathrm{C}$, the fluids that produced this vein had $\delta$ ${ }^{18} \mathrm{O}$ values of about +9.65 , which may indicate either the presence of magmatic fluids or water-rock interaction with the surrounding marine carbonate rocks. The high $\delta^{18} \mathrm{O}$ water values for these calcite veins indicate a history for these rocks that differs from the rest of the geothermal samples.

\section{Alteration mineralogy of Well 45-15}

Well 45-14 is collared 2,500 ft southeast from the Dixie Comstock gold mine in an area about 8 miles southwest of the geothermal field. The alteration in well 45-15 is characterized by young quartzlaumontite veins that are present at all depth intervals (3000 to $9000 \mathrm{ft}$ ). These veins may represent present-day geothermal conditions; maximum measured temperatures in the well are about $140^{\circ} \mathrm{C}$. Veins of quartz, calcite and pyrite are common at shallow levels of the drillhole and may be related to the goldbearing quartz breccias and hot-spring sinters exposed along the fault at the surface. Vikre (1994) estimates the gold mineralization to be mid-Pleistocene in age. Older alteration events are recorded by the presence of andalusite, biotite, actinolite, epidote, prehnite, illite, mixed-layer illite-smectite, chlorite and mixed-layer chlorite-smectite. XRD analysis indicates that the illite-smectite generally contains about 15 to $20 \%$ interlayered smectite. The proportion of smectite in the mixed-layer clay does not vary with depth, hence its formation may be related to a regional event rather than to earlier (and hotter) stages of the present hydrothermal system. Sericite (illite and/or illite-smectite) dated by Vikre (1994) in outcrops near the mine yielded mid-Miocene ages (11.1 to $15.0 \mathrm{Ma}$ ). Actinolite and prehnite alteration appears to be related to the presence of Miocene-age andesitic dikes that cut the Triassic rocks in the well. Andalusite and secondary biotite is present within strongly foliated, silty, carbonaceous, micaceous shales (phyllites). We have not observed this andalusite-biotite assemblage in rocks within the geothermal field or any of the other wells, and speculate that this assemblage formed as a hornblende hornfels by contact metamorphism with Cretaceous-age granitic intrusions described by Vikre (1991) as occurring in outcrops just south of the Comstock mine.

\section{FUTURE PLANS}

We hope to obtain radiometric dates from one or more of the alteration assemblages to further constrain the timing of mineralization and the history of alteration and faulting. The sericite along the $\mathrm{N}$-trending faults in outcrop and the sericite in the quartz arenite along the Boyer fault in the well cuttings are candidates for either K-Ar or Ar-Ar dating.

Because many of the vein assemblages in the geothermal reservoir are not represented in the footwall outcrops, we will turn our attention again to the geochemistry of alteration minerals within the reservoir rocks. Fluid-inclusion gas analyses and stable isotope analyses will further our understanding of the fluids that produced these mineral assemblages. 


\section{INDUSTRY INTEREST AND TECHNOLOGY TRANSFER}

Oxbow Power Services

Caithness Corporation
Fluid geochemistry and scaling in geothermal and injection wells History of permeability and fluid flow in the reservoir rocks

Exploration in the Basin and Range province or other extensional terrains

\section{REFERENCES}

Dilek, Y.M., and Moores, E.M., 1995, Geology of the Humboldt igneous complex, Nevada, and tectonic implications for the Jurassic magmatism in the Cordilleran Orogen, in Miller, D.M., and Busby, C., eds., Jurassic Magmatism and tectonics of the North American Cordillera, Volume Special Paper, Geological Society of America, v. 299, p. 229-248.

Lutz, S.J., Moore, J.N., and Benoit, D., 1996, Alteration mineralogy of the Dixie Valley geothermal system, Nevada: Geothermal Resources Council, Transactions, v. 20, p. 353-362.

Lutz, S.J., Moore, J.N., and Benoit, D., 1997, Geologic framework of Jurassic reservoir rocks in the Dixie Valley geothermal field, Nevada: Implications from hydrothermal alteration and stratigraphy:

Proceedings, Twenty-second Workshop on Geothermal Reservoir Engineering, Stanford University, Stanford, California, January 27-29, p. 131-139.

Lutz, S.J., Moore, J.N., and Benoit, D., 1998, Integrated alteration mineralogy and fluid-inclusion study at the Dixie Valley geothermal field, Nevada: Proceedings, Twenty-third Workshop on Geothermal Reservoir Engineering, Stanford University, Stanford, California, January 26-28, p. 315-321.

Parry, W.T., Hedderly-Smith, D., and Bruhn, R.L., 1991, Fluid inclusions and hydrothermal alteration on the Dixie Valley fault, Nevada: Journal of Geophysical Research, v. 96, n. B12, p. 19,733 - 19,748.

Plank, G.L., 1999, Structure, stratigraphy, and tectonics of a part of the Stillwater escarpment and implications for the Dixie Valley geothermal system: M.S. Thesis, Dept. of Geology, University of Nevada- Reno, in press.

Vikre, P.G., 1994, Gold mineralization and fault evolution at the Dixie Comstock Mine, Churchill County, Nevada: Economic Geology, v. 89, p. 707-719. 


\title{
Solute Isotopic Compositions in Geothermal Fluids at the Dixie Valley Geothermal Field
}

\author{
Gregory Nimz \\ Lawrence Livermore National Laboratory (LLNL)
}

\section{KEY WORDS}

geothermal hydrology, solute isotopes, ${ }^{36} \mathrm{Cl},{ }^{14} \mathrm{C},{ }^{87} \mathrm{Sr} /{ }^{86} \mathrm{Sr}$, chemical evolution, geothermal recharge

\section{PROJECT BACKGROUND AND STATUS}

As a collaborative effort between Lawrence Livermore National Laboratory (LLNL), Los Alamos National Laboratory (LANL), and the U.S. Geological Survey (USGS), we are using water chemistry and solute isotopic compositions to characterize the hydrology of the Dixie Valley (Nevada) geothermal system and its relationship with regional groundwater hydrology. This project is part of the ongoing work conducted by several agencies and researchers concerning the geology, geophysics, and hydrology of this geothermal system. We began this project in late 1996 and expect to complete it by the end of calendar year 1999; at present, it is about $80 \%$ complete. This work is being done in conjunction with the Oxbow Geothermal Corporation, operators of the Dixie Valley geothermal plant.

\section{PROJECT OBJECTIVES}

Our objectives are to better understand (1) fluid circulation within the geothermal production zones, (2) recharge to the system, and (3) the interface of the thermal water with regional cooler groundwaters. The purpose is to provide information that will (1) permit better siting of exploration, production, reinjection, and monitoring wells, (2) provide a basis for interpreting observed changes in the system and for predicting future behavior of the system, and (3) allow assessment of the affects of the geothermal operations, if any, on the regional groundwater system used for agriculture and ranching in the area.

\section{Technical Objectives}

- $\quad$ Determine the chemistry of Dixie Valley thermal fluids and groundwaters.

- Determine the isotopic compositions of solutes in the fluids and groundwaters.

- Use the chemical/isotopic data to model fluid origins, movement, and interactions.

- Use the chemical/isotopic data to model fluid/rock interactions, including those detrimental to the system, such as scaling, and those experienced by reinjected waters.

\section{Expected Outcomes}

- Better long-term management of the Dixie Valley geothermal resource both increasing production capacity and lengthening the lifetime of the field. Information from this project can also be used to reduce the cost of locating future wells for production, reinjection, and monitoring.

- Provide information useful in developing other geothermal resources because the Dixie Valley geothermal system is similar in many respects to other geothermal systems in the United States and prospective systems in the Basin-and-Range province. In particular, cost-savings during exploration would be anticipated. 
- Permit improvements in the employed techniques, allowing their wider application to geothermal fields in other geologic/hydrologic settings.

\section{APPROACH}

The chemical and isotopic compositions of thermal fluids and groundwaters indicate their origins, interactions, and clues to their ultimate fates; for example, the age and location of recharge and the relationship among different waters within and adjacent to geothermal systems can be determined. This approach was chosen for use in Dixie Valley so that we could better understand the role of local geologic structure and tectonics in determining fluid flow within the geothermal system. It addresses the following specific questions:

- Does the Stillwater fault impede or enhance fluid flow?

- Are the waters in the regional hot springs hydrologically connected to the economic production zone?

- How rapidly will the cone of depression caused by production pumping recover at reduced production rates?

- Why are reinjection tracers recovered in some parts of the geothermal field but not others?

We used an integrated multi-chemical, multi-isotope approach to address various aspects of the hydrology of the system. This approach involved capabilities from the LANL (major and trace elements, tritium, petrology), the USGS $\left(\delta^{13} \mathrm{C}, \delta^{18} \mathrm{O}, \delta \mathrm{D}\right)$, and LLNL $\left({ }^{14} \mathrm{C},{ }^{36} \mathrm{Cl} / \mathrm{Cl},{ }^{87 / 86} \mathrm{Sr}\right)$.

\section{Research Results}

The chemical and isotopic data indicate the following preliminary results:

- Waters issuing to the surface in the Clan Alpine and Augusta ranges to the east of Dixie Valley are dominantly relatively young ( $<50 \mathrm{yr}$ old) and bicarbonate in character. Waters issuing to the surface in the Stillwater range to the west of Dixie Valley are dominantly old (late-Pleistocene) and chloride in character.

- All thermal waters within Dixie Valley appear to be late-Pleistocene in age; therefore, because transport times are short, all recharge must be local (as opposed to long-distance underflow into the basin).

- Waters from thermal springs can be divided between those with chemical characteristics similar to Clán Alpine waters and those with chemical characteristics similar to Stillwater waters. The thermal springs are not closely similar to the deep production waters, and their maximum depth may be much shallower.

- Mixing between thermal waters and non-thermal waters appears to occur only in limited cases. Large-scale mixing does not seem to occur. Therefore, the production reservoir may be shielded or enclosed from the rest of the hydrologic system. These "barriers" are likely the controls of tracer movement at depth. Geothermal production zones outside of the enclosed zone, at the same depth, may be unlikely within Dixie Valley. Reinjection outside this zone may be ineffective; monitoring outside of this zone would provide misleading results at best. It is therefore important to spatially define this zone in future work. 
- Upward movement of deep waters is prevalent in the western half of Dixie Valley, whereas the eastern half is characterized by migration of shallower waters along geologic faults. This suggests either a heat source or a set of deep-seated geologic pathways for heat transport exists in proximity to the Stillwater range.

- This research is the first study to integrate a wide range of chemical and isotopic techniques for geothermal characterization. As a general result, it indicates that isotopic and chemical data can be very diagnostic of the hydrologic structure of geothermal systems.

\section{FUTURE PLANS}

This project will continue throughout FY99, with further field work (November 1998 and May 1999), chemical/isotopic analyses, and publication of results. The work will culminate at the end of calendar year 1999 with a presentation/paper at the October 1999 Reno Geothermal Resources Council meeting, and a publication in a peer-reviewed hydrology journal.

\section{INDUSTRY INTEREST AND TECHNOLOGY TRANSFER}

\section{Organization}

Oxbow Corporation, (operators of the Dixie Valley geothermal plant)

\section{Type and Extent of Interest}

Technical guidance and logistic support. 


\title{
APPLICATION OF MICROGRAVIMETRY TO GEOTHERMAL RESERVOIR MANAGEMENT
}

\author{
Rick Allis \\ Energy \& Geoscience Institute \\ University of Utah
}

\section{KEY WORDS}

gravimetry, gravity monitoring, reservoir engineering, reservoir storage

\section{PROJECT BACKGROUND AND STATUS}

This project was initiated in late 1998 with the purchase of a Scintrex GC3M gravimeter to facilitate research into the applications of microgravimetry to reservoir engineering and management. Gravity changes of the order of 100 s of $\mu \mathrm{gal}$ are associated with most large geothermal developments. These changes are mostly caused by saturation changes in the reservoir. Normally, saturation and liquid storage changes must be inferred from assumptions about relative permeability relationships, and the changes in reservoir pressure, temperature, mass flow and enthalpy obtained from production wells (or monitor wells if available). Microgravimetry provides an independent source of information about reservoir changes that helps improve the validity of reservoir simulations.

The microgravity method relies on repeated measurements of the gravity at stable benchmarks (monuments) around a borefield. Normally these measurements are repeated annually, or at longer intervals of time depending on the size of the development and the magnitude of expected gravity changes. Modern gravimeters such as the Scintrex GC3M can achieve a measurement accuracy of $5 \mu$ gal, and depending on the measurement circumstances, theoretically achieve differential readings to better than this accuracy. Gravity readings are sensitive to elevation $(3 \mu \mathrm{gal} / \mathrm{cm})$, so benchmark and meter elevations are required if elevation changes of more than $1 \mathrm{~cm}$ are suspected during the monitoring period.

Very little microgravimetry has been carried out at US geothermal developments, despite the method having been applied at overseas fields for many years (e.g. Allis and Hunt, 1986). Some early gravity stations were installed by the USGS at the Geysers during the 1970s, and these revealed decreases of up to $100 \mu \mathrm{gal} /$ year (Isherwood, 1981). However, the measurements have not been repeated since then, and the monuments have not been maintained. Some absolute gravity monitoring was also carried out by Goodkind. Based on simple assumptions about net mass withdrawn from the The Geysers reservoir, the total gravity change should now have reached around-1 mgal. Gravity monitoring has been occurring at Coso field during the 1990s, but nothing has been published on this. The measurements apparently show significant differences between injection areas and productions areas (F. Monastero, pers. com.).

\section{PROJECT OBJECTIVES}

The goal of this project is to demonstrate the value of microgravimetry for assisting reservoir management in U.S. fields presently under development, or being considered for development. Objectives are:

1. Optimize the field measurement techniques required for precise gravity monitoring using precision gravimetry, and establish the characteristic measurement sensitivities achievable in the vicinity of typical cultural noise levels around a geothermal borefield. Use the Dixie Valley geothermal field 
(Nevada; Oxbow Power Co.) as the main field test area, but some measurements could be carried out at The Geysers Field, California to establish feasibility of long-term monitoring at that field. Topics include:

- $\quad$ Benchmark design

- Length of measurement duration/sampling versus stacking repeat measurements (using EGI's Scintrex GC-3M)

- $\quad$ Source of measurement errors

- Performance comparison between traditional La Coste-Romberg meters and Scintrex meter

- Attempt repeat measurements of USGS precise gravity measurements between 1973 and 1977 at The Geysers

- Role of absolute gravimetry for base station control

- $\quad$ Possible role of gravity gradient measurements for resolving mass changes at depth

2. Investigate the amplitude and causes of gravity changes other than those due to reservoir fluid mass changes, and develop methods for correcting for their effect. Topics include:

- $\quad$ Finding optimal GPS leveling technique(s) for achieving $1-2 \mathrm{~cm}$ accuracy

- Comparing results with other potential leveling methods such as electronic siting and bar coded invar rods, satellite radar interferometry

- Amplitude of long-term rainfall and meteoric infiltration on gravity changes

- Optimum timing for precise gravity surveys

3. Apply numerical reservoir simulation techniques to the interpretation of precise gravity changes and reservoir mass changes. Topics include:

- Comparison of gravity change measurements with other reservoir engineering and geoscientific data in Dixie Valley field

- Adapt TOUGH simulator and gravity change algorithm to allow forward calculation of varying subsurface saturation-porosity changes in the reservoir

- Estimation of reservoir recharge flux regime by comparison of inferred mass changes with production and reinjection fluxes in different parts of the reservoir

- Investigation of inverse calculation methods for mass changes

\section{APPROACH}

A student in the Dept. of Geology and Geophysics has been selected to begin a M.Sc.-Ph.D. thesis on this topic (Paul Gettings). Initial work on optimizing measurement techniques, minimizing measurement errors, and data reduction techniques has begun. Eight stations in the Salt Lake Valley have been set up to 
investigate the amplitude of seasonal variations in groundwater storage and their effects on gravity changes. This factor could be an important source of gravity change in geothermal fields.

Plans have been made for two field trips to Dixie Valley during the summer of 1999. The first trip will install a network of benchmarks suitable for long term microgravity monitoring. The second trip in late summer will ensure all marks have an initial gravity value, and also an elevation value. Differential GPS techniques will be used for most elevation measurements, and will hopefully achieve a $1 \mathrm{~cm}$ elevation accuracy. Oxbow Power is assisting with these measurements.

The possibility of locating and reoccupying the mid-1970s gravity stations at The Geysers will be investigated late in the year.

\section{RESULTS}

At present the gravimeter is being "run-in". These meters typically start with a relatively high drift rate, and this settles down to a lower, more stable drift rate after several months of use. A graph showing the change in drift rate with time since acquisition in late October, 1998, is shown as Figure 1. The drift rate has decreased by over $50 \%$, and the meter now has a drift rate of less than $20 \mu \mathrm{gal} / \mathrm{hour}$. Whether this drift will stabilize at around $350 \mathrm{ugal} / \mathrm{day}$ in mid 1999 (quadratic curve fit), or continue to gradually decline in amplitude (exponential decay) remains to be seen. The characteristics of the meter appear to be ideal for the microgravimetry required for this project.

Repeat gravity measurements are being made at 8 sites spanning from the center of Salt Lake Valley to Little Cottonwood Canyon (i.e. across Sandy City). These measurements are enabling both acquisition and data reduction techniques to be optimized. Interpretation of the results is continuing. Planning for the summer field program at Dixie Valley field has also begun. Over 50 benchmarks will be established for long term monitoring.

\section{FUTURE PLANS}

The objectives outlined above give an indication of the sequence of the research. Once the results from gravity change surveys become available, sensitivity studies with numerical simulations of reservoir changes will be carried out. TOUGH 2 will be used for this. The application of inverse methods for deriving mass changes from the observations of gravity changes at depth will be an important part of these simulation studies.

\section{REFERENCES}

Allis, R.G. and Hunt, T.M., 1986, Analysis of exploitation-induced gravity changes at Wairakei geothermal field, Geophysics, 51, 1647-1660.

Isherwood, W.F., 1981, Geophysical overview of The Geysers. In: McLaughlin and Donnelly-Nolan, eds. Research in the Geysers-Clear Lake Geothermal area, Northern California. Geological Survey paper $1141,83-96$. 


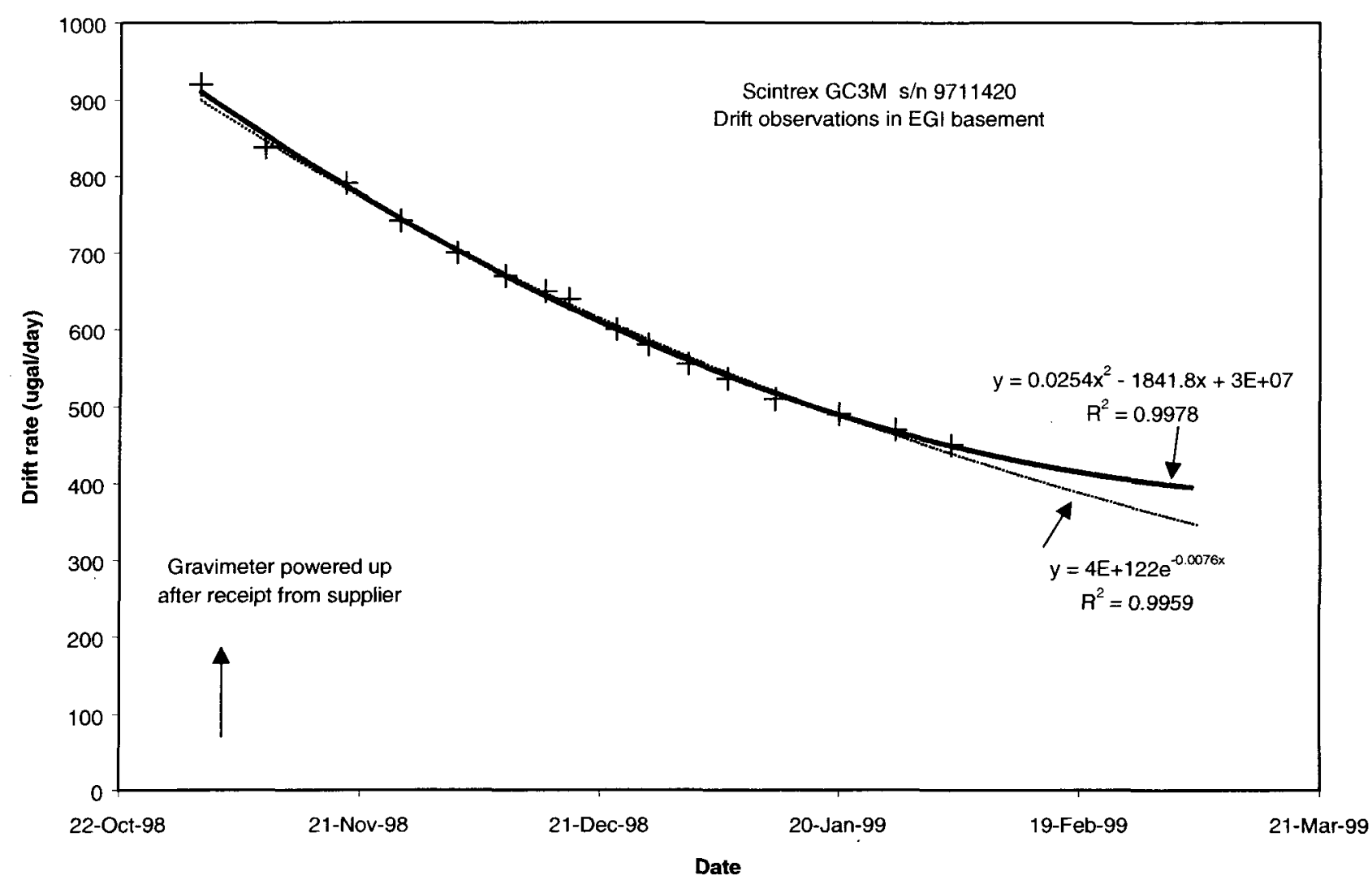

Figure 1. Trend in drift rate of the Gravimeter since its acquisition in late October, 1998. The drift rate has halved during the first 3 months. An exponential and a quadratic decay trend have been fitted to the data. The drift rate is now low a relatively low $2 \mu \mathrm{gal} /$ hour. 


\section{LIST OF CONTACTS FOR RESERVOIR TECHNOLOGY}

Michael C. Adams

Energy and Geoscience Institute

University of Utah

423 Wakara Way

Salt Lake City, UT 84108

Phone: (801) 585-7784

Fax: (801) 585-3540

e-mail:madams@egi.utah.edu

Rick Allis

Energy \& Geoscience Institute

423 Wakara Way

Salt Lake City, UT 84108

Ph. (801) 581-7849; fax (801) 585-3540

Email: rallis@egi.utah.edu

Dick Benoit

Oxbow Power Sve Inc

9790 Gateway Dr \# 220

Reno, NV 89511 Oxbow Corporation

Phone: (702) 851-1199

Email: Dick_Benoit@opsi.oxbow.com

K. K. Bloomfield

Idaho National Engineering Laboratory

P. O. Box 1625

Idaho Falls, ID 83415-3830

Tel: (208) 526-5250

Fax: (208) 526-0969

Greg Boitnott

New England Research Inc.

76 Olcott Drive

White River Junc. VT 05001

Tel: 802-296-2401

boitnott@ner.com

Brian Bonner

LLNL

L-201

Livermore, CA 94550

Tel: 510-422-7080

bonner1@llnl.gov

Peggy Brookshier

Office of Program Management

U.S. Department of Energy

Idaho Operations Office

785 DOE Place, MS 1220
Idaho Falls, ID 83402

Phone: (208) 526-1403

Fax: (208) 526-6249

Email: BROOKSPA@INEL.GOV

Robert Creed

U.S. Department of Energy

Idaho Operations Office

785 DOE Place

Idaho Falls ID 83402

Phone: (208) 526-9063

Stephanie Daveler

Lawrence Livermore National Laboratory

7000 East Avenue, L-200

P.O. Box 808

Livermore, CA 94551-0808

Phone: (925) 423-2249

Fax: (925) 423-6907

Email: daveler2@llnl.gov

Stefan Finsterle

Phone: (510) 486-5205

E-mail: SAFinsterle@lbl.gov

Raymond Fortuna

Office of Geothermal Technologies, EE-12

U.S. Department of Energy

1000 Independence Avenue, SW

Washington, D.C. 20585

Phone: (202) 586-1711

Fax: (202) 586-1711

George A. Frye

Phone: (707) 579-9305

1412 Lorraine Way

Fax: (510) 486-7070

Santa Rosa, CA 95404

e-mail: gafrye@lbl.gov

Fraser Goff

MS D462 EES-1 : Geology \& Geochemistry

Los Alamos National Laboratory

Los Alamos, New Mexico 87545

Phone: (505) 6678060

Email: fraser@lanl.gov

Miroslaw S. Gruszkiewicz

Phone: (423) 574-4965 


\section{J. Michael Simonson}

Phone: (423) 574-4962

Juske Horita

Phone: (423) 576-2750

Chemical and Analytical Sciences Division

Oak Ridge National Laboratory

P. O. Box 2008, Bldg. 4500S, MS-6110

Oak Ridge, TN 37831-6110

FAX: (423) 574-4961

Juske Horita

Phone: (423) 576-2750

David R. Cole

Phone: (423) 574-5473

David J. Wesolowski Phone: (423) 574-6093

J. Michael Simonson Phone: (423) 574-4962

Chemical and Analytical Sciences Division

Oak Ridge National Laboratory

P.O. Box 2008, MS 6110

Oak Ridge, TN 37831-6110

FAX: (423) 574-4961

Roland N. Horne, Kewen Li, Dorie Lysaght

Stanford Geothermal Program

Dept. of Petroleum Engineering

Stanford University

Stanford, CA 94305-2220

(650)725-2723, fax:(650)725-2099

e-mail: horne@pangea.stanford.edu

Jeffrey B. Hulen

Energy \& Geoscience Institute

423 Wakara Way, Suite 300

Salt Lake City, Utah 84108

Phone: (801) 581-8497

Fax: (801) 585-3540

Email: jhulen@egi.utah.edu

Cathy Janik

U.S. Geological Survey

Bldg 15, McKelvey Building

345 Middlefield Road, MS 910

Menlo Park, CA 94025

Phone: (650) 329-5213

Email: cjanik@usgs.gov

cjanik@mojave.wr.usgs.gov

Stuart Johnson

Oxbow Power Svc Inc

9790 Gateway Dr \# 220

Reno, NV 89511 Oxbow Corporation

Phone: (702) 851-1199

Email: Stu_Johnson@opsi.oxbow.com
Raymond LaSala

Office of Geothermal Technologies, EE-12

U.S. Department of Energy

1000 Independence Avenue, SW

Washington, DC 20585

Phone: (202) 586-4198

Fax: (202) 586-8185

Email: Raymond.Lasala@hq.doe.gov

Marcelo J. Lippmann

Phone: (510) 486-5035

Earth Sciences Division, MS 90-1116

Fax: (510) 486-5686

E.O. Lawrence Berkeley Natl. Laboratory

e-mail: mjlippmann@lbl.gov

Berkeley, CA 94720

Susan J. Lutz

Energy \& Geoscience Institute

423 Wakara Way, Suite 300

Salt Lake City, Utah 84108

Phone: (801) 581-8497

Fax: (801) 585-3540

Email: sjlutz@egi.utah.edu

Ernie L. Majer

Phone: (510) 486-6709

e-mail: elmajer@lbl.gov

Ann Kirkpatrick

Phone: (510) 486-6985

e-mail: akirkpatrick@lbl.gov

John E. Peterson

Phone: (510) 486-4267

e-mail: jepeterson@lbl.gov

Earth Sciences Division

Bldg 90-1116

E.O. Lawrence Berkeley National Laboratory

Berkeley CA 94720

FAX: (510) 486-5686

Nancy M $\phi$ ller and John H. Weare

Chemistry Department

U.C., San Diego 92093

Phone: 619-534-6374; 534-3286

Email: nweare@ucsd.edu; jweare@ucsd.edu

Joseph N. Moore

Energy and Geoscience Institute

University of Utah

423 Wakara Way

Salt Lake City, UT 84108 
Phone: (801) 585-6931

Fax: (801) 585-3540

e-mail: jmoore@egi.utah.edu

Dennis L. Nielson

Energy \& Geoscience Institute

423 Wakara Way

Salt Lake City, UT 84108

Phone: (801) 585-6855

Fax: (801) 585-3540

Email: dnielson@egi.utah.edu

Gregory Nimz

Lawrence Livermore National Laboratory

P.O. Box 808, L-219

Livermore, CA 94551-0808

Phone: (925) 423-2766

Fax: (925) 422-0208

Email: nimz1@Ilnl.gov

Randy Normann

Sandia National Laboratories

P.O. Box 5800, MS-1033

Albuquerque, NM 87185-1033

(505)-845-9675, FAX (505)-844-3952

e-mail ranorma@sandia.gov

Curtis Oldenburg

Phone: (510) 486-7419

cmoldenburg@lbl.gov

Karsten Pruess

Phone: (510) 486-6732

k_pruess@lbl.gov

Earth Sciences Division

Bldg. 90-1116

Lawrence Berkeley National Laboratory

Berkeley, CA 94720

Fax: (510) 486-5686

Donald A. Palmer Phone: (423)576-1509

Pascale Benezeth Phone: (423)574-4960

David J. Wesolowski Phone: (423)574-6903

Chemical and Analytical Sciences Division

Oak Ridge National Laboratory

P.O. Box 2008, Bldg. 4500S, MS-6110

Oak Ridge, TN 37831-6110

FAX: (423)574-4961

Peter Persoff

Earth Sciences Division, MS 90-1116

Lawrence Berkeley National Laboratory
One Cyclotron Road

Berkeley, CA 94720

Phone: (510) 486-5931

Fax: (510) 486-5686

e-mail: ppersoff@lbl.gov

Michael R. Prairie

Sandia National Laboratories

P.O. Box 5800, MS-1033

Albuquerque, NM 87185-1033

(505)-844-7823, FAX (505)-844-3952

e-mail mrprair@sandia.gov

Karsten Pruess

Lawrence Berkeley National Laboratory

Earth Sciences Division

One Cyclotron Road, Mail Stop 90-1116

Berkeley, CA 94720

Phone: (510) 486-6732

Fax: (510) 486-5686

E-mail:k_pruess@lbl.gov

Marshall Reed

Geothermal Division, CE-122

U. S. Department of Energy

Washington, D.C. 20585

Phone (202) 586-8076

Fax (202) 586-5124

Joel L. Renner

INEEL

PO Box 1625

Idaho Falls, ID 83415-3830

(208) 526-9824

(208) 526-0969 FAX

rennerjl@inel.gov

Peter E. Rose

Energy \& Geoscience Institute

423 Wakara Way suite 300

Salt Lake City, UT 84108

Prof. Paul Segall

Department of Geophysics

Stanford University

Office: $650-725-7241$

Fax: 650-725-7344

E-mail: segall@stanford.edu Stanford, CA

94305 
G. Michael Shook

INEEL

PO Box 1625

Idaho Falls, ID 83415-2107

(208) 526-6945

(208) 526-9822 FAX

ook@inel.gov

J. Michael Simonson

Donald A. Palmer

Phone: (423) 574-4962

Phone: (423) 576-5109

Chemical and Analytical Sciences Division

Oak Ridge National Laboratory

P. O. Box 2008, Bldg. 4500S, MS-61 10

Oak Ridge, TN 37831-6110

FAX: (423) 574-4961

Charles G. Stevens

Lawrence Livermore National Laboratory

P.O. Box 808, L-183

Livermore, CA 94551-0808

Phone: (925) 422-6208

Email: stevens2@llnl.gov

Daniel Swenson

Mechanical and Nuclear Engineering Dept.

Rathbone Hall, Room 302

Kansas State University

Manhattan, KS 66506

(785) $532-2320$

swenson@ksu.edu
Richard Thomas

California Division of Oil and Gas and

Geothermal Resources

801 K Street, MS-20

Sacramento, CA 95814-3530

Phone: (916) 323-1787

Fax: (916) 323-0424

Email: dthomas@consrv.ca.gov

Alfred H. Truesdell

Phone: (650) 322-6135

700 Hermosa Way

Fax: (650) 324-4009

Menlo Park, CA 94025

e-mail: ahtruesdell@lbl.gov

Jeffrey L. Wagoner

Lawrence Livermore National Laboratory 7000 East Avenue, L-22 1

P.O. Box 808

Livermore, CA 94551-0808

Phone: (925) 422-1374

Fax: (925) 422-2195

Email: wagoner1@Ilnl.gov

Yu-Shu Wu

Lawrence Berkeley National Laboratory

Earth Sciences Division, MS 90-1116

One Cyclotron Road

Berkeley, CA 94720

Phone: (510) 486-7291

Fax: (510) 486-5686

E-mail: yswu@lbl.gov 
Adams, Michael C. $3-43,3-71,3-171,3-177$

Albright, James $3-183$

Allis, Rick 3-205

Anderson, A.J. 3-177

Anovitz, L. M. 2-65

Bénézeth, $P$.

Blackwell, David D.

Blanton, Arnold J.

Blencoe, J. G. 2-65

Bloomfield, K. K. $3-43,3-147$

Boitnott, G. N.. 3-25

Bruton, Carol 3-165

Cochran, S. A. $2-25$

Cole, David R. $2-65,3-13$

Collister, James W. 3-189

Curry, Jim . 3-165

Daley, Thomas M. $2-47$

Daveler, Stephanie 3-85

DePaolo, Donald J. 2-55

Feighner, Mark A. $2-47$

Finger, John T.

Finsterle, Stefan

Frye, George A.

Goff, Fraser.

Gruszkiewicz, Miroslaw S.

Heizler, Matthew T. 
Henderson, J M.

Henfling, Joseph A

Hernandez, Michael W.

Ho, P. C

Horita, Juske

Horne, Roland N

Hulen, Jeffrey B.

Hutchings, Lawrence J

Janick, Cathy J.

Johnson, Stuart D

Kamola, Diane L

Kasameyer, Paul

Kennedy, B. Mack

Kirkpatrick, A.

Langton, David R.

Lee, Ki Ha.

Lippmann, Marcelo J.

Lowenstern, Jacob B.

Lutz, Susan Juch

M $\phi$ ller, Nancy .

Majer, E.L

Malin, Peter E.

Mariner, Robert $\mathrm{H}$

Marshall, S. L

Martini, Brigette A

Mesmer, Robert E 
Moore, Joseph N. $3-43,3-71,3-125,3-143,3-177,3-195$

Moridis, George $3-89$

Mossop, Antony 3-137

Nash, Gregory D.

Nielson, Dennis L.

Nimz, Gregory

Normann, Randy A.

Norton, Denis L.

Oldenburg, Curtis M.

Palmer, Donald A

Persoff, Peter.

Peterson, Jr. J.E.

Pickles, William L.

Potts, D. C

Priest, Susan S.

Pruess, Karsten

Rose, Peter E.

Ross, Howard P.

Rutledge, James

Sackett, Penelope C

Sass, John H.

Segall, Paul

Shalev, Eylon

Shook, G. Michel

Silver, E. A. 
Smith, Albert T.

Steele, John L

Stevens, Charles

Stodt, John A

Swenson, Daniel .

Thomas, Richard

Tripp, Alan C.

Truesdell, Alfred H.

Wagoner, Jeff

Walker, J. Douglas.

Wannamaker, Philip E.

Weare, John H.

Wesolowski, David J.

3-7, 3-13

Wisian, Kenneth W.

Wu, Yu-Shu

Young, H. W. 


${ }^{14} \mathrm{C}$

Awibengkok. $2-55,3-25,3-35,3-59$

Basin and Range normal faults 3-71, 3-195

biomarkers 3-189

Blue Mountain $.2-5$

boiling 3-1 13, 3-177

breakout $.3-97$

breccias ..3-59 brine $3-1,3-13,3-97$

CADOGGR chemical evolution

3-201

chemistry 3-97

chloride. 3-1

$\mathrm{CO}_{2}$ flux 2-71

core 3-59

core measurements 3-25

corrosion. 3-1

Coso Range $2-55,2-81$

coupled wellbore flow. 3-89

Cove Fort-Sulphurdale

creep

cross-dispersion infrared spectrometry ...... 3-165

CSAMT $2-41$

CSMT 2-1

database 3-85

deformation 3-137

dissolution 3-59

distributed temperatures systems 3-81

Dixie Comstock gold mine. 3-195

Dixie Valley $.2-19,2-55,3-189$

Dixie Valley geothermal system $2-71$ downhole sample 3-81

EarthVision 2-77

Eastern US. 2-13 echelle grating spectrometer. 3-165 effective continuum approach (ECM) 3-131 
El Hoyo-Monte Galan geothermal region ....2-35

Electrical Conductivity $.2-1$

electrical resistivity $.2-5$

Electromagnetics $.2-41$

electronic filing. $.3-85$

energy .3-97

enthalpy.

EOS

equilibrium .3-97

extensional basins $.2-81$

facies analysis $.2-81$

faults. 3-119

felsite $3-151$

field case studies $.3-47$

flow 3-119

fluid evolution. $.3-71$

Fluid geochemistry. $.2-71$

fluid inclusions. $2-55,3-151,3-177,3-189$

fluid migration and storage .3-59

fluid-inclusion gas chemistry $.3-71$

fluid-rock interactions $.2-65$

fluorescein $.3-65$

fluoroform 3-171

fracture and matrix interaction $3-131$

fracture closure .3-19

fracture imaging 3-183 fracture morphology.

3-25

Fractured reservoirs. 3-131

fractures. $3-59,3-119,3-125$

fumaroles 3-195

gas composition. $2-71$

gases. 3-97

geobotany $2-19,2-25$

geochemical reservoir-modeling 2-71

geochemistry

geochronology 2-81

Geologic studies 2-81

geology 2-77

geophysics $2-5,2-31$

geothermal 2-9, 3-65, 3-97, 3-165, 3-171, 3-189

geothermal conduits $2-35$

geothermal fluids 2-65

Geothermal Gradient $2-13$

geothermal hydrology 3-201

geothermal injection database 3-85

geothermal monitoring 3-157

Geothermal Potential $2-13$

geothermal power. $3-47$

geothermal production database. 3-85

geothermal recharge 3-201 geothermal reservoir. 3-35, 3-119 geothermal scale 3-189 
geothermal system $3-53,3-59,3-71$

geothermometer $.3-13$

geothermometry 3-151

GIS

granite .2-65

gravimetry 3-205

gravity monitoring 3-205

Great Basin .2-9

$\mathrm{H}_{2} \mathrm{~S}$, geothermal $3-165$

heat conduction 3-125

heat content $.2-55$

heat flow $2-9,2-13$

Heat Mining $.2-13$

heat transfer

heterogeneous reservoirs

higher-order differencing 3-113

high-temperature .3-59

high-temperature electronics

hot springs

hydraulic fracturing

hydrocarbons 3-189

hydrochloric acid 3-1

hydrogen .3-13

Hydrogeology $.2-77$

hydrothermal alteration 3-53, 3-143 3-151, 3-195

hydrothermal circulation hyperspectral images . $2-25$

Hyperspectral 2-19

igneous intrusion

imaging. $2-47$

Indonesia 3-59

induced seismicity 3-137, 3-183

injection correlated seismicity

injection $3-109,3-147,3-157$

instrumentation $2-41$

Intrusive 3-125

inverse modeling 3-93

isotope composition 2-71

isotopes $2-55,2-77,3-13$

ITOUGH2 3-93

kinetics 3-7

liquid-dominated geothermal systems 3-47

liquid-to-vapor-dominated 3-143

Long Valley. $2-25$

low-temperature geothermal 3-39

magma chamber evolution $2-55$

Magmatic gas $2-55$

magnetotellurics 2-41

Mahanadong and Mt. Apo $2-55$

Marabios Range 2-35

Medicine Lake, California 3-53

Medicine Lake Highland 
Medicine Lake Volcano

$.2-77$

microearthquakes

3-77, 3-157

microseismicity.

$.2-35$

mineral

3-13

mineral precipitation

3-19

mineralization

3-143

modeling $2-35,2-65,3-1,3-7,3-119$

models

moment analysis

3-109

MT $.2-1$

multicomponent fluid mixtures .3-89

multiphase flow

natural tracer

Nicaragua 2-35

noble gases $.2-55$

numerical dispersion 3-113

numerical modeling $2-31,3-89$

numerical reservoir simulation 3-131

numerical simulation $3-43,3-147$

optimization 3-105

oxygen

3-13

paragenesis 3-143

parallelization $.3-93$

parameter estimation $.3-93$

partitioning

permeability
$\mathrm{pH}$ 3-97

phase change $3-31$

phase coexistence 3-97

phase equilibria $2-65$

phase front 3-113

physical properties 3-25

polyaromatic sulfonates. 3-65

porosity. 3-59

porous materials 3-35

potentiometry 3-7

pressure solution 3-19

production correlated seismicity 3-137

quadrupole mass-spectrometry. 3-71

Quaternary volcanism

R-134a 3-171

R-23 3-171

recharge 2-71

regional geothermal system 3-39

reinjection 3-105

Relative permeability 3-31

remote sensing $2-25$

reservoir. 3-97

reservoir characterization 3-183

reservoir engineering. 3-205

reservoir processes 3-189

reservoir simulation $3-65$ 
reservoir storage . 3-205

resistivity

3-25

rocks

.3-35

Roosevelt Hot Springs

2-19

Salak .3-59

Salton Trough. $.3-47$

saturation .3-97

scaling 2-71, 3-97

seismic velocity.

seismicity

seismology $.2-47$

self-potential $2-5,2-31$

shear weakening.

silicate melts $.2-65$

simulations 3-97, 3-113

Single-hole EM $.2-1$

solubility 3-7, 3-97

solute isotopes 3-201

Source Effects $. .2-1$

stable isotopes 3-39, 3-195

steam caps ..3-1

steam fraction .3-97

steam 3-1, 3-13

steam-water .3-31

Stillwater Range 3-195

swept volume 3-109
Telephone Flat. 3-53

temperature 2-9, 2-13

temperature gradient. $2-5$

temperature-hardened downhole seismic receivers

tensile strength 3-25

tetrafluoroethane

The Geysers...2-25, 2-55, 2-71, 3-1, 3-35, 3-137, 3-143, 3-147, 3-151, 3-165, 3-171, 3-177

Thematic Mapper $2-19$

thermal

thermal breakthrough

Thermal Conductivity 2-13

thermal history 3-189

thermal-history modeling $3-143,3-151$

thermodynamics $2-65,3-1,3-97$

thermo-hydro mechanical modeling. 3-137

Tibet $2-55$

Tiwi $2-55$

tracer tests

$3-65,3-171$

tracer transport 3-131

tracers $3-13,3-43,3-65,3-109,3-119$

travertine 3-195

trifluoromethane 3-171

TVD 3-113

vapor-phase tracers 3-171

vein assemblages 3-71, 3-195 
veins $3-143$

.3-25

velocities

$.2-35$

3-151

$.3-1$

volatility

$2-35,3-59$

volcanic stratigraphy

volcano.
VSP

$2-47$

water composition

2-71, 3-39

wavelet analysis

3-105

wellbore sample

3-81

West Java

3-59

Western Geothermal Database .

$2-13$

Western US .

$2-13$

X-ray CT scanner.

3-31 